



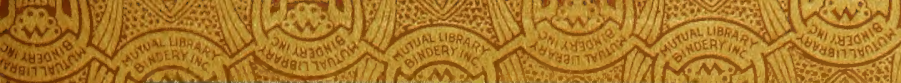

(a)

.

(1)

(i)

.

(8)

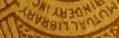

$($ (s)

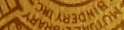

((A)

DATE DUE

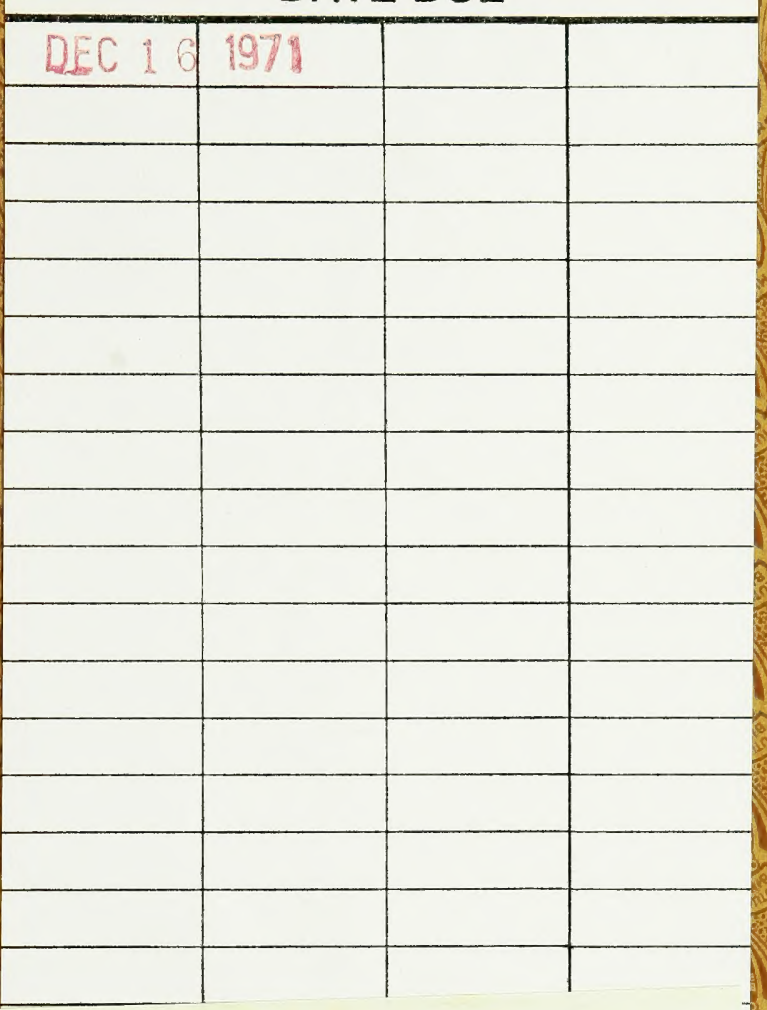

\section{RETURN TO}

ENTOMOLOGY LIBRARY Cornell University Ithaca, N. Y.

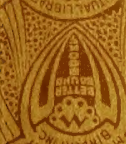

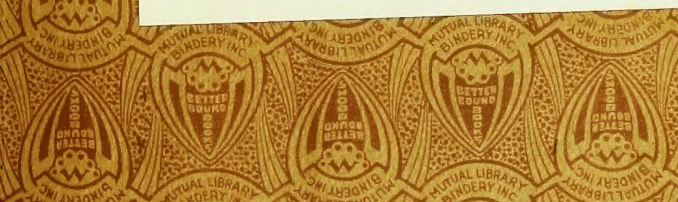

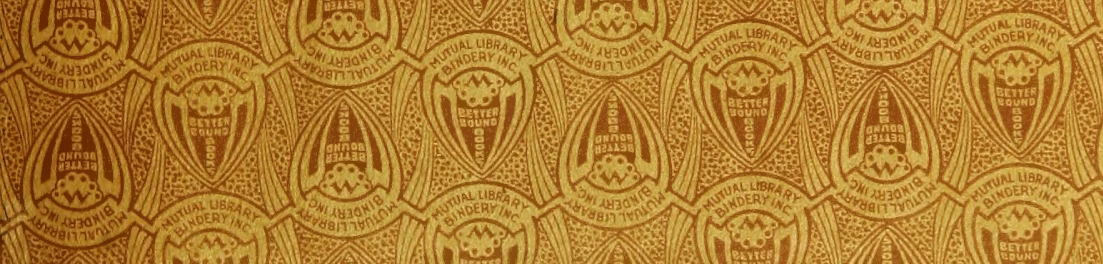




\section{QL591 $M 36$
LP}



is.
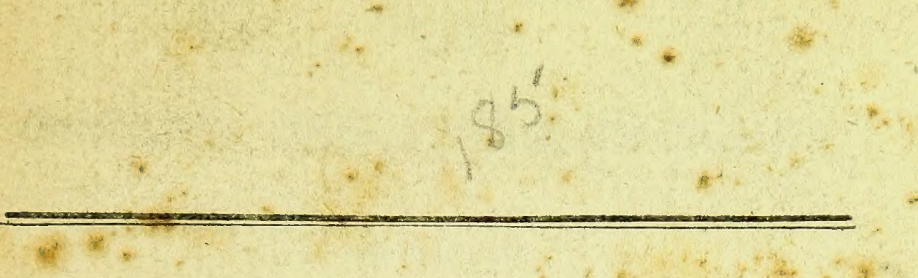

\section{ENTOMOLOGIA BRITANNICA.}

* TOMUS I.

줄:
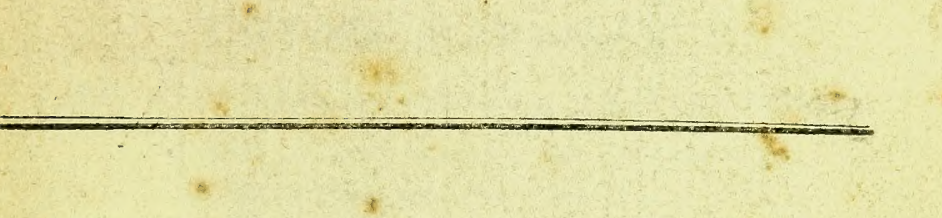

s.

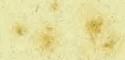

4.

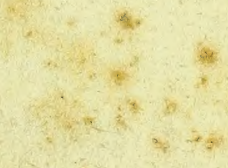

S

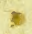

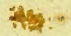

15* 



\title{
ENTOMOLOGIA BRITANNICA,
}

\author{
SISTENS
}

\section{INSECTA BRITANNIÆ INDIGENA,}

\author{
SECUNDUM
}

METHODUM LINNAEANAM

D I S P O S I T A.

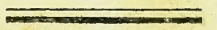

AUCTORE

THOMA MARSHAM,

SOC. LINNAAN. LONDINENS. THESAURARIO,

NECNON SOCIET. LITERAR. ET PHILOSOPH.

MANCUNII SOCIO HONORARIO.

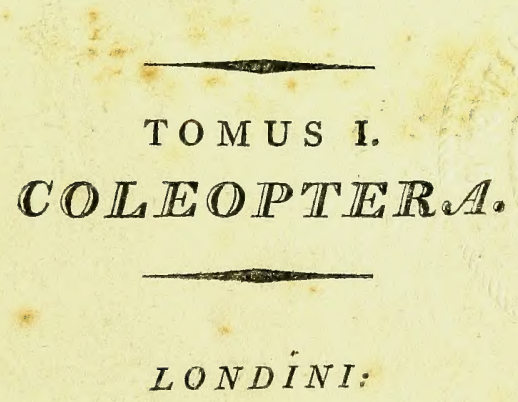

TYPIS WILKS ET TAYLOR,

PROSTAT YENALIS APUD J. WHITE, FLEET-STREET. 
Geove Samoncee

$$
\begin{aligned}
& \text { Q } 591 \\
& \text { m36. }
\end{aligned}
$$

(a) 39845 


\title{
SOCIETATI LINN IEAN死 LONDINENSI
}

\author{
OPUSCULUM HOC
}

IN PIGNUS

AMORIS SUI, BENEVOLENTIE, OFFICII,

SUMMÂ ANIMI REVERENTIÂ

UTI PAR EST,

D. D. D.

THOMAS MARSHAM. 



\section{E C T OR I S.}

Quicunque opus suum publici juris facit, rationes quibus inductus hoc ausit, lege quâdam coactum sese sentit exponere. Neque in ullo opere, lector amicissime, hoc magis necessarium fore putes, quam in illo quod jam in manibus habes. Quot enim libri de Re Entomologicâ jamjam evulgati fuerunt, insecta omnia quæcunque singulis scriptoribus innotuerint proponentes, quæ quidem illi ineptè sperabant numerum insectorum totius orbis terrarum explevisse : tum etiam quot Faunas diversarum regionum habemus, suarum terrarum insecta fideliter, quantum licuit, recensentes. Apud nos verò Entomologia parum subsidii accepit. Raius quidem de paucis admodùm insectis nos certiores fecit. Pennant autem in Zoologiâ suâ, opere pereximio, ad animalia so. lummodò grandiora animum flexit, insecta omninò negligens. 


\section{[ viii ]}

Multis igitur abhinc annis mecum cogitabam de describendis Britanniæ insectis, parum existimans quantum laboris susceperim. Dum enim opus Berkenhoutii, quod tenuis ille lineas exteriores rei naturalis nuneupaverat, tum etiam Forsteri catalogum insectorum Britannicorum, vix plusquam mille continentem, versabam, sperabam sanè, me intra duos aut saltem tres annos opus talismodi ad finem perducturum fore. Nec mora memet accinxi. At citiùs me de magnitudine operis deceptum dolui. Specimina profectò in variis Londini collectaneis asservata, rationem ferè excedebant : tum si quà iter ruri facerem, tot nova indies insecta ante oculos ubique volitabant, quôd quid agerem, planè nescirem. Opus nimis diffcile, quam quod aliquis tantis negotiis domesticis alienisque, quibus ego tunc temporis obrutus laborabam, ad exitum felicem perducat, seriò visum est.

Interea autem tentamen meum amicis quibusdam cognitum fuerat. Hi, ne deficerem, strenuè hortari, et isto aures personare,

Dimidium facti, qui bene copit, babet.

Tum suasum est, consilium paululùm immutare ; viz. vice omnes septem ordines insectorum uno opere complectendi, Coleoptera solummodo primum claborare, et mox ad Hemiptera et ad cæteros ordines progredi : hâc lege autem, quòd haud ali- 


\section{[ ix ]}

quem novum ordinem libeat adire, priusquam illum qui præcessit, probè perspectum et delineatum habuerim. Huic proposito lubentius cessi. Opus igitur habes, lector amicissime, per multos licet annos elaboratum, imperfectum tamen: Neque etiam spes est ad umbilicum perducendi, quippe indies, nova specimina etiamnum inveniuntur; et quid fructûs ex boreali insulæ nostræ regione, Entomologiæ fas sit recipere, omninò latet.

Quod ad dispositionem rerum spectat, plerumque illum summum ducem Linnæum, rei naturalis lumen beatissimum, secutus fui. Illius opera verè aurea, Systema Nature et Faunam Suecicam, naturæ scilicet apprimè consona, in conspectu nocte dieque habui, ardens, si potis sit, in majus provehere. Cumque hoc mihi persuasissimum fuerit, quod multiplicatio systematum artificialium ad impediendum potius quam accelerandum aut promovendum naturæ studium aptior sit, (neque systema verè naturale hominis est nostri temporis aut excogitando invenire aut sperare) melius duxi priscum Linnæi Systema perfectius reddere conari, quam novum ambitiosus extundere. Hoc idem fecit sedulus ille investigator, Baro de Geer, Suecix ornamentum. Confirmavit animum doctissimus D. Villars, qui varia apud alios scriptores genera insectorum ad normam Linnæanam reduxit, et cuique locum inter genera Linnæi 


\section{$\left[\begin{array}{lll}2 & 0\end{array}\right]$}

suum dedit. Gmelin idem voluit facere, at infelicior evasit. Inter præmissa ad Bigas Insectorum Linn., hæc etiam observatio sese obtulit :

" Plurima insectorum genera jam tum esse de" tecta, observamus, eorum consideratâ historiâ. "Dom. Doct. Thunberg, qui singularem om" ninò operam rebus impendit entomologicis, per " literas commemorat, se sub trienniiad Caput Bonæ "Spei vix ullum genus novum reperire potuisse; " et longius latiusque peregrinatus Dom. Doct. "Forster, qui regiones invisit circa polum antarc" ticum sitas, neque ibi nova insectorum genera, sed "paucissimas tantummodò species se deprehendisse, " narrat. Unde patet, genera insectorum nova "admodum esse rara, nisi ante cognita quispiam "vellet separata, ut Hydroum a Dytiscis, Ipsidem "a Dermestibus."

Hæc duo genera et ipse adscivi ; Hydroum quidem cum recentioribus scriptoribus Hydropbilum nominans: quippe ex Linnæi ipsius MSS. quæ mecum amicissimus D. Smith musæi Linnæani possessor liberalis communicavit, hæc genera a se in proximâ Systematis editione conscribenda fore patet.

Systema Entomologice Fabricii, tum plurima alia opera hujusce verè indefessi auctoris, quæ præ. lum per hos proximos annos mirè effudit, præcipuè me, quo minus hoc opusculum in lucem edam, tardaverunt. 


$$
\text { [. } x i]
$$

fardaverunt. Quamvis enim nolo illius systemati incumbere, neque omnia genera quæ nimis curiose efformavit, meo operi adsciscere (neque enim, palam fateor, me posse, qui sint generum istorum certi limites satis exploratum habcre), at synonyma ejus conferre in animo fuit, ut illis, quibus ejus classificatio placet, liceat intelligere, quænam insecta descripserim, et quem locum in Syst. Fabriciano sibi quodque vindicet. Hâc etiam ratione, synonyma aliorum auctorum, quà potui, (omissis quibusdam antiquioribus et jam præ vetustate obsoletis,) adscripsi; nec memorem, quanto labore, quo temporis dispendio, demum collata fuerint. At Systema Linnæi sperabam utilius reddere, ideoque laboris necquicquam me pœnituit. Ausus sum porrò paucula quædam nova genera effingere, quæ insecta cum Linnæana, tum plurima nuper inventa, justiori concinniorique serie instruantur.

- In ordine Coleöptera, Linnæus 33 genera tantùm, Ipe et Hydropbilo inclusis, scripsit: his ego I6 nova addidi. In Entomologià Systematicâ Fabricii, genera, omissâ Forficulâ, ad numerum I I 7 augentur. In Supplemento ejus, 7 alia adjiciuntur. Omnia hæc I 24 sedulò perlegere, siquidem in dubio hæreas quis sit alicujus animalculi locus, opus erit perdifficile et ingratissimum. Huic etiam tædio forsitan memet subjecerim, modo hæc classificatio 


\section{[ $\mathrm{xii}]$}

sificatio omnibus placuerit. At res longè aliter sese habet. Nam quisque novus auctor hactenus inventa dividit, et divisa subdividit adinfinitum.

Defectus Systematum artificialium indies magis patet. Argumentum hujusce rei ex Systemate Fabricii unius sumas: nam quicunque operam insumet varia ejus opera evolvendi et conferendi, mutationes in omnibus perpetuas generum inveniet : adeò ut qui ad primum Fabricii opus insecta sua sollicitus digesserit, òbstupebit sanè, si quà in musæum inciderit ad posteriora ejus opera designatum: novos ordines, nova genera, nova nomina ubique immutata inveniet.

Veruntamen hâc confusione nihil obstante, plurimi auctores per Europæ continentem, Systema Fabricii plerumque sequi nituntur; omnes autem auctores mutationes suas et additamenta sua, nec parcâ manu, inferunt. At si reverà omnes hi auctores genera sua ad instrumenta cibaria effinxerunt, dolet me sanè meos oculos, licet etiam optimè armatos, non posse has partes minutas detegere, saltem adeò ut depingam : minimè quidem in minutis insectis, neque etiam in grandioribus post mortem, absque dissectione. Quis autem unicum insecti rarioris specimen dissectioni tradat? Quid igitur valeat methodus cui tot difficultates obstant undique? Os, oujus partes facilè sine dissectione distinguendx 


\section{[ xiii ]}

guendæ sunt, in usum generis formandi in nonnullis cogendum debere, sententiam meam ascribo. Linnæus ipse quorundam generum characterem inde desumpsit. In ordine Hymenoptera characteres ex aculeis sumptos cuique generi assignavit: intereà confitendum est, si cuidam curæ sit studium scientiæ facile reddere, imprimis characteres quam maximè conspicuos proferat.

Alteri etiam hæc nova Fabricii aliorumqueSystemata objectioni patent; viz. quod nomen generis ab alio auctore dati assumunt, et insecta descriptionis longè diversæ ac auctor ipse adstruxerat, sub eodem collocant. Neque hoc tormenti sufficit, quin et insecta quæ olim sub genere suo auctor ille cooptaverat, hi officiosi investigatores ad novum genus et novum nomen amandant. Exempli gratiâ, in genere Byrrbus Linnæi: hujus veri Byrrbi, a Fabricianis Antbreni denominantur, excepto qui dicitur, ut illi opinantur, Byrrbus Pilula. Hoc autem insectum certo certius aut nobis incognitum, aut ex crrore malè acceptum fuit. Nam in Fucunâ Suecciâ, $\mathrm{N}^{\circ} \mathbf{4 2 7}$ ad quam in Systemate Nature relatio habetur, Byr. Pihulam describit illustrissimus vir ad hunc modum: "Magnitudo dimidii pisi, s. "Coccinella, ejusdemque figuræ, sed colore omninò "murino, s. ex nigro fusco: thorax glaber nitidior. "Elytra vix manifestè striata; saltat pedibus."

Huic 


\section{[ $\mathrm{xiv}]$}

Huic descriptioni Byrrbus Pitula hodiernorum auctorum minimè convenit. Nam neque Coccinellam staturâ refert, neque quisquam alicubi prosilientem vidit. Hoc insectum est Cistela fasciata Forsteri Centuria, et in Linnæi ipsius musæo hoc nomen præ se fert Forsteri manu scriptum. Apud Geoffroyum Cislela satinée audit. Vetus nomen ego reddidi ut ratio jubet, et lex artis nostræ.

Nomen Ips perillustris De Geer primus instauravit, quod genus Dermesies quosdam Linnæanos amplectitur, quam mutationem Linnæus ipse comprobavit prout antedictum est: at quod genus De Geer Ips nominaverat, ei Fabricius nomen Bostricbus imposuit. Huic mutationi forsan venia danda foret, ecce autem quid inde evenit! Fabricius etiam generi cuidam nomen $I_{p s}$ dedit: idem etiam Olivier fecit; at insecta quæ sub genere Ips Olivier conscivit, longè a Fabricianis eodem nomine vocatis abhorrent; et insecta utriusque auctoris, $a b$ istis a De Geer ita nominatis, toto cœlo discrepant. Genus Ips Olivieri sub tria genera, Collydium scilicet Hypopblaus et Lyctus, digeritur in Fabricii Entomologia Systematicâ; in prioribus autern Fabricii operibus sub Bostricbus, Anobium, Hispa et Scarites: quorum ne unum quidem quod ad partes oris spectat, cum Ipe Fabricii 


\section{[ $\mathrm{xV}]$}

bricii constat; neque etiam unum cum altero convenit. Confusio quotuplex !

Alia itidem res in Fabricii operibus animum distrahit : nempè, quod non solum genera perpetuò in alia nova dividit, sed divisa in locos maximè dissitos transfert. Exempli gratiâ, in Systemate Entomologice genus Scarabous, in Scarabaus, Trox, Melolontba, Tricbius et Cetonia dividitur, quæ genera ibi rectâ seric connexa deducuntur, quasi catenatim. At in Entomologiâ Systematicâ, Scarabaus 2do loca ponitur, Trox 7 mo, Tricbius 75 to, Cetonia 76 to, et Melolontba $77 \mathrm{mo:}$ hæc tria ultima genera in 2 dam partem voluminis detruduntur. In Supplemento suo tria alia genera nova construxit, nempè Geotrupes, Onitis et Copris : ita octo genera ex uno Scarabaus Linnæi, (et quot alia mox prolaturus!) protulit vir eximius, mirè indies oculatior.

Scarabeus cylindricus Linn. a Fabricio ad genus Synodendron amandatur, consociandus cum Dermeste Capucino Linn.: cui, me judice, ne minnimam quidem jactet affinitatem. Nam reverà Lucanus est: hoc vultus, habitus, œconomia monent. In hanc sententiam Scopoli et Laicharting ibant. Re probè perpensâ, visum est mihi genus Scarabous integrum asservare, et in tres familias, prout De Geer voluit, dividere, Naturâ ip̣â duce et auspice.

Genus Cbrysomela receptaculum insectorum du-

biorum 


\section{[ xvi ]}

biorum potius quam genus absolutum haberi voluit Linnæus. Fabricius, et rectè quidem, Cbrysomelas Linnæi sub diversa genera disposuit: infelix autem opere in summo fuit, quippe quæque sua publicatio recentior nomina priora mutata adbibuit. Genus quod in primo opere suo Cbrysomela audit, in 2do Altica, in 3 tio autem Galleruca evadit. Genus quidem Galleruca Fabricii insecta plurima complectitur, namque haud tantùm quxdam ex Imâ, 2dâ et 4tâ familiis Chrysomela Linnæi continet, quin et quædam Chrysomela et Altica suorum priorum operum. Fatendum est, quod errores suos alicui indies detur detegere, et sapientis est detectos corrigere: at procul dubio partes oris insectorum (cum Dei optimi MaXiMI IMMUTABILIs manu facta fuerint) nequeunt per se aut alium quempiam mutari. At varias formas induere visæ sunt Fabricio. Liquet igitur, instrumenta cibaria cùm sint, aut nimis minuta quam quæ satis conspiciantur, aut interdum ex casu quodam latitcnt, aut injuriæ obnoxia sint, ideoque formas novas videantur assumere, ne minimè quidem, undè characteres stabiles fidendique excudantur, apta fore. Et adhuc magis mirandum est, quod duo viri tam docti, tam oculati quam Fabricius et Olivier meritò dicantur, cum unum idemque animalcul'rm de indastrià describerent, adeò a se invicem discreparent de formâ situque

harum 


\section{[ $x$ vii ]}

harum partium oris minutarum. Hæc discordia, confusio atque immutatio generum non solum tyroni quamplurimum impedimenti objicit, verum etiam plurimos, quorum animus huc impulsus fuerit, a scientiâ Entomologiæ omninò deterret.

Quin et hæc classificatio, cum Linnæanâ nihilo conferenda, vel in limine ipso titubat. Exempli gratiâ, Terminus Coleoptera (hunc ordinem magis libet proferre, cum hujusce solummodo in præsens satagimus) facilè quodque insectum sub hoc ordine comprehendendum innuit. Quâ igitur ratione apud hosce novos auctores in Eleuterata mutatur? Terminus Eleuterata, modò rectè intellexerim, a maxillis sumitur, oris parte minimè conspicuâ, et sæpiùs, nisi ad injuriosam dissectionem res redit, aciem oculorum prorsus fugiente. Et indè ad aliam observationem ducimur. Maxillæ, prout a Fabricio designantur, non eam oris partem constituunt quam Linnæus hoc nomine innuerat, et quam in opere suo, cui titulus, Fundamenta Entomologie, Andreas Johannes Bladh tam accuratè descripserat. Hæ autem maxill a a Fabricio mandibulde vocantur. Olivier in opere suo pereximio Entomologie, ou Histoire Naturelle des Insectes, quod quidem tam diu suspensum fuisse, sæpiùs modò non lacrymans dolui, classificationis Linnæanæ vestigiis' plerumque innititur: (præterquam quod Hemiptera in duos ordines dividit): at ille etiam numeros generum, licet Fabricio modestior 


\section{[ xviii ]}

mirè auxit, et characteres sumpsit ex instrumentis cibariis, quorum icones seorsim adumbratorum auctas exhibet in Imâ cujusque generis tabulâ. Cui autem bono hæe erunt, nisi si imprimis in vivis animalibus liceat eadem sine molestiâ conspicere.

Egomet ipse vim animi indomitam industriamque Olivieri, dum adhuc apud nos commorabatur, vidi. At nunquam, characteres generum ex partibus oris nimium minutis sumi feliciùs aut posse aut debere, induxi animum. Palam professus sum, me nunquam genera Linnæi adeo naturæ consentanea mutari pati posse. Nova genera ad nova Insecta digerenda necesse confingantur. At nisi--

-Dignus vindice nodus

\section{Intersit-}

prisca genera, prisca nomina suo maneant ordine, et suo jure gaudeant. Vellem sanè operibus tantorum virorum, tanto labore, et in plurimis locis tanto judicio confectis, laudem summam dare. Utpote autem suadeam aliis, quod hi libri studium Entomologiæ facilius reddant, cum egomet ipse nequeo satis intelligere?

Plurimum me fefellit editio Faune Suecice a Don. Gustavo Paykull vulgata. Confusionem ab antecessoribus illatam adhuc magis auget. Nam vir illustris, alumnus quamvis Linnæi, systema Fabricii anteponit, et magistrum suum immortalem rejicit : et quasi hoc leve forct, cum synonyma auctorum citat, primo loco Fabriciana sistit, deinde 


\section{[ six $]$}

inde, licct ut ætate prior, sic scientiâ, dignitate, judicio, longè decem mille Fabricios superet, Linnæi synonyma, proh pudor! inferiori ordine dinumerat. At judicent populares sui. Me judice, scicntiam Entomologiæ ne minimè quidem in majus provexit iste Paykull. Varietates specierum undique cogere, mentem apprimè visum est occupare, et opusculum ejus quidem varictatibus temerè adsutis, abundat. Hæc constrictio multorum insectorum sub uno nomine triviali coactorum, rem valdè perturbat : nam quæ insecta constanter, etiamsi in variis terrarum regionibus capta, easdem notarum differentias præ se ferunt, haud ea insectorum aliorum, quæ essentialiter signis omnibus differunt, varietates voco.

Quæ de hisce Entomologis, verè laudandis, viris, Fabricio et Oliviero ausus sum proferre, invitus sanè dixi. Nam neque mei est, neque cordi est, alterutri bona sua detrahere. Scio quod illorum labor fuit major quam qui verbis exprimi possit; et fautores scientiæ, pro summâ illorum industrîa de tantum (verè mirabilem) numerum insectorum ex variis Europæ musæis colligendo et verbis tam fideliter exponendo, nequeunt par referre. Neque hoc meum tencie opusculum, (quod vero nomine tentamen potiùs dicatur) cum illorum grandioribus operibus ausus sum conferre. Characteres, quibus genera sua distinxerunt, uti nimium difficiles quam 


\section{$\left[\begin{array}{ll}\mathrm{xx} & ]\end{array}\right.$}

qui usui tyronum accommodentur, (hoc ferè unicum) reprobo. Vellem sanè scientiam Entomologiæ præ cæteris mihi jucundam, faciliorem reddere. Vellem difficultates tollere, viam planiorem instaurare, quo alios ad hoc studium alliciens, et quasi blandiens, adducam. Hoc in animo habens pauca quædam genera ab aliis scriptoribus conscripta cooptavi, et duo nova ipse addidi catalogo Linnæano. At forsan spes me fefellerit, et in errores majoris momenti inciderim, quam quos studerem corrigere. Si ita res sese habeat, liceat mihi exclamare, "Humanum est errare," et veniam tuam, lector amicissime, huic meo primo tentamini suppliciter orare.

Genera quæ addidi, præter Ips et Hydrous, ( $H_{y}$ dropbilus) quæ, uti antedictum fuit, Linnæus ipse in MSS. proposuerat, sunt hæc:

Cistela

Corticariat

Nitidula

Boletaria

Opatrum

Cryptocepbalus

Aucbenia

Crioceris
Tillus

Scapbidium

Clerus

Pyrocbroa

Parnus

Heterocerus

Blaps

Lytta.

Genus Cistela, uti prius monui, a Geoffroyo et Forstero sumitur: Auchenia a Thunbergi dissertatione, 


\section{[ $\mathrm{xxi}]$}

tione, cui titulus Periculum Entomologia quo Cbaracteres Generum Insectorum publica censura proponit Samuel Torner. Corticaria ita dicitur, quia insecta hujus generis omnia in corticibus arborum habitant : Boletaria pariter, quia in variis boletorum speciebus inveniuntur, Cætera genera ab Oliviero et Fabricio mutuatus sum, illorum nomenclaturæ succumbens, meâ, ne confusioni subministrem, posthabitâ.

Supervacaneum foret plura dicere. At saltem liceat gratias agere amicis summis meis, et publicè agnoscere, quale subsidii in hoc opere conficiendo accepi. Gaudeo quidem, necnon superbio memorans - Imprimis, honorabili admodùm Josepho Banks, baronetto, ordinis balnei equiti, Reg. Soc. presidi, gratias ago summas pro liberali benevolentiâ, quâ studiosos rei naturalis largus amplectitur, me etiam inter cæteros. Ex hujus favore, libris bibliothecæ suæ, præ omnibus aliis copiosæ, uti licuit; tum etiam collectanea sua insectorum, ad Fabricii methodum a seipso digestorum inspicere, undè occasio data est plurima Fabricii insecta rectiùs dignoscendi, et plurimos libros evolvendi, haud alibi apud nostrates reperiendos. Amico summopere estimando, Jacobo Edvardo Smith, M. D. F. R. S. societatis Linnæanæ Londinensis præsidi, et thesauri illius nimiùm invidendi, musæi Linṇæani possessori agnosco lubens, quâ animi 


\section{[ $\mathbf{x x i i}]$}

promptitudine musæum suum, tum varias observationes illustrissimi Linnæi MSS. consulendi facultatem dedit. Plurimos indè errores detexi, et multum lucis studio insectorum dare potui. Suas etiam observationes, quandocunque consilium peterem, communicavit vir doctissimus, verè amicus.

Utinam alterius amici nomen palam proferre liceret, qui mecum sæpissimè in colligendo laboriosus, in describendo collecta felix, corrigendo hallucinationes meas cæterorumque patiens, et totius operis negotium perpendendo sobrius, hand mediocre auxilii mihi attulit. At vir doctissimus gavisus sanè opem huic tentamini tulisse, satis præmii ait se accepisse, neque se ultra palam memorari sinet. Reverendum Gulielmum Kirby, soc. Linn. socium, qui plurima mihi obtulit, summo operis commodo, descripsitque insecta, antehàc haud cognita indigenas esse Britanniæ, pari animo, paribus gratiis excipio.

Amico summo meo nequaquam nimis laudando, et in hoc opere instruendo tædii mecum participi indefesso, Alexandro MacLeay armigero, soc. Linn. socio, omnia quæ gratus animus excogitet, vellem dicere: scilicet illius ingenio, quod nullus labor, nulla impedimenta potuerunt frangere, debeo hujusce operis plurimum, si qua sit, excellentiæ. Ille plurima mecum descripsit, varia genera speciesque mecum investigavit, summo animi acumine. 
mine. Ille etiam jroeli errores castigavit patientissimus, unde haud tenue nostro libello affulget decus.

Gratias ago amicis qui sequuntur, pro benevolentiâ quâ me prosecuti sunt, mutuum dando specimina insectorum rariora, et collectanea sua otiosè inspicere permittendo, vizo

Reverendis J. Burrell,

R. B. Francis,

P. Lathbury,

J. Lyon,

Dominis Bracy Clark,

E. Donovan,

D. Drury,

J. Francillon,

A. H. Haworth,
G. Jones,

A. B. Lambert,

J. Latham, M. D.

- Latham,

G. Milne,

- Scrimshire,

G. Shaw, M. D.

R. Sheppard,

J. Sowerby.

Quin et memorem paucos quosdam, jam inter beatos, a quibus auxilium variè accepi. (f́cientia ipsa horum mortem dolet) nempè Dom. Beckwith, cujus musæum pretiosum sanè, jamdudum Domino Allen cessit - Dom. Lee - Dom. Lewin, cujus collectanea hodie Dom. MacLeay possidet-et præcipuè Gulielmum Curtis, heu nimis deflendum, auctorem Flor:e Londinensis et Butanical Magazine, quæ quidem erunt famæ ejus monumenta ære perenniora.

Dominus Gray, M. D. cui cura Musæi Britannici commissa est, gratias meas jure quodam sibi postub 4 lat, 


\section{[ xxiv ] .}

lat, qui collectanea J. R. Forster, atque alia aliorum in illo repositorio, quod satis mirari non potis est, seposita, mihi adeundi copiam fecit.

Postremas, at non minimas gratias habeo Dominæ Hill, ex Tawftock in agro Devoniensi, fœminæ, sexûs sui ornamento; quæ summâ de industriâ collegit, parilique benevolentiâ communicavit plurima insecta rariora, qua catalogum nostrum splendidè nobilitaverunt: Insecta, quæ licet ager Devoniensis jactet haud parcâ protulisse manu, vicinia Londini ne extitisse quidem speraverit.

Dabam Londini,

Idibus Junii, I802. 


\section{A U C TOR E S}

\section{IN OPERE SEQUENTI CITATI.}

Act. Acad. Suec.-Kongl. Svenska Vetenskaps Academiens Handlingar. Stockholm, 1739, \&c. 8vo.

Act. Nidros.-Det.Trondhiemske, SelskabsSkrifter. Kiöbenhavn I76r, \&c. 8vo.

Admiral. - Jacob L'Admiral Veranderingen van veele Insekten. Amsterdam I774. fol.

Alb. Ins. Ang.-Insectorum Angliæ Naturalis Historia illustrata Iconibus in centum Tabulis Æneis eleganter ad vivum expressis, \&c. Auctore Eleazare Albin. Londini 1731 . 4to.

Aldrov. Ins. - De Animalibus Insectis Libri septem, Autore Ulysse Aldrovando. Bonon. 1602. fol.

Barbut. Gen. Ins.-The Genera Insectorum of Linnæus, exemplified by various Specimens of English Insects, drawn from Nature by James Barbut. London I781. 4to.

Bergstr. Nomencl.-Nomenclatur und Beschreibung der Insekten in der Grafschaft Hanau-Münzenberg, von Joh. Andr. Benignus Bergstraesser. Hanau 1778 . 4to.

Bonsd. Cur. Suec.-Historia Naturalis Curculionum Suecicæ. Pars prima et secunda. Auctor Gabriel briel Bonsdorff, \&c. \&c. Upsaliæ I785. 4to.

Bradl. Natur.-A philosophical Account of the Works of Nature. \&c. by Richard Bradley. London I739. 8 vo.

Brabm. Ins. Kal.-Insekten von-Kalender. Nicolaus Joseph Brahm. Mainz. I790. 8vo.

Daubent. P. enlum.-Planches enluminées, par Daubenton le jeune. fol. 
De Geer.-Mémoires pour servir à l'Histoire des Insectes, par Charles De Geer. Stockholm I 752: 7 tom. 4 to.

Don. Brit. Ins.-The Natural History of British Insects, explaining them in their several States, illustrated with coloured Figures, \&c. By E. Donovan. London. 8 vo. to vol.

Drury.-Illustrations of Natural History, by D. Drury, London I 770.4 to, 3 vol.

Epkem. Nat. Cur. - Ephemerides Academiæ Cesareæ Naturæ Curiosorum. 4to.

Ent. Helv.-Entomologie Helvétique, ou Catalogue des Insectes de la Suisse, rangés d'après une nouvelle Méthode, avec Descriptions et Figures. Vol. i. Zurich 1798. 8vo.

Fab. Syst. Ent.-Jo. Christ. Fabricii Systema Entomologiæ, sistens Insectorum Classes, Ordines, Genera, Species, 8c. 8cc. Flensburgi et Lipsiæ 1775. 8vo.

Fab. Sp. Ins.-Jo. Christ. Fabricii Species Insectorum, \&c. Hamburgi et Kilonii r7.8r. 2 tom. 8vo.

Fab. Mant.-Jo. Christ. Fabricii Mantissa Insectorum, 8zc. Hafnix 1787.2 tom. 8 vo.

Fab. Gen. Ins. - Jo. Christ. Fabricii Genera Insectorum, \&c. Chilonii. 8vo. 1776.

Fab. Entt. Syst.-Jo. Christ. Fabricii Entomologia Systematica emendata et aucta. Hafniæ 1792.4 tom. 8vo.

Fab. Supp.-Jo. Christ. Fabricii Supplementum Entomologiæ Systematicæ. Hafniæ 1798. I tom. 8vo.

Faun. Etrusc.-Fauna Etrusca, sistens Insecta quæ in Provinciis Florentinâ et Pisanâ præsertim collegit Petrü Rossius. Liburni 1790.4 to.

Faun. Fred.- Fauna Insectorum Fridrichsdalina; sive Methodica Descriptio Insectorum Agri Fridrichsdalensis, \&cc. Hafniæ et Lipsiæ 1764 . 8vo.

Faun. Ingr.-Faunæ Ingricæ Prodromus, exhibens Methodicam Descriptionem Insectorum Agri Petropolensis, \&c. Auctore Johanne Cederhielm. Lipsiæ I798. 8vo.

Faun. Suec.-Caroli Linnæi Fauna Suecica, Editio altera auctior. Stockholmix 1761. 8vo.

Forst. Cent. - Novæ Species Insectorum, Centuria I. Auctore Joanne Reinoldo Forstero, Londini 1771 . 8 Yo. 
Fourc. Ent. Par.-Entomologia Parisiensis, sive Catalogus Insectorum quæ in Agro Parisiensi reperiuntur, \&c. Edente A. F. Fourcroy, M. D. Parisiis 1785 . I 2 mo. 2 tom.

Frisch.-Johann Leonhard Frischs Beschreibung von a!lerley Insekten in Deutschland. Berlin 1766.4 to. Fuesl. Arcb. ed. Gal. -Archives de l'Histoire des Insectes publiées en Allemand par Jean Gaspar Fuesly, traduites en François. Winterthur 1794. 4to.

Fuesl. Nov. Mag.-Neues Magazin für die Liebhader der Entomologie, herausgegeben von Joh. Caspar Fuesly. Winterthur 1782.8 vo.

Geoff:- Histoire Abrégée des Insectes, dans laquelle ces Animaux sont rangés suivant un Ordre Méthodique, par M. Geoffroy, M. D. Paris 1764.4 to. 2 tom.

Gleich. Obs. Micros.-Découvertes les plus Nouvelles dans le Riègne Végétal, ou Observations Microscopiques, traduit de l'Allemand de Baron de Gleichen par Jacques Frederic Isenflamm, \&cc. Nurnberg I770. fol.

Gmel.-Caroli a Linné, Systema Naturæ per Regna Tria Naturæ. Editio decima tertia, aucta, reformata, curâ Jo. Frid. Gmelin. Lipsiæ I788. 8vo. 3 tom.

Goeze.-Entomologische Beyträge zu des Ritters Linné Zwölften ausgabe des Natursystems, von Joh. Aug. Ephraim Goeze.. Leipzig I777. 8vo.

Gronov. Zoopb.-Laurentii Theodori Gronovii Zoophylacii Gronoviani, Fas. I. 2. 3. Lugd. Bat. I763. 1764. $178 \mathrm{r}$. fol.

Harr-Georg. Albrecht. Harrers Beschreibung derjenigen Insecten welche Herr D. Jacob Christoph Schæffer in CCLXXX ausgemahlten Kupfertafeln herausgegeben hat. Regensburg I784. 8vo.

Hellw.-Fauna Etrusca, \&c. iterum edita et Annotatis perpetuis aucta, a D. Joh. Christ. Lud. Hellwig. Helmstadii 1795: 8vo.

Herbst. Arcb. - Archiv der Insectengeschichte herausgegeben von Johann Caspar Fuesly 4. 5. 6. 7. 8. heft. Herbsts Insektensammlung.

Herbst. Jablonsk. - Natursystem aller bekannten inund ausländischen Insecten, \&c, von Carl. Gustav. Jablonsky 
Jablonsky, und fortgesetzt von Johann Friedrich

Wilhelm Herbst. Berlin 1789 . \&c. 8vo.

Hefn. Ins.-Diversæ Insectarum Volatilium Icones ad vivum accuratissimè depictæ per celeberrimum Pictorem D. G. Hoefnagel. 1630.

Hoppe Ins. Erl.-David. Henrici Hoppe M. D. Enumeratio Insectorum Elytratorum circa Erlangam Indigenarum. Erlangæ 1795. 8vo.

Ins. Helv. - Joh. Gaspar Fueslins Verzeichnis der Schweizerischen Insekten. Zürich und Winterthur

177.5. 4to.

Jonst. Hist Nat. Ins.-Historiæ Naturalis de Insectis

Libri 3. Amstelodami 1657. fol.

Iter Gotl. -Carl Linnæi Gothlandska resa. I74I. 8vo.

Jablonsk. Coleopt.-Natursystem aller bekannten in-und ausländischen Insecten, \&c. von Carl Gustav Jablonsky. Berlin I 785 . 8vo.

Illiger. Kugel. Kaf. Preus.-Verzeichniss der Käfer

Preussens entworfen von Johann Gottlieb. Kugelann, ausgearbeitet von Johann Karl Wilhelm Illiger. \&c. \&c. Halle I798. 8vo.

Knocb.-Beiträge zur Insektengeschichte von August Wilhelm Knoch. Leipzig I 781 . 8vo.

Laicb. Ins. Tyr.-Johann Nepomuk Verzeichnifs von Laicharting der Ty roler Insecten. Zurich. 178x. 8vo. Lin. Amœn. Acad.-Caroli a Linnè Amœnitates Academicæ, Volumen Sextum. Holmiæ 1 7 63 . 8vo.

Linn. Syst. Nat.-Caroli a Linné Systema Naturæe per Regna Tria Naturæ. Editio decima tertia. Vindobonæ 1767.3 tom.

List. Goed.-Johannes Goedartius de Insectis in Me. thodum redactus. cum Notularum Additione, operât M. Lister. Londini 1685.8 vo.

List. Ins. Angl.-Mart. Lister Scarabæorum Anglicanorum quædam tabulæ mutæ, editæ cum ejus Gœdartia. in methodum redacto. Londini 1685 . 8vo.

Lyon. Less. Theol. Ins. - Theologie des Insectes, ou Demonstration des Perfections de Dieu dans tout ce qui concerne les Insectes. Traduit de l'Allemand de Mr. Lesser, avec des Remarques de Mr. Lyonnet. A la Haye I742. 8vo. 
Mart. Eng. Ent.-The Englith Entomologist, exhibiting all the Coleopterous Insects found in England, \&c. by Thomas Martyn. London I792. folio.

Merian Ins. Eur.-Erucarum Ortus, Alimentum et Paradoxa Metamorphosis, \&c. per Mariam Sibillam Merian. Amstelodami. 4to.

Mouff. Theat. Ins.-Insectorum sive Minimorum Animalium Theatrum Tho. Mouffeti. Londini 1634. folio.

Mus. Lud. Ulric.-Car. von Linné Musæum Ludovicæ Ulricæ Reginæ. Holmiæ 1764. 8vo.

Oliv.-Entomologie, ou Histoire Naturelle des Insectes, avec les Caractères génériques et spécifiques, \&rc. Par M. Olivier, M. D. A Paris, 1789. 4 to. 4 tom.

Pall. Icon.--Icones Insectorum præsertim Rossiæ Sibiriæque peculiarum, quæ collegit et Descriptionibus illustravit Petrus Simon Pallas, M. D. Erlang. I781. 4to.

Panz. Ent. Germ.-Georg. Wolfg. Franz. Panzeri Entomologia Cermanica,exhibens Insecta per Germaniam Indigena, \&c. Norimbergæ 3795. $12 \mathrm{mo}$.

Panz. Faun. Germ. - Faunæ Insectorum Germanicx Initia. D. Georg. Wolfgang. Franz. Panzer. Nurnberg 1798 . \&c.

Panz. Voet.-Joannis Eusebii Voet Icones Insectorum Coleopterorum, \&c. illustravit D. Georg. Wolfgang. Panzer. \&c. Erlang. I794. 4to.

Payk. Monog.-Monographia Staphylinorum Sueciæ a Gustavo de Paykull. Upsaliæ $\mathbf{1} 789.8$ vo.

Monographia Caraborum Sueciæ. 1790.

Monographia Curculionum Sueciæ. I792.

Payk. Faun. Suec.-Gustavi Fauna Suecica. Insecta. Upsaliæ. 3 tom. 8 vo.

Petagn.Ins. Cal.-Vincentii Petagnæ Specimen Insectorum Uilterioris Calabriæ. Francofurti et Moguntiæ 1787.

Petiv. Gazoph.-Jacobi Petiver Gazophylacium Naturæ et Artis. folio.

Pod. 
Pod. Mus. Grec.-Nicolai Poda. Insecta Musei Græes censis. Græcii 1761. 8vo.

Pontop. Dan. All.-Den Danske Atlas ved Erich Pontoppidan. Kiöbenhavn 1763 , 1764, I 467. 4to: 3 tom.

Preys. Boh. Ins.-Johann Daniel Preysler Verzeichniss Böhmischer Insekten. Prag. I790. 4to.

Rai. Ins.-Historia Insectorum, Autore Johamne Rạio. Londini I7Io. $4^{\text {to. }}$

Reivb. Mant. Ins.-Mantissæ Insectorum Iconibus illusd tratæ, Species Novas aut nondum depictas exhibentis, Fasc. I. Autore Godofredo Christiano Reich, \&c. Noribergæ 1797. 8vo.

Roem.-Genera Insectorum Linnæi et Fabricii Iconibus illustrata a Joanne Jacobo Roemer. Vitoduri Helvetorum I7 89 , 4 to.

Rocs.-Insecten Belustigung, von August Johann Roesel. Nürnberg 1746 . 4 to. 4 tom.

Scbaff. Icon.-D. Jacobi Christiani Schæfferi Icones Insectorum circa Ratisbonam Indigenarum, \&c. Regensburg $1769 \cdot 4$ to. 3 tom.

Scbaff. Elem.-Jacobi Christiani Schæffer, Elementa Entomologica. Regensburg I766. 4 to.

Scbneid Neus. Mag.-Nenestes Magazin für die Liebhaber der Entomologie, herausgegeben von D. H. Schneider 5 hefte. Stralsund 1791, I792, I794. 8 vo.

Scbrank.-Francisci de Pavla Schrank Enumeratio Insectorum Austriæ Indigenarum. Augustæ Vindelicorum $\mathrm{I} 78 \mathrm{r}$. $8 \mathrm{vo}$.

Scop.-Joannis Antonii Scopoli Entomologia Carniolica, exhibens Insecta Carnioliæ Indigena, \&c. Vindobonæ 1763 . 8vo.

Scop. Ann. Hist.-Joannis Antonii Scopoli Anni Historico-Naturales. Lipsiæ 1769. 8vo.

Scriba.-Beiträge zu der Insekten-Geschichte, herausgegeben von Ludwig Gottlieb Scriba. Frankfuri, 3 hefte. I790, I791, I793. 4to.

Share. Nat. Misc.-Vivarium Naturæ, or The Naturalists

Miscellany, 
Miscellany, by G. Shaw. The Figures by E. P. Nodder. London I790. 8 vo.

Sulz. Hist. Ins,-Johann Heinrich Sulzers Abgekürzte geschichte der Insecten. 2 theile. Winterthur I776. 4to.

Tbunb. Ins. Suec.-Dissertatio Entomologica sistens Insecta Suecica. Partes I, 2, 3, 4. Upsaliæ I784. 4to.

Trans. Linn. Soc.-Transactions of the Linnean Society of Londun. London I791, I794, I797, I798, 1800, I802. 6 tom.

Vill.-Car. Linnæi Entomologia \&c. \&c. curante et augente Carolo de Villers. Lugduni I 789 . 8vo. 4 tom. Voet. Coleopt.-Johannis Eusebii Voet Descriptionse et Icones Coleopterorum. 4to.

Udd. Diss.-Novæ Insectorum Species. Difs. Refp. Isaac. Uddman. Aboæ I753. 4to. 



\title{
ENT O M O O G I A
} BBRITAANNICA.

\author{
Ordo I. \\ COLEOPTERA.
}

Elytra alas tegentia, suturâ rectâ.

\section{CHARACTERES GENERUM.}

* Antennis clavá lamellatá.

r. SCARAB AEUS. Antenne clavâ fissili.

2. LUCANUS. Antenne clavâ compressâ, latere latiore pectinato-fissili. Maxilla porrectæ.

* Antennis clavâ perfoliatá.

4. DERMESTES. Caput inflexum sub thorace vix marginato. Elytra immarginata.

9. CISTELA. Thorax convexus. Elytra abdominis latera obvolventia.

1. CORTICARIA. Caput prominens. Tborax et elytra marginata. Corpus sublineare.

II. SILPHA Caput inflexum. Thorax et elytra marginata. Corpus vel ovatum, vel oblongoovatum.

13. BOLETARIA. Thorax marginatus, postice foveolis tribus mediâ obsoletiori, utrinque angulatus. Elytra marginata.

Vor. I. 
39. HYDROPHILUS. Antenna palpis breviores. Corpus ovale, convexum.

23. SCAPHIDIUM. Corpus ovatum, anticè posticèque acuminatum.

37. PARNUS. Antenna brevissimæ. Caput intra thoracem retractile. Thorax posticè utrinque angulis acuminatis. Pectus mucronatum.

\section{*** Antennis clavâ solidâ.}

3. IPS. Tborax caput recipiens. Corpus cylindricum.

6. HISTER. Caput intra thoracem retractile: Elytra corpore breviora. Corpus subquadratum.

8. BYRRHUS. Caput sub thorace reconditum. . Elytra abdomen æquantia. Corpus ovatum, convexum.

12. NITIDULA. Caput insertum. Thorax et elytra marginata. Corpus ovatum, depressiusculum.

16. COCCINELLA. Palpi exteriores clavâ trun. catâ. Thorax et elytra marginata. Corpus hemisphæricum.

7. GYRINUS. Antenne rigidulæ, capite breviores. Oculi quatuor.

25. CURCULIO. Antenne rostro elongato corneo insidentes. Caput posticè incrassatum. 26. ATTELABUS. Antenne rostro insidentes. Caput posticè attenuatum.

*******antenis moniliformibus, plùs minùs extrorsum crassioribus.

2\%. CLERUS. Caput declinatum. Thorax convexus, posticè attenuatus. Corpus elongatum. 47. STA- 


\section{CHARACTERES GENERUM.}

47. STAPHYLINUS. Elytra dimidiata, alas tegentia. Cauda exserens vesiculas duas.

14. OPATRUM. Caput inflexum. Thorax marginatus, anticè lunatus. Elytra immarginata, abdomine longiora, apice inflexa.

15. CASSIDA. Caput clypeo thoracis tectum. Elytra dilatato-marginata.

I7. CHRYSOMELA. Caput insertum. Corpus ovatum, convexum, immarginatum.

42. TENEBRIO. Caput exsertum. Thorax marginatus. Corpus oblongum.

44. MELOE. Caput gibbum, inflexum. Thorax subrotundus. Elytra mollia, flexilia, abbreviata.

***** Antennis filiformibus.

24. BRUCHUS. Antenne sensim crassiores. Thorax anticè attenuatus. Elytra abdomine breviora.

43. BLAPS. Caput exsertum. Thorax plùs minùs marginatus. Elytra rigida, abdomen amplectentia.

5. PTINUS. Tborax ángulatus, subrotundus, caput recipiens.

18. CRYPTOCEPHALUS. Caput insertum. Corpus cylindricum, immarginatum.

19. AUCHENIA. Caput exsertum. Thorax cylindricus, elytris angustior. Corpus oblongum.

20. CRIOCERIS. Caput exsertum. Thorax planus, submarginatus, anticè parum angustatus. Corpus oblongum, depressum.

31. LAMPYRIS. Tboracis clypeus caput obumbrans recipiensque. Elytra flexilia. Abdominis latera plicato-papillosa.

$$
\text { B } 2
$$


33. CANTHARIS. Thorax marginatus, capite brevior. Elytra flexilia. Abdominis latera plicato-papillosa.

45. LYTTA. Caput gibbum, inflexum. Thorax cylindricus. Elytra mollia, linearia.

32. PY ROCHROA. Antenne dentato-pectinatæ. Caput exsertum. Thorax planus. Elytra Alexilia. Corpus posticè incrassatum.

21. TILLUS. Antenne serratæ. Caput subdeclinatum. Thorax convexus. Corpus linearielongatum.

36. BUPRESTIS. Antenne serratæ. Caput dimidium intra thoracem retractum.

34. ELATER. Thorax anticè attenuatus, posticè angulo utrinque prominulo. Pectoris mucro e poro abdominis resiliens.

46. MORDELLA. Caput deflexum. Elytra posticè deorsum curva. Laminæ ad basin abdominis.

38. HETEROCERUS. Antenne breves, recurvæ, articulis ultinis subserratis. Caput porrectum. Maxille exsertr.

22. HISPA. Antenne porrectæ, approximatæ, fusiformes. Thorax et elytra sæpiùs aculeata. 41. CARABUS. Thorax obcordatus, posticè truncatus. Femora postica basi appendiculata. **********antenis setaceis.

28. CER AMBYX. Oculi lunati, antennas amplectentes. Thorax caput pecipiens. Corpus oblongum.

29. LEPTURA. Oculi rotundi. Caput exsertum. Tharax anticè attennatus. Corpus oblongum. 35. CICINDELLA. Muxille cxsertæ, denticulatæ. Oculi prominuli. Thorax rotundato-marginatus. 


\section{CHARACTERES GENERUM.}

40. DYTISCUS. Corpus ovatum. Sternum bifidum. Pedes postici ciliati, natatorii. 30. NECYDALIS. Elytra alis minora. Cauda simplex.

48. FORFICULA. Elytra dimidiata alas tegentia. Cauda forcipata. 



\title{
$\mathbb{C O L} \mathbb{E} O \mathbb{P}^{T} \mathbb{E} \mathbb{A}$
}

\section{SCARABÆUS.}

\section{Antenne clavatæ, capitulo fissili.} Tibice antice sæpiùs dentatæ.

A. Terrestres, elytris ad anum pertingentibus, sive aqualibus.

\author{
* Scutellati. \\ * Exscutellati.
}

B. Arborei, corpore convexo, elytris non ad anum pertingentibus, sive abbreviatis.

C. Florales, corpore depresso, elytris non ad anum per. tingentibus, sive abbreviatis. A. Terrestres, elytris ad anum pertingentibus, sive aqud
libus.

\section{* Scutellati.}

I. Sc. niger, thorace tricorni : intermedio minore, Typhous.. lateralibus porrectis longitudine capitis mutici.

Linn. Syst. Nat. 543. 9. Mus. Lud. Ulric. 8. Payk. Faun. Surc. 1. Fab. Syst. Ent. 10. 26. Sp. Ins. i. 10. 30. Mant. i. 6.33. Ent. Syst. i. a. 12. 34. Vill. Ent. i. 10. 1. Gmel. I53 I.9. Raii Ins. 103? Faun. Etrus. ed. 4to. 4. 7. ed. 8vo. 3. 7. Hoppe Ins. Erlang. 24. Harr. I4. Herbst. Arcb. 3. I. Fuesl. Arch. ed. Gall. 66. I. Ins. Helv. 1.1. Fourc. Ent. Par. i. 6. 4. Panz. Ent. Germ.I.I.

Panz. Faun. Germ. I. t. 23. Friscb. 4. t. 8. Geoff: i. 72. 4. t. I. f. 3. mas. De Geer. iv. 262. 6. t. 10. $f .{ }_{5}$ Scbaff. Icon. t. $26 . f .4$. mas. Oliv. i. 3.59 .2 t. $7 . f .52$ a, b. Voet. Coleapt. t. 19. f. 124. mas. Iz - foern, Jablonsk. Coleopt. i. 278. 33 . t, 6. $f_{0}$ i, z. Bersetr. Nomencl. i. 26. 6. to 4. $\mathrm{B}+$ 
f. 6. Petiv. Gazoph.t. 23.f. 3. Mouff. Tbeat. Ins. 152. f. 2. Barbut Gen. Ins. t. I. f. I. Martyn Eng. Ent. t. I. f. 3, 4 .

Longitudo corporis 9 lin.

Habitat in stercore.

Descriptio. Corpus atrum. Caput angustum, muticum, depressum, lateribus villosum. Antennæcapitulo sub-griseo. Thorax glaber spinis tribus ; lateralibus porrectis, acutis, longitudine capitis; intermedia breviore, erectiore. Elytra striata. Sexus alter loco spinarum gerit tantùm rudimenta truncata. Tibia admodum pilosæ. Linn. Syst. Nat.

pumilus. 2. Sc. niger, thorace tricorni : intermedio brevissimo, lateralibus porrectis capite brevioribus, lateribusque thoracis rugosis.

Long. corp. 5 lin.

Habitat — Captus prope Holt in Norfolciâ. Dom. Burrell.

Descr. Simillimus præcedenti, at satis differt. Magnitudo duplo minor. Cornta breviora, et latera thoracis valde rugosa. Corpus totum nigrum, nitidum. Antennæ nigræ lamellis ferrugineis. Elytra sulcata. Fomina thorace mutico.

mobilicornis. 3. Sc. thorace quadridentato, capitis cornû recurvo mobili.

Fab. Syst. Ent. Ir. 32. Sp. Ins. i. 12.38. Mant. i. 6. 40. Ent. Syst. i. a. 15. 43. V.ill. i. 12. 4. Gmel. 1532. II6. Panz. Ent. Germ. 2. 4. Brabm. Ins. Kal. i. 122. 424. Payk. Faun. Suec. 3.

oliv. i. 3. 63. 7 T. t. 10. $f .88$. a, d. t. $25 \cdot f$. 88 , e. Jablonsk. Coleopt. i. 298.t. 6.f. 6, 7 . Panz. Faun. Germ. 12. t. 2. Mart. Eng. Ent. t. 4. f. 40, $4 \mathrm{I}$. Sc. armiger, Scop. ann. Hist. $78,16$. Laich Ins. + i. $f$. 11 .

Long. corp. 4 lin.

Habitat Hertfordiæ. D. Drarv Prope Dartford, Cantio, D. Lewin. 
Descr. Antennæ lamellatæ, clava ferruginea. Capitis cornu compressum, recurvum, thorace brevius basi articulo mobili. Thorax punctatus elevatus, canaliculatus, lateribus utrinque dente compresso, elevato, recurvo, apice flexuoso. Pone hunc fovea parva, orbiculata, cxcavata. In medio dentes duo reliqui erecti, brevissimi. Scutellum rotundatum. Elytra striata, sub-ferruginea. Pedes et abdomen pubescentia, ferruginea. Fab. Syst. Ent.

4. Sc, niger, thorace cornû brevissimo obtuso, inermis. subtùs ferrugineus pilosus.

Mart, Eng. Ent. t. 4.f. 35 .

Long: corp. $6 \frac{1}{2}$ lin.

Habitat__ In musæo Dom. Beckwith.

DESCr. Totum corpus suprà læve, piceo-nigrum. Antennæ ferrugineæ. Capitis clypeus anticè margine elevato, dentato. Thorax valde convexus, punctis impressis sparsis; medio marginis anticè cornu brevissimum, obtusum, et pone cornu scrobs excavata. Elytra punctis impressis, rugoso-striata. Abdomen subtùs ferrugineum, pilosum. Pedes etiam ferruginei, extùs nigricantes,

5. Sc. niger, capite unituberculato, thorace lævi, erraticus. elytris testaceis subdepressis.

Linn. Syst. Nat. 548. 29. Faun. Suec. 383 . Faun. Etrusc. Rossi 6. 12. Hellwig 6. 12. Fab. Syst. Ent. 16.53. Sp. Ins. i. 17. 66. Mant. i. 9.72. Ent. Syst. i. a. 27. 86. Faun. Ingr. 3.5. Vill. i. I7. 14. Gmel. I548. 29. De Geer. iv. 270. 15. Panz. Ent. Germ. 6. 21. Payk. Faun. Suec. 19.

Oliv. i. 3. 79.83.t. I8. f. 163. a, b. Scheff. Icon.t. 26. f. 9. Jablonsk. Coleopt. t. 12. f. 6. Fuesl. Arcb:ed. Gall. 68. 9. t. 19.f. 2. Herbst.Arcb. 5. 10. t. I9.f.2. Panz. Faun. Germ. 47:4. Mart. Eng. Ent.t. 4. f.37.

Long. corp. 4 lin. ,

Habitat in stercore.

Descr. Thorax convexus lævis, uti totum corpus 
nigrum. Elytra testacea, vel fusco-testacea, suturâ obscuriore, punctato-striata, subdepressa.

sordidus. 6. Sc. capite tuberculato, thorace nigro: margine pallido; puncto nigro, elytris testaceis.

Fab. Syst. Ent. 16.55. Sp. Ins. i. 17.68. Mant. i. 9. 75. Ent. Syst. i. 2.29.90. Vill. i. 20. 24. Gmel. I546. I73. Preys. Bob. Ins.36.33. Udd. Diss. 6. 2. Panz. Ent. Germ.7. 24. Payk. Faun. Suec. I5. Brabm. Ins.' Kal. i. I3I. 448 .

Panz. Faun. Gern. 48. 2. Jablonsk. Coleopt. t. 12.f. 9. Scbaff. Icon. t. 74. f. 3. Oliv. i. 3. 82. 87. t. 25. f. 216. a, b. Fuest. Arch. ed. Gall. 68. II. t. I9. f. 3. Herbst. Arch. 6. 13. t. 19.f.3. Mart. Eng. Ent.t.2. f. I3. mal.

Long. corp. $3 \frac{3}{4}$ lin.

Habitat in stercore bovino primo vere.

DESCR. Antennæ pallidæ. Caput pallidum, sive piceum tuberculis tribus. Thorax punctatus, niger, marginibus omnibus pallidis, lateralibus latioribus puncto nigro. Elytra sordidè testacea, striata, striis ex punctis impressis, fcutello suturâque brunneis, maculis duabus vel punctis nigris in singulo elytro interdum distinctis et interdum vix manifestis. Pedes pallidè picei, femoribus paljidioribus.

fimetarius. 7. Sc. capite tuberculato, elytris rubris, corpore nigro.

Linn. Syst. Nat. 548. 32. Faun. Suec. 385. Faun. Ingr. 2. 5. Payk. Faun. Suec. I3. Fab. Syst. Ent. 15. 51. Sp. Ins. i. 16. 64. Mant. i. 9.70. Ent. Syst. i. a. 27.84. Geoff. i. 81. I8. Pod. Mus. Grac. 18. 4. Preys. Bob. Ins.37.34. Faun. Fred. 1.4. Scop. 20. Scbrank.4. Laicb.1 1. 5. Fuesl. Arcb. 68.8. Herbst. Arcb. 5. 9. Ins. Helv. 10. Vill. i. 18. 16, Gmel. 1545.32. Faun. Etrusc. Rossi 5. 10. Hellw.5. Io. Harr. 9. 7. Raii Ins. 106. 9. Panz. Ent. Germ.5. 18.

Panz. Faun. Germ. 3r. 2. De Geer. iv. 266. 10. $t$. Io. $f .8$. Roes. Ins. ii. I. $t$. A.f. 3. Scbaff. Icon. $t$. I44. f. 6. Voet. Coleopt. t. 21. f. 147. Oliw. i. 3.78.82. 
t. I8. f. 167. Jablonsk. Coleopt. t. 12. f. 4, Frisch. Ins. 4.35. t. I9. f. 3. Mart. Eng. Ent. t. 3. f. 22. Sc. bicolor. Fourc. i. 9. 18.

Lang. corp. $3 \frac{1}{2}$ lin.

Habitat in stercore bovino, copiosè.

Descr. Caput nigrum, clypeatum, subrotundum. Thorax punctatus niger, margine anticè utrinque maculà testaceâ. Color elytrorum variat, interdum rufo-brunneus, interdum rubens. Elytra novem striis exarantur. Abdomen totum nigrum. Pedes nigri, tarsis rufis.

8. Sc. capite tuberculato, elytris abdomineque rufis. Scrutator. Fab. Ent. Syst. i. a. 24. 73. Panz. Ent. Germ. 3. 7. Panz. Faun. Germ. 3I. I. Jablonsk. I. t. 16. f. 6. Sc. ribidus. Oliv. i. 3. 77. 81, t. 26.f. 224 .

Long. corp. 4 lin.

Habitat in stercore. Ex musæo D. MacLeay.

Descr. Statura et summa affinitas Sc. fimetarii. Clypeus rotundatus tuberculis tribus. Thorax punctatus ater, nitidus, margine laté rufo. Elytra striata, rufa, puncto baseos et apicis elevato. Abdomen totum rufum. Pedes nigri. Fab. Ent. Syst.

9. Sc. rufo-ferrugineus, capite trituberculato.

unicolor.

Long. corp. $2 \frac{x}{3}$ lin.

Habitat in stercore.

DESCR. Sc. fimetario similis sed minor, magis oblongus, obscurior. Clypeus trituberculatus; in altero sexû intermedio subcornuto. Thorax confertius punctulatus, saturatior, lateribus pallidioribus puncto nigricanti. Elytra striata, striis crenulatis. Corpus subtùs dilutius. Variat elytris griseis, suturâ saturatiori.

IO. Sc. ater, thorace inermi immaculato, elytris conflagrastriatị griseis : maculâ fuscâ. tus.

Fab. Ent. Syst. i. a. 27. 85. Fuesl. Arch.ed. Gall.68. 10. Herbst. Arcb. 5. J1. Panz. Ent. Germ. 6. 20. Panz. Faun. Germ. 47.2. Oliv. i. 3. 80. 85. t. 26. $f$. 220. Jablonsk. Coleopt. ii. 133. 87. t. I2. f. 2. Don. Brit. Ins. t. $70 . f .2$.

Long. corp. 3 lin. 


\section{Habitat in stercore.}

DESCR. Statura et magnitudo omnino Sc. fimetarii, at differt thorace omnino immaculato et elytris griseis, maculâ magnâ disci fuscâ. Scutellum nigrum. Corpus nigrum, pedibus piceis. Fab. Ent. Syst.

soprinus. II. Sc. ater, elytris punctato-striatis testaceis: suturâ nigrâ.

An Sc. fordens. Gmel. I546. 413?

An Sc. fimetarius. Fourc. Ent. i. 10. 19?

Long. corp. $3 \frac{1}{4}$ lin.

Habitat in stercore. D. MacLeay.

Descr. Statura et magnitudo Sc. conflagrati, at differt elytris totis testaceis suturâ exceptâ. Elytra striata, striis punctis distinctis valde impressis.

castaneus. I2. Sc. capite tuberculato, elytris antennis pedi* busque testaceis.

Long. corp. $2 \frac{x}{2} \operatorname{lin}$.

Habitat in stercore.

Mus. D. Latbam.

Descr. Capitis tubercula vix conspicua. Thorax subcastaneus medio saturatior, punctulis adspersis impressis. Elytra testacea, striato-punctata.

conspurca- I $_{3}$. Sc. capite thoraceque nigris glabris: marginibus tus.

lateralibus albido-flavis, capite tuberculato, elytris lividis nigro-maculatis.

Linn. Syst. Nat. 549. 34. Faun. Suec. 387.

Sc. sticticus. Panz. Faun. Germ. 58.t. 4 .

Long. corp. $2 \frac{1}{2} \cdot \operatorname{lin}$.

Habitat in stercore.

Descr. Sc. inquinato similis, at paulo major et satis distinctus. Caput nigrum, tuberculis tribus obsoletis, marginibus sive angulis anticis interdum albido-flavis, interdum rufis. Thorax niger, glaber, minutissimè punctatus, lateribus albido-flavis. Scutellum fuscum. Elytra livida sive testacea, striata, maculis septem vel octo oblongiusculis fuscis sive nigris ordinibus duobus ab angulis extérioribus anticis ad suturam obliquè dispositis. Corpus subtùs piceum.' Pedes pallidi. 
Variat maculis elytrorum confluentibus.

Entomologi visi sunt dubitare quisnam sit reverà $S c$. conspurcatus Linnæi. Cùm nulli iconi fides satis dari possit, hanc descriptionem, ex Linnæi ipsius specimine desumptam, accuratiùs elaboravi. Plerique quidem horum parvorum Scarabæorum elytris griseis testaceisque nigro-maculatis notabilium, sive habitum sive formam spectes, tam valde affines sunt, quod meras varietates esse facilè diceres. At cùm hæ varietates notas suas constanter præ se ferunt; porrò autem cùm alii auctores species distinctas haberi voluerunt, illorum exemplo ductus et ipse distinctas scripsi: eòque lubentiùs hoc feci, quod icones plurimorum in Panzeri Faunâ Germanicâ, opere eximio, depictas, demum licet conferre.

14. Sc. thorace atro, capite trituberculato, elytris inquinatus. testaceis striatis: maculis baseos posticè confluentibus nigris.

Oliv. i. $3 \cdot 84 \cdot 90 . t .26 \cdot f \cdot 22 \mathrm{I}$.

Long. corp. $2_{4}^{\mathrm{x}}$ lin.

Habitat in stercore.

Descr. Caput atrum, tuberculis tribus medio acuto; clypeo subemarginato, margine utrinque reflexo. Thorax ater, glaber, punctulatus, margine subrufescente. Scutellum nigrum. Elytra testacea, punctato-striata; suturâ, liturâ marginali, maculisque tribus a medio baseos ad dorsum obliquè confluentibus nigris, et maculis quatuor parvis nigris tesselato-positis inter terminum posteriorem lituræ et suturam.

15. Sc. thorace nigro glabro, capite tuberculato, attamina-, elytris testaceis: maculis quinque nigris. tus.

Sc. inquinatus. Panz. Ent. Germ.7.23.

Panz. Faun. Germ. 28. t. 7 .

Long. corp. $2 \frac{\pi}{2} \operatorname{lin}$.

Habilat in stercore.

DESCR. Caput et thorax atra immaculata, oculo armato punctata. Elytra testacea, striata, maculis quinque nigris in singulo elytro; unâ ad basin oblongiusculâ, alterâ 
prope marginem exteriorem longiori, tertiâ irregulari prope suturam, quartâ pone medium angulari, ultimâ ad apicem transversim positâ. Corpus subtùs nigrum. Pedes picei.

$V$ ar. Interdum thoracis lateribus rufescentibus.

fadatus. 16. Sc. ater, capite subtuberculato, elytris testaceis : suturâ lituris binis obliquis lunulâque nigris.

Long. corp. $2 \frac{T}{4}$ lin.

Habitat in stercore.

DESCR. Caput nigrum, emarginatum, obsoletè tuberculatum. Thorax ater, punctulatus. Scutellum nigrum. Elytra testacea, punctato-striata, suturâ nigrâ, lituris duabus nigris, ad basin, intimâ obliquâ, exteriore ferẻ longitudinali, et lunulâ nigrâ prope apicem extrorsum versâ. Corpus subtùs nigrum. Pedes picei.

ciliaris. $\quad$ I 7 . Sc. pilosus, thorace planiusculo ciliato: lateribus pallidis, elytris luridis nigro-maculatis.

An Sc. contaminatus var.? Fab. Ent. Syst. i. a.35. II 4. An Sc. pubescens? Oliv. i. 3. 91. 101.t.24. $f .205 . a$, b. Lons. corp. 3 lin.

Habitat in stercore equino copiosissimè, quod brevi tempore dissipat.

Descr. In omnibus simillimus Sc. conspurcato, at primò pilosus evadit, et conspurcatus glaber; tum thorax modicè convexus est. Denique latera thoracis ciliata sunt in Sc. ciliari, at in Sc. conspurcato glaberrima. In cæteris hæc animalia apprimè conveniunt:

centrolinea-I 8. Sc. ater, elytris griseis: suturâ liturâque lineâ tus. mediâ griseâ exceptâ nigris.

Panz. Faun. Germ. 58. 1.

Long. corp. 2 lin.

Habitat in stercore.

Descr. Habitus et statura Sc. inquinati, sed major. Clypeus ater, punctatus, nitens, trituberculatus, anticè emarginatus, margine antico reflexo. Thorax ater, nitens, punctatus, margine immaculato. Scutellum nigrum, triangulare. Ely tra grisea, punctato-striata, nitida, 
suturâ maculisque oblongis nigris: hæ maculæ in dorso ita confluunt, ut in centro lineolam griseam relinquant, quæ constanter observatur: macula ad apicem utriusque elytri nigra semper adest. Pedes fusci. Corpus subtùs atrum, nitidum. Faun. Germ.

19. Sc. capite tuberculato, thoracis margine pal- Gilituratus. lido: puncto nigro, elytris griseis: liturâ nigrâ. An. Sc. lividus? Oliv. i. 3. 86. 93.t. 26. $f .222$. a, b. Long. corp. 2. lin.

Habitat in stercore.

DESCR. Totum corpus nitidiusculum. Thorax margine pallido, at punctum nigrum utrinque in margine pallido. Elytra grisea, suturâ et liturâ maximâ longitudinali nigris. Pedes flavescentes, tibiis tarsisque piceis. Corpus subtùs flavescit. Punctum marginis thoracis constans. Litura variat maxima aut minor, et interdum deest. Elytra Sc. conspurcati, sed lituram unicam satis magnam, neque maculas plures gerit, aut puncta. Differt a Sc. conspurcato, corpore subtus omni flavo nec nigro.

20. Sc. niger, capite tuberculato, margine thoracis spbacelatus. pallido, elytris griseis punctato-striatis: liturâ unicâ fuscâ.

Panz. Faun. Germ. 58.t.5.

Long. corp. $2 \frac{1}{2}$ lin.

Habitat in stercore copiosissimè.

DEscr. Antennæ nigræ. Caput obsoletè tuberculatum, nigrum. Thorax niger, nitidus, minutissimè punctatus, marginibus lateralibus lividis. Scutellum fuscum. Elytra grisea sive sordidè testacea, striata, striis ex punctis impressis, suturâ liturâque magnâ longitudinali ad angulum exteriorem baseos eroso-attenuatâ fuscis. Corpus subtùs nigrum. Pedes pallidi.

Variat elytris scabriusculis, et puncto fusco prope scutellum.

21. Sc. niger obscurus, capite trituberculato, turpis. elytris brunneis duplicato-striatis.

Sc. Anachoreta? Panz. Faun.Germ.35. I. Long. corp. $2 \frac{x}{4} \operatorname{lin}$. 
Habitat in stercore.

DESCR. Thorax niger, punctulatus, punctulis numeroassimis, margine anticè tenuissimo pallido. Elytra brunnea, punctato-striata, striis per paria arctè approximatis. Abdomen subtùs nitidiusculum. Pedes picei.

rifficrus. 22. Sc. niger, capite obsoletè trituberculato, elytris pedibusque rufis, femoribus piceis.

Long. corp. 2 lin.

Habitat in stercore ovino. Captus Septembre ineunti 797 apud Brightwell juxta Woodbridge, Suffolciâ.

Mus. D. Kirby.

Descr. Sc. turpi similis, sed minor. Elytra rufa, striata, striis punctatis, striarum interstitiis punctulatis. Alæ nigræ.

testaceus. 23. Sc. testaceus, capite bituberculato, elytris punctato-striatis.

Fab. Syst. Ent. 15. 50. Sp. Ins. i. 16. 63. Mant. i. 9. 69. Ent.Syst.i.a.27.83. Vill.1.20.22. Gmel.1548. 185. Panz. Ent. Germ. 5. 17.

Panz. Faun. Germ. 28. t. 5. Oliv. i. 69. 77. t. I7. $f$. I58. Jablonsk. Coleopt. t. 12. f. 3 .

Long. corp. 4 lin.

Habitat

Mus. D. Lee.

DEScr. Statura Sc. vernalis, at triplo minor, totus pallidè testaceus. Tubercula duo parva in fronte. Thorax convexus, punctis vagis plurimis adspersus. Elytra striata, striis punctatis. Subtùs hirtus. Fab. Syst. Ent.

Frossor. 24. Sc. niger, thorace subretuso, capite tuberculis tribus : medio subcornuto.

Linn. Syst. Nat. 548. 31. Faun. Suec. 384. Pontop. Dan. Atl. 665. 6. Payk. Faun. Suec. 7. Fab. Syst. Ent. 14. 17. Sp. Ins. i. 15. 59. Mant. i. 8. 62. Ent. Syst.i. a. 23. 72. Vill.i. I7. I 5. Gmel. I546.3i. Geoff. i. 82. 20. Fourc. Ent. 10. 20. Faun. Fred.1.3. Hoppe Ins. Ert. 26. Laich. 10. 4. Preys. Bob. Ins. 18. I4. Herbst. Arch. 5. 8. Brabm. Ins. Kal. i. 38. 125. Fues. Nov. Mag. Ven. Moll. 371. 4. Harr. 9. 6. Ins. Helv. I. 9. Panz. Ent. Germ. 2.6. Faun. Ingr. 2.3. Goeze. E. B. ..2I.3I. 
Oliv. i. 3. 75. 78. t. 20. f. 184. a, b. Voet. Coleopt. t. 21. f. I4I, I42. Jablonsk, Coleopt. t. I2. f. I. Scheeff. Icon. t. I44. f. 7, 8. Mart. Eng. Ent.t. 3 . f. 3o. Panz. Faun. Germ. 28. t. 4. Act. Nidr. 4. 314. 2. $t$. 16. $f$. 1. mala.

Long. corp. 6 lin.

Habitat in stercore.

DESCR. Corpus totum atrum, glabrum, læve, nitidum. Elytra oblonga, concolorat, striata. Antennæ lamellatæ. Alæ fuscæ. Thorax valde convexus.

25. Sc. niger, thorace inermi, capite tuberculis tri-fcetens. bus: medio acuto, elytrorum limbo ferrugineo.

Fab. Mant. i. 8.63. Ent. Syst.i. a. 24.75. Payk. Faun. Suec. i. I1. I4. Gmel. I547. I76. Jablonsk. ii. I73. 109. Faun. Ingr. 2. 4. Panz. Ent. Germ.3. 9.

Panz. Faun. Germ.48. t. I. Oliv. i. 3.85.92. t. 9. f. 7 I. a, b.

Sc. vaccinarius. Jablonsk. 138.t. I2. $f \cdot 5$.

Long. corp. 3 lin.

Habitat in stercore.

Descr. Fortè mera varietas Sc. fimetarii. Duplo minor Sc. Fossore. Thorax lævis, ater, nitidus, maculâ marginali ferrugineâ. Elytra striata, nigra, limbo imprimis baseos ferrugineo. Abdomen atrum, ano rufo. Pedes atri. Ent. Syst.

An varietas Sc. Scrutatoris, potius quam fmetarii?

26. Sc. niger nitidus, capite tuberculis tribus terrestris. æqualibus, elytris leviter ftriatis.

Fab. Syst. Ent. 15.48. Sp. Ins. i. 16.61. Mant. i. 8. 66. Ent. Syst. i. a. 25.78. Vill. i. 20.21. Gmel. 1547. I79. Jablonsk. ii. I70. 107. Goez. Ent. Beytr. I. 68. I8. Panz. Ent. Germ. 4. II.

Panz. Faun. Germ. 47.t.3. Oliv. i. 3. 76. 80. t. 24. f. 209. a, b. Mart. Eng. Ent.t. 2.f. 14.

An Sc. ater? De Geer, iv. 270. I6.

Long. corp. $2 \frac{1}{2}$ lin.

Habitat in stercore bovino et equino.

Vox. I. 
Descr. Affinis Sc. Fossori, at triplo minor. Tubercula capitis minora, breviora, obtusiora. Elytra striata. Syst. Ent.

pusillus. 27. Sc. niger, capite tuberculis tribus æqualibus, elytris lévissimè striatis brunneis.

Panz. Ent. Germ. 8. 28. Payk. Faun. Suec. i. 10. 12. Panz. Faun.Germ.49.t. II.

Long. corp. $2 \frac{1}{2}$ lin.

Habitat in stercore.

In musæo D. Kirby.

DESCR. Præcedenti simillimus (si varietas constans) sed obscurior. Thorax punctulatissimus. Elytra brunnea sive rufo-fusca, striata, striis quasi acu ductis levissime punctulatis.

obscurus. 28. Sc. niger, capite tuberculis tribus: intermedio subcornuto, elytris obscuris striatis.

Long. corp. 3 lin.

Habitat in stercore.

In musæo D. Kirby.

DesCr. Duobus præcedentibus simillimus, fed major. Clypeus tuberculis tribus, medio subcornuto, lineâque anticè carinatâ curvâ. Thorax profundus, convexus, punctulatus, nitens. Elytra thorace obscuriora, fusca, suturâ nigrâ, punctato-striata, striarum interstitiis punctulatis. Pedes nigri, femoribus anticis magnis. $V$ ariat elytris totis nigris.

subterraneus.

29. Sc. ater, thorace inermi glabro, capite tuberculis tribus, elytris striis crenatis.

Linn. Syst. Nat. 548. 28. Faun. Suec. 382. Payk. Faun. Suec. i. 7, 8. Fab. Syst. Ent. I4. 46. Sp. Ins. i. 15. 58. Mant. i. 8.61. Ent. Syst. i. a. 23.70. Vill.i. 17.13. Gmel.1546.28. De Geer, iv. 267. 12. Schrank. 7. Fourc. i. 8. I1. Fuesl. Arcb. ed. Gall. 67.7. Herbst. Arcb. i. 4. 7. Ins. Helv. 1. 8. Faun. Etrusc. 9. Hellw. 9. Panz. Ent. Germ. 2. 5. Faun. Ingr. 2. 2.

Panz. Faun. Germ.28.t.3. Oliv. i. 3. 76. 79. t. 18. f. 162, a, b. Jablonsk. Coleopt. t. 11 , f. 6. Preys. Bob. Ins. 20. 16. t. I. f. 3. Mart. Eng. Ent. t. 4. $f \cdot 33$. mala. 
Long. corp. 3 lin.

Habitat in collibus, Linn. In stercore.

Descr. Clypeus obtusissimus. Thorax punctis rarioribus adspersus. Elytra striata, striis singularibus excavato-punctatis. Faun. Suec.

Affinis Sc. Fossori, at multo minor. Fab.

30. Sc. niger, thorace inermi, capite tuberculis bamorrboitribus, elytris striatis posticè rufis. dalis.

Linn. Syst. Nat. 548. 33. Faun. Suec. 386. Fab. Ent. Syst.i. a. 29.33. Faun. Ingr. 3. 8. Vill. i. 18. 17. Gmel. 1545.33. De Geer, iv. 27 I. 17. Scbrank. 8. Fourc. i. 15. 7. Panz. Ent. Germ.8. 27. Payk. Faun. Suec. i. 8. 10.

Oliv. i. 3.83.89.t.26.f.223. a, b. Jablonsk. Coleopt. ii. t. 12.f. I1. Mart. Eng. Ent.t.4.f.3 1. mala. Panz. Faun. Germ. 28. $t .8$.

Sc. sanguinolentus. Fuesl. Arch. ed. Gall. 68. 12. t. I9. f. 4. Herbst. Arcb. 6. 15. t. 19. f. 4 .

Sc. alpinus Scop. 2I. ?

Sphæridium ustulatum. Preys. Bob. Ins. 24. 31. t. 2.f. 8. Long. corp. 3 lin.

Habitat in stercore.

Descr. Clypeus subemarginatus. Caput tuberculis tribus, lateralibus vix conspicuis. Thorax lævis punctatus. Elytra sulcata, apice fusco-ferruginea. Pedes nigri, interdum picei.

3 I. Sc. niger, thorace inermi, clypeo tuberculo granarius. solitario, elytris substriatis margine postico testaceis.

Linn. Syst. Nat. 547.23. Vill.i. I4. 8. Gmel. 1548.23. Payk. Faun. Suec. i. 9. I I. Fab. Syst. Ent. 16. 56. Sp. Ins. i. I7. 70. Mant. i. 9. 27. Ent. Syst. i. a. 29.92. Herbst. Arcb. 6. 4. Faun. Etrusc. 15. Hellw. 15. Panz. Ent. Germ. 7. 26. Harr. 9.

Panz. Faun. Germ. 43. t. 3. mala. Oliv. i. 3.82.88. t. 18. f. I72. a, b. Jablonsk. ii. 1 50. 94. t. 12. f. 10. Scbaff: Icon. t. 144.f.5. Preys. Bob. Ins, 29.28.t. I. f. 5. mala. 
Long. corp. $2 \frac{x}{2}$ lin.

Habitat in ligno putrido, locis suffocatis. Panz.

DESCR. Statura et magnitudo ferè Sc. terrestris, et forté mera varietas. Corpus nigrum nitidum, margine posticè tantum elytrorum ferrugineo. Clypeus emarginatus. Caput tuberculo unico. Thorax muticus, lævis, punctatus. Elytra striata. Pedes nigri, interdum brunnei. Oliv.

Obs. Similis omninò Sc. bcemorrboidali, sed differt, major et scutello longiori.

stercora- $\quad 32$. Sc. ater glaber, elytris sulcatis, thorace utrinque puncto excavato, capite rhombeo.

Linn. Syst. Nat. 550. 42. Faun. Suec. 388. Pontop. Dan. Atl. i. 665. Io. Fab. Syst. Ent. I7. 60. Sp. Ins. i. 18. 74. Mant. i. 10. 81. Ent. Syst. i. a. 30, 97. Vill. i. 23. 34. Gmel. 1549. 42. Scbrank. 23. Scop. 26. Raii Ins. 74. 1.-90.7. Payk. Faun. Suec. i. 4. 4, Geoff. i.75.9. Fourc. i. 7.9. Fuesl. Arcb.69. 15. Herbst. Arcb. 7. I8. Ins. Helv. 2. 15. Laicb. 9. 2. Faun. Fred. 1. 5. Goetze. i. 26. 42. Faun. Ingr. 3. 9. Harr. 12. Preys. Boh. Ins. 26. 24. Panz. Ent. Germ. 8. $3^{\circ}$. Brabm. Ins. Kal. i. I1. 40.

Panz. Faun. Germ. 49. I. Oliv. i. 3.64. 72. t. 5. f. 39 . a-d. De Geer, iv. 259.4. t. 9. f. 10, 11. Voet. Coleopt. t. 20, f. 134. Jablonsk. ii. 252. I57. t. A.

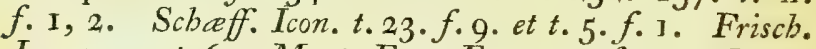
Ins. 4. 13. t. 6. Mart. Eng. Ent. t. 3.f.25. Faun. Etrusc. I7.t. 1.f. т. Hellw. 17.t. . $f$. .

Long. corp. I unc.

Habitat in stercore et cloacis.

DESCR. Caput clypeo munitum, rhomboide obtuso medio elevato, ac si esset squama. Antennæ clavatæ, capitulo pallido, caule rubicundo, bulbo sive infimo articulo magno, setis coronato, utrinque piloso. Oculorum septum setis ciliatum. Thorax latus, lævis, ad margines punctulatus, puncto insuper majori utrinque excavato. Scutellum latum, medio punctatum. Elytra striata, striis plurimis punctatis. Corpus subtùs atro- 
cærulescens villosum. Os maxillis duabus setis nigris ciliatis. Pedes setosi, setis femorum longitudinaliter per lineas dispositis. Femora postica denticulo instructa. Tibiæ anticæ sex-dentatæ ; intermediæ et posticæ tridentatæ, dentibus per totam tibiæ crassitiem ductis, setis coronatis.

Var. $\beta$. subtùs viridi-cæruleus, femoribus posticis simplicibus, tibiis anticis serratis, dentibus tribus extremis majoribus. Elytrorum striæ vix punctatæ.

33. Sc. niger, thorace utrinque impresso, femori-spiniger. bus posticis bidentatis.

Long. corp. I I lin.

Habitat — Captus apud Barham, Suffolciâ, exeunte Octobre. D. Kirby.

DESCR. Ad Sc. stercorarium proximè accedit, sed totus niger. Antennæ caule fusco sive piceo, capitulo nigricanti. Thorax obscurus, utrinque excavato-punctatus, puncto majori impresso; posticè lineâ intermediâ dimidiatâ e punctis excavatis constante. Scutellum medio longitudinaliter subdepressum. Elytra obscura, striata, striis subpunctatis. Femora tincturâ sed łix distinguendâ violaceo-viridi imbuuntur; postica dentibus duobus validis armantur, quorum exterior major, interior continuatio est femorum appendiculi. Tibiæ anticæ, quod in hoc genere singulare est, trigonæ, septemdentatæ, dente tertio ab apice magis extante, recto.

34. Sc. niger, elytris sulcatis, thorace utrinque foveatus. punctis duobus excavato, scutello violaceo.

Long. corp. 7 lin.

Habitat in stercore humano. D. Kirby.

DESCR. Præcedenti simillimus, sed thorax punctis quatuor excavatis, disco rarius lateribus confertius punctulatis. Scutellum violaceum. Elytrorum et thoracis margines atro-cærulescentes. Femora postica denticulo uno alterove instructa. Tibiæ anticæ sexdentatæ. Tarsi picei. 
Sexus alter punctis duobus interioribus thoracinis majoribus, quasi foveatis.

Variat colore, totus scilicet nigro-æneus.

Mutator. 35. Sc. violaceus, thorace punctis quatuor impressis, elytris sulcatis, scutelli margine membranaceo. Scbaff. Icon. $t \cdot 23 \cdot f$. I.?

Long. corp. $9 \frac{\mathrm{x}}{3}$ lin.

Habitat in stercore humano. D. Kirby.

DESCr. Antennæ caule fusco, capitulo nigricanti. Thorax atro-violaceus, lateribus confertiùs, disco rariùs punctatus, punctis insuper utrinque duobus foveatis, exteriore majori fundo punctato, interiore minori lunulato. Linea intermedia longitudinalis, quæ a capite ultra dimidiam thoracis profunditatem e punctis excavatis constat, dein continua exaratur, et demum in punctum unum alterumve desinit. Margo omnis et puncta violaceo-inaurata. Scutellum viride, medio longitudinaliter depressum, margine utrinque membranaceo. Elytra amethystina cum tincturâ rubini, striata, striis punctatis variis intervallis ductis. Stria suturæ proxima a basi per tertiam partem longitudinis latè et profundè sulcata est. Corpus subtus viride, pedibus violaceis, sed tarsi omnes picei.

Var. $\beta$. thoracis punctis interioribus magis obsoletis, rotundatis, intra quæ et marginem anticum lineola transversa, obsoletè impreffa. Scutellum atro-cærulescens, medio longitudinaliter subdepresso, punctato, punctis excavatis, cæruleo-inauratis. Elytra reverà nigra sed cærulea apparent. Color cæruleus ex striis cæruleo-inauratis, certis intervallis ductis, punctatis exoritur. Corpus subtus amœnè amethystinum, violaceum.

niger.

36. Sc. suprà obscurus niger lævie, subtùs atroviolaceus, pedibus æneis.

An Sc. hemisphæricus? Oliv. i. 3. 66. 74. t. 2.f. ${ }_{5}$. Long. corp. 7 lin.

Habitat

Ex museo D. MacLeay. Descr. 
Descr. Antennæ, caput, thorax et elytra tota nigra, glabra. Caput clypeo rhombeo vertice prominulo ut in Sc.stercorario. Thorax marginatus, lineâ longitudinali in medio obsoletè impressâ, puncto laterali utrinque impresso. Elytra oculo armato obsoletè striata. Corpus subtùs atro-violaceum. Pedes viridi-ænei.

37. Sc. elytris glabris læviffimis, capitis clypeovernalis: rhombeo: vertice prominulo.

Linn. Syst. Nat. 551. 43. Faun. Suec. 389. Faun. Ingr. 4. I0. Fayk. Faun. Suec. i. 6. 6. Fab. Syst. Ent. 17.61. Sp. Ins. i. 19. 75. Mant. i. 10.82. Ent. Syst. i. a. 31.98. Vill. i. 23.35. Gmel. 1549. 43. Scbrank. 24. Scop. 27. Laich. 9. 3. Brabm. Ins. Kal. i. 12. 4I. Geoff. i. 77. 10. Fourc. i. 7. 10. Herbst. Arch. i. 7. I9. Ins. Helv. 16. Pontop. Dan. Atl. i. 665. I1. Poda.Mus. Grac. 19. 6. Faun. Fred. 1.6. Preys. Bob. Ins. 27.25. Faun. Etrusc. 18. Hellw. 18. Panz. Ent. Germ. 9.32. Harr. 13.

Panz. Faun Germ. 49.t. 2. De Geer, iv. 262. 5.t. 10. f. 4. Oliv. i. 3. 66. 73.t. 4. f. 23. a, b. Jablonsk.ii. 258. 158.t.18.f. 1. Voet. Coleopt.t. 20. f. 135. Sulz. Hist. Ins. t. 1. f. 6. Mart. Eng. Ent.t. 2.f.9.

Long. corp. 9 lin.

Habitat in stercore primo vere.

Captus juxta Woodbridge tempore autumnali copiosè I 795, I 796 .

DESCR. Loco et facie adeo similis Sc. stercorario, ut facilè solâ ætate differre crederetur; differt tamen a stercorario, $\mathbf{I}^{\circ}$. magnitudine qua stercorario cedit; $2^{\circ}$. elytris non sulcatis; 3 . colore cyaneo sive cæruleo nitido; $4^{\circ}$. antennis omnino nigris, nec femoribus maculâ ferrugineâ.. Faun. Suec.

$3^{8}$. Sc. violaceus nitidus, thorace utrinque im-sylvaticus. presso, elytris substriatis, tarsis piceis.

Payk. Faun. Suec. i. 5. 5. Panz. Ent. Germ.8.31. Scriba. Epbem. 3. 250. Harr. 10.

Long. corp. 8 lin.

Habitat in stercore. 
Descr. Caput cæterorum hujus familiæ. Thorax et elytra reverà nigra; sed color violaceus, qui per totam insecti paginam superiorem nudis oculis obduci videtur, in thorace ex punctis excavatis, et in elytris ex striis obliteratis violaceo-inauratis exoritur. Hæ striæ variis intervallis ducuntur, interstitiis transversim rugulosis. Tibiæ anticæ serratæ, serraturis 6. Ad Sc. vernalem proximè accedit.

In stercore tempore autumnali sed rarò occurrit. Ubi provenit hæc species $S c$. vernalis nunquam invenitur. D. Kirby.

39. Sc. niger opacus, tuberculis rugosis, fronte immarginatâ obtusâ.

Linn. Syst. Nat. 551.48. Faun. Suec. 390. Geoff. i. 78. II. Scbrank.26. Vill. i. 25. 28. Brabm. Ins. Kal. i. 32. 110.

Mart. Eng. Ent. $t .3 \cdot f \cdot 26$.

Sc. femoratus. De Geer, iv. 269. I4. t. 10.f. I2.

Sc. subterraneus. Fourc. i. 8. 1 I.

Trox sabulosus. Fab. Syst. Ent. 31. J. Sp. Ins. i. 34. I. Mant. i. I8. I. Ent. Syst. i. a. 86.2. Gmel. 1585. 48. Herbst. Arch. 12. i. Ins. Helv. I9. Faun. Fred. 1. 7. Preys. Bob. Ins. 48. 50. Panz. Ent. Germ. 35. I. Petagn. Ins. Cal.3. I०. Laicb. 28. 1. Faun. Ingr. 10. 31. Payk. Faun. Suec. i. 79. I. Oliv. i. 4. 8. 6. t. I. $f$. I. a, b, c. Sulz. $t .34 \cdot f \cdot 3 \cdot$ Panz. Faun. Germ. 7. t. I. Jablonsk. Coleopt. 3.t.2I. f. I. Scriba. 44. 9.t. 5.f.2.2. a.

Long. corp. $4 \frac{x}{2}$ lin.

Habitat in sabulo et terrâ siccâ.

Descr. Simillimus Silpbae sabulosce. Antennæ pallidæ, basi intùs valde pilosæ. Caput deflexum, punctulatum, fronte lunatâ. Thorax caput semiambiens, rugosus, posticè obsoletè trilobus, angulo intermedio subbifido. Scutellum basi excavatum. Elytra valde convexa quasi fornicata, latera abdominis obvolventia, tuberculis rugosa, striis quatuor elevatis albo-punctatis striata, interstitiis striarum duarum suturæ proximarum sub lente élevato-lineatis. Abdomen planiusculum, minus opacum. Tibiæ anticæ tridentatæ. 
40. Sc. fusco-cinereus, elytris elevato-striatis line-lutosus. at isque, fronte marginatâ acutâ.

Long. corp. 6 lin.

\section{Habitat - In mus. D. Latbbury.}

Descr. Totum insectum polline fusco-cinereo obducitur quasi lutosum. Caput angulatum, medio elevatum, fronte marginatâ acutâ. Antennæ ut in præcedenti. Thorax subrugosus, posticè obsoletè quinquelobus, angulo intermedio acuto. Elytra sicut præcedentis convexa, latera abdominis obvolventia, striata, striis quatuor punctorum elevatorum oblongorum, interstitiis lineis elevato-punctatis notatis. Abdomen planum, intra fornicem elytrorum retractum. Tibiæ anticæ simplices, compresso-clavatæ.

$4 \mathrm{I}$. Sc. fuscus obscurus, thorace subcanaliculato, arenarius. elytris obsoletè striatis.

Sc. arenosus. Gmel. 1586. 398 .

Trox arenarius. Fab. Mant.i. 18.2. Ent. Syst, i, a.87.3. Payk. Faun. Suec. i. 80. 2.

Long. corp. 3 lin.

Habitat- estuaries In mus. D. Kirby.

Descr. Statura et habitus præcedentium, sed Sc. sabuloso duplo minor. Totus fuscus valde obscurus. Antennæ rufescentes, basi pilosæ. Caput deflexum, clypeo planiusculo, fronte obtusâ. Thorax punctulatus, obsoletè lon • gitudinaliter canaliculatus. Elytra convexa, substriata, striis circiter decem, striarım interstitiis elevato-punctatis. Abdomen planiusculum. Tibiæ anticæ extrorsum tridentatæ, introrsum spinulis duabus instructæ.

42. Sc. piceus, antennis pallidis, elytris læevibus. rufipes.

Linn. Syst. Nat. 559. 86. Faun. Suec. 403. Faun. Ingr. 4. I1. Fab. Syst. Ent. 19. 68. Sp. Ins. i. 20. 84. Mant. i. 10. 92. Ent. Syst. i. a. 34. I 10. Vill. i. 36.60. Gmel. 1552. 86. Scbrank. 30. Panz. Ent. Germ. 9. 34. Herbst. Arch. 7. 20.

. Oliv. 
Oliv. i. 3. 87. 94. t. 18. f. 171. Voet. t. 2. f. 143.? Mart. Eng. Ent.t.3.f. 29. Panz. Faun. Germ. 47. t. 10.

Sc. capitatus. De Geer, iv. 263. 7.t. 10. $f$. 6 .

Sc. oblongus. Scop. 19. Brabm. Ins. Kal. i. 63.206. Scriba. 36.6.t. 4.f.6. a, b.

Long. corp. 5 lin.

Habitat in stercore.

Descr. Totus ater, glaber: capitis clypeo obtuso. Antennæ summo apice præsertim rufæ, alias fusco-pallidæ. Pedes extimis articulis rufo-pallidi. Elytra striata, nigra, posticè obtusa sive inflexa. Alæ longæ. Faun. Suec.

Variat interdum totus piceus.

Gagates. 43. Sc. niger, elytris striatis lævibus, tarsis sanguineis.

Geoff: i. $83 \cdot 2$ I.

Oliv. i. 3.87.95.t.24.f. 213. Mart. Eng. Ent. t. 4. f. 39 .

Sc. gagatinus. Fourc. i. IO. 2 I.

Sc. nigripes. Fab. Ent. Syst. i. a. 35. I I. Panz。 Ent. Germ. 9. 35. Faun. Germ. 47. t. 9.

Sc. Juridus var. $\beta$. Payk. Faun. Suec. 16.

Long. corp. 4 lin.

Habitat in stercore tempore vernali.

Descr. Niger, tarsis solum sanguineis. Clypeus lunatus, margine reflexo, pofticè lineis duabus impressis in angulum obtusum conniventibus. Suprà punctulatissimus, etiam elytra, quæ striata sunt. Tibiæ omnes tridentatæ.

variegatus. 44. Sc. niger, elytris striatis dimidiato-flavis. Herbst. Arcb. 9.27.t. I9.f. 12. Panz. Faun. Germ.47. t. 8 .

Sc. varius. Gmel. 1553.209.

Long. corp. $4 \frac{1}{2}$ lin.

Habitat in stercore.

DESCR. 
DEscr. Præcedenti per omnia simillimus, sed elytrorum apex et margo lateralis sordidè flavus, quæ flavedo dentes introrsum immittit.

45: Sc. niger, elytris sordidè flavis : sulcis nigris, luridus. interstitiis nigro maculatis.

Fab. Syst. Ent. 19.69. Sp. Ins. i. 17.69. Mant. i. 9.76. Ent. Syst. i. a. 29.91. Vill. i. 20. 25. Gmel. 1546. 174. Hoppe. Ins. Erl. 26. Payk. Faun. Suec. i. I3. 16. Faun. Etrusc. 14. Hellwu. 14. Preys. Bob. Ins. 38. 37. Panz. Ent. Germ. 7. 25.

Panz. Faun. Germ. 47.t.6. Oliv. i. 3.90. 100. t. 18. f. 168.t. 26.f. 168. b. Jablonsk. 2. t. 18.f.3. Voet. t.21.f. 144. Scbaff. Icon. t.26.f.8.? Mart. Eng. Ent. t. $3 \cdot f \cdot 23$.

Sc. interpunctatus. Gmel. 1553. 208. Fues. Arcb. 70. 2I. t. 19. a. f. II. Herbst. Arch. 8. 26. t. I9. f. II.

Long. corp. 4 lin.

Habitat in stercore vaccino.

DESCr: Caput et thorax atra nitida. Elytra striata, grisea, lineolis maculisque nigris. Syst. Ent.

Variat maculis pluribus.

46. Sc. niger, elytris sordidè flavis : sulcis nigris. nigro-sulLong. corp. $4 \frac{1}{4}$ lin.

catus,

Habitat in stercore vaccino cum quatuor præcedentibus vere. D. Kirby.

$V a r$. a. Pedibus intermediis, posticis, anoque rufescentibus.

B. Pedibus anoune nigris.

Quatuor præcedentes in omnibus sibi invicem adamussim respondent, colore vario et maculis elytrorum solum distinguuntur. Omnibus palpi fusci; antennæ nigræ stipite fusco ; caput punctulatum, lunatum, marginatum, vertice sub-prominulo, posticè exaratum, lineis duabus obsoletis in angulum obtusum conniventibus; thorax utrinque marginatus, latus, punctulatissimus; scutellum 
scutellum basi punctulatum; elytra punctato-striata, interstitiis striarum punctulatis ; pedes nigri, tarsis sanguineis.

Sc. contaminatus Panz. Faun. Germ. 47. t. 7. varietas etiam hujusce speciei videtur, at iste nondum in Angliâ captus est.

4-macula- 47. Sc. nigeroblongus, elytris maculis duabus rubris. tus. Linn. Syst. Nat. 558. 84. Faun. Suec. 398. Faun. Ingr. 4. 12. Fab. Syst. Ent.19. 70. Sp. Ins. i. 21. 86. Mant. i. ј0. 94. Vill. i. 35.38. Gmel. I551. 84. Faun. Etrusc. 20. Hellw. 20. Brabm. Ins. Kal. i. 65. 209.

Oliv. i. 3. 92. ro3. t. I9: f. I74. a, b. Jablonsk. 2. t. 18.f. 10. Don. Brit. Ins. t. 70.f.3.

Sc. 4-pustulatus. Fab. Ent. Syst. i. a. 36. г г6. Panz. Ent. Germ. 10.39. Faun. Germ.43. t. 5. Payk. Faun. Suec. i. 24. 29.

Long. corp. $\mathrm{I} \frac{3}{4}$. lin.

Habitat in stercore.

Mus. D. Kirby.

DEscr. Corpus oblongum, nigrum. Capitis clypeus intrusus. Elytra striata; macula parva in angulo elytrorum ad basin sita est, et major versus apicem elytri. Pedes nigri. Faun. Suec.

sanguino- 48. Sc. niger oblongus, elytris striatis maculâ ad lentus. basin apiceque rubris.

Long. corp. $2 \frac{x}{2}$ lin.

Habitat in stercore.

DESCR. Similis omnino SC bemorrboidali, sed distinetus. Paulo major. Scutellum longius. Macula parva, obscura; rubra, in angulo elytrorum ad basin sita est; apices elytrorum manifestè rubri. Pedes nigri, tarsis rufis.

testutina- 49. Sc. niger, elytris sulcatis piceis ferrugineorius. punctatis.

Fab. 
Fab. Syst. Ent. 19. 72. Sp. Ins. i. 21. 89. Mant. i. 11. 98. Ent. Syst. i. a. 38, J22. Vill. i. 37.63. Gmel. I551. 200. Preys. Bob. Ins. 95. 92. Panz. Ent. Germ. II. 43 .

Panz. Faun. Germ. 28. t. I2. Don. Brit. Ins. t. 70. f. r. Oliv.i. 3.93.105.t. 20.f. 186. a, b. Jäblonsk. 2.t. 18. f. 13. mala. Herbst. Arch. 7.21. t. 19.f.7. mala.

Long. corp. 2 lin.

Habitat in stercore bovino primo vere. D. Kirby et D. MacLeay.

Descr. Capitis clypeus rotundatus, emarginatus, vix tuberculatus. Thorax scaber, ater. Elytra profunde sulcata, picea, punctis ferrugineis per paria distributis adspersa. Pedes picei. Syst. Ent.

50. Sc. flavescens, capite thoraceque fuscis, elytris Sus. sulcatis nigro-maculatis.

Fab. Ent. Syst. i. a.36. II7. Panz. Ent. Germ.11.4I. Brabm. Ins. Kal. i. 203. 683.

Panz. Faun. Germ. 28.t. II. Jablonsk. ii. 271. 165. t. 18.f. 9. Herbst. Arcb. 4. 29. t. 19. f. 14.

Sc. pubescens. Oliv. i. 3. 9I. IOI. t. 24. $f$. 205. a, b.

Long. corp. $2 \frac{1}{3}$ lin.

In mus. D. Kirby.

Habitat in stercore. Captus a $D$. Sowerby juxta Nordovicum.

Descr. Statura Sc. testudinariz. Totus sub-hirtus. Caput rufo-fuscum. Thoracis latera flavescentia, puncto nigricanti. Elytra flavida, lineis duabus interruptè nigris picta. Cætera sordide flavescentia, sed pedes exceptis femoribus rufescunt.

51. Sc. niger, elytris apice piceis, plantis rbododacrufis. tylus.

Long. corp. $\mathrm{I} \frac{\mathrm{T}}{2}$ lin.

Captus in stercore ovino Julio ineunte 1797, in ericeto 
ericeto prope Newmarket, juxta viam ad Barton Mills ducentem. D. Kirby.

Descr. Niger obscurus. Thorax punctulatus. Elytra striata, apicem versus profundiùs. Pedes piceo-nigri, tarsis rubellis.

merdarius. 52. Sc. ater, thoracis lateribus fub-ferrugineis, elytris testaceis: suturâ nigrâ.

Fab. Syst. Ent. 19.73. Sp.Ins. i.21.90. Ent. Syft. iv. App. 435. Vill. i. 37.64. Herbst. Arcb. 69. 17. Payk. Faun. Suec. i. 22.26. Preys. Bob. Ins. 37-35.

Oliv. i. 3: 94. 107.t.19.f. 173. a, b. Jablonsk.2.t. 18. f. 5. Mart. Eng. Ent. t. $4 \cdot f \cdot 34$.

Long. corp. 2 lin.

Habitat in stercore.

Descr. Corpus nigrum. Clypeus subemarginatus. Caput inerme. Thorax lævis, inermis, niger, lateribus testaceis. Elytra striata, flavo-testacea, suturâ nigrâ. Pedes nigri. Oliv.

Variat pedibus sordidè testaceis.

punctula- 53. Sc. niger, thorace punctato, tibiis anticis tus. plantisque omnibus rufis.

An Sc. niger. Panz. Faun. Germ. 37. t. x.?

Long. corp. 2 lin.

Habitat in sabulosis. Captus propter fluvium UR, prope Crickhowell.

Descr. Caput sed præcipue thorax punctis plurimis impressis. Elytra striata, striæ autem punctis impressis ornantur. Abdomen atrum, nitidum. Pedes atri, nitidi. Tibiæ autem anticæ, et tarsi omnes rufescunt.

Obs. Puncta omnia thoracis et elytrorum, pro ratione animaculi, majuscula, et fundo albicanti gaudent. An hoc ex loco limoso-sabuloso evenit ?

porcatus. 54. Sc. piceus, thorace punctato: lineâ impressâ dimidiatâ, elytris sulcatis.

Fab. 
Fab. Syst. Ent. 20. 75. Sp. Ins. i. 21. 92 . Mant. i. Ir. Iоr. Ent. Syst. i. a. 38 . 126 . Vill. i. 37.65. Gmel. 1552. 204. Panz. Ent. Germ. 12. 47. Payk. Faun. Suec. i. 29. 35 .

Herbst. Arcb. 8. 24. t. 19. a. f. 9. a-c. mala. Panz. Faun.Germ. 28. $t$. I4.

Long. corp. $1 \frac{1}{2}$ lin.

Habitat in stercore vaccino, primo vere. Ex mus. D. Mac Leay.

DESCR. Totum animal piceum. Antennæ rufæ. Caput planum. Thorax punctatus, lineâ longitudinali excavatâ abbreviatâ. Elytra profundè sulcata, sulcis punctis impressis.

$$
\text { * Exscutellati. }
$$

55. Sc. thorace bicorni: intermedio obtuso bifido, hunaris. capitis cornu erecto, clypeo emarginato.

Linn. Syst. Nat. 543. 10. Fuun. Suec. 379. Gronov. Zoopb. 453. Raii Ins. 103. Fab. Syst. Ent. 22. 86. Sp. Ins. i. 24. 108. Mant. i. 13. I20. Ent. Syst. i. a. 46. 150. Preys. Bob. Ins. 27. 26. Vill. i. I1.2. Gmel. 1535. 10. Scop. 22. Scbrank. I. Faun. Etrusc. 24. Hellw. 24. Laich. 16. 10. Brabm. Ins. Kal. i. 67.215. Geoff. i. 88. 1. Fourc. i. 13. I. Panz. Ent. Germ. 13. 51. Faun. Ingr. 5. 14. Pont. Dan. Atl. i. 664. 2. 8. Payk. Faun. Suec. i. 30. 37. Oliv. i. $3.114 .132 . t .5 \cdot f \cdot 36$. a, b. Roes. ii. $t$. в. $f=2$. Jablonsk. ii. t. 8. f. 7. De Get, iv. 257. 2. t. 10. $f$. I. Voet. t. 25. f. 24, 2.5. Petiv. Gazoph. t. 8. f. 4. Friscb. 4. 25.t.7. Bergstraes. Nom. i. t. 1. f. 9.t. 4. f. 7. Mart. Eng. Ent. t. 2. f. 15, 16. Scbaeff. Elem. t. 49. f. 2. t. 3.f. 2. Icon.t. 63. f. 3. Panz, Faun. Germ. 49. t. 4. Poda. Mus. Grac. 18. 3. t. I. f. 1. Don. Brit. Ins, t. 154, f. 4 .

Long. corp. Io lin.

Habitat in stercore.

Descr. Caput tegitur clypeo lunato, magno, margine elevato, antice emarginato, in cujus medio corniculum 
breve. Thorax gibbus, lævis, in medio margine acuto prominulo, longitudinaliter lineâ exaratus. Elytra lævia, singula 7 , sive 8 , sulcis minùs profundis. Faun. Suec.

Sexûs varietas thorace retuso, lævi, absque corniculis thoracinis, quare difficiliùs primùm dignoscitur. Omnibus thorax lineâ exaratus. Clypeus lunaris, emarginatus tantùm. Syst. Nat.

emargina- 56. Sc. thorace inæquali subtricorni, capitis cornu tuks. erecto emarginato.

Fab. Ent. Syst. i. a. 46. I51. Panz. Ent. Germ. I $3 \cdot 52$.

Oliv. i. 3. II5. 133.t. 8. f.64. Panz. Faun. Germ. 49. t. 5. De Geer, iv. 257.2.t. IO.f. I.

Sc. lunaris. Var. B. Laich. I6. I0.

Sc. lunaris fem. Payk. Faun. Suec. 37.

Long. corp. Io lin.

Habitat in stercore.

Descr. Nimis affinis $\delta_{c}$. lunari. Clypeus emarginatus, centro cornu parro, erecto, emarginato. Thorax anticè inæqualis, vix cornutus, at utrinque puncto lato impresso. Elytra striata. Ent. Syft.

Obs. Hic Scarabceus a præcedente valdè distinctus est, tametsi ambo sub nomine Sc. lunaris a Linnxo confunduntur; nam character specificus Faun. Suec. ed. I. n. 34I, quæ ad Sc.emarginatum certè pertin t, citatur in Faun. Suec. ed. 2. 379 ut synonyma vera Sc.lunaris qui hic perspicue describitur, quamvis descriptio specialis ed. 2. usque evidenter est ea Sc. emurginati.

nucbicornis.57. Sc. thorace rotundato nigro æneo, occipite spinâ erectâ armato, ely tris griseis nigro-irroratis. Linn. Syst. Nat. 547. 24. Faun. Suec. 381. Faun. Ingr. 5. 15. Payk. Faun. Suec. i. 3 1.38. Fab. Syst. Ent. 26. 104. Sp. Ins. i. 30. 132. Mant. i. 15. I50. Ent. syst. i. a.58. 192. Vill. i. 14. 9. Gmel. 1543. 24. Scbrank. 3. De Geer, iv. 265.9. Geoff. i. 89.3, 4. Fourc. i. 14. 3, 4. Laicb. 21. I4. Iter. Goll. 4 I. Poda. 
Mus. Grac. 18.2. Faun. Fred. 1.2. Fuesl. I1.39. Ins. Helv. I. 5. Faun. Etrusc. 29. Hellw. 29. Panz. Ent. Germ. 16.62. Pontop. Dan. Atl. i. 164.3. Gron. Zooph. 454.

Panz. Faun. Germ. 4. t. x. Oliv. i. 3. J47. I77.t.7. f.53. Roes. Ins. 2. Scar. t. A.f. 4 . Voet. t. 25. $f$. I8. Scbaff. Elem. t. 49.f. I. Icon. t. 96. $f$. I. fem. Preys. Bob. Ins. 45. 48. t. 2. f. 10. a, b. -Jablonsk. 2. t. I. $4 \cdot f \cdot 5,6$.

Long. corp. $2 \frac{5}{2}$ lin. mas. 3 lin. fem.

Habitat in stercore bovino.

-DESCR. Elytra striata, rufo-grisea, maculis nigris reticulato-confluentibus nec striatim positis depicta.

58. Sc. thorace rotundato æneo, occipite spinâ Conobita. erectâ armato, elytris rufis immaculatis.

Fab. Ent. Syst. i. a. 58. 191. Gmel. 1543. 24. Var. $\beta$. Fuesl. Arch. 73. 33. Herbst. Arcb. II. 40. Panz. Ent. Germ. 15. 59 .

Panz. Fain. Germ. 48.t.6. Oliv. i. 3. 147. 178. t. 26. $f .228$. a, b. Voet.t. 25. $f$. 20. Jablonsk. 2. t. I4. $f_{.}$., 8. Preys. Bob. Ins. 44. 47.t. 3.f. I. Mart. Eng. Ent. t. I. f. 5. ?

Long. corp. 4 lin.

Habitat in stercore bovino.

DESCR. Similis S. nucbicorni, sed thorax æneus, elytra rufa immaculata. Est tamen ubi maculæ nigræ rariores in elytris etiam hujusce apparent.

Variat cornu brevi reclinato.

59. Sc. thorace rotundato viridi-æneo, occipite $X_{i p}$ bias. spinâ erectâ armato, elytris griseis viridi-punctatis eroso-striatis.

Fab. Ent. Syst. i. a. 59. I93. Payk. Faun. Suec. i. 32. 39. Panz. Ent. Germ. 16. 36. Scbaff. Elem. t. 49. f. r. Icon. t. 73.f. 4, 5. Panz.

Faun. Germ. 49. t. 8. Mart. Eng. Ent. t. I. $f .6$. Vol. I. 
Long. corp. 5 lin.

Habitat in stercore bovino.

Descr. Statura omnino Sc. nucbicornis. Clypeus rotundatus, integer, niger, occipite spinâ erectâ, acutâ。 Thorax rotundatus, anticè subacuminatus. Elytra lævia, testacea, nigro maculata.

Fœmina clypeo lineis duabus transversis, elevatis. Ent. Syst.

verticicor- 6o. Sc. thorace griseo nigro punctato, capitis cornû nis. erecto brevissimo.

Fab. Syst. Ent. 27. 105. Sp. Ins. i. 30. 135: Mant. i. 16. I54. Ent. Syst. i. a. 61. 199. Vill. i. 20. 27. Gmel. 1544. I70. Herbst. Arcb. I2. 4I. Jablonsk. ii. 240. 147 .

Long. corp. 4 lin.

Habitat

Musæo D. Tunstall.

Descr. Statura et summa affinitas $S_{c}$. Vacca, at minor. Capitis clypeus rotundatus, æneus, cornu brevissimo recurvo. Thorax rotundatus, inermis, griseus, punctis duobus anticis et unico ad latera nigris. Elytra lævia, grisea. Pedes pallidi. Syst. Ent.

Vacca. 6r. Sc. thorace retuso, occipite spinâ geminâ erectâ.

Linn. Syst. Nat. 547. 25. Fab. Syst. Ent. 26. IOI. Sp. Ins. i. 28. I26. Mant. i. 15. 143. Ent. Syst. i. a. 55. I79. Vill. i. I5. 10. Gmel. I543. 25. Faun. Etrusc. 28. Hellw. 28. Ins. Helv. I. 6. Preys. Boh. Ins. 40. 39. Panz. Ent. Germ. 14. 57\% Laich. 20. 13.

Oliv. i. 3. I28. 15 1. t. 8. f. 65. a, b. Jablonsk. ii. t. I4. $f_{\cdot}$ 3, 4. Scbaff. Icon. t. 73.f. 4, 5 ? Panz. Faun. Germ. 12. t. 4 .

Copris. Geoff. i. 90. 5.

Copris conspurcatus. Fourc. 14.5.

Long. corp. 5 lin.

Habitat in stercore bovino.

Desce. 
Descr. Simillimus Sc. nucbicorni. Thorace æneo. Elytris fuscis, atomis fuscis; sed differt thorace anticè retuso : medio prominulo subemarginato; capitis occipite non spinâ unicâ longâ, sed 2 brevibus, erectis, nonnihil distantibus. Syst. Nat.

Obs. Similior Sc. Xipbice quam Sc. nucbicorni.

62. Sc. niger, thorace rotundato anticè impresso, nutans. occipite spinâ erectâ armato, elytris obsoletè punctato-striatis.

Fab. Mant. i. I5. I5I. Ent. Syst. i. a.59.194. Gmel. 1544. 167. Panz. Ent. Germ. 16. 64.

Sc. verticicornis.' Laich. 22. 15 .

Oliv. i. 3. 145. 176. t. 21. f. I80. a, b, c, d. Panz. Faun. Germ. 8. t. I. Jablonsk. ii. t. I4. f. IO.

Long. corp. 4 lin.

Habitat in stercore bovino.

DESCR. Simillimus S. nucbicorni, sed differt corpore toto nigro unicolore, thorace anticè impresso, et spinâ occipitis apice nutante.

63. Sc. niger, clypeo emarginato, thorace sub-ovatus. æneo, elytris abbreviatis.

Linn. Syst. Nat. 55 1. 46. Payk. Faun. Suec. i. 33. 40. Fab. Syst. Ent. 30. 124. Sp. Ins. i. 34. 158. Mant. i. 18. 180. Ent. Syst. i. a.70.237. Vill. i. 24.37. Gmel. I557. 46. Laich. i. 26. I9. Preys. Bob. Ins. 46. 49. Faun. Etrusc. 38. Hellw. 38. Panz. Ent. Germ. 19. 75. Ins. Helv. 18. Brabm. Ins. Kal. i. 67.217 .

Oliv. i. 3. I75. 220. t. 20. f. 187. a, b. Herbst. Arcb. 12. $45 . t$. 19. b. $f$. 18. Fuesl. Arcb. t. 19. b. $f .18$. Jablonsk. ii. t. 20.f. 9. Mart. Eng. Ent. t. 4. f. $3^{6 .}$ Panz. Faun. Germ. 48. t. Ix.

Long. corp. $2 \frac{1}{4}$ lin.

Habitat in stercore bovino.

DESCR. Simillimus Sc. nucbicorni, sed spina erecta occipitis deest: differt etiam corpore toto nigro unicolore. 
B. Arborei, corpore convexo, elytris non ad anum pertingentibus, sive abbreviatis.

Fullo.

64. Sc. antennis heptaphyllis, corpore nigro pilis albis, scutello maculâ duplici albâ.

Linn. Syst. Nat. 553.57. Faun. Suec. 394. Vill. i. 25. 40. Gmel. 1558.57 . Scop. 12. Scbrank. 9. Raii Ins. 93. 9. Brabm. Ins. Kal. i. 202. 679.

Friscb. xi, $23 . t$. I. f. I. Petiv. Gazopb. t. 138. f. I. Hoefn. Ins. t. 6. $f$. ult. Roes. Ins. iv. t. $3^{\circ}$. f. i-3. Schaeff: Icon. t. 23. f. 2. Daubent. Pl. enlum. t. I6. f. media. Voet. t. 6. f. 48, 49. Mart. Eng. Ent. $t$. I. f. 1, 2. Mouff. Theat. Ins. 160. f. ult. Jonst. Hist. Nut. Ins, lib. iii. 70. t. 14. Sulz. Hist. Ins. I. f. a.d.

Sc. hololeucus. Pall. Icon. I. 19. t. B. f. 2r.

Melolontha Fullo. Fab. Syst. Ent. 31. I. Sp. Ins. i. 35. I. Mant. i. 19. I. Ent. Syst. I. b. I54. I. Faun。 Etrusc. 40. Hellw. 40. Herbst. Arcb. I3. I. Ins. Helv. 20. Panz. Ent. Germ. 221. I.

Sc. pictus. Epbem. Nat. Cur. Dec. I. Ann.6. Obs. 239: p. 350. 10. f. a, b, c.

Oliv. i. 5.9. 1. t. 3. f. 28. a, b, c. Jablonsk. iii. t. 22. f. I, 2. Petagn. Ins. Calab. 3. II. t. I. f. I.

Long. corp. I unc. 4 lin.

Habitat

Descr. Antennæ brunnex, clavâ maris longissimâ, heptaphyllâ, femine verò minori, ovatâ. Clypeus subemarginatus, reflexus. Corpus brunneum aut testaceum. Caput squamis albidis. Thorax lineis tribus longitudinalibus, albis, lateralibus interruptis. Scutellum maculis duabus ovatis, aibis, paribus. Elytra albo variegata. Abdomen cinereum. Pectus villosum, villo rufo.

Melolon- 6.5. Sc. testaceus, thorace villoso, caudâ inflexâ, tha. incisuris abdominis albis.

Limn. Syst. Nat. 554.60. Faun. Suec. 392. Vill. i. 28. 
28. 43. Gmel. 1562. 60. Scop. 16. Scbrank. II. Poda. Mus. Grace. 19. 8. Geoff. i. 70. 3. Fourc. i. 5. 3. Rai. 104. I. Mouft. Theat. Ins. 160. 2. Pontop. Dan. Atl.666. 14. Brabm, Ins. Kal. i. 53. 173 .

De Geer, iv. 273. 20. t. 10. f. 14. Petiv. Gazopb. 29. t. I9. f. 2. Alb. Ins. Ang. t. 60. Roes. Ins. ii. Sc. I. t. I. omnes. Scbaff: Icon. Ins. t. 93. f. I, 2. t. 102. f. 3 , 4. Scbaff. Elem. t. 8. f. 3. t. Jog. $f .2$. Voet. t. 6. f. 45, 46. List. Goed. 265. III.f. III. Dawbent. Pl. enlum.t. 16.f. 3 . Merian Ins. Eur. i. 2. f. 4. Mart. Eng. Ent. t. 2. f. 12. List. Ins. Ang. 379. 1. mut. 18. f. 16. Aldrow. Ins. 554. t. super.f. 2 .

Sc. arboreus. Jonst. Hist. Nat. Ins. 70. t. 14 .

Melolontha vulgaris. Fab. Syst. Eni. 32. 2. Sp. Ins. i. 35. 3. Mant. i. 19. 3. Ent. Syst. 1. b. 155. 3. Laich.i.34. I. Petagn. Ins. Cal. 4. I2. Panz. Ent. Germ. 221. 2. Herbst. Arcb. 13. 2. Ins. Helv. 24. Faun. Etrusc. 4I. Hellw. 4I. Preysl. Bob. Ins. 50, 51. Faun. Ingr. 77.235.

Oliv. i. 5. I2. 5. t. I. $f$. I. a-d. $f .3$, a-c. Var. Jablonsk. iii. t, 22. $f \cdot 6$.

Long. corp. I unc. 2 lin.

Habitat in graminosis.

DFsCr. Inter majores est hic Scarabaus, cui caput, thorax et elytra testacei coloris funt. Thorax villosus. Elytra singula quatuor striis elevatis, glabriusculis. Anus acuminatus, deorsum flexus. Abdomen fuscum, ad latera subtùs maculâ acutâ, in singulâ incisurâ, albâ. Oris labium superius obtusum. Faun. Suec.

Animalculum inter onnia nostratia maximè fatale. Larva mollis, grisea, capite pedibusque testaceis, per plures annos sub terrâ degit, et devorat radices vegetabilium, agros prataque desolans. Imago, vesperi volitans cum susurro, devastat folia arborum: tilia intacta.

Devoratur a suibus, corvis, cornicibus, picis, gallinis, meleagribus, carabis majoribus. Per diem arboribus concussis facillimè colligitur a pucris. Fab. Ent. Syst. 
solstitialis. 66. Sc. testaceus, thorace villoso, elytris luteopallidis: lineis tribus albis parallelis.

Linn. Syst. Nat. 554. 61. Faun. Suec. 393. Rai. 105. 2. Scop.3. Vill.'i. 29.44. Gmel. I563. 6r. Scbrank. 12. Geoff: i. 74. 7. Fourc, i. 6, 7. Poda. Mus. Grac. 21. 16. Laich. i. 35. 2. Pontop. Dan. Atl. 666. I5.

De Geer, iv. 276. 21, t. xo. f. 15. Schaff. Icon. t. 93. f.3. Friscb. Ins. 9. p. 30. t. I5.f. 3. Mart. Eng.: Ent. t. 2. f. 17. Voet. t. 6.f. 51, 52. Mouff. Theat. 160. f. 3: Daubent. Pl. enlum. t. I6. f. 4.

Melolontha solstitialis. Fab. Syst. Ent. 33.5. Sp. Ins. i. 37. 7. Mant. i. 19. 9. Ent. Syst. i. b. 157. I1. Faun. Etrusc. 42. Hellw. 42. Panz. Ent. Germ. 221. 4. Herbst. Arch. 13. 3. Ins. Helv. 25. Laich. 35. 2. Faun. Ingr. 77. 236.

Oliv. i. 5. I7. 10. t. 2. f. 8. a, b. f. 11. a. Jablonsk. t. 22. $f .9$.

Long. corp. Io lin.

\section{Habitat -}

Descr. Totus testaceus. Clypeus subemarginatus, reflexus. Oculi nigri. Thorax et scutellum villosa. Elytra glabriora, pallidiora, lineis tribus elevatis longitudinalibus, quæe in vivâ dicuntur esse albæ, at nobis vix conspicuæ sunt.

brunneus. 67. Sc. testaceus, elytris striatis, thorace utrinque puncto notato.

Linn. Syst. Nit. 556.72. Faun. Suec. 396. Vill. i. 32. 52. Gmel. 1568. 72. Scbrank. 21. Geoff. i. 83. 22. Scop. Ann. Hist. v. 81. 22. Fourc. i. 10. 22. Herbst. Arch. I4. 7.

Voet. t. 7. f. 53, 54. Mart. Eng. Ent. t. 3.f.24. Act. Nidros. iv. 316: 4. t. 16. f. 3 .

Sc. fulvus. De Geer, iv. 277.23. t. I०. $f$. I7.

Melolontha brunnea. Fab. Syst. Ent. 36. 20. Sp. Ins. i. 39. 26. Mant. i. 21. 32. Ent. Syst. i. b. 165. 42. Panz. Ent. Germ. 223. Iо.

Jablonsk. $.24 \cdot f \cdot 3 \cdot \quad$ Oliv. i. $5 \cdot 43 \cdot 55 \cdot t \cdot 4 \cdot f \cdot 3^{8}$.

Long. 
Long. corp. 5 lin.

Habitat -

DESCR. Totus brunneus, sive rufo-ferrugineus. Antennæ longitudinaliter fissiles, ut in Sc. Melolonţ̧â.

68. Sc. ater sericeus, elytris rufis : margine sutu-Ruricola. râque nigris.

Vill. i. 38.74. Gmel. 1558. 235. Geoff. i. 80. 15. Brabm. Ins. Kal. i. 153. 494 .

Mart. Eng. Ent. t. I. $f \cdot 7$.

Sc. marginatus. Fourc. i. 9. 15 .

Melolontha Ruricola. Fab. Syst. Ent. 38. 30. Sp. Ins. i. 43. 45. Mant. i. 23. 58. Ent. Syst. x. b. I73. 75. Faun. Etrusc. 47. Hellw. 47. Panz. Ent. Germ. 224. 18.

Oliv. i. 5. 52.71.t. 3. f. 25. Jablonsk.t. 25.f.2.

Melolontha Floricola. Laicb. i. 4I. 6.

Long. corp. $3 \frac{3}{4}$ lin.

\section{Habitat -}

Captus in ericeto dicto Newmarket-Heath, prope fossam vulgo dictam Devil's Dyke, Julio ineunte 1797 , copiosè.

DESCR. Clypeus rotundatus, integer. Caput, thorax et abdomen atra, holosericea, immaculata. Elytra rufotestacea, undique cincta margine nigro holosericeo. - Syst. Ent.

Variat interdum elytris obscuris, margine tamen semper obscuriore. Ent. Syst.

Variat etiam elytris nigris, disco testaceo.

69. Sc. ater pilosus, elytris glabris cyaneo rufoque varius. versicoloribus.

Long. corp. $3 \frac{1}{2}$ lin,

Habitat Captus in campis apertis

Sussexiæ. D. Green.

DESCR. Caput, thorax, pectus, abdomen et pedes atra D 4 pilosa. 
pilosa. Elytra striata, variè pro lucis incidentiâ rufo cyaneoque exornata, glabra. Margo autem ciliatus. Elytra variant magis minusve cyanea. An sexûs differentia?

Arvicola. 7०. Sc. villosus, capite thoraceque nigro-cærulescentibus, elytris pedibusque nigris.

Melolontha Arvicola. Fab. Ent. Syst. i. b. I72. 71. Oliv. i. 5. 64. 87.t. 7.f. 84 .

Long. corp. $4 \frac{\mathrm{T}}{2}$ lin.

Habitat _ Captus prope Castellum Corby dictum, in agro Eboracensi. D. Smith.

Descr. Totum corpus pilosum, nitidum. Piliabdominis et pedum flavescentes, cæteroquin artubus concolores. Caput et thorax nigro-cærulescentia, punctulata. Elytra nigra, striata, striis ex punctis excavatis confluentibus. Pedes nigri. Notandum autem est quod certo lucis respectu, color quidam cærulescens etiam elytrorum, abdominis et pedum superficiem leviter perstringit.

Frischï. ๆr. Sc. æneus, elytris testaceis : suturâ virescenti.

Vill. i. 38.70. Gmel. 1561. 250.

Voet. t. $7 \cdot f \cdot 55 . \quad$ Mart. Eng. Ent. t. $4 \cdot f \cdot 42$.

Sc. æneus. De Geer, iv. 277. 22.?

Melolontha Frischii. Fab. Syst. Ent.37.25. Sp. Ins. i. 4I. 33. Mart. i. 21. 40. Ent. Syst. I. b. 167.53. Faun. Etrusc. 51. Hellw. 51. Panz. Ent. Germ. 223. 12. Faun. Ingr. 77. 238.

Oliv. i. 5.35 40.t. 4. f. 29. a-d. Herbst. Jablonsk. iii. I26. $77 \cdot t \cdot 25 \cdot f \cdot 8$.

Long. corp. 7 lin.

Habitat_- Inter rejectamenta maris inventus est, prope Braunton Boroughs, Devoniâ. Miss Hill.

Descr. Caput, thorax et scutellum punctata, viridi-cuprea. Elytra substriata, viridi-testacea, suturâ virescentiore. 
tiore. Cauda viridi-cuprea. Corpus subtùs pedesque nigro-ænea.

72. Sc. viridis, thoracis lateribus flavis.

Vill. i. 38.71. Gmel. 1560.249.

Voet. t. 7. $f \cdot 56,57$. Sulz. Hist. Ins. t. I. f. 1 I. Mart. Eng. Ent. t. 1. f. 8.

Sc. dubius. Brabm. Ins. Kal. i. 143.478. Friscb. iv. 29. t. I4.

Melolontha Vitis. Fab. Syst. Ent. 37.26. Sp.Ins. i. 4I. 34. Mant. i. 21. 41. Ent. Syst. I. b. 167. 54. Herbst. Arcb: 14. 9. Fuesl. Arcb. 75. 6. Panz. Ent. Germ. 223.23. Faun. Etrusc. 52. Hellw. 52. Petagn. Ins. Calab. 5. I9.

Oliv. i. 5. 34. 39.t.2.f. 12. a, b, c.

Long. corp. 7 lin.

Habitat - In mus. D. Latham et D. Drury.

Descr. Nimis precedenti affinis. Totum corpus viride, thoracis lateribus flavis. Pedes nigri.

C. Florales, corpore depreffo, elytris non ad anum pertingeniibus, jave abbreviatis.

73. Sc. auratus, segmento abdominis primo la- auratus. teribus unidentato, elytris albo-maculatis.

Linn. Syst. Nat. 557. 78. Faun. Suec. 400. Act. Nidros, iv. 313. I. Vill. i. 33.54. Gmel. I580. 28. Scop. 17. Scbrank. 14. Rai. 76. 7. Herbst. Arcb. 18. I. Geoff. i. 73. 5. Fourc. i. 6. 5. Poda Mus. Grece. 19. 7. Pontop. Dan. Atl. 666. 16. Faun. Fred. 2. I2. Brabm. Ins. Kal. i. 34. II5.

Rocs. ii. 1. t. 2. f. I-9. Scbaff. Icon. t. 26. f. 2, 3: Jablonsk. t. 29.f. 2. Frisch. 12.25.t.3.f. I, 2, 3. Voet. t. I. f. I. Bergst. Nomenc. i, 14. 5. t. 2. f. 5 . Hoefn.t, I6. Mart. Eng. Ent.t.3.f.27. Admiral. t. 15 .

Sc. Smaragdus. De Geer, iv. 279. 25. $t$. II. $f$. I. Cetonia aurata. Fab. Syst. Ent. 43. 4. Sp. Ins. i. 50. 4. Mant. i. 26. 4. Ent. Syst. I.b. I27.8. Laicb.i. 48. I. Faun. Etrusc. 56. Hellw. 56. Fuesl. Coleop. 
Fuesl. Coleop. 18. I. Ins. Hilv. 58. 32. Petagn. Ins. Calab.6.23. Panz. Ent. Germ.219. I. Faun. Ingr. 76.234 .

Oliv. i. 6. 12.7.t. r.f. 1.a-i. Panz. Faun. Germ. 4r. t. 15 .

Long. corp. 9- I I lin.

Habitat -

Descr. Color viridissimus nitens. Capitis clypeus sub-quadratus, anticè emarginatus, valde punctatus, posticè lineâ elevatâ, abbreviatâ. Thorax punctatus, posticè latior. Scutellum triangulare, elongatum. Elytra punctata, superficie inæquali, punctis lineisque transversis albis, margine inæquali : basis etiam ad marginem excavatur. Per hanc autem excavationem, abdominis primus articulus segmentorum sese dentis instar protrudit, faciem elytruli spurii quodammodo gerentem, triangularem, acutum. Caput subtus et pectus villis ferrugineis hirta; femora interius pilis ferrugineis ciliata. Anus supra utrinque puncto albo. Color variat viridissimus et auratus.

Obs. Quoniam auctores primarii de hoc Scarabeo nimis parcè disseruerunt, nobis liceat descriptionem fusius dare.

welitis.

74. Sc. auratus lævis, abdomine posticè albo punctato, elytris rugosis.

Linn. Syst. Nat. 558. 8I. Faun. Suec, 40r. Udd. Diss. I. Brabm. Ins. Kal. i. I45.480. Vill. i. 34 . 56. Gmel. 1582. 81. Geof: i. 73. 6. Fourc. i. 6. 6. Scbrank.15. Scop. I8.

Voet. t. 4. f. 28. Roes. ii. I. t. 3.f. I-5. Mart. Eng. Ent.t. $3 \cdot f \cdot 28$.

Cetonia nobilis. Fab. Syst. Ent.43.5. Sp. Ins, i. 5 I. 6 . Mant. i. 27.9. Ent. Syst. i. b. I19. 2. Fuesl. Ins. Helv. 34 .

Oliv. i. 6.59.72.t.3.f. 10. a-c. Jablonsk.t. 27.f. 6. Trichius nobilis. Panz. Ent. Germ. 218.3. Faun. Ingr. 75. 232.

Long. corp. 9 lin.

Habitat

DESCR. 
DESCR. Corpus suprà viridi-cupreum, nitidum. Thorax punctatus, lineâ longitudinali impressa. Elytra scabriuscula, interdum immaculata, interdum maculis albis adspersa. Abdomen ad latera et posticè albopunctatum. Corpus subtùs cupreum, pectore villoso.

75. Sc. niger flavo-tomentosus, clytris flavis : fas-fasciatus. ciis tribus nigris interruptis.

Linn. Syst. Nat. 556.70. Faun. Suec. 395. Vill. i. 3I. 5I. Gmel. I583. 70. Scop. 5. Scbrank. I6. Geoff. i. 80. 16. Fourc. i. 9. 16. Poda. Mus. Grac. 20. I I. Fuesl. Nov. Mag.375. I9. Petagn. Ins. Cal. 5. 20.

De Geer, iv. 299. 27. t. Io. f. I9. Voet. t. 5. f. 43 . Scbeff. Icon. $t$. I. f. 4. Mart. Eng. Ent. t. 2. f. 10. Don. Brit. Ins. t. 140. Drury Ins. i. t. $3^{6 .} f .2$. Act. Nidros. iv. 315. 3. t. 16. f. 2. mala.

Melolontha fasciata. Jablonsk. t. 27. f. Io. Fuesl. Arcb.77. 12. Herbst. Jablonsk. iii. I79. 128. t. 27. f. 10 .

Cetonia fasciata. Oliv. i. 6. 61.74. t. 9.f. 84 .

Trichius fasciatus. Fab. Syst. Ent. 40. I. Sp. Ins. i. 48. 1. Mant. i. 25. I. Ent. Syst. i. b. II9. 4. Herbst. Arcb. I7. 17. Fuesl. Arch. 77. 12. Ins. Helv. 30. Faun. Etrusc. 54. Hellw. 54. Panz. Ent. Germ. 218. 4. Laich. Tyr. Ins. 45. I. Faun. Ingr. 75. 233. Payk. Faun. Suec. ii. 200. 4.

Roemer. $t .34 \cdot f \cdot 4$.

Long. corp. $8 \mathrm{lin}$.

Habitat in floribus Syringe, Filipendule. Linn.

Captus prope Aberdoniam. D. Torenson.

DEscr. Antennæ nigro-brunnea. Caput et thorax nigra, pilis densis, erectis, fulvis. Scutellum nigrum. Elytra pallide flava, maculis tribus transversis marginibusque tenuissimè nigris. Corpus subtùs nigrum, thorace pilis rufis. Abdominis apex luteus, maculâ nigrâ. Pedes nigri. Oliv.

76. Sc. nigro-aneus, thorace villoso, elytris lividis: Agricola. limbo fasciâque arcuatâ nigris. 
Linn. Syst. Nat. 553. 58. Scbrank. 17. Poda Mus. Grac. 2I.

Sc. Cyathiger. Scop. 6.

Melolontha Agricola. Fab. Syst. Ent. 37. 29. Sp. Ins. i. 43, 44. Mant. i. 23.57. Ent. Syst.i. b. 173. 74. Laich. i. 39. 4. Panz. Ent. Germ. 224. I7.

Oliv. i. 5. 61. 84.t. 9.f. 104.t.2.f. 19. Petagn. Ins. Cal. 5.t. 1.f.2, 3, 4. Scbaff. Icon. t. 63. f. 1. Panz. Faun. Germ. 47.t. 18. Voct. t. 8.f.67. Herbst. Jablonsk. iii. 101. 51.t. 24.f.10, II.

Long. corp. 7 lin.

Habitat Glamorganix. In mus. D. Donovan.

Descr. Statura Sc. Horticoles sed minor, nigro-reneus, villosus. Caput et thorax nigro-ænea, albo-villosa. Elytra glabra, livida, maculà scutellari ambitu nigro; fasciâ in medio recurvatâ nigrâ, quæ non tangit nigredinem lateralem. Ungues purpurei. Capitis labium adscendens. Brachia bidentata. Linn. Syst. Nat.

Variat elytris nigris, maculâ scutellari nigrâ testaceo cinctâ. Oliv.

Donovani. 7\%. Sc. nigro-æneus, elytris punctato-striatis testaceis : suturâ limbo apice fasciâque undulatâa nigris.

An Melolontha crucifer. Herbst. Jablonsk. iii. Ioo. $50 . t \cdot 24 \cdot f \cdot 9 \cdot$ ?

Long. corp. 5 lin.

Habitat Glamorganiæ. In mus. D. Donovan.

Descr. Antennæ ferrugineæ. Caput, thorax et scutellum nigro-ænea. Elytra punctato-striata, testacea, fasciâ mediâ undulatâ suturâ apice lateribusque nigris. Corpus subtùs piceum, cinereo-pubescens. Pedes picei.

Horticola. 78. Sc. capite thoraceque cæruleo subpiloso, elytris testaceis, pedibus nigris.

Linn. Syst. Nat. 554.59. Faun. Suec.391. Vill. i. 
27. 42. Gmel. I559-59. Scbrank. I8. Geoff.i. 75. 8. Fourc. i. 7, 8. Pontop, Dan. Atl. i. 665. I3. Scbaff.Icon.t.23.f.4. Voet.t.10.f.86. et $t .8 . f .69$. ?

Mart. Eng. Ent. t. 4. f. 43 .

Sc. viridicollis. De Geer, iv. 278. 24. t. Io. f. 18.

Sc. adiaphorus. Scop. 10.

Melolontha [lorticola. Fab. Syst. Ent. 37. 28. Sp. Ins. i. 42.41. Mant. i. 22. 50. Ent. Syst. i. b. 17. 68. Laicb. i. 40.5. Faun. Etrusc.46. Faun. Ingr. 78. 239. Helv. 46. Panz. Ent. Germ 223. I4. Petign. Ins. Cal. 5. 17.t. 1.f.5. Jablonsk.t.25.f. 1. Herbst. Arch. I5. t. 19. b. f. 23. Fuesl. Arcb. 76. a. t. Ig. b.f. 23. Ins. Helv. 22. 76. a. Oliv. i. 5. 62.85.t.2.f. I7. Panz. Faun. Germ. 47.t. 15 .

Long. corp. 5 lin.

Habitat in hortis.

DEscr. Antennarum caulis ferrugineus est.

Variat capite thoraceque viridi et cæruleo. An sexûs differentia?

Obs. I. Variat capitulo antennarum toto rufo, et corpore magis oblongo. Villers.

Obs. 2. Tibiæ anticæ bidentatæ, necnon unidentatæ, uti posuit Scop.

79. Sc. niger, subtis argenteo-nitens, elytris cas-argenteus var: taneis, pedibus nigris.

Gmel. I564.265. Scop.9. Brabm. Ins. Kal.i. 127. 443. Petagn. Ins. Cul. 4. 15. Poda Mus. Grec. 20.9.

Voet. t. 8.f. 68.? Mart. Eng. Ent.t. 2.f. II. Melolontha argentea. Fab. Syst. Ent. 38. 32. Sp.
Ins. i. 44. 48. Mant. i. 23. 6r. Ent. Syst. i. b. I74. 80. Laich. 42. 7. Faun. Etrusc. 48. Hellw. 48. Ins. Helv. 35. 3. Panz. Ent. Germ. 225. 21. Panz. Faun. Germ. 28. t. 18. Oliv. i. 5.67.91, t.3. f. 22. a-d.

Long. corp. $4 \frac{1}{2} \operatorname{lin}$.

Habitat in floribus.

Descr. Affinis Sc. Horticole, sed obscurior. Caput et thorax nigra, obscura, punctulata, pilis brevissimis obsita. Scutellum nigrum, concavum, obtusum. Ely- 
tra rufo-testacea, posticè gibba. Corpus subtùs nitet, polline sive squamulis viridi-argenteis. Pedes variant picei et rufo-testacei ; ungues postici parum elongati.

Obs. I. Squamulæ argenteæ abdominis sæpius vix conspiciende forsan vi quâdam illatâ deciduæ.

Obs. 2. Habitat in pratorum plantis et arboribus, primum a me visus Julii $6^{\circ} .1793$, quando innumeri circa fraxinos in prato quodam instar apum volitabant, et post horam meridianam omninodisparuere. D. Kirby.

pulveru- 80. Sc. niger, corpore polline virescenti-argentco, lentus. elytris pedibusque rufis.

Gmel. $1565 \cdot 273$.

Sulz. $t$. 丁. $f$. 8 . mala.

Melolontha pulverulenta. Fab. Sp. Ins. i. 45.56. Mant. i. 24. 69. Ent. Syst. i. b. 178.93.

Long. corp. $4 \frac{x}{2}$ lin.

Habitat $\longrightarrow$ Captus volando in horto. D. Kirby.

Descr. Clypei margo, oculi, antennæ, palpi rufa. Thorax subtus ubj caput inseritur setis fulvis ciliatis. Pedes et elytra rufa, conspersa, uti totum insectum, præsertim subtùs, squamis viridi-argenteis. Ungues primi et secundi paris fissi, unguiculis interioribus brevioribus. Unguiculus posticus unicus.

\section{LUCANUS.}

Antennœ fractæ clavatæ; clavâ compressâ, latere latiori pectinato-fissili. Maxilla porrectæ, exsertæ, dentatæ. Corpus oblongum.

Tibia anticæ dentatæ.

Cervus. I. Lu. niger, maxillis exsertis apice bifurcatis Linn. 
Linn. Syst. Nat. 559. I. Faun. Suei. 405. Payk. Faun. Suec. iii. 45. I. Fab. Syst. Ent. 1, 2. Sp. Ins. i. 1, 2. Mant. i. т, 2. Ent. Syst. i. b. 236. 2. Vill. i.41. I. Gmel. I588. I. Scop. I. Scbrank. 32. Raii Ins. 74. 2. Laicb. i. I. Poda Mus. Grac. 21. 17. Faun. Etrusc. I. Hellw. I. Herbst. Arch. 2. 1. Ins. Helv. 39. Preys. Bob. Ins. 9. 4. Goez. E. B. i. I18. 1. Panz. Ent. Germ. 244. I. Brabm. Ins. Kal. i. I30. 446. Harr. 4. I.

oliv. i. I. 9. 2. t. I. f. I. a-d. Roes. Ins. ii. Scar. I. t. 5.f.7.9. De Geer, iv. 327. I. t. 12.f. I. Scbaff: Icon. $t .133 . f$. I. Hoefn. Ins. $t$. 10. Bergst. Nomencl. iii. I8. 1, 2, 3. t. 3. f. I, 2, 3. et $t .4$. $f$. x. Donov. Brit. Ins.t. I3. Mart. Eng. Ent. t. 5. f. I. Voet. t. 29. $f$. I. Schluga. to I. $f$. I. Aldrov. Ins. 45 I. t. super. f. I.

Scarabæus Cervus. Faun. Fred. 2. I4.

Platycerus. Le grand Cerf volant. Geoff. i. 6r. 1. t. I. f. 1. Fourc. i. 2. r.

Long. corp. maris 2 unc. 2 lin. fœem. I unc. 8 lin. Habitat in ligno quercino putrido.

Descr. Os prominens maxillis duabus lunulatis, nigris angulatis, prominentibus, a latere interiore duplici denticulo armatis, qui denticuli in utrâque maxillâ duo sive pares, quorum unus inferior, alter superior. Thorax læevis, convexus, niger, marginatus, absque marginibus ullis elevatis. Elytra lævia, nigro subpurpurascentia, marginata. Pedes serrati. Thoracis margines antici et postici villis cæsis instructi. Faun. Suec.

Fomina mari omnino formâ simillima at minor; tum etiam maxillæ dentibus circiter 7 sub-æqualibus approximatis, nec uno maximo remoto. Inter omnes auctores qui de hoc Lucano dixerunt, nemo foeminam bene distinxit. Geoffroyus foeminam Linnæi ritè nominatam esse negavit. Roeselius hunc marem et inermem foeminam copulâ conjunctos vidit, et indè ejusdem speciei habuit. Auctoritas tanti viri alios etiam Linnæum ipsum cepit. At sanè sæpius licet species varias suis congeneribus variè conjunctas videreCoccinellee et Cicadce exempla satis superque exhibent. 
bent. Fæminam igitur Linnæi excludens, et synonyma cidem adscripta ad $L$. inermem referas: et nos etiam Geoffroyii sententiam comprobamus, cornutos enim copulâ conjunctos cepimus.

inermis. 2. Lu. convexus brunneus, maxillis brevibus: dente laterali elevato.

Lucanus Cervus. Faun. Suec. 405. Var. B. Gmel. 1 588. I. Var. (b). Gron. Zoopb. 446. Fab. Ent. Syst. i. b. 236. 2. Var. $\beta$.

Oliv, i. I. 10. t. I. f. x. Roes, ii. I. t. 5.f.8. De Geer, iv. 33 I. t. 12. f. 7. Scbceff: Icon. t. I33.f. 2. Elem. t. 9.f. . . Bergst. Nomencl. i. 25. 2, 3. t. 4 . f. 2, 3, Mart. Eng. Ent.t. 5.f. 2. Voet.t.29.f.2. Lucants Dorcas. Harr. 5.2.

Platycerus, La grande Biche. Geoff.i. 62. 2. Fourc, i. 2. 2 .

Long. corp. 1 unc. 7 lin.

Habitat

DESCR. Hæc species a plurimis foemina præcedentis ducta est. Geoffroyus primus errorem feliciter detexit. Marem quippe et foeminam copulâ conjunctos cepit. Non plurimum absimilis Lu. purallelipipedo, at differt colore brunneo nec nigro, et corpore valdè convexo; tum plusquam quadruplo major.

parallelipi-3. Lu. depreffus niger, maxillis dente latcrali pedus. elevato.

Linn. Syst. Nat.56r.6. Fab. Syst. Ent. 2.6. Sp. Ins. i. 2. 6. Mant. i. I. 7. Ent. Syst. i. b. 239.11. Vill. i. 42. 2. Gmel. I590. 6. Scbrank. 19. 33. Laicb. 3. 2. Scop. Ann. Hist. 5. 76. 1 2. Faun. Etrusc. 3. Hellw. 3. Preys. Bob. Ins. 10. 5. Herbst. Arcb. 2. 2. Fuesl. Arcb. 65. 1. Ins. Helv. 4I. Panz. Ent. Germ. 244. 2. Brabm. Ins. Kal. i. 133-.454. Goez. E. B. i, i22.6. Payk. Faun. Suec. iii. 47. 2.

Oliv. i. I. 17. I1. t. 4. f. 9. a, b. De Geer, iv. 334. 2. t. 12. $f .9$, I0. Scbreff. Icon. t.63.f. 7. Elem. t. 101 . 
t. 101. f. 1. Voet. t. 30.f. 7. Bergst. Nomencl. i. 3, 4. t. I. f. 3, 4. Panz. Faun. Germ. 1. I9. Jablonsk. t. $34 \cdot f_{:} 5$. Mart. Eng. Ent. t. 5. f. 3,4 . Pont. Dan. Atl. i. 666. 21. t. 29. f. I.

Lucanus infractus. Bergst. Nomencl. i. 8. 2. t. 8.f. 2.

Lu. bipunctatus. Pont. Dan. Att. i. 666, 21. t. 29. f. 2. mas.

Lu. Damæ. Harr. $5 \cdot 3 \cdot$

Lu. Capra. Panz. Faun. Germ. 58. t. I2.

Platycerus. La petite Biche. Geoff.i. 62.3. Fourc. i. 2, 3. Long. corp. I unc.

Habitat in Fraxini excavationibus putrescentibus. D. Latbbury.

DESCR. Ita similis facie, structurâ, antennis et omnibus Lu. inernit, ut, nisi multo minor esset, eundem diceres; sed color ater, non brunneus, et corpus magis depressum.

Alter sexus capite nitidiusculo scabriusculo, tuberculis duobus mediis approximatis. Alter capite lævi, obscuro, inermi.

Synonymis auctorum ritè perpensis profiteor me quodammodò hærere, an iste cui caput tuberculis ornatur species distincta sit, an mera ex sexu differentia. Sin sententia mea necesse in alterutram cogatur partem, potiùs videtur speciem distinctam non esse, tametsi Panzer, Bergstraesser aliique locum inter species adhibuerint. Invenimus enim ambos hos semper consociatos, in iisdem arboribus, eodemque tempore. Neque etiam consenserunt Entomologi, uter horum sit mas aut foemina. Tuberculatum Geoffroyus marem esse affirmat; Bergstraesser autem suam parallelipipedi foeminam tuberculis insigniri strenue contendit. Differentia sane summa inter hos Lucanos patet. Scilicet $L u$. parallelipipedus verus dentem in maxillis lateralem elevatum habet, prout Illust. Linnæus optimè disseruit ; in altero, verò, dentes minores sunt, nec elevati. Caput etiam et thorax prioris minùs convexa sunt, porrò obscura nigra, punctulis minutissimis impressis--Posterus autem nitet, et punctis profundè impressis obsitus est, unde fere rugosus evadit. voL. I. 
cylindricus. 4. Lu. cylindricus ater, thorace anticè truncato quinquedentato, capite anticè cornû erecto.

Laicb. Tyr. Ins. 3, 4 .

Lucanus Tenebroides. Scop. Ann. 5. Nat. Hist. Io.

Scarabæus cylindricus. Linn. Syst. Nat.544. II. Faun. Suec. 380. Fab. Syst. Ent. 12. 33. Sp. Ins. i. I2. 39. Mant. i. 6. 4I. Gmel. I532. II. Preys. Bob. Ins. 29. 27. Herbst. Arch. 4. 4. Harr. 8. 5. Goeze, i. 10, II. Fuesl. Nov. Mag. Van Mol. 378 . 27.

Oliv. i. 3. 47.54. t. 9. f. 80. a-c. De Geer, iv. $25^{8}$. 3. t. 10. f. 2. Voet. t. 20. f. 13I. Schaff: Icon. 3. t. 20I. f. 1, 2. Jablonsk. t. 6.f. 8, 9. Vill. i. I2. 3.t. I.f. r. Panz. Faun. Germ.2.t. I. mas. Mart. Eng. Ent. t. 3.f. 20, 21 .

Sinodendron cylindricum. Fab. Ent. Syst. i. b. 358. I. Payk. Faun. Suec. iii. I40. I. Panz. Ent. Germ. 282. I. Fuesl.Arch. 67. 4. Faun. Ingr. I01. 306.

Panz. Faun. Germ. I. t. 9. fœm.

Long. corp. $8 \frac{1}{2}$ lin. mas, 7 lin. fœm.

Habitat in truncis arborum.

De SCr. Niger cylindricus. Cornu ex apice rostri erectum, anticè glabrum, ponè villis fulvis hirtum. Thorax cylindricus, crassus, supra glaber, anticè excavatotruncatus, margine quinquedentato, quorum dens intermedius utrinque cavinate distinctus. Scutellum minutum. Elytra sulcata punctis excavatis scabra. Faun. Suec.

Maxillæ parvæ, exsertæ, lunulatæ. Cornu fominæ brevius.

Caraboides.5. Lu. cærulescens, maxillis lunulatis, thorace marginato.

Linn. Syst. Nat. 56r. 7. Faun. Suec. 407. Payk. Faun. Suec. iii. 49. 4. Fab. Syst. Ent. 3. 8. Sp. Ins. i. 3. 9. Mant. i. 2. 12. Ent. Syst. i. b. 239. 14. Gmel. I591. 7. Herbst. Arcb. 2. 4. Ins. Helv. 42. Faun. Etrusc. 4. Hellw. 4. Preys. Bob.Ins. Ir. 6. Scop. 2. Uddm. Diss. 40.? Laich. Tyr. Ins. 3. 3. Harr. 6. 4. Faun. Ingr. 85. 263. Goeze, E. B. i. I23. 7 .

Oliv. 
Otiv. i. I. 20. I4. t. 2. f. 2. c, d. Vill. i. 43.3.t. I. $f .4$. Scbaeff. Icon. $t .6, f .8$. Voet. t. 30. f. 8. Jablonsk. t. 34.f. 6, 7. Mart. Eng. Ent. t. 5.f.5. Lucanus Caprea. De Geer, iv. 334. 3. t. I2.f. II. Platycerus. La Chevrette bleue. Geoffi.63.4. Fourc.i 3,4 .

Long. corp. 6 lin.

Habitat

Descr. Statura Carabi minoris. Cærulescenti-niger. Thorax marginatus. Maxillæ prominentes, lunatæ. Antennæ capitulo latere quadrifoliato. Pedes nigri. Femora antica ad basin maculâ albâ mutilata. Faun. Suec.

Variat colore viridi et cæruleo. Vill.

\section{IPS.}

Antenna clavatæ, capitulo sub-solido. Thorax sub-globosus, caput recipiens. Corpus cylindricum. Tibice sæpiùs dentatæ.

I. I. testaceus pilosus, elytris striatis retusis præ- typographus. morso-dentatis.

De Geer, v. 193. t. 6. f. 1, 2. .Act. Acad. Suec. I752. t. 3. f. II, I2.

Dermestes typographus. Linn. Syst. Nat.562.7. Faun. , Suec. 418. Vill. i. 46.6. Scbrank. 25. 42. Act. Nidros. $3 \cdot 3^{8} 3$. I.

Sulz. Ins: $t .2 . f \cdot 4$.

Bostrichus typographus. Fab. Syst. Ent.59.2. Sp. Ins. i. 67.3. Mant. i. 36. 4. Ent. Syst. i. b. 365.3. Gmel. 1601. 4. Panz. Ent. Germ. 285. 2. Fuesl. Arch. 83. 2. Payk. Faun. Suec. iii. I 45. I. E 2

Pans, 
Panz. Faun. Germ. 15. t. 2. Faun. Ingr. 102. 30\%. t. 2. f. Herbst. Jablonsk. v. 8I. I. t. 48.f. x.

Long. corp. 3 lin.

Habitat intra cortices truncorum labyrinthos formans. Linn.

DESCR. Elytra striata, striis ex punctis impressis, postice retusa, marginata, tridentata.

microgra- 2. I. testaceus glaber, elytris apice retuso-dentatis. phos.

-De Geer, v. I95. 4 .

Dermestes micrographus. Linn. Syst. Nat.562.9. Faun. Suec. 4I9. Vill. i. 47.8.

Bostrichus micrographus. Fab. Mant. i. 37.7. Ent. Syst. i.b. 366.8. Gmel. 1601. 7. Payk. Faun. Suec. iii. I55. 14. Fuesl. Arcb. 83.5.

Panz. Faun. Germ. 66. t. I3.

Long. corp. $\mathrm{I} \frac{\mathrm{x}}{4}$ lin.

Habitat intra cortices arborum emortuarum; Quercuum etiam robur perforans. Linn.

DESCR. Corpus nigrum, teres. Antennæ, thorax, elytra, pedesque testacea. Syst. Nat. Elytra apicem. versus pilis longis adspersa. Faun. Suec.

polygrapbus. 3. I. testaceus pilosus, elytris glaucis obtusiusculis.

De Geer; v. 196. 5 .

Dermestes polygraphus. Linn. Syst. Nat. 562. 10. Faun. Suec. 420. Vill. i. 47.9. Scbrank. 33.58.

Bostrichus polygraphus. Fab. Gen. Ins. Mant. 211 . 3, 4 . Sp. Ins. i. 68. 5. Mant. i. 37.6. Ent. Syst. i. b. 365. 6. Gmel. 16ог. 6. Panz. Ent. Germ. 285.4. Faun.Ingr. 102. 309. Payk. Faun. Suec. iii. 155. I5. Fuesl. Arch. 83. 3 .

Panz. Faun. Germ. I5. $t .5$.

Long. corp. $1 \frac{x}{4}$ lin.

Habitat sub arborum corticibus : labyrinthis pinnatis. Linn.

DESCR. 


\section{IPS.}

Descr. Minor I. micrograpbo, cylindricus. Elytris non striatis, magis glaucis, posticè obtusis, vix rufis. Faun. Suec.

4. I. rufo-ferrugineus, antennis pedibusque tes-villosus. taceis, elytris subretusis punctato-striatis.

Fab. Ent. Syst. i. b. 367. 16. Payk. Faun. Suec, iii. I54. I3.

Panz. Faun. Germ. I5. t. 8.

Long. corp. $I \frac{3}{4}$ lin,

Habitat -

DEscr. Pilis longis rariús adspersus, præsertim apices elytrorum. Thorax punctulatissimus, teretiusculus. Elytra excavato-punctata, punctis per stria digestis, retusa.

5. I. fuscus, antennis pedibusque testaceis, ely-fuscus. tris retusis confertiùs punctulatis.

Long. corp. $I \frac{x}{3}$ lin,

\section{Habitat $\longrightarrow$}

Descr. Præcedenti simillimus, sed dimidio minor, magis fuscus. Elytra confertim absque ordine leviter punctulata.

6. I. glaber, elytris truncatis integris, abdomine $S$ colytus. retuso, fronte villosâ cinerascenti.

Le Scolite, Geoff. i. 3 Io. I. $t .5 \cdot f \cdot 5$,

Bostrichus Scolytus. Fab. Syst. Ent. 59. 4. Sp. Ins. i. 68. 6. Mant. i. 37. 9. Ent. Syst. i. b. 366. 9. Gmel. I602. 9. Payk, Faun. Suec. iii. I5I.9. Panz. Ent. Germ. 286. 7.

Panz. Faun. Germ, I5. t, $\sigma$. Scbaff. Elem. t. II2. Sulz. $t$. II. $f$. I3.

Ekkoptogaster Sçolytus. Herbst. Jablonsk. v. I25. I. t. 49.f. I, 2.

Long, corp. $I \frac{x}{2}-3$ lin. 
Habitat sub corticibus Ulmi, quas miserè destruit. Fab.

Descr. Totus glaber nitidus. Caput et thorax atra, lævissima, nitida, longitudine elytrorum. Elytra striata, picea, apice truncata, integra, abdomine paulo longiora. Abdomen nigrum, valde retusum. Ent. Syst.

inermis. 7. I. fuscus, elytris testaceis: maculâ communi fuscâ, abdomine inermi.

Long. corp. $\mathrm{I} \frac{\mathrm{x}}{2}$ lin.

Habitat

In mus. D. Kirby.

DESCR. I. multistriato similis, sed abdomen non mucronatum. Supra glaber, nitens. Antennæ testaceæ, clavis compressis obtusis. Elytra testacea, leviter striata, interstitiis inordinatim punctulatis. Pedes ex luteo testacei, femoribus fuscis.

multistria- 8. I. fuscus, elytris sub-truncatis piceis striis plutus. rimis punctatis, abdomine subtus inucronato.

An Bostrichus crenatus. Fab. Mant. i. 37. 10. Ent。 Syst. i. b. 366. 10. Panz. Ent. Germ. 286. 8.?

Panz. Faun. Germ. I5. 7.7 . ?

Long. corp. $I_{4}^{\frac{1}{4}}$ lin.

Habitat

DESCR. Fuscus, glaberrimus. Caput nudum. Thorax punctulatus. Elytra leviter striata, interstitiis striatim punctulatis. Abdominis segmentum primum (a basi) mucrone, anum versus spectante, armatum. Pedes rubelli.

varius. 9. I. subvillosus, corpore nigro cinereoque vario. Bostrichus varius. Fab. Syst. Ent.60. 6. Sp. Ins. 69. 8. Maint.1.38. 15. Gmel. 1603. 5 .

Long. corp. $2 \frac{3}{4}$ lin.

Habitat in Fraxino quam perforat.

DESCR, Niger. Antennæ clavâ subacuminatâ solidiusculâ, 
culâ, stipite rubello, Thorax et elytra fusca, sive fusco-nigra, villis subcinereis maculata. Pedes nigri, tarsis fuscis. Corpus subtùs villosulum.

I0. I. ferrugineus, capite nigro, supra ferrugineo griseus. testaceoque varius.

Bostrichus griseus. Soland. Mss.

Long. corp. 2 lin.

Habitat in cortice trabium navalium. Captus prope Hastingas, Sussexiâ.

DESCR, Præcedenti similis. Caput sub-nigrum. Antennæ ferrugineæ, capitulo minùs acuto. Corpus subtùs ferrugineum, pedibus anoque testaceis.

II. I. subtùs luteus, suprà rufus, elytris luteo-rufescens. nebulosis.

Long. corp. $I \frac{2}{3}$ lin,

Habitat in cortice trabium navalium. Captus prope Hastingas, Aug. I 787 .

DESCr. Statura præcedentium. Caput, thorax et elytra rufa, villis flavis consita et nebulosa. Subtùs totus testaceus, immaculatus. Oculi fusci.

B. Variat colore dilutiore.

12. I. cinereus, pedibus fuscis.

sericeus.

Long. corp. $\frac{7}{8}$ lin,

\section{Habitat}

DEscr. Totus villis cinereis vestitus. Antennæ stipite testaceo. Elytra ferrugineo obscurè nebulosa, striata.

I3. I. ferrugineus, elytris lineâ obliquâ furcatâfurcatus. annuloque ad apicem albidis.

An Bostrichus vittatus. Fab, Mant, i. 38.16.? Ent. Syst. i. b. 368.22.?

Long. corp. I lin. 


\section{Habitat}

Ex mus. D. Kirbys

DESCR. Antennæ, caput et thorax fusco-ferruginea. Thorax lineis tribus longitudinalibus, undulatis, subinterruptis, albidis, unde videtur quasi albido maculatus. Elytra ferruginea. In utroque elytro linea albida angulosa obliqua a medio ad basin decurrens, denuo furcata. In ipso apice annulus albidus : linea prope suturam, quam autem non tangit, ortum capit. Pedes ferruginei.

scaber. I4. I. ater, antennis tarsisque rufis, elytris striatis hispidiusculis.

Long. corp. I lin.

Habitat Captus in Horto Kensingtoniano.

DESCR. Corpus quam præcedentium magis ovatum. Thorax sub lente punctulatissimus. Elytra striata, striis profundis, punctis impressis; porro pilis brevissimis rigidiusculis obsita. Abdomęn atrum. Pedes atri, plantis ferrugineis.

bemorrboi-15. I. niger, antennis ferrugineis, elytris striatis dalis. posticè rufis.

An Bostrichus minutus. Panz. Faun. Germ. 15. t.11.? Long. corp. $I \frac{1}{2}$ lin.

Habitat

In mus. D. Kirby.

DESCR. Antennæ ferrugineæ. Caput nigrum, glabrum. Thorax niger, punctulatus. Elytra punctato-striata, anticè nigra, posticè rufa. Corpus subtùs et pedes nigra.

platycepha-16. I. niger, thorace globoso magno nitido, lus. elytris obscuris fuscis profundè striatis,

Long. corp. I $\frac{8}{4}$ lin.

\section{Habitat}

DESCR. Antennæ ferrugineæ. Caput retusum, nigrum, nitidum. Thorax pro ratione animalculi magnus, glo: bosus, 
bosus, niger, nitidus. Elytra profundè striata, striæ punctis impressis. Abdomen nigrum. Pedes picei.

17. I. fuscus, elytris obscurè rubris.

obscurus.

Long. corp. I $\frac{1}{4}$ lin.

Habitat

DESCR. In plerisque thorax fuscus sive niger, sæpe etiam ejusdem cum elytris coloris est. Thorax et elytra pilis brevissimis rigidiusculis obtecta. Elytra striata, striis profundis, punctis impressis. Abdomen fuscum. Antennæ et pedes ferruginei.

18. I. subcylindricus nigro-piceus, elytris cre-piniperda. nato-striatis, antennis plantisque ferrugineis.

De Geer, v. 194. 2. t. 6. $f .8$, 9 .

Dermestes piniperda. Linn. Syst. Nat. 563. II. Faun. Suec. 42 I.

Bostrichus piniperda. Fab. Syst. Ent. 6o. 5: Sp. Ins. i. 68. 7. Mant. i. 37. 13. Ent. Syst.i. b. 367.17. Gnel. 1602. 13. Panz. Ent. Germ.287. 13. Faun. Ingr. I03. 310. Payk. Faun. Suec. iii. 152. II. Laich. 67.2 .

Panz. Faun. Germ. I5.t. 9.

Long. corp. $\mathrm{r}_{\frac{\mathrm{T}}{4}}$ lin.

Habitat in ramulis inferioribus $P$ ini, quos perforat, exsiccat, unde naturæ hortulanus in hac arbore. Linn. In Pinis Suffolciæ. D. Kirby. Wiltoniæ. D. Lambert.

DESCR. Antennæ ferrugineæ. Caput et thorax nigropicea. Thorax punctulis numerosissimis conspersa. Elytra scabra, sive irregulariter striata. Totum corpus pilis rigidis obtectum. Plantæ ferrugineæ.

Variat colore testaceo. Nuper forsan e nympha declaratus. Payk. .

I9. I. ferrugineo-rufus, antennis pedibusque di-rufus. lutioribus.

Long. 
Long. corp. $1 \frac{1}{4}$ lin.

\section{Habitat -}

DESCR. Totum corpus fere ejusdem coloris, et pilosum. Antennæ et pedes amœeniores. Thorax punctulatissimus. Elytra punctulatissima et striata; striæ punctis impressis.

coadunatus, 20. I. fuscus, coleoptris rufescentibus : maculis communibus obsoletiusculis coadunatis.

Long. corp. $I \frac{1}{2}$ lin.

Habitat

DESCr. Antennæ et pedes rufi. Caput et thorax fusca, sive nigra. Elytra striata ex ferrugineo rufa: ad suturam maculæ duæ sive tres communes utrique elytro, et coadunatæ, paulo saturatiores.

piceus.

2I. I. niger, elytris pedibusque rufo-piceis.

Long. corp. $I \frac{T}{4}$ lin.

Habitat

DESCR. Caput et thorax nigra. Thorax punctis confertissimis impressis, lineâque longitudinali elevatâ. Elytra obscuro-picta, striata, striæ ex punctis valde impressis. Subtùs niger. Pedes picei.

rbododac- 22. I. niger, villosus totus, plantis rufis. tylus. Long. corp. $\frac{x}{2}$ lin.

Habitat in ligno putrido Ulicis Europeei. D. Kirby. DESCR. Totum corpus nigrum. Elytra striata, villosa, pilis argenteo-cinerascentibus. Plantæ pedum solæ rufæ.

pubescens. 23. I. villosus niger, antennis pedibusque flavescentibus, fronte villosâ.

Bostrichus pubescens. Fab. Ent, Syst, i. b. 368. Ig.

Long. corp. $\frac{x}{2}$ lin.

Habitat

DESCR。 
Descr. Minor I. piniperdâ. Caput nigrum, fronte cinereo-viliısâ. Thorax et elytra pubescentia, integra, nigra. Antennæ et pedes flavescentes.

24: I. subcylindricus niger, thorace punctulato, niger. elytris crenato-striatis, plantis piceis.

Long. corp. 2 lin.

\section{Habitat}

Ex mus. Mifs Hill.

DESCR. Corpus nigrum, elongatum, subcylindricum, punctulis sub lente numerosissimis conspersum. Elytra striata, striæ punctis impressis. Pedes concolores; at plantæ et aliquando tibiæ ex piceo rufescunt.

25. I. subcylindricus niger, thorace punctulato ater. carinato, elytris crenato-striatis, plantis piceis.

Long. corp. $\mathrm{I} \frac{\mathrm{T}}{2}$ lin.

Habitat

Ex mus. D. Kirby.

DESCR. Corpus nigrum, elongatum, subcylindricum. Thorax punctulis impressis, lineâ mediâ longitudinali elevatâ sive carinatâ. Elytra striata. Pedes concolores, plantis piceis.

26. I. subcylindricus niger, elytris sulcatis punc-sulcatus. tis magnis valdè impressis.

Long. corp. 2 lin.

Habitat

DESCR. Antennæ ferrugineæ. Corpus nigrum. Caput punctis minutissimis conspersum. Thorax punctis majoribus numerosissimis confluentibus. Elytra sulcata, et intra sulcos puncta magna profundè impressa. Plantæ rufæ.

27. I. fuscus elongatus, elytris crenato-striatis. Boleti. Long, corp. $2 \frac{\pi}{2}$ lin.

Habitat in Boleto.

Ex mus. D. Crabbe. DESCR. 
Descr. Statura fere I. atri, sed major, longior. Totus fusscus, seu nigro-piceus. Antennæ autem paululum rufescunt. Thorax nitidus, punctulatus. Elytra punctato-striata, striarum interstitiis punctulatis.

\section{DERMESTES.}

Antenne clavatx: capitulo perfoliato, articulis tribus crassioribus.

Caput sub thorace inflexum conditum. Thorax convexus, vix marginatus.

Elytra immarginata.

* Corpore oblongo.

* Corpore ovato, aniennarum articulo extremo obtuss.

*** Corpore ovato, antennarum articulo extremo acatiusculo,

* Corpore oblongo.

lardarius. 1. D. niger, elytris anticè cinereis : punctis atris. Linn. Syst. Nat. 561. I. Faun. Suec. 408. Faun. Ingr. 40. I24. Fab. Syst. Ent. 55. I. Sp. Ins. i. 63. 1. Mant. i. 34. 1. Ent. Syst. i, a. 227. 1. Vill. i. 44. I. Gmel. 1592. I. Geoff. i. IOI. 5. Fourc. i. 18. 5. Raii Ins. 107. 4. Scope 34. Scbrank, 40. Pod. Mus. Grac. 22. I. Preys. Bob. Ins. 13. 10. Faun. Fred. 2. 15. Pontop. Dan. Atl. i. 6.66. I. Panz. Ent. Germ. 94. I. Faun. Etrusc. 73. Hellw. 73. Laich. 59. 1. Payk. Faun. Suec. i. 276 . I. Harr. 4 I.

De Geer, iv. I92. 1. t. 7. f. I5. Gleich. Obs. Micros. Sup. 
Sup. 20. t. 9. f. 1-9. Oliv. ii. 9.6. г. t. r. f. 1-6. Voet. t. 31.f. I. Friscb. v. 25. t. 9. Herbst. Jablonsk. iv. II 5. I. t. 40.f. I. Lister. Goed. t. II4. ? Long. corp. 4 lin.

Habitat in animalibus, lardo, carnibus, repositoriis culinariis infestus. Linn.

DEscr. Niger. Elytra anticè cinerea, punctis tribus atris.

2. D. tomentosus fusco cinereoque nebulosus, scu- murinus, tello fulvo.

Linn. Syst. Nat. 563. 18. Faun. Suec. 426. Faun. Ingr. 41. 128. Fab. Syst. Ent. 56. 7. Sp. Ins. i. 64. I0. Mant. i. 35. I2. Ent. Syst. i. a. 230. I4. Vill. i. 50. I7. Gmel. 1595. I8. Scop. 35. Scbrank, 41. Faun. Fred. 3.21. Geoff. i. I02. 7. Fourc. i. I9. 7. Pontop. Dan. Atl. 667. 8. Faun. Etrusc. 74. Hellav.74. Laich. i. 60. 2. Payk. Faun. Suec. i.277.2. Panz. Ent. Germ. 98. I5. Harr. 44. Oliv. ii. 9. 9. 5. t. I. f. 3. Voet. 57.t. 3 I. f. I r. Scbaff. Icon. t. 42. f. 1, 2. Brabm. Ins. Kal. i. 33. II4. Frisch. iv. t. I8. Herbst. Jablonsk. iv. 120. 2. $t .40 . f .2$.

Dermestes nebulosus. De Geer, iv. 197.2.

Long. corp. 4 lin.

Habitat in cadaveribus.

Descr. Corpus convexum, murini coloris, cinereum sive potiùs nigrum incano maculatum, læve, non striatum. Superficies (lente visa) hirsuta. Scutellum dorsi flavescens. Pectus et abdomen subtùs alba, sive ex nigredine alba. Antennæ compressæ perfoliatæ. Caput. non retrahit, sed pectore prominet incurvato capite. Datur alia duplo major, magis nigricans: an foemina? Complicat pedes miro artificio: complicatus ovatus est. Faun. Suec.

3. D. ater, pilis argenteis undique obsitus.

tessellatus.

Fab. Ent. Syst. i, a. 230. I5. 
An Dermestes tessellatus. Oliv. ii. 9.9.7. $t$. 2. fi: 10\% a, b. ?

Long. corp. 4 lin.

Habitat

DEscr. Affinis præcedenti, sed planior. Tum elytra obsoletè striata, punctata, punctis numerosissimis minutissimis. Antennarum clava rufo-ferruginea. Corpus totum pilis longiusculis appressis argenteis obsitum. Thorax ut in præcedenti.

undatus. 4. D. niger, elytris fasciâ albâ lineari duplici undulatâ.

Linn. Syst. Nat.562.3. Vill.i.45.3. Gmel. I592.3. Panz. Ent. Germ. 96. 9. Fab. Syst. Ent. 56. 5 . Sp. Ins. i. 64. 6. Mant. i. 34. 6. Ent. Syst. i. a. 228. 6. Fuesl. Arch. 80. 1. Faun. Ingr. 4T. 127. De Geer, iv. 199. 5. Laich. 6r.3. Poda, 22. ß. 4. Payk. Faun. Suec. i. 278.3. Harr. 46.

Oliv. ii. 9. I2. II. t. I.f.2. a, b. Scbeff. Icon. $t$. I57. $f_{.7}$. a, b. Herbst. Jablonsk. iv. I31. I2. t. 40.f.9. G. Scriba, 221. 32. t. I4.f. 3 .

Dermestes undulatus. Faun. Suec. 4 Io.

Long. corp. I $\frac{3}{4}-2 \frac{1}{2} \operatorname{lin}$.

Habitat in putridis, suffocatis, in floribus, et sub corticibus arborum. Panz.

DEscr. Niger. Elytra duplici lineâ transversâ albâ et undulatâ notata, quarum alia ab alterâ valdè remota. Faun. Suec.

Multo minor $D$. lardario. Thorax maculis tribus albis posticè, una ad scutellum juncta, una major ad angulum posteriorem utrinque posita.

rufpes. 5. D. niger, elytris striatis, tibiis plantisque rufis. Long. corp. $1 \frac{3}{4}$ lin.

Habitat - Captus in littora prope LandguardFort, Suffolciâ. D. Kirby.

DEscr. Caput valdè deflexum. Elytra striata, striis circiter 
circiter decem. Abdomen pilis pallidis adpressis subtomentosum.

6. D. niger, coleoptris punctis albis binis.

Linn. Syst. Nat. 562. 4. Faun. Suec. 41 I. Vill. i. 45. 4. Gmel. 1593. 4. Scop. 37. Scbrank, 48. Fab. Syst. Ent. 53. 4. Sp. Ins. i.63.5. Mant. i. 34. 5. Ent. Syst. i. a. 228.5. Faun. Ingr. 41. 126. Geoff. i. 100. 4. Fourc. i. 18.4. Faun. Fred.2. I6. Pod. Mus. Grec. 22. 3. Rai. 85. 35. Pontop. Dan. Atl. i. 667.2. Faun. Etrusc. 75. Hellw. 75. Laich. 62. 4. Panz. Ent. Germ. 95. 5. Payk. Faun. Suec. i. 279. 4. Harr. 45.

Oliv. ii. 9. II. 10.t. 2. f. I1. a, b. Scbaff. Icon. t. 42. f. 4. Donov. Brit. Ins. t. $23 \mathrm{I} \cdot 3$. Frisch. v. 22. t. 8. Sulz. Cbar. Ins. t. 2.f.5, 6. Herbst. Jablonsk. iv. I28. II. $t$. 4 O. $f .8$.

Dermestes bipunctatus. De Geer, iv. $197 \cdot 3$.

Long. corp. $2 \frac{3}{4}$ lin.

Habitat in carnibus, pellibus, vestimentis, cibis, parietibus. Larva cauda pilosa.

Descr. Ater. Punctum album in singulo elytro, ut clausis elytris duo puncta alba in dorso appareant. Sunt tamen, si probè adspicias, adhuc 5 alia puncta alba, scilicet unum ad scutum dorsale, unum utrinque ubi pectus adnectitur ely tris, et unum lineare in singulo elytro versus ejus basin, quæ quinque puncta minima sunt, et in quibusdam planè absunt, excepto puncto scuti. Venter cinereo-villosus. Femora et tibiæ piceæ, plantis rufis. Tactus, terrefactus, aut ubi periculum videt, contrahit pedes et caput.

Variat elytris rufo-fuscis nec atris.

7. D. niger, antennis flavis : clavâ oblongâ serratâ. Serra.

Fab. Ent. Syst, i. a. 234. 40.

Long. corp. 2 lin.

Habitat in Boleto, Salice, et sub cortice Quercuis.

Captus in Horto Kensingtoniano.

Pellio. 
DESCR. Insectum singulare. Statura et habitus $D . P e l-$ lionis. Corpus totum atrum, nitidum, immaculatum. Antennæ solæ flavæ, clavâ oblongâ haud perfoliatâ, sed altero latere tantum serrato. Ent. Syst.

Obs. Pedes ferruginei.

flavescens. 8. D. testaceus tomentosus, oculis nigris.

Long. corp. 2 lin.

Habitat in floribus umbellatis ubique.

DESCR. Totum corpus unicolor sub-testaceum, tomentosum. Oculi solummodo nigri.

tomentosus. 9. D. tomentosus griseo-murinus, oculis nigris, antennis pedibusque testaceis.

Fab. Syst. Ent. 57. 13. Sp. Ins. i. 66. 17. Mant. i. 35. 20. Ent. Syst. i. a. 232. 24. Vill. i. 54. 30. Gmel. 1596.38. Payk. Faun, Suec. i. 282. 7.

Oliv. ii. 9. 14, 15.t.3.f. 17. a-d. Herbst. Jablonsk. iv. I33. 14.t.40.f. II. De Geer, iv. 199. 4. t. 7.f. I8. Long. corp. 2 lin.

Habitat cum præcedenti, sed rarior.

DESCR. Totum corpus supernè fuscum, griseo-murinum, tomentosum. Antennæ, pedes et abdomen subtùs pallide testacea. Oculi nigri. Nimis affinis præcedenti.

An species distincta? An sexûs differentia?

ocbropus. Io. D. sub-griseus, antennis capite thoracis dorso abdomineque fuscis, elytris apice pallidis.

Long. corp. $1 \frac{x}{2}$ lin.

Habitat

Descr. Oblongus. Antennæ capitulo nigro, caule pallido. Caput nigro-fuscum. Thorax punctulatissimus, fuscus, lateribus rufescentibus. Elytra striata, striarum insterstitiis punctulatissimis, saturatè grisea, apicibus pallidis. Pectus et pedes grisei. Abdomen nigrofuscum. 
11. D. glăber testacens, oculis nigris.

fumatus.

Linn. Syst. Nat. 554. 22. Fab. Syst. Ent. 57. I2. Sp.Ins. i.66: 16. Mant. i. 35. 19. Ent. Syst. i. a. 231.23. Vill.i.51.20. Scbrank.60. Gmel.1595. 22. Faun. Etrusc. 84. Hellw. 84. Geoff. i. 104. I2. Laich. 63.5.

Dermestes stercoreus. Faun. Suec. 432. Fourc. i. 20. I2. Dermestes Rosæ. Scop. 39.

Long. curp. $\frac{x}{2}$ lin.

Habitat

DESCr. Corpus magnitudine pediculi, glabrum, testaceum colore ligni, pilis tectum, vix nisi oculo armato conspicuis. Faun. Suec.

* Corpore ovato, antennarum articulo extremo obtuso.

12. D. niger, coleoptris maculis duabus rubris Scarabaoiduabus ferrugineis, thoracis margine pallido. des.

Linn. Syst. Nat. 563. 17. Faun. Suec. 428 . Vill. i. 50. I6. Scop. 36 . Geoff. i. 106. 17. Brabm. Ins. Kal. i. 67.218. Laich. 80. I.

Don. Brit. Ins. t. 23 I. f. 4. Herbst. Jablonsk, iv. 62. I, . t.37.f. I. Voet. t. $3^{2} . f$. I.

Dermestes 4-maculatus. Scbrank. 43.

Dermestes hortensis. Fourc. i. 21 . I7.

Sphæridium Scarabæoides. Fab. Syst. Ent.66. I. $s p$. Ins. i. 78. 1. Mant. i. 43. I. Ent. Syst. i. a. 77. I. Faun. Etrusc. 1 I4. Hellw. II4. Panz. Ent. Germ. 25. 1. Faun. Ingr. 7. 20. Payk. Faun. Suec. i.54. I. Panz. Fun.Germ.8.2. Oliv. ii. I5.4. I. t. I. f. a-e. Hister testudinarius. $D e$ Geer, iv. 345 . t. I2. $f$. I7.

Long. corp. $3 \frac{1}{4}$ lin.

Habitat in stercore bovino, sed non in floribus, ut ait Linn.

DESCr. Suprà sub lente punctulatissimus. Caput nigrum. Thorax niger, margine pallido pellucido. Elytra singula in disco maculâ rubrâ, in apice maculâ aliâ majore ferrugineâ, qui color apud marginem exteriorem altiùs excurrit. Pedes testacei, pellucidi, femoribus yot. $\mathbf{I}$.

maculâ 
maculâ nigrâ, tibiis spinosis. Agillimus, velocissime sepeliens se in stercore vaccino.

bipustula- 13. D. niger, coleoptris maculis duabus ferrutus. gineis, thoracis margine nigro.

Vill. i. 54. 32 .

Dermestes hæmmorrhous. Scbrank. 44.

Dermestes testudinarius. Fourc. i. 24. 29.

Sphæridium bipustulatum. Fab. Sp. Ins. i. 78. 2. Mant.i. 43.2. Ent. Syst.i. a.78.3. Panz. Ent. Germ. 26. 3. Preys. Bob. Ins. 64. 62.

Oliv. ii. I5. 5.2. t. 2.f. II. a, b. mala, Herbst. Jablonsk. iv. 66.2.t. $37 \cdot f \cdot 2$.

Long. corp. 3 lin.

Habitat in stercore bovino.

DESCr. Præcedenti simillimus, sed thorax margine nigro. Elytra apicibus ferrugineis, colore in marginem exteriorem non excurrente. Pedes nigri, femorun basi testaceâ.

lunatus. 14. D. ater, elytris maculâ apicis lunatâ margineque exteriore rubris.

Long. corp. 3 lin.

Habitat in stercore. Ex mus. D. Cobbold.

DESCR. D. 4-maculato simillimus proximus, sed thorax margine atro, nec pallido, subtùs utrinque maculâ magnâ testaceâ, et elytra tantùm maculâ unicâ rubrâ.

4-macula- 15. D. niger, elytris maculis duabus rubris.

tus. Long. corp. $2 \frac{x}{3}$ lin.

Habitat in stercore.

Descr. Præcedentibus simillimus, sed minor. Thorax et elytra margine exteriore pallido. Pedes testacei, femoribus maculâ nigrâ. Tibiæ spinosæ.

margina- 16. D. ater glaber, margine elytrorum flavescenti, tus. pedibus rufis : femoribus nigro-annulatis. 
Geoff. i. 107. 18.

Dermestes gagatinus. Fourc. i. 21, I8.

Sphæridium marginatum. Fab. Mant. i. 43.5. Ent. Syst. i. a. 80. II. Panz. Ent. Germ. 27. 8. Preys. Bob. Ins. 65. 63. Payk. Faun. Suec. i. 55.2.

Oliv. ii. I5.6. 4.t. x. f. 3. a, b. Herbst. Jablonsk. iv. $67 \cdot 3 \cdot t \cdot 37 \cdot f \cdot 3 \cdot$

Long. corp. 2 lin.

Habitat in stercore bovino.

Descr. Corpus atrum, glabrum, depressiusculum. Sub lente thorax et elytra punctulis minutissimis conspergi videntur. Margo ipse elytrorum tenuis flavescens. Pedes rufescentes, femoribus latis, compressie, nigroannulatis.

I 7. D. niger subrotundus, elytris punctato-striatis, lugubris. pedibus brunneis.

Geoff. i. 107. I9. Fourc. i. 22. 19.

Sphæridium lugubre. Oliv. ii. I5.7.7.t.2.f. 12.a, b. Sphrridium atomarium. Fab. Syst. Ent. 67.3. Sp. Ins. i. 78.5. Mant. i. 43.7. Ent. Syst. i. a.80. 13.? Payk. Faun. Suec. i. 58.6.

Long. corp. $1 \frac{x}{2}$ lin.

Habitat in stercore.

DESCR. Similis D. marginato, at elytra punctatostriata. Corpus sub-hemisphæricum, nigrum, nitidum, pedibus abdominisque apice fusco-brunneis. Oliv.

18. D. ater glaberrimus nitidus, elytris maculâ bumeralis. magnâ baseos sanguineâ: puncto atro medio.

Tritoma bipustulata. Fab. Syst. Ent. 68. I. Sp. Ins. i. 8o. I. Mant. i. 44. I. Ent. Syst. i. b. 505. I. Panz. Ent. Germ.343. I. Gmel. I634. I. Payk. Faun. Suec. iii. 335. I.

Long. corp. $2 \frac{3}{4}$ lin.

Habitat in Corylo.

D. Beckwith.

DESCR. 
Descr. Totum corpus glaberrimum nitet. Elytra maculam magnam sanguineam subtetragonam, ad marginem exteriorem baseos gerit. In hầc autem maculâ ad basin punctum atrum.

ruficollis. 19. D. niger, thorace pedibusque rufis, elytris lævibus.

Sphæridium ruficolle. Oliv. ii. I5. 9. II. t. 2.f.7. a, b. Long. corp. lin.

Habitat

In mus. D. Francis.

DESCR. Corpus ovatum, subrotundatum, nigrum, nitidum, antennis, thorace, pedibusque rufis. Elytra lævia. Tibiæ inermes. Oliv.

melanoce- 20. D. ater glaber, elytris castaneis : maculâ comphahus. muni baseos nigrâ.

Linn. Syst. Nat.563. 16. Faun. Suec.425. Vill.i.49. I5. Sphæridium melanocephalum. Fab. Syst. Ent. 67.4. Sp. Ins. i. 78. 6. Mant. i. 43. 8. Ent. Syst. i. a. 80. 14. Panz. Ent. Germ. 28. I6. Faun. Ingr.8. 23. Payk. Faun. Suec. i. 61. 10.

Oliv. ii. 15. 8, 9.t. I.f. 4. a, b. Herbst. Jablonsk. iv. 74. 10. t. $37 . f$. I0.

Long. corp. $\frac{7}{8}$ lin.

Habitat

DESCR. Antennæ ferrugineæ. Caput et thorax nigra. Elytra sub lente obsoletissimè striata, castanea, maculâ ad basin communi trigonâ nigrâ. Pedes castanei.

similis.

2I. D. ater glaber, elytris totis castaneis.

Long. corp. I lin.

\section{Habitat}

Descr. Simillimus D. melanocepbalo, à quo differt elytris omninò castaneis, nec maculâ communi ad basin suturæ atrâ: tum elytra in hoc pellucidiora; porro pedes ferruginei, nec castanei. 
2. D. niger glaberrimus, elytris pedibusque pi-piceus. ceis.

Long. corp. $\mathbf{I} \frac{\mathrm{r}}{4}$ lin.

Habitat in hortis, ad capsas fimo æstuanti superimpositas.

Descr. Caput et thorax ex piceo-nigra, nitida, glaberrima. Elytra, præcipuè si paulùm eleventur, tota picea, apice pallidiori. Pedes etiam picei unicolores. Sub lente, elytra apparent obsoletissimè striata, striis punctatis, et porrò tota superficies punctulis minimis numerosissimis ornatur. Oculo optimè armato, thorax etiam punctula vix autem conspicienda præ se ferre visus est.

Variat elytris magis minusve striatis. An sexûs differentia?

23. D. piceus glaberrimus nitidus, thoracis la-lateralis. teribus pallidioribus, elytris obsoletè striatis.

Long. corp. $\mathrm{I}_{\frac{\pi}{4}}$ lin.

Habitat -

DESCR. Totum corpus unicolor, præterquam thoracis Jatera, quæ pallidiora. Thorax et elytra oculo armato punctulis minutissimis numerosissimis conspergi videntur. Elytra obsoletè striata punctulis impressis.

24. D. ater glaberrimus nitidus, elytris pedibus-picinus. que piceis.

Long. corp. $1 \frac{x}{2}$ lin.

\section{Habitat-}

DESCR. Antennæ atræ. Caput et thorax atra punctulatissima. Elytra striata, picea, striis ex punctulis impressis. Abdomen subtùs nigro-testaceum. Pedes picei.

25. D. obscuro-piceus, capite nigro, elytris striatis, sordidus. Long. corp. 1 lin.

\section{Habitat}

Descr. 
DesCr. Antennæ nigræ, basi rufæ. Caput nigrum. Thorax nigro-piceus, punctulatus. Elytra rufo picea, striata, punctulis impressis. Pectus nigrum, punctulatum. Abdomen subtùs rufo-ferrugineum, sive piceum. Pedes picei.

Caltha. 26. D. ater nitidus, elytris striatis apice obsoletè ferrugineis.

Scop. 18. 49. Sbrank. 50. Vill. i. 55.39.

Sphæridium hæmorrhoidale? Fab. Syst. Ent. 67.5. Sp. Ins. i. 79.7. Mant. i. 43. 9. Ent. Syst. i. a.8I. 18. Panz. Ent. Germ. 29. I9. Laich. 44. I.

Oliv. ii. 1 5.9, 10. t.2.f.6. a, b.? Herbst. Jablonsk. iv. $73 \cdot 9 \cdot t \cdot 37 \cdot f \cdot 9 \cdot$

Long. corp. r. lin.

Habitat in floribus Caltbe palustris. Aprili.

DESCr. Saltatorius. Antennæ capitatæ arctissimè perfoliatæ, basi pallidâ. Totum corpus sub lente punctis minutissimis aspergi videtur. Pedes setis rigidis spinosi, ut in Scarabceis.

terminatus. 27. D. niger glaberrimus, elytris striatis ad apicem ferrugineis, pedibus piceis.

Long. corp. $1 \frac{x}{4}$ lin.

Habitat

DESCR. Corpus nigrum, glaberrimum. Antennæe et pedes ferruginei. Elytra nigra, striata, striis concinnè punctatis. Ad marginem apicis exteriorem macula magna pallidè ferruginea; hæc macula apicem ipsum, et plus dimidiâ marginis exterioris parte occupat. Maximè affinis $D$. piceo, etiam striis et punctulis thoracis et elytrorum; sed minor, et macula apicis longè clarior et decuplo major.

unipuncta- 28. D. niger, elytris lividis : maculâ communi nitus. grâ mediâ.

Coccinella unipunctata. Linn. Syst. Nat.579.6. Faun. Suec, 470. Vill. i. 94.3.

Scarabæus 
Scarabæus unipunctatus. Fab. Syst. Ent. 19.78. Sp. Ins. i. 22. 95. Mant. i. II. 104. Jablonsk. ii. 295. 190.

Sphæridium unipunctatum. Fab. Ent. Syst. i. a. 81. 20. Laicb. i. 82. 2. Panz. Ent. Germ.29. 20. Faun. Ingr. 8.24.

Panz. Faun. Germ. 3. t. 1. Oliv. ii. 15.6.5.t.2. f. 8. a, b. Herbst. Jablonsk. iv, 68. 4. t. 37.f. 4.

Long. corp. $\frac{x}{8}$ lin.

Habitat in fim̌ æostuanti.

DESCr. Caput et thorax atra, nitidiuscula. Elytra lurida, sive sordidè testacea, suturâ et maculâ utrique elytro communi, sub-cordatâ, sive subtrigonâ, medio dorsi sitâ, nigris. Antennæ, pedes et abdomen nigra, sive ex nigro picea. Antennis hujusce animalculi probè examinatis, procul dubio Dermestem censendum esse dicimus.

29. D. ater glaber, elytris testaceis obsoletè striatis. quisquilius: Scarabæus quisquilius, Linn. Syst. Nat.558.83. Faun. Suec. 397. Fab. Syst. Ent. 20. 74. Sp. Ins. i. 21. 9I. Mant. i. II. I00.

Scarabæus minimus, - Scop. 29 ,

Long. corp. $\frac{3}{4}$ lin.

Habitat in stercore equino, Maio.

DESCR. Caput et thorax aterrimus, nitidiusculus. Elytra testacea, obsoletè striata, maculâ sæpiùs unâ aut alterâ obsoletâ, fuscâ. Abdomen nigrum. Pedes subferruginei. Femora autem basi nigra. Facies Scarabai, at certè antennis Dermestis.

3०. D. ater glaber, thoracis lateribus elytrisque flavus. luteis.

Long. corp. $I \frac{y}{3}$ lin.

\section{Habitat}

DESCR. Præcedenti simillimus, sed major, thoracis margine externo latè luteo. Ped̦es lutei.

$$
\text { F } 4 \text { 3I. D. }
$$


atricapillus.3x. D. rufo-testaceus, capite atro, elytris testaceils striatis.

Long. corp. $\frac{3}{4}$ lin.

Habitat -

Descr. Antennæ testaceæ. Caput atrum. Thorax rufo-testaceus, nitidus. Elytra testacea striata.

obscurus. 32. D. obscuro-piceus, margine thoracis elytrorumque apicibus rufis.

Long. corp. $\frac{3}{4}$ lin.

Habilat -

DESCR. Caput piceum. Thorax piceus, margine rufo. Elytra plana, non striata, picea, apicibus rufis. Pedes picei.

boletopha- 33. D. niger, antennis pedibusque rufis, elytris gus. apice fuscis.

Long. corp. I lin.

Habitat in Boleto putrido. D. Kirby.

DESCR. Parvus, valde convexus. Elytra levissimè striata, nigricantia, apicibus fuscis.

nigriceps. 34. D. ater nitidus, thoracis lateribus antennis elytris pedibusque rufo-ferrugineis.

Long. corp. $\frac{3}{4}$ lin.

Habitat

DESCR. Antennæ rufo-ferrugineæ. Caput atrum. Thorax ater, lateribus piceis, sive rufo-ferrugineis. Elytra ferruginea, obsoletè striata, striis ex punctulis minutissimis impressis. "Corpus subtùs atrum. Pedes ferruginei.

pulcbellus. 35. D. nitidus, capite thoraceque atris, elytris castaneis ad basin piceis.

Long. corp. $\frac{\pi}{3}$ lin.

Habitat

DESCR. 
DESCR. Antennæ rufæ. Caput et thorax atra, nitida. Elytra fusco-castanea, apicibus dilutioribus. Pedes rufi.

$3^{6}$ D. lutcus suprà pubescens, elytris lævibus. luteus. Sphæridium luteum. F. M. Mant. App. 378. Ent. Syst.i. a. 79. 6. Panz. Ent. Germ.26.5.

Nitidula lutea. Oliv. ii. 12. J6. 22. t. 3.f.28. a, b.

Long. corp. $2 \frac{\pi}{4}$ lin.

Habitat

DESCR. Totum corpus suprà infràque unicolor, sordidè luteum, obscurum, supernè pubescit, subtùs glabrum est, et sub-nitescit. Elytra lævia, nec striata.

37. D. castaneus nitidiusculus. levis.

Long. corp. $\frac{3}{4}$ lin.

Habitat in Boleto putrido. D. Kirby.

Descr. Totum corpus castaneum, nitidiusculum. Elytra punctato-striata.

38. D. ater, capite thoraceque convexis.

convexus.

Long. corp. $\frac{x}{2}$ lin.

Habitat

Ex mus. D. Kirby.

DESCr. Antennæ et pedes picei. Caput, thorax, et elytra aterrima, glaberrima, nitida. Quod in hoc singulare admodùm, caput, thorax, et abdomen omnia convexa, adeo ut cùm corpus depressum est, ex articulis tribus moniliformibus constare videtur, quorum abdomen major, thorax medius, caput minimus dicatur.

39. D. sub-ovalis luteus, corpore suprà infràque oralis. tomentoso.

Long. corp. 2 lin.

Habitat

Ex mus. Miss Hill.

Descr. 
DEScr. Corpus unicolor, luteum, qvale, potiusquam ovatum tomentosum, pilis brevibus, reflexis, appressis, neque minimè erectis. Simillimus $D$. luten, at major, tum abdomen subtùs tomentosum, nec læve, nitidum. Oculi nigri. Elytra non striata.

concinmes. 40. D. ater nitidus, thoracis margine elytrisque testaceis.

Long. corp. $\frac{2}{3}$ lin.

Habitat

Descr. Simillimus $D$. flavo, sed differt colore et magnitudine. Elytra multo saturatiora. Pedes rufi.

ferrugineus. 4I. D. ferrugineus, elytris striatis.

Sphæridium ferrugineum. Fab. Mant. i. 43.6. Ent. Syst. i. a. 80. I2. Payk. Faun. Suec. 1.72. 24. Panz. Ent. Germ. 27.9.

Oliv. ii. I5. 7.6. Suppl.t. 3. f. I4. a, b.

Long. corp. I lin.

Habitat — Ex mus. D. Kirby.

DESCR. Corpus totum ferrugineum, immaculatum.

** Corpore ovato, antennarum articulo extrema acutiusculo.

fimetarius. 42. D. ater glaberrimus nitidus.

Dermestes fimetariús. Vill. i. 55. 33 .

Sphæridium fimetarium. Fab. Syst. Ent. 68. 7. Sp. Ins. i. 79. 9. Mant. i. 43. I2. Ent. Syst. i. a. 82. 25. Panz. Ent. Germ.30.25. Faun.Ingr. 8. 25. Payk, Faun. Suec. i. 64, 13. Hersbst. Jablonsk. iv. 78. 15. Phalacrus coruscus. Payk. Faun. Suec. iii. Add.438, I. Long. corp. $I \frac{x}{4}$ lin.

Habitat in stercore.

DESCr. Totum corpus aterrimum, lævissimum. 
43. D. ater, elytris striatis, pedibus concolo-mimutus. ribus.

Dermestes minutus striatus. Vill. i. 55. 34 .

Sphæridium minutum. Fab. Ent. Syst. i. a.83.29. Faun. Ingr. 9.27. Payk. Faun. Suec, i. 63. I 2.

Sphæridium atomarium. Faun. Ingr. 7.22.

Sphæridium atomarium. Oliv. ii. I5. II. I4, t. 2. $f \cdot 5 \cdot a, b$.

Silpha atomaria. Linn. Syst. Nat. 574. 35. ?

Long. corp. $\frac{x}{2}$ lin.

Habitat -

DESCR. Elytra posticè pallidiora.

44. D. niger glaberrimus nitidus, antennis pe-nitidus. dibusque testaceis.

Long. corp. $\frac{3}{4}$ lin.

Habitat

Descr. Maximè affinis D. ovato, à quo differt colore nigro, sive atro, nec æneo; antennis pedibusque testaceis, nec concoloribus; tum abdomine piceo. Elytra autem in hoc etiam sub lente obsoletissimè striata.

45. D. piceus nitidus glaberrimus. politus.

Long. corp. $\mathbf{I} \frac{x}{4}$ lin.

Habitat in lignis vetustis.

DESCR. Totum corpus suprà unicolor, ex nigro piceum, politum. Notandum autem est, quod si forte elytra paulùm eleventur pallidiora videntur; imò in nonnullis ferè testacea. Nunquam striata, sunt. Antennæ et abdomen subtùs pallidiora.

46. D. fusco-ferrugineus nitidissimus, antennis consimilis elytrorum apicibus pedibusque ferrugineis.

Long. corp. $I \frac{\pi}{4}$ lin.

Habitat in arboribus.

Descr. 
Descr. Præcedenti simillimus, sed minor, colore saturatiori. Elytra striâ unicâ ad suturam.

stercorarius.

47. D. convexus ater nitidus, antennis pedibusque rufis.

Long. corp. $\frac{3}{4}$ lin.

Habitat

Descr. Antennæ rufæ. Corpus totum atrum, politum, valde convexum. Pedes rufi.

ovatus. 48. D. nigro-æneus politus, femoribus posticis crassissimis.

Long. corp. $\frac{3}{4}$ lin.

Habitat

DEsCr. Antennæ piceæ. Corpus suprà nigroæneum, subtùs piceum. Elytra sub lente obsoletissimè striata. Pedes picei, femoribus posticis crassissimis. Corpus valde convexum.

coadunatus. 49. D. ferrugineus glaber, elytris punctis tribus nigris coadunatis.

Long. corp. $I \frac{\pi}{4}$ lin.

Habitat

DESCr. Oculi et abdomen nigra; per cætera ferrugineus est. Elytra ponè medium punctis tribus nigris, remotiusculis, at coadunatis; quæ puncta fasciam subarcuatam referunt.

inustus. 50 . D. niger nitidus, coleoptris striatis testaceis: maculis tribus fuscis. .

Long. corp. I lin.

Habitat

DESCR. Antennæ testaceæ. Caput nigrum. Thorax niger, marginibus rufis. Elytra striata, testacea, maculâ fuscâ triangulari communi ad basin, et maculâ magnâ fuscầ in singulo elytro prope apicem. Pedes testacei. 
51. D. rufus, abdomine nigro.

Long. corp. I lin.

bypomela-

Habitat -

nus.

DESCR. Staturâ et magnitudine D. coadunati, cui simillimus, sed nullæ in elytris lituræ. Porrò rufus est, nec ferrugineus.

52. D. niger nitidus utrinque acutiusculus, an-Gyrinoides. tennis pedibusque testaceis.

Long. corp. circiter $\frac{x}{2}$ lin.

Habitat

In mus. D. Kirby.

DESCr. Staturâ et magnitudine $D$. Cassidoidis.

53. D. piceus, thoracis margine pallido pellucido, Cassidoipectore pedibusque ferrugineis.

Long. corp. $\frac{1}{3}$ lin.

Habitat

DESCR. Thorax anticè semicircularis, posticè transversus. Caput obumbrans et condens ut in Cassidibus. Statura et magnitudo præcedentis.

Variat ano pallido nigroque.

54. D. ovato-oblongus niger lævis nitidiusculus, nigrinus. pedibus piceis.

Long. corp. I. lin.

Habitat Ex mus. D. Kirby.

DESCR. Totum corpus suprà glaberrimum, et punctis immune. Antennæ et pedes picei.

55. D. niger obscuriusculus punctulatissimus, Absintbii. pedibus piceis.

Long. corp. I $\frac{ \pm}{2}$ lin.

Habitat in floribus Artemisie. D. Kirly.

DESCR. Corpus atrum, ovatum, depressiusculum, punctulis numerosissimis conspersum. Antennæ et pedes picei. 
picei. Facie omnino Chrysomelce bemispherica, at antennæ clavatæ distinctam satis probant.

piceorbaus. 56. D. ovato-oblongus niger lævis nitidiusculus, pedibus elytrorumque apicibus piceis.

Long. corp. $\frac{x}{2}$ lin.

Habitat

Ex mus. D. Kirby.

DESCR. Corpus omnino læve, nitidum: Elytra nigra, apicibus piceis. Ne confundatur cum $D$. Caltba, qui quadruplo major.

castaneus. 57. D. ater, elytris castaneis.

Long. corp. I lin.

Habitat

Ex mus. D. Kirby.

DESCr. Totum corpus suprà læve, nitidiusculum. Elytra castanea. Antennæ, caput, thorax et pedes atra. Oculo optimè armato elytra punctulata apparent. Corpus depressiusculum.

melas. $\quad 58$. D. oblongus niger, antennis pedibusque testaceis.

Long. corp. $\frac{1}{3}$ lin.

Habitat

Descr. Antennæ testacex, capite thoraceque longiores. Totum corpus unicolor, nigrum, nitidum. Pedes testacei.

brunneus. 59. D. oblongus brunneus nitidus, antennis pedibusque testaceis.

L'ong. corp. I lin.

Habitat

DESCR. Caput nigrum. Thorax et elytra brunnea, sive rufo-ferruginea. Pedes testacei.

pilosellus. 60. D. nitidus pilosus castaneus, antennis testaceis.

- Long. 
Long. corp. $\frac{r}{2}$ lin.

Habitat in Alno putricio.

DESCR. Totum corpus suprà castaneum, eapite thoraceque saturatioribus. Thorax et elytra pilis obtecta. Corpus subtùs pedesque ferruginei.

6r. D. testaceus pubescens, elytris punctatis. . pallidus. Long. corp. $1 \frac{1}{4} \operatorname{lin}$.

Habitat

Ex mus. D. Kirby.

DESCR. Totum corpus suprà pallido-testaceum, subtùs ferrugineum. Oculi nigri. Thorax et elytra oculo bene armato punctulata apparent. Antennæ et pedes pallido-testacei.

62. D. convexus minutissimus nigro-piceus pu-nitidulus. bescens, antennis pedibusque rufis.

Long. corp. $\frac{x}{3}$ lin.

Habitat

Descr. Totus nitidus pubescens. Antennæ rufæ. Caput et thorax nigro-picea, ad apicem pallidiora. Corpus subtùs et pedes rufa.

63. D. niger nitens, elytrorum apicibus pallidis, nitens. pedrbus ferrugineis.

Long. corp. $\frac{\pi}{3}$ lin.

Habitat

In mus. D. Kirby.

DEsCr. Minutissimus, oblongiusculus. Antennæ nigræ. Elytra striata.

64. D. æneus nitidulus, elytris lævissimis, pedibus aneus. nigris.

Sphæridium æneum. Fab. Ent. Syst. i. a. 83.27. Payk. Faun. Suec. i. 65. 15 .

Long. corp. $\frac{x}{2}$ lin.

Habitat

DESCR. 
Descr. Affinis D. fimetario, at duplo miñor, et totus æneus, nitidus. Pedes nigri.

perpusillus. $6_{5}$. D. ater nitidus minutissimus, elytris posticè piceis..

Long. corp. $\frac{\pi}{3}$ lin.

Habitat -

DESCr. Antennæ testaceæ.

minimus. 66. D. niger nitidus minutissimus, elytris truncatis apice pallidis.

Long. corp. $\frac{x}{3}$ lin.

\section{Habitat}

Descr. Corpus depressum. Antennæ ferrugineæ. Caput et thorax nigra, nitidiuscula. Elytra paulò dilutiora, truncata, apicibus pallidioribus. Pedes rufi.

picatus. 67. D. piceus levissimus, antennis basi rufis. Long. corp. vix $\frac{1}{2}$ lin.

Habitat - In mus. D. Kirby.

Descr. Statura fere D. fimetarii, sed Puliceminor, lævissimus, nitidissimus, totus piceus, exceptis antennarum basi palpisque rufis.

Punctum. 68. D. subrotundus livido-testaceus.

Long. corp. $\frac{\pi}{3}$ lin.

Habitat -

In mus. D. Kirby.

Descr. Minutissimus. D. Cassidoidi similis, sed thoracis figura vix eadem. Ferè hemisphæricus, lævis, livido-testaceus. 


\section{PTINUS.}

\section{Antenna filiformes.}

Thorax angulatus, subrotundus, immarginatus, caput recipiens.

* Antenne articulis ultimis tribus reliquis multo longioribus, corpore cylindrico breviores.

* Antennce articulis tribus reliquis majoribus, rotundatis sive moniliformibus, corpore cylindrico breviores.

** Antennce articulis omnibus aqualibus, corpus ovatum aut oblongum subcequantes.

* Antennce articulis ultimis tribus reliquis multo longioribus, corpore cylindrico breviores.

I. Pt. fuscus, antennis luteis pectinatis.

Linn. Syst. Nat. 565. 1. Faun. Fred.317. Scbrank, 64. nis. Vill. i. 61. I. Fuesl. Arch. 86. 2.

Sulz. Hist. Ins. t. 2. $f .6$.

Dermestes pectinicornis. Faun. Suec, 4r2.

Hispa pectinicornis. Fab. Syst. Ent.70.3. Sp. Ins. i. 82. 3. Mant. i. 47.3. Gmel. I733. I\%.

Ptilinus pectinicornis. Fab. Ent. Syst. i. a. 243.2. Geoff.i. 65. I. Panz. Ent. Germ. 115. 1. Payk. Faun. Suec. i. 316. I.

Panz. Faun. Germ. 3. t. 7. o. Oliv. ii. I7 bis. 4. I. t. I. $f$. I. $\mathrm{a}-\mathrm{g}$.

Ptilinus fuscus. Fourc. i. 4. I.

Ptilinus cylindricus. Harr. 228.

Long. corp. $2 \frac{\pi}{4}$ lin.

Habitat in domibus antiquis.

DEscr. Corpus cylindricum, fuscum. Antennæ luteæ, pectinatæ. Thorax convexus, obscurus. Elytra punctata, obsoletè striata. Pedes rufo-testacei, femoribus basi fuscis.

vol. I.

G

2. Pt. 
serraticornis.

2. Pt. fuscus, elytris pedibusque rufis, antennis serratis.

Ptilinus pectinicornis, foem. Panz. Faun. Germ. 3.t.7. • Long. corp. 2 lin.

Habitat cum præcedenti.

Descr. Habitus et fere statura Pt. pectinicornis. Antennæ autem serratæ, nec pectinatæ. Porro, antennæ, palpi, pedes et elytra, omnia rufa. Caput, thorax et abdomen fusca. Thorax posticè tuberculis' tribus obsoletis.

An Ptinus pectinicornis foem.? An species distincta?

fissicornis. 3. Pt. ferrugineus, thorace anticè scabro, elytris striatis.

Long. corp. $I \frac{i}{4}$ lin.

Habitat -

DESCR. Antennæ rufæ, articulis tribus ultimis serratis. Caput ferrugineum. Thorax obscurè ferrugineus, anticè mucronibus sparsis exasperatus. Elytra ferruginea, striata, nitida. Corpus subtùs pallidius. Redes ferruginei.

pertinax. 4. Pt. fuscus unicolor.

Linn. Syst. Nat. 565. 2. Vill. i. 61.2.

De Geer, iv. 227. I. t. 8. f. 24, 25.

Dermestes pertinax. Faun. Suec. 414.

Anobium pertinax. Fab. Mant. i. 39. I. Ent. Syst.i. a. 237. 5. Faun. Ingr. 43. I2 I. Payk. Faun. Suec. i. $305: 3$.

Oliv. ii. 16.6.2.t.I.f.4.a, b. Panz. Faun. Germ.66. t. 5. Herbst. Jablonsk. v. 54. 2. t. 47. $f \cdot 3$.

Long. corp. 2 lin.

Habitat in domibus, ubi vestimenta consumit. Linn.

DESCR. Insectum teres, oblongum, fuscum, opacum. Elytra oblonga, flexilia, punctis minutissimis, excavatis, octo striarum. Clypeus subrotundus, magis 
latus quam longus, supernè inæqualis margine cruciato prominulo; ad angulos thoracis posticos sive laterales sæpe punctum villis flavum. Abdomen nigrum est, certo tamen ad lumen situ albus omnino adparet. Faun. Suec.

5. Pt. subcylindricus fuscus, antennis tibiisque rufipes. rufescentibus.

Anobium rufipes. Fab. Ent. Syst. i. a. 236.3. Panz. Ent. Germ. Io9. 3.

La Vrillette des Tables. Geoff. i. III. I. $t$. I. $f .6$.

Long. corp. 2 lin.

Habitat

DESCr. Habitus omnino D. pertinacis, at antennæ, tibiæ et plantæ sub-ferrugineæ sunt. Color saturatè fuscus, sive potiùs nigro-fuscus.

6. Pt. subcylindricus fusco-ferrugineus, thorace cylindricus. gibbo læviusculo, antennis pedibusque rufescentibus.

Long. corp. $I \frac{x}{2}$ lin.

Habitat

DESCR. Maxime affinis $P$ t. rufipedi, a quo differt colore sub-ferrugineo, et pedibus omnino rufescentibus, nec solummodo tibiis.

An species satis distincta?

7. Pt. castaneus pubescens, thorace elevato, ely-castaneus. tris striato-punctatis.

Anobium castaneum. Fab. Ent. Syst. i, a. 237. 4. Panz. Ent. Germ. 109. 4.

Oliv. ii. 16. $7 \cdot 4 \cdot t \cdot$. $f \cdot 2$ : a, b.

Byrrhus fulvus obscurus. Geoff. i. 112.3.

Byrrhus mollis. Fourc. i. 26.3.

Long. corp. $2 \frac{x}{4}$ lin.

Habitat-Prope Crayford in agro Cantiano propter G 2 fepes, 
sepes, sole meridiano pleniùs lucenti, volantem cepi.

DESCR. Corpus totum pubescens, castaneum, immaculatum, oculis tamen nigris. Thorax marginatus, elevatus, lineâ longitudinali vix impressâ. Elytra striata, striis punctatis. Oliv.

mollis. $\quad$ 8. Pt. testaceus, oculis fuscis, elytris lævibus.

Linn. Syst. Nat.565.3. Vill. i. 62.3. Gmel. 1604.3. De Geer, iv. 230.4 .

Dermestes mollis. Faun. Suec.4I5. Faun. Fred.31. I8. Anobium molle. Fub Syst. Ent. 62. 6. Sp. Ins. i. 71. 2. Mant. i.39.3. Ent.Syst. i.a. 237. 7. Faun. Ingr. 43. 133. Payk. Faun. Suec. i. 306. 5 .

Oliv. ii. I6. 8: $5 \cdot t \cdot 2 \cdot f .8$.

La Vrillette de la farine. Geoff. i. II I, 2.

Long. corp. $1 \frac{1}{4}$ lin.

Habitat

DESCR. Corpus totum fusco-testaceum, immaculatum, oculis nigris. Thorax convexus, lavis, marginatus. Elytra lævia. Oliv.

lavis. 9. Pt. testaceus, thorace elytrisque lævibus.

Long. corp. 2 lin.

Habitat -

Descr. Thorax marginatus ferè ut in Cantbaridibus, et dentibus omnino caret. Elytra punctulatissima, at ne minime quidem striata.

tenuicornis. 10. Pt. oblongo-ovatus testaceus, thorace lævi, antennis tenuibus articulis tribus ultimis crassioribus longioribus.

Long. corp. I $\frac{3}{4}$ lin.

Habitat

DEscr. Thorax non dentatus, colore saturatiori sive fuscus. Elytra striata; striæ ex punctis impressis. Antennas præcæeteris hujuscegeneris animalculis tenues jactitat.

I I. Pt. 
11. Pt. oblongus tomentosus fusco-cinereoque tessellatus. nebulosus, abdomine fusco.

Vill. i. 54. 29.

Byrrhus nigro-fuscus. Geoff. i. I12. 4.

Anobium tessellatum. Fab. Ent. Syst. i. a. 236. I. Payk.

Faun. Suec. i. 305. 4. Panz. Ent. Germ. I08. I.

Oliv. ii. 16. 6. 1.t. r. f. a-c. Panz. Fuun. Germ. 66.

t. 3. Herbst. Jablonsk. v. 53. x. t. 47.f. 2.

Anobium pulsatorium. Scriba, 222. $33 \cdot t \cdot 14 \cdot f \cdot 4$.

Long. corp. $2 \frac{1}{2}$ lin.

Habitat -

DEscr. Antennæ rufæ, articulis tribus ultimis clavatis, longioribus. Corpus totum brunneum, thorace elytrisque villo cinereo nebulosis. Thorax convexus, lævis, marginatus. Elytra minimè striata. Pedes corpore concolores.

I 2. Pt. rubello-ferrugineus, elytris striatis.

Long. corp. 2 lin.

Habitat —Captus sub subere cistellæ ligneæ in- rubellus. sectis recipiendis factæ, ubi lignum cistellæ plurimùm roseat. D. Kirby.

Descr. Totus rubello-ferrugineus, oculis nigris. Thorax convexus. Elytra punctato-striata, villosula.

** Antennce articulis tribus reliquis majoribus rotundatis sive moniliformibus, corpore cylindrico breviores.

13. Pt. fuscus, thorace valdè convexo anticè re-Boletorum. flexo, elytris punctatis.

Long. corp. I $\frac{3}{4}$ lin.

Habitat

DESCR. Antennæ articulis tribus ultimis majoribus laxiusculis. Thorax valdè convexus. Elytra punctis impressis sub-confluentibus referta. Antennæ et pedes concolores. Color ex nigro-piceus.
G 3
14. Pt. 
villosutus. I4. Pt. fuscus aureo-villosus.

Long. corp. I $\frac{x}{2}$ lin.

\section{Habitat}

DESCR. Antennæ ferrugineæ. Thorax villis aureis sub-nebulosus. Elytra villis aureis micantia, punctulata. Subtùs niger, pedibus rufo-ferrugineis. Color variat mox fuscus, mox ferrugineus.

pyrrbocephalus.

I5. Pt. rufo-fuscus, thorace valdè convexo, elytris pilosis.

Long. corp. $\mathbf{I} \frac{\mathrm{x}}{4}$ lin.

Habitat

Descr. Statura omnino Pt. Boletorum, at duplo minor. Caput et basis thoracis rufa. Elytra rufo-fusca, pilis brevioribus flavis obtecta. Corpus subtùs femoraque nigra. Tibiæ tarsique rufi.

pygmaus. I6. Pt. ater, thorace valdè convexo, elytris piceis punctulatis, pedibus piceis.

Long, corp. I lin.

Habitat — Captus in sepibus prope Reading.

DESCR. Corpus elongatum, atrum, glabrum. Elytra punctulis minutissimis densè conspersa, et hâc notâ a Pt. Boletorum distinguenda est. Pt. Boletorum puncta majuscula, hic vero vel sub lente punctula minutissima gerit.

bidentatus. 17. Pt. piceus lævis, capite thoraceque anticè bidentatis.

Anobium bidentatum. Oliv. ii. I6. II. 9.t.2.f.5.a-c. Long. corp. I lin.

Habitat

Descr. Totum corpus piceum, sive sordidè piceum, unicolor. Animalculum hoc imprimis notabile denticulis duobus approximatis fronti insertis, totidemque margine 
margine thoracis antico. Sub lente thorax et elytra punctulatissima.

I 8. Pt. piceus lævis, capite thoraceque inermibus. inermis.

Long. corp. I lin.

Habitat

DEscr. In omnibus Pt. bidentato simillimus ut ovum ovo. Differt solummodo capite et thorace lævibus, nec denticulis armatis.

An sexûs differentia?

I9. Pt. ferrugineus pilosus, pectore pedibusque concinnus. rufis.

Long. corp. $\frac{3}{4}$ lin.

Habitat in Boleto. D. Kirby.

DESCR. Corpus suprà ferrugineum, oculo bene armato pilosum. Abdomen subtùs rufo-fuscum. Pedes ut et pectus rufi.

20. Pt. niger pilosus, thorace marginato, pedibus ruficornis. rufis.

Long. corp. I lin.

Habitat

DESCR. Totum corpus nigrum, pilis rufis tectum. Antennæ et pedes rufi.

2 I. Pt. niger, pedibus rufis.

nigricornis.

Long. corp. I lin.

Habitat in Boleto versicolore. D. Kirby.

Descr. Pt. ruficorni similis, sed antennæ nigræ. Thorax brevior, obscurus. Elytra lævia, villosula. Pedes testacei.

22. Pt. niger, antennarum stipite tarsisque rufis. rbododacLong. corp. I lin. 
Habitat in Boleto versicolore.

Descr. Sub-villosus, nitens, angustus. Antennæ pallidæ, clavâ nigrâ.

piceus. 23. Pt. cylindricus piceus, antennis clavâ sublamellatâ, thorace scabro.

Long. corp. $1 \frac{3}{4}$ lin.

Habitat — In granis et radicibus ex Indiấ orientali allatus, sæpiùs vivus captus.

DESCR. Statura ferè $P t$. cylindrici, sed duplo minor. Corpus cylindricum totum, antennis ferrugineis exceptis, piceum. Antennæ clavâ triarticulatâ, sublamellatâ, unde forsan ad genus Fabricianum Synodendron referendus. Thorax convexus, punctis elevatiusculis scaber. Elytra glabra, nitida, seriebus cir-. citer decem punctorum excavatorum. Tibiæ serrulatæ.

*** Antennce articulis omnibus cqualibus, corpus ovatum aut oblongum subcequantes.

imperialis. 24. Pt. oblongus fuscus, thorace subcarinato, coleoptris maculâ albâ aquilam expansam referenti.

Linn. Syst. Nat. 565. 4. Fab. Syst. Ent. 63.3. Sp. Ins. i. 73.5. Mant. i. 40.5. Ent. Syst. i. a. 240.5. Vill. i. 62.4.I Scbrank, 62. Panz. Ent. Germ.113.5. Payk. Faun. Suec. i. 313.2.

Petagn. Ins. Cal. 6. 26. t. 1. f. 27. Panz. Faun. Germ. 5. t. 7. Sulz. t. 2.f. 7 .

Oliv. ii. 17. 5. 2. t. x.f. 4. a-d.

Bruchus cruciatus. Fourc. i. 58.3.

Long. corp. 2-2 $\frac{x}{2}$ lin.

Habitat in arboribus.

DESCr. Antennæ ferrugineæ, longitudine corporis. Thorax carinâ posticè elevatâ. Scutellum niveum. Coleoptra nigra, maculâ communi albâ aquilam expansam quodammodo referenti. Pedes ferruginei. Syst. Nat. 
25. Pt. oblongus fuscus, antennis pedibusque germanus. ferrugineis, elytris fasciis duabus albis.

Fab. Sp.Ins, i.72.2. Mant. i.40.2. Ent. Syst. i. a. $239: 34$.

Oliv. ii. 17.7.6.t. I. f.6. a; b.

Long. corp. $2 \frac{2}{3}$ lin.

\section{Habitat}

DESCR. Statura et habitus Pt. Furis, sed major oblongus. Antennæ corpore ferè dimidio breviores, villosæ. Thorax quadridentatus, villosus, antice et posticè angustatus. Scutellum niveum. Elytra punctato-striata, villis albidis bifasciata, apicibus etiam albido-villosis.

26. Pt. fuscus, elytris albo obsoletè maculatis. Lichemum. Long. corp. $1 \frac{\pi}{4}$ lin.

Habitat sub Lichenibus in lignis vetustis aridis.

Descr. Totum corpus fuscum. Antennæ crassiusculæ, filiformes, articulis omnibus æqualibus. Scutellum album. Elytra striata, striæ ex punctis impressis. Maculæ elytrorum admodum variant, modò fasciatim positæ, modò sparsæ. Variant etiam magnitudine, et colore magis minusve saturato. Abdomen concinnè ovatum. Alæ longæ, ut in Coleopteris reliquis.

27. Pt. fusco-ferrugineus, thorace quadridentato, Fur. elytris fasciis duabus albis.

Linn. Syst. Nat.566.5. List. Goed. 276. iा4. Payk. Faun. Suec. i. $3{ }^{1} 3 \cdot 3$. Faun. Ingr. 44. 135. Fab. Ent. Syst.63. 2. Sp. Ins. i. 73.4. Mant. i. 40. 4. Ent. Syst. i. a. 2.39.4. Punz. Ent. Germ. Ir3. 4. Scbrank, 63. Vill.i.63.5. Gmel.1607.5. Laich. Tyr. i. $77 . \mathbf{x}$.

Oliv. ii. 17.6.3.t. I. f. I. Sulz. t. 2.f.8. Roem.6. 12. $t \cdot 2 \cdot f .8$.

Ptinus rapax. De Geer, iv. 23I. 5. t. 9. f. I-7.

Cerambyx Fur. Faun. Suec.651. Preys. Bob. Ins. 56, 57. Faun. Fred. 13. 127. Stroem. Act. Nidros. iii. 393.12. 
Pontop. Dan. Atl. i. 673. 10. $t .29$.

An Vrillette brune à bandes grises. Geoff. i. I12. 5. ? Bruchus. Harr. 49.

La Bruche à bandes. Geoff. i. 164. 1. t. 2.f. 6. Scbaff: Elem. $t$. 30. Scbeff. Icon. $t$. 145.f.3.

Buprestis Fur. Scop. 210.

Long. corp. I $\frac{3}{4}$ lin.

Habitat passim.

Descr. Valdè affinis Pt. testaceo, et Pt. ovato, sed differt a priori antennis filiformibus $\frac{3}{4}$ corporis æquantibus, nec sub-testaceis æquantibus aut superantibus; tum abdomine ovato-oblongo, nec oblongo-elongato; a posteriori verò abdomine ovato-oblongo, nec exactè ovato; tum elytris fasciatis, nec immunibus.

ovatus. 28. Pt. fusco-ferrugineus, abdomine ovato.

An Pt. crenatus. Fab. Ent. Syst. i. a. 240. 6? Panz. Ent. Germ. I14. 6.?

Long. corp. I lin.

Habitat cum Pt. Fure et testaceo.

DEscr. Valdè affinis $P$. Furi, sed minor; tum elytra fasciis carent. Abdomen exactè ovatum, nec oblongum. Thorax obsoletè quadridentatus. Antennææ $\frac{2}{3}$ corporis æquant.

Cerevisia. 29. Pt. globosus obscurè testaceus, elytris striatis. Long. corp. $I \frac{1}{4}$ lin.

Habitat — Captus in cerevisia, etiam in poculis et aliis utensilibus.

DESCR. Præcedenti similis. Tomentosus, obscurè testaceus. Antennæ corpore dimidio breviores. Thorax lineâ intermediâ longitudinali. Elytra striata, striis magis exaratis punctatis.

similis. $\quad 30$. Pt. oblongus niger, antennis pedibusque ferrugineis, elytris fasciis duabus undulatis albis. 
Long. corp. I $\frac{3}{4}$ lin.

Habitat in ligno.

Descr. Per omnia simillimus $P t$. Licheni, sed oblongus. Oculi prominuli. Antennæ mediocres. Thorax teretiusculus, maculâ albâ. Pedes magis rubent.

3I. Pt. oblongus testaceus, elytris facsiis duabus testaceus. albis obsoletis, antennis subtestaceis longitudine corporis.

Ptinus testaceus. Oliv.ii. 17.9.8.t.2.f. 9. a, b.

Long. corp. $\mathrm{i} \frac{3}{4}$ lin.

Habitat in cloacis per totam hyemem.

Descr. Antennæ filiformes admodum longæ. Corpus unicolor testaceo-ferrugineum. Oculi solùm nigri. Thorax lateribus omnino integris, nec dentatis. Elytra basi et pone medium fasciâ albâ obsoletâ interruptâ. Alæ longæ, ut in Coleopteris plerisque. Abdomen evato-oblongum.

32. Pt. thorace quadrisulcato villoso albido, ely-sulcatus. tris connatis fusco-testaceis nitidis.

Fab. Sp. Ins. i. 73.7. Mant. i. 40.8. Ent. Syst. i. a. 241. II.

Long. corp. I $\frac{9}{4}$ lin.

\section{Habitat -}

DESCR. Animalculum singulare, at hoc genus evincunt statura, antennæ, palpi, elytra connata, victus. Corpus Pt. Fure minus. Antennæ porrectæ, longitudine corporis, filiformes, albæ. Caput parvum, sub thorace absconditum, pallidum. Thorax albidus, sulcis quatuor profundis exaratus. Elytra gibba, lævissima, connata, nitida, obscurè testacea, immaculata. Pedes albi. Fab.

\section{HISTER.}




\section{[ 92 2 $]$ \\ 6. HISTER.}

Antenne capitatæ: capitulo globoso, solidiusculo; infimo articulo compresso, incurvato.

Cafut intra thoracem retractile.

Os forcipatum.

Elytra corpore breviora.

Corpus subquadratum.

Tibice antica dentatæ.

unicolor.

I. His. ater glaberrimus, elytris septemstriatis : striis aliquot abbreviatis, tibiis anticis denticulis sex acutis.

Linn. Syst. Nat. 567.3. Faun. Suec. 440. Vill. i. 65. 2. Gmel. 1609. 3. Rai. Ins. 91. 7. Fab. Syst. Ent.52.2. Sp. Ins. i. 60.2. Mant. i. 32.2. Ent. Syst. i. a. 72.2. Scop.30. Scbrank, 68. Faun. Fred. 4. 31. Faun. Etrusc. 62. Hellw. 62. Panz. Ent. Germ. 20. 2. Mus. Lud. Ulric. $3^{6 .}$ Payk. Faun. Suec. í. 35. I. Faun. Ingr. 6. I6. Harr. $3^{8}$. Oliv. i. 8. 7.5. t. I. f. I. a, b, c. Schaff. Icon. t. 208. f. 5. a, b. Panz. Faun. Germ. 4.t. 2. Stroem. Act. Nidros. iv. 316.5. t. I6.f. 4. Voet.t. 3 I.f.5. Herbst. Jablonsk. iv. 22. I. t. 35. f. I.

Hister ater. De Geer, iv. 342. I. t. I 2. $f$. I2.

L'Escarbot noir. Geoff. i. 94. I. t. I. f. 4 .

Attelabus unicolor. Fourc. i. 16. I.

Long. corp. 4 lin.

Habitat in terrâ, arenâ, stercore passim. Linn.

DESCR. Corpus quadratum, atrum, nitidum, glaberrimum. Elytra abdomine breviora, parum truncata, glaberrima, integerrima, striis aliquot vix manifestis. Thorax lævis, non striatus, sed lineâ excavatâ ambiente 
biente notatus. Caput omnium minimum, quod, terrefacta, totum intra thoracem retrahit, ac si decollata esset, nec, ut caput exserat, ullo tormento adigitur. Os forcipatum dentibus duobus acutis. Antennæ clavatæ, integræ. Posteriora abdominis truncata, glabra, elytris paulo longiora, obtusissima. Faun. Suec. Variat magnitudine.

2. His. niger, elytris septemstriatis: striis aliquot incequalis. abbreviatis, tibiis anticis denticulis tribus obtusis. Oliv. i. 8. 7. 4. t. . . f. 3 .

Long. corp. 4 lin.

\section{Habitat in stercore.}

Descr. Corpus nigrum, nitidum. Mandibulæ inæquales. Labium porrectum, apice obtusum. Elytra abbreviata, striata, versùs suturam lævia. Tibiæ anticæ bidentatæ, aut tridentatæ; aliæ extùs ciliatæ, subspinosæ. Oliv.

3. His. ater unicolor, elytris sex striatis: striis parvus. duabus interioribus abbreviatis.

Long. corp. 2 lin.

Habitat

DESCR. His. unicolori simillimus, sed in illo semper septem striæ, in hoc sex solùm proveniunt, et multoties minor. Tibiæ anticæ tridentatæ.

4. His. ater, elytris posticè rubris.

Linn. Syst. Nat.567.5. Faun. Suec. 442. Vill. i. tus. 67.4. Gmel. 1610. 5: Scbrank, 69. Fab. Syst. Ent. 53. 7. Sp. Ins. 1. 61.7. Mant. i. 33. Io. Ent. Syst. 1. a. 76.17. Faun. Etrusc. 72. Hellw.72. Preys. Bob. Ins. 52, 53. Brabm. Ins. Kal. i. 57.183. Panz. Ent. Germ. 22. I7. Payk. Faun. Suec. i. 38.5. Faun. Ingr. 6. I8.

Oliv. i. 8. II. IO. t. 2. f. I2. a, b. Herbst. Jablonsk. iv. $27 \cdot 3 \cdot t \cdot 35 \cdot f \cdot 3 \cdot$

Attelabus. Geof. i. 95.2. Fourc, i. 16.2.

Coccinella. 
Coccinella. Uddm. Diss. I2. 20.

Long. corp. $2 \frac{1}{4}$ lin.

Habitat sub stercore bovino. Vill.

Descr. Macula subovata fusco-ferruginea ad latera postica elytrorum.

bipustula- 5. His. niger, elytris maculâ rubrâ, tibiis anticis tus. tridentatis.

Scbrank, 67. Vill. i. 68. 8. Panz. Ent. Germ.23. I9. Preys. Bob.Ins. 82. 76. Brabm.Ins. Kal. i. 103.349. Oliv. i. 8. 10.9.t.3.f. 19. a, b.

Hister purpurascens. Payk. Faun. Swec. i. $3^{8 .} 4$.

Long. corp. $2 \frac{1}{2}$ lin.

\section{Habitat}

Descr. His. bimaculato paulo major. Antennæ nigræ. Mandibulæ unidentatæ. Corpus ovatum, nigrum, nitidum. Elytra abdomine paulò breviora, substriata, in medio macula rubra. Tibiæ anticæ tridentatæ. Oliv.

quadrima- 6. His. ater, elytris substriatis, maculis duabus culatus. rubris.

Linn. Syst. Nat. 567.6. Faun. Suec. 443. Vill. i. 67. 5. Gmel. 1610. 6. Scbrank, 66. Fab. Syst. Ent. 53.8. Sp. Ins. i. 61. 8. Mant. i. 33. II. Ent. Syst. i. a. 76. 18. Faun. Fred. 4. 32. Faun. Etrusc. 64. Hellw. 64. Panz. Ent. Germ. 24. 20. Brabm. Ins. Kal. i. 36. I19. Payk. Faun. Suec.36.2. Faun. Ingr. 6. 19.

Oliv. i. 8. 9. 7.t. 3.f. 18. a, b. Herbst. Jablonsk. iv. 26. 2.t. 35.f. 2. Scbaff. Elem. t. 24.f. 2. Icon.t.3. $f \cdot 9$.

Long. corp. 4 lin.

Habitat in stercore humano. Captus prope Dartford in agro Cantiano. D. Latbam.

DESCR, Major est His. unicolore. Macula magna ferruginea 


\section{HISTER.}

ruginea sublunata in singulis elytris; at in quibusdam est macula rubra inæqualis versus basin, et alia rubra lunata versus apicem elytri.

7. His. ater nitidus lævissimus, elytris punctis quadrigut: duobus albis. tatus.

Fab. Ent. Syst. Supp. 39. I8-19.

Long. corp. 2 lin.

Habitat-Captus prope Pembroke. D. Donoran.

DEscr. Caput et thorax atra, nitida, lævissima, immaculata. Elytra lævia, punctis quatuor albis: exteriori marginali, interiori versus angulum ani. Fab. Supp.

Variat punctis flavis.

8. His. nigro-æneus, elytris apice punctulatis semipuncbasi striis quinque recurvis. tatus.

Payk. Faun. Suec, i. 45. I2. Fab. Ent. Syst, i. a. 73.4.

Long. corp. $3 \frac{1}{4}$ lin.

Habitat in cadaveribus.

DESCR. Frons magis elongata quam in præcedentibus. Caput suprà punctulatum. Thorax punctulatus, disco lævi, nitido. Scutellum vix ullum. Elytra nitida, dimidiato-punctata, spatio inter striam secundam et tertiam lineolis quibusdam impressis notato. Anus punctatissimus. Tibiæ anticæ denticulatæ, intermediæ et posticæ spinosæ, tarsis piceis, setosis.

9. His. æneus, thorace disco glabro, elytris basi eneus. striis quatuor recurvis apice punctatis.

Fab. Syst. Ent. 53. 9. Sp. Ins. i. 62. 9. Mant. i. 33. I2. Ent. Syst. i. a. 76. 19. Vill. i. 68. 7. Gmel. 1610. I3. Faun. Etrusc. 65. Hellw. 65. Panz. Ent.Germ.24. 21. Payk. Faun, Suec, i. 46. I4. Oliv. i. 8. I2. I2. t. 2. $f$. 10. a, b. Attelabus. Geoff. i. 95. 3 . Attelabus cupreus. Fourc, i. 68. 7 . 
Long. corp. $x \frac{x}{2}-3$ lin.

Habitat in fimo vaccino. Vill.

Descr. Corpus totum æneum, splendens. Thorax glaber, lateribus punctatis. Elytra abdomine multò breviora, basi striis quatuor arcuatis impressa, quæ vix medium elytrorum attingunt, apice sparsim punctata. Variat niger.

violaceus. 10 . His. violaceus, thorace toto punctato, elytris basi striis quinque recurvis apice punctatis. Long. corp. $2 \frac{\pi}{3}$ lin.

Habitat

In mus. D. Kirby.

Descr. Præcedenti similis, sed violaceus. Elytra striis quinque magis exaratis. Thorax totus punctulatissimus, nec disco glabro.

virescens. I I. His. viridis, thorace toto punctato, elytris basi striis quatuor recurvis apice punctatis.

Payk. Faun. Suec. i. 48. I6.

Long. curp. $1 \frac{1}{2}$ lin.

Habitat—Captus juxta Nordovicum. D. Kirby.

Descr. Præcedenti simillimus, sed differt colore viridi, nec violaceo.

An varietas ?

duodecim- 12. His. niger nitidus, elytris duodecim-striatis. striatus. Scbrank, 70. Vill. i. 68.9. Panz. Ent. Germ. 20. 5. Brabm. Ins. Kal. I55.500. Payk. Faun. Suec. i. 39. 6. Faun. Etrusc. 23. Hellw. 23. Fuesl. Arch.80.I. Jablonsk. 4. t. 35. fig. 4. D.

Long. corp. $2 \frac{x}{4}$ lin.

\section{Habitat}

Descr. Omnia ut in Hist, binaculato, at nulla macula in elytris; per singula elytra striæ sex a basi ad apicem decurrunt, 
decurrunt, ita ut æqualibus a se invicem distantes spatiis discum totum occupant. Scbrank.

I3. His. ater, thorace elytrisque striis elevatis. striatius. Forst. Cent. Iт. Gmel. I610. I52.

Hister sulcatus. Fab. Ent. Syst, i, a. 74. I2. Panz. Ent. Germ. 21. I0.

Oliv. i. 8. 17.20. t. I. f. 6. a, b. Faun. Etrusc. 70. t. 2.f.3. Hellw. 70. t. 2.f.3. Herbst. Jablonsk. iv. 38. I2. t. 26. f. I. a, b.

Long. corp. $\frac{1}{2}$ lin.

Habitat in stercore bovino. D. Latbbury.

Descr. Totum atrum. Thorax latus, marginatus, striis elevatis in medio quatuor, ad utraque latera duabus. Elytra abbreviata, striis elevatis in utroque novem, punctisque impressis inter strias. Abdomen et pectus punctis crebris impressis. Tibiæ omnes glabræ. Forst.

I4. His. ferrugineus, elytris substriatis.

brunneus:

Fab. Syst. Ent.52.4, Sp.Ins. i.61.4. Mant. i.32.6. Ent.Syst. i. a.74.8. Vill. i.68.6. Gmel. 1609.10. Faun.Etrusc. 66. Hellw.66. Panz. Ent Germ.21.7. Oliv. i. 8. I7. 21. t. 3. f. 2I. a, b. Jablonsk. t. 35 . $f$ : го, a, b.

Long. corp. $2 \frac{\mathrm{T}}{2}$ lin.

Habitat in stercore.

Descr. Simillimus His, univolori, at color totus brunneus.

I5. His. totus piceus, elytris longitudine abdo-piceus. minis: striis quatuor.

Long. corp. I lin.

Habitat

DÉSCR. Maximè affinis var. minori His. canei, sed differt colore piceo, nec æneo; tum elytra abdomini subæqualia, nec abbreviata. Porro stria interior obliqua ut cæteræ sunt, nec arcuata; denique striæ

omnes, 
omnes, et puncta ad apicem valdè obsoletiora quam in His. eneo, et hæc quidem vix sub lente satis conspicua.

depressus. I6. His. depressus ater nitidissimus, elytris substriatis.

Fab. Mant. i. 32. 8. Ent. Syst. i. a. 74. 10. Gmel. I610. II. Panz. Ent. Germ. 21. 9. Payk. Faun. Suec, i. 4I. 8. Faun. Etrusc. 68. Hellw. 68.

Oliv. i. 8. I5. 17. t. 2.f. 9. a, b. Herbst. Jablonsk. iv. $34 \cdot 9 \cdot t \cdot 35 \cdot f \cdot 9 \cdot a, b$.

Hister compressus. Herbst. Arcb. 20. 7.

Long. corp. I lin.

Habitat sub Betule corticibus. Fab.

DESCr. Differt manifestè a His. pygman, magis depressus et nitidissimus. Elytra substriata. Fab. Mant.

pygmeus. I7. His. totus ater, elytris lævissimis.

Linn. Faun. Suec. 44I.

Long. corp. I lin.

Habitat

Descr. Minor est semine oryzæ, et elytra minimé striata sunt, quo a priori decuplo majore differt. Faun. Suec.

Quoniam plurimus apud auctores de Histeribus unicolore, aneo Fabricii et pygmao error valuit, hîc saltem liceat observare, quod unicolor et coneus mirè variant magnitudine majori, et quadruplo minori. Varietas autem minor unicoloris et anei pro pygmao sæpiùs assumpta fuit; Linnæus ipse in Syst. Nat. varietatem minorem His. anei pygmaeum esse voluit. At aliter in Faun. Suec. res sese habet. His. pygmaus, magis oblongus, sive elongatus, magnitudine pediculi majoris. Elytra subpicea, nec vel sub lente striata, lævissima, longitudine ferè abdominis. Pedes picei. - Linnæus in Faun. Suec, hunc non obscurè innuit. 
18. His. rufo fuscus punctulatus.

Long. corp. $\frac{1}{3}$ lin.

Habitat In mus. D. Kirby.

Descr. Convexus. Elytra subabbreviata, punctulata, punctulis sine lente non conspicuis.

19. His. niger glaberrimus nitidus.

minimus.

Long. corp. vix $\frac{1}{3} \operatorname{lin}$.

Habitat -

Descr. Omnium quos hactenus vidimus minimus est. Corpus politum, nitidum.

\section{GYRINUS.}

Antenne clavatæ, rigidæ, capite breviores, totæ confertissimè articulatæ.

Oculi quatuor: duo suprà, duo infrà.

Corpus ovatum, convexum.

Pedes postici breves, natatorii.

I. Gy. niger glaberrimus, elytris punctato-striatis, Natator: pedibus flavis.

Linn. Syst. Nat. 567. I. Vill. i.69. I. Gmel. 161 I. I. Scbrank, 72. Payk. Faun. Suec.i. 238.1. Fab. Syst. Ent. 234. I. Sp. Ins. i. 297. I. Mant. i. 194. I. Ent. Syst. i. a. 202. I. Panz. Ent. Germ. 82. I. Fourc. 1, 71. I. Faun. Ingr. 33. 102. Harr. 176.

Geoff: i. 194. 1.t.3.f.3. Panz. Faun. Germ. 3.t. 5. Roes. 3. cl. I. t. 31. f. 1, 2. Scbreff. Icon. t. I34. $f \cdot 5$. a, b. De Geer, iv. 355. I. t. I3.f. 4 . H 2

Dytiscus 
Dytiscus Natator. Faun. Suec.779. Faun. Fred. 19. I93. Scop. 299. Poda, 44. 4. Strcem. Act. Nidros. iv. $329.27 \cdot t$. $16 . f .13$.

Scarabæus aquaticus. Rai. 87. 10.

Long. corp. 3 lin.

Habitat in aquis stagnantibus. Velocissimè super aquas cursitans per orbes; dum vero urinatur, bullam æream, hydrargyri coloris, secum trahit.

DEscr. Noster niger omnino est. Pedes autem flavi, lati, brevissimi. Antennæ clavatæ, vel certè non versus apicem angustiores, nec, quantum video, fissæ. Faun. Suec.

Kirbii. 2. Gy. suprà nigro-zeneus, subtùs flavus.

Long. corp. I $\frac{3}{4}$ lin.

Habitat

DEscr. Caput, thorax et elytra nigro-ænea. Elytra striata, striis ex punctis impressis. Corpus subtus pedesque flava.

Obs. Hic Gyrinus non fœtens ut Natator. D. Kirby.

Modeeri. 3. Gy. suprà niger lævis subtomentosus, subtìs pallidè ferrugineus, pedibus posticis compressis. Long. corp. 3 lin.

- Habitat in aquis fluentibus.

Obs. Variat colore, subtùs modo pallidè ferrugineus, modo rufo-ferrugineus.

elongatus. 4. Gy. niger opacus elongatus, elytris punctatostriatis.

Long. corp. 3 lin.

Habitat

DESCR. Corpus suprà totum nigrum, opacum; subtùs piceum. 


\section{[ IOI ]}

\section{BYRRHUS.}

Antenne clavatæ, subsolidæ, subcompressæ. Caput sub thorace reconditum.

Elytra longitudine corporis, margine inflexo. Corpus ovatum, convexum, villosum, immarginatum.

I. Byr. fuscus, elyłris fasciis tribus undulatis pal-Verbasci. lidis.

Linn. Syst. Nat. 568. 3. Vill. i.71. 3. Laicb. i.75. 2. Anthrenus Verbasci. Fab. Syst. Ent.61. 4. Sp. Ins. i. 70. 4. Mant. i. 39. 4. Ent. Syst. i. a. 264. 5. Gmel. 16r4. 3. Panz. Ent. Germ. 132.5. Faun. Etrusc. 99. Hellw. 99. Payk. Faun. Suec. ii.4. 4. Fuesl. Arcb. 84. I.

Oliv. ii. I4. 7.2.t. I. f. 2. a-d. Herbst. Jablonsk. vii. 328. 2. t. II 5.f. 23 .

Long. corp. 1 lin.

Habitat in floribus umbellatis ubique.

Descr. Antennæ et pedes ferruginei. Clava antennarum perfoliata, ut in Dermestibus compressa. Caput nigrum. Thorax niger, lateribus ad basin pallescentibus. Elytra ex ferrugineo-nigra, fasciis tribus subinterruptis, albidis. Corpus subtùs, præcipuè certo lucis respectu, albicat. Fasciæ elytrorum ex pilis albidis constant. His detritis color niger evadit, unde sæpiùs difficultas oritur. Apex etiam elytrorum albidus.

2. Byr. niger, elytris fasciâ albâ apice ferrugineis : Pimpinelle. liturâ albâ. 
Anthrenus Pimpinellæ. Fab. Syst. Ent. 6r. т. Sp. Ins. i. 70. 1. Mant. i.39. 1. Ent. Syst. i. a. 263. I. Geoff. 1. II4. I. Panz. Ent. Germ. I3I. I. Faun. Etrusc: 96. Hellw.96. Gmel. 1614. 4. Payk. Faun. Suec. ii. I. I.

Oliv. ii. Iq.7. I. t. I.f. 4. a, b. Herbst. Jablonsk. vii. 330. 4. $t$. II $5 \cdot f \cdot 4 \cdot \mathrm{D}$.

Long. corp. $1 \frac{1}{2}$ lin.

Habitat

DFscr. Thorax niger, albo ferrugineoque varius. Elytra fasciâ undatâ albâ, punctoque ferrugineo versus apicem. Oliv.

Pini. 3. Byr. niger, elytris ferrugineis.

Long. corp. $\frac{3}{4}$ lin.

Habitat

Ex mus. D. Kirby.

Descr. Caput et thorax nigra, glabra. Elytra, quæ sub lente punctulatissima, ferruginea sunt. Sutura plerumque nigrescit. Pedes nigri.

\section{CISTELA.}

Antenne perfoliatæ, extrorsùm crassiores. Thorax convexus, non marginatus. Elytra abdominis latera obvolventia. Corpus globoso-cylindricum.

Pitula. I. Cis. obovata suprà cinereo-fusca, elytris striis atris interruptis.

Laich. ii. 7o. I. 
La Cistele satinée. Geoff. i. I 16. I. t. I. f. 8

Cistela fasciata. Forst. Cent. i. I2.

Cistela viridescens. Fourc. i. 28. I.

Byrrhus Pilula. Fab. Syst. Ent.60. I. Sp. Ins. i.69. т. Mant. i. 38.2. Ent. Syst. i. a.84.2. Vill. i. 71.4. Panz. Ent. Germ. 31. 2. Preys. Bob. Ins. 54, 55. Faun. Etrusc. 94. Hellw. 94. Payk. Faun. Suec. i. 73. 1. Faun. Ingr. 9. 29. Gmel. 1613. 4. Fuesl. Arcb. 24. $x$.

Oliv. ii. I3.5. I.t. I.f. I. a, b. Panz. Faun. Germ. iv. t. 3 .

Dermestes Pilula. Pontop. Dan.Atl. i. 667.9. Faun. Fred. 3. 22.

Long. corp. 4 lin.

Habitat in arenâ et campis arenosis.

DESCr. Suprà cinereo-fusca cum mixturâ aureâ. Thorax atro-nebulosus, elytris striis circiter quatuor interruptis atris. Subtùs nigra, punctulis elevatis consita.

2. Cis. obovata nigro-fusca, elytris striis quatuor undulata. interruptis atris fasciisque duabus transversis undulatis aureis.

Byrrhus undulatus. Panz. Ent. Germ.34. s6. Faun. Germ. 37. $t$. 14 .

Long. corp. $4 \frac{\mathrm{I}}{\mathrm{z}}$ lin.

\section{Habitat -}

Descr. Major C. Pilulâ. Thorax aureo-nebulosus. Elytra fasciis duabus transversis distantibus undulatis, ex villis aureis confectis.

3. Cis. obovata nigra, elytris striis quatuor inter-striata. ruptis atris.

Long. corp. $4 \frac{x}{3}$ lin.

Habitat

DESCR. Thorax obscurè sub-nebulosus. Elytra nigra, striis interruptis atris. 
ferruginea. 4. Cis. ovata suprà ferrugineo-fusca, striis ferrugineo-aureis.

Long. corp. $3 \frac{3}{4}$ lin.

Habitat —

DEscr. Præcedenti simillima, sed elytra absque striis interruptis nigriș.

Hæ omnes, si villis spolientur, nigræ, striatæ; ex colore villorum oriuntur distinctiones. An satis diversæ?

sericea.

5. Cis. ovata fusco-viridis, elytrorum striis versicoloribus interruptis.

Forst. Cent. 16. I6.

Cistela varia. Laicb. i. 7 x.2.

Byrrhus varius. Fab. Syst. Ent.60.2. Sp. Ins. i.69.3. Mant. i. 58. 5. Ent. Syst. i. a. 85. 7. Panz. Ent. Germ.33.14. Vill.i.72.7. Gmel.1613.5. Payk. Faun. Syec. i. 76. 2.

Oliv. ii. 13. 7. 5. t. I. f. 6. a-d. Panz. Faun. Germ. 32.t. 3.

Long. corp. $2 \frac{1}{2}$ lin.

Habitat

Descr. Caput et thorax viridi-fusca, nitentia. Elytra striis quinque vel sex longitudinalibus, viridi-sericeis, interruptis, maculis e pilis nigris erectiusculis. Intervalla striarum minùs lætè virentia.

dorsalis. 6. Cis. nigra, thorace coleoptrisque maculâ mediâ cinereo-rufescenti.

Byrrhus dorsalis. Fab. Mant. i.38, 4. Ent. Syst. i. a. 85. 6. Gmel. 1613.3 . Panz. Ent. Germ. 33. I3. Byrrhus Pilula. Var. d. Payk. Faun. Suec. i. 75.

Oliv. ii. I3. $7 \cdot 4 \cdot t$. I. $f \cdot 5 \cdot$ a, b.

Long. corp. 3 lin.

Habitat

DeSCr. Totum corpus nigrum, sive atro-rufescens. Thorax niger, maculâ magnâ variè sinuosâ, cinereorufescenti. 
rufescenti. Hæc macula discum ferè totum occupat. Quoniam elytra maculam comnunem gerunt, de Coleoptris dicendum est. Coleoptra igitur nigra sunt, et. quasi veluto obtecta; in medio autem maculam magnam sub-ferrugineam gerunt, quam maculam linea cinerascens paulo undique intervallo eingit.

Obs. Cistela nigra Forsteri (Cent. 14.) videtur esse Cis. dorsalis villis spoliata, ut sæpe accidit Cistelis villosis.

7. Cis. ovata fusca nitida, elytris striatis : striis fusca. decem impressis.

Long. corp. $2 \frac{x}{2}$ lin.

Habitat prope Holt in Norfolciâ. D. Scrimsbire.

Descr. Corpus totum fuscum. Thorax nitidus, punctulatissimus. Antennæ et pedes concolores.

8. Cis. suprà atra, subtùs picea.

bicolor.

Long. corp. 3 lin.

Habitat - Ex mus. D. Sbeppard.

DESCR. Cis. dorsali similis. Caput, thorax et elytra atra, villosa, immaculata. Antennæ nigræ. Corpus subtùs piceum.

9. Cis. ovata fusca obscura, antennis pedibusque picipes. rufis.

Byrrhus picipes. Oliv. ii. I3.9.9.t.2.f.9.a, b.

Long. corp. $1 \frac{1}{2}$ lin:

Habitat

In mus. $D$. Kirby.

DEscr. Totum corpus fuscum, pubescens. Elytra striata. Antennæ et pedes rufi.

I0. Cis. atra obscura setosa.

maritima:

Long. corp. $1 \frac{1}{2}$ lin.

Habitat

Capta tempore autumnali semel apud 
apud Landguard-Fort, Suffolciâ ; iterum apud Holme-juxta-mare, Norfolciâ. D. Kirby.

DESCR. Corpus atrum, obscurum, setosum, setis ritgidiusculis. Antennæ capitatæ, capitulo obtuso. Elytra striata. Os ferrugineum.

picea.

II. Cis. ovata picea nitida, elytris striatis, pedibus rufis.

Long. corp. I $\frac{x}{4}$ lin.

Habitat

In mus. D. Kirby.

DESCR. Totum corpus piceum, nitidum. Elytra striatạ. Antennæ pedesque rufo-testacei.

\section{CORTICARIA.}

Antenne clavatæ, clavâ perfoliatâ.

- Caput prominens.

Thorax et Elytra marginata.

Corpus sublineare, plerumque depressiusculum.

picipes.

I. Cor. nigra nitida, antennis pedibusque piceis.

Ips picipes. Oliv. ii. 18. 7. 7.t.2.f. 12. a-d.

Lyctus politus, Fab. Ent. Syst. i. b. 502. I.

Long. corp. $I_{\frac{1}{4}}$ lin.

Habitat sub arborum corticibus.

Descr. Corpus nigrum, nitidum. Antennæ fuscoferrugineæ, articulis duobus ultimis clayatis. Thorax lævis. Elytra sub-striata. Oliv.

taxicornis. 2. Cor. nigra lævis, elytris obsoletissimè striatis, antennis 
antennis pedibus elytrorumque maculâ ferrugineis.

Long. corp. ${ }^{-} \frac{T}{2} \operatorname{lin}$.

Habitat sub arborum corticibus. Ex mus. D. Latbbury.

Descr. Totum corpus nitidiusculum, depressum, nigrum. Thorax punctulis minimis conspersus. Elytra sub lente obsoletè striata, striæ ex punctulis impressis. Antennæ et pedes ferruginei. Corpus tenue, ne minimè quidem crassum.

3. Cor fusco-castanea elytris striatis, thoracis oblonga. medio longitudinaliter excavato.

Ips oblonga. Oliv. ii. 1 8. 7, 8. t. I. $f .5$. a, b.

Dermestoides unipunctatus. Herbst. Arch. iv. 40. 8. t.21.f. н. h. Fuesl. Arch. 95. t. 21.f. н. h.

Lyctus canaliculatus. Fab. Ent. Svst. i. b. 504. I I. Panz. Ent. Germ.342. 9. Payk. Faun. Suec. iii. 332. 9.

Panz, Faun. Germ. iv. $t$. 16.

Long. corp. 2 lin.

Habitat sub arborum corticibus.

DESCr. Elytra tenuiter striata; satis autem distincta. Thorax foveâ mediâ.

4. Cor. rufo ferruginea, thorace fusco: punctis dermestoiquatuor impressis. des.

Cucujus dermestoides. Fab. Ent. Syst. i. b. 96. Io.

Panz. Ent. Germ. 208. 7.

Panz, Faun. Germ. 3. t. 13.

Long. corp. $2 \frac{\pi}{3}$ lin.

Habitat sub arborum corticibus.

DESCR. Totum corpus ferè unicolor, oblongum, acutiusculum. Thorax vero disco sub-fusco, punctis quatuor impressis, colon geminum referentibus.

5. Cor. fusco-testacea, elytris striatis, thorace frumentastriis tribus elevatis : lateribus denticulatis.

ria. 
Ips frumentaria. Oliv. ii. I8. 10. I4. t. 2. f. I3. a-d. Collidium frumentarium. Fab. Ent. Syst. i. b. 496. 4.

Collidium 6-dentatum. Payk. Faun. Suec. iii. 313.2. Herbst. Jablonsk. vii. 283. 4. t. I I3. $f$. I.

Dermestes 6-dentatus. Panz. Faun. Germ. 14. $t$. I1.

Dermestes surinamensis. Linn. Syst. Nat. 565. 29. Gmel. I 597 . 29.

Tenebrio surinamensis. De Geer, v. 54. 5.t. I3. f. I2. Long. corp. $1 \frac{1}{2} \operatorname{lin}$.

Habitat

Descr. Corpus fuscum. Antennæ filiformes, articulis tribus ultimis subclavatis, perfoliatis. Thorax crenatus, dorso lineis tribus elevatis. Elytra striatopunctata, lineisque elevatis. Oliv.

dentata. 6. Cor. rufescens, elytris lineis elevatis tribus ob. soletis, thorace punctis duobus impressis: lateribus dentatis.

Long. corp. 2 lin.

Habitat Mrist Lym

DEscr. Corpus depressum, obscurè rufescens. Antennæ, caput et thorax ex nigro rufescunt. Elytra et pedes amœeniores. Thorax lateribus crenato-dentatis. Ad apicem thoracis puncta duo media impressa, ferè contigua. Elytra striis tribus elevatis, obsoletis, et inter has striæaliquot tenuiores ex punctulis impressis, unde elytra sub lente quasi reticulata. Femora postica dentata, dente único valido.

bipunctata.7. Cor. testacea, abdomine capite punctoque elytrorum nigris.

Notoxus bipunctatus. Fab. Ent. Syst. i. a. 212. 8. Panz. Ent. Germ. 87.3.

Panz. Faun. Germ. 26.t.9.

Long. corp. $2 \frac{1}{4}$ lin.

Habitat sub arborum corticibus.

DESCR. Antennæ apice nigræ, basi testaceæ. Thorax planiusculus, 
planiusculus, testaceus, immaculatus. Elytra sub lente punctulatissima, obsolete striata, puncto unico post medium atro. Abdomen atrum. Pedes testacei.

8. Cor. fusco-ferruginea pubescens, thorace posticè punctulata. scrobiculo transverso, elytris punctulatissimis.

Long. corp. I lin.

\section{Habitat}

DESCR. Totum corpus, præter abdomen quod nigrum est, fusco-ferrugineum. Pubescentia quædam totam superficiem occupat. Thorax posticè scrobiculum transversum, qui 'non ad margines attingit, medio latiorem, gerit. Elytra vix striata, punctulis minutissimis omninò conspersa. Antennæ articulis tribus ultimis majoribus.

9. Cor. fusco-ferruginea, thorace subrotundo pos- serrata. ticè scrobiculato: lateribus serrulatis, elytris punctulatis.

Long. corp. I lin.

\section{Habitat}

DEscr. Simillima Cor. punctulate in omnibus præterquam thorace denticulato. Antennæ articulis tribus ultimis majoribus. Sed quod singulare admodum, thorax penè rotundus est, posticè scrobiculo sive puncto majori impresso, et ad latera denticulatus sive serrulatus. Thorax et elytra punctulis minimis conspersa. - Elytra vix striata.

10. Cor. ferruginea, oculis nigris, thorace posticè transversa. lineâ transversâ, elytris punctato-striatis.

Ips transversa. Oliv. ii. I8. I4. 20.t. 3.f. 20. a, b. Tenebrio lardarius. De Geer, v. $45 \cdot 7 \cdot$ t. 2. $f .25,26$.

Long. corp. $\frac{7}{8}$ lin.

\section{Habitat}

DESCR. Tota (oculis nigris exceptis) ex brunneo ferruginea. Pedes et antennæ pallidiores. Elytra punc- 
tato-striata. Thorax posticè foveâ sive lineâ (pro magnitudine animalculi) satis latâ transversâ exaratur.

impressa. I I. Cor. nigra, elytris striatis, pedibus rufescentibus,

Ips impressa. Oliv. ii. I8. 1.4. 21. t. 3.f. 24. a, b.

Dermestes longicornis. Fuesl. Arcb. 82. 10.t. 20.f. 8. i.

Long. corp. $\frac{2}{3}$ lin.

Habitat

Descr. Habitus Aucbenice, thorax enim elytris angustior; at antennæ ad hoc genus amandant. Color ex nigro piceus. Thorax lineam inpressam, transversam, gerit. Elytra punctis omninò ornata, et striata sunt. Pedes ex rufo-ferruginei.

fumata. I2. Cor. ferruginea glabra, thoracis lateribus subcrenatis.

Long. corp. I lin.

Habitat in cloacis per totam hyemem, comes Ptimi Furis.

Descr. Oculi nigri. Cætera, totum corpus unicolor, modo testaceum, ferrugineum modo, modo nigro-ferrugineum. Thoracis latera crenâ unicâ alterâve ad basin emarginata. Caput, thorax elytraque punctulata.

contracta. I3. Cor. nigra, antennis pedibus elytrisque trun. catis ferrugineis.

Ips contracta. Oliv. ii. 18. 6.5. t. 2.f. 10. a, b.

Dermestes. Geoff. i. 103. 10:

Dermestes contractus. Fourc. i. 19. I0.

Lyctus contractus. Fab. Ent. Syst. i, b. 505. 13.

Long. corp. I lin.

Habitat in ligno putrido.

Descr. Caput nigrum. Thorax niger, ad apicem foveâ utrinque impressâ. Antennæ et pedes ferruginei.

- Elytra sub-abbreviata, truncata, punctis excavatis confertim sparsa. Abdomen nigrum. 
Variat elytris omninò, et nigris apice tantùm, ferrugineis.

14. Cor. fusco-ferruginea, capite nigro, elytris pulla. striatis.

Long. corp. $\frac{3}{4}$ lin.

Habitat

DESCr. Caput nigrum. Antennæ pallidè ferrugineæ. Thorax fusco-ferrugineus, lineâ mediâ longitudinali exaratus; insuper medio transversim elevatur; quæ elevatio lineâ longitudinali interrumpitur: omnia autem hæc non nisi sub lente conspicienda. Elytra striata, striis concinnè punctulatis. Abdomen et pedes fusco-ferruginei, sed pallidiores.

I5. Cor. ferruginea, elytris striatis: striis ex ferruginea. punctis impressis.

Long. corp. I lin.

Habitat -

DESCR. Totum animal ferrugineum.

16. Cor, rufa, oculis nigris.

Long. corp. lin.

Habitat

In mus. D. Kirby.

Descr. C. ferruginece similis, sed major. Antennæ rufæ, nec luteæ. Oculi prominuli. Elytra lævia, villosula.

17. Cor. rufa, thorace posticè lineâ transversâ im-ruficollis. pressâ, elytris fuscis punctato-striatis.

Long. corp. $\frac{3}{4}$ lin.

Habitat

DESCR. Antennæe, caput et thorax rufa. Elytra fusca, striata, striis ex punctis impressis. Pedes rufi.

x 8. Cor. obscurè rufa, thorace denticulo utrinque denticulata. instructo, elytris fuscis.

Long. 
Long. corp. I lin.

Habitat

In mus D. Kirby.

DESCR. Villosula, fusco-rufa. Antennæ articulis duobus capiti proximis majoribus. Elytra fusca, humeris rufescentibus. Pedes ferrugỉnei.

obcordata. 19. Cor. testacea, thorace anticè latiore, oculis nigris.

Long. corp. I lin.

Habitat —

In mus. D. Kirby.

Descr. Præcedenti simillima. Thorax subquadratus, anticè latior.

pilicornis. 20. Cor. oblonga picea, antennarum apice pallido piloso.

Long. corp. $I_{2} \frac{x}{2}$ lin.

Habitat sub cortice Quercûs.

DEscr. Antennæ ferrugineæ, clavatæ, clavà subsolidâ, pilosulâ. Thorax latus, punctulatus. Elytra striata. Pedes rubent.

dimidiata. 2 I. Cor. fusca, elytris dimidiato flavis.

Long. corp. I lin.

Habitat

DEscr. Suprà punctulatissima. Antennæ clavâ fuscâ. Thorax magis rotundatus quam in præcedentibus. Elytra lævia, dimidio anali flavo. Pedes testacei.

pallida. 22. Cor. ferruginea, elytris obsoletè striatis testaceis.

Long. corp. $\frac{1}{3}$ lin.

Habitat

Descr. Antennæ rufæ. Caput et thorax fuscò-ferruginea. Elytra testacea, obsoletè striata.

23. Cor. 
23. Cor. rufo-fusca, elytris testaceis acutis.

Ips rugicollis. Oliv. ii. 18. I3. I9. t. 2. f. I9. a, b.

Long. corp. $I \frac{2}{4}$ lin.

Habitat

DESCR. Oculi nigri. Antennæ thorace breviores. Thorax sub-marginatus, quadratus. Elytra nitida, punctato-striata, acuta, dilutè testacea. Pedes ferruginei.

\section{SILPHA.}

Antenne perfoliatæ, clavatæ, sive extrorsùm crassiores.

Caput parvum, inflexum.

Thorax clypeiformis, planiusculus, utrinque marginatus.

Elytra marginata.

Corpus depressum, vel ovatum vel oblongoovatum.

* Antenne capitulo magno quadriarticulato, articulis arctè imbricatis. Clypeus orbiculatus inequalis.

* Antennce sensim crassiores. Elytra abdomen aquantia. *** Antennce sensim crassiores. Elytra abbreviata truncata.

* Antenne capitulo magno quadriarticulato, articulis arctè imbricatis. Clypeus orbiculatus inequalis.

I. Sil. oblonga atra, elytris obtusissimis: margine germanica. laterali ferrugineo.

vol. I.

Linn. 
Linn. Syst. Nat.569. 1. Fill. i.73. I. Gmel. 1615... Rai. 107. I.

Pontop. Dan. Atl. i. 667. I.t.29. De Geer, iv. I73.2. t. 6.f. 4 .

Nicrophorus germanicus. Fab. Syst. Ent. 7r. r. Sp. Ins. i. 83. I. Mant. i. 48. I. Ent. Syst.i.a.246. I. Panz. Ent. Germ. II7. I.

Panz. Faun. Germ.4I. t. I. Oliv. ii. IO. 7. 3.t. I. f. 2. a, b. Herbst. Jablonsk. v. 154. 2. t. $50 . f .2$.

Le grand Dermeste noir. Geoff: i. 99.2.

Dermestes Listerianus. Fourc. i. 17.2.

Pollinctor niger. Voet. t. 30. f. 4. Panz. Voet. ii. 43. t. $30 . f .4$.

Long. corp. 9- I 5 lin.

Habitat in animalibus putridis.

DESCr. Reliquis major. Tota atra, glabra. Clypeus figura $S$. Vespillonis, sub-orbiculatus, sed latior quam longus. Elytra obtusissima, et ferè truncata. Margo lateralis elytrorum inflexus, et occultatus, ferrugineus est. Linn.

Obs. Frons ferrugineus est.

Humator. 2. Sil. oblonga tota atra, antennis apice rufis exceptis.

Nicrophorus Humator. Fab. Ent. Syst. i. a. 247. 2. Panz. Ent. Germ. II7.2.

Oliv. ii. Iо. 8. 4. t. I. f. 2. c, d, e. Panz. Faun. Germ. 4I. t. 2. Herbst. Jablonsk. v. I56.3.t. 50.f.3. Long. corp. 8 lin.

Habitat

DESCr. Præcedenti simillimus, at differt corpore duplo minore, et apicibus antennarum solùm rufis vel ferrugineis.

Tespillo. 3. Sil. oblonga atra, elytris truncatis: fasciâ duplici antennarumque clavâ ferrugineis.

Linn. Syst. Nat. 569. 2. Faun. Suec. 444. Vill. i. 73. 2. Gmel. I616. 2. Faun. Fred. 4. 33. Pontop. Dan. Atl. i. 667.2. Mus. Lud. Ulric. 37. Scbrank, 74.

Don.

difien from bespillo: Trucíanteren peradued inta

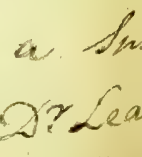


Don. Brit. Ins. t. 23. Poda Mus. Grac. 23. 4. t. I. $f .{ }^{2}$. Roem. t. $34 . f$. I2. Roes. iv, $t .1 . f .1-4$. De Geer, iv. 168. I. t. 6. $f$. т.

Nicrophorus vulgaris. Fab. Syst. Ent. 72.2.

Nicrophorus Vespillo. Sp. Ins. i. 84. 2. Mant. i. 48.2. Ent. Syst. i. a. 247. 4. Panz. Ent. Germ. II8. 3. Faun. Ingr. 45. 137. Faun. Etrusc. I3 I. Hellw. I3I. Oliv. ii. 10.5. 1.t. I. f. I. a-e. Panz. Faun. Germ. r. t.21. Schaff. Elem.t. I14. Herbst.Jablonsk. v. 157. 4. t. 50.f. 4,5 . Bergstraes. I. 10. I4. t. I. f. I4.

Le Dermeste à point d'Hongrie. Geoff: i. $9^{8}$. I. $t .1 . f \cdot 5$. Dermestes Vespillo. Scop. 33. Fourc. i. I7. I.

Scarabæus foetidus primus Aldrovandi. Rai. 1о6.

Pollinctor vulgaris major. Voet. Coleopt. 53.t. 30.f. I. Panz. Voet. ii. 4 I. t. 30. f. I.

Long. corp. 9- 12 lin.

Habitat in cadaveribus.

DESCR. Antennæ nigræ, articulis tribus ultimis ferrugineis. Caput nigrum. Thorax niger, rufo-villosus, marginatus, anticè truncatus, postice rotundatus. Elytra abdomine breviora, nigra, fasciis duabus undatis, flavis aut ferrugineis. Corpus nigrum. Pectus villo rufo denso tectum. Oliv.

4. Sil. oblonga atra, elytris fasciâ maculâque fer-Mortuorugineis.

rum.

Nicrophoris mortuorum. Fab. Ent. Syst. i. a. 248. 5. Panz. Ent. Germ. I 8.4.

Panz. Faun. Germ. 4 I. $t \cdot 3$.

Nicrophorus Vespilloides. Fuesl. Arch. 89. 1.

Pollinctor vulgaris minor. Voet. Coleopt.t.30.3. Panz. Voet. ii. $42 \cdot t \cdot 30 . f \cdot 3 \cdot$ ?

Long. corp. 7 lin. et ultra.

Habitat in cadaveribus et in fungis. Pans.

Descr. Simillima Sil. Vespilloni, sed differt clavâ antennarum nigrâ, nec ferrugineâ. Elytra truncata, fasciâ mediâ maculaque rotundâ ad apicem ferrugineis, nec fasciâ duplici ferrugineâ. Pedes nudi, nec fulvo-tomentosi. 
* Antenne sensim crassiores. Elytra abdomen equantia.

littoralis. 5. Sil. atra, elytris lævibus : lineis elevatis tribus, clypeo orbiculato nitido.

Linn. Syst. Nat.570. I1. Faun. Suec. 450. Vill. i. 76. 8. Gmel. 1620. Ir. Scop. 55. Scbrank, 75. Fab. Syst. Ent.72.2. Sp. Ins. i. 85.2. Mant. i. 48.2. Ent. Syst. i. a. 249.2. Pontop. Dan. Atl.668.3. Panz. Ent. Germ. 118. 1. Faun. Ingr.45.138. Faun. Etrusc. 132. Hellw. 132.

Oliv. ii. II.6. 2. t. I.f. 8. a, b. Panz. Faun. Germ. 40.t. I5. Sulz. t. 2.f. I4. foem. Voet. t. 32. f. I. $\beta$. Silpha rufo-clavata. De Geer, iv. 176. 4 .

Le Bouclier à bosses. Geoff. i. I20. 3 .

Peltis gibbosa. Fourc. i. 30. 3 .

Long. corp. 9 lin. mas.

$$
11 \frac{x}{2} \text { lin. fœm. }
$$

Habitat sub Fucis putridis.

DESCr. Tota nigra. In singulo elytro strix tres longitudinales, elevatæ; quarum extima major. Antennarum tres extimi articuli ferruginei. Faun. Suec.

Femora postica fœminæ incurva, crassissima sunt.

atrata. 6. Sil. atra, elytris subpunctatis: lineis elevatis tribus lævibus, clypeo anticè integro.

Linn. Syst. Nat.571. 12. Faun.Suec.451. Vill. i. 76. 9. Gmel. 1620. 12. Fab. Syst. Ent. 74. 9. Sp. Ins. i. 87. 10. Mant. i. 49. II. Ent. Syst. i. a. 25I. II. Scop.56. Scbrank, 80. Faun: Fred.4.35. Poda Mus. Grac. 23.2. Rai.84.33. Panz. Ent. Germ. 119.6. Faun. Ingr.46.141. Faun. Etrusc. 133. Hellw. I33.

Oliv. ii. II. I6. I5.t. I. f. 4. t. 2. $f \cdot 4 \cdot$ b. Scbaff: Elem.t. $9^{6} \cdot f . \mathrm{I}$.

Silpha punctata. De Geer, iv. $177 \cdot 5 \cdot t .6 \cdot f$. I $5 ; 16$.

Le Bouclier noir à trois raies et corcelet lisse. Geoff. i. II8. I.

Peltis atrata. Fourc. i, 29. I. 


\section{Long. corp. 6 lin.}

Habitat in arvis, hortis, et in cadaveribus.

Descr. Clypeus parùm convexus, anticè minimè truncatus, sed rotundatus. In singulo elytro strix tres, æquales, elevatæ, minimè dentatæ, præter marginis striam, quæ major prominet. Totum animal suprà punctis minutissimis excavatis adspersum, atrum, depressum. Faun. Suec.

$V$ ariat elytris ferrugineis.

7. Sil. atra, clytris sub-punctatis: lineis elevatis recta. tribus lævibus, clypeo anticè truncato.

Long. corp. 8 lin.

\section{Habitat - Mus. Miss Hill.}

Descr. Omnia ferè ut in Silp̧̧âa atratâ; at in hâc thorax anticè non rotundatus, sed excavato-truncatus. Punctaetiamin hacomnia minora, obsoletiora. S. atratz major.

8. Sil. nigra, elytris obscuris:- lineis elevatis, thoracica. clypeo retuso testaceo.

Linn. Syst. Nat. 571. 13. Faun. Suec. 452. Vill. i. 77. I0. Gmel. 1621. I3. Fab. Syst. Ent.73.6. Sp. Ins. i. 86. 6. Mant. i. 48. 7. Ent. Syst. i. a. 250. 7. Scop. 54. Scbrank, 76. Faun. Fred. 4. 36. Poda Mus. Grac. 23. 1. Rai. go. 10. Preys. Bob. Ins. 13.9. Pontop. i.668. 5. Panz. Ent. Germ. II9.4. Faun. Ingr. 46. I39. Payk. Faun. Suec. i. 334. Io.

De Geer, iv. I74. 3.t. 6.f. 7. Oliv. ii. I1.8.5.t. I. f.3.a, b. Donov. Brit. Ins. t. 63. f. I. Panz. Faun. Germ. 40. t. 16. Stroem. Act. Nidros. iii. 384. 2. t. $6 . f$. I.

Le Bouclier"à corcelet jaune. Geoff. i. I21, 6.

Peltis thoracica. Fourc. i. 31, 6.

Long. corp. 7 lin.

Habitat

Descr. Reliquis simillima. Tota atra; sed clypeus I3 antice 
anticè truncatus, ferrugineus, pilis luteis. Elytra atra, lineis elevatis, unâ acutâ, semel interruptâ.

quadri- 9. Sil. nigra, elytris pallidis: puncto baseos mepunctata. dioque nigris, thorace emarginato.

Linn. Syst. Nat. 571. 14. Faun. Suec. 453. Vill. i. 77. II. Gmel. 1621. I4. Payk. Faun. Suec. i. 335. I1. Fab. Syst. Ent. 75. I4. Sp. Ins. i. 88. I7. Mant.i. 49. 20. Ent. Syst. i.a. 253. I9. De Geer, iv. 181. 6. Pontop. i. 668.6. Panz. Ent. Germ. i. 52. $12 \mathrm{I}$.

Oliv. ii. II. IO.7.t. I.f. 7.a, b. Don. Brit. Ins. $t .56$. f.2. Panz. Faun. Germ.40.t. I8. Bergst. Nom. iii. 24. 7.t. $3 \cdot f: 7$.

Le Bouclier jaune à taches noires. Geoff. i. I22. 7. t. 2. $f$. I.

Long. corp. 7 lin.

Habitat in Quercu.

Descr. Corpus nigrum. Thoracis latera testacea. Scutellum nigrum. Elytra singula puncto nigro majusculo in basi, et alio in medio disci. Faun. Suec.

obscura. Io. Sil. nigra, elytris punctatis: lineis elevatis tribus, clypeo truncato.

Linn. Syst. Nat.572. I8. Faun. Suec.457. Vill. i. 80. T5. Gmel. 1623. 18. Payk. Faun. Suec. i. 328.3. Fab. Syst. Ent. 74. I1. Sp. Ins. i. 88. I4. Mant. i. 49. 16. Ent. Syst.i. a.252. 15. Poda Mus. Grac. 23. 3. Scbrank, 77. Scop. 57. Faun. Fred. 5: 39. Panz. Ent. Germ. i. I20.9. Faun. Ingr. 47. I43.

Oliv.ii. II. I5.14.t.2.f. I8. Don. Brit.Ins.t.63.f.4. Scbaff. Icon. $t \cdot 75 \cdot f \cdot 5$. Herbst. Jablonsk. v. I88. I5. t. 5I.f. 4 .

Long. corp. 8 lin.

Habitat in cadaveribus.

DESCR. Corpus atrum. Elytra punctis excavatis tecta, lineisque tribus obsoletis. Thorax anticè truncatus, 
nec emarginatus, posticèque sub-rotundatus. Faun. Suec.

II. Sil. nigra, elytris punctatis: lineis elevatis granulata. tribus; dorso punctato-rugoso.

Tbunb. Ins. Suec, v. 72. Payk. Faun. Suec. i. 329. 4.

Long. corp. 6 lin.

\section{Habitat}

Descr. Simillima S. obscure, at minor; tum differt, elytrorum dorso punctato-rugoso, nec punctato ; latera omninò punctulatissima. Ne cum $S$. atratâ confundas notandum est, quòd obscura est, nec nitida.

I2. Sil. atra, elytris lævibus sub-punctatis.

Fab. Syst. Ent. 74. Io. Sp. Ins. i. 87. I3. Mant. i. 49. I5. Ent. Syst. i. a. 252. 14. Payk. Faun. Suec. i. 331.6. Gmel. 1623.59. Rai. 90. 9. Petagn. Ins. Calab.7.28. Panz. Ent. Germ. i. 120.8. Faun. Ingr: 46. I42.

Oliv. ii. II. I4. 13. t. I. f. I. b. Herbst. Jablonsk. v. I87. I4. $t$. 5 I. $f \cdot 3$ :

La Gouttière. Geoff. i. 122. 8.

Long. corp. 6 lin.

Habitat in sylvis.

DESCR. Nimis affinis $S$. atratce, a quâ tamen differt elytris lævibus, nec striis tribus elevatis. Fab. Syst. Ent.

13. Sil. fusca, elytris concoloribus : lineis elevatis opaca. subternis, thorace anticè truncato.

Linn. Syst. Nat.57I. I5. Faun. Suec.454. Vill. i. 78. I2. Gmel. I622. I5. Payk. Faun. Suec. i. 336. 12. Fab. Syst. Ent.74. I2. Sp. Ins. i. 88. I5. Mant. i. 49. I8. Ent. Syst. i. a.252.17. Panz. Ent. Germ. i. I20. II. Faun. Ingr. 47. 144. Laich. Tyr. 100. I2.

Herbst. Jablonsk. v. Igo. I7. t. 51.f. 6.

Long. corp. 5 lin. 
Habitat in cadaveribus.

DESCr. Caput villosulum, villis nonnihil rufescentibus. Thorax latus, marginatus, scaber, seu tuberculis elevatis, pubescens, pube cinereâ; partes autem elevatæ pube destituuntur. Elytra marginata, lineis tribus elevatis, acutis.

sinuata. 14. Sil, thorace emarginato rugosissimo, elytris lineis elevatis tribus apice sinuatis.

Fab. Syst. Ent. 75. 13. Sp. Ins. i. 88. 16. Mant. i. 49. I9. Ent. Syst. i. a. 252. 18. Gmel. I622. 56. Payk. Faun. Suec. i. 332. 8. Panz. Ent. Germ. i. I21. I2.

Oliv. ii. II. I8. 17.t. 2.f. I2.

Le Bouclier noir à corcelet raboteux. Geoff. i. 119. 2. Peltis scabra. Fourc. i. 30. 2.

Long. corp. 5 lin.

Habitat

Descr. Statura omninó S. opaca, cujus fortè varietas. Thorax anticè emarginatus, fuscus, argenteo colore splendens, punctis nigris elevatis scaber. Elytra nigra, apice sinu rotundo excavata.

tomentosa. 15. Sil. suprà nigro-fusca, subtùs atra, capite tomentoso, elytris lineis tribus elevatis.

De Geer, iv. 183. 8. Vill. i. 89. 58. Panz. Ent. Germ. i. 123.23.

Hersbt. Jablonsk, v. 203. 27.t.51.f. 16. Bergstraes. Nom. I. 9. 59. II. t. 9. $f$. II.

Long. corp. 5 lin.

Habitat

Descr. Antennæ capite thoraceque breviores. Caput, thorax et elytra tomentosa. Elytra striis tribus elevatis, quarum exterior major prominet.

rugosa. I6. Sil. nigricans, elytris rugosis : lineis elevatis tribus, thorace emarginato. 
Linn. Syst. Nut.571. 16. Faun. Suec, 455. Vill. i. 78. 13. Gmel, 1622. 16. De Geer, iv, 182. 7. Payk. Fuun. Suec. i.333.9. Scbrank, 58. Scop. 53. Faun. Fred. 4. 17. Rai. 90. 9.? Fourc. i. 30. 4. Fab. Syst. Ent. 74. 8. Sp. Ins. i. 86. 9. Mant. i. 49. 10. Ent. Syst. i. a. 251. 10. Panz. Ent. Germ. i. II9. 5. Faun. Etrusc. I34. Hellw. I34. Faun. Ingr. 46 . 140.

Oliv. ii. I1. 17. 16. t. 2.f. 17. Panz. Faun. Germ. 40. t. 17 . et $5 . t$. 9 .

Le Bouclier noir chiffonné à corcelet raboteux. Geoff. i. I 20. 4 .

Long. corp. $4 \frac{x}{2}$ lin.

Habitat -

Descr. Corpus ovale, parùm oblongum. Caput ante clypeum exsertum. Clypeus convexus, latus, anticè truncatus, margine prominulus, superficie in aliis glabrâ, atrâ; in aliis pubescente, lanugine cæsiâ, et punctis prominulis duris tuberculatâ. Elytra striis quinque, elevatis, longitudinalibus (numeratis inclusivè striis lateralibus, sine quibus striæ modo tres); inter singulas ordo longitudinalis punctorum elevatorum. Alæ nigricantes, ut et totum corpus atrum (excepto in quibusdam cæsio clypeo aut capite), opacum, minimèque nitidum. Faun. Suec.

17. Sil. oblonga rufa, antennis pectore elytrisque russica. nigris.

Linn. Syst. Nat.570. 10. Faun. Suec. 449. Vill. i. 75. 7. Gmel. 1619. 10. Fab. Syst. Ent. 73. 5. Sp. Ins. i. 85. 5. "Mant. i. 48. 6.

Dermestes. 7. Udd. Dissert.

Ips nigripennis. Fab. Ent. Syst. i. b. 513. 10. Panz. Ent. Germ. i. 348. 5. Petagn. Ins. Calab. 7. 27.

Panz: Faun. Germ. 50.t. 17 .

Triplax russica. Payk. Faun. Suec. iii. 345. r. Anthribus ruber. De Geer, v. 283. 1. t. 8. f. 12-15.

Long. corp. 3 lin.

Habitat

DEsCR. 
Descr. Rubra est, sed elytra striata, glabra, nigra, uti oculi. Antennæ et pectus subtùs cæruleo-nigra.

bicolor. I8. Sil. oblonga rufa, antennis elytrisque nigris. An Ips ænea? Fab. Ent. Syst. i. b. 514. I3. Triplax ænea. Payk. Faun. Suec. iii. $348 \cdot 3 \cdot$

Long. corp. 2 lin.

\section{Habitat —}

DESCr. Staturâ et habitu simillima S. russice, sed dimidio minor; tum differt, corpore subtùs unicolori, nec pectore cæruleo-nigro.

An sexûs differentia?

flava. 19. Sil. flava, capite antennisque rufescentibus, oculis nigris.

Long. corp. I lin.

Habitat -

In mus. D. Kirby.

DEscr. Insectum totum pingui colore succini obducitur. Caput et antennæ rufescunt.

castanea. 20. Sil. oblonga, elytris castaneis, capite thoraceque flavis.

Long. corp. 2 lin.

Habitat -

Ex mus. D. Shaw.

Descr. Statura et habitus $S$. russice, at minor; tum elytra castanea, nec atra. Facie Tenebrionis pallentis, at satis distincta. Antennæ extrorsùm crassiores, nec moniliformes. Elytra obsoletissimè striata. Corpus subtùs flavescens.

Spharice. 21. Sil. oblonga nigra, colcoptris strigâ albâ angulari literam $\mathrm{V}$ referenti.

Long. corp. $1 \frac{x}{2} \operatorname{lin}$.

Habitat in Spberia fraxineâ. D. Kirby.

DEscr. Antennæ et pedes rufo-picei. Thorax punctulatus, 
tulatus, marginibus crassis. Elytra punctulata, striata, striis punctis in ressis. Ad medium elytiorum punctum album; hiec puncta strigâ, hinc in angulum flexâ, conjunguntur; forma strigæ literæ Vau haud multùm absimilis.

22. Sil. ferruginea hirta, elytris nigris basi apice- bumeralis. que ferrugineis.

Krytophagus pilosus. Herbst. Jablonsk. iv. 177. 7. t. 42. f. I5.

Long. corp. 2 lin.

Habitat

Descr. Antennæ, caput, thorax et pedes ferruginea. Oculi nigri. Elytra nigra, basi apiceque ferruginea. Abdomen subtùs ferrugineum. Corpus suprà pilis subhirtum.

23. Sil. fusca glabra, pedibus testaceis, elytris truncateila. sub-truncatis.

Long. corp. $\frac{2}{3}$ lin.

Habitat

DESCR. Superficies corporis suprà omnis glaberrima. Quod autem singulare, elytra valdè obtusa, et obliquè sub-truncata. Pedes pallidiores.

24. Sil. atra nitida, elytris piceis: apicibus dilu-nitidula. tioribus, antennis pedibusque rufo-testaceis.

Long. corp. $\frac{2}{3} \operatorname{lin}$.

Habitat.

DEscr. Elytra abdomen omninò obtegunt. Pedes pallidi.

25. Sil. rufa oblonga, oculis abdomineque nigris. rosea. Long. corp. I $\frac{x}{2}$ lin.

Habitat

DESCR. 
DESCR. Corpus suprà pubescens. Elytra sub lente punctulata, at nec minimè quidem striata. Oculi nigri. Abdomen nigrum, apice rufo. Corpus oblongum. Nitidulâ cestivâ, cui simillima est, ferè duplo major.

polita. 26. Sil. ovata castanea nitida, elytris striatis.

Long. corp. $\mathrm{I} \frac{\mathrm{x}}{4} \operatorname{lin}$.

Habitat

DEscr. Antennæ articulis quatuor extimis majoribus. Totum corpus unicolor, castaneum, nitidum. At thorax glaberrimus præcipuè nitet. Elytra striata, striis punctis impressis.

Media inter Silpbas et Dermestes.

ruficollis. 27. Sil. ferrugineo-rufa, elytris striatis punctulatissimisque.

Long. corp. $1 \frac{1}{4}$ lin.

Habitat

DESCR. Antennæ nigræ, basi rufo-ferrugineæ. Caput rufo-ferrugineum. Oculi nigri. Thorax rufus. Elytra obtusissima, striata, et per totam superficiem punctulis numerosissimis ornata. Color ex rufo-nigricans.

pbeorrbea. 28. Sil. nigra nitida, elytris dimidiatis piceis.

Long. corp. $\frac{3}{4}$ lin.

Habitat

DESCR. Antennæ rufæ. Caput et thorax nigra, punctis minutissimis impressis. Elytra dimidiata, ad basin nigra, ad apicem picea. Pedes rufi. Abdomen nigrum.

birta.

29. Sil. oblonga ferruginea hirsuta, pedibus pallidioribus.

Long. corp. I lin.

Habitat _-

DESCR. 
Descr. Totum corpus ferrugineum, sive rufo-ferrugineum. Antennæ et pedes concolores.

30. Sil. nigra, antennis extrơrsùm subcrassioribus, minutissima. pedibus rufis.

An Chrysomela minutissima? Linn. Syst. Nat. 588. I5.

Long. corp. $\frac{1}{2}$ lin.

Habitat -

DESCR. Insectum minutissimum. Antennæ sub-incrassatæ, ferè filiformes, nigræ. Elytra truncata, sub-abbreviata. Pedes rubri. Alæ singulares capillaceæ.

31. Sil. ferruginea tota oblonga, antennis sub-ferruginea. clavatis.

Long. corp. I. lin.

Habitat in Boleto.

DESCr. Antennæ subclavatæ, clavâ obovatâ. Thorax et elytra punctulatissima.

32. Sil. nigra, thorace fusco, antennis rufis.

ruficornis.

Long. corp. $\frac{1}{2}$ lin.

Habitat in Boleto. Ex mus. D. Kirby.

Descr. Statura $S$. ferrugines, sed major. Antennæ ferrugineæ. Caput et thorax fusca. Elytra nigra, nitida, uti tota pagina supina. -Pedes rufi.

33. Sil. rufa, elytris anticè abdomineque fuscis. PhrogasLong. corp. $\frac{r}{3}$ lin.

Habitat

In mus. D. Kirby.

DESCR. Præcedenti minor. Antennæ thorace longiores, testaceæ. Oculi nigri. Caput, thorax, elytrorum dimidium anale, pectus et pedes rubelli. Cætera nigro-fusca. Abdomen glabrum, nitidum. 
evanescens. 34. Sil. oblonga piceo-nigra nitida, antennis pedibusque pallidè ferrugineis.

Long. corp. $\frac{1}{2}$ lin.

Habitat

Descr. Elytrorum apices minùs nigri. Der. pilosello affinis.

**Antenna sensim crassiores. Elytra abbreviata truncata.

punctulata.35. Sil. nigro-ferruginea punctulatissima, elytris ferrugincis: apice anguloque interiori baseos nigris.

Long. corp. I lin.

Habitat in foliis Caricis acute.

DESCR. Antennæ ferrugineæ, articulis tribus ultimis crassioribus, saturatioribus. Oculi nigri. Thorax nigro-ferrugineus, punctulis numerosissimis conspersus. Elytra etiam punctulatissima, abdomine paulò breviora, truncata, apice et angulo baseos suturali nigra; hinc maculæ utriusque elytri (elytra cum coadunata sint) quasi unicam maculam triangularem efficiunt. Abdomen nigrum. Pedes ferruginei.

Variat thorace nigro, et nigro-ferrugineo.

bimaculata. 36. Sil. nigra, elytrorum puncto medio pedibusque ferrugineis.

An Lyctus abbreviatus? Panz. Ent. Germ.34I. 4. Panz. Faun, Germ. 24. t. 2I.

Long. corp. 2 lin.

Habitat - Capta apud Barham ineunti Aprile. D. Kirby.

Descr. Nitidiuscula, suprà punctulatissima. Os paululùm rufescit. Antennæ clavâ magnâ triarticulatâ. Thorax margine laterali obscurè rufo. Elytra nigra, abbreviata, 
abbreviata, truncata, maculâ mediâ ferrugineâ notata ; humeri etiam obscurè rufescunt. Pedes ferruginei.

37. Sil. ferruginea, oculis nigris. unicolor. Long. corp. $\mathrm{I} \frac{\mathrm{x}}{4}$ lin.

\section{Habitat $\longrightarrow$}

Descr. Totum corpus ferrugineum, præter oculos, qui nigri sunt. Elytra ut et thorax sub lente punctulata, abdomine breviora sunt, porro obtusissima; haud nigricant ut in priori; tum punctula minutissima, vix conspicienda.

38. Sil. rufu-tcstacea, oculis nigris, abdomnis basi similis. fuscâ.

Long. corp. I lin.

Habitat

Descr. S. unicolori similis, sed minor. Rufo-testacea, elytris dilutioribus. Antennæ thorace longiores. Abdomen basi fusco-ferrugineum.

39. Sil. rufo-testacea, capite atro.

Panz. Ent. Germ. 19. 122. Faun. Germ. 25.t.5.

melinoce-

Long. corp. I $\frac{\mathrm{I}}{4}$ lin.

Habitat

Descr. Antennæ nigræ, basi rufo-testaceæ. Caput nigrum. Per cætera, corpus ferrugineum, sive ex rufo-testaceum. Thorax et elytra punctulis numerosissimis impressis.

40. Sil. ferruginea, abdomine capiteque posticè torquata. nigris.

Dermestes semicoleoptratus. Panz. Ent. Germ. 103. $3^{6 .}$ Panz. Faun. Germ. 24. $t$. 6.

Long. corp. I lin.

Habitat in floribus Corni sanguinee. 
DESCR. Antennæ extrorsùm crassiores, nigræ, basi ferrugineâ. Oculi nigri. Caput ferrugineum, et posticè veluti torque nigro cinctum. Thorax ferrugineus. Elytra abbreviata, truncata, ferruginea, sed pallidiora. Abdomen atrum. Pedes ferruginei.

lutea. $4 \mathrm{~T}$. Sil. rufo-ferruginea, oculis nigris.

Long. corp. I lin.

Habitat

Descr. Nimium affinis Sil. torquate, at tota ex rufoferruginea est. Caput torque nigro caret; tum abdomen rufescens, et in mucronem furcatum desinit. Antennæ omninò ferrugineæ.

abbreviata.42. Sil. nigra, pedibus ferrugineis, elytris valdè abbreviatis truncatis, corpore depressiusculo.

Long. corp. I lin.

\section{Habitat}

DEscr. Corpus suprà læve, nigrum. Pedes solummodo ferruginei. Elytra abbreviata, ferè usque ad dimidium abdominis, et apice truncata sunt. Abdomen apice acutiusculum. Corpus depressiusculum.

pulicaria. 43. Sil. nigra, antennis pedibusque ferrugineis.

Linn. Syst. Nat. 574-33. Vill. i. 84. 30. Gmel. 1624. 33 .

Dermestes pulicarius? Linn. Syst. Nat. 564. 24. Faun. Suec. 435 .

Sphæridium pulicarium. Fab. Syst. Ent.68. 9. Sp. Ins. i. 72. I2. Mant. i. 44. I5. Ent. Syst. i. a. 83. 30. Nitidula pulicaria. Oliv. ii. 12.20.30.t.3.f.27. a, b. Long. corp. $\frac{3}{4}$ lin.

Habitat

Descr. Sub-villosus, obsurè niger. Antennæ clavatæ, clavâ oblongâ triarticulatâ, rubellæ. Elytra parùm abbreviata. Pedes rubelli. 
44. Sil. ovata atra glaberrima hemiptera. Linn. Syst. Nat. 570. 9. Faun. Suec. 448. Vill. i. 75. 6. Gmel. I6I9.9.

Dermestes agaricinus. Scop. 43 .

Long. corp. $\frac{x}{2}$ lin.

Habitat

Descr., Corpus aterrimum, facie Dytisci, magnitudine seminis Aquilegia. Abdomen 'acutım. Elytra abdomine breviora. Antennæ angustissimæ. Pedes pallidi. Faun. Suec. agaricina.

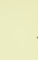




\section{Long. corp. 2 lin.}

\section{Habitat in carnibus; lardo.}

DEscr. Corpus depressum, nigrum. Antennarum clava obovata, compressa. Elytra marginata, maculâ rubrâ unicâ in medio, suturam versus. Pedes rufi.

4-pusiu- 2. Nit. nigra, elytris punctis duobus ferrugineis.

lata.

Oliv. ii. $12.8,9 . t .3 . f .22$. a, b.

Silpha 4-pustulata. Linn. Syst. Nat. 570. 5. ? Faun. Suec. 446. ?

De Geer, iv. 185. I2. t.6.f. 20, 2 I.

Ips 4-pustulata. Fab. Gen. Ins. Mant. 213. Sp. Ins. i. 80. 2. Mant. i. 45.5. Ent. Syst. i. b. 51 2.6.

Tritoma 4-pustulata. Fab. Syst. Ent. 69.3.

Long. corp. 3 lin.

Habitat

Descr. Corpus oblongum, depressum, nigrum, nitidum. Antennæ nigræx, clavâ magnâ ovatâ.. Mandibulæ apice bidentatæ. Thorax punctatus,' marginatus. Elytra leviter punctata, maculis duabus ferrugineis, primâ triangulari ad basin, aliâ sub-rotundâ ponè medium. Pedes nigri. Oliv.

obscura. 3. Nit. nigra obscura, pedibus piceis.

Fub. Gen. Ins. Mant. 2i5. Sp. Ins. i. 91.2. Mant. i. 51. 2. Ent. Syst. i. a. 255.3. Gmel. 1629.6. Payk. Faun. Suec, i.349.3. Panz. Ent. Germ. 124.3. Oliv. ii, I2. 5.3.t. 1.f.3. a, b.

Long: corp. 2 lin.

Habitat in cadaveribus.

Descr. Statura omninò Nit, bipustulatce, at paulò minor. Corpus suprà obscurè nigrum, minimè nitidum. Elytra lævia, immaculata. Pedes picei. Oliv.

rufpes. 4. Nit. nigra læris, thorace subemarginato, pedibus ferrugineis. 
Fab. Syst. Ent.78.8. Sp. Ins. i. 93. 16. Mant. i. 62. 21. Ent. Syst. i. a. 261. 29. Gmel. 1631. 24. Oliv. ii. I2: 21. Supp.t. v.f. 33.a, b.

Silpha rufipes, Linn. Syst. Nat.573.24. Vill. i. 82.21. De Geer, iv. 188. I5.

I.ong. corp. $1 \frac{x}{4}$ lin.

Habitat in floribus.

DESCR. Antennæ clavatæ, clavis magnis nigris. Corpus convexum, nigrum, nitidum. Thorax certâ lucis incidentiâ villis aureis obsitum.

5. Nit. virescenti-cærulea, pedibus rufis. viridescens. Fab. Ent. Syst. i. a. 261. 25. Gmel. 1631.21.

Oliv. ii. I2. I8. 26. t. 4. f. 30 .

Long, corp. $\frac{7}{8}$ lin.

Habitat —

Descr. Subtùs nigro-ænea, suprà ex viridi-cærulea. Antennæ nigræ. Pedes rufi, geniculis nigris.'

6. Nit. nigra villosula, tibiis dilatatis. Long. corp. I lin.

\section{Habitat - Ex mus. D. Kirby.}

DESCr. Nigra cum quâdam tincturâ æneâ. Antennarum clava magna, Tibiæ anticæ paululùm sed obscurè rubent; omnes valdè dilatatæ sunt; quâ notâ a Nit. aneâa optimè distinguitur: cæateris simillima, sed paulò major.

7. Nit. convexa atra, antennis pedibusque rufis. ruficornis. Long. corp. $\frac{\pi}{3}$ lin.

Habitat

DEscr. Nigra, nitens, punctulata.

8. Nit. nigro-ænea villosula, tibiis anticis obscurè enea. rufis.

Fub. Syst. Ent. 78. 7. Sp. Ins. i. 93. 13. Mant. i. 52. 17. Ent. Syst.i. a.261. 24. Gmel. 1630. 20.

K 2

Oliv. 
Oliv. ii. 12. 17.25:t. 3.f. 20. a, b.

Silpha ænea. Vill. i. $87 \cdot 42$.

Long. corp. I lin.

Habitat -

Descr. Staturâ Nit. rufipedis, sed tota villosula, tibiis solis obscure rufis.

cerulea. 9. Nit. subtùs nigra, suprà cærulea, tibiis anticis obscurè rufis.

Long. corp. $\frac{3}{4}$ lin.

\section{Habitat}

DEscr. Præcedenti simillima, sed nudiuscula, cærulea, Perit color cæruleus cum vitâ.

erytbropa. Iо. Nit. nigro ænea, antennis pedibusque rufis.

Long. corp. $\frac{3}{4}$ lin.

\section{Habitat -}

Descr. Cæeteris minor, villosula, subtùs nigra. Pedes obscurè rufi.

Colon.

I I. Nit. nigra, elytris ferrugineo variis, thorace emarginato : tergo duplici puncto impresso.

Fab. Syst. Ent. 78. 4. Sp. Ins. i. 92. 9. Mant. i. 52. 10. Ent. Syst. i. a. 259. I6. Gmel. I630. I3. oliv. ii. 12, 13. 16. t. I. $f .4$. a, b. Herbst. Jablonsk. v. 234 . 6.t. $53 \cdot f \cdot 5$.

Nitidula hæmorrhoidalis. Payk. Faun. Suec. i. 352. 7 . Silpha Colon. Linn. Syst. Nat. 573.27. Faun. Suec. 462. Vill. i. 83.24. Faun. Ingr. 48. 147. Panz. Ent. Germ. 127. I5.

De Geer, iv. I87. I4. t. 6. f. 24.

Ostoma Colon. Laich. i. 107. 4.

Long. corp. $\mathbf{I} \frac{\mathrm{r}}{2}$ lin.

Habitat -

Descr. Thorax vix emarginatus. Elytra ad apicem subtestacea, et pallidiora.

1 2. Nit. 
12. Nit. thorace marginato nigro, elytrorum discoidea. disco ferrugineo.

Fab. Syst. Ent. 78. 5. Sp. Ins. i. 92. II. Mant. i. 52. 13. Ent. Syst. i. a. 259. 19. Gmel. 1630. 16. Panz. Ent. Germ. 127. 18.

Oliv. ii. 12. 15. 21.t. 2.f.8. a, b. Herbst. Jablonsk. $\mathrm{v} .234 \cdot 6 \cdot t \cdot 53 \cdot f \cdot 5$.

Nitidula hæmorrhoidalis var. R. Payk. Faun. Suec. i.

Silpha discoidea. Vill. i. $87 \cdot 4 \mathrm{I}$.

Long. corp. $\mathbf{I} \frac{x}{2} \operatorname{lin}$.

Habitat -

DESCr. Caput atrum. Thorax inæqualis, marginatus, margine obscurè ferrugineo. Scutellum nigrum. Elytra nigra, maculâ magnâ orbiculatâ communi ferrugineâ. Pedes nigri.

I 3. Nit. rufo-fusca, elytris basi exteriore apiceque flexuosa. testaceis.

Fab.Ent. Syst. i. a. 258.4. Payk. Faun. Suec, i. 354.9. Panz. Ent. Germ. 126. I3.

Oliv. ii. I 2. 7.6. t. I. f. 6. a, b. Herbst. Jablonsk. v. 246.21. t. 54. $f \cdot 5$.

An Dermestes Hemipterus Linn. Syst. Nat. 565. 30.?

Long. corp. $1 \frac{2}{3}$ lin.

Habitat —_ Capta prope Woodbridge, Suffolciâ, copiosè. D. Latbbury.

DESCr. Antennæ capitulo fusco, stipite ferrugineo. Oculi prominuli. Thorax sub-quadratus, punctulatissimus. Elytra abdomine dimidio breviora ; in singulis macula lutea cuneiformis in apice, et punctum testaceum ad basin exteriorem. Pedes ferruginei.

14. Nit. ferruginea, elytris lævibus, thorace depressa. emarginato.

Silpha depressa. Linn. Syst. Nat. 573.29. Faun. Suec. 463. Vill. i. 84. 26. Gmel. 1624. 29. 
Long. corp. $2 \frac{x}{4}$ lin.

Habitat

DEscr. Corpus ferrugineum depressum. Elytra ferrugineo nigroque varia, striis elevatis, obsoletis : hæ striæ ex pilis confici videntur.

grisea.

I5. Nit. rufescens, thorace emarginato, elytris lævibus: lineolis maculisque nigris.

Silpha grisea. Linn. Syst. Nat. 574. 30. Faun. Suec. 464. Vill.i.84.27. Gmel.1624.30. Pontop. i. 668. 16.

Trans. Linn. Soc. i. 86.t. 5:f.6-II.

Silpha maculata. De Geer, iv. 184. Io.

Long. corp. 2 lin.

Habitat - Larva in Salice viminali. D. Curtis.

Descr. Totum corpus læve. Thorax et elytra variè maculis lineolisque amœnè depicta.

undata. I6. Nit. picea, elytris fasciis duabus ferrugineis arcuatis: primâ longitudinali abbreviatâ ; alterâ transversâ integrâ.

Oliv. ii. I2. I4. I8.t. $3 \cdot f \cdot 17 \cdot$ a, b.

Long. corp. I $\frac{2}{3}$ lin.

\section{Habitat}

DesCr. Antennæ piceæ, clavâ subferrugineâ. Caput piceum. Thorax piceus, lateribus ferrugineis. Elytra picea, fasciis duabus obsoletiusculis; prima ad basin longitudinalis, ad marginem suturalem inflexa; altera pone medium transversa, lunulæ instar arcuata. Margo elytrorum et præcipuè ad apicem ferrugineus. Abdomen et pedes piceí.

nebulosa. 17. Nit. grisea, elytris lævibus nitidiusculis disco albido nigroque variis.

Long. corp. $\mathrm{I} \frac{\mathrm{T}}{4}$ lin.

Habitat 


\section{Habitat}

Descr. Antennæ ferrugineæ. Caput nigro-ferrugineum, sive piccum. Thorax niger, sive piceus, margine ferrugineo. Elytra margine omni suturâque ferrugineis ; discus autem allbido nigroque varius. Fundus scilicet albidus maculis circiter quatuor nigris : unâ parvâ ad basin; duabus mediis sub.contiguis, quarum exterior major est ; quartâ maximâ sub-lunari, ad suturam apicem versus.

18. Nit. testacea subtomentosa, thorace emargi- astiva. nato, oculis nigris.

Fab. Syst. Ent.77.2. Sp. Ins. i.9I.5. Mant. i.51.5. Ent. Syst. i. a. 256.6. Gmel. 1629. 9 .

Oliv. ii. 12. 16. 23.t. $3 \cdot f \cdot 23 \cdot \mathrm{a}, \mathrm{b}$.

Silpha æstiva. Linn. Syst. Nat.574.32. Faun. Suec. 465. Vill. 1. 84. 29. Faun. Fred. 54I.

Long. corp. $1 \frac{r}{2}$ lin.

Habitat in floribus.

Descr. Corpus ovatum, depressum, subtomentosum, testaceum. Oculi nigrị.

19. Nit. testacea, coleoptris maculâ niğrâ obso- obsoleta. letâ cruciformi.

Long. corp. I $\frac{i}{2}$ lin.

Habitat

DESCR. Antennæ, caput, thorax, sternum, pedes et abdomen omnia ejusdem coloris testacea. Elytra ne minimè quidem striata; at maculam quandam nigram obsoletam, communem, quæ crucis rudem imaginem refert, exhibent.

20. Nit. rufo ferruginea, elytris guttis quinque Io-guttata. oblongis pallidis.

Fub. Ent. Syst. i. a. 258. II. Payk. Faun. Suec. i. 354. 10. Panz. Ent. Germ. 126. 10. Oliv. ii. 12. 10.12.t. $3 \cdot f \cdot 24 \cdot$ a, b. 
Long. corp. 2 lin.

Habitat — Capta prope Vigorniam. D. Clark.

DESCR. Totum corpus punctulis minimis conspersum. Caput et thorax rufo-ferruginea. Thoracis latera et punctum medium ad apicem pallidiora. Elytra rufoferruginea, maculis quinque oblongis, pallidis ; quarum tres ad marginem exteriorem, duæ ad suturam. Abdomen nigrum. Pectus et pedes testacei.

fulva. 21. Nit. ferruginea, abdomine subtùs nigricanti, elytris punctato-striatis.

Long. corp. 2 lin.

Habitat in Lycoperdo Boviste. Ex mus. D. Hill.

DEscr. Totum corpus suprà pilosum, et ferè ejusdem coloris est, at caput saturatius. Thorax anticè lunulatim excavatus, porro punctulatus est, punctulis minimis numerosissimis. Elytra obsoletè punctato-striata. Abdomen subtùs ex piceo nigrum. Pedes ferruginei.

melanoce- 22. Nit. nigra, antennis, elytris abbreviatis pediphala. busque sordidè testaceis.

Long. corp. I lin.

Habitat -

DESCr. Antennæ testaceæ. Caput et thorax nigra. Elytra sordidè testacea, abbreviata. Abdomen acutum. Corpus subtùs nigrum. Pedes testacei.

nufa. 23. Nit. ferruginea lævis nitidiuscula, oculis abdomineque nigris.

Long. corp. $I \frac{x}{4}$ lin.

Habitat in Boletis exsiccatis. D. Kirby.

DESCR. Totum corpus læve est, et paulùm nitescit. Oculi et abdomen nigra.

ruffrons. 24. Nit. picea lævis nitidiuscula, fronte ferrugineâ, thorace atro. 
Ips ruffrons. Fab. Ent. Syst. i. b. 514. I6. Sp. Ins. i. 8I. 6. Mant. i. 46. гб. Panz. Ent. Germ.349. II. Panz. Faun. Germ. 36. t. I9.

Tritoma rufifrons. Fab. Syst. Ent. 69.5.

Long. corp. $1 \frac{1}{3}$ lin.

Habitat in Boletis exsiccatis. D. Kirby.

DESCr. Antennæ ferrugineæ. Frons ex ferrugineo rufa. Thorax ater. Elytra picea, lævissima. Abdomen atrum. Pedes ferruginei. Totum corpus glaberrimum, nitidum. Nimis affinis Nit. rufae.

An sexûs differentia?

25. Nit. nigra, thoracis lateribus rufis, elytris Staphyliabbreviatis: lineis tribus elevatis. noides.

Long. corp. $\frac{3}{4}$ lin.

\section{Habitat}

DEscr. Antennæ ferrugineæ. Caput nigrum. Thorax niger, marginibus latiùs rufis; per medium porcæ duæ, sive lineæ elevatæ, decurrunt. Elytra vix dimidium abdominis æquant, striis tribus elevatis. Pedes rufi. Substantia hujusce animalculi dura admodum.

26. Nit. nigra, thorace rugoso, elytris abbre-porcata. viatis : lineis tribus elevatis.

Staphylinus porcatus. Payk. Monog. 50. Payk. Faun.

Suec. iii. 413. 59. Fab. Ent. Syst. i. b. 530. 56.

Oliv. iii. $42 \cdot 35 \cdot 50 \cdot t \cdot 4 \cdot f \cdot 33 \cdot$ a, b.

Long. corp. I lin.

Habitat

Descr. Nimium affinis Nit. Stapbylinoidi, at tota nigra est. Thorax et abdomen valdè marginata. Porro, thorax sulcis duobus longitudinalibus, Elytra vix dimidium abdominis æquant, posticè truncata, lineis tribus valdè elevatis. Abdomen clathratum, sive lineis longitudinalibus et transversis, elevatis, quadras conficientibus, intra quas puncta valdè impressa sunt. 
nigrina. 27. Nit. atra glaberrima nitida:

Long. corp. I lin.

Habitat

Ex mus. D. Kirby.

DeSCr, Statura et magnitudo Nit. cenece. Corpus omninò atrum, et ne minimè quidem æneum. Antennæ et pedes concolores. Oculo optimè armato, elytra punctulis obsoletis ornari videntur.

psyltia. 28. Nit. ovata nigra, elytris subabbreviatis, pe. dibusque ferrugineis.

Long. corp. $\frac{x}{2}$ lin.

Habitat

Ex mus. D. Kirby.

Descr. Antennæ, pedes et elytra ex testaceo ferruginea. Thorax et elytra sub lente punctulata. Corpus obscurum.

pyrrbopa. 29. Nit. nigra punctata, elytris abdomine brevioribus, pedibus rufis.

Long. corp. I lin.

Habitat in Alno putrido.

D. Kirby.

Descr. Statura ferè Nit. rufpedis, at duplo minor; tum elytra abdomine breviora. Antennæ et pedes rufi.

\section{BOLETARIA.}

Antenne perfoliatæ, extrorsùm crassiores. Thorax marginatus, posticè foveolis tribus, mediâ obsoletiori, utrinque angulatus.

Elytra marginata.

Corpus ovatum.

4-pustu- I. Bol. suprà nigra, elytris rufo bimaculatis. Chrysomela 
Chrysomela quadripustulata. Linn. Syst. Nat.597. 80. Faun. Succ. 549. Vill. i. 149. 120.

Donow. Brit. Ins. $t$. $185 . f$. 2 .

Cryptocephalus 4-pustulata. Fab. Syst. Ent. I1 I. 28. Sp. Ins. i. I 45.42. Mant. i. 83. 55. Ent. Syst. i. b. 68. 76. Faun. Etrusc. 253. Hellw. 253. Harr. 72. Scbaff. Icon. t. $30 . f .6$.

Tritoma. Geoff. i. 335. I. t. 6.f.2.

Mycetophagus 4-maculatus. Panz. Ent. Germ. 336. I. Panz. Faun. Germ. I2. $t .9$.

Long. corp. 3 lin:

Habitat in Boleto.

Descr. Tota suprà nigrior, subtùs ferruginea. Caput ferrugineum. Thorax niger, punctis duobus impressis. Elytra nigra, maculâ ad basin majore rufâ; aliâ ante apicem minori rufâ. Pedes et abdomen ferruginei. Faun. Suec.

2. Bol. rufo-ferruginea, elytris post basin nigro- rufa. variis, antennis subclavatis.

Lon g. corp. 2 lin.

Habitat in Boleto.

DESCR. Antennæ, caput, thorax et abdomen rufoferruginea. Elytra maculâ baseos et puncto ad apicem rufo-ferruginea, cæteroquin nigro ferrugineoque varia. Pedes ferruginei. Antennæ subclavatæ. Corpus latum et planum. Elytra punctulatissima, striata.

3. Bol. nigra, elytris minutè striatis, ferrugineo multipuncnigroque variis.

Mycetophagus multipunctatus. Fab. Ent. Syst. i. b. 498.5. Panz. Ent. Germ.337. 4.

Panz. Faun. Germ. 12. t. II,

Dermestes multipunctatus. Thunb. Ins. Suec. 79. 6.

Long. corp. 2 lin.

Habitat in Boletis exsiccatis.

DEscr. 
Descr. Antennæ articulis quinque ultimis crassioribus, distinctis, ex ferrugineo-rufescentes. Thorax niger, posticè punctis duobus impressis distantibus, lineolâ mediâ impressâ interjacente. Elytra sub lente punctulatissima, minutissimè striata, maculâ communi ad basin suturæ nigrâ; per cætera ferruginea sunt, et characteres nigros præ se nec hebræis multùm absimiles gerunt, unde nigro et ferrugineo varia. Apex antem semper niger, puncto rotundo ferrugineo. Abdomen nigrum. Pedes rufo-ferruginei. Corpus oblongum, et quodammodo elongatum.

similis.

4. Bol. fusca, elytris pallidis apice fusco-nebulosis.

Long. corp. 2 lin.

Habitat in Boleto.

Descr. Subtùs fusca. Abdomen fuscum, ano luteo. Antennæ ferrugineæ, uti os. Pedes lutei.

varia.

5. Bol. fusca, antennis, pedibus, elytrorumque fasciis duabus punctoque rufis.

Long. corp. 2 lin.

Habitat - Capta in Boleto quodam quercino, Septembre ineunti I797, apud Melton juxta Woodbridge, Suffolciâ.

Descr. Corpus fuscum. Elytra substriata, basi latè rufâ, sed punctum fuscum utrinque apud scutellum; dein fasciâ, seu potius maculâ irregulari fuscâ notantur, quam sequitur fascia rufa; demum apices fusci, puncto rufescenti.

undulata. 6. Bol. nigra, pedibus elytrorumque fasciis undulatis rufis, antennis ferrugineis.

Panz. Faun. Germ.2. t. 22. var.

Long. corp. $2 \frac{1}{3} \operatorname{lin}$.

Habitat - Capta in Boleto quodam quercino in Barham, Octobre ineunti I 797. D. Kirby.

DESCR. 
Descr. B. variae simillima, sed major. An satis distincta? Antennæ ferrugineæ. Thorax hirtulus. Elytra fasciis, seu potiùs maculis duabus undulatis pallidè rufescentibus; inter has punctum marginale; punctum aliud intra apicem.

Variat thorace obscurè ferrugineo.

7. Bol. nigra, elytris punctis fasciâque posticâ atomaria. fulvis.

Ips atomaria. Fab. Mant. i. 46. 9.

Mycetophagus atomarius. Fub. Ent. Syst. i. b. 498.4 . Panz. Ent. Germ. 337.3.

Panz. Faun. Germ. I2.t. Io.

Long. corp. 2 lin.

Habitat in Boleto.

DESCR. Elytra striata, nigra, maculâ majori ad basin, punctis quinque in medio, fasciâ posticâ undatâ punctoque apicis fulvis. Pedes nigri. Fab.

8. Bol. flava, capite elytrisque cæruleis.

Tetratoma Fungorum. Fab. Ent. Syst. i. b. 507. 1. Panz. Ent. Germ. 345. 1. Faun. Ingr. 35 I.

Panz. Faun. Germ. 9. t. 10.

Long. corp. 2 lin.

Habitat in Boleto arborum.

DEscr. Subtùs tota flava. Caput nigrum sive nigrocæruleum, ore flavo. Oculi magni. Antennæ subclavatæ, clavâ quadriarticulatâ, nigrâ, admodum longâ, stipite brevi flavo. Thorax glaber, flavus. Elytra cærulea, nitentia, punctulata.

Obs. Silpbe bicolori simillima est; adeo ut tyronem faciliùs fallat. Antennæ vero, tum thoracis foveolæ, Boletariam esse, nec Silpbam, abunde probant. 


\section{$\left[\mathrm{I}_{42}\right]$}

\section{OPATRUM.}

Antenne moniliformes, extrorsùm crassiores. Caput parvum, inflexum.

Thorax utrinque marginatus, anticè lunatus. Elytra immarginata, abdomine longiora, apice inflexa.

Corfus oblongum, convexum.

sabulosum. I. Op. fuscum, elytris lineis elevatis tribus utrinque dentatis, thorace subemarginato.

Fab. Syst. Ent.76. I. Sp.Ins. i.89.2. Mant. i. 50.2. Ent. Sy.t.i.a.89.3. Preys. Bob.Ins. 89. 83. Faun. Fred.5.38. Pelagn. Ins. Calab.7.32. Panz. Ent. Germ.35.1. Gmel. 1632.2. Payk. Faun. Suec. i. 81. I. Faun.Ingr. II. 32.

Panz. Faun. Germ.3. t. 2. Oliv. iii. 56.6.5.t. I.f. 4 . Silpha sabulosa. Linn. Syst. Nat. 572. 17. Faun. Suec. 456. Vill. i. 79. 14. Scop. 58.

Tenebrio atra. Geoff: i. 350.7 .

....... rugosus. Ge Geer, v. 43.5. t. 2.f. 2 1.

Long. corp. 4 lin.

Habitat in arena.

Descr. Corpus nigrum, minimè nitidum, sed ferè cinereo-sordidum. Caput maxinina ex parte sub clypeo latet. Clypeus anticè enıarginatus. Elytra gaudent striis quinque (inclusivè cum marginalibus) elevatis, obsoletè versus latera denticulatis, punctata enim non sunt, sed quasi tubercula sive puncta elevata striis adnata. Faun. Suec.

Obs. Similis Scaratico sabuloso. Vill.

tibiale. 2. Op. nigrum, elytris punctatis subrugosis, tibiis anticis compresso-triangularibus.

$F a b$. 
Fab. Ent. Syst. i. a. 91. 13. Sp. Ins. i. 90. 7. Mant. i. 51. 7. Panz. Ent. Germ. 1.36. 4. Payk. Faun. Suec. i. 83.3. Gmel. 1632.7.

Panz. Faun. Germ. 43. t. Io. Oliv. ii. 56. I0. Io. t. I. f. IO. a, b.

Silpha tibialis. Vill. i. 86.35 .

Long. corp. $1 \frac{x}{2}$ lin.

Habitat sub lapidibus.

DESCR. Clypeus emarginatus. Caput et thorax lævia, nigra, immaculata. Elytra lineis elevatis obsoletis rugosa. Tibiæ anticæ basi bidentatæ, apice compressæ, triangulares.

3. Op. nigrum, thorace punctulato, elytris ob-Agricola. scuris piceis profundè striatis punctatisque.

Faun. Etrusc. I39. Hellw. I39. Fab. Ent. Syst. i. a. 9r. 14. Payk. Faun. Suec. 1. 84. 4.

Long. corp. $1 \frac{3}{4} \mathrm{lin}$.

Habitat in Boleto.

Descr. Antennæ ferrugineæ. Caput et thorax nigra. Thorax punctulis numerosis impressis. Elytra ex nigro picea multi-striata; striæ pro ratione animalculi satis profundæ, punctis profundis impressis. Pedes ferruginei.

\section{CASSIDA.}

Antenne moniliformes, extrorsùm crassiores. Caput sub thoracis clypeo plano reconditum. Thorax et Elytra dilatato-marginata. Corpus ovale, convexum, subtùs planum.

I. Cas. viridis, punctis sparsis confluentibus. viridis. Linn. 
Linn. Syst. Nat. 574. I. Faun. Suec.467. Vill. i. 90. t. Gmel. 1635. I. Scbrank, 92. Scop. II7. Fab. Syst. Ent.88. I. Sp. Ins. i. I07. 1. Mant. i. 62. I. Ent. Syst. i. a. 292. 1. Faun. Fred. 5. 43. Panz. Ent. Germ. I53. I. Pontop. i. 668. I. Faun. Etrusc. 180. Hellw. 180. Faun. Ingr. 56. 172, Payk. Faun. Suec. ii. 45. 2. Laich. III.3. Harr. 147. Roes. 2. Scar. 3.t.6.f. I-5. Scbceff. Icon.t. 27.f.5. Frisch. 13. t. 29. Herbst. Jablonsk. viii. 209. I. t. $130 . f .8$.

Cassida Cardui. De. Geer, v. I74. 2.

La Casside verte. Geoff. i. 3I2. I.

Long. corp. $4-4 \frac{1}{2}$ lin.

Habitat in Mentbâ et aliis plantis verticillatis ubique. Larva tecta incedit proprio stercore.

Descr. Antennæ nigræ, basi pallidæ. Clypeus, scutellum et elytra viridia. Clypeus depressus, punctulis impressis. Scutellumlæve. Elytra rugoso-punctata, punctis confluentibus. Corpus subtùs atrum, margine pallido. Pedes pallidi.

similis.

2. Cas. viridis, elytris striato-punctatis.

An Cassida prasina Hersbt. Jablonsk. viii. 221 . 4. $t$. I29. f.6.?

Long. corp. 4 lin.

Habitat in Antbemide Cotulâ, \&xc. D. Kirby.

DEsCr. Antennæ pallidæ, supernè fuscæ. Coleoptra viridia. Clypeus in medio longitudinaliter elevatus, punctis minutissimis sparsis. Scutellum læve. Elytra striato-punctata, marginibus pallidioribus. Corpus subtùs atrum, margine pallido. Pedes pallidi.

Obs. Minor præcedenti, præsertim latitudine.

Spergule. 3. Cas. pallidè-viridis, clypeo Javi, elytris punctato-striatis.

Long. corp. 3 lin.

Habitat in Spergulâarvensi. D. Kirby.

DESCR. 
Descr. Antennæ pallidæ. Clypeus, scutellum et elytra pallidè viridia. Clypeus lævis. Elytra striata, striis ex punctis impressis. Corpus subtùs atrum, abdominis margine pallido. Pedes albidi.

4. Cas. viridis, elytris maculâ ad basin communi cruentata. sanguineâ.

Donov. Brit. Ins. t. $63 \cdot f \cdot 2,3$.

Cassida sanguinolenta. Payk. Faun. Suec. ii. 46. 3 .

Herbst. Jablonsk. viii. 229. II. t. I29. f. I2.,

Long. corp. 2 lin.

\section{Habitat}

Descr. Simillima Cassida viridi; at quoniam macula ad basin elytrorum communis sanguinea constans est, haud minimè sui juris esse censere dubitamus.

5. Cas. nigra suprà viridis, thorace emarginato, liriopbora. elytrorum suturâ basi internè punctisque duobus nigris.

Trans. Linn. Soc. iii.p. 8.

Long. corp. 3 lin.

Habitat in Serratulá arvensi. D. Kirby.

Descr. Caput nigrum. Antennæ subclavatæ, pallidæ, apicibus nigris. Thorax subemarginatus, viridis, punctulatus. Elytra viridia, maculâ longitudinali communi, (quæ utrinque ad eorum insertionem dilatatur, atque florem Lilii cujusdam non injucundè refert,) punctisque duobus nigris. Scutellum viride. Abdomen nigrum, ano pallido. Pedes pallidi, femoribus nigris. Larva viridis, colore dilutiori punctata: radii lividi. Caput nigrum, regione intra oculos viridi nigro-punctatâ. Trans. Linn. Soc.

6. Cas. pallido-nebulosa.

nebulosa.

Linn. Syst. Nat.575.3. Faun. Suec.468. Vill.i.91.3. Gmel. I636. 3. Fab. Syst. Ent. 90. I r. Sp. Ins. i. VOL. I. 
108. 5. Mant. i. 62. 5. Ent. Syst. i. a. 293. 7. Faun. Etrusc. 183. Hellw. 183. Faun. Fred. 5. 44. Petagn. Ins. Cal. 8. 38. Pontop. i. 668. 2. Panz. Ent.Germ. 154.6. Faun.Ingm 56. 174. Harr. 149. Payk. Faun. Suec. ii. $47 \cdot 4$.

Friscb. 4. 20. t. 15. Scriba 83. I6. t. 8.f. 2. Herbst. Jablonsk. viii. 236. I5. t. I30.f. II.

La Casside brune. Geoff.i.3I3. 2.

Long. corp. 3 lin.

Habitat in Melissâ.

DEscr. Similis admodùm C. viridi. Est enim dimidio minor, colore griseo, punctis inæqualibus nigris adspersa, et inde nebulosa. Clypeus lunam refert, anticè minimè emarginatus, totus lævis, nec maculatus, sed pallidus. Elytra rugosa, punctis excavatis striata, striis curvis et flexuosis. Corpus nigrum, totum clypeo et elytris absconditum. Antennæ nigræ, filiformi-clavatæ. Faun. Suec.

7. Cas. grisea, elytris lineâ cæruleâ nitidissimâ.

Linn. Syst. Nat. 575. 4. Faun. Suec. 469. Vill. i. 92. 4. Gmel. I636. 4. Fab. Syst. Ent. 90. II. Sp. Ins. i. I10. I7. Mant. i.63.21. Ent.Syst. i. a. 297. 24. Pans. Ent. Germ. 155. II. Pontop. i. 658. 3. Faun. Fred. 5. 45. Faun. Etrusc. 182. Hellw. 182. Faun. Ingr. 57. I75. Harr. ${ }_{51}$. Payk. Faun. Suec. ii. 49. 7.

Scbeff: Icon. t. 96. f. 6. Scriba 87. I8. t. 8.f. 4. Don. Brit. Ins. t. 138.f. 1, 2, 3. Herbst. Jablonsk. viii. $238.16 . t$. $130 . f$. 15 .

La Casside à bandes d'or. Geoff. i. 313.3.

Long. corp. $2-2 \frac{1}{2}$ lin.

Habitat in hortis et sylvis.

DESCR. Capitis clypeus integer. Antennæ subclavatæ, nigræ, basi pallid̋æ. Corpus suprà pallide griseum, subtùs nigrum. Linea cærulea nitidissima in singulo elytro juxta suturam longitudinalem, quæ evanescit cum vitâ. Faun. Suec. 
8. Cas. grisea, elytris lineâ strigâque cupreo-au-splendidula. ratis.

Long, corp. $2 \frac{\pi}{2}$ lin.

Habitat —

DESCR. Cas. nobili simillima; sed linea juxta suturam cupreo-aurata, nec cærulea; et striga insuper aurata in medio singuli elytri apicem versus, vix sine lente conspicua.

9. Cas. viridis, elytris rariùs, suturâ dorsali con-maculata. fertiùs nigro-maculatis.

Linn. Syst. Nat.575.6. Vill. i. 92. 6. Gmel. 1638.6. Trans. Linn. Soc. iii. p. Io. Fab. Syst. Ent. 88.2. Sp. Ins. i. 107. 2. Mant. i. 62.5.

Cassida Murræa var. $\beta$. Payk. Faun. Suec. ii. 48. 5. De Geer, v. I75. 3 .

La Casside panachée. Geoff. i. 3I4. 5. t. 5.f. 6.

Long. corp. $3^{\frac{\mathrm{x}}{2}}$ lin.

Habitat in Inule dysenterice foliis. D. Kirby.

DESCR.

Iо. Cas. nigra, clypeo rubro, elytris sanguineis : Murrea. punctis nigris sparsis.

Linn. Syst.Nat.575.2. Vill. i.91.2. Gmel. 1635.2. Fab. Syst. Ent.90. 10. Sp. Ins. i. 108. 6. Mant. i. 62. 8. Ent. Syst. i。a. 294. 9. Panz. Ent. Germ. I54. 8. Preys. Bob. Ins. 90. 84. Faun. Etrusc. 181. Hellw. 181. Payk. Faun. Suec. ii. 48.5.

Herbst. Jablonsk. viii. 240. I7. t. 130. f. I2, I3.

C. rubra, maculis nigris variegata. Geoff. i. 3I4. 5. $\beta$.

Long. corp. 3-4 lin.

Habitat in hortis.

DESCR. Statura C.viridis. Elytra substriata, punctis 3 seu 5 nigris ad suturam, et unico ad basin maximo; reliquis in disco. Linn.

Obs. Hanc differre a C. maculatâ æatate tantùm provectiori credit Geoffroyus. Habui equidem specimina, I 2

elytris 
108. 5. Mant. i. 62. 5. Ent. Syst. i. a. 293. 7. Faun. Etrusc. 183. Hellw. 183. Faun. Fred.5. 44. Petagn. Ins. Cal. 8. 38. Pontop. i. 668.2. Panz. Ent.Germ. I54.6. Faun. Ingn. 56. I74. Harr. I49. Payk. Faun. Suec. ii. $47 \cdot 4$.

Frisch. 4. 20. t. 15. Scriba 83. 16. t. 8.f. 2. Herbst. Jablonsk. viii. 236. I5. t. I30.f. I I.

La Casside brune. Geoff.i. 3I3. 2.

Long. corp. 3 lin.

Habitat in Melissâ.

DEsCr. Similis admodùm C. viridi. Est enim dimidio minor, colore griseo, punctis inæqualibus nigris adspersa, et inde nebulosa. Clypeus lunam refert, anticè minimè emarginatus, totus lævis, nec maculatus, sed pallidus. Elytra rugosa, punctis excavatis striata, striis curvis et flexuosis. Corpus nigrum, totum clypeo et elytris absconditum. Antennæ nigræ, filiformi-clavatæ. Faun. Suec.

7. Cas. grisea, elytris lineâ cæruleâ nitidissimâ.

Linn. Syst. Nat. 575. 4. Faun. Suec. 469. Vill. i. 92. 4. Gmel. I636. 4. Fab. Syst. Ent. 90. II. Sp.Ins. i. I10. I7. Mant. i.63.21. Ent.Syst.i. a. 297. 24. Panz. Ent. Germ. 155. II. Pontop. i. 658. 3. Faun. Fred. 5. 45. Faun. Etrusc. I82. Hellw. 182. Faun. Ingr. 57. 175. Harr. ${ }^{51}$. Payk. Faun. Suec. ii. 49. 7.

Scbaff. Icon. t. 96. f. 6. Scriba 87. I8. t. 8.f. 4. Don. Brit. Ins. t. I38.f. I, 2, 3. Herbst. Jablonsk. viii. $238.16 . t .130 . f$. 15 .

La Casside à bandes d'or. Geoff. i. 3 r3. 3 .

Long. corp. $2-2 \frac{1}{2}$ lin.

Habitat in hortis et sylvis.

Descr. Capitis clypeus integer. Antennæ subclavatæ, nigræ, basi pallidæ. Corpus suprà pallidè griseum, subtùs nigrum. Linea cærulea nitidissima in singulo elytro juxta suturam longitudinalem, quæ evanescit cùm vitâ. Faun. Suec. 
8. Cas. grisea, elytris lineâ strigâque cupreo-au-splendidula. ratis.

Long, corp. $2 \frac{\pi}{2}$ lin.

Habitat

DESCr. Cas. nobili simillima; sed linea juxta suturam cupreo-aurata, nec cærulea; et striga insuper aurata in medio singuli elytri apicem versus, vix sine lente conspicua.

9. Cas. viridis, elytris rariùs, suturâ dorsali con-maculata. fertiùs nigro-maculatis.

Linn. Syst. Nat. 575.6. Vill.i. 92. 6. Gmel. 1638.6. Trans. Linn. Soc. iii. p. 10. Fab. Syst. Ent. 88. 2. Sp. Ins. i. 107. 2. Mant. i. 62.5.

Cassida Murræa var. . Payk. Faun. Suec. ii. 48. 5. De Geer, v. $175 \cdot 3 \cdot$

La Casside panachée. Geoff. i. 3I4. 5. t. 5.f.6.

Long. corp. $3 \frac{\mathrm{I}}{2}$ lin.

Habitat in Inule dysenterice foliis. D. Kirby.

DESCR.

Iо. Cas. nigra, clypeo rubro, elytris sanguineis : Murraa. punctis nigris sparsis.

Linn. Syst.Nat.575.2. Vill. i.91.2. Gmel. 1635.2. Fab. Syst. Ent. 90. 10. Sp. Ins. i. 108.6. Mant. i. 62. 8. Ent. Syst. i. a. 294. 9. Panz. Ent. Germ. 154. 8. Preys. Bob. Ins. 90. 84. Faun. Etrusc. 181. Hellw. 181. Payk. Faun. Suec. ii. 48.5.

Herbst. Jablonsk. viii. 240. I7. t. 130. f. I2, I3.

C. rubra, maculis nigris variegata. Geoff. i. 3I4. 5. $\beta$.

Long. corp. $3-4$ lin.

Habitat in hortis.

DESCR. Statura C. viridis. Elytra substriata, punctis 3 seu 5 nigris ad suturam, et unico ad basin maximo; reliquis in disco. Linn.

Obs. Hanc differre a C. maculatâ æatate tantùm provectiori credit Geoffroyus. Habui equidem specimina,

I 2 elytris 
elytris suturâ dorsali confertiùs nigro-maculatis; at mihi distincta species. Hellw.

Cassidam maculatum et Murrcam unam eandemque esse speciem satis pro comperto habemus; utramque enim semel atque iterum aluimus. Color variat pro ætate animalculi.

ferruginea. I I. Cas. nigra, thorace elytrisque ferrugineis immaculatis.

Scbrank, 90. Fab. Ent. Syst. i. a.294. 10. Sp. Ins. i. 108. 7. Mant. i. 62. 9. Vill..i. 93.9. Gmel. 1637. 44. Panz. Ent. Germ. I54.9. Faun. Etrusc. 184. Hellw. I84. Petagn. Ins. Cal. 9. 39.

Herbst. Jablonsk. viii. 245. 19. t. I30.f. I4.

Long. corp. 3 lin.

\section{Habitat}

DEscr. Suprà tota ferruginea, subtùs nigra. Elytra punctato-striata. Pedes ferruginei.

\section{COCCINELLA.}

Antenne clavatæ, truncatæ, clavâ solidâ. Palpi antici clavâ semicordatâ. Thorax et Elytra marginata. Corpus hemisphæricum, abdomine subtùs plano.

* Coleoptris rubris flavisve: punctis nigris maculatis.

** Coleoptris rubris flavisve: albo-maculatis. *****oleptris nigris : rubro-maculatis. *** Coleoptris nigris: albo-flavove maculatis.

* Coleoptris rubris favisve: punctis nigris maculatis. impunctata. $\mathbf{T}$. Coc. colcoptris rufis: puncto nullo.

Linn. 
Linn. Syst. Nat.579.4. Vill. i. 94. J. Gmel. 1645.4. Scbrank, 93. Fab. Syst. Ent.79.4. Sp.Ins. i.93.4. Mant. i. 53. 6. Ent. Syst. i. a.267.9. De Geer, v. 369. 1. Panz. Ent. Germ. 131.3. Faun. Etrusc. 149. Hellw. I49.

Panz. Faun. Germ. 36. t. 4. Herbst. Jablonsk. v. 368. 91. t. 58.f. 17. Mant. Eng. Ent. t. 13. 20.

Coc. aptera. Payk. Faun. Suec. ii. II. II.

Long. corp. ' $\mathrm{I} \frac{\mathrm{T}}{2}$ lin.'

\section{Habitat}

DESCR. Elytra rufa, immaculata. Thorax ruber, disco medio fuscescente. Subtùs nigra est. Pedes antici ferruginei. Frons maculâ albâ tricuspidi, Linn.

Variat pedibus omnibus ferrugineis.

2. Coc. coleoptris rubris : maculâ subannulari annulata. nigrâ.

Linn. Syst. Nat.579.5. Vill. i. 94. 2. Gmel. 1646.5. Fab.Sp.Ins. i. 94. 8. Mant. i. 53. I1. Ent. Syst, i. a. 268. 14. Panz. Ent. Germ. 134. 7.

Coc. dispar var. ?. Payk. Faun. Suec. ii. 17. 18.

Herbst. Jablonsk. v. 340. var. 4 .

Long. corp. $2 \frac{3}{4}$ lin.

\section{Habitat}

Descr. Media, nigra. Thorax marginibus lateralibus pallidis. Elytra sanguinea; in medio fascia nigra, posteriùs fascia alia, quæ non tangit marginem exteriorem, sed exteriùs connectitur cum priore fasciâ. Syst. Nat.

3. Coc. coleoptris rubris : fasciâ mediâ atrâ. unifasciata. Fab. Gen. Ins. Mant. 2т6. Sp. Ins. i. 94.7. Mant. i. 53. 10. Ent. Syst. i. a. 268. 13. Vill. i. 106. 30. Gmel. 1646. 58. Panz. Ent. Germ. 134.6. Mart. Eng. Ent. t. 13.f.24.

Coc. dispar var. \%. Payk. Faun. Suec. ii. I7. 18.

Long. corp. $2 \frac{1}{4}$ lin.

Habitat 
Descr. Caput et thorax atra, immaculata. Elytra rubra, fasciâ mediâ latâ, atrâ, quæ suturam tamen haud attingit, et ad marginem punctis duobus parvis terminatur. Lineola parva obliqua nigra ad scutellum. Corpus atrum. Fab.

$V$ ariat punctis duobus capitis, thoracisque margine albis. Fab.

margine- 4. Coc. coleoptris flavis: margine albido; puncpunctata. tis duobus nigris.

Fab. Ent. Syst. i. a. 268. I I.

Long. corp. 2 lin.

Habitat -

DEscr. Caput flavum. Oculi nigri. Thorax flavus, punctis quinque nigris; duobus anterioribus, tribus posterioribus, intermedio minuto. Elytra sordidè fulva, sive flava, margine exteriore luteo, sive albido, puncto medio minuto, nigro. Corpus nigrum. Pedes anusque rufo-fulvi.

2-punctata. 5. Coc. coleoptris rubris: punctis nigris duobus.

Linn. Syst. Nat.580.7. Faun. Suec.471. Vill.i.94.4. Gmel.1647.7. Scop.234. Scbrank, 94. Fab. Syst. Ent. 79. 6. Sp. Ins. i. 94. 10. Mant. i. 54. I6. Ent. Syst. i. a. 270. 21. Scop. 234. Petagn. Ins. Cal. 8. 33. Poda Mus. Grac. 24. I. Faun. Fred. 6. 46. Act. Nidros. iv. 318.6. Bradl. Natur. t. 27. f.4. Panz. Ent. Germ. 134:9. Faun. Ingr.50. I51. De Geer, v. 369. 2. Geoff. i. 320. I. Faun. Etrusc. I50. Hellw. I50. Harr. 154.

Sulz. t. 3.f.3. Herbst. Jablonsk. v. 337.85.t.58.f. I. Scbaff: Icon. t.9.f. 9. Mart. Eng. Ent.t. I3.f. I7. Coc. dispar var. a. Payk. Faun. Suec. ii. I7. I8.

Long. corp. $2 \frac{1}{4}$ lin.

Habitat in Alro, ubi aphides devorat larva. Linn.

DEscr. Abdomen, antennæ, pedes et omnia terram spectantia, nigra. Thorax niger, maculâ laterali albâ : puncta duo alba minima ad basin thoracis, et totidem 
similia ad antennarum insertionem. Elytra rubra, puncto, in utriusque medio, nigro. Faun. Suec.

6. Coc. coleoptris rubris : punctis duobus nigris perforata. fissurâque elongatâ; margine nigro.

Long. corp. $2 \frac{x}{4}$ lin.

Habitat - Mus. D. Latbam.

Descr. Omnibus simillima C. 2-punctatce, fissurâ exceptâ.

An lusus ejusdem insecti ?

7. Coc. coleoptris flavis: punctis nigris quatuor. 4-punctata.

Linn. Syst. Nat.580. 9. Vill. i.96.6. Gmel. 1647.9. Fab. Syst. Ent.80. 10. Sp. Ins. i. 95. I6. Mant. i. 56. 28.

Long. corp. $2 \frac{i}{2}$ lin.

Habitat

Mus. D. Sbar.

DESCR. Thorax flavus, punctis 4 nigris. Elytra flava, punctis in medio 2 , ad singulum marginem singula, ita ut omnia 4 puncta in medio transversim posita sint. Subtùs nigra, pedibus flavis. Linn.

8. Coc. coleoptris sanguineis: punctis nigris 5-punctata. quinque.

Linn. Syst. Nat.580. II. Faun. Suec.474. Vill. i. 96. 8. Gmel. I647. II. Scop. 96. Scbrank, 96. Fah. Syst. Ent. 80. II. Sp. Ins. i. 96. 17. Mant. i. 56. 31. Ent. Syst. i. a. 273. 36. Laich. II5. 2. De Geer, v. 370. 3. Geoff.i.390. 2. Faun. Fred. 6. 47. Panz. Ent. Germ. 136. 15. Faun. Etrusc. 152. Hellw. 152. Faun.Ingr.51. I54. Harr. 155. Payk. Faun. Suec. ii. I6. I6.

Scbaff. Icon.t.9.f. 8. Scriba, 94. 21. t. 8.f. 7. Mart. Eng. Ent. t. I3. f. 26.

Long. corp. $2 \frac{3}{4}$ lin.

Habitat in hortis passim.
L 4
DESCR. 
DEscr. Elytra rubra, singula punctis duobus, et uno communi ad basin. Thorax niger angulis anticis albis. Hellw.

6-punctata. 9. Coc. coleoptris fulvis: punctis nigris sex.

Linn. Syst. Nat.580. 12. Vill. i. 97.9. Gmel. 1648. 12. Scbrank, 97. Fab.Sp.Ins. i.96.18. Mant.i.56.33. Ent. Syst. 1. a. 274. 38. Panz. Ent. Germ. 137. I7. Faun. Ingr. 51. 155 .

Mart. Eng. Ent. t. I3.f. I5.

Long. corp. $2 \frac{x}{4} \operatorname{lin}$.

Habitat -

DEscr. Thorax pallidus, maculis 5 subfuscis. Elytra fulva, punctis 3 nigris, transversim positis in medio. Margo exterior elytrorum flavus. Linn.

7-punctata. Iо. Coc. coleoptris rubris: punctis nigris septem. Linn. Syst. Nat. 581. I5. "Faun. Suec. 477. Vill. i. 98. 12. Gmel. 1649. I5. Scbrank, 98. Fab. Syst. Ent. 81. I3. Sp.Ins. i. 96.21. Mant. i. 57.36. Ent. Syst. i. a. 274. I8. Scop. 235. Faun. Fred. 6. 49. Poda Mus. Grac. 24.3. Pelagn. Ins. Cal. 8. 34. Act. Nidros. iii. 388.5 Panz. Ent. Germ. 137. 18. Faun. Etrusc. 153. Hellw. T53. Faun: Ingr, 51. 156. Harr. I56. Payk. Faun. Suec. ii. 5. 5 . Laich. I16. 3 .

De Geer, v.370.4.t. 10.f. I4. Albin. Ins. t.6I. a, b, c. Roes. 2. Scar. 3.t. 2.f. I-3. Donov. Brit. Ins.t. 39. f. 5. Admiral. Ins.t. I3. Herbst. Jablonsk. v. 3I 7.76. t. 57.f. 8. Bergstraes. Nom. 9. 53.7.t.9.f.7. Sulz. Cbar. Ins. t. 3.f. I3. Frisch. 4. t. I.f. 4. Scbaff: Icon. $t \cdot 9 \cdot f \cdot 7$.

Long. corp. 4 lin.

Habitat in plantis frequertissimè, aphides devastans.

DESCR. Caput nigrum, fronte punctis duobus albis. Thorax niger, utrinque ad latera albus. Elytra rubra, in singulo puncta tria nigra, æqualiter remota; et ad 
basin elytrorum punctum utraque elytra conjungens nigrum, anticè album. Antennæ minimæ, clavatæ. Animal subtùs atrum. Larva cinerea: maculis nigris et albis adspersa. Pupa lutea, maculis nigris et quasi deusta, ano adfixa. Faun. Suec.

I I. Coc. coleoptris rubris : punctis septem nigris, 7-notata. thoracis margine punctisque duobus albis.

Fab. Ent. Syst. i. a. 275.43. Panz. Ent. Germ. 137. 20.

Coc. mutabilis. Payk. Faun. Suec. ii. 39, 40.

Scriba, 96. 22. t. 7.f. 8 .

Coc. constellata. Laicb. 121. 6.

Long. corp. 2 lin.

Habitat

DESCR. Etsi coleoptra puncta septem nigra gerunt, at profectò a $C$. septem-punctatâ omnino differt. In utroque elytro puncta tria nigra, at postica omnia; punctum primum majusculum, duo exteriora parva, et punctum commune ut in C. septem-punctatâ ad basin situm est. Thorax differentiam clat certissimam, nam macula quæ ferè totum occupat, anticè quadriloba est; margo anticus flavus.

I2. Coc. coleoptris rubris: punctis quinque li-lineolata. neolisque humeralibus duabus nigris.

Long. corp. 2 lin.

Habitat Capta prope Holt in Norfolciâ. D. Burrell.

DESCR. Caput nigrum, punctis duobus flavis. Thorax niger, angulis anticis flavis. Elytra rubra sive fulva, puncto communi scutellari, et in singulo lineolâ longitudinali nigrâ ad basin, puncto unico in medio, et altero minùs posticè.

I3. Coc. coleoptris rubris : punctis nigris octo. Fab. Syst. Ent. 81. I4. Sp. Ins. i. 97.23. Mant. i. 57.38. Ent. Sysí. i. a. 275.44. Vill. i. 107.34. 
Gmel.1650.79. Panz.Ent. Germ.138.21. Laich. II 8 . 4 .

Mart. Eng. Ent. t. $13 \cdot f$. 19 .

Long. corp. $2 \frac{1}{4}$ lin.

Habitat in plantis frequentissimè.

DEscr. Caput albicans, punctis duobus nigris in fronte. Thorax albicans, punctis quinque nigris ad basin, et unico utrinque ad marginem. Elytra rubra, punctis quatuor nigris, quorum unicum ad basin et tria in medio. Fab.

9-punctata. 14. Coc. coleoptris rubris: punctis nigris novem. Linn. Syst. Nat.581. I6. Faun. Suec.478. Vill. j. 99. 14. Gmel.1651. I6. Scop.236. Scbrank, Io0. Fab. Syst. Ent. 81. 16. Sp. Ins. i. 97.27. Mant. i. 57. 42. Ent. Syst. i. a. 276. 48. Geoff. i. 322, 4. De Geer, v.373.6. Panz. Ent. Germ.38.22. Herbst. Jablonsk. v. 372. I02. Faun. Etrusc. I54. Hellw. I 54 .

Coc. collaris var. B. Payk. Faun. Suec. ii. $37 \cdot 37$. Long. corp. $2 \frac{\pi}{2}$ lin.

Habitat in plantis. Mus. D. Beckwith.

DEscr. Caput punctis duobus albis in fronte. Thorax niger, maculis solitariis lateralibus albis. Elytra singula punctis nigris duorum parium, et communi baseos nigro, anticè albo. Faun. Suec.

Io.punctata. I5. Coc. colcoptris fulvis: punctis nigris decem, Linn. Syst. Nat.58r. I7. Faun. Suec.479. Vill. i. 99. 15. i. 108. II. Gmel. 1651. 17. Fab. Syst. Ent.82. 17. Sp. Ins. i. 98. 28. Mant. i. 57.43. Ent. Syst. i. a. 276.49 . De Geer, v. 374. 7. Faun. Fred. 6. 51. Panz. Ent. Germ. 138.23. Faun. Ingr. 52. ${ }^{2} 5$.

Herbst. Jablonsk. v. 347.87.t. 58.f. I2.

Long. corp. $2 \frac{\mathrm{t}}{2}$ lin.

Habitat in plantis.

DESCR. Caput nigrum, maculâ albâ frontis tridentatâ. Thorax 
Thorax maculis quatuor albidis. Elytra fulva, margine exteriore flavo, notata puncto nigro ad basin, tribusque transversim positis in medio, et minimo ad apicem elytri. Pedes pallidi. Faun. Suec.

I6. Coc. coleoptris rubris : punctis nigris undecim. Ir-punctata. Linn. Syst. Nat.581. 18. Faun. Suec. 480. Vill. i. 100. 16. Gmel.1651. 18. Scbrank, Ior. Fab. Syst. Ent. 82. 19. Sp. Ins. i. 98. 31. Mant. i. 57. 46. Ent. Syt. i. a. 277.53. De Geer, v. 375. 8. Faun. Fred. 6. 52. Panz. Ent. Germ. 139. 24. Faun. Ingr. 52. 159. Faun. Etrusc. ${ }^{156 .}$ Helliw. 156. Act. Nidros. iii. 388. 6. t.6.f. 2. Herlst. Jablonsk. v. 352. 88. $t$. I8. $f$. I3.

Coc. collaris var. $\gamma$. Payk. Faun. Suec. ii. $37 \cdot 37$.

Long. corp. $2 \frac{x}{2}$ lin.

Habitat in sepibus.

DESCR. Puncta in singulo elytro quinque parva: sextum majus est, sese extendens ad utrumque elytron. Thorax niger, punctis duobus albis. Faun. Suec.

I7. Coc. colcoptris rubris: punctis nigris un- II-notata. decim margine basi flavo, corpore nigro.

Long. corp. 2 lin.

Habitat _ Capta in Horto Kensingtoniano, Julio.

DesCr. Caput flavum, margine antico et punctis duobus nigris. Thorax flavus, punctis quinque nigris. Elytra rubra, puncto baseos communi bilobo, unicoad basin, tribus in medio transversim positis, et altero apicem versus. Margo elytrorum anticè flavus. Corpus nigrum, pedibus flavis.

18. Coc. coleoptris flavis: punctis nigris duo- I2punclata. decim; extimis linearibus repandis.

Linn. Syst. Nat.581. 19. Vill. i. 100. 17. Fab. Syst. 
Ent. 82. 20. Sp. Ins. i. 98.32. Mant.i. 57. 48. Ent. Syst. i. a. 278.55. Panz. Ent. Germ.139. 25. Harr. 160. Payk. Faun. Suec. ii. 23. 24.

Herbst. Jablonsk. v. 357.90. t. 58. f. I6.

Coc. 16-punctata? Linn. Syst. Nat.582. 22. Faun. Suec. 483. Gmel. 1653. 22.

Long. corp. $1 \frac{x}{3} \operatorname{lin}$.

\section{Habitat}

DESCR. Thorax flavus, punctis maculisque duabus nigris. Elytra flava: puncta 5 nigra, præter exterius, quasi ex 4 punctis connatum, lineare, repandum, ad narginem exteriorem, inter primum et ultimum punctum. Sutura longitudinalis nigra. Subtùs nigra, tibiis flavis. Syst. Nat.

3-punctata. I 9. Coc. colcoptris luteis: punctis nigris tredecim, corpore oblongo.

Linn. Syst. Nat. 582. 20. Faun. Suec.481. Vill. i. 101. I8. Gmel. I653.20. Scop. 238. Scbrank, 102. B. Fab. Syst. Eint. 83.25. Sp. Ins. i. 99.38. Mant. i. 58. 54. Ent. Syst. i. a. 279. 6r. Panz. Ent. Germ. 139.27. Geoff. i. 324. 7. De Geer, v. 375. 9. Faun. Fred. 6. 53. Act. Nidros. iv.318.7. Faun. Etrusc. 157. Hellw. I57. Faun.Ingr. 52. I60. Payk. Faun. Suec. ii. 4.2. 44.

Scbaff. Icon. t. 48.f.6. Herbst. Jablonsk. v. 323. I3. t. $57 \cdot f$. II.

Long. corp. 3 lin.

Habitat in Armoracia.

DESCR. Corpus magnitudine inter maximas et minimas medium. Thorax niger, lateribus utrinque albis, cum puncto nigro. Elytra lutea: puncta in singulis sex nigra, quorum duo in medio elytri ferè contigua; unicum punctum nigrum ad basin elytri connectit utramque crustam, adeoque impar est. Abdomen ad latera luteum. Antennæ, os et tibiæ luteæ. Femora nigra. Faun. Suec.

20. Coc. 
20. Coc. coleoptris flavis: punctis nigris tredecim, I 3-macucorpore orbiculato.

Fab. Syst. Ent. 83. 24. Sp. Ins. i. 99.37. Mant. i. 58. 53. Ent. Syst. i. a. 279. 60. Vill. i. 107. 35. Gmel.1652.90. Geoff. i. 324. 8.var. Forst. Cent.18. Panz. Ent. Germ. 139.25. Herbst. Jablonsk. v.351. var. 9 .

Mart. Eng. Ent. t. I3.f. 18.

Long. corp. 2 lin.

\section{Habitat}

Descr. Distincta sanc̀ a C. I3-punctatá, tota ferè orbiculata. Thorax albus, maculis quatuor nigris. Coleoptra flava, punctis nigris 13 , nempe, 1, 3, 2, et communi. Fab.

21. Coc. coleoptris flavis : punctis nigris quatuor-14-punctata. decim; quibusdam contiguis.

Linn. Syst. Nat.582.21. Faun. Suec. 482. Vill. i. 101. 19. Gmel. 1653. 21. Scbrank, 104. Fab. Syst. Ent. 83. 26. Sp. Ins. i. 99. 39. Mant. i. 58. 56. Geoff. i. 328. 15. Poda Mus. Grac. 25. 4. Faun. Fred. 6. 54 .

Herbst. Jablonsk. v. $334 \cdot$. 84. t. $57 \cdot f \cdot 16$.

Coccinella conglomerata var. Fab. Ent. Syst. i. a. 282.75 .

Coccinella tessulata. Scop. 243.

Long. corp. $2 \frac{x}{4} \operatorname{lin}$.

Habitat in Salice.

Descr. Elytra flava, quorum in singulo puncta duo paria oblonga, distincta suturâ longitudinali nigrâ, cum quâ unicum in singuli elytri medio connatum, quadrangulare; dein aliud connatum cum opposito in formam trianguli: punctum terminale elytri etiam adnexum suturæ longitudinali. Thorax a tergo posticè tectus maculâ magnầ nigrâ antrorsùm tetralobâ. Faun. Suec.

22. Coc. coleoptris luteis: suturâ punctisque I4-macuquatuordecim nigris distinctis. 
fava. 27. Coc. coleoptris pedibus thoracisque lateribus flavis.

Long. corp. $\mathrm{I} \frac{\mathrm{r}}{2}$ lin.

Habitat

DESCr. Caput flavum, punctis mediis nigris. Thorax ater, margine anticè lateribusque flavis. Coleoptra flava, sive testacea, immaculata. Corpus subtùs ferè omninò atrum. Pedes et antennæ testaceæ.

sinuata. 28. Coc. coleoptris rubris: punctis in utroque elytro duobus tetragonis confluentibus; tertio rotundo remoto.

Act. Acad. Suec. 1792. 171. 4. t. 7 .

Long. corp. 2 lin. -

Habitat

Mus. D. Jones.

DESCR. Thorax niger, lateribus ad basin flavis. Elytra rubra, suturâ ad basin nigrâ. Puncta in hoc animalculo admodum singularia : duo basin versus tetragona confluentia, maculam quasi irregularem efficiunt; tertium post medium rotundum remotum; lineola autem nigra ab hoc priora versus ducitur, nec attingit. Puncta simul sumpta quasi notum interrogationis indicant.

simuosa. 29. Coc. coleoptris fulvis : vittis duabus abbreviatis sinuosis punctoque utrinque atris.

Long. corp. 2 lin.

Habitat

Descr. Caput atrum, punctis duobus lutescentibus. Thorax ater, anguis ancicis flavis. Elyira rufo-fulva, vittâ mediâ sinuatá, posticè abhreviatâ, pun to rotundo laterali apicem versus, lineuluqua coum baseos atris. 
* Coleoptris rubris flavisve: albo maculatis.

30. Coc. coleoptris luteis : punctis albis decem. ro-guttata.

Linn. Syst. Nat. 583. 33. Vill. i. 108. 44. Gmel. 1659. 33. - Rai. 86. 3. Fab. Syst. Ent. 85. 37. Sp. Ins. i. 102. 51. Mant. i.60.73. Ent. Syst. i. a. 284. 82. Panz. Ent.Germ. 143. 4I. Faun. Ingr. 54. I65. Laich. 132. I3.

Don. Brit. Ins. t. 243. f. I. Herbst. Jablonsk. v. 376. 105. t. 59.f. I. Mart. Eng. Ent. t. I3.f. 23 .

Long. corp. 2 lin.

Habitat

DESCR. Puncta in singulo elytro 5 ; scilicet $2,2, \mathrm{I}$. Linn.

3. Coc. coleoptris rufis: punctis quatuordecim I4-guttata. albis.

Linn. Syst. Nat. 583. 34. Faun. Suec. 492. Vill. i. I09. 14. Gmel. 1659.34. Fab. Syst. Ent. 85.38. Sp.Ins, i. 102. 52. Mant, i.60.74. Ent. Syst. i. a. 284.85. Scop.248. Scbrank, 112. Geoff. i. 327.13. De Geer, v. 385. 20. Panz. Ent. Germ. I44. 44. Harr. 165. Faun. Ingr. 54. 166. Goeze E. B. i. 227. 34. Payk. Faun. Suec. ii. 21. 20. Poda Mus. Grac. 25. 7. B. Laich. 132. 14.

Scloaff: Icon. t. 9.f. I I. Herbst. Jablonsk. v. 376. I0\%. t. 59.f. 3. Mart. Eng. Ent. t. I3.f. 28.

Long. corp. $2 \frac{3}{4}$ lin.

Habitat in nemoribus et hortis.

DESCR. Thorax ruber, lineolâ albâ longitudinali in medio, et maculâ utrinque albâ. Elytron singulum notatur 7 punctis, eo ordine a thorace versus caudam numerando puncta, ut I, 3, 2, I. Faun. Suec.

32. Coc. colcoptris luteis: punctis albis sedecim. 16-guttata. Linn. Syst. Nat. 584. 35. Faun. Suec.493. Vill. i. I09. 46. Gmel. 1659. 35. Scop. 249. Fab. Syst. Ent. 85. 39: Sp. Ins. i. 103.54. Mant. i. 60. 76. VOL. I. 
Payk. Faun. Suec. ii. 36. 36. De Geer, v. $3^{85} \cdot 21$. Panz. Ent. Germ. 145. 47. Faun. Ingr. 54. 167. Herbst. Jablonsk. v. 379. I 10. t. 59.f.6. Mart. Eng. Ent. t. $13 \cdot f \cdot 27$.

Long. corp. 3 lin.

Habitat

In mus. D. Beckwith.

Descr. Thorax luteus, maculis 5 flavis, absque ullâ lineâ intermediâ. Elytron singulum luteum notatur punctis octo, a thorace numerando $2,3,2, x$. Caput flavum. Faun. Suec.

18-guttata. 33. Coc. coleoptris rubris : punctis albis octodecim; duobus primis lunatis.

Linn. Syst. Nat. 584.36. Faun. Suec. 494. Vill. i. I09. 47. Gmel. 1660. 36. Fab. Sp. Ins. i. 103. 55. Mant.i. 60.77. Ent. Syst. i.a.285.89. Scop.24I. Payk. Faun. Suec. ii. 39. 39. Panz. Ent. Germ. 145. 48. Poda Mus. Grac. 25. 8. Harr. 166. Goeze E. B. i. 24I. 23 .

Herbst. Jablonsk. v. 378 . Iog. t. 59.f.5.

Long. corp. 2 lin.

Habitat in Pinu — Capta prope Barton. D. Sheppard.

Descr. Caput rubrum, punctis duobus albis inter oculos. Thorax ruber, maculis magnis lunulatis albis ad margines, inter has maculas puncta duo alba contigua prope apicem. In singulis elytris, quæ rubra sunt, puncta novem sunt alba, quorum primum ad basin prope suturam lunulatum est.

ollongo-34. Coc. coleoptris rubris: lincis punctisque guillata. albis.

Linn. Syst. Nat. 584.38. Faun. Suec. 496. Vill. i. 110. 49. Gmel. 1660.38. Scop.242. Scbrank, 112. Fub. Sp. Ins. i. 103. 57. Mant. i.60.79. Ent. Syst. i. a. 296. 9r. De Geer, v. 384. 19. Panz. Ent. Germ. I46.50. Harr. 168. Goeze E. B. i. 229. 38. Payk. Faun. Suec. ii. 14. I4. Laicb. I3I. I2. Herbst. 
Herbst. Jablonsk. v. 380. II . t. 59.f. 7. Scbaff. Icon. t. 9. f. 10. Bergstraess. Nom. t. 9.f.6. Mart. Eng. Ent. t. 13. $f \cdot 25$.

Long. corp. 4 lin.

Habitat in Pinu sylvestri.

DESCR. Elytra et thorax rubra; latera thoracis utrinque alba: singulum elytron notatur duabus lineolis longitudinalibus albis, quarum interior puncto albido aucta est, vel in medio interrupto, duobus punctis oblongis constans. Faun. Suec.

** Coleoptris nigris : rubro maculatis.

35: Coc. coleoptris nigris: lunulâ punctoque ru-4-verrucata. bris, margine prominulo.

Fab. Ent. Syst. i. a. 288. 104. Payk. Faun. Suec. ii. 26. 27.

Coc. cassidoides. Don. Brit. Ins. t. $243 \cdot f \cdot 3$.

Geoff. i. 333. 25 .

An De Geer, v. t. ro.f. 25 ?

Long. corp. $\mathrm{I} \frac{3}{4}$ lin.

Habitat

Descr. Corpus fere orbiculare. Margo exterior prominulus. Totum corpus nigrum, præter abdominis marginem maculasque elytrorum, quæ rubræ sunt. Macularum altera major ad basin prope marginem exteriorem lunulam sive comma referens, altera minor pone medium ad suturam, tetragona, oblonga.

36. Coc. coleoptris atris: maculis rubris duabus. Cacti.

Linn. Syst. Nat. 581. 44. Gmel. 166r. 4r. Fab. Syst. Ent. 85. 44. Sp. Ins. i. 104. 60. Mant. i. 60.83. Ent. Syst. i. a. 287.99.

Long. corp. 2 lin.

Habitat

Descr. Similis C. bipustulate, etiam abdomine rubro, sed macula elytrorum longè major, simplicissima. Linn.

Obs. 
Obs. In medio baseos elytrorum tuberculum sive punctum prominulum.

bipustulata. 37. Coc. coleoptris nigris : punctis rubris duobus margine prominulo, abdomine sanguineo.

Linn. Syst. Nat. 585. 42. Faun. Suec. 498 . Vill. i. II 2. 54. Gmel. 166r. 42. Scbrank, II5. Fab. Syst. Ent. 86. 45. Sp. Ins. i. 104. 61. Mant. i. 60.84. Ent. Syst. i. a. 287. 100. De Geer, v. 387.23. Panz. Ent. Germ. 147. 57. Faun. Etrusc. 169. Hellw. 169. Faun. Ingr. 55. 168. Payk. Faun. Suec. ii. 24. 25 .

Herbst. Jablonsk.v. 383. 115. t. 59.f. I1. Mart. Eng. Ent.t. I3. $f$. 2 I.

Long. corp. $1 \frac{3}{4}$ lin.

Habitat

Descr. Ferè orbiculata, tota nigra, nitida, margine prominulo. Thorax absque maculis. Elytron singulum in medio fert maculam, sive punctum latum, sanguineum, sæpè ex tribus punctis conflatum. Abdomen inferiùs rufescit. Aliàs tota subtùs nigra. Tergum sub elytris etiam sanguineum. Pupa hispida est. Faun. Suec.

4-pustulata. 38. Coc. coleoptris nigris: punctis rubris quatuor; interioribus longioribus.

Linn. Syst. Nat. 585.43. Faun. Suec. 499. Vill. i. II2. 53. Gmel. I662. 43. Scop. 244. Fab. Syst. Ent. 86. 46. Sp. Ins. i. 104. 63. Mant. i. 61. 87. Ent. Syst. i. a. 288. 103. Scbrank, II7. Geoff. i. 333.25. De Geer, v. 389. 24. Poda Mus. Grae. 25. 4. Panz. Ent. Germ. 150.67. Faun. Etrusc. I7I. Hellw. I7I. Harr. 103.169. Goeze E. B. i. 232.43 .

Long. corp. $2 \frac{7}{4}$ lin.

Habitat in Urticis.

Descr. Ovata, nitida, atra. Caput atrum. Thorax ater, cum pari punctorum excavatorum a tergo. Elytra nigra, singula juxta basin ad marginem exteriorem maculâ 
maculâ minori rubrâ cum puncto ferrugineo, et aliâ minori, in medio elytri, versus marginem interiorem, itidem rubrâ. Anus ruber est. Faun. Suec.

39. Coc. coleoptris nigris : punctis rubris sex. 6-pustulata. Linn. Syst. Nat. $5^{8} 5 \cdot 44 . \quad$ Faun. Suec. 500 . Vill. i. II3.56. Gmel. 1663.44. Fab. Syst. Ent. 85. 47. Sp. Ins. i. 105. 64. Mant. i. 61. 89. Ent. Syst. i. a. 289.87. Scop. 245. Scbrank, ri9. Geoff.i.331.20. De Geer, v. 390. 25. Faun. Fred.7.58. Poda Mus. Grac. 25. 9. Panz. Ent. Germ. 151. 72. Faun. Etrusc. 172. Hellw. 172. Harr. 104. 170. Goeze E. B. i. 232. 44. Faun. Ingr. 55. 169.

Donov. Brit. Ins. t. 39.f. 3. Mart. Eng. Ent. t. ${ }_{3}$. f. 22 .

Long. corp. $2 \frac{x}{2}$ lin.

Habitat in arboribus.

Descr. Thorax totus niger. Elytra atra, nitida, singula tribus punctis sanguineis, quorum quod thoraci proximum majus est; ultimum punctum versus ipsum apicem elytri situm, at intermedium propius margini interiori, quam exteriori collocatum. Faun. Suec.

40. Coc. coleoptris nigris : punctis rubris septem. 7-pustulata. Long. corp. $2 \frac{1}{4}$ lin.

\section{Habitat}

Descr. Caput nigrum, maculis duabus flavis inter oculos. Thorax niger, margine anteriori flavo. Elytra atra, nitida, singula maculis quatuor sanguineis, quarum una magna dorsalis communis. Hinc coleoptra primâ facie 7-pustulata apparent.

4I. Coc. coleoptris nigris: punctis fulvis de-ro-pustiicem. lata.

Linn. Syst. Nat. 585. 45. Faun. Suec. 501. Gmel. 1663. 45. Vill. i.113.57. Fab. Syst. Ent.87. 49. Sp. Ins. i. 105. 66. Mant. i.6I. 91. Ent. Syst. i. a. 
289. I09. Scbrank, I20. Rai. 87. 15. Geoff: i. 330. I9. De Geer, v. 391.26. Panz. Ent. Germ. I5.73. Faun. Etrusc. I75. Hellw. I75. Harr. I05. I72. Faun. Ingr. 55. 170. Goeze E. B. i. 233. 45. Laich. 138.18.

Herbst. Jablonsk. v. 387. I20. $t$. 59. f. 16. Schaff. Icon. $t$. I' I. $f$. 20.

Coc. variabilis. Payk. Faun. Suec. ii. 31. 33. var. ?.

Long. corp. 2 lin.

Habitat in hortis.

Descr. Puncta elytrorum 2, 2, I : duo baseos lunata, interdum connata. Pedes fulvi. Hellw.

bimaculata. 42. Coc. tomentosa, coleoptris nigris : maculis duabus rufis.

Long. corp. $I \frac{x}{4}$ lin.

Habitat

Descr. Antennæ et os rufa. Totum corpus nigrum. Coleoptra maculis duabus rufis. Pedes rufi, femoribus nigris. Sub lente tomentosa videtur.

bumeralis. 43. Coc. coleoptris nigris: punctis duobus baseos rubris, thorace immaculato, pedibus omnibus testaceis.

Coccinella : Scymnus bipustulatus. Panz. Faun. Germ. 24. $t$. 10.

Long. corp. I lin.

Habitat in floribus.

DEscr. Thorax et elytra villosula. Maculæ coleoptrorum ovatæ sunt, et prope basin horum cernuntur. Pedes omnes obscurè testacei. Panz.

biliturata. 44. Coc. tomentosa, capite ferrugineo, coleoptris nigris : lituris duabus ferrugineis, pedibus testa. ceis.

Long. corp. I lin. 
Descr. Antennæ, caput et pars antica thoracis ferruginea. Pars postica thoracis et elytra nigra. Elytra liturâ apiceque ferrugineis. Pedes testacei. Corpus sub lente tomentosum.

45. Coc. tomentosa nigra, capite thorace utrinque 4-maculata. coleoptrorumque punctis quatuor rufis.

Long. corp. $I \frac{T}{2}$ lin.

Habitat

DeSCr. Corpus ferè hemisphæricum. Oculi nigri. Thorax utrinque anticè rufus. Elytra maculâ disci majore et alterâ ante apicem minore rufis. Tarsi rufi. Variat interdum capite flavo.

46. Coc. tomentosa, coleoptris nigris : punctis qua- bis-bipustuor rubris, capite thoraceque nigris immacnlatic. tulata.

Fab. Ent. Syst. i. a. 288. 105.

Panz. Faun. Germ. 13. t. 5 .

Long. corp. I lin.

Habitat

DESCr. Præcedenti minor. Caput et thorax nigra. Elytra nigra, maculâ oblongâ, obliquâ, basi propiore, alterâ subrotundâ infra apicem. Pedes antici rufi.

47. Coc. coleoptris atris, rapite thoracis lateribus parvula. pedibusque testaceis.

Fab. Ent. Syst. i. a. 286. 94.

Panz. Faun. Germ. 13. t. 2.

An Scymnus collaris? Hersbst. Jablonsk. vii. 345. 9. t. II6.f. 9 .

Long. corp. $\frac{3}{4}$ lin.

Habitat in horto Kensingtoniano, in lignis vetustis.

Descr. Totum corpus atrum, minimè nitens. Caput testaceum. Oculi nigri. Thoracis latera et pedes testacea. Elytra sub lente punctulis minutissimis plurimis conspersa.

$$
\text { M } 4 \text { 48. Coc. }
$$


fulvifrons. 48. Coc. atra, fronte fulva.

Long. corp. $\frac{3}{4}$ lin.

Habitat in agris aridis, in umbrosis, Ang.

DESCR. Totum corpus aterrimum. Frons sola fulva, sive ferruginea. Affinis C. parvulae, a quâ differt, thorace immaculato, nec lateribus flavis. Pedés præcipuè postici flavescentes.

bamorrboi-49. Coc. atra, fronte elytrorum apicibus pedibusdalis.

\section{que fulvis.}

An Scymnus hæmorrhoidalis? Herbst. Jablonsk. vii. 342. 4. t. $116 . f \cdot 4$.

Long, corp. $\frac{7}{8}$ lin.

\section{Habitat}

Ex mus. D. Kirby.

DESCR. Corpus totum aterrimum, minimè nitens. Caput flavum. Oculi nigri. Thoracis latera præcipuè ad basin fulva. Elytra atra, apicibus fulvis. Pedes flavescentes. Affinis C. parvula et C. fulvifronti, a quibus differt, elytris apicibus fulvis.

**** Coleoptris nigris: albo-flavove maculatis.

humularis. 50. Coc. coleoptris nigris: maculâ lunari albidâ. An Coc. renipustulata? Scriba, 105. 27. t. 8. f. I4. Long. corp. 2 lin.

Habitat

Descr. Corpus orbiculatum, nitidissimum. Caput atrum, maculis 2 albis inter oculos. Thorax ater, marginibus albis. Macula coleoptrorum lunaris magna ad basin, punctum etiam minutissimum obsnletum ad marginem exteriorem prope apicem situm est. Abdomen subtùs atrum, nitidissimum. Pedes flavescentes.

I2-pusiu- 5I. Coc. coleoptris nigris: punctis duodecim allata. bis; exterioribus margine connexis.

Fab.Gen.Ins. Mant.219. Sp. Ins, i, 106.67. Mant. i. $6 \mathrm{I}$. 
i. 61. 92. Ent.Syst.i. a. 290. 110. Vill.i. I15. 62. Gmel. 1665. I50. Panz. Ent. Germ. 152.74. Faun. Etrusc. 173. Hellw. I73. Harr. 173.

Scbaff. Icon. $t .30 . f$. I3.

Long. corp. 2 lin.

Habitat

D. Coyte.

Descr. Caput albidum, puncto frontali nigro. Thorax ater, margine antico et laterali pallido. Elytra atra, punctis sex albis 2, 3, I, tribus exterioribus margine connatis; punctum ultimum lunatum. $F a b$.

Obs. Ex coitu Coccinellarum inter omnes familias promiscuo, varietates plurimæ ortæ sunt. Nullam autem sneciem introduxi, quæ non suam formam in omni solo, et sub quocunque casu, constanter servat.

\section{CHR YSOMELA.}

Antenna moniliformes, extrorsùm crassiores. Caput insertum.

Thorax et Elytra immarginata.

Corpus ovatum, convexum.

* Thorace margine plano.

** Tborace margine utroque incrassato.

** Saltatoriæ, femoribus posticis crassissimis.

\section{* Tborace margine plaño.}

I. Chry. aptera atro-purpurea, punclis elytrorum tenebriuniformibus. cosa.

Fab. Syst. Ent. 94. I. Sp. Ins. i. II6. 1. Mant. i. 66. 1. Ent. Syst, i. a. 308.3. Panz. Ent. Germ. 156. 
156. 1. Faun. Etrusc. 186. Hellw. 186. Petagn. Ins, Cal. 9. 40. Harr. 230. Laicb. I5I. I. Schaff. Icon. t. 126. f. I. Elem. t. 1. f. 6. Panz. Faun. Germ. 44. t. 1. Mart. Eng. Ent. t. 16. f. 43 . Don. Brit. Ins. t. 276.

Chrysomela tenebrioides. Gmel. 1667. I.

La Chrysomele à un seul étui. Geoff.i. 265. I9.

Tenebrio lævigatus. Linn. Syst. Nat. 678. 29.

Long. corp. 8 lin.

Habitat in pratis, ericetis, \&zc.

Descr. Puncta elytrorum omnia ferè ejusdem magnitudinis, plerumque confluentia. Articuli tarsorum lati sunt, et subtùs testacei, tomentosi, sive holosericei.

coriaria.

2. Chry. aptera atro-purpurea, punctis elytrorum difformibus.

Fab. Ent. Syst. i. a. 309. 6. Panz. Ent. Germ. 156. 2. Laich. I43. 2.

Panz. Faun. Germ. 44. t. 2.

Long. corp. 4 lin.

Habitat in ericetis.

Descr. Hæc Cbry. tenebricose omnino similis ut ovum ovo, at ferè dimidio minor. Porro facillimè di. stinguenda est, si puncta elytrorum probè spectes : in Cbry. enim tenebricosâ puncta omnia ferè xqualia, et ex maximâ parte confluunt; in hâc autem valdè difformia sunt. Scilicet quædam majora sunt, quædam autem dimidio minora, majoribus interspersa; omnia distincta sunt, et rariùs confluunt.

iopa. 3. Chry. nigro-cærulea, elytris obscuris punctatis : punctulis confluentibus, pedibus violaceis nitidis.

Long. corp. $4 \frac{x}{2}$ lin.

Habitat

DESCR. Totum corpus suprà nigro-cæruleum, obscurum. Thorax punctulis minimis, at non confluentibus, adspersus. Elytra punctula majora exhibent, 


\section{CHRYSOMELA. $(*)$}

quae et sæpiùs confluunt. Corpus subtùs nigro-cæ ruleum, obscurım, punctatum. Pedes nitidi, violacei.

4. Chry. violacea, articulis infimis antennarumgettingentarsisque ferrugineis. sis.

Linn. Syst. Nat.586. 4. Faun. Suec. 506. Vill. i. II7. 1. Gmel. 1667. 4. Fab. Syst. Ent. 94. 2. Sp. Ins. i. 116.2. Mant. i. 67.3. Ent. Syst. i. a. 309. 8. Panz. Ent. Germ. 156.3. Faun. Ingr. 57. I76. Faun. Etrusc. Mant. 67. Hellw. Mant. 67. Faun. Fred. 7.60. Goeze, i. 25 I. 4. Payk. Faun. Suec. ii. 5 I. I.

Roes. ii. Scar. 3.t. 5.f. 4. ? Mart. Eng. Ent. t. 16. f. 4I. Panz. Faun. Germ. 44. t. 3. Don. Brit. Ins. $t .286 . f .2$.

Chrysomela violacea nigra. De Geer, v. 298. 8 .

Long. corp. $4 \frac{\pi}{2}$ lin.

\section{Habitat}

Descr. Tota violacea, articulis infimis antennarum tarsisque exceptis, qui ferruginei sunt. Elytra sub lente punctulata.

5. Chry. nigro-violacea, antennarum basi rufâ. bcemoptera. Linn. Syst. Nat.587. I1. Faun. Suec.512. Vill. i. 120.8. Gmel. 1672. II. Fab. Syst. Ent. 96.11. Sp.Ins. i. II8. I8. Mant.i. 68. 23. Ent. Syst. i. a. 315. 37. Panz. Ent. Germ. 158. 13. Faun. Ingr. 58. 179. Faun. Etrusć. 187. Hellw. 187. Petagn. ro. 44. Faun. Fred. 7.64. Goeze, i. 56. II. Payk. Faun. Suec, ii. 52. 2. Laich. 146. 5 .

Mart. Eng. Ent. t. 15.f. 22. Panz. Faun. Germ. 44. $t .7$.

Chry. Hyperici. De Geer, v. 312. 20. t. 9. f. I3.

La Chrysomele violette. Geoff: i. 258.5.?

Long. corp. $4 \frac{3}{4}$ lin.

Habitat

DESCR. Corpus suprà nigricans, sive sub-cærulescens; subtùs 
subtùs unà cum pedibus cæruleum. Antennæ nigræ, basi rufx.

Graminis. 6. Chry. viridi-cærulea nitida, antennis pedibusque concoloribus.

Linn. Syst. Nat. 587.7. Faun. Suec. 509. Vill. i. 118. 4. Gmel. 1670. 7. Scop. 220. Scbrank, 132. Fab. Syst. Ent. 96. 9. Sp. Ins. i. 118. 16. Mant. i. 68.21. Ent. Syst.i.a.314.33. Harr. 235. Faun. Fred. 7.61. Faun. Ingr. 58. 178. Faun. Etrusc. 195. Hellwu. 195. Panz. Ent. Germ. 158.11. Goeze, i.252.7. Poda, 26. I. Payk. Faun. Suec. ii. 63.16. De Geer, v. 304. 16.

Mart. Eng. Ent. t. I4. f. 10.

Le Grand Vertubleu. Geoff. i. 260. I0.

Long. corp. $4 \frac{3}{4}$ lin.

Habitat in gramine pratorum.

Descr. Tota e viridi et cæruleo colore sericea, sive aurata. Elytra margine parùm prominentia, et punctis minutissimis excavatis distinctis, nec contiguis, adspersa. Admodum convexa sunt hæc elytra, et proin subtùs magis concava. Antennæ et pedes virides. Abdomen viride. Faun. Suec.

Ani. 7. Chry. oblongo-ovata violacea, elytris punctis excavatis sparsis, antennis pedibusque nigris.

Iinn. Syst. Nat. 587. 9. Faun. Suec. 5II. Vill. i. 119. 6. Gmel. 1671.9. Scop. 211. Fab. Syst. Ent. 103.53. Sp. Ins. i. 128.72. Mant. i. 74. 97. Scbrank, I40. Faun. Fred. 7. 63. Faun. Etrusc. 199. Hellw. 199. Poda Mus. Greec. 26. 2. Goeze, i. 254.9. De Geer, v. 3 ז4. 2r. t. 9.f. 18.

Galleruca Alni. Ent. Syst. i. b. 16. 13. Faun. Ingr. 63. 127. Panz. Ent. Germ. I71: 4.

Le Gribouri bleu de l'Aune. Geoff. i. 232. I.

Long. corp. $3 \frac{1}{2}$ lin.

- Habitat in Betulâ Alno.

DESCR. 
Descr. Betula Chrysomelee adeo similis est, ut ovum ovo, modo major, et elytris quidem punctis excavatis, sed sparsis, nec uti Betulce in strias longitudinaliter digestis. Caput et thorax subtùs, uti et pedes et antennæ, nigra sunt. Color Viole martiæ odoratce. Faun. Suec.

8. Chry. suprà viridi-æenea, elytris cupreis per paria Hyperici. striato-punctatis: punctis alternis.

Forst. Cent. 20.

Chrysomela anglica. Gmel. 1689. 187.

An Chry. gemellata? Vill. i. 138.68. Hellw. Faun. Etrusc, Mant.72. Fourc. i. 110. 22.

Panz. Faun. Germ. 44. t. 6. Mart. Eng. Ent.t. 4. $f \cdot 9$.

An Chry. geminata? Payk. Faun. Suec. ii. 65. I9.

Long. corp. 3 lin.

Habitat in Hyperico perforato. D. Lyon.

DEscr. Antennæ fuscæ. Caput, thorax et scutellum viridi-ænea. Elytra cuprea, subobscura, novemstriata, striis octo exterioribus per paria dispositis, e punctis alternis distantibus, valdè excavatis, constantibus, interstitiis punctulatis. Corpus subtùs rufofuscum. Pedes æneo-fusci.

9. Chry. suprà cupreo-virens, elytris per paria Quinquestriato-punctatis : punctis oppositis. Long. corp. 3 lin.

Habitat

Descr. Præcedenti simillima, sed antennæ rufo. fuscæ, basi dilutiore. Elytra nitentia, decem-striata, striis per paria dispositis, e punctis leviter impressis, oppositis, constantibus, interstitiis punctulatis. Corpus subtùs nitens, piceo nigrum. Pedes nigro-ænei.

10. Chry. thorace viridi-æneo, elytris cupreis vagè Marshami. punctatis.

Don. 
Don. Brit. Ins, t. 286.f. I.

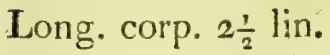

Habitat

Mus. D. MacLeay.

Descr. Simillima Cbry. Hyperici, at minor, et elytra vagè punctata sunt, nec striata. Antennæ fuscæ. Corpus subtùs cyaneum. Pedes cuprei. Femora viridiænea.

fastuosa. I I. Chry. aurata, colcoptris lincis tribus cæruleis. Linn. Syst. Nat. 588. 18. Vill. i. I22. 14. Gmel. 1674. 18. Scbrank, I75. Payk. Faun. Suec. ii. 64. 8. Fab. Syst. Ent. Ior. 36. Sp. Ins. i. 1 $24 \cdot 48$. Mant. i. 71. 60. Ent. Syst. i. a. 324. 80. Laich. 157. 15. Harr. 243. Panz. Ent. Germ. 162. 31. Faun. Etrusc. Mant.68. Hellw. Mant. 68. Goeze, i. 258.18 .

Don. Brit. Ins. t. 194. Scbaff. Iron. t. 21.f. 7. Panz. Faun. Germ. 44.t. I2, Mart. Eng. Ent. t. I4.f. II. I2. 13 .

Coccinella fastuosa. Scop. 232.

Long. corp. 3 lin.

Habitat in Lamio albo. Fab.

DEscr. Tota perfectè aurea. Linea cærulea longitudinalis in medio elytrorum, et unica communis in suturâ. Linn.

pallida.

I2. Chry. flavescens tota, oculis nigris.

Linn. Syst. Nat. 589. 25. Faun. Suec.521. Vill. i. 126. 21. Gmel. 1676. 25. Scbrank, 147. Fab. Syst. Ent. 99. 26. Sp. Ins. i. I22. 34. Mant. i. 70. 44. Ent. Syst.i. a.321.64. Panz. Ent. Germ. 161.27. Faun. Ingr.60. 187. Goeze, i. 261.25. Laich. I53. I2.

Mart. Eng. Ent. t. 16.f. 35 .

Le Criocère aux yeux noirs. Geoff. i. 2,43. 6.

Chry. dispar. Payk. Faun. Suec. ii. 66. 20.

Long. corp. 3 lin. 


\section{Habitat in Salicibus. Linn.}

DESCR. Color griseus, sive testaceus, toto corpore. Cbry. Stapbylece simillima, sed paulo minor. Plantæ pedum subtùs exalbescentes. Oculi nigri. Præcipua nota, quâ a Cbry. Stapbyleâ differt, (præterquam colore longè pallidiore) consistit in singulis elytris punctis per novem ordines longitudinaliter digestis, cùm in illâ puncta sparsa, nec per strias distributa. Faun. Suec.

I3. Chry. flava, thoracis punctis sub-connexis ro-notata. dúobus elytrorumque quinque nigris.

Chrysomela 10-punctata var. e. Linn. Syst. Nat. 590. 32. Vill. i. I29. 27. Gmel. 1678.32. Scbrank, I38.

Mart. Eng. Ent. t. I6. f. 40.

Chrysomela rufipes. De Geer, v. 295 4. t. 8. f. 25.

Coccinella Io-punctata. Scop. 237 .

Long. corp. 3 lin.

Habitat in Populo tremulâ.

DESCR. In omnibus simillima $C$. IO-punctatre, at facilè distinguatur ore pedibusque flavis, et thoracis punctis nigris duobus, quæ remota sunt; basi tantùm aliquando connexa.

Variat mirè numero punctorum.

I4. Chry. rufa, thoracis maculâ bilobâ elytrorum ro-puncpunctis subquinis pedibusque nigris.

tata.

Linn. Syst. Nat.590.32. Faun. Suec. 525. Vill. i. 129. 27. Gmel. 1678. 32. Fab. Syst. Ent. 99. 25. Sp.Ins. i. I21. 33. Mant. i.69.42. Ent. Syst. i. a. 320. 62. Panz. Ent. Germ. 161. 25. Goeze, i. 265. 32. Fuun. Ingr. 59. I85. Harr. 228. Laich. I52. II.

Chrysomela nigripes. De Geer, v. 296. 5 .

La Chrysomele rouge à points noirs. Geoff. i. 258. 4 . Long. corp. 3 lin.

Habitat cum præcedenti.

DESCR. 
DESCr. Hæc cum Cbry. IO-nctata malè confunditur. Hanc dignoscas maculâ thoracis unicâ hinc bilobâ, lobis approximatis. Os et pedes nigra, nec flava. An sexûs differentia? An species distincta?

Boleti.

I5. Chry. nigra, elytris fasciis tribus flavis repandis.

Linn. Syst. Nat.591.36. Faun. Suec. 527, Vill. i. I30. 29. Gmel. I679. 36. Scbrank, I34. Fab. Syst. Ent. 97. 18. Sp. Ins. i. 120. 25. Mant. i. 69. 34. Faun. Etrusc. 198. Hellw. I98.

Don. Brit. Ins. t. 78. f. I. 2. Sulz. Ins. t. 3. f. 9. Mart. Eng. Ent. t. 16. f. 30.

Tenebrio Boleti. De Geer, v. 49. 9. t. 3. $f \cdot 3$.

Coccinella fasciata. Scop. 247 .

Dermestes Boleti. Uddm. 6. 4. t. I. f. 3 .

La Diapère. Geoff: i. 337 . 1. $t$. 6. f. 3 .

Diaperis fasciata. Fourc. i. 153. 2. Harr. 186.

Diaperis Boleti. Payk. Faun. Suec. iii. 357. I. Panz. Ent. Germ. 350. I. Fab. Ent. Syst. i. b. 5 I6. I.

Panz. Faun. Germ. 10. t. I2.

Diaperis. Scbreff. Elem. t. 58. Icon. t. 77.f.6.

Long. corp. 3 lin.

Habitat in Boletis arborum.

DEscr. Corpus majusculum, ferè hemisphæricum, atrum, glabrum. Elytra fasciis tribus, flavis, repandis, latis; quarum prima in basi, ultima in apice minima. Fautn. Suec.

abenea. 16. Chry. nigro-renca nitida, pedibus piccis. Long. corp. 2 lin.

Habitat Ex mus. D. Kirby.

Descr. Totum corpus nigro-æneum, et nitet. Pedes picei. Elytra striata, striis punctulis impressis.

Antennæ in hac et in C. Boleti singuiares adinodum: scilicet breves sunt, sive vix thoracem æauantes, compressæ, crassæ, articulatæ, articulis quasi perfoliatis, inde 
inde Geoffroyus taxiformes dicit; omnia hæc in Cbry. Boleti manifestiora, quippe grandior est.

17. Chry. atra punctata, antennis pedibusque ni- Tanaceti. gris.

Linn. Syst. Nat. 587. 5. Frun. Suec. 507. Vill. i. I17. 2. Gmel. 1669. 5. Fab. Syst. Ent. 103. 51 . Sp. Ins. i. 128. 70. Mant. i. 74. 94.. Faun. Etrusc. 190. Hellw. 190. Act. Nidros. iii. 389. Goeze, 25.5 .

De Geer, v. 299. 9. t. 8. f. 27. Scbaff. Icon.t. 2I. f. I4. Roes. ii. 2.t. 5. Mart. Eng. Ent. t. I6.f. 3 I.

Galleruca Tanaceti. Fab. Ent. Syst. i. b. I5. I0. Panz. Ent. Germ.' I70. 2. Faun. Ingr. 63. I96. Harr. 254. Payk. Faun. Suec. ii. 86. I.

La Galleruque brune. Geoff: i. 252. 1. $t$. 4. $f .6$. Tenebrio tristis. Scop. 256. Scbrank, 139.

Long. corp. 5 lin.

Habitat in Tanaceto vulgari.

Descr. Tota atra, minimè nitida. Thorax et elytra punctis minutissimis confertissimis excavata. Elytra satis flexilia, mollia et obtusa sunt. Antennæ undecim articulis. Margo elytrorum prominens. Faun. Suec.

18. Chry. flava, capite elytrisque aurato-viridibus, balensis. " antennis plantisque fuscescentibus.

Linn. Syst. Nat.589. 20. Vill. i. 123. I6. Scbrank, I46. Goeze, i. 259. 20.

Mart. Eng. Ent. t. I5:f. 20.

Cryptocephalus halensis. Gmel. I7I9. I35.

Galleruca nigricornis. Fab. Ent. Syst. i. b. 24. 53 .

Long. corp. $2 \frac{1}{2}-3$ lin.

Habitat_- In insulâ Mersey, culmos juncorum et graminum amplectentem, Septembre ineunti, cepit D. Curtis.

Descr. Occiput et elytra viridia. Elytra punctatissima. VOL. I. 
Oculi atri. Frons, pedes ct thorax testacea. Thorax inæqualis, punctis duobus impressis.

Variat colore viridi, et viridi-cæruleo.

- Polygoni. I9. Chry. cærulea, thorace femoribus anoque rufis.

Linn. Syst. Nat. 589.24. Faun. Suec.520. Vill. i. 125. 20. Gmel. 1676. 24. Scbrank, 142. Fab. Syst. Ent. 100. 32. Sp. Ins. i. 123. 43. Mant. i. 70. 54. Ent. Syst. i. a. 322. 73. Payk. Faun. Suec. ii. 6I. I4. De Geer, v. 322. 26. Faun. Fred. 8. 69. Faun. Etrusc. 209. Hellw. 209. Laich. 154. I3. Panz. Ent. Germ. 161. 29. Faun. Ingr. 60. 188. Goeze, i. 260. 24. Harr. 24I.

Scbeff. Icon. t. 16I.f. 4. a. b. Don. Brit. Ins. t. 96. f. I. Mart. Eng. Ent. t. I4.f. 2.

Buprestis salicina. Scop. I99.

Le Criocère bleu à corcelet rouge. Geoff. i. 242. 4.

Long. curp. 2 lin.

Habitat in Polygono aviculari.

DEScr. Caput et elytra nitida, viridi-cærulea, punctis sparsis excavatis. Thorax minor, viridi-ruber, seu testaceo-ruber, crassus, convexus. Antennæ nigræ, subulatæ: Femora rufa. Palmæ nigræ. Faun. Saec.

Betule. 20. Chry. violacea, elytris punctis excavato-striatis. Linn. Syst. Nat. 587. 10. Faun. Suec.514. Vill. i. 120.7. Gmel. I671. 10. Fab. Syst. Ent. I04. 54. Sp. Ins. i. 129.76. Mant. i. I74. IoI. Poda Mus. Grac. 26.3. Faun.Fred.7.66. Faun. Etrusc. 201. Hellw. 201. Goeze, i. 255. 10. Laich. 162. I9. Roes. ii. 3. tri.

La Chrysomele bleue de Saule. Geoff. i. 264. I7.

Chrysomela cærulea Salicis. De Geer, v. 318. 24. t. 9. $f .24$.

Galleruca. Fab. Ent. Syst. i. b. 17. I9. Panz. Ent. Germ. I 71. 5 .

Coccinella Betulæ. Scop. 22 I. 
Long. corp. $1 \frac{x}{2}$ lin.

Habitat in Belulâ, cujus foliis pascitur.

DESCR. Insectum atro-cæruleum ad purpuram vergens, seu propriè violaccum, floris Violce martiæ omninò colore; solus venter, pedes et antennæ nigræ. Caput et thorax punctis excavatis minutissimis inordinatis ferè contiguis adspersa; at elytra striis vix ocülis percipiendis, ex punctorum excavatorum minutissimorum serie, notantur, quibus, ut in parvitate, a sequenti differt.

Larva satis similis facie est Coccinellarim erucis; incisuræ singulæ in medio, verrucarum ordine transversali instructæ, quæ verrucæ apice pilosæ sunt, et humorem excernentes. Abclomen pallidius est, etiam verrucosum. Faun. Suec.

21. Chry. nigra nitidissima subcærulescens, sub-Armoracia. tùs nigra.

Linn. Syst. Nat.588. 16. Faun. Suec.515. Vill. i. 122. I2. Gmel. 1673. I6, Scbrank, I43. Fab. Syst. Ent. 103. 50. Sp. Ins. i. 127. 66. Mant. i. 73.84. Ent. Syst. i. a. 330. II2. Faun. Fred.7.67. Faun. Etrusc. Mant. 74. Hellw. Mant. 74. Faun. Ingr. 6I. 191. Panz. Ent. Germ. 166. 53. Goeze E. B. i. 258.16.

Panz. Faun. Germ. 44. t. I4.

Chrysomela Plantaginis. De Geer, v. 322.25.

Long. corp. $\mathbf{I}_{\frac{3}{4}}$ lin.

Habitat in Cocbleariâ Armoraciá, Ranunculo aquatili.

Descr. Corpus magnitudine seminis cannabis, suprà cæruleo aut viridi nitens, subtùs unà cum pedibus nigrum, nitidum, ovatum. Ad basin mediam elytrorum quasi foveola adparet. Faun. Suec.

22. Chry. oblongo-ovata cærulea, antennis basi vulgatissiferrugineis.

ma. 
Linn. Syst. Nat. 589. 22. Faun. Suec. 517. Vill. i. 124. I8. Gmel. 1675.22. Scbrank, 126. Fab. Syst. Ent. I04. 56. Sp. Ins. i. 130.79. Mant. i. 75. 104. Faun. Etrusc. Mant. 73. Hellw. Mant. 73. Goeze, i. 259. 22.

Mart. Eng. Ent. t. I4. f. 8.

Chrysomela cærulea Betulæ. De Geer, v. 317 . 23.

Coccinella vulgatissima. Scop. 222.

Galleruca Vitellinæ var. ß. Faun. Ingr. 64. I98. Fab. Ent. Syst.i. b. I8. 22.

Long. corp. $2 \frac{x}{2}$ lin.

Habitat in nemoribus.

Descr. Corpus colore Cbry. Armoracice, sive obscurè cærulescens, sive æneum, nitidum, at magis oblongum quam ovatum. Faun. Suec.

Differt a C. Vitellina quod major, non ænea, sed cærulea, et magis oblonga. Linn. Syst. Nat.

Vitelline. 23. Chry. oblongo-ovata nigro-ænea, ano rufo.

Linn. Syst. Nat. 589. 23. Faun. Suec. 519. Vill. i. 124. 19. Gmel. 1676. 23. Scbrank, 135. Fab. Syst. Ent. 104. 5.5. Sp. Ins. i. 130.78. Mant. i. 74. 103. Faun. Etrusc. 200. Hellw. 200. Goeze, 1. 259.23. Faun. Fred. 9. 84.

Roes. ii. Scar. 3. t. 1. f. I-5. Mart. Eng. Ent.t. I4. f. $\mathbf{x}$.

La Chrysomele bronzée de Saule. De Geer, v. $3^{23}$. 27.

Galleruca Vitellinæ. Fab. Ent. Syst. i. b. 18. 22. Panz. Ent. Germ. 171. 7. Faun. Ingr. 64. 198. Payk. Faun, Suec, ii. 94. I2.

Panz. Faun. Germ. 44. t. I6.

Coccinella Vitellinæ. Scop. 224.

Long. corp. $2 \frac{5}{4}$ lin.

Habitat in Salicibus glabris Populoque, folia subtùs consumens. Dum pascuntur, larvæ disponuntur per lineas parallelas. Linn. Syst. Nat.

DESCR. Hæc mediocris magnitudinis, tota e rubro ænea, 
ænea, sive ænei politi coloris, vel etiam nigricantiænei coloris. Faun. Suec.

Obs. Anus semper rufus.

24. Chry. cyanea, thorace nitido, elytris punc-aucta. tatis: margine rubro.

Fab. Mant. i. 72.69. Ent. Syst. i.a.326.94. Gmel. 1680. 128. Panz. Ent. Germ. 164. 41.

Panz. Faun. Germ. 16.t. 14. Scbaff.Icon.t.21.f. 19. Mart. Eng. Ent. t. I5.f. 27.

Chrysomela marginata. Act. Nidros. iii. 390. 8.

Long. corp. $1 \frac{1}{2} \operatorname{lin}$.

Habitat -

Descr. Caput, thorax et elytra cyanea, nitida, margine elytrorum late rufo. Antennæ et pedes nigri. Fab. Mant.

25. Chry. oblongo-ovata nigro-cærulea, thorace marginella. - elytrisque margine luteis.

Linn. Syst. Nat. 591. 40. Faun. Suec. 531. Vill. i. 131. 33. Gmel. 1681. 40. Fab. Syst. Ent. 102. 42. Sp. Ins. i. 125. 55. Mant. i. 72. 70. Ent. Syst. i. 326. 96. Panz. Ent. Germ. I64. 42. Faun. Ingr. 61. 190. Gocae, i. 268. 40. Act. Nidros. iii.390.9. Laich. 162. 18. Payk. Faun. Suec. ii. 73. 27.

Panz. Faun. Germ. I6. t. 15. Don. Brit. Ins. t. III. f. 5. 6. Mart. Eng. Ent. t. 15.f. 26.

Chrysomela marginella Ranunculi. De Geer, v. 304. I5.

Long. corp. 2 lin.

Habitat

DESCR. Margo exterior elytrorum et thoracis flavescens. Thorax et caput nigro-ænea. Subtùs tota atra. Corpus ovale est. Pedes nigri. Faun. Suec.

26. Chry. olivaceo-testacea, oculis elytrorumque olivacea. suturấ nigris.

Forst. Cent. 22. 
Long: corp. 2 lin.

Habitat

DESCr. Antennæ fuscæ, basi pallidæ. Caput olivaceo-testaceum, posticè ad thoracem nigrum. Oculi nigri. Thorax punciulatus, capire concolor. Elytra etiam olivaceo-testacea, striata, striis novem ex punctis excavatis. Sutura eiytrorum nigra. Abdomen subtùs atro-cæruleum, punctatum. Pedes olivacei. An varietas sequentis?

- Litura. 27. Chry. olivacea rubrave, elytrorum suturâ liturâque nigris.

Fab. Syst. Ent. 102. 44. Sp. Ins. i. 126.57. Mant. i. 72. 74. Ent. Syst. i.a.328. 103. Vill. i. 136. 56. Gmel. 1681. 132. Panz. Ent. Germ. 165.47. Payk. Faun. Suec, ii. 74. 28.

Mart.Eng. Ent.t. 16. $f \cdot 37$.

Long. corp. I $\frac{3}{4} \operatorname{lin}$.

Habitat in Spartio Scopario.

DeSCr. Color hujusce animalis admodum variat, modo virescens, modo olivaceus, modo ruber. In utroque elytro, plerumque litura nigra, quæ interdum major paginam ferè totam occupat, interdum minor longitudinalis, irregularis, interrupta. Interdum omnino deest; at sutura semper nigra est, et pedes elytris concolores. Caput posticè nigrum, maculâ plerumque bilobâ, aut bifidâ. Corpus nitidiusculum. Thorax punctulis sparsis. Elytra punctato-striata. Margo elytrorum immaculatus.

rufitarsis. 28. Chry. oblongo ovata nigra, clytris punctatostriatis, antennis tarsisque rufescentibus.

Long. corp. 2 lin.

Habitat in Spartio Scopario. Maio ineunti. D. Davie.

Descr. Staturâ et ferè magnitudine Cbry. Liturce, quâcum 
quâcum etiam habitat; sed tota nigra, antennis solummodo et plantis obscurè rufescentibus.

29. Chry, atra nitida, thorace glaberrimo, elytris aterrima. striatıs, pedibus subferrugineis.

Lang. eorp. I lin.

Habitat

In mus. D. Allen.

DESCR. Thorax glaberrimus politus. Striæ elytrorum punctulis impressis.

30. Chry. convexa gibba atra, thorace punctulato, stygia. elytris striatis.

Long. corp. $\mathrm{I} \frac{3}{4}$ lin.

\section{Habitat}

In mus. D. Allen.

DESCR. Antennæ extrorsùm paulò crassiores, nigræ; basi rufescunt. Corpus nitidiusculum, convexum, anticè et posticè gibbum. Thorax punctulis majusculis conspersus. Elytra striata, striis ex punctulis majusculis impressis. Pedes atri,

31. Chry. ænea, elytris obsoletè punctato-striatis. chalcea. Long. corp. $\mathbf{3} \frac{3}{4}$ lin.

\section{Habitat - In mus. D. Allen.}

DESCR. Totum corpus unicolor, nitidiusculum, posticè gibbum. Thorax punctulatus. Elytra obsoletè striata; striæ ex punctis minutissimis constant.

32. Chry. ovato-oblonga ferrugineo-testacea pu-pubescens. bescens, oculis nigris.

Long. corp. $2_{4}^{\frac{\pi}{4}}$ lin.

\section{Habitat}

DESCR. Totum corpus ex testaceo-ferrugineum unicolor, pubescens. Thorax autem et elytra præ ceteris artubus pilis brevissimis obteguntur. Elytra punctulis minutissimis numerosissimis. Oculi nigri.
N 4
33. Chry. 
viridi-enëa. 33. Chry. viridi ænea punctulatissima, antennis pedibusque concoloribus.

Long. corp. $2 \frac{1}{2}$ lin.

Habitat -

DESCR. Totum corpus unicolor, viridi-æneum, sive ex viridi-cupreum, punctulatissimum, punctulis minimis confertissimis; plantæ solummodo, quod in plurimis aliis accedit, subius fulvæe. Affinis Chry. Graminis, sed duplu rninor; tum color viridi-æneus, neque viriri-cæruleus, neque nitet; porro corpus exactè ovatum, nec oblongo-ovatum. In Cbry. Graminis punctula omnia distincta, remotiuscula ; in hac autem confertissima, et multo minora quam in Cbry. Graminis.

atro-violes-34. Chry. ovata atro-violacea, elytris striatis, pecens. dibus piceis.

Long. corp. $1 \frac{2}{3}$ lin.

Habitat - Capta semel apud Holme, Norfolciâ, Septembre ineunti. D. Kirby.

DESCR. Corpus suprà atro-violaceum, nitidum; subtùs nigrum. Antennæ nigræ, basi piceæ. Elytra novemstriata, striis punctulatis. Femora picea, tibiis tarsisque rufo-piceis.

Hypoche- 35. Chry. tota viridi-aurata nitida.

Linn. Syst. Nat.589.21. Faun. Suec. 516. Vill. i. 123. 17. Gmel. 1675.21. Scbrank, 173. Goeze, i. 259. 21 .

Buprestis syngenesia. Scop. 193 .

Long. corp. 2 lin.

Habitat

Descr. Hoc animal apud nos nomen Hypocberidis obtinuit; an reverà Cbry. Hypocbaridis Linnæi sit, non satis apparet, elytra enim non abbreviata. Forsitan Linnæus fœminam gravidam descripsit; certè unicolor 
unicolor est viridi-aurata, nitida. Antennæ etiam concolores.

$V$ ariat viridis, nec viridi-aurata, et semper nitida.

36. Chry. aurata, thorace lineis tribus coleoptris-cerealis. que quinque cæruleis.

Linn. Syst. Nat. 588. 17. Vill. i. 122. I3. Gmel. $10 \%$. I\%. Fab. Syst. Ent. 100.33. Sp. Ins. i. 124. 45. Mant. 1. 71. 57. Ent. Syst. i. a. 323.76. Panz. Ent. Germ.152.30. Faun. Etrusc. 206. Hellw. 206. Goeze, i. 258. I7. Harr. 242. Laich. I56. I4. Don. Brit. Ins. t. II 5. Scbaff. Ieon. t. I. f. 3 .

L'Arlequin doré. Geoff.i. 262. 14.

Long. corp. $3 \frac{1}{2}$ lin.

Habitat _ Capta in montibus Cambro-britannicis. D. Hudson.

DESCR. Corpus medium, suprà auratum, subtùs obscurè violaceum. Thorax lineis tribus cæruleis. Coleoptra lineis quinque cæruleis, quarum intermedia suturæ communis. Linn. Syst. Nat.

37. Chry. nigro-cærulea nitidiuscula punctula-unicolor. tissima.

Long. corp. 2 lin.

Habitat

DEscr. Totum corpus ejusdem coloris, atro-cæruleum, suprà punctulis numerosissimis impressis ornatum.

38. Chry. oblonga nigra, thorace elytrisque lineis Pbellanduabus luteis.

- drii.

Linn. Syst. Nat. 601. II1. Faun. Suec. 569. Vill. i. 163. I72. Faun. Fred. 9. 86.

De Geer, v. 324. 28. t. 9.f. 34 .

Crioceris Phellandrii. Fab. Syst. Ent. I22.20. Sp. Ins.i.

156. 36. Mant. i.90. 46. Ent. Syst. i. b. II. 43. Faun. Etrusc. 272. Hellw. 272. Preys. Bob. Ins. 72. 67. Panz. Ent. Germ. I69. 12.

La Chrysomele à bandes jaunes. Geoff. i. 266. 20. Helodes Phellandrii. Payk. Faun. Suec. ii. 84. I. 
Long. corp. 3 lin.

Habitat in Pbollandrio aqualico ad radices.

Descr. Oblonga admodum est. Tota suprà nigroænea; thoracis margine laterali flavo, et singula elytra in medio et margine exteriore lineâ longitudinali flavâ. Tibiæ et femorum interior pars Hava. Antennæ nigræ. Structurâ oblongâ a cæeteris differt. Faun. Suec.

Beccabun- 39. Chry. oblonga cærulea, thorace planiusculo. ge. Panz. Faun. Germ. 25. t. 1 I.

Galleruca Beccabungæ. Panz. Ent. Germ. 171. 8.

La Galeruque violette. Geoff. i. 254. 6.

Crioceris violacea. Fab. Ent. Syst. i. b. II. 42.

Long. corp. 2 lin.

Habitat in Veronicâ Beccabungâ.

Descr. Habitus Cbry. Pbellandrii. Affinis Auchenice Cyanella, a quâ abundè differt, thorace ut in Elateribus convexiusculo, nec gibboso. Antennarum articuli -5 ultimi crassiores, ut in Silpbis quibusdam conspiciendum est.

$$
\text { ** Tborace margine utroque incrassato. }
$$

- incrassata. 40. Chry. atro-cærulca, thorace nitido: latcribus elcvato-incrassatis, elytris punctis impressis striatis.

Long. corp. 4 lin.

Habitat -

Descr. Antennæ nigræe, basi piceâ. Caput et thorax atro-cærulea, glaberrima, nitida. Thorax lateribus elevatis valdè incrassatis. Elytra glabra striata, striæ ex punctis impressis parùm inter se distantibus.

- stapbylea. 41. Chry. obcurè testacea tota.

Linn. Syst. Nat. 590. 26. Faun. Suec. 518. Vill. i. 126. 22. Gmel. 1677.26. Fab. Syst. Ent. 97.14. $S p$. 
Sp.Ins. i. II9.21. Mant. i.69.29. Ent. Syst.i. a. 317. 47: Scbrank, I29. Act. Nidros. iv. 319. 9. Goeze, i. 261. 26. Panz. Ent. Germ. I59. I9. Faun. Etrusc. 192. Hellw. 192. Faun. Ingr. 58. I81. Faun. Fred. 8.68. Harr.236. Laich. I51.9. Payk. Faun. Suec. ii. 53. 4 .

Mart. Eng. Ent. $t$. I4. f. 3 .

La Chrysnmele briquetée. Geoff. i. 263. I5.

Chrysomela cupræa. De Geer, v. 294. 3. t. 8. f. 24. Scbaff. Icon. $t .21 \cdot f \cdot 12$.

Long. corp. 3 lin.

Hablat

DESCR. Color totius corporis, elytrorum, thoracis, antennarum, abdominis et pedum unicus idemque obcurè testaceus, sive castaneus; sed omninò simillimus est semini Stapbylece, sive Stapbylodendri, nec novi aliud hujus singuiaris coloris, a quo similitudinem desumam. Antennarum extimus articulus ovatus est, reliqui breviores. Elytra punctis minutissimis inordinalis excavatis adspersa. Thorax utrinque margine crassiusculo notatus, et utrinque maculâ depressâ. Corpus ovatum. Oculi soli nigri. Antennæ et pedes magis rubent. Plantæ pedum subtùs albæ. Faun. Suec.

42. Chry. suprà ænea, subtùs testacea.

Fab. Syst.Ent. 95.4. Sp.Ins. i. I17.7. Mant. i.67.9. Ent.Syst. i. 3 10. I6. Vill. i. 135.50. Gmel. 1668.76. Panz. Ent. Germ. 157.6. Petagn. Ins. Calab. 10. 48. Faun. Etrusc. I88. Hellw. I88.

Don. Brit. Ins. t. 138.f. 4. Mart. Eng. Ent. t. 16. $f \cdot 42$.

Long. corp. 5 lin.

Habitat

DEscr. Caput æneum, ore testaceo, antennisque fuscis. Elytra ænea, punctata. Subtùs tota cum pedibus et elytrorum margine inferiori testacea. Syst. Ent. 
43. Chry, thorace aurato, elytris rufis.

Linn. Syst. Nat.590. 27. Faun. Suec.522. Vill. i. 127. 23. Gmel. 1677. 27. Scbrank, 124. Fab. Syst. Ent.97. 16. Sp. Ins. i. II9. 23. Mant. i. 69. 31. Ent. Syst.i. a.317.49. Poda Mus. Grac. 27.5. Goeze, i. 252.27. Panz. Ent. Germ. 160.20. Laich. I51. 10. Faun. Fred. 8. 70. Faun. Etrusc. 193. Hellw. 193. Faun. Ingr. 59. 182. Payk. Faun. Suec. ii. $54 \cdot 5$.

De Geer, v. 294. 2. t. 8.f. 23. Mart. Eng. Ent. t. I4. $f \cdot 5$.

La Chrysomele rouge à corcelet doré. Geoff. i. 257 2. Coccinella polita. Scop. 229.

Long. corp. $3^{\frac{1}{2}}$ lin.

\section{Habitat}

Descr. Caput et thorax pulchrè nitent. Elytra rubrotestacea, apicibus immaculatis. Faun. Suec.

Populi. 44. Chry. cærulescens, elytris rubris apice nigris.

Linn. Syst. Nat. 590.30. Faun. Suec. 523. Vill. i. 127.25. Gmel. 1678. 30. Scbrank, 123. Fab. Syst. Ent. 96. 13. Sp. Ins. i. II9. 20. Mant. i. 69. 27. Ent. Syst. i. a. 316. 44. Faun. Fred. 8. 7r. Faun. Etrusc. 191. Hellw. I91. Faun. Ingr. 58. 180. Panz. Ent. Germ. 159. 17. Goeze, i. 263. 30. Harr. 234. Laich. I50. 8. Payk. Faun. Suec. ii. 55. 6 .

De Geer, v. 290. I. t. 8.f. Í. Albin, t. 63. a, b, c. Schaff: Icon.t. 21. f. 9. Mart. Eng. Ent. t. I5: f. 18.19 .

La grande Chrysomele rouge à corcelet bleu, Geoff. i. 256 . I.

Coccinella Populi. Scop. 228.

Long. corp. $5 \frac{x}{2}$ lin.

Habitat in Populo.

DESCR. Elytra rubra, punctis minutissimis excavatis adspersa : apex elytrorum minimam maculam nigram habet. 
habet. Thorax glaber, viridi-nigroque cæruleus, ut et scutellum et abdomen et caput et pedes. Antennæ magis nigricantes; margo thoracis lineâ impressâ distinctus. Margo elytrorum inflexus corpus arctè ambiens. Alæ et dorsum nigricantes. Variat elytris rubris et flavis, fortè sexu? Antennæ Cbrysomela hujus non lamellatæ sunt, uti a Listero descriptæ, sed ut in reliquis II articulis filiformes, infimo majori.

Larva tacta dimittit oleosum quoddam flavescens per tubercula lateralia, foetidissimaque est, ut nullo modo ferri queat. Faun. Suec.

45. Chry. cærulescens, elytris testaceis.

Fab. Mant. i. 69.28. Ent. Syst. i. a. 317.45. Gmel. 1678. 30. Panz. Ent. Germ. 159. 18. Payk. Faun. Suec. ii. $55 \cdot 7$.

Chrysomela Populi var. Faun. Etrusc. 191. Hellw. I9I.

La grande Chrysomele rouge à corcelet bleu var. Geoff. i. 257 .

Long. corp. $4 \frac{3}{4}$ lin.

Habitat in Populo.

Descr. An satis a Cbry. Populi distincta? at duplo minor, et elytra apice concolora. Fab. Mant.

Obs. Diversam a Cbry. Populi hanc esse dicimus, monitu Geoffroii et Fabricii. At fatendum est quod nostra specimina vix cedunt magnitudine; ideoque sexû differre nec speciem distinctam esse suspicamur.

46. Chry. oblongo-ovata viridis nitida, abdomine anew. posticè ferrugineo.

Linn. Syst. Nat. 587.8. Faun. Suec. 510. Vill. i. I1.9. 5. Gmel. 1670. 8. Scbrank, I31. Fab. Syst. Ent. 104.57. Sp.Ins. i. I30. 80. Mant. i. 75. 106? Ent. Syst.i. a. 329. 109. Faun. Fred. 7. 62. Faun. Etrusc. 196. Hellw. 196. Panz. Ent. Germ. 165. 50. Poda Mus. Grac. 26. 4. Petagn. Ins. Calab. 10. 45. Goeze, i. 253. 8. Harr. 25 t. Payk. Faun. Suec. ii. 59. II. 
Panz. Faun. Germ. 25.t. 9. Scbaff. Icon. t. 21.f.3.4. Chrysomela viridis Alni. De Geer, v. 305. I8. t. 9. f. 4. Le petit Vertubleu. Geoff: i. 26I. I2.

Long. corp. 4 lin.

Fabitat in Aho. Limn. In mus. D. Latham.

Descr. Tota nitida. Thorace anticè non equaliter truncato, sed sinu excavato. Punctum excavatum in medio sterni. Pedes et antennæ nigræ. Hæ basi pallidæ. Faun. Suec.

marginata. 47. Chry. nigro ænea, elytris margine luteis.

Linn. Syst. Nat. 59r. 39. Faun. Suec. 530. Vill. i. 131. 32. Gmel. 1680. 39. Scbrank, I70. Fab. Syst. Ent. IоI. 41. Sp. Ins, i. I25. 54. Mant. i. 71. 68. Ent. Syst. i. a. 325. 91. Goeze, i. 268.39. Faun. Etrusc. 204. Hellw. 204. Preys. Bob. Ins. 77. 71. Petagn. Ins. Calab. 9. 42. Harr. 247. Payk. Faun. Suec. ii. 71. 24.

Scbaff. Icon.t.21.f. I9. Panz. Faun. Germ. I6. t. II. Long. corp. 3 lin.

Habitat in fruticibus.

Mus. D. Kirby.

DESCR. Thorax totus nigro-æneus. Elytra punctatostriata, marginibus luteis.

sanguino- 43. Chry. nigra, elytris margine sanguineis.

lenta.

Linn. Syst. Nat. 591. 38. Faun. Suec.529. Vill. i. 131. 3т. Gmel. 1680. 38. Scbrank, 133. Fab. Syst. Ent. Iоr. 40, Sp. Ins. i. 125.53. Mant. i. 71. 67. Ent. Syst. i. a. 325. 90. Faun. Fred. 8. 72. Faun. Etrusc. I94. Hellw. 194. Faun. Ingr.60. 189. Harr. 246. Panz. 'Ent. Germ. 163. 37. Petagn. Ins. Calab. 9. 41. Goeze, i. 267.38. Payk. Faun. Suec. ii. $52 \cdot 3$.

Don. Brit. Ins. t. III. f. 3. 4. Mart. Eng. Ent. t. I5. f. 23. Scbaff. Icon. t. 21.f. I5. Panz. Faun. Germ. 16. t. Io. Sulz. t. 3.f. 10.

Chrysomela rubro marginata. De Geer, v. 298. 7. t. 8. f. 26 . 
La Chrysomele noire à bordure rouge. Geoff. i. 259. 8. t. 4. $f .7$.

Buprestis sanguinolentus. Scop. 203.

Long. corp. $4 \frac{x}{2}$ lin.

Habitat in salicetis. Linn.

DESCR. Corpus nigrum, nitidum. Thorax sub-marginatus. Elytra margine exteriore sanguinea. Pedes nigri. Faun. Suev.

49. Chry. atra, coleoptrorum limbo sanguineo. limbata. Fab. Syst. Ent. Ior. 39. Sp. Ins. i. I25.52. Mant. i. 77.66. Ent. Syst. i. a. 325.88. Vill. i. I35.54. Gmel. I675. I12. Panz. Ent. Germ. 163.35. Harr. 245. Payk. Faun. Suec, ii. 70. 23.

Panz. Faun. Germ. 16.t. 8. Scbaff. Icon. t. 21. f. 20. La Chrysomele bleue à bordure rouge. Geoff. i. 260. 9. Long. corp. 4 lin.

Habitat - In mus. D. Lee.

DESPR. Statura et summa affinitas Cbry. sanguinolente, a quâ tamen manifestè differt, elytris multo lævioribus, et margine anteriori sangúineo; color omnis niger, parum æneo tinctus. Syst. Ent.

50. Chry. oblonga viridi ænea, thoracis margini-20-puncbus albis, clytris albis: maculis decem æneis. tata. Fab. Syst. Ent. 105. 65. Sp. Ins. i. 131. 86. Mant. i.75.112. Vill.i. 134.42. Gmel.1682. 138. Faun. Etrusc. 205. Hellw. 205. Scbrank, 137. Harr. 252. Panz, Ent. Germ. 166. 5 I.

Scbxff. Icon.t. 3.f. 4. Panz. Faun. Germ. 6. t. Iо. Galleruca 20-punctata. Fab. Ent. Syst. i. b. 21. $3^{6 .}$

Long. corp.

Habitat

In mus. Brit.

DESCR. Thorax æneus, marginibus incrassatis albis. Elytra suturâ maculisque decem oblongis æneis. Pedes ænei, geniculis albis. Syst. Ent.

5 r. Chry. 
buprestoi- 51. Chry. nigra, thorace caput recipiente : laterides. bus latiùs incrassatis, elytris striatis. An Dytiscus Volkmari? Panz. Faun. Germ. 7. t. 4. Long. corp. I lin.

Habitat in gramine propter semitas umbrosas. Capta prope Langattock juxta fluvium Usk.

DESCr. Animal singulare, facie et habitu Buprestidis, antennis Cbrysomela. Totum corpus nigrum, sive nigro-æneum, unicolor. Thorax præcipuè notandus est, latera enim late incrassata habet, haud secùs ac si lamella utrinque margini superinjecta adhæreret. Elytra striata, striæ punctis impressis.

** Saltatoriæ, femoribus posticis crassissimis.

oleracea. 52. Chry. oblongo-ovata viridi-ænea, antennis nigris, thorace lineâ transversâ.

Linn. Syst. Nat.593.51. Faun. Suec.534. Vill. i. 138.73. Gmel. 1691.51. Scop.212. Scbrank, I59. Fab.Sp.Ins. i. 133.94. Mant. i.77. I26. Faun. Etrusc. 214. Hellw.214. Petagn. Ins. Calab.10.46. Pontop. Dan. Atl. i. 670. I8. De Geer, v. 344. 49. Goeze E. B. i. 272. 5 I.

Altica oleracea. Fab. Syst. Ent. 112.3. Panz. Ent. Germ. I76. II.

Panz. Faun. Germ. 21. t. T.

L'Altise bleue. Geoff.i. 245. I.

Galleruca oleracea. Fab. Ent. Syst. i. b. 28.74. Faun. Fred. 8. 75. Faun. Ingr. 65. 202. Payk. Faun. Suec. ii. 96. 12.

Long. corp. 2 lin.

Habitat in cotyledonibus plantarum. Limn.

DESCR. Affinis admodum Cbry. vulgatissima, sed in plurimis differt. Femora postica crassa, et antennæ non sunt basi ferrugineæ. Thorax pośticè lineâ transversâ impressâ. Corpus nitidiusculum. Elytra punctulatá, punctulis 
punctulis oculo vel bene armato vix conspicuis. Pedes concolores.

Variat colore viridi-æneo.

53. Chry. oblongo-ovata cærulea nitida, antennis Éruca. * nigris, thorace lineâ transversâ.

Altica Erucæ. Panz. Ent. Germ. I76. 2.

Galleruca Erucæ. Fab. Ent. Syst. i. b. 28. 75. Faun, Ingr. 65. 203.

Panz. Faun. Germ. 21. t. 2.

Long. corp. $2 \frac{1}{4}$ lin.

Habitat

DEscr. Affinis certè Chry. oleracece, at alia, et distincta, tota glabra, cyanea, nitida, immaculata, antennis solis nigris. Ent. Syst.

54. Chry. atro-cærulea, fronte pedibusque qua- cbrysotuor anterioribus luteis.

Linn. Syst. Nat. 594. 53. Faun. Suec. 535. Scop.213. Vill. i. 139. 74.- Gmel. 1693. 53 .

Long. corp. I $\frac{1}{2}$ lin.

Habitat in plantis tetradynamiis.

Descr. Frons, antennarum basis, pedes quatuor anteriores tibiæque posteriores subferruginea. Thorax cæruleus, nitidus. Elytra striata, subcærulescenti-nigra.

55. Chry. virescenti-cærulea, pedibus testaceis. Hyoscyami, Linn. Syst. Nat. 594. 54. Faun. Suec. 536. Vill. i. 139.75. Gmel. 1693.54. Fab. Sp. Ins. i. 133.97. Mant.1.77.129. De Geer, v. 345.51. Scbrank, 16I. Goeze, i. 274. 54. Faun. Etrusc. 213. Hellw. 213. Faun. Fred. 8. 77 .

Mart. Eng. Ent. t. I4. $f$. 15 .

Altica Hyoscyami. Fab. Syst. Ent.113.5. Laicb. 196. I.

Panz. Ent. Germ. I76. 4.

Panz. Faun. Germ. 21, t. 4 .

L'Altise du Chou. Geoff. i. 248. Ir.

Galleruca Hyoscyami. Fab. Ent. Syst. i. b. 29. 79. Faun. Ingr. 65. 204. Payk. Faun. Suec. ii. 104. 25. vol. $\mathrm{I}$.

Long. 
Long. corp. I $\frac{3}{4}$ lin.

Habitat in Hyoscyamo nigro, Brassice cotyledonibus.

Descr. Tota cærulea, nitens, convexa, ovata. Femora crassa, nigra, saltatoria, alta. Tibiæ ferrugineæ. Faun. Suec.

Modeeri. 56. Chry. ænea nitida, elytris apice flavis, pedibus anterioribus tibiisque posticis luteis.

Linn. Syst. Nat.594.57. Faun. Suec.539. Vill. i。 140.78. Gmel. 1694.57. Fab. Sp. Ins, i. 134. 102. Mant. i. 77. 134. Petagn. Ins. Calab. 10. 47.

Altica Modeeri. Panz. Ent. Germ. 177.9.

Panz. Faun. Germ. 21. t. 7 .

Galleruca Modeeri. Fab. Ent. Syst. i. b. 30. 85. Faun. Ingr. 66. 206.

Long. corp. I lin.

Habitat

DEsCr. Corpus æneum, nitidum. Elytra striata, apice latè flava. Antennæ basi luteæ. Faun. Suec.

semi-anea. 57. Chry. ænea nitida, elytris posticè flavis, pedibus omnibus luteis.

Altica semi-ænea. Panz. Ent. Germ. I77. Io.

An Galleruca semi-ænea? Fab. Syst. Ent.i. b. 30. 86.

Long. corp. I lin.

Habitat in Astragalo glycypbyllo.

Descr. Simillima C. Modeeri, sed differt, nitidior et magis ænea. Elytra dimidiata posticè nec apice solo flava. Porro pedes omnes lutei.

Helxines. 58. Chry. viridi-ænea, antennis pedibusque testaceis.

Linn. Syst. Nat. 594. 58 . Faun. Suec. 540. Vill. i. 140. 79. Gmel. 1694. 58. Fab. Sp. Ins, i. उ34. 100. Mant.i.77. 132. Scbrank, I58. Faun. Etrusc. 216. Hellw. 216.

Chrysomela 
Chrysomela viridi-aurata. De Geer, v. $345 \cdot 52$. Altica Heixines. Fab. Syst. Ent. I13.8. Panz. Ent. Germ. $177 \cdot 7$.

Panz. Faun. Germ. 21. t. 6.

Altica aurea, pedibus flavis. Geoff. i. 249. 14.

Galleruca Helxines. Fab. Ent. Syst. i. b. 30.82.

Long. corp. 2 lin.

\section{Habitat}

DEscr. Subtùs nigro-ænca, suprà viridi-aurata, nitidissima. Antennæ totæ rufæ. Thorax nunctulatus. Elytra punctato-striata, punctis excavatis. Pedes rufi, femoribus nigricantibus. Sexus alter pedibus omnibus testaceis.

Var.e. cupreo-aurata cum tincturâ rubini.

59. Chry. viridi-anea, thorace aureo, antennis aurato. dimidiato nigris.

Alica nigro-aurata, thorace aureo, femoribus ferrugineis. Geoff.i. 249. I3.

Long. corp. $\mathrm{I} \frac{2}{3}$ lin.

Habitat

Descr. Præcedenti simillima, sed minor; subtùs nigro-ænea. Antenuæ nigræ, basi testaceæ. Thorax aureo micans, colore fulgidissimo punctulatus. Elytra viridi-aurata. Pedes flavi, femoribus posticis nigris.

$V a r$. . femoribus posticis testaceis maculâ brunneâ, et totis testaceis.

Var. . suprà cærulea.

6o. Chry. elytris caruleis, thorace aureo, pedibus nitidula. ferrugineis.

Linn. Syst. Nat. 594. 60. Faun. Suec.542. Vill. i. 141. 81. Gmel. 1694. 60. Fab. Sp. Ins. i. 134. 99. Mant. i. 77. I3I. Faun. Etrusc.219. Hellw.219. Scbrank, I63. De Geer, v. 346. 54.

Don. Brit. Ins. t. 273. Mart. Eng. Ent. t. I4.f. I4. Altica nitidula. Fab. Syst. Ent. II3.7. Panz. Ent. 
Germ. 177.6. Preys. Bob. Ins. 91. 86. Harr. 260. Laicb. 200. 5 .

Scbeff. Icon. t. I66. $f \cdot 5 \cdot$ a. b.

L'Altise rubis. Geoff. i. 249. ${ }^{3} 3$.

Galleruca nitidula. Fab. Ent. Syst. i. b. 30.81. Payk. Faun. Suec. ii. 105. 26.

Long. corp. 2 lin.

Habitat

DEscr. Thorax solùm auratus. Antennæ testaceæ. Elytra striata, striis obscuris e punctulis leviter impressis constantibus.

concinna. 6I. Chry. ovata ænea nitida, elytris striatis, tibiis testaceis.

Long. corp. $\frac{3}{4}$ lin.

Habitat

Descr. Corpus ovatum, æneum, sive cupreum, nitidum, punctulis minutissimis numerosissimis ornatum. Elytra oculo bene armato videntur striata; striæ ex punctis impressis. Tibiæ pallidæ, sive testaceæ.

cyanea. 62. Chry. ovata, thorace virescenti-cæruleo, elytris violaceis striatis, antennis pedibusque testaceis.

Chry. violaceo-punctata. De Geer, v. 344. 50.

Long. corp. I $\frac{\mathrm{r}}{4} \mathrm{lin}$.

Habitat

Descr. Corpus exactè ovatum, nitidiusculum. Antennæ testaceæ. Caput et thorax virescenti-cærulea, punctulis minimis ornata. Elytra nigro-cærulea, sive violacea, striata; striæ ex punctis impressis. Corpus subtùs nigrum. Pedes testacei, femoribus posticis nigris.

Tseudacori. 63. Chry. atro-carulca lævis nitida, antennis basi rufescentibus.

Long. 
Long. corp. $\mathrm{I} \frac{\mathrm{x}}{2}$ lin.

\section{Habitat in foliis Iridis Pseudacori.}

Descr. Totum corpus unicolor, ovatum, glabrum, nitidum. Antennæ, certâ lucis incidentiâ, et præcipuè ad basin, rufæ. Sub lente elytra punctulis minutis simis numerosissimis ornari visa.

64. Chry. oblonga nigro-ænea punctulatissima. nigro-anea. Long. corp. $I \frac{\mathrm{r}}{4}$ lin.

\section{Habitat}

Descr. Corpus oblongum, sive ellipticum. Elytra non striata, at unà cum thorace punctulis minutissimis numerosissimis conspersa.

65. Chry. atra, elytris lineâ flavâ, pedibus flavic. Nemorum. Linn. Syst. Nat.595. 62. Faun. Suec. 543. Vill. i. I42.83. Gmel. I695.62. Scop.2I5. Scbrank, I54. Fab. Sp. Ins. i. 136.114. Mant. i. 78. 147. Faun. Fred. 8. 78. Faun. Etrusc. Mant. 77. Hellw. Mant. 77 .

Chrysomela fasciata. De Geer, v. 347.55.

Sulz. Hist. Ins. t. 3. f. I I.

Altica Nemorum. Fab. Syst. Ent. I 15. 20. Panz. Ent. Germ. 181. 27. Laich. 201. 6.

Panz. Faun. Germ. 21. t. 19.

L'Altise à bandes jaunes. Geoff. i. 247 . 9.

Galleruca Nemorum. Fab. Ent. Syst. i. b. 34. 104. Faun. Ingr. 211.67. Payk. Faun. Suec. ii. 98. 16.

Long. corp. I lin.

Habitat in Pulmonariâ, Dentariâ, Cardamine, et ubique.

Descr. Corpus oblongum, nigrum, minimè nitens. Antennæ setaceæ, truncatæ, articulis undecim nigris, exceptis in quibusdam secundo et tertio albis. Elytra nigra, singula in medio longitudinaliter flavescentia, undique tamen margine nigro cincta, etiam ad suturam longitudinalem. Pedes saltatorii pallidi. Daturque reliquis duplo major. Faun. Suec.

$$
\text { o } 3
$$

66. Chry. 
Aemuosa. 66. Chry. atra, elytris vittâ flavâ undulatâ.

Scbneid. Neus. Mag.v. 601.8. Panz.Ent.Germ.181. 28. Panz. Faun. Germ. 25. t. I2.

Long. corp. $1 \frac{\pi}{4}$ lin.

Nabitat in hortis.

Ex mus. D. Lebmann.

Descr. Omninò distincta a C. Nemorum. Antennæ nigræe, articulis tribus inferioribus pallidis. Caput et thorax atra, punctata. Elytra atra, vittâ flavâ distinctè undulatâ.

4-pustu- 67. Chry. atra, elytris lineâ flavâ medio interruptâ.

Vill. i. 145.98. Fab. Sp. Ins. i, 135. I0\%. Mant. i. 77.139.

Altica 4-pustulata. Fab. Syst. Ent. II4. 13.

L'Altise à points rouges. Geoff. i. 250. I5.

Galleruca 4-pustulata. Fal. Ent. Syst. i, b. 32. 93. Payk. Faun. Suec. ii. 99. 17.

Long. corp. I lin.

Habitat

Descr. Simillima C. Nemorum, at linea flava elytrorum medio sæpissimè interrumpitur, adeo ut utrumque elytrum flavo biguttatum videtur. Linea flava elytrorum variat interrupta, et subinterrupta. Per cætera corpus atrum.

rufipes. 68. Chry, cærulea obovata, capite thorace pedibus antennisque rufis.

Linn. Syst. Nat.595. 65. Faun. Suec. 545. Vill. i. 143. 86. Gmel. 1695. 65. Scop. 214. Fab. Sp. Ins. i. 135. 108. Mant. i. 77. 140. Faun. Etrusc. 217. Hellw. 217. Faun. Fred. 8. 79.

De Geer, v. 343.47 . $t$. IO. $f$. II.

Altica rufipes. Fab. Syst. Ent. I14. I4. Panz. Ent. Germ. 179. I7.

Panz. Faun. Germ. 21. t. Io.

Galleruca rufipes. Fab. Ent. Syst, i, b. 32. 94. Faun. Ingr, 66, 208.

Long. 
Lor. corp. $I \frac{1}{2}$ lin.

Habitat in plantis.

Descr. Elytra atro-cærulea, nitida. Faun. Suec.

69. Chry. violacea, capite thoraceque rufis, pe-fuscipes. dibus nigris.

Fab. Sp. Ins. i. 135. 109. Mant. i. 77. I41. Gmet. 1696. 224. Faun. Etrusc. 218. Hellw. 218.

Altica fuscipes. Fab. Syst. Ent. II4. I5. Panz. Ent. Germ. 179. I 8.

Panz. Faun. Germ.2I. t. II.

Galleruca fuscipes. Fab. Ent. Syst. i. b. 32. 95. Faun. Ingr. 67. 209. Payk. Faun. Suec. ii. 107.28.

Long. corp. I $\frac{3}{4}$ lin.

Habitat

Descr. Fortè varietas C. rufipedis, a quâ solis pedibus nigris differt. Syst. Ent.

70. Chry. cærulea, capite thorace antennis pedi-ruficornis. busque rufis, elytris crenato-striatis.

Chrysomela cæruleo-striata. De Geer, v. 343. 48.

Altica ruficornis. Panz. Enit. Germ. 179. 19.

Galleruca ruficornis. Fab. Ent. Syst. i. b. 32.96. Panz. Faun. Gern. 21. 12. Payk. Fann. Suec. i1. 108. 29.

Long. corp. $I \frac{x}{2}$ lin.

Habitat

Descr. Statura et magnitudo omninò C. rufipedis, at alia, Antennæ totæ rufæ. Thorax rufus, nitidus, lineâ transversâ posticâ impressâ. Elytra crenatostriata, cærulea. Peles rufi. Ent. Syst.

7 I. Chry. nigra hemisphærica, tibiis piceis. bemispheLinn. Syst. Nat. 595. 68. Vill. i. 143.89. Gmel. rica. 1696. 68. Fab. Sp. Ins. i. I37. 116. Miant. i. 78. 149. Faun. Etrusc. 223. Hellw: 223.

Chrysomela fusca. De Geer, v. $34^{8}, 56$.

o 4

Altica 
Altica hemisphærica. Fab. Syst. Ent. II5. 22. Panz. Ent. Germ. 181.30.

Galleruca hemisphærica. Fab. Ent. Syst. i. b. 34. 107. Cyphon hemisphærica. Payk. Faun. Suec. ii. I19.2.

Long. corp. $1 \frac{x}{2}$ lin.

\section{Habitat}

Descr. Tota nigra, vel nigro-picea, pedibus dilutioribus. Elytra oculo bene armato subtilissimè punctulata.

orbiculata. 72. Chry. suborbiculata convexa supernè viridis, antennis pedibusque ferrugineis.

Long. corp. $\mathrm{I} \frac{\pi}{3}$ lin.

Habitat

DESCR. Statura ferè $C$. bemispbarica, sed minor, et convexa. Thorax viridis, punctulatissimus. Elytra viridia, striata. Corpus subtùs nigro-æneum. Antennæ et pedes ferruginei. Femora postica viridia.

punctulata. 73. Chry. tota atra oblonga ovata.

An Chrysomela cruciferąum? Gmel. 1699. 246.

Long. corp. I lin.

Habitat

Descr. Totum corpus atrum, immaculatum. Thorax et elytra punctulis referta. Elytra non striata.

atricilla. 74. Chry. nigra, thorace elytris tibiisque testaceis, suturâ nigrâ.

Linn. Syst. Nat.594.55. Faun. Suec.537. Vill. i. 139.76. Gmel. 1693.55. Scop. 217. Fab. Sp. Ins. i. 135. 104. Mant. i. 77. 136. Scbrank, 156. Altica atricilla. Fab. Syst. Ent. II5. 17. Panz. Ent. Germ. 178. I4.

La Paillette. Geoff. i. 25I. I9.

Galleruca atricilla. Fab. Ent. Syst, i. b. 31.89. Payk. Faun. Suec, ii, 102, 23. var, $\beta$. 
Long. corp. I lin.

Habitat

Descr. Caput, pectus, abdomen, femoraque postica atra. Antennx, thorax, elytra et pedes testacea. Faun. Suec.

75. Chry. livida, pedibus testaceis, abdomine ca-exoleta. piteque fusco.

Linn. Syst. Nat.594.59. Faun. Suec.541. Vill. i.

I41. 80. Gmel. 1694. 59. De Geer, v. 338. 42.

Long. corp. $\frac{3}{4}$ lin.

Habitat

Descr. Caput fuscum. Antennæ, thorax et elytra fulvo-Hlava. Abdomen fuscum. Pedes testacei.

76. Chry. elytris pallidis, capite thoraceque rufo-femoralis. ferrugineis.

Chrysomela melanocephala? De Geer, v. 348. 57 .

'Long. corp. $\frac{3}{4}$ lin.

Habitat

DESCR. Antennæ nigræ, basi ferrugineæ. Os et oculi atri. Caput et thorax rufo-ferruginea, nitida. Elytra pallida, punctatissima, subnitida, suturâ obsoletè ferrugineâ. Corpus subtùs nigrum. Pedes quatuor antici omninò pallidè-testacei; duo postici testacei, femoribus ferrugineis, apice nigris. Affinis $C$. ocbroleucce, at caput et thorax rufo-ferruginea, nec flava; et totum corpus subtùs nigrum, nec flavescens, ut in C. ocbroleucâ.

77. Chry. nitida, thorace æneo, elytris lividis: suturalis. margine suturâque nigris.

Long. corp. I lin.

Habitat -

DESCR. Nigredo elytrorum marginis latior quam su- 
turæ. Pedes quatuor antici pallidi. Femora postica valde incrassata, rufa, apicibus nigris.

Verbasci. 78. Chry. rufo-picea, thorace elytrisque pallidis.

Altica Verbasci. Panz. Ent. Germ. I78. I3.

Panz. Faun. Germ.21. t. I7.

Long. corp. 2 lin.

Habitat in foliis Verlusci, juxta Nordovicum.

Descr. Antennæ rufæ, apice nigricantes. Corpus rufo-piceum. Elytra pallida. Thorax paululùm rufescit.

Thapsi. 79. Chry. fusca, thorace elytrisque pallidis, his suturầ nigrâ.

Long. corp. 2 lin.

Habitat in Verbasci Tbapsi foliis, tempore autumnali, non rarò.

Descr. Simillima C. Verbasci, at satis distincta. Antennæ totæ, et elytrorum sutura nigræ. Corpus et pedes fusco-nigri.

ocbroleucá. 80. Chry. elytris pallidis, capite thoraceque flavis. Long. corp. $\frac{3}{4}$ lin.

Habitat in hortis, sylvis, \&c.

DESCR, Antennæ nigræ, basi flavescentes. Os et oculi atri. Caput et thórax flava, nitida. Elytra pallida (non striata), sub-nitida. Corpus subtús flavescens. Pedes quatuor antici omninò flavescentes; duo pustici flavescentes, femoribus apice nigris, præcipuè margine exteriori.

testacea. 8r. Chry. hemisphærica rufa, oculis nigris.

Fab. Sp. Ins. i. 136. I Iо. Mant. i. 77. I42.

Altica testacea. Fab. Syst. Ent. I14.26. Panz. Ent. Germ. I80. 2 I.

Panz. Faun. Germ. 2I. t. I3.

Galleruca 
Galleruca testacea. Payk. Faun. Suec. ii. 104. 24. Fab. Ent. Syst. i. b. 33. 99.

L'Altise fauve sans stries. Geoff. i. 250.17.

Long. corp. $2 \frac{\pi}{4}$ lin.

Habitat

Descr. Magnitudo Coccineller 2-punctatce. Cocinellis omninò simillima, adco ut, nisi antennæe aliter suaderent, Coccinellam diceres. Tota rufa vel rufo-testacea, oculis nigris solummodò exceptis. Femora postica incrassata.

82. Chry. pallida testacea, oculis antennarumque tabida. apice nigris.

Fab. Sp. Ins. i. 136. 13. Mant. i. 78. 145.

Altica tabida. Fab. Syst. Ent. II5. I9. Panz. Ent. Germ. 180.24.

Panz. Faun. Germ. 21. t. I5.

Galleruca tabida. Fab. Ent. Syst, i, b. 33. I02.

L'Altise jaune. Geoff: i. 250. 18.

Long. corp. I $\frac{x}{2}$ lin.

Habitat

Descr. Totum corpus testaceum. Oculi solummodò et antennarum apices nigri sunt.

83. Chry. oblonga ferruginea glabra, thorace po-transversa. sticè foveolâ transversâ abbreviatâ impressâ.

Chrysomela exoleta. Fab. Sp.Ins. i. I36. II. Mant. i. 78. I43. Faun. Etrusc. 220. Hellw. 220.

Altica exoleta. Fab. Syst. Ent. I15. 17. Laich. 197.3.

Panz. Ent. Germ. I80. 22.

Panz. Faun. Germ. 21. t. I4.

Galleruca exoleta. Fab. Ent. Syst. i. b. 33. 100. Payk.

Faun. Suec. ii. 108. 30.

L'Altise fauve à stries. Geoff. i. 250 . I6.

Long. corp. 2 lin.

Habitat

DESCR。 
Descr. Totum corpus unicolor, ferrugineum. Oculi solummodò nigri. Ad apicem thoracis foveola sive linea transversa, quæ medium solùm occupat, neque ad latera pertingit. Elytra punctulis minimis conspersa, sub-striatim sitis.

Eupborbia. 84. Chry. oblonga atra, antennis tibiisque omnibus rufis.

Schrank, I55. Vill. i. I44. 91.

Galleruca Euphorbiæ.. Fab. Ent. Syst. i. b. 34. Io6. Payk. Faun. Suec. ii. I01. 20.

Long. corp. i lin.

Habitat in Eupborbiâ amygdaloide. Ex mus. D. Kirby.

DEscr. Tota atra, nitida, minimè ad æs aurumve inclinans. Elytra impunctata, nec striata. Antennæ tibiæque omnes rufæ.: Scbrank.

Pules. 85. Chry. atra nitens, antennis tibiisque rufis. Scbrank, I6o. Vill. i. 144. 93 .

Long. corp. $I \frac{x}{4}$ lin.

Habitat

Ex mus. D. Kirby.

Descr. Oblonga, tota nigra, nitens; thorace elytrisque subtilissimè at irregulariter punctatis. Scbrank.

adicornis. 86. Chry. cuprea tota, antennarum articulo tertio valdè incrassato.

Long. corp. $\mathrm{I} \frac{1}{4}$ lin.

Habitat in Resedâ luteâ. Ex mus. D. Kirby.

Descr. Totum corpus unicolor, sed quod in hoc singulare admodum, articulus tertius antennarum dilatatus, sive incrassatus, compressus.

$O b s$. In sexu altero antennæ æquales.

arata. 87. Chry. nigro-ænea, elytris striatis, antennis basi pedibusque rufis.

Long. 
Long. corp. $\frac{3}{4}$ lin.

Habitat -

Descr. Totum corpus nigro-æneum. Elytra obsoleté striata. Pedes rufi.

88. Chry. nigra lavis, elytrorum maculis duabus Cynoglossi. antennarum basi pedibusque rufis.

Long. corp. $1 \frac{8}{4}$ lin.

Habitat in Cynoglosso officinali.

DESCR. Corpus totum nigrum. Antennæ fuscæ, basi rufæ. Elytra nigra, lævia, sub lente punctata, maculis duabus magnis rufis; alterâ ad basin, alterâ ad apicem. Pedes rufi, femoribus posticis nigris.

89. Chry, testacea, capite nigro, pedibus testa- Ballota. ceis.

Long. corp. I lin.

Habitat in Ballotâ nigrâ.

D. Kirby.

DESCr. Antennæ longæ, fuscæ, basi testaceæ. Caput nigrum. Thorax rufo-testaceus. Elytra testacea, oculo armato punctulatissima, suturâ rufo-testaceâ. Pedes testacei.

90. Chry. nigra, elytris punctato-striatis, antennis striatula. pedibusque rufis.

Long. corp. $\frac{x}{2}$ lin.

\section{Habitat}

Descr. Minima in hâc familiâ, nitidiuscula. Tota nigra exceptis antennis pedibusque ferrugineo-rufis.

91. Chry. rufescens, thorace nigro-æeneo, elytris nigricollis. pallidis, abdomine nigro.

Long. corp. vix 2 lin.

Habitat in plantis tetradynamiis.

DESCR. 
Descr. Caput rufescens. Antennæ nigræ, basi rufie, Thorax nitidus, nigro-æneus. Elytra pallida, striata. Pedes rufi, femoribus posticis apice nigris.

picina.

92. Chry. picea nilida, thorace punctato, elytris striatis.

Long. corp. I lin.

Habitat In mus. D. Kirby.

Descr. Antennæe et os fulva. Caput, thorax, elytra et femora postica picea. Thorax punctis minutissimis

- conspersus. Elytra striata; striis ex punctis impressis. Pedes fulvi.

\section{CRYPTOCEPHALUS.}

Antenne filiformes.

Caput retuso-retractum.

Thorax valdè convexus, anticè parùm anm gustatus.

Elytra abdomine ferè longiora.

Corpus cylindricum, immarginatum, anticè posticèque obtusum.

tridentatus. I. Cryp. thorace cæruleo, elytris testaceis.

Fab. Syst. Ent. 106. 5. Sp. Ins. i. 139.8. Mant. i. 79. 9. Ent. Syst. i. b. 55. 14. Gmel. 1701.9. Faun. Etrusc. 234. Hellw. 234. Payk. Faun. Suec. ii. 129.2 .

Chrysomela tridentata. Linn. Syst. Nat.596.73. Faun. Suec.546. Vill.i. I47.1I4. Scbrank, I44. Petagn. I1. $5^{2}$.

Scbceff: Icon. t. 77. f. 5. t. 36. f. I3. De Geer, v. 333 . $3^{6 . t .}$. I0. f. 10.

Clytra 
Clytra tridentata. Fab. Supp. 112, 15. Panz. Ent。 Germ. I89.4. Laicb. I\%०. 4 .

Panz. Faun. Germ. 48, t. 12 .

Long. corp. $3 \frac{1}{2}$ lin.

Habitat in Populo, Salice.

DESCR. Corpus mediæ magnitudinis, capite, thorace et abdomine viridi sive cærulco nitidis. Elytra pallidè testacea. Antennæ nigræ, subpectinatæ. Pedes nigricantes. Singularis est nota, quod thorax posticè tricuspidatus dente medio, loco scutelli. Faun. Suec。

2. Cryp. thorace nigro, elytris rubris: punctis 4-punctatus, duobus nigris, antennis brevibus serratis.

Fab. Syst. Ent. 106. 2. Sp. Ins. i. 138.3. Mant. i. 78.3. Ent. Syst. i. b. 54. 6. Farn. Etrusc. 229. Hellw. 229. Faun. Ingr. 68. 212. Payk. Faun. Suec. ii. I28. I. Gmol. 1700.3.

Chrysomela 4-punctata. Linn. Syst. Nat. 596. 75. Faun. Suec. 547. Vill. i. 147. 116. Scbrank, 164. Don. Brit. Ins. t. I I . f. 1. 2. Scbaef. Icon. t. 6.f. I.2. Elem. t. 83. De Geer, v. 329.32.t. 10. f. 7. Act. Nidros. iv.320. 10. t.16.f.6. Mart. Eng. Ent.t.17. $f \cdot 50$.

Clytra 4-punctata. Fab. Supp. I10. 4. Panz. Ent. Germ.188. 3. Laicb. 167.2 .

Buprestis 4-punctata. Scop. 206.

La Melolonte quadrille à corcelet noir. Geoff. i. I95. I. t. $3 \cdot f \cdot 4$.

Long. corp. 5 lin.

Habitat in Salice. Lim.

Descr. Major reliquis omnibus, teretior, oblongior. In singulo elytro puncta majora duo, quorum prius magis ovatum, posterius majus transversum. Antemæe ferè pectinatæ. Thorax brevis. Fann. Suec.

3. Cryp. thorace atro polito, elytris rubris: ma-Lineala. culâ longitudinali atrâ.

Fab. Ent. Syst. i. b. 59. 30. Faun. Ingr. 69. 214.

Panz. Ent. Germ. I93. 7.

Crypt. 
Crypt. dispar var. ß. Payk. Faun. Suec. ii. 142. 15.

Crypt. oblongo-guttatus. Harr. 78.

Chrysomela bipunctata var. B. Linn. Syst. Nat. 597. 78. Faun. Suec. 548. Udd. Diss. 2 I.

Scbeff. Icon. $t .87 \cdot f \cdot 5$.

Chrysomela biliturata. Don. Brit. Ins. t. 99.f. т. 2. 3 .

Long. corp. $2 \frac{\pi}{2}$ lin.

Habitat

Descr. Corpus crassiusculum, oblongo-cylindricum. Thorax ater, nitidissimus. Elytra rubra, striata, punctis impressis; macula atra lata longitudinalis per medium decurrit.

Coryli.

4. Cryp. thorace elytrisque testaceis, pedibus nigris.

Fab. Syst. Ent. Iog. I6. Sp. Ins. i. I42. 24. Mant. i. 81. 28. Ent. Syst. i. b. 60.38. Faun. Ingr. 69.116. Payk. Faun. Suec. ii. 137. 10. Gmel. 1704. 28.

Panz. Faun. Germ.68. t.6.

Chrysomela Coryli. Linn. Syst. Nat. 598. 88. Faun. Suec. 555 .

Don. Brit. Ins. t. 321 . f. I. Scbaff. Icon. t. I87.f. 4 .

Long. corp. $2 \frac{x}{2}$ lin.

Habitat in Corylo. Ex mus. D. Burrell.

Descr. Corpus mediæ magnitudinis. Caput nigrum, inflexum, cum lineolâ arcuatâ flavâ ante singulos oculos. Antennæ corpore breviores. Thorax rufus, glaber. Elytra rufa, obtusa, striata, apice inflexa. Faun. Suec. Obs. Sexus alter variat thorace atro, nitido.

6-punctatus. 5. Cryp: thorace variegato, elytris rubris: maculis tribus nigris.

Fab. Syst. Ent. 109. 18. Sp. Ins. i. 142.27. Mant. i. 81. 34. Ent. Syst. i. b. 62. 44. Gmel. I705. 34. Faun. Etrusc. 242. Hellw. 242. Faun. Ingr. 69. 217. Panz. Ent. Germ. 195. I6. Payk. Faun. Suec. ii. I36. 9. Harr. 75. Laicb. 175. 5.

Chrysomela 6-punctata. Linn. Syst. Nat. 599. 92. 
Faun. Suec. 559. Scbrank, 167. Vill. i. 154. 6. Petagn. II. 54.

Scbeff. Icon. $t \cdot 3 \circ \cdot f \cdot 3$.

Buprestis 6-punctata. Scop. 208.

Long. corp. $2 \frac{3}{4}$ lin.

\section{Habitat - In mus. D. Lewin.}

Descr. Caput, antennæ, pedes, abdomen et omnia subtùs nigra. Thorax suprà ruber, maculis duabus margineque posticè nigris. Elytra rubra : in singulo tria puncta nigra, quorum duo anteriora paria parva; unicum posticum duplo majus. Faun. Suec.

6. Cryp. thorace cæruleo, elytris pedibusque cæ- sericeus. ruleis.

Fab. Syst. Ent. 112. 33. Sp. Ins. i. 146. 49. Mant. i. 84. 66. Ent. Syst. i. b. 63. 56. Faun. Etrusc. 237. Hellw. 237. Gmel. x706. 43. Panz. Ent. Germ. 196. 20. Payk. Faun. Suec, ii. I39. I2. Harr. 50. Laicb. I7I. I.

Chrysomela sericea., Linn. Syst. Nat. 598. 86. Faun. Suec. 554. Vill. i. 152. 126. Scbrank, 174. Petagn. 10. 50. De Geer, v. 334. 37.

Sulz. t. 3.f. 13. Scbaff. Icon. t. 87.f.5. Don. Brit. Ins.t.321.f. 2. Mart. Eng. Ent. t. 14. f. 6. 7.

Le Velours vert. Geoff. i. 233. 3.

Long. corp. $3_{4}^{1}$ lin.

Habitat in floribus syngenesiis.

DESCR. Insectum sericeo-viride, punctis, si lente observentur, contiguis, seque invicem tangentibus, excavatis. Elytra ponè dehiscunt. Thorax æqualis, minùs punctatus. Antennæ et pedes nigricantes. Faun. Suec. .

7. Cryp. thorace nitido elytrisque cæruleis, pedi- nitens. bus testaceis.

Fab. Syst. Ent. I10. 22. Sp. Ins. i. I44.33. Mant. i. 82. 44. Ent, Syst, i, b. 64. 57. Gmel. I706. 44. vol. I. Faun. 
Faun. Etrusc. 238. Hellw. 238. Panz. Ent. Germ. I96. 21. Payk. Faun. Suec. ii. I40. I3.

Panz. Faun. Germ. 68. t. 8.

Chrysomela nitens. Linn. Syst. Nat. 598. 84. Faun. Suec. 551. De Geer, v. 334. 38 . Vill. i. I51. 24. An Chry. nitida? Poda, 27. 8. $\beta$.

La Melolonte bleuette. Geoff. i. I97. 4.

Long. corp. $2 \frac{1}{2}$ lin.

Habitat

Ex mus. D. Clark.

DEScr. Variat colore viridi, cæruleo et nigricante. Os flavum. Pedes testacei, nunc omnes, nunc tantùm anteriores. Antennæ basi flavæ. Faun. Suec.

dorsalis. 8. Cryp. ferrugineus, suturâ nigrâ ad apicem ferrugineâ.

Long. corp. $\mathrm{I}_{\frac{2}{2}}$ lin.

Habitat

Descr. Totum corpus supernè, præter suturam elytrorum, unicolor, ferrugineum. Sutura nigra ; nigredo autem suturæ paulò ante apicem desinit. Abdomen subtùs fuscum, sive nigro-ferrugineum.

p̧usillus. 9. Cryp. flavus nitidus, elytris puncto maculâque nigris.

Fab. Ent. Syst. i. b. 69.86. Panz. Ent. Germ. 199.37. Faun. Etrusc. 255. Hellwe. 255. Gmel. I709.64.

Crypt. minutus. Fab. Ent. Syst. i. b. 70. 87. Panz. Ent. Germ. 200. 38. Payk. Faun. Suec. ii. 149.22.

Long. corp. I $-\mathbf{I} \frac{1}{2}$ lin.

\section{Habitat}

Descr. Antennæ nigræ, tenues, longitudine corporis, basi flavæ. Caput flavo-ferrugineum, margine postico nigro. Oculi nigri. Thorax nitidus, valdè gibbosus, flavo-ferrugineus. Elytra flava, punctato-striata, puncto calloso humerali nigro, maculâque dorsali apicem versus nigrâ. Pedes flavi. Abdomen atrum, nitidum. Foriat absque maculâ dorsali. An sexûs differentia?

Io Cryp. 
Io. Cryp. niger, capite thorace pedibus coleop-margineltrorumque limbo flavis. hom lus.

Chrysomela marginella. Don. Brit. Ins. t. 335 .

Long. corp. I $\frac{x}{3} \operatorname{lin}$.

Habitat

Captus in sylvâ dictâ Combe-

Wood, prope Kingston, in com. Surriensi. D. Kirby et D. MacLeay.

DESCR. Statura præcedentis. Caput fulvum, pallidovariegatum. Oculi nigri, reniformes. Antennæ corporis ferè longitudine, nigræ, basi rufæ. Thorax lævis, nitidissimus. Elytra nigra, nitida, punctatostriata, lateribus apicibusque latè flavis. Macula item communis flava, literam $\mathrm{X}$ referens, coleoptrorum basin signat. Abdomen nigrum.

I r. Cryp. ater, thorace nitido, ore pedibus anticis labiutus. basique antennarum lutescentibus.

Fab. Syst. Ent. 112. 33. Sp.Ins. i. 146.49. Mant. i. 84. 66. Ent. Syst. i. b. 65. 62. Gmel. 1709. 66. Faun. Etrusc. 244. Hellw. 244. Panz. Ent. Germ. 197.23. Payk. Faun. Suec. ii. 147. 22.

Panz. Faun. Germ. 68. t. 9.

Chrysomela labiata. Linn. Syst. Nat. 598.87. Faun. Suec. 553. Vill. i. 152. 127.

Long. corp. $\mathrm{I}_{4} \mathrm{l}$ lin.

Habitat in plantis.

DESCR. Elytra nigra, nitida, punctato-striata.

I 2. Cryp. ater nitidus, fronte thoracis margine ely-frontalis. trorumque latere exteriori anticè pedibusque flavis.

Long. corp. $I \frac{x}{2}$ lin.

Habitat

In mus. D. Kirby.

DESCR. Habitus et statura præcedentis, sed major. Caput anticè flavum, flavedine posticè bilobâ. Punctula duo nigra frontem signant. Antennæ nigræ, 
basi flavæ. Thorax ater, nitidissimus, margine laterali antice flavo. Pedes rufo-fulvi, femoribus posticis nigris.

Barbarec. 13. Cryp. cylindrico-ovatus ater, antennis basi oreque ferrugineis.

Gmel. 1709.7 .

Chrysomela Barbareæ. Linn. Syst. Nat.598.85. Faun. Suec. 552. Vill. i. 151. I25.

Long. corp. 2 lin.

Habitat in floribus. In mus. D. Latbbury.

Descr. Antennæ corpore vix breviores, basi ferrugineæ. Os flavescens. Thorax ater, politus. Elytra nigra, non nitida, punctis substriata, sed apice glabriora. Pedes nigri. Femora crassiuscula. Faun. Suec.

Morai. 14. Cryp. thorace nigro, elytris nigris: maculis duabus rubris marginalibus.

Fab. Syst. Ent. 110. 25. Sp. Ins. i. 144.37. Mant. i. 82. 49. Ent. Syst. i. b. 66. 67. Gmel. 1707. 49. Faun. Etrusc. 235. Mant. 81. Hellw. 235. Mant. 81. Payk. Faun. Suec. ii. 145. 17. Panz. Ent. Germ. 198. 28. Harr. 70.

Panz. Faun. Germ. 68. $t$. II.

Chrysomela Moræi. Linn. Syst. Nat. 597.82. Faun. Suec. 550. Vill. i. I50. 122. Poda, 28. 9. $\beta$. Scbeff. Icon. t. $138, f \cdot 2 \cdot t \cdot 30 \cdot f \cdot 5$.

Buprestis Moræi. Scop. 202.

J_ong. corp. $2 \frac{x}{4} \operatorname{lin}$.

Habitat -

Ex mus. D. Hill.

DESCR. Caput nigrum, fronte punctis duobus testaceis. Thorax ater, lævis, margine antico angulisque posticis albis. Elytra nigra, lævia; in singulis maculæ duæ flavæ, altera ad apicem, altera ad marginis exterioris medium. Femora antica a latere anteriori subferruginea. Faun. Suec. 


\section{[ 213 ]}

\section{AUCHENIA.}

Antenne filiformes.

Gaput exsertum.

Thorax cylindricus, elytris angustior.

Corpus oblongum.

J. Auch. rubra, thorace utrinque impresso.

merdigera.

Chrysomela merdigera. Linn. Syst. Nat.599.77. Faun. Suec. 563. Vill. i. 159. 161. Scbrank, 182. Faun. Fred. 9.82.

Sulz.t. 3.f. I4. Scbaef. Elem.t.52. Icon.t.4.f.4. et t. 34.f. 4. Mart. Eng. Ent. t. I7. f. 47.

Chrysomela rubra Liliorum. De Geer, v. 338. 43 .

Crioceris merdigera. Fab. Syst. Ent. I 20. IO.

Ins. i. I52. 19. Mant. i. 88. 25. Ent. Syst. i. b. 6. 19. Faun. Etrusc. 265. Hellw. 265. Faun. Ingr.61. 192. Petagn. 12.57. Panz. Ent. Germ. 167. 3. Payk. Faun. Suec. ii. 80. 5. Laich. 186. I. Panz. Faun. Germ. 45. $t .2$.

Le Criocère rouge du Lys. Geoff. i. 239. I.

Cryptocephalus merdigera. Gmel. 1720. 147 .

Attelabus Lilii. Scop. I12.

Lema merdigera. Fab. Ent. Syst. Supp.9r. 5 .

Long. corp. $3 \frac{x}{2}$ lin.

Habitat in Lilio.

DESCR. Rubra sunt thorax, elytra, caput supernè, pedes. Nigra vero antennæ, oculi, pedum genicula, abdomen, scutellum, caput subtùs, ut et thorax subtùs. Thorax elytris longè angustior, teres, sed ad utrumque latus cavitate impressầ notatus. Elytra punctis minutissimis excavatis striata sunt.

Variat capite et pedibus nigris. Faun. Suec.
P 3
2. Auch. 
I2-punctata. 2. Auch. rufa, elytris punctis sex, pectore pedumque geniculis nigris.

Chrysomela 12-punctata. Linn. Syst. Nat. 601. II0. Faun. Suec. 568. Vill. i. 162. 170. Scbrank, 183. Poda, 28. 10. Harr. 261.

Scbaff. Icon. t. 4.f.5. Friscb. 13. t. 28. Mart. Eng. Ent. t. $16 . f \cdot 3^{6}$.

Crioceris 12-punctata. Fab. Syst. Ent. I20. II. Sp. Ins. i. 128.71. Mant. i. 88. 26. Ent. Syst. i. b. 7. 20. Panz. Ent. Germ. 168.5. Faun. Ingr. 62. 193. Laicb. 187.2. Payk. Faun. Suec. ii. 81.6. Faun. Etrusc. 266. Hellw. 266.

Panz. Faun. Germ. 45. t. 3 .

Le Criocère rouge à points noirs. Geoff. i, 240. $t .4 \cdot f \cdot 5$. Cryptocephalus I2-punctatus. Gmel. I669. 6. Attelabus 12-punctatus. Scop. II 5 .

Lema I2-punctata. Fab. Ent. Syst. Supp. 91. 6.

Long. corp. $2 \frac{2}{3}$ lin.

Habitat in Asparago.

Ex mus. D. Latham.

Descr. Antennæ nigræ sunt. Thorax immaculatus. Faun. Suec.

Asparagi. 3. Auch. thorace rubro: punctis duobus nigris, elytris flavis : cruce punctisque quatuor nigris.

Chrysomela Asparagi. Linn. Syst, Nat. 601. I12. Faun. Suec. 567. Vill. i. 163. 173. Scbrank, 185. Faun. Fred. 9. 83. De Geer, v. 34I. 45.

Friscb. t. 6. Don. Brit. Ins. t. 28. Roes. 2. Scar. 3. t. 4.f. I-3. Scbaef. Icon. t. 52.f. 9. 10. Mart. Eng. Ent. t. I7.f. 49 .

Crioceris Asparagi. Fab. Syst. Ent. I2r. 19. Sp. Ins. i. I55. 25. Mant. i. 90. 45. Ent. Syst. i. b. I0. 4I. Preys. Bob. Ins. 94. 89. Panz. Ent. Germ. 169. II. Faun. Ingr. 62. 195. Payk. Faun. Suec. ii. 82.7 .

I.e Criocère porte croix de l'Asperge. Geoff. i. 24r. 3. Cryptocephalus Asparagi. Gmel. 1723. 167.

Attelabus Asparagi. Scop. I I 3 .

Lemą Asparagi. Fizb. Ent. Syst. Supp. 93. 24.

Long. 
Long. corp. $2 \frac{3}{4}$ lin.

Habitat in Asparagi ramis, quos consumit larva.

DESCr. Caput nigro-cæruleum. Antennæ nigræ. Thorax angustus, cylindraceus, punctis duobus nigris a tergo. Elytra oblonga, flava, versus marginem exteriorem secundum totam longitudinem fulva. Macula cruciformis cærulea tegit coleoptra, cujus truncus incumbit margini elytri utriusque interioris secundum totam longitudinem; at rami breves sunt, nec marginem exteriorem elytrorum adtingunt; ad basin elytri macula oblonga cærulea, quæ non conjungitur cum cruce; versus apicem elytri punctum cæruleum rotundatum, quod sæpè adnascitur basi crucis.

Larva nigro-fusca, glabra. Faun. Suec.

4. Auch. cærulea, thoracis lateribus gibbis.

cyanella.

Chrysomela cyanella. Linn. Syst. Nat. 600. 104. Faun. Suec. 572. Vill. i. 161. 167. Scbrank, 186. De Geer, v. 340.44.

Mart. Eng. Ent. t. I5 $f_{\cdot} \cdot 25$.

Crioceris cyanella. Fab. Syst. Ent. т21. I6. Sp. Ins. i. I54. 30. Mant. i. 89.39. Ent. Syst. i. b. 9. 35. Faun. Etrusc. 269. Hellw. 269. Panz. Ent. Germ. 168. 8. Payk. Faun. Suec. ii. 83.9.

Le Criocère tout bleu. Geoff. i. $243 \cdot 5$.

Cryptocephalus cyanellus. Gmel. 1722. 161.

Lema cyanella. Fab. Ent. Syst. Supp. 93. 19.

Long. corp. $\mathrm{I}_{\frac{4}{4}}$ lin.

\section{Habitat}

DESCR. Corpus totum obscurè cæruleum, nitidum. Antennæ solæ nigræ. Faun. Suec.

5. Auch. cærulea, thorace pedibusque rufis.

melanopa.

Chrysomela melanopa. Linn. Syst. Nat. 601. 103. Faun. Suec. 573. Vill. i. 162. I68. Scbrank, 179. Faun. Fred.9.87. De Geer, v. 342. 46.

Mart. Eng. Ent. t. I $7 . f .53$.

Crioceris melanopa. Fab. Syst. Ent. 121, 17. Sp.Ins.

$$
\text { P } 4 \text { i. I55. }
$$


i. I55.31. Mant. i. 89.48. Ent. Syst. i. b. 10.36. Panz. Ent. Germ. I68. 9. Faun. Ingr. 62. 194. Faun. Etrusc. 270. Hellw.270. Payk. Faun. Suec. ii. 82. 8. Laich. 189.4 .

Le Criocère bleu à corselet rouge. Geoff. i. 242. 4.

Cryptocephalus melanopus. Gmel. 1722. 162.

Lema melanopa. Fab. Ent. Syst. Supp. 93. 20.

Long. corp. $2 \frac{1}{4}$ lin.

Habitat in nemoribus et pratis.

Descr. Corpus oblongum, cæruleum. Thorax subglobosus, ferrugineus. Femora ferruginea. Palmæ nigræ, Faun. Suec.

favipes. 6. Auch. nigra, thorace pedibusque flavis.

Chrysomela flavipes. Linn. Syst. Nat.601. 106. Vill. i. 152.169 .

Crioceris flavipes. Fab. Sp. Ins. i. I55.32. Mant. i. 89. 41. Ent. Syst.' i. b. 10. 37. Payk. Faun. Suec. ii. $79 \cdot 4$.

Panz. Faun. Germ. 32.t. 4.

Galleruca flavipes, Panz. Ent. Germ. I74. 20.

Le Lupère noir à corcelet et pattes rouges. Geoff. i. 23 T. I. t. 4 . f. 2 .

Lema flavipes. Fab. Ent. Syst. Supp. 93. 21 .

Long. corp. $I_{4}^{3}$ lin.

Habitat

DESCr. Simillima Aucb. melanope, sed thorax pallidior planior. Elytra atra. Antennæ fuscæ. Pedes flavi, exceptâ basi femorum, Linn. Syst. Nat.

subspinosa. 7. Auch. nigra, capite thorace pedibusque rufis, thorace spinoso.

Chrysomela subspinosa. Vill. i. 165. 179.

Crioceris subspinosa. Fab. Sp. Ins. i. I 55.33. Mant. i. 89. 42. Ent. Syst. i. b. 10. 38. Panz. Ent. Germ. I69. Iо. Payk. Faun. Sucec. ii. 78.3 .

Cryptocephalus subspinosus, Gmel. 1723 . I64. 
Lema subșinosa. Fab. Ent. Syst. Supp. 93. 22.

Long. corp. $1 \frac{1}{2}$ lin.

Habitat in Ulmo campestri.

DESCR. Caput rufum, antennis filiformibus nigris, basi rufis. Thorax utrinque unispinosus, subpunctatus, rufus, immaculatus. Elytra punctata, obscurè nigra. Abdomen nigrum. Pedes rufi. Fab. Sp. Ins.

Obs. Color thoracis pedumque flavescit potiùs quàm rufescit.

8. Auch. atra, ore thorace spinoso pedibusque flavicollis. flavis.

Long. corp. 2 lin.

Habitat

DESCR. Habitus et statura præcedentis, sed major. Caput flavum, vertice oculisque atris. Maxillæ nigræ. Antennæ basi flavæ. Truncus flavus. Thorax punctatus, utrinque dente armatus. Elytra aterrima, nitida, excavato-punctatissima. Abdomen atrum. Pedes flavi.

9. Auch. atra nitida, antennarum basi pedibus-rufipes. que flavis.

Crioceris rufipes. Fab. Mant. i. 43. 89. Ent. Syst. i. b.

39. I0.

Panz. Faun. Germ. 32. t. 5 .

Galleruca rufipes. Panz. Ent. Germ. I74. 2I.

Chrysomela Xanthopoda. Scbrank, I77.

Luperus Xanthopoda: Harr. $25^{8}$.

Le Lupère noir à pattes rouges. Geoff. i. 231. 2.

Long. corp. 2 lin.

Habitat in Salicibus.

DESCr. Animalculum hoc pulcherrimum est. Totum. corpus suprà amœnè nitet. Antennæ nigræ, basi flavæ. Thorax et elytra atra, lævissima, punctulis minutis conspersa. Corpus subtùs atrum, læve. Pedes flavi, femoribus basi nigris.

10. Auch. 
birla. Io. Auch. villosa nigra, elytris testaceis.

Chrysomela hirta. Linn. Syst. Nat. 602. I19. Faun. Suec. 578. Vill. i. 167.189. Scbrank, 189. Faun. Fred. 9.88.

Mart. Eng. Ent.t. I7 f. 55 .

Cryptocephalus hirtus. Gmel. 1730. 226.

Lagria hirta. Fab. Syst. Ent. 125.8. Sp. Ins. i. I60. I1. Mant. i. 93. 13. Ent. Syst. i. b. 79. 4. Faun. Etrusc. 274. Helliv. 274. Panz. Ent. Germ.292.2. Payk. Faun. Suec. ii. I54. I.

Tenebrio villosus. De Geer, v. 44. 6. t. 2.f. 23. 24 .

Long. corp. $3 \frac{3}{4}$ lin.

Habitat in sepibus.

DESCr. Thorax ater. Elytra aureo-testacea, punctulacissima. Antennæ et pedes atri. Corpus totum pubescens. Elytra subdiaphana, subflexilia, ut in Cantbaridibus.

4-maculata. II. Auch. thorace pedibusque flavis, elytris flavis: maculis duabus nigris remotissimis.

Chrysomela 4-maculata. Linn. Syst. Nat. 600. I03. Faun. Suec. 571. Vill. i. 161. 166.

Petagn. Ins. Calab. II. 54. t. 30.31. mala. Pontop. Dan. Atl.t. 29.

Cryptocephalus 4-maculatus. Fab. Syst. Ent. 107. 10. Sp. Ins, i. 140. 14. Mant. i. 87.18.

Galleruca 4-maculata. Fab. Ent. Syst. i. b. 20. 35. Payk. Fain. Suec. ii. 9I. 9.

Crioceris 4-maculata. Fab. Ent. Syst. i. b. 12. 50. Long. corp. 3 lin.

Habitat—Capta prope Richmond. Miss Hill.

Descr. Corpus oblongum, totum pallidè flavum. Caput, exceptâ fronte, nigrum. Elytra maculâ rotundâ nigrâ ad basin, et majore apicem vergas. Faun. Suec.

Macula postica elytrorum in quibusdam gemina. Syst. Nat, Thorax aliis niger, aliis flavus, Linn. Mss.

12. Auch. 
12. Auch. oblongiuscula ferruginea, elytris mar-tenella. gine thoraceque flavis.

Chrysomela tenella. Linn. Syst. Nat.600. 102. Faun. Suec. 564. Vill. i. 16r. 165.

Mart. Eng. Ent. t. I6.f.34.

Crioceris tenella. Fab. Syst. Ent. I19.6. Sp. Ins. i. I5I. Io. Mant. i. 87. II. Faun. Etrusc, 268. Hellw. 268.

Cryptocephalus tenellus. Gmel. 1719. 133.

Galleruca tenella, Fab. Ent. Syst. i. b. 23. 50. Panz. Ent. Germ. 174. 22. Faun. Ingr. 65. 201. Payk. Faun. Suec. ii. 93. II.

Long. corp. $2 \frac{1}{2}$ lin.

Habitat in sepibus.

Descr. Thorax flavus, absque maculis. Elytra ferruginea, flavo marginata. Antennæ flavescentes. Pedes flavi. Abdomen fuscum. Faun. Suec.

\section{GRIOCERIS.}

Antennce filiformes.

Cafut exsertum.

Thorax planus, submarginatus, anticè parùm angustatus.

Corpus oblongum, depressum.

I. Cri. flava tota.

Chrysomela sulphurea. Linn. Syst. Nat. 602. 14. Vill. sulpburea.

i. 166.184. Scbrank, 187.

Mart. Eng. Ent.t. I7. $f \cdot 44$.

Cryptocephalus sulphureus. Gmel. I7I4. 98.

Cistela 
Cistela sulphurea. Fab. Syst. Ent. I17.5. Sp. Ins. i. 147. 6. Mant. i. 85. 8. Ent. Syst. i. b. 43. 8. Faun. Eirusc. 262. Hellw. 262. Panz. Ent. Germ. 187. 5. Payk. Faun. Succ. ii. 125. 7.

oliv. iii. $54 \cdot 6 \cdot 5 \cdot t$. 1.f. 6 .

Tenebrio tlavus. Scop. 260 .

I. Ténébrion jaune. Groff: i. 35 I. II.

Long. corp. 4 lin.

Habitat in floribus umbellatis. Fab.

DEscr. Corpus totum flavum, sive sulphureum. Oculi nigri. Antennæ et palmæ pedum fusco-ferrugineæ.

cervina.

2. Cri. livida, thorace posticè transverso.

Chrysomela cervina. Linn. Syst. Nat.602. I15. Faun. Suec. 575. Vill. i. 166.185.

Don. Brit. Ins. t. 78. f. 4. Mart. Eng. Ent. t. I7. $f \cdot 5^{6}$.

Cistela cervina. Fab. Syst. Ent. 116. 1. Sp. Ins. i. I46. I. Mant. i. 42. I. Ent. Syst. i.b.42. I. Faun. Etrusc. 258. Hellw. 258. Panz. Ent. Germ. I83. I. Oliv. iii. 54. 4. I. t. 1. $f$.2. a.

Cryptocephalus cervinus. Gmel. 1713. 92. Petagn. Ins. Calab. I1. 55 .

Atopa cervina. Pay'k. Faun. Suec. ii. I16. I. var. B.

Long. corp. 5 lin.

Habitat in arboribus. Linn. In com. Devon. cepit D. Hill.

Descr. Corpus oblongum, suprà fuscum, subtùs nigrum. Thorax subovatus, posticè transversus, convexus. Elytra parùm marginata. Faun. Suec.

Color dorsi constat e pilis vix conspicuis, glauco-fuscis. Syst. Nat.

cinerea, 3. Cri. testacca, thorace posticè transverso, antennis concoloribus, abdomine nigro.

Cistela cinerea. Fab. Ent. Syst. i. b. 42. 2. Cryptocephalus cinereus. Gmel. I713. 93 . 
Atopa cervina R. Payk. Faun. Suec. ii. 116. 1.

Chrysomela cervina. Don. Brit. Ins. $t .78 . f \cdot 3$.

Long. corp. 5 lin.

Habitat

Capta prope Dubrem, Cantio.

D. Lyon.

DESCr. Habitus, forma, magnitudo Cri. cervine, at differt, thorace elytrisque testaceis, nec lividis. Antennæ et pedes testacei. An sexûs differentia?

Obs. At hanc cum illa una habitare nunquam accepimus. Hæc in Cantio sæpiùs, illa in agro Devoniensi rarò capta eșt.

4. Cri. nigra, elytris subcæruleis, plantis ferru-caraboides. gineis.

Chrysumela caraboides. Linn. Syst. Nat. 602. 16. Faun. Suec. 574. Vill. i. 166. 186.

Mart. Eng. Ent. t. I7.f. $5^{8}$.

Helops serratus. Fab. Syst. Ent. 257.3. Sp. Ins. i. 3.325. Mant. i. 213.4. Ent. Syst. i. a. 118. 8. Payk. Faun. Suec. i. 94. I.

Pimelia serrata. Gmel. 2009. 64.

Serropalpus caraboides. Oliv. iii. 57 bis 5. I. $t$. 1 . $f$. 1 . Long. corp. 7 lin.

Habitat sub cortice Salicis.

DEscr. Statura Carabi, sed thorax anticè rotundatus, posticè subtrilobus, angulis acutis. Elytra striata, nigro-cærulẹa. Faun: Suec.

5. Cri. thorace planiusculo posticè transverso, nigra. elytris striatis punctulatissimis.

Long. corp. 7 lin.

Habitat $\longrightarrow$ Capta jamdudùm mortua sub cor-

- tice. D. Sheppard.

Descr. Primo intuitu Cri. caraboidi similis, sed magis ovata. Antennæ desunt. Caput exsertum. 
Thorax planiusculus, punctulatissimus. Elytra octo striata, striâ abbreviatâ aliâ ad basin per quartam partem suturæ longitudinis ductâ; striarum interstitia punctulatissima.

ceramboi- 6. Cri. nigra, elytris testaceis, antennis serratis. des.

Chrysomela ceramboides. Linn. Syst. Nat. 602. II7. Faun. Suec. 576. Vill. i. 166. 187. Scbrank, 188.

Cistela ceramboides. Fab. Syst. Ent. II6. 3. Sp. Ins. i. 147.4. Mant. i. 85.5. Ent. Syst. i. b. 42.4. Petagn. Ins. Calab. 12. 56. Fann. Etrusc. 257. Hellw. 257. Panz. Ent. Germ. 183. 3. Payk. Faun. Suec. ii. 121. I.

Oliv. iii. 54.4.2. $t$. 1. $f \cdot 4 \cdot$ a. b.

Cryptocephalus cēramboides, Gmel. I713. 95.

Long. corp. 5 lin.

\section{Habitat}

Descr. Corpus nigrum. Thorax ovatus, anteriùs angustior, posticè sub-transversus. Elytra testacea, substriata. Faun. Suec.

murina: 7. Cri. nigra, elytris pedibusque testaceis.

Chrysomela murina. Linn. Syst. Nat. 602.118. Faun. Suec. 577. Vill. i. 167. 188.

Mart. Eng. Ent. t. 16. f. 32 .

Cistela murina. Fab. Syst. Ent. Iт7. 7. Sp. Ins. i. 147. 9. Mant. i. 85. 13. Ent. Syst. i. b. 44. 16. Faun. Etrusc. 260. Hellw. 260. Panz. Ent. Germ. 185. 12. Payk. Faun. Suec. ii. 126. 8.

Oliv. iii. 54.7.7.t. I. f. 10. a. b.

Cryptocephalus murinus. Gmel. I7 I4. 103.

Long. corp. 3 lin.

Habitat in floribus umbellatis.

DEscr. Corpus præcedenti dimidio minus, ovato-oblongum, nigrum. Thorax semiovatus, convexus, posticè transversus. Pedes ferruginei. Elytra tsstacea, minimè striata. Faun. Suec. 
8. Cri. nigro-fusca tomentosa, antennis pedibus-fusea. que ferrugineis.

Long. corp. $2 \frac{1}{2}$ lin.

Habitat in floribus umbellatis.

DEscr. Color obscuriusculus, ex fusco-niger. Thorax et elytra tomento subfulvo vestiuntur. Elytra striis impressis obsoletissimis. Abdomen nigrum. Alæ nigræ. Antennæ solummodo et pedes ferruginei.

9. Cri. ferruginea tota, elytris striatis.

castanea.

Long, corp. 5 lin.

Habitat $\longrightarrow$

Descr. Antennæ ferrugineæ plus quam medium corporis attingunt. Thorax subfuscus, punctulatus. Elytra striata.

I0. Cri. nigra nitida, elytris striatis, antennarum erytbropa. basi pedibusque ferrugineis.

An Cistela fulvipes? Fab. Ent. Syst, i. b. 44. 14.

Long. corp. 5 lin.

Habitat

In mus. D. Milne.

Descr. Statura et magnitudo Cri. castanea, cui maximè affinis, sed in plurimis differt. Antennæ fuscæ, basi solâ ferrugineâ, nec ferrugineæ totæ. Corpus nigrum, sive nigro-æneum. Elytra nigro-ænea, striata, margine exteriori prope apicem ferrugineo. Pedes ferruginei.

I I. Cri. atra, antennarum apice ferrugineo.

Long. corp. 2 lin.

Habitat

Descr. Totum corpus aterrimum, obscurum. Elytra obsoletè striata. Antennarum articuli penultimus et antepenultimus ferruginei; basis ipsa atra est.

12. Cri. 
Nymplece. 12. Cri. fusca, elytris flavescentibus : margine prominulo.

Fab. Syst. Ent. 118. 1. Sp.Ins. i. 150.3. Mant. i. 86. 3 .

Chrysomela Nymphææ. Linn. Syst. Nat. 600. 99. Faun. Suec. 565. Vill. i. 159. 162.

Mart. Eng. Ent, t. I7. f. 46 .

Chrysomela Nymphææ. De Geer, v. 326. 31. t. 10. f. I. 2 .

Cryptocephalus Nymphææ. Gmel. I718. 125.

Galleruca Nymphææ. Fab. Ent. Syst. i. b. 21. 39. Panz. Ent. Germ. I73. I6. Faun. Ingr. 64. I99. Payk. Faun. Suec. ii. 92. Io.

La Galeruque aquatique. Geoff. i. 254. 4.

Long. corp. 3 lin.

Habitat in foliis Nymphece.

Descr. Caput fuscum. Thorax sub-flavus, inæqualis. Elytra planiuscula, nigra, opaca, punctis excavata, margine laterali et postico (non vero suturam versus) flavo. Pedes flavi. Antennæ nigro et flavo alternatæ, corpore dimidio breviores. Alæ fuscæ, venis nigris. Abdomen a tergo flavescens, lineâ transversâ, nigrâ, latâ, in singulo segmento, at latere terram spectante nigrum.

Larva nigra est, glabra, subtùs flava. Faun. Suec.

Viburni. 13. Cri. obscuro-ænea, marginibus thoracis punctoque elytrorum nigris.

An Crioceris lineola? Fab. Sp. Ins. i. I49. 2. Mant. i. 86. 2.

An Galleruca lineola? Fab. Ent. Syst. i. b. 21. $3^{8 .}$ Pans. Ent. Germ. 173. I5.

Long. corp. 3 lin.

Habitat in foliis Viburni Opuli. D. Curtis et D. Sbeppard.

Descr. Totum corpus sordidè testaceum, sive obscuroæneum. Antennæ nigræ. Oculi nigri Thorax prsticè lineâ abbreviatâ nigrầ excavatâ, et marginbus rịugris. 
Elytra marginata ; intra marginem linea longitudinalis elevata, cujus lineæ basis nigra, punctum nigrum refert. Porro ad suturam linea obtusa; et gibbositas quædam longitudinalis elevatior. Pedes et abdomen subtùs sordidè testacei.

14. Cri. nigra, thorace elytrisque obscurè-testa-Capree. ceis, thorace punctis quatuor impressis.

Fab. Syst. Ent. 118. 2. Sp. Ins. 1. 150. 4. Faun. Etrusc. Mant. 35.85 .

Chrysomela Capreæ. Linn. Syst. Nat, 600. 100. Faun. Suec. 566. Vill. i. 160. 163.

Mart. Eng. Ent. t. 17. $f$. 45 .

Chrysomela grisea Alni. De Geer, v. $3^{25} \cdot 30 \cdot t \cdot 9 \cdot f \cdot 3^{6}$. Cryptocephalus Capreæ. Gmel. I718. 126.

Galleruca Capreæ. Fab. Ent. Syst. i. b. 21. 40. Panz. Ent. Germ. I73. 17. Faun. Ingr. 64. 200. Payk. Faun. Suec. ii. 88. 4.

La Galeruque grisette. Geoff. i. 254. 5 .

Long. corp. $2 \frac{1}{2}$ lin.

Habitat in Salice Capreá.

Descr. Antennæ, caput et oculi nigra. Thorax obscurè testaceus, punctis sive scrobibus quatuor impressis, quorum duo lateralia, duo autem in lineâ excavatâ medium thoracis percurrenti sita sunt. Elytra mollia, flexilia, obscurè-testacea, immaculata, punctato-rugosa, marginata, margine prominulo. Abdomen nigrum. Pedes quatuor antici femoribus nigris, tibiis tarsisque lividis; duo postici nigri, geniculis lividis.

15. Cri. testacea, thorace posticè transverso, an-mollis. tennis nigris.

Long. corp. $2 \frac{1}{4}$ lin.

\section{Habitat}

Descr. Antennæ nigræ, basi testaceæ. Oculi nigri. Per cætera animal omninò testaceum est. Elytra mollia, flexilia, ut in Cantbaridibus, villo brevissimo obsita. Variat thorace disco nigro et testaceo.

$$
\text { voL. I. }
$$

I6. Cri. 
impressa. 16. Cri. nigro-ænea villosa, punctis numerosissimis impressis.

Long. corp. $2 \frac{x}{2}$ lin.

Habitat

DESCR. Totum corpus unicolor, nigro-æneum, hirtum. Thorax valdè convexus, punctatus. Elytra punctis majusculis, numerosissimis, impresşis, subconfluen-

- tibus, nullo ordine positis, conspersa. Antennarum articuli duo primi, nec basis ipsa, testacei. Tibiæ testaceæ, annulo nigro. Plantæ testaceæ.

nigricans. 17. Cri. fusco-nigricans, antennis pedibusque ferrugineis.

Long. corp. $1 \frac{2}{3}$ lin.

Habitat

DeSCR. Habitu et staturâ cum Cri. molle concordat. Ex fusco nigricans, villosulus totus.

padi. I8. Cri. obscurè ferruginea, capite abdomineque nigris.

Chrysomela Padi. Linn. Syst. Nat. 588. I4. Faun. Suec. 513. Vill. i. 121. 10. Goeze, i. 257. 16.

Long. corp. $I_{4}^{\frac{t}{4}}$ lin.

Habitat sub muscis ad arborum radices.

Descr. Antennæ tenues, et ferè dimidium corporis æquant, basi ferrugineæ, apice nigræ. . Caput et abdomen ex fusco-nigra. Thorax ferrugineus, glaber, nitidiusculus. Elytra ferruginea, et sub lente villosa, punctulis minutis ornata. Pedes pallidiores.

concolor. 19. Cri. testacea, oculis nigris.

Long. corp. $I \frac{1}{5}$ lin.

Habitat

DESCR. Staturâ cum præcedenti concordat. Villosula tota, testacea, oculis solis nigris.

20. Cri. 
20. Cri. testacea, elytris apice nigris.

Cistela pallida. Fab. Syst. Ent. II7. 8. Sp. Ins. i. I48. I. Mant. i. 86. I7. Ent. Syst. i. b. 46.26. Panz. Ent. Germ. 187. 25.

Panz. Faun. Germ. 8. t. 7 .

Long. corp: 2 lin.

Habitat

DEscr. Facies omninò Cantharidis, antennis et thorace; sed abdominis latera non plicato-papillosa. Elytra non ut in Cantbaridibus obtusa, sed acutiuscula, tomentosa, apice nigra. Abdomen subtùs nigrum, nitidiusculum. Pedes testacei.

21. Cri. oblongiuscula ferruginea, elytris maculâ calmarienlongitudinali nigricante.

pallida:

Fab. Syst. Ent. i19. 4. Sp. Ins. i. 150.6. Mant. i. 87.7. Faun. Etrusc. 264. Hellw. 264.

Chrysomela calmariensis. Linn, Syst. Nat. 600. I0I. Vill. i. I60. 164.

Galleruca calmariensis. Fab. Ent. Syst. i. b. 23. 46. Panz. Ent.Germ. I73. 18. Payk. Faun. Suec, ii.90.8.

Long. corp. 2 lin.

Habitat

Descr. Statura Cri. Caprea. Antennæ fuscæ. Thorax testaceus, utrinque depressus, medio longitudinali nigro. Elytra testacea, lineâ longitudinali nigrâ, a basi ferè ad apicem ductâ. Abdomen fuscum. Pedes pallidi. Linn. Syst. Nat.

22. Cri. nigra, thorace anticè flavo, elytris flavis: circumfusa. margine exteriori suturâque nigris.

Long. corp. $1 \frac{3}{4}$ lin.

Habitat

Ex mus. Miss Hill.

DESCR. Antennæ ferè longitudine corporis, nigræ, basi rufescentes. Caput nigrum. Thorax anticè flavus, posticè niger, glaber; nigredo medio biloba est. Elytra glabra, flava, suturâ et margine toto exteriori

Q 2 nigris. sis. 
nigris. Abdomen subtùs atrum. Pedes atri, tibiis sordicliùs ferrugineis.

Cratagi. 23. Cri. rubra, elytris maculis duabus linearibus nigris.

Chrysomela Cratægi. Forst. Cent. Ins. 28.

Mart. Eng. Ent.t. 14.f. 4 .

Long. corp. 2-2 $\frac{x}{2}$ lin.

Habitat in Cratego Oxyaciantbâ.

Descr. Antennæ nigræ, articulis ad basin rufescentibus. Oculi nigri. Caput, thorax et elytra obscurè rubra, rugoso-punctata. Elytra lineis duabus abbreviatis nigris, quarum una ad basin media inter suturam et marginem exteriorem, altera ad medium marginis exterioris, ambæ longitudinales. Pedes rufi. Scutellum et abdomen atra.

Variat pedibus nigris.

Obs. Linea baseos elytrorum post mortem obsoletior evadit.

angulosa. 24. Cri. ferruginea, capite thoraceque saturatioribus convexis nitidis, elytris angulis binis longitudinalibus clevatiusculis.

Long. corp. $\mathrm{I} \frac{3}{4}$ lin.

Habitat

Descr. Antennæ nigræ, basi ferrugineæ. Os ferrugineum. Caput et thorax picei. Thorax convexus admodum, politus, nitidus. Elytra ferruginea, punctulatissima, et subindè nebulis nigris tenuibus maculata; at quod singulare, per medium anguli bini elevatiusculi obsoleti longitudinaliter decurrunt. Corpus subtùs ferrugineum.

ptinoides. 25. Cri. fusco-ferruginea, elytris puncto baseos fasciâque transversâ mediâ castaneis.

Long. corp. $1 \frac{1}{2}$ lin. 
Habitat

In mus. D. Kirby.

DESCr. Antennæ pallidè ferrugineæ. Oculi nigri. Caput fusco-ferrugineum. Thorax subrotundus. Elytra punctum sive maculam minimam subtetragonam, et fasciam sub medio transversam, castaneam, gerunt. Abdomen fuscum. Pedes ferruginei. Thorax et elytra sub lente tomento tenuissimo obtecta.

26. Cri. violacea, capite thorace pedibusque rufis. cantharoiFab. Syst. Ent. 120. 9. Sp. Ins. i. 152. 15. Mant. i. des. 87. I7. Ent. Syst. i. b. 3. 4 .

Chrysomela cantharoides. Vill. i. 165.177.

Cryptocephalus cantharoides. Gmel. 1720. I39.

Long. corp.

Habitat - In mus. Brit.

Descr. Statura Cri. Nymphace. Antennæ filiformes, basi rufescentes. Caput et thorax exactè Nympbace, rufa immaculata. Elytra et abdomen cyanea, nitida. Syst, Ent.

\section{TILLUS.}

Antenne filiformes, hinc serratæ.

Caput subdeclinatum.

Thorax convexus, oblongus, anticè posticèque attenuatus.

Corpus lineari-elongatum.

I. Til. ater villofus, thorace rubro.

Fab. Ent. Syst. i. b. 77. I. Panz. Ent. Germ. 201. 1. elongatus. Payk, Faun. Suec. ii. I53. I.

Oliv. ii. 22. 4. I. t. 1. f. 1. a. Faun. Germ. 43. t. I6. e 3 Chrysomela 
Chrysomela elongata. Linn. Syst. Nat.603. 122. Vill. i. I68. I91.

Pontop. Dan. Atl. i. 671. $3^{8 . t .29 . f . u l t . ~}$

Lagria elongata. Fab. Syst. Ent. I25. 6. Sp. Ins. i. 160. 8. Mant. i. 93.8.

Cryptocephalus elongatus. Gmel. I729. 221 .

Long. corp. $3^{\frac{3}{4}}$ lin.

Habitat

De scr. Antennæ crassiusculæ, serratæ, et caput villosa, atra. Thorax ruber, villosus, angustus ratione elytrorum, margine antico nigro. Elytra aterrima, sive aterrimo-purpurea, striata, villosa ; striis ex punctis impressis. Abdomen subtùs et pedes aterrimi, villosi. Corpus totum nitet.

ambulans. 2. Til. ater villosus, elytris punctatis.

Fab. Ent. Syst. i. b. 78. 2. Panz. Ent. Germ. 201.2. Tillus elongatus var. B. Payk. Faun. Suec. ii. 153. I.

Lagria ambulans. Fab. Mant. i: 93.9 .

Long. corp. 4 lin.

Habitat

DEscr. In omnibus $T$. elongato simillimus, ut ovum $\therefore$ ovo; differt solummodo thorax corpore concolor, ater nec ruber.

reneus:

3. Til. nigro-æneus pubescens.

Lagria ænea. Faun. Etrusc. Mant. 86 ?

Long. corp. 2 lin.

Habitat

Descr. Totum corpus unicolor cyaneum, pubescens, nitidum. Antennæ corpore dimidio breviores. Thorax subcylindricus.

virens.

4. Til. æneo-virens tomentosus, tibiis rufis.

Long. corp. $1 \frac{3}{4} \operatorname{lin}$.

Habitat

DESCR。 
Descr. Totum corpus, præter tibias quæ rufæe, ex nigro-æneo-virens est et tomentosum. Elytra acutiuseula, non obtusa, truncata, ut in T. aneo, cui affinis; sub lente punctulatissima sunt.

5. Til. ater pilosus, elytris fasciâ incurvâ albâ basi unifasciarufis. tus.

Clerus unifasciatus. Fab. Mant. i. 125. 8. Ent. Syst. i. a. 207. 8. Faun. Etrusc. 352. Hellw. 352. Hoppe Ins. Erl. 33.

Attelabus unifasciatus. Gmel. I8II. 25 .

Attelabus serraticornis. Vill. i. 222. 16.

Attelabus formicarius minor. Sulz. Hist. Ins. t. 4. f. I3.

Long. corp. 3 lin.

Habitat

Descr. Primo intuitu Clerum formicarium diceres, at antennæ serratæ; tum thorax ater, nec rufus; porro in elytris fascia unica alba, nec duæ. Totum corpus, præter basin rubram et fasciam albam elytrornm, atrum est.

\section{HISPA.}

Antenno fusiformes, basi approximatx, inter oculos sitæ, porrecta.

Caput exsertum.

Thorax anticè parùm angustatus.

Elytra rigida, longitudine abdominis.

Corpus immarginatum, sæpiùs aculeatum.

I: H. aculeata, corpore toto atro.

Linn. Syst. Nat. 603. I. Fab. Sp. Ins. i. 83. Io. Mant. i. 47. 9. Ent. Syst. i, b. 70. I. Gmel. 1732. r.

$$
{ }_{4} P_{a y} k_{0}
$$


Payk. Faun. Suec. ii. I5r. I. Panz. Ent. Germ. 200. I.

Roem. Gen. Ins. $t$. frontis. $f$. $\mathbf{r}$.

Crioceris tota atra, spinis horrida. Geoff. i. 243 7.

Long. corp. $I \frac{x}{2}$. lin.

Habitat ad radices graminum. Linn. In mus. D. Lee.

Descr. Corpus atrum. Caput ad antennas aculeum fetaceum porrigit. Antennæ filiformes, extrorsùm ferè crassiores, corpore dimidio breviores, articulis brevissimis. Thorax utrinque spinâ triplici, et a tergo binị duplicibus. Elytra adspersa serie sextuplici longitudinali aculeorum. Syst. Nat.

2. H. inermis nigra, antennis pilosis, elytris striatis.

Linn. Syst. Nat.604. 4. Vill. i. 170.3. Gmel. r732.4. Fab. Syst. Ent. 71. 6. Sp. Ins. i. 83. 9. Mant. i. 47.7. Ent. Syst. i. b. 7I. 4 .

Ptilinus muticus. Fab. Ent. Syst. iv. App. 443-5. Panz. Ent. Germ. II5. 4. Payk. Faun. Suec. i. 3I7. 3:

Panz. Faun. Germ. I. t. 8.

Dermestes clavicornis. Faun. Suec. 413.

Tenebrio hirticornis. De Geer, $\mathrm{v}_{i} 47 \cdot t \cdot 3 \cdot f$. I.

Long. corp. $\mathrm{I}_{\frac{3}{4}} \mathrm{lin}$.

Habitat

In mus. D. Kirby.

DESCR. Antennæ totæ clavatæ, atræ: articulis octo valdè pilosis. Caput exsertum. Thorax angulatus, marginatus. Elytra striis quinque elevatis, interstinctis ordine punctorum excavatorum. Antennæ fusiformes, sive filiformes, medio sensim crassiores. Syst. Nat. 


\section{[ 233 ]}

\section{SCAPHIDIUM.}

Antenna tenuiores, articulis tribus ultimis majoribus, perfoliatis.

Caput cernuum, acuminatum.

Thorax posticè dilatatus.

Corpus ovatum, posticè acuminatum.

x. Scaph. fusco-griseum, elytris striatis, anten-griseum. narum basi pedibusque ferrugineis.

Long. corp. 2 lin.

Habitat Ex mus. D. Latbbury.

DESGR. Totum corpus, præter antennarum basin et pedes, fuscum et griseum, sive griseo-punctatum. Color ex pilis brevissimis oritur. Striæ elytrorum punctis minutis impressæ.

2. Scaph. atrum nitidum, elytris maculis duabus 4-macularubris.

tum.

Fab.Ent. Syst. i. b.509. I. Payk. Faun. Suec. iii.338. i. Panz. Ent. Germ. 346. I.

Oliv. ii. 20. 4. I.t. I.f. I. a-c. Panz. Faun. Germ.2.

t. I. Herbst. Jablonsk. v. 132. I, t. 49. 'f. 4.

Long. corp. 2 lin.

Habitat

DESCr. Antennæ nigræ, articulis quinque postremis crassioribus. Thorax ater, nitidus, valdè convexus, punctulatus, ad apicem verò serie punctorum impressorum transversâ. Elytra abbreviata, punctulata, maculis duabus rubris, aliâ ad basin, alterâ ad apicem. Basis elytrorum serie punctorum impressorum, ut in thorace 
thorace accedit. Porro ad scutellum utrinque stria impressa. Abdomen et pedes atri, nitidiusculi.

arzuninatum. 3. Scaph, piccum nitidum, abdomine valdè acuminato.

Long. corp. I lin.

Habitat

Descr. Nigro-piceum, nitidissimè lævigatum. Antennæ gracillimæ, vix sine lente conspicuæ, tamen apice crassiores. Elytra parum abbreviata, apicibus extremis pallidis. Pedes rufo-picei.

dubium.

4. Scaph. rufo-fuscum, thorace elytrorumque apicibus pallidis.

Long. corp. vix $\frac{t}{2}$ lin.

Habitat

Descr. Minimum insectum, mirificé componens se, applicando caput et pectus abdomini. Elytra nitida, subpubescentia.

Buteti. 5. Scaph. piceum nitidum, elytris apice truncatis. Panz. Ent. Germ.347. 4.

Panz. Faun. Germ. I2. t. 16.

Long. corp. $\frac{3}{4} \operatorname{lin}$.

Habitat in Boleto.

DESCR. Totum corpus ovatum, piceum, glaberrimum, nitidum. Facie Dytisci, sed pedes unguiculati. Tibiæ posticæ valdè graciles, adeo ut ungues non nisi oculo optimè armato conspiciendi. 


\title{
COLEOPTERA BRITANNICA,
}

\author{
SISTENS
}

INSECTA COLEOPTERA BRITANNIF

\author{
INDIGENA,
}

SECUNDUM

\author{
METHODUM LINN \&ANAM \\ D I S P O S I T A.
}

AUCTORE

THOMÄ MARSHAM,

SOC. LINNAAN. LONDINENS. THESAURARIO, NECNON SOCIET. LITERAR. ET PHILOSOPH, MANCUNII SOCIO HONORARIO.

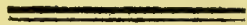

IN TWO VOLU MES.

VOL. II.

\section{LONDINI:}




PL. I3.

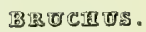

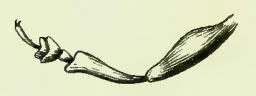

a
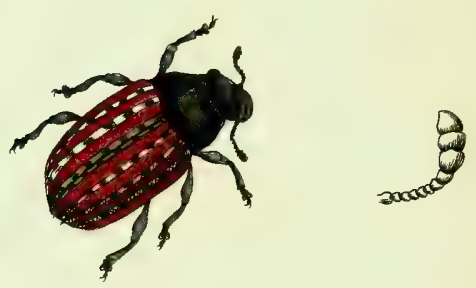

B. scabrosus. 


\section{[ 235$]$ \\ 24. BRUCHUS.}

Antenne filiformes, sensim crassiores.

Caput retracto-inflexum.

Thorax anticè attenuatus.

Elytra truncata, abdomine breviora.

I. Bru. niger, elytris elevato-striatis rufis, nigroscabrosus. albidoque variis.

Fab.Syst. Ent. 64.3. Sp.Ins. i.75.5. Mant. i.4I. 7. Vill.i.I72.6. Gmel. I735. II.

Anthribus fasciatus. Forst. Cent. 9 .

Anthribus scabrosus. Fab. Ent. Syst. i. b. 377.: 6. Panz. Ent. Germ. 293. 6. Payk. Faun. Suec. iii. 163. 4. Panz. Faun. Germ. I5. t. I5. Fuesl. Arch. 86. I. t. 20. f. I5:

L'Antribe marbré. Geoff. i. 306.t.5. f.3.

Curculio scabrosus. Payk. Monog. 114.

Long. corp. 2 lin.

Habitat

DESCr. Antennæ et caput nigro-fusca. Thorax nigro fuscoque varius. Elytra rufa, striis quinque longitudinalibus elevatis, nigro albidoque variis : inter strias elevatas series punctorum excavatorum.

2. Bru. elytris nigris : atomis albis, pedibus anticis granarizs. antennarumque basi rufis.

Linn. Syst. Nat.605.5. Vill. i. 171. 2. Scbrank, r9r. Gmel. 1736. 5. Fab. Syst. Ent. 65. 6. Sp. Ins. i. 76. I r. Mant. I.42. 15. Ent. Syst. i. b. 372: 15. Faun. Etrusc. 109. Hellw. 109. Panz. Ent. Germ. 291.4. Payk. Faun. Suec. iii. I57. I.

Panz. Faun. Germ. 6i. t. 8.

Curculio atomarius. Faun. Suec. 628.

\section{Long.}


Long. corp. $I \frac{r}{2}-2$ lin.

Habitat in seminibus Vicie Fabe.

Descr, Corpus fuscum. Elytra atra, punctis albis, vix conspicuis. Ani regio albida. Antennæ crassiusculæ, ni ræ, basi angustiore rufæ. Femora postica dente armata. Faun. Suec.

seminarius. 3. Bru. ater, antennarum basi pedibusque anticis testaceis, femoribus muticis.

Linn. Syst. Nat.605. 6. Vill. i. I7r.3. Gmel. I737.6. Fab. Syst. Ent. 65. 8. Sp. Ins. i. 76. 14. Mant. i. 42. I8. Ent. Syst. i. b. 373. 19.

Le Mylabre satiné. Geoff. i. 268. 3.

Long. corp. I $\frac{x}{2}$ lin.

Habitat — Captus d. 28. Jun. prope Henley. $\mathrm{Fab}$.

DESCR. Statura Bru. granarii, at paulo minor. Caput prominens, antennis quasi pedunculatis, crassis, serratis. Thorax anticè attenuatus. Elytra striata abdomine breviora. Pedes inermes. Syst. Ent.

aler.

4. Biu. totus ater unicolor, elytris striatis.

Long. corp. $1 \frac{x}{2} \operatorname{lin}$.

Habitat -

DESCR. Totum corpus atrum, sub lente leviter pubescens tomento cinerascenti. Elytra striata. Thorax lævis, punctulis numerosissimis.

\section{CURCULIO.}

Antennce subclavatæ, rostro insidentes. Rostrum corneum prominens, Caput posticè incrassatum. 
PLI.1.

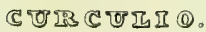

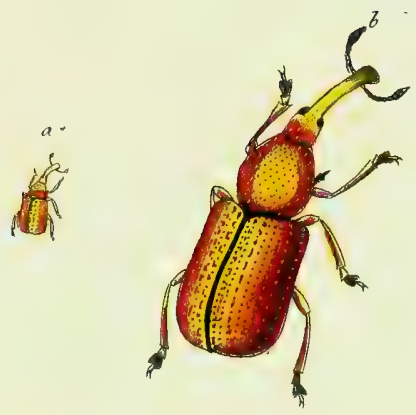

6. Bactous. 



\section{CURCULIO.}

A. Longirostres.

a. Antennis integris, femoribus simplicibus.

* Abdomine ovato obtuso, rostri apice dilatato, tborace utrinque attenuato. Villosuli, paucis exceptis.

* Abdomine ovato acuto, rostro filiformi, thorace teretiusculo. Nudiusculi.

b. Antennis fractis, femoribus simplicibius.

* Corpore ovato, rostro pectori intra pedes sese applicante, sive pectus premente.

* Corpore bujato, rostro sese pectori applicante, femoribus posticis crassis.

** Corpore ovato, rostro breviusculo nec pectori applicabali.

**** Corpore oblongo, tborace globoso. Pilosi.

***** Corpore cylinidrico.

c. Antennis fractis, femoribus dentatis.

* Corpore ovato obtuso, rostro sese pectori intra pedes applicante.

* Corpore ovato acuto, rostro longissimo filiformi.

***. Corpare oblongo, rostro crassiori.

**** Corpore oblongo, rostro filiformi.

****** Corpore cylindrico.

B. Brevirostres.

a. Antennis integris, femoribus simplicious.

b. Antennis fractis, femoribus simplicilus.

* Corpore ovato.

* Corpore oblongo.

c. Antennis fractis, femoribus dentatis.

* Corpore ovato.

** Corpore oblongo.

A. Lon: 


\section{A. Longirostres.}

a. Antennis integris, femoribus simplicibus.

* Abdomine ovato obtuso, rostri apice dilatato, tho. race utrinque altenuato. Villosuli, paucis exceptis.

aquatus. I. Cur. thorace rostroque æneis, elytris pedibusque rubris.

Linn. Syst. Nat.607.9. Vill. i. 175.6. Gmel. 1744.9. Payk. Monog. I26.

Don. Brit. Ins. t. 121. f. 1. 2.

Attelabus æquatus. Fab. Ent. Syst. i. b. 388.20. Faun. Ingr.316. Panz. Ent. Germ. 296. 8. Payk. Faun. Suec. iii. 173.6.

Rynchites æquatus. Herbst. Jablonsk, vii. 132. 8. t. I04. f. 8. B.

Le Becmare doré à étuis rouges. Geoff. i. 270.4.

Long: corp. $2 \frac{1}{2}$ lin.

Habitat in Cratago Oxyacantbâ.

DESCR. Antennæ clavâ triarticulatâ perfoliatâ, ut in Dermestibus. Totum corpus pilosum. Rostrum apice furcatum, longum, depressum, ex rufo-æneum. Thorax æneus. Elytra rubra, striata, striis ex punctis excavatis. Pedes rubri. Abdomen nigrum.

Alliarie. 2. Cur. violaceus totus pilosus, rostro thorace breviori.

Linn. Syst. Nat. 606. 4. Faun. Suec. 580. Vill. i. I73. I. Fab. Sp. Ins. i. 168. 40. Mant. i. 101. 53. Attelabus Alliarize. Fab. Ent. Syst. i. b. 390. 27. Payk. Faun. Suec. 1ii. 175. 8. Panz. Ent. Germ. 297. 16.

Long. corp. 2 lin. sed variat magnitudine.

Habitat in Cratego Oxyacantbá.

DESCR.

namus.

3. Cur. violaceus totus tomentosus, rostro thoracis longitudine. 
Payk. Monog. 97 .

Curculio cæruleus. De Geer, v. 25I. 39.

Attelabus nanus. Payk. Faun. Suec iii. I76.9.

Long. corp. I $\frac{\pi}{2} \operatorname{lin}$.

Habitat

Descr. Hi duo Curculiones admodum affines; at hic tomentosus ille pilosus evadit; porro hic rostrum thoracem longitudine æquans præ se fert, at ille non item. In utroque elytra striata, striæ ex punctis majusculis impressis.

4. Cur. obscurè æneus, subtùs obscurior.

Linn. Syst. Nat.608. 21. Faun. Suec.593. Vill. i. cupreus. 179. I7: Gmel.1748.21. Fab. Syst. Ent, I31. 20. Sp.Ins.i.166.26. Mant.i.100.34. Payk. Monog. I25.

Attelabus cupreus. Fab. Ent. Syst.i.b.389.23. Faun. Ingr. 317. Panz. Ent. Germ.296. 10. Payk. Faun. Suec. iii. 173. 5 .

Panz. Faun. Germ. 20. t. 9.

Rhinomacer cupreus. Harr. 304.

Rynchites cuprems. Herbst. Jablonsk. vii. $138.14 . t$. 105 . $f .2 \pi$.

Long. corp. $2 \frac{3}{4}$ lin.

Habitat — Captus in foliis virgultorum, Hor * sington-wood.

DEScR. Color tristis cupri, qui a pilis colore cupri adsper $\leqslant$ is dependet. Elytra punctis latis excavatis striata. Faun. Suec.

5. Cur. æneo-viridis subtùs ater, clytris punctis aneo-viexcavato-striatis.

rens.

Long. corp. I $\frac{x}{2}$ lin.

Habitat _ Captus in folis virgultorum, Horsington-wood.

DESCR. Totum corpus villosum, villis mollissimis. In omnibus, præterquam magnitudine et colore, simil- 
limus Cur. cupreo. Rostrum pariter bifurcum. Thorax punctulis (sublente) prominulis scabriusculus. Elytra punctis excavato impressis striata. Corpus pilosum, subtùs nitens. Antennæ articulis tribus perfoliatæ.

Bacchus. 6. Cur. aureus, rostro plantisque nigris.

Linn. Syst. Nat. 61 1. 38. Vill. i. 184.33. Gmel. 1752. 38. De Geer, v. 250. 38. Fab. Syst. Ent. I30. 14. Sp. Ins. i. 165. 22. Mant. i. 99.29. Payk. Monog. 124. Faun. Etrusc. 286. Hellw. 286. Scbrank, I99.

Don. Brit. Ins.t. 34. f. I. Sulz. Hist. Ins. t. $4 . f .4$. Schaff: Icon. t. $37 \cdot f_{\cdot} \mathrm{I} 3$.

Attelabus Bacchus. Fab. Ent. Syst. i. b. 387.15. Panz. Ent. Germ. 295. 5. Payk. Faun. Suec. iii. I72. 4 .

Panz. Faun. Germ. 20. t. 5 .

Rhinomacer Bacchus. Harr. 308. Laich. i. 238. I.

Long. corp. 4 lin.

Habitat in Pruno spinoso.

DESCR. Corpus rubro-aureum, suprà subvillosum.

pubescens. 7. Cur. violaceus hirtus, rostro atro.

Fab. Syst. Ent. 131. 19.

Attelabus pubescens. Fab. Sp. Ins. i. 200. 5. Mant. i. 124. 9. Ent. Syst. i. b. 387. 14. Faun. Etrusc.359. Hellw. 359. Vill. i. 222. 13. Gmel. 1810. 18. Panz. Ent. Germ. $295 \cdot 4$.

Rynchites pubescens. Herbst. Jablonsk. vii. I38. 15. t. $105 \cdot f \cdot 3$.

Long. corp. 4 lin.

Habitat in Quercû.

DESCR. Rostrum longitudine thoracis, sulcis duobus exaratum, atrum. Oculi flavescentes. Thorax cylindricus, lateribus gibbis, uti in Cur. Betule, et elytra violacea, pilis plurimis erectis, fuscis, hirta. Syst. Ent.

Obs. Magnitudo et statura Cur. Bacchi, cui omninò simillimus, sed differt colore, eoque solo.

8. Cur. 
8. Cur. thorace antrorsùm sæpè spinoso, corpore Betula. viridi-aurato subiùs concolore.

Linn. Syst. Nat.611.39. Faun. Suec. 605. Vill. i. 185.34. Gmel. 1752.39. Scop. 77. Fab. Syst. Ent. 130. г6. Sp. Ins. i. 165. 23. Mant. i. 99. 30. Scbrank, 197. Faun. Etrusc. 287. Hellw. 287. Poda, 29.3.

De Geer, v. 248. 36. t. 7.f. 25. Don. Brit. Ins. t. 74 . var. viridis. Scbaff. Icon.t. I04. $f \cdot 4$.

Curculio Populi. Payk. Monog. 123 .

Attelabus Betuleti. Fab. Ent. Syst. i. b. $3^{87}$. 16. Faun. Ingr. 314. Panz. Ent. Germ. 295. 6.

Attelabus Populi. Payk. Faun. Suec. iii. 170. 3 .

Rhinomacer Alni. Harr. 309. Laicb. i. 239.2.

Rynchites Betuleti. Herbst. Jablonsk. vii. 136. 2. t. 104. $f .2$.

Le Becmare vert. Geoff. i. 270. 2.

Long. corp. $3 \frac{x}{2}$ lin.

Habitat in Betulâ Alno.

Descr. Totus capite, thorace, rostro, elytris, abdomine, pedibus cæruleo viridi-inauratus, seu sericeo nitidissinus. Posteriora versus admodum obtusus. Totum corpus punctis minutissimis excavatis perfusum. Oculi et antennæ solæ nig̣ræ; harum infimus articulus reliquis nullo modo longior est, ut in reliquis ; clavatæ tamen sunt antennæ, ut in congeneribus. Hic minimè salit. Faun. Suec.

Alter sexus thoracis spinas habet; alter non. Syst. Nat.

9. Cur. thorace antrorsùm spinoso, corpore viridi Populi. ignito subtùs atro-cærulescente.

Linn. Syst. Nat. 61 I. 40. Faun. Suec.606. Vill. i. 185. 35. Gmel. 1752. 40. Scop. 74. De Geer, v. 249.37. Fab. Syst.Ent. I31. 17. Sp.Ins. i. 166.24. Mant. i. 99. 29. Payk. Monog. 123 . var. $\gamma$.

Attelabus Populi. Fab. Ent. Syst.i. b. 388. 17. Fun. Ingr. 315. Panz. Ent. Germ. 295. 7. Payk. Faun. Suec. iii. 170. 3. var. $\gamma$.

Panz. Faun. Germ. 20. t. 7 . YOL. I.

Rhinomacer 
Rhinomacer Populi. Harr. 303. Ent. Helv. Iso. 2.

Le Becmare doré. Geoff. i. 270. 3 .

Long. corp. $2-3$ lin.

Habitat in Populo, Corylo.

DEscr, Simillimus præcedenti, sed dimidio minor.

Viridi-inaurata sunt caput, thorax, elytra substriata. Nigro-virescentia caput subtùs et pectus. Antennæ nigræ, infimo articulo reliquis non longiore. Fossula inter oculos. Faun. Suec.

Mas thorace utrinque spinoso, femina vero non. Syst. Nat.

nitens.

Io. Cur. violaceus nitidus, thorace pedibus abdomineque viridi-caruleis.

Curculio Populi var. $\beta$. Payk. Monog. I23.

Curculio Betulæ. Don. Brit. Ins. t. 74. var. violacea.

Attelabus Populi var. $\beta$. Payk. Faun. Suec. iii. I70. 3. An Rhinomacer bispinis. Harr. 310?

Long. corp. $3-5$ lin.

Habitat

Descr. Elytra omninò violacea, punctata, punctis numerosissimis confertis, vix striata. Rostrum et pedes, certo lucis respectu præcipuè, viridescunt. Totum animal nitet.

Variat elytris subviridi-cæruleis.

* Abdomine ovato acuto, rostro filiformi, thorace tere. tiusculo. Nudiusculi.

frumenta- 11. Cur. sanguineus, oculis nigris.

rius.

Linn. Syst. Nat.608. I5. Faun. Suec. 586. Vill. i. 177. 12. Gmel. 1745. 15. Fab. Syst. Ent. 132. 34. Sp. Ins. i. 169. 49. Mant. i. 102. 65. Act. Nidros. iii. 391. 10. Faun. Etrusc. 301. Hellw. 301. Faun. Fred. 10.94. Payk. Monog. I30.

Cur. sanguinetis: De Geer, v. 25 I. 40.

Attelabus frumentarius. Fab. Ent. Syst. i. b. 392. 35 . 
Faun. Ingr. 320. Panz. Ent. Germ.298. 24. Payk. Fain. Suec. iii. 177. 10.

Panz. Faun. Germ. 20. t. 14.

Rhinomacer frumentarius. Ent. Helv. Iog. I, t. I3. $f$. I. 2 .

Apion frumentarium. Herbst. Jablonsk. vii. 10\%. 6. t. 102. $f .6$.

Long. corp. 2 lin.

Habitat in frumento diutiùs asservato.

Descr. Totum corpus sanguineum. Elytra punctatostriata. Pedes sanguinei.

I2. Cur, ater, elytris nitidis cæruleis: scutello cbalceus. concolore.

An Attelabus Astragali? Payk. Faun. Suec. iii. 180. I5. Long. corp. 2 lin.

Habitat

Descr. Totum corpus, præter elytra viridi-cærulea, atrum est. Scutellum elytris concolor. Elytra leviter striata.

13. Cur. niger, elytris æneis.

Fab. Syst. Ent. т31. 22. Sp. Ins. i. 166. 28. Mant. i. 100.36. Ent. Syst. i. b. 405. 46. Vill. i. 187.4I. Gmel. 1748. 132. Payk. Monog. 134.

Attelabus æneus. Fab. Ent. Syst. i. b. 389.23. Panz. Ent. Germ. 296. I1. Payk. Faun. Suec. iii. 179. 14. Attclabus Cracce. Panz. Faun. Germ. 20. $t$. 10.

Apion æneum. Herbst. Jablonsk. vii. 101. I. t. 102. $f$. I, Long. corp. $1 \frac{x}{4}$ lin.

\section{Habitat}

DESCR。Parvus, corpus nigrum, elytris solis æneis. Syst. Ent.

Obs. Magnitudine et staturâ simillima Cur. cbalceo, sed differt elytris æneis, nec viridi-cæruleis. An species distincta? An sexûs differentia?

R 2 14. Cur. 
aterrimus. 14. Cur. niger, elytris cæruleis striatis obscuris, abdomine elliptico.

Linn. Syst. Nat. 607. 10. Faron. Suec. 582? Faun. Fred. 10. 90?

Long. corp. 2 lin.

Habitat

Descr. Elytra cæruleo-viridia, obscuriuscula. Affinis Cur.cbalceo, sed differt apprimè, elytris obscuriusculis, nec nitidis.

Sorbi. 15. Cur. ater, elytris cæruleis striatis, antennis rostro basi insidentibus.

Curculio lævigatus. Payk. Monog. 133 .

Attelabus Sorbi...Fab.Ent. Syst. i. b. 390. 29. Payk. Faun. Succ. iii. 178. 12.

Panz. Faun. Germ. 20. t. II.

Apion Sorbi. Herbst. Jablonsk. vii. 1 II. 9. t. I02. f. 9.

Long. corp. $1 \frac{\pi}{2}$ lin.

Habitat

DESCR. Elytra profundè striata, punctis striarum impressis.

obscurus. 16. Cur. niger albido-villosulus, elytris obscurè nigro-æneis, pedibus quatuor anterioribus rufis. Long. corp. $I \frac{3}{4}$ lin.

Habitat

Ex mus. D. Lambert.

DESCR. Statura ferè precedentis, sed major. Corpus nigrum, pilis albidis scatens. Rostrum thorace longius, glabrum. Antennæ basi rufæe. Thorax anticè attenuatus. Elytra obscurè nigro-ænea, striata, striis subpunctatis. Pedes quatuor anteriories rufi, genubus nigris.

fuscicornis. I7. Cur. niger, elytris nigro-cæruleis striatis, antennarum basi testaceâ. 
An Curculio punctiger. Payk. Monog. I32 ?

An Attelabus punctiger. Payk. Faun. Suec. iii. I79. I3?

Long. corp. $1 \frac{1}{2}$ lin.

Habitat $\longrightarrow$

DESCR. Rostrum tenue, ferè longitudine thoracis. Antennæ nigræ, parte inferiori testaceâ.

I8. Cur. niger, rostro subulato brevi, abdomine Cracice. pallido.

Linn. Syst. Nat.606. 6. Gmel. 1743. 6. Payk. Monog. I3I. Vill. i. 174.3.

Cur. Viciæ. De Geer, v. 253. 43. t. 6. $f \cdot 3$ I. 32 . Attelabus Craccæ. Payk. Faun. Suec. iii. I77. II. Apion Craccæ. Herbst.Jablonsk. vii. 102. 2. t. 102.f. 2. B. Long. corp. I lin.

Habitat in Vicie Cracce seminibus.

DESCR. Corpus nigrum. Elytra striata, striis latitudine interstiticrum. Antennarum primus articulus testaceus. Oculi subtùs ciliati, imprimis in masculis. Syst. Nat.

19. Cur. ater glaber, rostro subulato, antennis basi glaber. rufis.

Long. corp. $2 \frac{1}{3}$ lin.

Habitat

In mus. D. Kirby.

Descr. Præcedentis staturâ sed major. Totus ater obscurus. Rostrum subulatum, basi admodùm incrassatum, punctulatum, acumine lævi. Antennæ rostri medio insidentes, articulo primo rufo. Thorax teres, punctulatus, pofticè lineâ longitudinali exaratus. Elytra sulcato-striata, striiis nitidè punctatis. Pedes nigri.

20. Cur. niger, rostro piloso subulato, thorace carulescens. elytrisque cæruleis.

Long. corp. 2 lin.

Habitat 
Descr. Corpus suprà cæruleum, subtùs nigrum. Elytra striata; puncta minima in fundo striarum.

rufirostris. 21. Cur. niger, rostro dimidiato pedibusque rufis. Fab. Syst. Ent. 132. 25. Sp. Ins. i. 167.35. Mant. I. 100.46. Vill.i. 187.44. Gmel. 1744. 107. Fun. -Etrusc. 293. Hellw. 293.

Attelabus rufirostris. Fab. Ent. Syst. i. b. 390. 26.

Apion rufirostris. Herbst. Jablonsk. vii. III. I0. $t .102$. f. 10 .

Long. corp. $1 \frac{\pi}{2}$ lin.

Habitat in Malvis.

Descr. Caput nigrum, at anterior dimidia rostri pars rufa, apice tamen puncto parvo nigro. Thorax niger. Elytra striata, immaculata. Pedes rufi, femoribus simplicibus. Syst. Ent.

Trifolii. 22. Cur. ater, rostro porrecto, pedibus ferrugineis: plantis nigris.

Linn. Syst. Nat. iii. App. 224. Gmal. I758. 209.

Trans. Linn. Soc. vi. 142. t. 5. f. a-c.

Curculio flavipes. Fab. Syst. Ent. 133. 33. Sp. Ins. i. 169.47. Mant. i. 102.63. Gmel.1745. I11. Laich. i. 232.23. Payk. Monog. 135.

Attelabus flavipes. Fab. Ent. Syst. i. b, 39ז. 33. Panz. Ent. Germ. 298. 22. Payk. Faun. Suec. iii. 182. I7. Panz. Faun. Germ. 20. $t$. 13.

Apion flavipes. Herbst. Jablonsk. vii. 106. 5. t. 102. f.5. Le Becmare noir à pattes fauves. Geoff. i. 272. 8 .

Long. corp. I $\frac{1}{2}$ lin.

Habitat in floribus Trifolii pratensis.

Descr. Corpus atrum. Rostrum thorace paulo longius. Antennæ piceæ. Thorax punctulatus. Elytra striata. Pedes ferruginei, plantis semper nigris : est ubi tibiis nigris variat. Abdomen niveum.

Malve. 23. Cur. thorace nigro, elytris pedibusque testaceis. 
Fab. Syst. Ent. 132. 30. Sp. Ins. i. I68. 42. Mant. i. 101. 57. Vill. i. 188. 49. Gmel. I743. 101.

Curculio Pineti. Payk. Monog. 6r. $5^{8 .}$

Attelabus Malvæ. Fab. Ent. Syst. i. b. 391.32. Panz. Ent. Germ. 297. 21 .

Rynchites Malvæ. Herbst. Jablonsk. vii. 138. I5.

Long. corp. I lin.

Habitat in floribus Malve sylvestris non infrequens.

DEscr. Rostrum nigricans. Thorax et abdomen pilis cinereis grisea. Elytra testacea. Pedes testacei, femoribus inermibus. Syst. Ent.

24. Cur. ater, antennis ferrugineis, thorace bitu-Pruni. berculato.

Linn. Sy'st. Nat. 607. 12. Faun. Suec. 583. Vill. i. 176.9. Scop. 84. Fab. Gen. Ins. Mant. 223. Sp. Ins. i. 167.30. Mant. i. 100.38. Ent. Syst. i. b. 405. 50. Payk. Monog. 128. Panz. Ent. Germ. 301. I3. Herbst. Jablonsk. vi. $445 \cdot 443$.

Long. corp. I lin.

Habitat in foliis Cerasi.

DEscr. Totus ater. Elytra striata. Antennæ subferrugineæ. Femora mutica. Thorax a lergo tuberculis duobus, elevatis, vix mucronatis. Sy'st. Nat.

25. Cur. ater lævis, corpore oblongo utrinque radiolus. acutiusculo, thorace punctulato.

Long. corp. $1_{\frac{3}{4}} \mathrm{lin}$.

Habitat

Ex mus. Miss Hill.

DEscr. Curculiones atros difficile est rite dignoscere. In hoc forma corporis quodammodo singularis est. Radium quippe textoris refert, anticè enim et postice acutior quam in congeneribus accidit. Thorax punctulatus, punctis minutissimis, numerosissimis, impressis. Elytra striata; striæ absque punctis impressis, satio profundè exaratæ.

$$
\text { R } 4 \text { 26. Cur. }
$$


concimus. 26. Cur. griseo-cinerascens, elytris striatis: fasciis duabus fusco-ferrugineis, pedibus rufis. Long. corp. I lin.

Habitat

Ex mus. D. Kirby.

Descr. Caput et thorax fusco-ferruginea, vellere cinerascenti obtecta. Elytra profundè pro magnitudine animalculi striata; fasciis duabus sub-arcuatis, fuscoferrugineis, primâ ad medium, secundâ pone medium, parvo intervallo. Pedes pallidè rufi.

metanopus. $2 \%$. Cur. nigricans, elytris striatis griseis, pedibus rufis : plantis atris.

Long. corp. 2 lin.

Habitat

DESCR. Rostrum tenue, nigrum, nitidum. Caput et thorax nigro-fusca. Elytra profundiùs striata, fuscoferruginea, pilis brevissimis cinerascentia. Pedes ruf, plantis atris.

cinerascens. 28. Cur. nigricans, vellere argenteo-cinerascenti, tibiis ferrugineis.

An Attelabus Viciæ? Payk. Faun. Suec. iii. 18r. I6.

Long. corp. $I \frac{1}{4}$ lin.

Habitat

Descr. Antennæ præter clavam ferrugineæ. Elytra tenuissimè striata, tomentosa, pilis argenteo cinerascentibus. Rostrum pro animalculi magnitudine crassiusculum, et vix dimidium corporis superat.

bnuneus. 29. Cur. piccus, pedibus testaceis.

Long. corp. i lin.

Habitat

DESCR. Rostrum, caput, thorax et elytra ex nigro-picea. Thorax scaber, punctulis numerosissimis elevatis. Elytra profundè striata; striæ ex punctis impressis. Pedes omninò testacei.

30. Cur. 
30. Cur. ater, thorace scabro, coleoptris globosis striatus. profundè striatis : punctis profundiusculis impressis.

Long. corp. I $\frac{3}{4}$ lin.

\section{Habitat}

Ex mus. D. Kirby.

DESCR. Antennæ nigræ. Rostrum atrum, porrectum, leviter arcuatum, glaberrimum, politum. Caput atrum, punctis prominulis scabrum. Elytra pro magnitudine animalculi striis latioribus et profundioribus exarata. In striis punctula profundiuscula impressa. Pedes atri, punctulis prominulis scabri.

3r. Cur. ater, elytris viridescenti-cæruleis, rostro viridescens: longissimo.

Long. corp. 2 lin.

Habitat

DESCr. Totus ater, elytris solis viridescenti-cæruleis. Thorax punctulatissimus, fossulâ longitudinali impressus. Elytra punctato-striata, striis quasi acuductis, et nitidè punctatis.

32. Cur. ater, elytris cæruleis subsulcatis, anten-subsulcatus. nis rostro medio insidentibus.

Long. corp. $\mathrm{j} \frac{2}{3}$ lin.

Habitat

DESCR. Ater, elytris cæruleis, sulcato-striatis, strïs punctis impressis. Thorax punctulatus, fossulâ nullâ.

33. Cur. ater viridescenti-cæruleus, rostro brevi Hydrolape crassiusculo.

tbi.

Long. corp. $1 \frac{2}{3}$ lin.

Habitat in Rumice Hydrolapatbo.

DESCR. Rostrum brevius, crassius quam in cæteris hujus ordinis. Thorax leviter punctulatus. Elytra striata, striis nitidè punctatis.

34. Cur. 
villosulus. 34. Cur. ater villosulus, elytris nigro-cærulcis subsulcatis, antennis basi testaceis.

Long. corp. $\mathrm{I}_{\frac{3}{4}}^{\frac{3}{3}}$ lin.

Habitat

DEscr. Totus cinerascenti-villosulus. Antennæ rostri longiusculi medio insidentes. Thorax punctulatus, lineâ longitudinali obsoletè exaratus. Elytra sulcatostriata, striis punctatis.

\section{b. Antennis fractis, femoribus simplicibus.}

* Corpore ovato, rostro pectori inira pedes sese applicante, sive pectus premente.

nigrinus. 35. Cur. niger sub-pubescens, elytris striatis. Long. corp. $\mathbf{I} \frac{1}{2}$ lin.

Habitat

DEscr. Rostrum tenuissinum. Corpus pilis brevissimis obsitum, subtùs argenteum.

contractus. 36. Cur. ater unicolor, thurace anticè contracto. Long. corp. 1 lin.

\section{Habitat}

DESCR. Rostrum tenue, arcuatum, thorace paulo longius. Thorax anticè quasi filo circumdatus, subitò contractus; sub lente punctis prominulis scabriusculus. Elytra striata; striæ punctis impressis. Interstitia etiam punctulata. Abdomen subtùs punctulatum. Pedes tenues.

melano- 37. Cur. rufo-testaceus, elytris nebulis albicanrhynchus. tibus, rostro nigro.

Long. corp. $1 \frac{3}{4}$ lin.

\section{Habitat -}

In mus. D. Kirby.

Descr. Rostrum, quod thorace duplo longius, nigrum est. Thorax anticè contractus, quasi filo arctè circumdatus et obstrictus. Elytra rufo-testacea, nebulis albicantibus, 
albicantibus, quæ aliquando posticè fasciæformes sunt : porro striata ; striæ punctis impressis. Totum corpus subtùs vellere albicanti. Distinguendus a Cur. melanocepbalo rostro solo, nec capite nigro.

38. Cur. niger, thoracis iateribus elytrisque pro-pallens. terquam ad basin pallidè testaceis.

Long. corp. $\mathrm{I}_{4} \frac{2}{4}$ lin.

\section{Habitat}

Descr. Rostrum nigrum, thorace paulo longius. Caput nigrum. Thorax dorso nigro, lateribus pallidè testaceis. Elytra satis profundè striata, basi et suturâ nigris ; per cætera pallidè testacea. Abdomen fusco-nigrum. Pedes, præter basin femorum posticorum quæ nigra, ferruginei sunt, sive testacei. Ad apicem utriusque elytri punctum elevatum, pustulum referens.

39. Cur. rufo testaceus, thorace griseo, elytris ne-ruber. bulis albicantibus.

Long. corp. $1 \frac{3}{4}$ lin.

\section{Habitat}

Descr. Totum corpus rufo-testaceum, sed caput et thorax fuscescentia. Elytra striata, villositate nebulisque albicantibus obsita. In medio elytrorum nebula sive fascia recurva.

40. Cur. niger, antennarum basi coleoptrorum Salicarice. disco tibiisque testaceis.

Fab. Sp. Ins. i. 167.36. Mant. i. 101. 48. Ent. Syst. i. b. 407.59. Vill. i. 187. 46. Panz. Ent. Germ. 362. 21. Gmel. I744. 109.

Panz. Faun. Germ. 17. t. 4.

Curculio Lythri var. F. Payk. Monog.7r. Faun. Suec. iii. 263.85 :

Long. corp.

Habitat in Lytbro Salicarit. Fab.

Descr. Corpus parvum nigrum. Antennæ clavatæ, nigræ, 
nigræ, basi testaceæ. Rostrum elongatum, striatum, et thorax nigra, immaculata. Coleoptra striata, disco testaceo, margine omni nigro. Pedes testacei, femoribus apice fuscis. Ent. Syst.

Eytbri.

4r. Cur. niger, elytris testaccis: basi margine exteriori fasciâque mediâ abbreviatâ obliquâ niggris.

Fab. Ent. Syst. i. b. 4Io. 73. Payk. Faun. Suec. iii. 263. 85. Monog. 71. Herbst. Jablonsk. vi. 451.453. Panz. Ent. Germ. 3०5. 33.

Panz. Fuin. Germ. I $7.6,8$.

Cionus Lythri. Ent. Helv. 69. 2.

Long, corp. $1 \frac{x}{4}$ lin.

Habitat in Lytbri floribus. Ex mus. Miss Hill.

Descr. Animal mirè variat. Thorax modo niger, modo ferrugineus. Elytra variant testacea basi nigrâ, et testacea basi margine exteriori et fasciâ mediâ abbreviatâ obliquâ nígris; fascia interdum latior, et longior; discum fere totum occupat, et ad marginem exteriorem attingit. Observandum autem, quod rostrum, caput et abdomen semper nigra. Basis elytrorum semper nigra. Pedes semper testacei.

An varietas Cur. Salicarice?

4. macula-42. Cur. nigricans, colcoptris maculis quatuor altas. bidis.

Linn. Syst. Nat. 609. 29. Faun. Suec.600. Vill. i. 181. 25. Herbst. Jablonsk. vi. 447. 447. Fab. Syst. Ent.133.31. Sp.Ins. i. 169.44. Mant. i. 101.58. Ent. Syst. i. b. $410.7 \mathrm{x}$.

Le Charanson quadrille à longue trompe. Geoff. i. $287 \cdot 22$.

Long. corp. 3 lin.

Habitat

DEscr. Corpus depressiusculum, ovatum, suprà nigricans, subtùs album. Rostrum, antennæ et pedes nigra. Elytra naculâ albâ communi unâ ad apicem, et unâ loco scutelli, nec non punctum album ad marginem exteriorem singuli elytri. Faun. Suec.

43. Cur。 
43. Cur, ater, rostro inflexo, pedibus ferrugineis: inflexus. ungue nigro.

An Curculio acridulus? Panz. Fann. Germ. 42. t. Io.

Long: corp. $\frac{3}{4}$ lin.

Habitat

Descr. Simillimus Cur. Trifolii, sed rostrum inflexum est, non porrectum, et ungues solùm nigri.

44. Cur. capite thoraceque nigris, pedibus elytris- melano. que rufis. cepbahis.

Long. corp. (rostro autem inflexo) I lin.

Habitat Captus in foliis virgultorum,

Coombe-wood.

DESCR. Rostrum circiter dimidium corporis æquat. Abdomen, thorax, caput, oculi et rostrum nigra. Pedes et elytra rubra. Elytra profundiùs striata; striæ subcrenatæ, ex punctis impressis.

45. Cur. thorace bituberculato fusco: lateribus leucogaster. pallidis, elytris fusco-cinereis striatis, corpore subtùs pallido.

Long. corp. $1 \frac{1}{2}$ lin.

\section{Habitat}

DESCR. Rostrum crassiusculum, thorace brevius. Thorax dorso fusco, lineâ longitudinali lateribusque albis; et tuberculo minuto in utroque latere. Elytra satis profunde striata, striis integris, fusca, vellere cinereo. Totum corpus subtùs pallidum, sive album. Pedes rufescentes, geniculis nigris. Color hujusce animalculi ubique ex squamulis sive vellere aut tomento efficitur.

46. Cur. cinereo-albus, elytris nigro-nebulosis, Sisymbrii. rostro longo tenui inflexo.

Fab. Gen. Ins. Mant. 224. 26. 27. Sp. Ins. i. 168. 38. Mant. i. I01. 50. Ent. Syst. i. b. 409. 66. Payk. Monog. 52. Faun. Suec. iii. 247. 66. Panz. Ent. Germ.303.26. Gmel. 1750, 143. Vill. i, I87.47. 
Herbst.Jablonsk. vi. 159. I16. t.70. f. 12. Panz. Fann. Germ. 7 7. t. 6.

Long, corp. 2 lin. rostro producto.

\section{Habitat - In mus. D. Kirby.}

Descr. Rostrum deflexum, et incurvum, nigrum. Thorax lateribus cinereo-albis, medio fuscescit, lineâ mediâ albidâ longitudinali. Elytra striata, cinereoalba, nebulis queisdam nigris, sive maculis : quæ ad basin sitæ sunt arcuatim confluunt; una ante apicem singularis. Pedes concolores.

Lapatbi. 47. Cur, albido nigroque varius muricatus.

Linn. Syst. Nat. 608. 20. Faun. Suec. 591. Vill. i. 178. 16. Gmel. 1763. 20. Fab. Syst. Ent. 138. 61. Sp. Ins. i. 176.86. Mant. i. 106. 109. Ent. Syst. i. b. 429. 149. Payk. Monog. 35. Faun. Ingr. 329. Panz. Ent. Germ.311. 71. Laich. i. 220. 15. Payk. Faun. Suec. iii. 187.4.

Trans.Linn. Soc. i. 86. t. 5.f. 1-5. Panz. Faun. Germ. 42.t. I5. Don. Brit. Ins. t. 205. f. I. Herbst.Jablonsk. vi. I53. III. t. $70 . f$. 6 .

Curculio albicaudis. De Geer, v. 223. 16. t. 7. f. 1. 2. Long. corp. 5 lin.

Habitat in Rumicibus Lapatbis. Linn. In truncis Salicis viminalis. D. Curtis.

Descr. Latera capitis thoracis elytrorumque alba, muricata. Elytra posticè contracta, albida, at a tergo nigricantia, muricata. Abdomen nigricans. Tibiæ rufescentes. Faun. Suec.

Equiseti. 48. Cur. thorace lævi, elytris muricatis nigris: punctis duobus apiceque albis.

Fab. Syst. Ent. 130. 14. Sp. Ins. i. 165. 20. Mant.i. 99. 26. Ent. Syst. i. b. 403. 39. Payk. Monog. 36. Vill. i. 186. 39. Gmel. 1748. 128. Panz. Ent. Germ. 301. 10. Payk. Faun. Suec. iii. 226. 44. Herbst. Jablonsk. vi. 287.258.t. 82. f. 4 . Curculio nigro-gibbosus. De Geer, v. 224. I7. 
Long. corp. 4 lin.

Habitat in Equiseto arvensi.

Descr. Nimis affinis videtur Cur. Lapatbi. Rostrum atrum. Thorax niger, vix tuberculatus, lateribus albis. Elytra muricata, lateribus apiceque albis; in parte anteriori nigrâ, puncta duo, parva, alba. Syst. Ent.

49. Cur. ater, elytris porcis duobus elevatis crena-porcatus. tis: interiori subinflexo, thorace pedibusque albo villosis.

Long. corp. 3 lin.

Habitat ad radices Ornilbogalorum in horto suo, Hammersmith. D. Lee.

Descr. Color hujusce animalculi omninò aterrimus; at thorax et pedes tomento densissimo, sive villo albo, obvestiuntur. Elytra admodum singularia : ad latera plana sunt, et punctis maximis quasi pertusa ; in medio porci duo longitudinales crenati elevantur, quorum exterior subrectus, interior subincurvus, sive arcuatus, et ad apicem subinterruptus. Porci non ad apicem pertingunt.

50. Cur. niger, cineritie albicanti, thorace anticè obstrictiıs. contracto.

Long. corp. 2 lin.

\section{Habitat}

Descr. Rostrum quod lentiùs inflexum, ferè dimidio longitudinem thoracis superat. Thorax post juncturam capitis circulo impresso quasi filo artctè obstrictus fuerit. Totum corpus, et præcipuè subtùs, cineritie notatur. Hæc autem cinerities ex tomento sive pilis brevissimis oritur.

51. Cur. niger, corpore subtùs pallido, elytris leucostigma. nigro-cinerascentibus : maculâ communi dorsali albâ, rostro crassiusculo. 
Long. corp. $1 \frac{1}{2}$ lin.

\section{Habitat}

DESCR. Rostrum crassiusculum, thorace brevius. Thorax dorso nigro, lateribus pallidis. Elytra satis profundè striata, striis integris, nigra, vellere cinereo : ad basin suturæ macula parva oblonga communis alba. Totum corpus et pedes ut in Cur. leucogastere.

Resede. 52. Cur. niger, corpore subtùs pallido, elytris striatis : maculâ communi dorsali albâ, rostro teretiusculo.

Long. corp. $I \frac{x}{4}$ lin.

Habitat in Resedâ luteâ. D. Kirby.

Descr. Rostrum teretiusculum, thorace longius. Thorax dorso nigro, lateribus pallidis. Elytra striata, nigra, maculâ parvầ oblongâ communi albâ, ut in Cur. leucostigmate. Pedes ferruginei.

melano- 53. Cur. niger, corpore subtùs pallido, elytris stigma. nigro-cinerascentibus : maculâ communi nigrâ.

Long. corp. $1 \frac{x}{4}$ lin.

\section{Habitat}

DEscr. Statura Cur. leucostigmatis, cui valdè affinis, at facilè distinguendus maculâ lineari atrâ dorsali communi medium suturæ inficienti; basis suturæ albescit.

Ulicis. 54. Cur. cincreus, pedibus anticis ferrugineis. Forst. Cent. 3 I.

Long. corp. 2 lin.

Habitat in Ulice Europeâ. D. Kirby.

DESCr. Rostrum tenue, nigrum, nitidum, ferè longitudine corporis. Totum corpus cinereum, præter oculos et sinciput quæ nigra, et pedes anticos qui ferruginei sunt. Elytra striis plurimis, circiter novem. Antennæ nigræ.

55. Cur。 
55. Cur. niger, thorace bituberculato canaliculato- assimilis. que, elytris striatis.

Fab. Ent. Syst. i. b. 409. 65. Payk. Monog. 69. 67. Faun. Suec. iii. 257. 77.

Panz. Faun. Germ. $42, t, 6$.

Long. corp. 2 lin.

Habitat

Descr. Rostrum tenue, nigrum. Thorax subdepressus, niger, anticè angustatus, margine anteriore parùm elevato, sulculo longitudinali et tuberculo utrinque laterali. Elytra nigra, striata; callo baseos in angulo exteriore. Totum corpus subtùs nigrum, squamulis cinerascentibus. Pedes nigri.

56. Cur. niger lævis, thorace bituberculato, elytris Erysimi. cyaneis profundè punctato-striatis.

Fab. Mant. i. Ior. 54. Ent. Syst. i. b. 410.70. Faun. Ingr. 325. Gmel. 1743. 100. Panz. Ent. Germ. 304. 30. Payk. Faun. Suec. iii. 265. 87. Monog. 76. 73 .

Panz. Faun. Germ. 17. t. 7. Herbst. Jablonsk. vi. 407. 388. t. 92. $f$. I.

Long. corp. $I \frac{x}{2}$ lin.

\section{Habitat -}

DESCR. Rostrum nigrum. Thorax obscurè viridis, tuberculo utrinque elevato. Elytra striata, cyanea. Pedes nigri. Ent. Syst.

57. Cur. niger, rostro deflexo thorace longiori pyrrborbynrufo basi nigro.

Long. corp. $\frac{x}{2}$ lin.

Habitat

Descr. Antennæ rufæ. Rostrum deflexum, præter basin, rufum. Totum corpus nigrum, subtùs argenteo-album. Thorax punctulatus. Elytra striata, tomentosa, pilis argenteo-cinerascentibus: in striis punctula minuta, impressa. Pedes' nigri.

VOL. I. $\mathrm{s}$ 58. Cur. 


\section{8}

CURCULIO. (A. b.*)

pheorbyn- 58. Cur. nigricans, vellere argenteo-cincrascenti, chus. rostro ferrugineo.

Long. corp. $1 \frac{3}{4}$ lin.

Habitat

Descr. Antennæ nigræ, apicibus clavarum cinerascentibus. Rostrum longissimum, ferrugineum. Elytra tentissimè striata, tomentosa, pilis argenteo-cinerascentibus.

ptinsides. 59. Cur. brunneus, thorace scabro, elytris profundè striatis squamulis testaceis nebulosis obtectis, rostro rufo.

Long. corp. I $\frac{1}{2}$ lin.

Habitat

DESCr, Rostrum rufun, depressum, apice dilatato. Antennæ rufæ. Thorax globosus, scaber, squamulis testaceis obtectus. Elytra profundè striata, squamulis testaceis albisque varia. Pedes ferruginei, squamulis obvestiti.

Obs. Hoc animal primâ facie simillimum Ptino Furiest.

ruficrus. 60. Cur. niger, elytris obscurè rufis cinereo-striatis, tibiis testaceis.

Long. corp. circiter I lin.

Habitat -

DESCR. Thorax anticè angustatus, quasi constrictus, albido-villosus. Elytra obscurè rufa, villis cinereis jucundè et distinctè striatula. Corpus subtùs nigrum, polline albido irroratum. Pedes nigri, tibiis solis rufis.

constsictus:6I. Cur. niger, elytris cincreo striatis.

Long. corp. I lin.

Habitat in Cocbleariâ Armoraciá.

DESCr. Præcedenti simillimus, sed totus niger, albido-villosus.

62. Cur. 
62. Cur. piceus, capite thoracisque striis tribus canescens. obsoletè canescentibus, elytris striatis: suturâ nigrâ.

Long. corp. $1 \frac{x}{2}$ lin.

Habitat $\longrightarrow$

Ex mus. Miss Hill.

DESCR. Rostrum subinflexum, ex nigro piceum, glaberrimum. Oculi nigri. Caput pilis incanis tomentosum. Thorax piceus, striis tribus, unâ mediâ, duabus lateralibus, obsoletè cinerascentibus. Elytra ex rufo-picea, striata; striis satis profundis, punctis impressis. Sutura nigra. Abdomen ex nigro piceum. Pedes ex rufo-picei.

63. Cur. niger, elytris striatis, tarsis rufis. Long. corp. 3 lin.

Habitat

In mus. D. Kirby.

DEscr. Totus niger. Thorax punctatus, lineâ longitudinali elevatâ in medio. Elytra valdè striata. Corpus subtùs squamis cinerascentibus obtectum. Tarsi rufi.

64. Cur. niger, thorace anticè contracto subspi-pallidactynoso, elytris striatis, tarsis pallidis.

pyrrbodactylus.

Long. corp. 2 lin.

Habitat

DESCR. Totus niger. Thorax punctatus, lineâ longitudinali impressâ in medio, anticè circulo valdè impresso, et hinc margo anterior elevatus et subspinosus videtur. Elytra striata. Tarsi pallidi.

65. Cur. niger, elytris nigris ferrugineo canoque tricolor. variis, tibiis plantisque rubellis.

An Curculio pygmæus? Herbst. Jablonsk. vi. I42. I02. t. 69. $f .7$.

Long. corp. $1 \frac{1}{4}$ lin.

Habitat in gramine.

D. Sheppard. 
DEscr. Niger, cano pilosulus. Elytra striata, nigra, vittâ laterali introrsùm ramosâ, ferrugineâ : in utroque elytro punctum album, prope apicem.

villosus. $\quad 66$. Cur. tomentosus pallidus, thorace subgriseo. Long. corp. $\mathrm{I} \frac{2}{3}$ lin.

Habitat in Tritici culmis.

D. Kirby.

DEscr. Reverà niger, sed totus, etiam rostri basis, pilis brevissimis squamulisve pallidis obtectus. Thorax subglobosus, parùm rufescens.

* Corpore ovato, rostro sese pectori applicante, femoribus posticis crassis:

Alni. 67. Cur. niger villosus, elytris testaceis : maculis duabus obscuris.

Linn. Syst. Nat. 611. 42. Faun. Suec. 608. Vill. i. 192. 82. Gmel. 1760. 42. Fab. Syst. Ent. I44.90. Sp. Ins. i. 183. 23. Mant. i. I10. I51. Ent. Syst. i. b. 445. 2I5. Faun. Etrusc. i. 32r. Hellw. 32I. Panz. Ent. Germ. 318. rog. De Geer, v. 262. 49. Payk. Monog. I9. Faun. Suec. iii. 220. 39.

Don. Brit. Ins. t. 249. f. 2. Herbst. Jablonsk. vi. 425. 4 II. $t \cdot 93 \cdot f \cdot 7$.

Le Charanson sauteur à taches noires. Geoff. i. 286. 20.

Long. corp. 2 lin.

Habitat in Betulâ Alno.

Descr. Niger villosus. Thorax rufo-testaceus, fasciâ abbreviatâ nigrâ. Elytra testacea, striata, maculâ baseos oblongâ, et posticè aliâ majore transversali, communi, obscuriore.

ferrugineus. 68. Cur. ferrugineus, rostro capite abdomineque anticè aterrimis.

Long. corp. $\mathrm{I} \frac{\mathrm{I}}{2} \mathrm{lin}$.

Habitat in Quercu.

DEscr. Elytra villosa, striata. Abdomen atrum, seg- 
mentis ultimis, præcipuè ad latera, ferrugineis. Antennæ ferrugineæ. Pedes ferruginei, geniculis nigricantibus.

69. Cur. rufus, oculis pectore abdomineque an-rufus. ticè nigris.

Scbrank, 220. Vill. i. 193. 86.

Don. Brit. Ins. t. 249. f. I.

Curculio viminalis. Fab. Syst. Ent. 145. 92. Sp. Ins. i. 184. 126. Mant. i. I10, I55. Ent. Syst. i. b. 447.223. Payk. Monog. I8. Faun. Suec. iii. 219.38. Panz. Ent. Germ. 319. I16.

Cur. saltator Ulmi. De Geer, v. 260. 48. t. 8. f. 5 .

Le Charanson sauteur brun. Geoff. i. 286. 19.

Long. corp. I $\frac{\mathrm{I}}{2}$ lin.

Habitat in Corylo.

Descr. Totus, etiam rostro antennis pedibusque, rufus, et ferè ruber; sed oculi, pectus et abdomen nigra. Femora dentata, postica crassiora. Scbrank.

Obs. Simillimus Cur. ferrugineo, a quo differt, rostro rufo nec nigro, et abdomine subtùs toto nigro, nec segmentis ultimis ferrugineis.

70. Cur. niger pilosus, antennis elytris ano pedi-nigricollis. busque ferrugineis.

Long. corp. I $\frac{1}{2}$ lin.

Habitat

DESCR. Antennæ ferrugineæ. Rostrum ferrugineum, basi nigrâ. Caput et thorax nigra, pilosa. Elytra striata, pilosa, ferruginea, disco obscuriusculo. Corpus subtùs nigrum, ano rufo. Pedes ferruginei.

$7 \mathrm{~J}$. Cur. testaceus, capite sterno abdominisque atricapillus. basi subtùs nigris.

Long. corp. $1 \frac{x}{4}$ lin.

Habitat

Descr, 
DEsCr. Corpus oblongum, subangustum. Thorax, elytra et pedes testacei. Elytra punctato-striata. Abdomen subtùs testaceum, basi nigrâ.

$V$ ariat thorace disco nigro, et pedibus sordidè testaceis.

pilosus. $\quad 72$. Cur. hirtus niger albido maculatus, antennis plantisque rufis.

Fab. Sp. Ins. i. 183. 124. Mant. i. I10. I52. Ent. Syst. i. b. 446. 217. Vill. i. 194.87. Gmel. I761. 222. Payk. Faun. Suec. iii. 218. 26.

Long. corp. 2 lin.

Habitat

DESCR. Rostrum nigrum, inflexum. Thorax macula albâ médiâ sub-asterisciformi. Elytra nigro-maculata, sed sutura baseos albida : maculæ aliquot aliæ albidæ obsoletiores conspersæ conspiciendæ sunt.

Variat coloribus sordidis.

depressus. 73. Cur. nigro-fuscus hirsutiusculus, corpore subdepresso, thorace lineolâ dorsali impressâ obsoletâ.

Long. corp. $I_{\frac{3}{4}} \operatorname{lin}$.

Habitat -

DESCR. Rostrum rubrum, inflexum. Totum corpus suprà pilis brevissimis rigidiusculis obsitum, nigrofuscum. Thorax sub lente lineolâ dorsali impressâ. Antennæ, tibiæ et plantæ obscurè-rufescentes. Femora postica dentata.

rbododac- 74. Cur. niger, elytris virescenti-fuscis, tarsis rufis. tylus.

Long. corp. $1 \frac{x}{4}$ lin.

\section{Habitat}

DESCr. Antennæ rufæ. Elytra fusca, pilis virescentibus obvestita. Rostrum inflexum. Corpus, præterquam tarsi qui rufi sunt, omninò nigrum. Elytra admodùm punctulata, et striata; striæ punctis impressis. 
75. Cur. fuscus, elytris striatis subtomentosis, Fragarie. antennis tarsisque rufis.

Fab. Ent. Syst. i, b. 448. 227. Payk. Faun. Suec. iii. 217. 3.5. Panz. Ent. Germ. 320.120.

Herbst. Jablonsk. vi. $423 \cdot 407 \cdot t \cdot 93 \cdot f \cdot 3 \cdot$

Curculio Calcar. Payk. Monog. 17. Fab. Ent. Sy'st. i. b. 446.219. Panz. Ent. Germ.319. 112.

I_ong. corp. I $\frac{x}{4}$ lin.

Habitat

DESCR. Rostrum crassiusculum, capite thoraceque longius. Caput et thorax minima fusca. Elytra fusca, striata, subtomentosa, capite thoraceque quadruplo longiora. Pedes nigri, tarsis rufis.

76. Cur. rugosus fuscus, antennis tarsisque rufis. rbodopus. Long. corp. I lin.

Habitat

Descr. Simillimus Cur. Fragarice at minor, et differt etiam elytris rugosis, non striatis, nec tomentosis.

77. Cur. minutus niger, elytris striatis: striis ex Oxyacanpunctulis impressis.

the.

Long. corp. $\frac{x}{2}$ lin.

Habitat in Cratego Oxyacanthâ.

D. Kirby.

DESCR. Totus niger. Porrò hic minimus est generis Curculionum.

78. Cur. niger, elytris striatis: basi interne lunulâ Avellane. fasciâque ante apicem albis.

Don. Brit. Ins. t. 205. $f \cdot 3 \cdot$

Long. corp. I lin.

Habitat in Corylo.

DEscr. Thorax albido villosus. Elytra obscure nigra, striata, maculâ communi apud scutellum X literam referenti. Antennx, tibiæ et tarsi testacei. Femora nigra.

$$
\text { s } 4 \text { 79. Cur. }
$$


Salicis. 79. Cur. ater, elytris striatis : fasciis duabus suturâque baseos albis.

Linn. Syst. Nat. 611. 43? Faun. Suec.610? Vill. i. 193. 83? Gmel. 176I. 43? Fab. Syst. Ent. 144. 9I. Sp. Ins. i. 183. 125. Mant. i. I10. 154. Ent. Syst. i. b. 447.222 . Panz. Ent. Germ. 3 19, I15. De Geer, v. 264. 5I. Faun. Etrusc. 320. Hellw. 320. Faun. Ingr. 338. Payk. Monog.62. Faun. Suec. iii. $269.9 \mathrm{I}$.

Herbst. Jablonsk. vi. 422. 406. t.93.f. 2. Panz. Faun. Germ. I8. t. I5?

Curculio Capreæ. Don. Brit. Ins. t. I2I. f. 5. 6. 7.

Long. corp. $1 \frac{x}{4}$ lin.

Habitat in Salice.

Descr. Caput atrum. Thorax ater, punctulatus, lineolâ dorsali cinerascensti. Scutellum album. Elytra striata, atra, fasciis duabus albis, marginem exteriorem haud attingentibus; anteriore latiore, sinuatâ, pilis quibusdam ferrugineis suturam versus; posteriore undulatâ. Pedes nigri.

* Corpore ovato, rostro breviusculo nec pectori applicabili.

Antirrbini. 80. Cur. ater, villis brevissimis albicantibus, rostro thorace breviori, capite posticè gibbo.

Payk. Faun. Suec. iii. 257. 78 .

Cur. Linariæ. Panz. Ent. Germ.304. 27.

Panz. Faun. Germ. 26. t. I8.

Long. corp. $1 \frac{1}{2}$ lin.

Habitat in Antirrbino Linariâ.

DesCR. Quæ in hoc animalculo admodùm singularia sunt, Rostrum lineare, obtusiusculum, quod non thoracem longitudine æquat, et caput quod posticè gibbum, sive gibbosum est; sed hæc sub lente. Elytra striata, villis brevissimis albicantibus. Thorax sub lente punctulis prominulis scabriusculus.

crassus. $8 \mathrm{I}$. Cur. fuscus, rostro incrassato thorace breviori, pedibus rufescentibus.

Long. 
Long. corp. $1 \frac{x}{4}$ lin.

\section{Habitat}

DESCR. Rostrum incrassatum, nigrum, thorace paulo brevius. Caput et thorax punctulis numerosissimis prominulis scabriuscula. Elytra punctulata, striata; striæ punctis impressis. Pedes rufescentes. Corpus subtùs, certo lucis respectu, albescit.

82. Cur. ater punctulatus, rostro brevi crassius-brevis. culo, elytris striatis.

Long. corp. $\mathrm{I}$ lin.

Habitat

Ex mus. Miss Hill.

DESCr. Curculiones atri maximam inter se habent affinitatem. Ideoque singula cautè inspicienda sunt membra. Hunc exponemus præcipuo rostri brevis crassi signo. Thorax punctulatus. Elytra etiam punctulata, et insuper striata, et in striis punctula minuta, impressa. Corpus totum ejusdem coloris est.

83. Cur. ater, elytris opacis oblongis.

Cerasi.

Linn. Syst. Nat. 607. II. Faun. Suec. 583. Gmel. I762. II. Scop. 84 .

Long. corp. $\mathrm{I} \frac{x}{2}$ lin.

Habitat in Cerasi foliis, quorum epidermidem exèdit larva. Linn.

DESCR. Totus ater, elytris punctis striatis opacis, nec ullo modo nitidiusculis. Faun. Suec.

**** Corpore oblongo, thorace globoso. Pilosi.

84. Cur. elytris cinereis : maculâ mediâ fuscâ. PlantagiFab. Mant. i. 103. 72. Ent. Syst.i.b. 413. 85. Vill. nis. i. 191. 78. Gmel. 1749. 139. Payk. Monog. 4I. Faun. Suec. iii. 23I. 48. Panz. Ent. Germ.307. 45. De Geer, v. 237. 24. t. 7.f. I7. 18. Herbst. Jablonsk. vi. $254.233 . t .80 \cdot f \cdot 2$.

Long. 
Long. corp. $2 \frac{\pi}{2}$ lin.

Habitat

Descr. Statura et omninò Cur. Rumicis. Rostrum nigrum. Thorax cinereus, medio fuscus, lineâ dorsalị, cinereâ. Elytra cinerea, maculâ magnâ, mediâ, fuscâ, et præterea puncta aliquot ejusdem coloris. Fab. Mant.

Rumicis. 85. Cur. cincrascens, elytris fusco cinereoque obsoletè tessellatis, antennis basi rubris.

Linn. Syst. Nat.614. 60. Faun. Suec. 590. Gmel. I754. 60. Vill. i. 197.94. Fab. Syst. Ent. 134. 38 . SP. Ins. i. 170. 55. Mant. i. 103.73. Ent. Syst. i. b. 4I3. 86. Payk. Monog. 40. Faun. Suec. iii. 229. 47. Faun. Fred. 10. 97. Panz. Ent. Germ. 307.46.

De Geer, v. 231. 20. t. 7.f. 10. II. Herbst. Jablonsk. vi. $24 \mathrm{I} \cdot 205 \cdot t \cdot 77 \cdot f \cdot 9$.

Long. corp. $2 \frac{3}{4}$ lin.

\section{Habitat}

DESCR. Totum corpus nigrum, vellere cinereo obtectum. Elytra tenuiter striata, fusco cinereoque varia, sive obsoletè tessellata. Antennæ rufæ, clavâ nigrâ. Pedes nigri, vellere cinereo.

bimacula- 86. Cur. piceus, elytris striatis apice rufo-ferrutus. gineis.

Long. corp. $2 \frac{x}{2}$ lin.

Habitat Captus prope Hastingas.

DESCR. Rostrum nigrum. Thorax et elytra anticè picea. Elytra posticè rufo-ferruginea; porro striata sunt, punctis impressis. Antennæ et pedes rufescentes, sive ex rufo-ferruginei.

arator. 87 . Cur. subovatus, thorace fusco: lineis tribus pallidis, elytrorum suturâ nigrâ dentatâ.

Linn. Mant.531. Gmel. 1762.284.

Curculio 
Curculio Polygoni. Fab. Ent. Syst. i. b.454. 291. Payk.

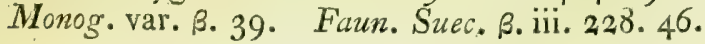

Long. corp. $3 \frac{1}{4}$ lin.

Habitat in Spergula arvensi.

DESCR. Rostrum fuscum. Antennæ clavatæ, articulis duobus nodosis. Pedes fusci, edentuli. Thorax fuscus, lineis tribus testaceis. Elytra testacea, suturâ communi nigrâ, dentatâ; lineæ 2 sive 3 abruptæ singuli elytri. Linn. Mant.

88. Cur. testaceus, rostri apice nigro, thorace stramineus. subferrugineo: lineis tribus pallidis.

Long. corp. I $\frac{3}{4}$ lin.

Habitat

DESCR. Rostrum testaceum, apice nigrum. Oculi nigri. Thorax ferrugineus, lineis tribus longitudinalibus pallidis, quarum media tenuior. Elytra testacea, lineolis punctisque ferrugineis, obsoletis, striata, (striæ punctis impressis) villosa, villis brevissimis rigidis, suturâ sub-elevato-incrassatâ. Pedes testacei.

89. Cur. holosericens viridis, pedibus elytrorum-nigrirostris. que margine sordidè rufescentibus.

Fab. Syst. Ent. 132. 24. Sp. Ins. i. 167.33. Mant. i. I00.44. Ent. Syst.i.b. 407.56. Vill. i. 187. 43 . Gmel. 1744. 105. Payk. Monog.53. Faun. Suec. iii. 247.67. Faun. Etrusi. 292. Hellw. 292. Panz. Ent. Germ. 302. I9.

Panz. Faun. Germ.36.t. I4. Herbst. Jablonsk. vi. 28I. 254. t. 8I. f. II. I2.

Long. corp. 2 lin.

Habitat

Descr. Corpus oblongum, viride, holosericeum. Thorax globosus. Antennæ sordidè rufescunt. Pedes etiam obscurè rufescentes, geniculis nigris. Elytrorum margo inflexus, pedibus concolor. 
frilineatus. 90. Cur. fusco-ferrugineus, thorace lineis tribus pallidis, pedibus testaceis.

Long. corp. $1_{4}^{\frac{3}{4}}$ lin.

\section{Habitat}

Descr. Rostrum fuscum. Thorax fusco-ferrugineus, lineis tribus albis, longitudinalibus, quarum media tenuior, Elytra ut in Cur. stramineo, sed colore saturatiori. Pedes testacei.

An a Cur. stramineo satis distinctus?

resinosus. 91. Cur. piceus, elytris punctis excavato-striatis, antennis pedibusque obscurè rufescentibus.

Long. curp. 3 lin.

Habitat

DESCR. Totum corpus piceum, villositate quâdam cinerascenti adspersum. Thorax punctulis prominulis scabriusculus, lineâ mediâ elevatâ, lævi. Elytra striata ; striæ punctis impressis. Pedes et antennæ rufo-piceæ.

cnemery- 92. Cur. ater, tibiis plantisque rufis, thorace cotbrus. leoptris duplo angustiori.

Long. corp. 2 lin.

Habitat In mus. D. Kirby.

DESCR. Rostrum crassiusculum, thorace paulo brevius. Thorax ovatus, coleoptris ferè duplo angustior. Corpus hujusce animalculi oblongum est, et nigrum, at ex pilis plurimis brevissimis cineritie quâdam albicanti obvestitum. Antennarum basis et tibiæ solummodò piceæ, et hæc quidem obscurâ, nec, ut in pice solet, clarâ et quasi pellucidâ tincturâ. Elytra striata; striæe punctis impressis.

Gitenialus. 93. Cur. thorace fusco: lineâ utrinque pallidâ, elytris cinereis fusco-conspersis punctato-striatis. Long. corp. $2 \frac{3}{4}$ lin.

Habitat

DESCR. 
DESCR. Rostrum nigricans, thorace brevius. Thorax fuscus, ex ovato rotundus, lineâ utrinque pallidâ. Elytra fusco-cinerea, striata ; striæ punctis impressis : inter strias punctula plurima nigricantia.

94. Cur. oblongo-ovatus fusco-cinereus, antennis striatiplantisque rufescentibus, rostro striato.

rostris.

Long. corp. $3 \frac{x}{2}$ lin.

\section{Habitat}

Descr. Affinis Cur. bitaniato, sed lineæ pallidæ thoracis desunt. Rostrum latiusculum, crassum, nigrum, lineâ mediâ exaratum. Elytra cinerea, thorace pallidiora, punctis aliquot nigris ornata, striata sunt; striis punctatis. Antennæ rufescentes, clavâ saturatiori. Pedes cinerei, plantis rufescentibus.

95. Cur. oblongo-ovatus griseo-cinereus, clytris interrupsus. lineolis albis interruptis, tibiis plantisque rufescentibus.

Long. corp. $2 \frac{\mathrm{T}}{2}$ lin.

\section{Habitat}

Descr. Rostrum nigrum, vix thorace longius. Thorax et elytra griseo-cinerea. Thorax lineâ dorsali pallidâ. Elytra striata, punctis aliquot nigris, lineolisque albis interruptis, quæ præcipuè posticè sița sunt. Antennæ, tibiæ plantæque rufescentes.

96. Cur. fuscus, colcoptris griseis : maculâ posticâ seleneus. communi lunulari pallidâ, antennis pedibusque rufescentibus.

Long. corp. $2 \frac{x}{4}$ lin.

Habitat

DESCR. Rostrum, eaput et thorax fusca, sive fusco-grisea. Coleoptra grisea, maculâ pone medium communi lunari, pallidà, fusco marginatâ. Antennæe et pedes rufi. Elytra in acutius desinunt. 


\section{CURCULIO. (A. b.****)}

rigidus. $\quad 97$. Cur. niger, elytris striatis: puncto albo villoso obsoleto, pedibus piceis.

Long. corp. $2 \frac{x}{2}$ lin.

Habitat

Mus. D. Beckwith.

Descr. Thorax valdè punctatus, punctis sæpiủs confluentibus. Elytra villis raris albidis conspersa, omninò punctulata sunt, imo et striata; striæ punctis impressis. Pone medium propter suturam in utroque elytro punctum album, ex villis albidis confectum. Corpus subtùs atrum, punctulatissimum. Pedes picei.

tomentosus. 98. Cur. fusco-cinereus tomentosus, elytris obsoletè striato-punctatis, plantis nigris.

Long. corp. 3 lin.

Habitat_- Captus sub stercore bovino, propter fluvium Usk, prope Crickhowell.

Descr. Totum corpus tomento sive vellere brevissimo densissimo obtectum. Elytra obsoletè striata; striæ ex punctis impressis, quæ puncta præ vellere denso vix nisi oculo armato conspicienda. Antennæ rufescentes. Abdomen obtusum. Rostrum thorace brevitus.

rufimanus. 99. Cur. fusco-cinereus, elytris obsoletè punctatostriatis rufis.

Long. corp. 3 lin.

Habitat -

Captus cum præcedenti.

DESCR. Præcedenti simillimus adẹo ut ferè varietatem sexûs dicas. Differt sanè abdomine tenuiori, acutiusculo, nec obtuso, plantis rufis, nec nigris : porrò tomento non æqualiter denso obvelatur. Rostrum thorace brevius.

ebeneus. I00. Cur. niger, thorace scabriusculo, elytris obsoletè striatis punctulatissimisque.

Long. corp. 5 lin.

Habitat -

Ex mus. Miss Hill.

Desch. 
Descr. Rostrum crassum, thorace paulo longius. Thorax punctis numerosissimis prominulis scaber. Elytra punctulis numerosissimis minutissimis conspersa. Porro striata sunt, striis obsoletis; striæ punctis impressis. Abdomen et pedes concolores.

IOI. Cur. cinerascenti-villosus, rostro nigro, an-fusco-cinetennis basi tibiisque ferrugineis.

reus.

Long. corp. $2 \frac{3}{4}$ lin.

Habitat Captus in cretario, Aprili medio.

$$
\text { D. Kirby. }
$$

Descr. Fusco-niger, villis cinerascentibus adspersus. Rostrum nigrum. Antennæ nigricantes, basi ferrugineæ. Elytra fusca, punctato-striata. Tibiæ femorumque apices ferruginei, tarsis obscurioribus.

102. Cur. pubescens, capite intra thoracem re-acephalus. tractili, elytris cinereo-striatis.

Long. corp. $1 \frac{2}{3}$ lin.

\section{Habitat}

Descr. Rostrum breviusculum, pubescens, cujus medio insident antennæ breves, capitulo majori. Caput intra thoracem omninò retractile. Thorax albido pubescens. Elytra villis cinereis jucunde striata. Corpus subtùs albido pubescens.

103. Cur. elongatus piceus, thorace punctato, linearis. elytris striatis.

Fab. Ent. Syst. i.b. 419. I10. Panz. Ent. Germ. 309. 60. Payk. Faun. Suec. iii. 242. 60. Herbst. Jablonsk. vi. 53.15 .

Panz. Faun. Germ. 18. t. 7 .

Cossonus linearis. Ent. Hclv. 60, I. t. I. f. I. 2.

Long. corp. $2 \frac{3}{4}$ lin.

Habitat in Boleto.

D. Sheppard.

DESCR. Antennæ rufo-picer, capitulis dilutioribus. Rostrum et thorax nigro-picea. Thorax punctatue, 
lineâ mediâ elevatâ, longitudinali. Elytra rufo-picea, valdè striata, et inter strias punctis impressis notata. Pedes rufo-picei.

picipes.

104. Cur. niger obscurus, elytris punctato-striatis,' antennis tarsisque rufo-piceis.

Long. corp. 4 lin.

\section{Habitat}

DESCR. Antennæ rufæ, villosæ. Caput et rostrum nigra, plana. Thorax scabriusculo-punctatus, lineấ. mediầ longitudinali, elevatâ, lævi. Elytra striata, striis ex punctis excavatis. Pedes villosi, nigri, sive nigro-picei, tarsis rufo-piceis.

vernalis. 105. Cur. cinereus tomentosus, rostro atro nitido apice ferrugineo, thorace elytrisque vittis luteis. Reicb. Mant. Ins. i. 8. t. I. f.4.

Long. corp. $\mathrm{x} \frac{\mathrm{x}}{2}$ lin.

Habitat sub foliis putridis primo vere.

Descr. Caput cinereum, seu potiùs nigrum, pilis squamulisque cinereum. Rostrum thorace vix longius, arcuatum, basi albidum, medio atrum nitidum, apice ferrugineum. Oculi laterales, prominuli, Antennæ ferruginex, rostro vix æquiparantes. Thorax pilis confertissimis albidus, vittis duabus luteis vix distinctis. Elytra oblonga, punctato-striata, pilis albidis undique tecta, vittâ in medio elytrorum vix distinctâ, luteâ. Scutellum albidum, triquetrum. Sternum et abdomen pilis numerosissimis albida. Pedes clavati, femoribus muticis, cinereis, tibiis tarsisque ferrugineis, pilis rarioribus cinereis. Reich.

\section{******* Corpore cylindrico.}

paraplecli- 106. Cur. subcinereus, elytris mucronatis. cus.

Linn. Syst. Nat. 610. 34. Faun. Suec. 604. Vill. i. 183. 29. Gmel. 1750.34. Panz. Ent. Germ.307.49. Fab. Syst. Ent. 135. 44. Sp. Ins. i. 172.62. Mant. i. 103 . 
i. 103. 77. Ent. Syst. i. b. 4I4.9r. Faun. Fred. 10. 100. Fanen. Etrusc. 295. Hellw. 295. Harr. 290. Poda Mus. Grac. 29. 4. Payk. Monog.50. Faun. Suec. iii. 244.63.

Panz. Faun. Germ. 6. t. I5. Pontop. Atl. Dan. i. 671. 14. t. 29. Scbreff. Icon.t. 44. f. I. Voet. ii. t. 37. f. I. Herbst. Jablonsk. vi. 42. 1. t. 62.f. I. Don. Brit. Ins. t. 348. f. 2.

Le Charanson à suture noire. Geoff. i. 279.4?

Curculio Phellandrii. De Geer, v. 204. 18.t. $7 \cdot f \cdot 3$.

Long. corp. 8 lin.

Habitat in Pbellandrio, Sio, intra caules. Larva alba capite luteo, equis lethalis. Captus in Insulâ Eliensi. D. Curtis.

Descr. Rostrum longum, teres. Thorax punctis excavatis. Elytra minus quam in reliquis gibba, recta, in apicem seu angulum acutum desinentia, oblonga, singula striis decem longitudinalibus exarata et simul excavato-punctata; hæ striæ coëunt per paria ante apicem, in singulo elytro. Totum corpus atrum, villis conspicuis cinereis tectum, hinc totum cinereum rore flavo sæpè pictum. Antennæ magnæ, infimo articulo longissimo, rufescenti ; apice nigræ. Fuun. Suec.

107. Cur. ater, elytris obtusis punctatis.

Fab. Syst. Ent. 135. 46. Sp. Ins. i. I72.66. Mant. i. 104.83. Ent. Syst.i. b. 418 . 106. Vill. i. 189.56. Gmel. I751. I51. Panz. Ent. Germ. 308. 55. Harr. 291.

Mart. Ling. Ent. t. 20, f. 43. Scbaff. Icon. t.79.f. I. Panz. Faun. Germ. 42. t. 12. Herbst. Jablonsk. vi. 44. 2. t. 62. f. 2. Herbst. Arcb. t. 24.f. 7 .

Long. corp. 6 lin.

Habitat

DESCR. Statura Cur. paraplectici. Thorax scaber. Elytra striato-punctata. Syst. Ent.

I08. Cur. cincreo-albus, elytris nigro-nebulosis, Alismatis. rostro abbreviato crasso porrecto sulcato.

vol. I. 
Long. corp. $I \frac{x}{2}$ lin.

Habitat

Descr. Rostrum curtum, crassiusculum, basi suprà sulco longitudinali, abbreviato, exaratum. Elytra pariter nebulosa, sed macula singularis pone medium sita est, et fasciæformis. Elytra striata, striis profundiusculis.

bypoleucus. I09. Cur. ater subcylindricus, elytris striatis, abdomine subtùs albo.

Long. corp. $1 \frac{3}{4}$ lin.

Habitat in culmis Junci marcidis exsiccatis.

Descr. Totum corpus aterrimum, glabrum, nitidiusculum. Thorax politus, punctulis impressis. Elytra glabra, striata. Abdomen subtùs, præcipuè apicem versus, argenteo-album.

circulatus. IIO. Cur. nig̣er, lineâ pallidâ subgriseâ utroque latere marginatus.

Long. corp. 2 lin.

Habitat

Descr. Villosus. Rostrum breve, deorsùm spectans apice rufo. Antennæ rufæ, capitulo fusco. Thorax lateribus lineâque intermediâ albido-villosis. Scuteklum albidum. Elytra albido latè marginata : punctum etiam album gerunt ante apices. Subtùs albidovillosus., Pedes rufi, femoribus fuscis.

sranarius. IIr. Cur. piceus, thorace punctato longitudine elytrorum.

Linn. Syst. Nat.608. I6. Faun. Suec. 587. Vill.i. I77. 13. Gmel. 1745.16. Scop. 89. Scbrank, 207. Fab. Syst. Ent. 134.39. Sp. Ins. i. I71. 56. Mant. i. I03. 74. Ent. Syst. i. b. 4I4. 88. De Geer, v. 239. 25. Faun. Ingr. 327. Harr. 288. Faun. Fred. 10. 95. Faun. Etrusc. 302. Hellw. 302. Payk, Monog. 51. Faun. Suec. Hii. 245. 64. Rai.88. L.ich. i. 218.14 . 
Le Charanson brun de bled. Geoff. i. 285. I8.

Pontop. Dan. Atl. i.671.5.t.29.

Rhynchophorus granarius. Herbst. Jablonsk. vi. I4. 8. t. 60. $f .7$.

Calendra granaria. Ent. Helv. 62. I. t. 2. $f$. 1. 2.

Long. corp. 2 lin.

Habitat frequens in granulis avenaceis decorticatis; in mercatorum tabernis frequens. Linn.

DESCR. Totus omnibus partibus concolor, rufo-testaceus. Corpus admodùm oblongum est, et, quod in hac specie singulare est, thorax valdè longus et magnus, ut longitudinem elytrorum ferè (non tamen omninò) adtingat. Thorax punctis excavatis adspersus, et elytra striis excavata. Faun. Suec.

I I 2. Cur. ferrugineus unicolor punctatus. unicolor. Long. corp. I lin.

\section{Habitat}

Descr. Simillimus Cur. granario, sed minor, et differt colore etiam.

I 3 . Cur. nigro-piceus totus, rostro crassiusculo, Tignarius. thorace punctato elytris breviori.

Long. corp. $\mathbf{I} \frac{\pi}{2}$ lin.

\section{Habitat}

DesCr. Hoc animalculum primo intuitu Cur. granarium diceres, at differt, thorace elytris multo breviori, et punctis thoracis rotundis, nec oblongis, sive sublinearibus. Rostrum crassum. Thorax omninò punctulatus. Elytra striata; striæ punctis impressis.

II4: Cur. niger, elytris maculis quatuor ferru- Oryze. gineis.

Linn. Amcen. Acad. vi. 395. 19. Fab. Syst. Ent. I30. 40. Sp. Ins. i. I71. 57. Mant. i. 103.75. Ent. Syst. i. b. 4r4. 89. Vill. i. 188. 54. Gmel. I745. Ir3. Curculio frugilegus, De Geer, v, 273.7 . 
Rhynchophorus Oryzæ. Herbst. Jablonsk. vi. I8. 10. t. $60 . f .9$.

Long. corp. $1 \frac{3}{4} \operatorname{lin}$.

Habitat in Oryze seminibus, ab exteris regionibus allatis. Limn.

Descr. Magnitudo grani Oryze. Totus niger, sive piceo-niger, punctis cavis scaber, oblongus, subtùs piceus est. Elytra striata; in singulis maculæ duæ ferrugineæ, quarum prior ad basin elytri, posterior ante apicem elytri. Amoen. Acad.

picicornis. I 15 . Cur. subtùs niger suprà atro-caruleus, antennis piceis.

Long. corp. $\mathbf{z} \frac{2}{3}$ lin.

Habitat

Drscr. Suprà nitidus. Rostrum deorsủm spectans apice dilatato, cui insident antennæ. Antennarum clava magna. Thorax anticè angustatus, excavato punctatus. Elytra striata. Certo situ tarsi rufescunt.

laticollis. $\quad 16$. Cur. ater nitidus, thorace lato, elytris striatis. Long. corp. 2 lin.

Habitat

Descr. Totus ater, nitidus. Caput et thorax suprà subtilissimè punctata. Elytra striata. Totum corpus subtùs valdè punctatum. Pedes concolores.

\section{c. Antennis fractis, femoribus dentatis.}

* Corpore owato obtuso, rostro sese pectori intra pedes applicante.

Seropbula- I 17. Cur. coleoptris maculis duabus atris albisque rite. dorsalibus, elytris striis elevatis nigro albidoque variis.

Linn. Syst. Nat. 614. GI. Faun. Suec. 603. Vill. i. 197.95. Gmel.1767.61. Laicb. i. 224.18. Fab. Syst. 
Syst. Ent. 140. 68. Sp. Ins. i. 177.95. Mant. i. 107. I 20. Ent. Syst. i. b. 434. 167. Payk. Monog. 22. Faun. Etrusc. 3 10. Hellw.310. Faun. Fred. 10. 99. Faun. Ingr.330. Panz. Ent. Germ.312. 76. Payk. Faun. Suec. iii. 207. 24.

Le Charanson à lozange de la Scrofulaire. Geoff.i. 296.44. Donov. Brit. Ins. t. 60. De Geer, v. 208. 3. t. 6. f. 17-20. Herbst. Jablonsk. vi, 184. 147. t. 73.f. 1. Mart. Eng. Ent.t. 19. f. 25.

Long. corp. 3 lin.

Habitat in Scropbularia.

DESCR. Rostrum nigricans, thorace longius, quod terrefactus sub ventrem maximè inflectit. Thorax exalbidus, pilis cinereis vestitus, cum maculis duabus atris a tergo. Elytra glabra, sulcata, cinereo-testacea : singula striis quinque, interjacentibus lineis elevatis nigris, albis punctis; in medio dorso, clausis elytris, inque ipsâ suturâ, punctum atrum cum puncto albo adnexo a parte posticâ: pone hoc punctum, aliud punctum nigrum in ipsâ suturâ coleoptrorum versus anum albedine cinctum; antennarum infimus articulus longus. Pedes nigri; plantæ ferrugineæ. Faun. Suec.

I 8. Cur. coleoptris maculis duabus dorsalibus Thapsi. atris simplicibus.

Fizb. Ent. Syst. i. b. 434. 168. Panz. Ent. Germ. 312. 77 .

Herbst. Jablonsk. vi. 187. 148. t. $73 \cdot f \cdot 2$.

Curculio Scrophulariæ var. $\beta$. Payk. Faun. Suec. iii. 207. 24. Monog. 22. var. $\beta$ et $\%$.

Long. corp. 3 lin.

Habitat in Verbasco Thapso.

DESCR. Mera varietas præcedentis, teste D. de Paykull. Caput et thorax villosa, cinerea, immaculata, antemnis ferrugineis. Coleoptra villosa, cinerea, lineis plurimis e punctis nigris albisque alternis. In medio veł in suturâ puncta duo magna, orbiculata, omninò simplicia. Corpus et pedes cinerea. Ent. Syst. 
Hortulanus. I 1 9. Cur. cinereus, coleoptris maculis duabus atris dorsalibus.

Vill. i. 202. I8.

Don. Brit. Ins. t. 205. f. 2.

Long. corp. $2 \frac{x}{2}$ lin.

Habitat in Scropbulariâ.

Descr. Cur. Scropbularice affinis, sed griseus. Elytra striis elevatis punctis albis fuscisque variegatis, maculis duabus nigris ad suturam supernè infernèque. An varietas Cur. Scropbularice? Vill.

Obs. Nulla sexûs differentia.

immunis. I20. Cur. subgriseus, elytrorum lineis tribus elevatis albo nigroque tessellatis, tibiis plantisque rufis.

Long. corp. I $\frac{3}{4}$ lin.

Habitat in Scropbulariâ aquaticâ. D. Sheppard.

Descr. Statura et summa affinitas Cur. Scropbularice, sed minor. Totus pilis grisescenti-cinereis adspersus. Antennæ rufæ, clavâ nigrâ. Thorax subnebulosus. Elytra striis tribus elevatiusculis, punctis alternè albis nigrisque tessellatis. Pedes rufi, femoribus nigris. A cæteris Curculionibus in Scropbulariâ victitantibus hæc species præcipuè differt, quod punctá duo magna atra, suturæ communia, nequicquam gerit; unde nomen.

bipusula- I2I. Cur. cinereo-griseus, elytris striis elevatis: tus. maculis duabus, atris dorsalibus; posteriore rotundatâ.

Curculio Fraxini. De Geer, v. 2I2. 4.

Le Charanson gris de la Scrophulaire. Geoff. i. 298. 45. An Curculio Blattariæ. Fab. Ent. Syst. i. b. 435. 170 ? Ent. Germ. 3I3: 79?

An Cionus Blattaria. Ent. Helv. 66. I. t. 3.f. I ?

Long. corp. $1 \frac{3}{4}$ lin.

Habitat

DESCR. 
Descr. Affinis Cur. Scroploularice, sed minor. Corpus cinereum, nec cinereo-testaceum, punctis nigris. Elytra maculis binis atris, velutinis, dorsalibus, communibus ; alterâ ad basin minùs distinctâ, aliâ ad apicem amœniori. Cinerities purior maculam apicis amplectitur. Porrò scutellum immersum esse videtur, et undique nigredine cingitur.

I22. Cur. nigro-fuscus squamosus lincolis albis Echï. variegatus.

Fab. Ent. Syst. i. b. 436. 176. Panz. Ent. Germ. 3I. 4.85 .

Herbst. Jablonsk. vi.39I.370. t. 91.f. I. Panz. Faun. Germ. I7. $t$. I2.

Cur. geographicus. Vill. i. 201. I16. t. I. $f$. 22. iv. 275. I16. Fourc. i. 128. 43. Gmel. I778.329. Le Charanson geographie. Geof. i. 294. 40.

Long. corp. 3 lin.

Habitat in Ficbio.

DESCr. Fusco-niger, squamulis albis suprà infràque tectus, quæ squamæ supra thoracem elytraque varias lineas formant. Thorax tribus lineis longitudinalibus tribusque aliis transversalibus. Variæ elytrorum lineæ secantur, aliis duabus a scutello oblique descendentibus. Pedes nigri, albo variegati. Vill.

Variat absque tribus lineis transversalibus.

123. Cur. nigro cinereoque nebulosus, thorace ovalis. puncto utrinque nigro.

An Curculio ovalis? Linn. Syst. Nat.612.47. Faun. Suec.613. Vill. i. 194. 89.

Long. corp. (rostro deflexo) $1 \frac{2}{3}$ lin.

Habitat in pratis.

DEscr. Totum corpus suprà nigro albidoque nebulosum. Thorax medio, et utrinque puncto nigro. Subtùs, certo lucis respectù, totum corpus cinerascit. Thorax utrinque denticulato spinosus. Pedes, rostrum et antennæ nigra. 
fuliginosus. 124. Cur. niger subgriseus, coleoptris maculis tribus communibus: duabus albidis; mediâ atrâ.

An Curculio guttula? Fab. Mant. i. I07. 124. Ent. Syst. i. b. 436. 174. Panz. Ent. Germ. 314. 83 .

Herbst. Jablonsk. vi. $393 \cdot 372 . t \cdot 91 \cdot f \cdot 3$ ?

Long. corp. $I_{\frac{1}{2}}^{\frac{1}{2}}$.

Habitat

DEsCr. Totum corpus nigrum, et quasi fuliginosum, villis tamen cinerascentibus obsitum. Thorax utrinque denticulatus. Elytra striata, maculis tribus communibus; prima quæ proximè scutellum sita est albida, et punctum refert; secunda, quæ huic contigua est, atra, oblonga, basi præmorsa ; tertia autem ad anum locatur oblonga, albida.

dentatus. I25. Cur. piceus, thorace utrinque dentato, plantis rufis.

Long. corp. $1 \frac{3}{4}$ lin.

Habitat

Descr. Thorax scaber. Elytra striata. Color ex nigro obsoletiùs rufescit. Tarsi rufi.

Quercicola. I 26. Cur. fusco-griseus, thorace utrinque dentato, rostro deflexo thorace longiori.

Fab. Ent. Syst. i. b. 408. 64. Payk. Monog. 68. Faun. Suec. iii. $215 \cdot 33$ :

Herbst. Jablonsk. vi. 403. $3^{8} 3 \cdot$ t. 9 I. f. $\mathbf{I} 3$.

Long. corp. $1 \frac{1}{2}$ lin.

\section{Habitat}

Descr. Rostrum deflexum, leviter arcuatum, nigrum, thorace paulo longius. Thorax margine baseos elevato, anticè angustior, utrinque ad medium dentatus. Abdomen ovatum. Elytra scabriuscula, fusco-grisea, striata. Pedes cinereo-rufescentes. 
127. Cur. rufo-ferrugineus, thorace strigis albis Trogloobsoletiusculis, elytris striatis.

Fab. Mant. i. 108. 131. Ent. Syst. i. b. 439. $87 \%$ Gnel. 1763. 224. Panz. Ent. Germ. 315. 94. Payk. Monog. 29. Faunt. Suec, iii. 214.3I. Herist. Sablonsk. vi. $473 \cdot 484$.

Long. corp. $1 \frac{1}{2}$ lin.

Habitat

DESCR. Rostrum arcuatum, nigrum, thorace subduplo longius. Per cæetera animalculum ferrugineum est. Thorax dorso subcarinato, margine antico elevato. Elytra satis profundè striata, apicem versùs scabriuscula.

I28. Cur. niger subtùs incanus, thorace lineâ Urtice. mediâ exarato, elytris profundè striatis.

An Cur. pollinarius? Forst. Cent. 33 .

Long. corp. $\mathrm{I} \frac{\mathrm{T}}{2}$ lin.

Habitat in Urticâ dioicâ.

DESCR. Corpus ovatum, suprà convexiusculum, subtùs ventricosum. Thorax lineầ mediâ exaratus, nec punctatus. Elytra, pro ratione animalis, satis profundè striata. Femora omnia dentata. Totum corpus, præcipuè pectus, pedes et abdomen subtùs, polline quodam albido obtectum. An Cur. pollinarius Forsteri? At neque thorax neque elytra suprà plana sunt, sed convexa.

I29. Cur. cinereus, suprà fasciis duabus longi-bivittatus. tudinalibus olivaceis integris.

An Curculio Parallelus? Panz. Ent. Germ. 306. 44.

Panz. Faun. Germ. 18. t. 5 .

Long. corp. (rostro autem inflexo) $1 \frac{x}{2}$ lin.

Habitat

Descr. Totum corpus pilis brevissimis sive tomento cinereo vestitum. Depilatus niger est. Per dorsum duæ fasciæ longitudinales, olivaceæ, obsoletiusculæ,

a capite 
a capite usque ad elytrorum apices decurrunt. In nonnullis hæ fasciæ retrò $a b$ apice elytrorum sursùm marginem versùs exteriorem referuntur; non autem ad marginem aut ad basin attingunt, sed sub medio deficiunt. Plantæ obsoletè rufescentes. Femora omnia dentata.

nervosus. I30. Cur. griseus, elytris striatis: striis elevatis nigro alboque variis.

Long. corp. I $\frac{1}{2}$ lin.

Habitat

DEscr. Satis distinctus. Elytra grisea, elevato-striata. Rostrum et pedes rufo-testácei.

pleurostigma.

I 3 I. Cur. obscurè niger, pectorc utrinque puncto albo.

Long. corp. $\mathrm{J} \frac{2}{3}$ lin.

Habitat

DEscr. Subtùs albido squamosus; inter thoracem et elytrorum basin puncto albo pectus notatur. Thorax utrinque obsoletè dentatus, posticè et anticè fossulâ intermediâ exaratur. Femora omnia denticulata.

melanostictus.

132. Cur. cinereus, elytris nigro-tessellatis, tarsis testaccis.

Long. corp. I lin.

Habitat

DESCR. Suprà cinereo villosus, subtùs cinereo squamosus. Rostrum et antennæ nigræ. Thorax nigricans, lineâ intermediâ et lateribus albidis, anticè minus constrictus. Elytra cinereo villosa, nigro tessellata. Tarsi testacei.

subrufus. I33. Cur. obscurè rufus cinereo-nebulosus, elytris apice subretusis.

Long. corp. I lin.

Habitat

DEsCR. 
Descr. Totus obscurè rufus, squamis cinereis nebulosus. Rostrum nigricans. Thorax anticè angustatus, utrinque obsoletè dentatus.

134. Cur. cinereus, clytris basi lineâ suturali ab-cinereus. breviatâ anticè albâ pusticè nigrâ, tarsis rubellis. Long. corp. $1 \frac{2}{3}$ lin.

Habitat

DESCR. Subtùs squamis albidis tectus, suprà cinereovillosus, etiam rostrum et caput. Thorax anticè angustatus, utrinque sub-dentatus. Elytra striata, striis nigris, interstitiis cinereo-villosis. Sutura basi lineâ dimidiatâ anticè albâ posticè nigrâ.

I35. Cur. cinerascenti-squamosus, elytris cano-uniguttanebulosis: maculâ communi nigricanti, plan- tus. tis rufescentibus.

Long. corp. circiter 1 lin.

Habitat

In mus. D. Kirby.

DESCR. Subtùs totus squamulis incanis obsitus. Thorax anticè constrictus, utrinque tuberculo armatus, cinerascenti-squamosus, lineâ intermediâ obscurâ, incanâ. Elytra striata, squamulis cinereo-fuscis canisque nebulosa, maculâ mediâ suturali fuscâ notata. Tibire quatuor anticæ tarsique omnes rufescentes.

* Corpore ovato acuto, rostro longissimo filiformi.

I36. Cur. corpore grisco longitudine rostri rubri. Nucum.

Linn. Syst. Nat. 6I3.59. Faun. Suec.616. Vill. i. 196.93. Gmel. I767.59. Fab. Syst. Ent. I4I. 77. Sp. Ins. i. 179. I06. Mant. i. 108. 135. Ent. Syst. i. b. 440. 192. De Geer, v. 205. 2. Scop. 105. Panz. Ent. Germ. 317. Ic0. Faun. Etrusc. 314. Hellav. 314. Faun. Ingr. 334. Harr. 297. Udd. Diss. 24. Payk. Monog. 20. Faun. Suec, iii. 204. 20.

Mart. Eng. Ent. to I9. f. 26. Panz, Faun. Germ. 
42.t. 21. Roes.3.t. 67.f. 1.5.6. Poda, 29.7.t. 1. f. 3. Sulz. Ins. t. 3. f.22. Scbaff: Icon. $t \cdot 50 \cdot f \cdot 4$. Herbst. Jablonsk. vi. I 97 . I58. t. 73. f. 10.

Le Charanson trompette. Geoff. i. 295. 42.

Long. $\operatorname{corp} \cdot 3 \frac{1}{2}-5$ lin.

Habitat intra Coryli nuces.

Descr. Statura Cur. Pini, sed minor. Rostrum filiforme, tenuissimum, inflexum, rubrum, longitudine totius corporis. Femora omnia apice introrsùm denticulo instructa, sed priora majore. Faun. Suec.

Glandium. 137. Cur. cinereus, femoribus omnibus dentatis, rostro pedibusque rufis.

Long. corp. $4 \frac{1}{2}$ lin.

Habitat in Glandibus.

Descr. Staturâ et magnitudine Cur. Nucum. Rostrum longitudine corporis est, et rufum. Pedes rufi. Totum corpus vellere cinereo vestitum; sed scutellum, et punctum utrinque ad latera sterni sub elytrorum basi saturatiùs lucent; unde tripunctatus videtur.

Cerasorum. 138. Cur. corpore griseo longifudine rostri nigri. Fab. Syst. Ent. 142. 80. Sp. Ins. i. 180. 109. Mant. i. 109. 138. Ent. Syst. i. b. 442.200. Vill. i. 200. 107. Gmel. 1767.250. Panz. Ent. Germ.317. I0I. Payk. Faun. Suec. iii. 206.21. Monog.2I.

Panz. Faun. Germ.42. t. 22. Herbst. Jablonsk. vi. Ig6. I $57 \cdot t \cdot 73 \cdot f \cdot 9 \cdot$

Long. corp. $2 \frac{1}{2}-4$ lin.

\section{Habitat}

Descr. Maximè affinis Cur. Nucum, sed primo intuitu dignoscatur; nam hic minor est, et rostro nigro; ille rufo gaudet. Elytra posticè fasciâ transversâ lutescenti, magis minùsve manifestâ.

demuirostris. 139. Cur. niger, elytris albo subfasciatis, antennis rufis.

Fab. 
Fab. Sp. Ins. i. 180. I2. Mant. i. 109. 14 r. Ent. Syst.i.b. 443. 204. Vill. i. 200. 10\%. Gmel. 1767. 253. Rai. 89. Herbst. Jablonsk. 210.173.

Don. Brit. Ins. t. 249. f. 3. Mart. Eng. Ent. t. 20. f. 40 .

Long. corp. 3 lin.

\section{Habitat}

DESCR. Caput nigrum, rostro porrecto, tenui, glabro, atro. Antennæ rufæ, clavâ cinèreâ. Thorax niger, pilis brevissimis cinereis. Scutellum cinereum. Elytra nigra, fasciis plurimis, undatis, pallidioribus. Fab. Sp. Ins.

140. Cur. niger, femoribus omnibus dentatis, ely-clavatus. tris striatris, rostro clavato : clavâ compressâ.

Lony. corp. $I_{2}^{1}$ lin.

\section{Habitat}

DESCR. Affinis Cur. stygio, at rostrum clavatum satis indicat; apex sive clava rostri compressa est, et quod singulare, ad basin clavæ unguiculus quidam incurvus apicem spectans prodit. Abdomen subtùs argenteo nitens.

I 4. I. Cur. ater, rostro tenui parùn elongato. ater.

Long. corp. 2 lin.

\section{Habitat In mus. D. Kirby.}

DESCR. Inter Curculiones atros differentia tenuior; quæ igitur notanda sese exhibent cantè observanda. In hoc thorax sub lente punctis prominulis scabriusculus, opacus est, etiam rostrum elongatum, $\frac{2}{3}$ longitudinis corporis. Elytra striata, striæ punctis impressis.

142. Cur. corpore griseo nebuloso, scutello albo, Pomorum. elytris obliquè fasciatis.

Linn. Syst. Nat. 612.46. Faun. Suec. 6r2. Vill. i. 194. 88. Gmel. 1764. 46. Fab. Syst. Eitt, 143. Ste 
Sp. Ins. 181. I15. Mant. i. 109. 145. Ent. Syst. i. b. 444. 209. Panz. Ent. Germ. 317. 105. Faun. Fred. I. Iоз. Harr. 3 I. Payk. Faun. Suec, iii. I99. 16. Monog. I2.

Friscb. i. 32. t. 8. Scbaff. Icon. t. 221. f. 2. a. b. Herbst. Jablonsk. vi. I57. I 5. t. 70. f. II.

Long, corp. $2 \frac{x}{4}$ lin.

\section{Habitat in floribus Pomonæ.}

DESCR. Totus nebulosus, sive griseo-cinereus, fasciâ duplici transversâ supra elytra, quarum antica ad angulum rectum, in medio, ad juncturas suturarum, pone coit, et alia fascia fusca posterior magis transversa; ad apicem thoracis a tergn punctum album. Antennæ pedesque subfusci. In femorum primi paris latere interiore apicem versus, denticulus robustus, quâ notâ manifestè differt $\mathrm{ab}$ aliis. Faun. Suec.

pedicula- I43. Cur. corpore rubro, elytris albidis sub-fasrius. ciatis.

Linn. Syst. Nat. 6т5. 66. Faun. Suec. 620. Vill. i. 199. 100. Gmel. 1769. 66.

Long. corp. 2 lin.

Habitat-Captus in foliis Crategi Oxyacantka.

Descr. Rostrum rubrum, rectum, longitudine ferè corporis. Elytra grisea, obsoletè fasciata. Femora omnia dentata. Faun. Suec.

fasciatus. I 44. Cur. fusco-ferrugineus, elytris albo fasciatis, pedibus rufis.

An Curculio incurvus? Panz. Faun. Germ. 36. t. 7 .

Long. corp. 2 lin.

Habitat in foliis Crategi Oxyacantba.

DESCR. Antennæ, rostrum et pedes rufa. Thorax fuscoferrugineus, lineâ dorsali tenui, albâ. Scutellum album. Elytra fusco-ferruginea, striata; striæ punctis impressis; ad basin elytrorum macula magna, alba, fasciæformis, ad marginem latior, intùs sensim decrescens, 
crescens, sed ad suturam minimè pertingit; post me. dium fascia alba, lata, quæ tamen suturam ipsam non tangit. Simillimus Cur.pediculario. An sexûs differentiâ ?

145. Cur. thorace rufo, elytris striatis posticè ru- Ulmi. fescentibus, femoribus anticis longiùs dentatis. Vill. i. 20r. I15. Gmel. 1772. 296.

De Geer, v. 215. 8. t. 6. f. 26. 27 .

Long. corp. 2 lin.

\section{Habitat}

DESCR. Rostrum longiùs nigrum. Caput nigrum. Thorax sub lente punctulis prominulis scaber, rufus, lineâ albidâ mediâ, obsoletâ. Elytra striata, basi nigra, posticè rufa. Pedes rufescentes. Femora duo antica crassiora, dente firmo longiusculo; quatuor postica dente qualis in plerisque observatur. Ut color elytrorum probe judicetur, paululum sub-leves, inde color verus perspicitur.

I46. Cur. globoso-uvatus niger, thorace strigis strigosus. tribus albis, elytris inciso-striatis.

Long. corp. 3 lin.

Habitat -

Ex mus. D. Allen.

DESCr. Rostrum nigrum. Thorax anticè angustior, posticè ventricosus, gibbus, strigis tribus albis ; quarum una media, duæ ad latera: media in lineolam dorsalem tenuem impressam abbreviatam desinit. Elytra striata; striæ valdè tenues, quasi incisionibus factis. Femora dente valido.

147. Cur. ater, rostro tenuiori arcuato, antennis curvatus. rufis.

Long. corp. $I \frac{\pi}{2}$ lin.

Habitat In mus. D. Kirby.

DESCR. Rostrum arcuatum, circiter $\frac{2}{3}$ longitudinis corporis æquat, glabrum et politum. Thorax ater, opaens, 
süb) lente scabriusculus. Elytra striata. Antennæ rufa. Simillimus Cur. nigrino, at antennæ rufæ.

arcuatus. I 48. Cur. suprà subcinereus subtùs albus, rostro arcuato thorace longiore.

Long. corp. 2 lin.

Habitat in Salicibus.

Ex mus. D. Kirby.

Descr. Rostrum filiforme, atrum, nitidum, thorace longius, arcuatum. Antennæ nigræ, cinerascenti-villosulæ, articulo primo glabro, fusco. Thorax subconicus, punctulatus. Scutellum niveum. Elytra atra, striata, striarum interstitiis pilositate vix conspicuâ cínerascentibus. Corpus subtùs syuamulis albis vestitum. Pedes villosuli.

pyrrbaceras.

I 49. Cur. suprà subcinereus subtùs albus, antennis rostrique apice rufis.

Long. corp. $I_{3}^{2}$ lin.

Habitat -

Descr. Statura præcedentis, sed paulo minor. Rostrum thorace brevius, basi nigrun, villosulum, apice glabrum, sanguineum. Antennæ rostri medio insidentes, testaceæ, capitulo nigro. Caput atrum, oculorum orbitâ cinerascenti. Thorax ater, subconicus, punctulatissimus. Elytra atra, profundè striata, striarum interstitiis pilositate parvâ subincanis. Corpus subtùs squamulis albis tectum.

intermedius.

150. Cur. suprà subcinercus subtùs albus, rostro thorace breviore, antennis tes aceis.

Long. corp. I lin.

Habitat in Salicibus.

Descr. Rostrum totum nigrum ut in Cur. arcuato, sed thorace brevius, et antennæe testaceæ capitulo nigro, ut in Cur. pyrrbacerate. An satis distinctus? Intermedius videtur inter has species; aut sexus alter prioris?

I5 . Cur. 
151. Cur. niger, thorace subpubescente, elytris melanonitidiusculis, antennarum articulo primo lon- plerus. gissimo fusco.

Long. corp. $1 \frac{2}{3}$ lin.

\section{Habitat}

Descr. Rostrum apice latiori. Antennæ prope apicem insident. Thorax obscurè trilineatus. Elytra magìs nitida, striata, striis punctatis.

*** Corpore oblongo, rostro crassiori.

I52. Cur. niger, elytris fuscis: fasciis nebulosis. Pini. Linn. Syst. Nat, 608. 19. Faun. Suec. 589. Vill. i. 178. 15. Gmel. 1746. 19.

Curculio Abietis. Fab. Syst. Ent. 138. 59. Sp. Ins. i. I75. 84. Mant. i. 106. 107. Ent. Syst.i. b. 428. I44. De Geer, v. 204. I. Payk. Monog. II. Panz. Ent. Germ. 299. I. Payk. Faun. Suec, iii, 186. 3. Faun. Etrusc. 3II. Hellw. 3II. Mart. Eng. Ent.t. 21. f. 60.

Long. corp. 6 lin.

Habitat in Pino sylvestri. Captus in Rivelstonwood, prope Edinburgum. D. Smith.

Descr. Abdomen valdè gibbum est a tergo anum versus. Animalculum totum e griseo nigrum; totum corpus, rostrum, thorax, elytra et pedes punctis minutissimis, contiguis, excavatis. Signaturæ aliquæ testaceæ in thorace ex villis tenuissimis, similes etiam in formam fasciarum duarum transversarum linearum, quarum quæ thoraci proprior ad suturam elytrorum interrupta est. Antennarum apices flavescunt. Faun. Suec.

Obs. Illustrissimus Linnæus hoc insectum et Cur. Abietis haud solitâ virtute distinxit. Descriptio enim specifica cum in Syst. Nat. tum in Fauná Suecicâ, utraque Cur. Abietis spectat. Quicunque autem vult hæc duo insecta probè dignoscere Faunam Suecicam adeat: in quo opere, descriptio auctior sub alterıtrâ specie, utriusque signa ritè notavit. Cur. Pini Curculione Abietis VOL. I. 
duplo major est; tum elytris fuscis gaudet. Porro Cur. Pini femoribus dentatis, Cur. Abietis autem femoribus simplicibus insignitur. Cur. Pini cum specimine Linnæano contuli, unde quod in numero nostratum habendus sit, certus scio. Cur. Abietis nunquam in Britanniâ inveni.

germanus. I 53. Cur. corpore ovato-oblongo nigro punctis testaceis adsperso.

Linn. Syst. Nat. 613. 58. Vill. i. 195. 92. Gmel. 1766.58. Scbrank, 210. Faun. Fred.11. 110. Poda, 29. 6. Harr. 293. Payk. Monog. I. Laich. i. 204. I.

Mart. Eng. Ent. t. 22. f. 68. Panz. Faun. Germ. 42. t. 16. Scbaff. Icon. t. 25.f. 2. 5.t. 62. f. II. t. Ior. f. 6. Sulz. Ins. t. 4.f. 8 .

Curculio fusco-maculatus. Payk. Faun. Suec. iii. 184. I. Herbst. Jablonsk. vi. 329. 304. t. 86. f.2.

Le Charanson tigré. Geoff. i. 292. 35 .

Long. corp. Io lin.

Habitat

Ex mus. D. Lyon.

Descr. Inter maximos Europæos. Rostrum crassiusculum. Thorax subrotundus, utrinque punctis tribus ferrugineis. Coleoptra abdomen tegentia, ovata, nigra, punctis ferrugineis adspersa. Femora postica obsoletius dentata; anteriora quatuor mutica, cum rudimento dentis. Similis Cur. Pini. Syst. Nat.

anglicanus. I54. Cur. corpore ovato-oblongo atro, thorace puncto utrinque testaceo gemino.

Curculio germanus. Fab. Syst. Ent. I39. 67. Sp. Ins. i. I77. 94. Mant. i. I07. II9. Ent. Syst. i. b. 433. 166. Panz. Ent. Germ.312. 75. Payk. Faun. Suec. iii, $185 \cdot 2$.

Don. Brit. Ins. t. 34. f. 3. Mart. Eng. Ent. t. 18.f.7. Herbst. Jablonsk. vi. 328. 303 .

Le Charanson à corcelet couromé. Geoff. i. 291. 34.

Long. corp. 7-9 lin. Habitat in locis præcipuè cretaceis.

Descr. 
Descr. Statura Cur. germani, cui maximè affinis; at colcoptra nunquam punctis testaceis adspersa, et thorax punctis duobus utrinque nec tribus ornatur. Pedes omnes dentati, dente robusto. Thorax et elytra punctata, punctis impressis, ut in Cur. germano; scilicet, thorax punctis plurimis distinctis, elytra autem punctis confluentibus, adeò ut quodammodò rugosa videntur.

I55. Cur. ater, thorace punctato, elytris punctato-punctatus. striatis.

Long. corp. $\mathrm{I} \frac{\mathrm{r}}{\mathrm{z}}$ lin.

\section{Habitat}

Descr. Statura Cur.anglicani, atmultoties minor. Thorax punctatissimus, punctis majusculis impressis. Elytra striata ; striæ ex punctulis majusculis impressis. Femora antica subdentata. Antennæ et plantæ rufescentes. Coleoptra erosa, dura, ut in Cur. germano et anglicano. Corpus punctis albis omninò caret.

Viriat. thorace pedibusque omninò rufo-ferrugineis, rostro piceo.

\section{*****ar* Corpore oblongo, rostro filiformi.}

156. Cur. nigricans, elytris striatis griseo irroratis. Tremula. Fab. Mant. i. Iog. 147. Ent. Syst. i. b. 445. 212. Gmel. 1769. 263. Payk. Monog. 4. Faun. Suec. iii. I89. 6.

Long. corp. 3 lin.

Habitat in Populo.

Descr. Statura et magnitudo Cur. Tortricis. Rostrum porrectum, atrum. Thorax ater, lævis, nitidus, posticè rubro nitens. Elytra crenata, striata, nigra, atomis plurimis griseis. Fab. Mant.

157. Cur. corpore testaceo, pectore fusco.

Linn. Syst. Nat. 615.67. Faun. Suec.622. Vill. i. I99. I0I. Gmel. 1769.67. Fab. Syst. Ent. 143. 85. Sp. Ins. i. 181. 116. Mant. i, 109. 146. Ent. Syst. U 2 
i. b. 444.2II. Payk. Monog. 6. Faun. Suec. iii. 192. 9. Panz. Ent. Germ. 318. 108. Faun. Etrusc. 315. Helliv. 315. Faun. Ingr. 337.

Mart. Eng. Ent. t. 18. f.2. Panz. Faun. Germ, 18. t. 14. Ent. Helv. 92. 8. t. 9. f. 3. 4. Herbst. Jablonsk. vi. I55. I I 3. $t$. $70 . f .8$.

Le Charanson couleur de rouille. Geoff. i. $300.5 \mathrm{I}$.

Curculio fulvus. De Geer, v. 2 I4. 6.

Long. corp. 3 lin.

Habitat in Populi Tremula foliis, quæ contorquet. Linn.

DEscr. Corpus oblongum, subcylindricum, testaceum, sive triste flavescens. Pectus inter femora duo postrema, nigricans. Elytra subtilissimè striata. Femora omnia dentata. Faun. Suec.

maculatus. I58. Cur. griseus nigro nebulosus, elytris obtusiusculis.

Long. corp. 2 lin.

Habitat

DESCR. Totum corpus (præter abdomen nigrum) obscurè rufum, sive griseum, maculis punctisque nigris nebulosum. Sub lente elytra striata; striæ punctulis impressis ornantur. Rostrum thorace longius, nigro-rufum. Femora omnia dentata. Coleoptra minimè acuminata. Thorax margine antico nigro-rufo.

Fructuum. 159. Cur. ferrugineus, elytris nigro obsoletè nebulosis.

Long. corp. 2 lin.

Habitat

Descr. Maximè affinis Cur. maculato sed minor. Rostrum brevius ferrugineum, concolor, nec, ut in Cur. maculato, nigro-rufum. Thorăx unicolor. Antennæ etiam ferrugineæ, concolores. Oculi solùm nigri. Abdomen ferrugineum.

caliginosus. I6o. Cur. ater, elytrorum striis punctatis approximatis. 
Fab. Syst. Ent. 137.58. Sp. Ins. i. 175.82. Mant. i. 105. 103. Ent. Syst. i. b. 427. 140.

Long. corp.

Habitat - In mus. Brit.

DESCR. Statura oblonga Cur. paraplectici, at paulo minor. Totus ater, obscurus, minimè nitens. Thorax rotundatus, punctatus, carinatus. Elytra striatopunctata, striis per paria approximatis profundis. Fe. mora acutè dentata. Fab. Syst. Ent.

Obs. Hoc animal non nisi in Musæo Britannico inter collectanea D. Dandridge vidi. Ideoque non nisi metu quodam dubius speciebus Britannicis conscripsi.

I6I. Cur. piceus pilis cinereis tomentosus nebu-longimanus. losus, manibus longissimis.

Forst. Cent. 32 .

Long. corp. 4 lin.

Habitat

Descr. Corpus oblongum, piceum, pilis cinereis tomentosis nebulosum. Antennæ rufæ. Rostrum cum thorace longitudinem elytrorum æquat. Manus seu pedes primi paris tertiâ parte ad minimum reliquos pedes superant. Elytra cinerea, punctis nigris sparsis. Tarsi rufi. Forst. Cent.

I62. Cur. rufus, elytris disco fusco albidoque ne- rubellus. bulosis.

Long. corp. 2 lin.

Habitat in Salice.

Descr. Cur. maculato affinis. Totus rufus, albidovillosus, exceptis oculis nigris, et elytrorum disco abdominisque basi fuscis. Femora omnia dentata.

\section{******* Corpore cylindrico.}

163. Cur. ater obovatus, thorace anticè utrinque atramentaunidentato, elytris striatis.

บ 3 rius.

Curculio 
Curculio Cerasi. Fab. Ent. Syst. i. b. 440. I9o. Payk. Monog: 7. Faun. Suec. iii. 193. I0. Panz. Ent. Germ. 316. 98. Faun. Etrusc. 307. Hellw.307. Herbst. Jablonsk. vi. 68.32.t.64. f. 2. Panz. Faun. Germ. 42. $t$. I9.

Le Charanson noir à corcelet armé. Geoff. i. 299. 48 .

Long. corp. $2 \frac{x}{2}$ lin.

\section{Habitat}

Descr. Totum corpus aterrimum, opacum, obovatum, abdomine obtuso. Thorax antice utrinque dente brevi acuto, scaber, ex punctulis numerosissimis prominulis. Elytra satis profundè striata; striæ punctis impressis.

Obs. Auctores suprà citati omnes de hoc insecto erravere; quippe Cur. Cerasi Linnæi temerè dixerunt. Cur. autem Cerasi verus non modo locum inter Longirostres femoribus simplicibus, sibi vindicat, quin et tboracem simplicem inermemque habet. Insectum autem quod illi male Cur. Cerasi nominaverunt, cum meo Cur. atramentario satis convenit: nempè inter Longirostres femoribus dentatis numeratur, et tboracem anticè utrinque bidentatum jactat. Icon Herbstii meum Cur. atramentarium planè exhibet, quod et Panzeri item; hæc autem infelicior.

Hellwig in Faunâ Etruscâ hunc errorem de Cur. Cerasi Linnæi ex animis nostris conatus est detrahere. Quis non inter thoracem et femora dentata et mutica facile dijudicet ?

semicylindricus.

I64. Cur. ater, elytris striatis, corpore elongato semicylindrico.

Long. corp. $2 \frac{3}{4}$ lin.

Habitat

DESCR. Thorax sub lente punctulis prominulis scabriusculus. Elytra striata, punctis in fundo striarum impressis.

stygius. $\quad 165$. Cur. ater oblongus, elytris striatis, thorace lævi antrorsùm utrinque dentato. 
Long. corp. $1 \frac{x}{2}$ lin.

Habitat

DesCr. Affinis admodum Cur. atramentario, sed dimidio minor; tum thorax lævis, nec punctis excavatus.

B. Brevirostres.

a. Antennis integris, femoribus simplicibus.

I66. Cur. niger, fronte anoque albis, thorace tu-albinus. berculato.

Linn. Syst. Nat. 616. 79. Faun. Suec. 632. Vill. i. 208. 147. Gmel. 1783. 79. Scop. 66. Fab. Syst. Ent. I51. 127. Sp. Ins. i. 192. I80. Mant. i. 118. 236. Payk. Monog. I12. Udd. Diss. 27. Faun. Ingr. 3 II.

Bonsd. Cur. Suec. I. f. I. De Geer, v. 255. 44. t. 8. f. I. Knocb. i, 81. t. 6. f. I-7. Don. Brit. Ins. t. $348 \cdot f \cdot 3$.

Anthribus albinus. Fab. Ent. Syst. i. b. 375. T. Panz. Ent. Germ. 292. I. Payk. Faun. Suec, iii. I60. 2. Panz. Faun. Germ. 3. t. І6.

Long, corp. 5 lin.

Habitat

DESCR. Rostrum breviusculum, planum, suprà lacteum. Thorax a tergo tuberculis tribus, mucronatis, transversis. Elytra griseo-fusca, punctis nonnullis mucronatis, apice lacteo. Pedes et antennæ annulis albis et nigricantibus: hæ longitudine corporis. Faun Suec.

Color ferè Curculionis Lapatbi. Syst. Nat.

I67. Cur. rostro latissimo plano, elytris apice albis : latirostris. punctis duobus nigris.

Fab. Syst. Ent. 15I. 128. Spec. Ins. i. 193. I81. Mant. i.118.237. Vill.i.214.173. Gmel.1783.360. Payk. Monog. III.

Bonsd. Cur. Suec. 2. f. 2, Schaff. Icon, t. 89, f.6. Don. Brit. Ins. t. 348. f. I. 
Anthribus latirostris. Fab. Ent. Syst.i.b.376. 2. Faun. Ingr. 312. Panz. Ent. Germ. 292. 2. Payk. Faun. Suec. iii. I59. I.

Panz. Faun. Suec. I5. t. I2.

L'Antribe noir strié. Geoff. i. $307 \cdot 3 \cdot t \cdot 5 \cdot f \cdot 2$.

Long. corp. 6 lin.

Habitat in Spbariâ entomorrbizá.

Descr. Statura Cur. albini, at major. Corpus nigrum. Rostrum latissimum, planum, album, apice nigrum. Thorax niger, canaliculatus. Elytra nigra, striis interruptis glaucis, apice alba, punctis duobus nigris. Pedes nigri, albo annulati. Abdomen subtùs album, lateribus nigris. Fab. Syst. Ent.

brevirostris. I68. Cur. griseo-niger, rostro dilatato, scutello elytrorum apicibus anoque albis.

Anthribus brevirostris. Panz. Faun. Germ. 57. t.9.

Long. corp. 2 lin.

\section{Habitat}

Descr. Affinis Cur. latirostri at quadruplo minor; tum abdomen subtùs griseo-nigrum, nec album. Antennæ ferrugineæ. Frons sive rostrum latum, album. Thorax niger, puncto albo, scutello albo subcontiguo. Elytra nigra, apicibus omninò albis. Anus suprà albus. Pedes albido obsoletè annulati.

ruficollis. I69. Cur. ferrugineus, elytris capitisque basi atrocæruleis.

Linn. Syst. Nat.609.24. Faun. Suec. 595. Vill. i. 179. 20. Gmel. 1748.24.

Curculio rostratus. De Geer, v. 252. 42.t. 7.f. 27.28.

Curculio Roboris Payk. Monog. I 18.

Anthribus ruficollis. Panz. Ent. Germ. 293. 5.

Panz. Faun. Germ. 24. t. I9. Ent. Helv. I22. I. t. 15. f. 4.5 .

Anthribus Roboris. Fab. Supp. I6I. 4-5. Payk. Faun. Suec, iii. $165 \cdot 7$. 
Long. corp. $\mathrm{I} \frac{\mathrm{x}}{4}$ lin.

\section{Habitat}

Descr. Antennæ fusco-nigræ, basi flavescentes. Caput et thorax ferruginea. Elytra glaberrima, polita, nitida, atro-cærulea. Pedes pallidi, sive flavescentes.

I 7o. Cur. æneus nitidus, rostro pedibusque fer-planirostris. rugineis.

Fab. Mant. i. I19. 239. Gmel. I784. 362.

Cur. fulvirostris. Fab. Mant. App. ii. 381. 16r. 2. Payk. Monog. II7.

Anthribus planirostris. Fab. Ent. Syst. i. b. 377. 5. Payk. Faun. Suec. iii. 167. 9. Panz. Ent. Germ. 293. 4.

Panz. Faun. Germ. 15. t. I4.

Long. corp. $I \frac{x}{4}$ lin.

\section{Habitat}

DESCR. Rostrum breve, depressum, sub-sulcatum, ferrugineum. Thorax æneus, nitidus. Elytra ænea, nitida, punctato-striata. Abdomen subtùs castaneum. Pedes ferruginei.

I 7I. Cur. niger, rostro thoraceque ferrugineo, 4-pustulaelytris maculis duabus ferrugineis.

tus.

Long. corp. $I_{\frac{x}{4}}$ lin.

Habitat

DESCR. Caput et thorax ferruginea. Maculæ elytrorum ovatæ, satìs magnæ; altera ad basin, altera pone medium sitæ sunt. Abdomen nigrum. Pedes ferruginei.

b. Antennis fractis, femoribus simplicibus. * Corpore ovato.

I72. Cur. niger nitidus, elytris striatis, pedibus niger. rufis.

Fab. 
Fab.Syst. Ent. т50. 12r. Sp. Ins. i. 19r. 168. Mant. i. I18. 223. Ent. Syst. i. b.473.332. Vill.i. 2 I3 - I 71. Gmel. I786.380. Payk. Monog.98. Faun. Suec. iii. 295. II .

Ent. Helv. $85 \cdot 5 \cdot t .8 . f$. 1. 2.

Curculio clavipes. Bonsd. $35 \cdot f \cdot 36$.

Curculio ater. Herbst. Jablonsk. vi. 332. 306.

Long. corp. 6 lin.

\section{Habitat}

DEScr. Habitus et ferè magnitudine Cur. anglicani. Thorax sub lente punctis numerosissimis prominentibus scaber. Elytra punctatissima, obsoletè striata. Pedes rufi, femoribus medio incrassatis, adeo ut inflata videntur. Antennæ articulo inferiori longissimo, apice clavato.

Lima. 173. Cur. oblongo-ovatus niger totus, punctis prominulis scaber.

Long. corp. 8 lin.

Habitat

Descr. Inter maximos nostratum. Totum corpus ejusdem coloris nigrum, et omninò punctis prominentibus inæqualibus scabrum. Thorax ovatus, anticè et posticè truncatus. Abdomen ovatum, posticè acutiusculum.

scabrosus. I74. Cur. oblongo-ovatus scaber, femoribus subdentatis, thorace fusco, elytris striatis pedibusque brunneis.

Long. corp. 3 lin.

Habitat $\longrightarrow$

Descr. Antennæ, pedes et elytra rufo-ferruginea. Thorax scaber, punctulis confertis elevatis. Elytra etiam scabra, striis decem elevatis; striæ autem punctis sive scrobiculis excavantur, undè elytra rugoso-scabra, limæ instar apparent; porro elytra pilis brevissimis rarioribus obsita.

175. Cur. 
I75: Cur. fusco-cinereus oblongo-ovatus, elytris pilosulus. pilofis obfoletè striatis acutiusculis, pedibus nigris.

Cur. obscurus. Fab. Ent. Syst. i. b. 472. 330. Payk Monog. 95. Faun. Suec. iii. 292. 116.

Herbst. Jablonsk. vi. $344.317 . t .87 \cdot f \cdot 3$. An Curculio murinus? Bonsd. $30 . f \cdot 3 \mathbf{I}$.

Long. corp. 5 lin.

Habitat

DESCR. Rostrum, pedes et abdomen ex nigro cinerea ; in his autem cinerities ex villis brevissimis sive tomento constat. Thorax obsoletè scabriusculus. Elytra fusco-cinerea, pilosa, satìs acuta; porro obsoletiùs striata sunt, punctis obsoletis impressis inter strias interpositis.

176. Cur. fuscus, elytris cinereis: lineis duabus carinatus. suturaque elevatis nigris; punctis intermediis impressis.

Long. corp. 4 lin.

Habitat In mus. D. Sheppard.

DESCr. Antennæ fuscæ, clavâ ferrugineâ. Caput fuscum, dorso sulcatum. Thorax fuscis, punctatus, lineâ dorsali obsoletâ, impressâ. Elytra cinerea, lineis duabus suturaque elevatis, nigris : inter has lineas striæ duæ punctorum impressorum. Pedes picei.

I77. Cur. elytris maculâ et figurâ $V$ communi albis. Vau.

Scbrank, 227. Vill. i. 214. 174 .

Long. corp. 3-4 lin.

Habitat - Captus inter gramina, sub lapidibus. D. Kirby.

DESCR. Corpus pilosum. Rostrum crassum. Insectum oblongum, cinereum. In singulo elytro infra medium macula albida, tum in medio macula oblonga, obliqua, cum alterâ alterius elytri signum arietis $r$ seu literam V constituens, Scbrank.

178. Cur. 
3- guttatus. I78. Cur. nigricans, coleoptris griseis: maculis tribus albis ; posteriori majore cordatâ communi. Fab. Syst. Ent. 148. 109. Sp. Ins. i. I88. I53. Mant. i. I16. 202. Ent. Syst. i. b. 464. 293. Vill. i. 212. 163. Gmel. 1780.336. Harr. 270. Panz. Ent. Germ. 324. I 43 .

Scbaeff. Icon. t. 43. f. 9. Herbst. Jablonsk. vi. 238. 203. t. $77 \cdot f \cdot 7$.

Cur. vau var. Scbrank, 227.

Curculio cordiger. Sulz. t. 4.f. II. Ent. Helv. 85. 4. t. $7 \cdot f \cdot 3 \cdot 4$.

Long. corp. $3 \frac{x}{2}$ lin.

Habitat - Captus inter gramina, sub lapidibus. D. Kirby.

Descr. Corpus pilosum. Rostrum breve, canaliculatum. Thorax fuscus, immaculatus. Elytra substriata, grisea, puncto parvo albo in medio, et maculâ apicem versùs majore communi. Hic et præcedens sunt medii inter longirostres et brevirostres.

ratcus. I79. Cur. femoribus subdentatis fuscus, thorace globoso scabro, elytris punctis majoribus excavato-striatis.

Fab. Ent. Syst.i. b. 472. 327. Payk. Monog.94. Faun. Suec. iii. 29I. II4.

Herbst. Jablonsk. vi. 343. 316. t. 87. f.2.

Long. corp. $2 \frac{3}{4}$ lin.

Habitat

DESCR. Thorax subglobosus, niger, punctis prominulis scaber, lineâ mediâ elevatâ, abbreviatâ. Elytra villosa, villis cinerascentibus, punctis magnis excavatis striatâ.

vastalor. I So. Cur. fuscus, thorace varioloso, elytris striatis: striis elevato punctatis.

Long. corp. 4 lin.

Habitat -

DESCr. Antennæ pilosæ, fusc $x$, thorace longiores, rostri 
rostri apice insidentes. Rostrum brevissimum, apice dilatato. Oculi nigri. Caput vix a rostro distinetum. Thorax globosus, punctis elevatis variolosus. Elytra abdominis latera obvolventia, striata, striis circiter sex e punctis elevatis constantibus, squamis pallidis tecta, pilis rigidis exasperata. Corpus subtùs fuscum, pilis brevibus pallidis adpressis consitum. Pedes rufi, femoribus clavatis, subdentatis.

I 8 I. Cur. fuscus, thorace varioloso, elytris striatis : asper. striis squamulis albidis seriatim dispositis.

Long. corp. 3 lin.

Habitat

DEscr. Antennæ pilosæ, fuscæ, clavâ pallidâ. Thorax globosus, punctis elevatis confertis variolosus, lateribus squamulis albidis tectus. Elytra latera obvolventia, decemstriata, striis leviter sed latè exaratis, squamulis albidis seriatim dispositis ornata, fusco albidoque squamosa, pilis rigidis exasperata. Corpus subtùs nigro-fuscum, pilis albidis adpressis consitum. Pedes rufi. Femora clavata, antica subdentata.

182. Cur. testaceus, capite fusco, elytris elevato-squamiger. striatis: squamis pallidis testaceisque marmoratis.

Long.corp. $3 \frac{x}{2} \operatorname{lin}$.

Habitat in arbore cujus nomen me fefellit. Semel legi.

Descr. Caput fuscum, pilis albidis consitum. Antennæ fuscæ, clavâ pallidâ. Thorax globosus, punctis elevatis confertis variolosus, lateribus pallido squamosis. Elytra striata, striis circiter sex elevatiusculis, setis rigidis exasperata; tota squamis albidis testaceisque subnebulosa. Corpus subtùs testaceum, pilis brevibus adpressis consitum. Femora clavata, sed vix dentata.

183. Cur. oblongo-ovatus tomentosus fuscus, tho-limbalus. racis marginibus striisque duabus ely trorumque marginibus obsoletè pallidis.

Long. 
Long. corp. $2 \frac{\mathrm{T}}{2} \operatorname{lin}$.

Habitat

Ex mus. Miss Hill.

Descr. Fomina marem corporis longitudine paulùm superat, et adhuc magis rotunditate abdominis. Totum corpus tomentosum, ex cinereo-fuscum. Thorax duas strias subundulatas, longitudinales, et latera pallides cinerea, habet. Elytra semper marginibus exterioribus obsoletè pallentibus; nec non aliquando striis tribus, aut quatuor, per discum, longitudinalibus, obsoletissimè pallidis. Sed hoc incertum, neque in omnibus videtur. Elytra striata, striis circiter septem concinnè punctatis, punctulis impressis. Corpus subtùs fuscum, tomentosum.

austriacus. I84. Cur. fuscus sub-griseus, thoracis lateribus elytrorumque marginibus pallidis.

Scbrank, 234.

Long. corp. 4 lin.

Habitat in sepibus.

Descr. Corpus ovatum, ferè unicolor. Thorax fuscus, lineolâ mediâ lateribusque pallidis. Elytra striata, punctis impressis, rufescenti-fusca, punctis nigris aliquot sparsis ad suturam, tum etiam inter strias. Margines exteriores latiùs pallidi, sive sordidè testacei.

medius. $\quad 185$. Cur. fuscus, elytris lineatis : punctis impressis; marginibus pallidis.

Long. corp. $3 \frac{\pi}{2}$ lin.

Habitat

DESCR. Totum corpus vellere fusco.cinerascenti obsitum. Elytra fusca, punctorum impressorum non excavatorum et quasi per paria ductorum seriebus novem. Inter tria paria suturæ proxima lineæ totidem longitudinales, pallidiores, (sutura ipsa primam conficit) obsoletiusculæ; latera pallida. Thorax lineis tribus pallidis, obsoletioribus.

plumbeus. 186. Cur. plumbeus, oculis antennisque rufis.

Long. 
Long. corp. 3 lin.

\section{Habitat - Captus propter Haftingas Aug.}

Descr. Corpus nigrum, vellere cinerascenti, unde quasi plumbi colorem refert. Abdomen pro magnitudine animalculi grossum, valdè ovatum. Elytra striata; striæ punctis impressis ornantur. Oculi rufi, et pyroporum instar (post mortem scilicet) micantes. Antennæ rufæ. Pedes ex nigro picei; at tibiæ plantæque pallidiores, rufescentes.

I 87 . Cur. cinereo fuscoque varius, elytrorum suturâ Coryli. dimidiatâ atrâ.

Fab. Syst. Ent. 148. I10. Sp. Ins. i. 189. I54. Mant. i. I16. 205. Ent. Syst. i. b. 456. 301. Vill. i. 213. 164. Gmel. 1780.339. Payk. Monog. 90. Panz. Ent. Germ. 325. I 49. Payk. Faun. Suec, iii. 287. I IO. Mart. Eng. Ent.t. 19. f. 20. Panz. Faun. Germ. 19. t. 12. Herbst. Jablonsk. vi. 349. 322. t. 87. f. 8.

Curculio capitatus. Bonsd. 23. f. 24. De Geer, v. 245 . 32 ?

Long. corp. $2 \frac{\mathrm{T}}{4}$ lin.

Habitat in Corylo.

DESCR. Affinis Cur. cervino. Rostrum brevissimum, apice atrum. Thorax elytraque pilosa, hispidiuscula, cinereo-fuscoque varia; dimidia suturæ pars, basi proxima, atra, glabra, Fab. Syst. Ent.

188. Cur. fuscus, elytris cinereis profundiuscule exaratus. striatis : striis punctatis.

Long. corp. $2 \frac{\mathrm{T}}{2}$ lin.

\section{Habitat}

Descr. Rostrum latiusculum, crassum, ferè longitudine thoracis. Caput et thorax saturatè fusca. Elytra pallidè fusca, sive cinerea, striata, striis satìs profundis, punctatis. Totum corpus subtùs pilis brevissimis obtectum, et inde cinereum. 
setosus.

I89. Cur. fusco-cinereus hispidus, antennis pedibusque rufis.

Long. corp. $2 \frac{x}{2}$ lin.

Habitat

DESCr. Totum corpus suprà cinereum, sive fuscocinereum, porro setis sive pilis brevissimis rigidiusculis erectis hispidum. Elytra striata, striis punctatis. Antennæ et pedes rufescentes. Rustrum longitudine thoracis.

subrotundus. i 9o. Cur. griseus, abdomine ovato subrotundo, antennis pedibusque rufescentibus.

Long. corp. $2 \frac{1}{2}$ lin.

Habitat

DESCR. Totum corpus suprà griseum, in juventute ferè cupreum. Thorax ovatus. Abdomen ovale, teres, atque rotundum. Elytra striata, striis punctatis. Antennæ et pedes rufescentes.

$V$ ariat colore cupreo, griseo, et ferè fusco.

obesus. Igr. Cur. crassus fusco-cinereus, elytris obsoletè punctato-striatis, pedibus rufescentibus.

Long. corp. 2 lin.

Habitat

DESCR. Totum animal crassum est, quasi robustum, vellere cinereo brevissimo rigido obductum. Thorax scabriusculus. Elytra obsoletè striata; strix ex punctis minutis impressis. Pedes obscurè rufescentes. Antennæ piceæ.

scabriculus. 192. Cur. cinereus hispidus, elytris striatis.

Linn. Mant.531. Vill. i. 21 I. I56. Fab. Syst. Ent. 149. I13. Sp. Ins. i. I89. 159. Mant. i. II7. 212. Ent. Syst. i. b. 469. 313. Payk. Monog. 88. Faun. Etrusc. 234. Hellw. 234. Bonsd. 20. f. 21. 
Panz.Ent. Germ. 327. 162. Payk. Faun. Suec. iii. 285. 108.

Herbst.Jablonsk. vi. 351, 324.t.87, f. 10.

Long. corp. $1 \frac{1}{2}$ lin.

\section{Habitat}

Descr. Totum corpus unicolor, cinereum, squamis teretibus erectis, sive pilis brevibus crassis obsitum. Elytra sulcato-striata : pili elytrorum per porcos striis interjacentes siti sunt.

193. Cur. subcinereus, colcoptris globosis setis ri- birsutulus. gidis exasperatis, antennis pedibusque rufis.

Fab. Ent. Syst. i. b. 468. 312. Panz. Ent. Germ. 327.

I6I. Payk. Faun. Suec, iii. 286. rog.

Panz. Faun. Germ. 7.t. 7 .

Cur. echinatus. Bonsd. 2I.f. 22. Payk. Monog. 89.

Long. corp. $1 \frac{2}{3}$ lin.

\section{Habitat}

Descr. Medius inter Cur. scabriculum et Cur. scabrosum. Rostrum brevissimum. Antennæ ferrugineorufæ. Thorax cinereo-squamosus, vittis duabus mediis fuscis. Elytra punctato-striata, squamulis cinerascentibus albida, setis rigidissimis, itidem thorax et caput, exasperata. Prona pars corporis squamulis subcinereis cana. Pedes rufi.

194. Cur. piceus nitidus, abdomine ovato, antennis piceus. pedibusque rufescentibus.

Long. corp. $\mathrm{I} \frac{\mathrm{T}}{2} \mathrm{lin}$.

\section{Habitat}

DESCr. Antennæ, femora, tibiæ, plantæque rufo-ferruginea. Cætera piceus est. Thorax subglobosus, punctis plurimis impressis. Abdomen ovatum. Elytra glabra, striata ; striæ ex punctis impressis. Corpus nitidum.

195. Cur. fuscus, elytris cinereis : striis sex dorsali- sex-striatus. bus fuscis.

VOL. I. 
Long. corp. 4 lin.

\section{Habitat}

DESCr. Rostrum, caput et thorax fusca, immaculata. Elytra pallidiora, cinerea, striis sex dorsalibus fuscis, et tribus aliis lateralibus, obsoletioribus. Pedes fusci. Abdomen ovatum, tumidum, thorace multoties majus.

retusics.

I96. Cur. cupreo-cinereus nitidus, thorace brevi scabriusculo, antennis pedibusque rufescentibus.

Long. corp. $\mathrm{I} \frac{\mathrm{I}}{2}$ lin.

\section{Habitat}

DEScr. Animalculum breve, compactum, utrinque obtusum. Superficies tota cinerea, cupreo quodam nitido, sublucente. Caput suprà planum. Thorax punctulis prominulis scabriusculus, rotundus, capite ferè brevior. Elytra striata. Abdomen ovatum, pingue. Antennæ et pedes rufescentes.

elevatus. 197. Cur. fusco-cinereus oblongus, elytris pilosis striatis acutiusculis : striis quatuor elevatis.

Long. corp. $4 \frac{x}{2}$ lin.

Habitat

In mus. D. Kirby.

DESCR, Antennæ ferrugineæ. Thorax scabriusculus. Elytra fusco-cinerea, pilosa: porci striis quatuor elevatis ; inter porcos striæ ex punctis impressis. Corpus subtùs nigrum. Pedes rufi, pilis cinereis obtecti.

parapleurus. 198. Cur. niger hispidus, elytris striatis fuscis : maculis lateribusque albidis, antennis rufis.

Long. corp. 3 lin.

\section{Habitat}

DESCr. Antennæ rufæ. Rostrum, caput et thorax punctata, nigra, hispidula. Elytra fusca, striata, hispida, lateribus et maculis irregularibus albis, quæ ex pilis coloratis effictæ sunt. Corpus subtùs et pedes nigra, tomentosa. 
199. Cur. niger, thorace foveâ utrinque magnâ, scrobiculaelytris obsoletè striatis squamulis rufis obtectis. tus.

Long. corp. 2 lin.

Habitat $\longrightarrow$

DEscr. Antennæ rutæ. Totum corpus nigrum, squamulis rufis obtectum. Thorax punctatus, foveâ utrinque màgnâ, laterali. Elytra obsoletè striata。 Pedes nigri.

200. Cur. nigro-fuscus, clytris valdè striatis squa- tessellatus. mulis fuscis cinerascentibusque variis obtectis.

Long. corp. 2 lin.

Habitat

DESCR. Totum corpus suprà et antennæ nigro-fusca.

Caput et thorax squanulis fuscis tecta, thoracis margine anteriori albido. Elytra valdè striata, squamulis fuscis et cinerascentibus variis tessellata. Corpus subtús et pedes obscurè rufa.

20r. Cur. squamosus obscurè auratus, coleoptris Ëcidii. apices versùs lineis tribus elevatis.

Long. corp. 3 lin.

Habitat Lectus mense Maio, Aicidium

Serratula arvensis depascens. D. Kirby.

Descr. Totus squamulis obscurè auratis tectus. Rostrum thorace brevius. Antennæ fuscæ. Oculi subimmersi. Thorax lineâ elevatiusculâ, obsoletâ. Elytra substriata, colore obscuriori tessellata, versùs apices utrinque lineâ elevatiusculâ, et unâ communi; omnes apud anum convergentes.

202. Cur. globosus suprà fuscus subtùs cinereus, maritimus. elytrorum lateribus atomisque sparsis incanis, antennis fuscis.

Long. corp. $3 \frac{3}{4}$ lin.

Habitat _- Captus in littore juxta LandguardFort. D. Kirby.
X 2
DESCR. 
DESCR. Statura et summa affinitas Cur. limbati, sed major et alius. Subtùs totus squamulis cinerascentibus tectus, suprà fuscis. Rostrum brevissimum. Antennæ fuscæ. Thorax posticè lituris duabus incanis. Coleoptra globosa, lateribus intra margines, atomisque disci sparsis incanis; setis brevibus rigidis aspersa.

\section{* Corpore oblongo.}

nebulosus. 203. Cur. canus, elytris fasciis obliquis nigris, rostro carinato.

Linn. Syst. Nat.6г7. 84. Faun. Suec.635. Vill. i.210. I52. Gmel. I787.84. Fab. Syst. Ent. I47. I04. Sp. Ins. i. 186. 142. Mant. i. I14. 184. Ent. Syst. i. b. 457. 265. Payk. Monog. IOI. Harr. 266. Bonsd. 3. Panz. Ent. Germ. 321. 125. Faun. Etrusc. 324. Hellw. 324. Faun. Ingr. 341. Payk. Faun. Suec. iii. 298 . I22.

Herbst. Jablonsk. vi. 76. 38. t. 64. f. 8. Act. Acad. Suec. 1785.48. 18. t. 2. f. 18 ? Scbaff. Icon. t. 25. f. 3 .

Le Charanson à trompe sillonnée. Geoff.i. 278. $t$.4. f. 8. Curculio carinatus. De Geer, v. 241. 27 .

Long. corp. 8 lin.

Habitat

Descr. Color ex niveo et nigro variè mixtus, quasi per fascias obliquas. Thorax sub-ferrugineus. Faun. Suec.

sulcirostris. 204. Cur. cinereus subnebulosus, rostro trisulcato. Linn. Syst. Nat. 6I7. 85. Vill. i. 210. I53. Gmel. I787. 85. Fab. Sp. Ins. i. I87. I43. Mant. i. I14. 185. Ent. Syst. i. b. 458. 268. De Geer, v. 240.26. Payk. Monog. 100. Bonsd. 4. $f_{.}$5. Harr. 267. Panz. Ent. Germ. 321. I28. Faun. Etrusc. 325. Hellw. 325. Faun. Ingr. 342. Laich. i. 233. 24. Payk. Faun. Suec. iii. 297. I21.

Mart. Eng. Ent. t. 19. f. 23. Act. Acad. Suec. I785. 49. 19. t. 2. $f$. 19. mala. Scbaff. Icon. t. 25. $f$. IO. Herbst. Jablonsk. vi. $74 \cdot 37 \cdot t .64 \cdot f \cdot 7$.

Long. 
Long. corp. 8 lin.

Habitat

DESCR. Simillimus Cur. nebuloso, at rostrum non dorso carinatum, sed tribus sulcis parallelis excavatum. Linn. Syst. Nat.

205. Cur. fusco-cinereus, elytris striatis tomen-diffinis. tosis, pedibus concoloribus.

Long. corp. 5 lin.

Habitat

Descr. Simillimus Cur.pilosulo; adeo ut primo intuitu eundem diceres; sed differt corpore oblongiori, elytris satis profundè striatis, et pedibus concoloribus. Striæ elytrorum punctis impressis ornantur. Elytra tomentosa, nec pilosa.

206. Cur. griseus, thorace striis tribus pallidio-lineatus. ribus.

Linn. Syst. Nat. 616.80. Faun. Suec. 630. Vill. i. 208. I48. Gmel. 1784. 80. Fab. Syst. Ent.I48. III. Sp. Ins. i. I89. 155. Mant. i. I16. 206. Ent. Syst. i. b. 466. 302. Payk. Monog. 108. Harr. $27 \mathrm{I}$. Bonsd. I6. De Geer, v. 247. 35. Faun. Etrusc.

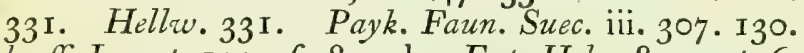
Scbaef. Icon. t. I03. f. 8. a. b. Ent. Helw. 80. 1. t.6. f. I. Herbst. Jablonsk. vi. 497.527.t. 95. f.5. 6.

Le Charanson à corcelet rayé. Geaff. i..283. 13 .

Long. corp. $2 \frac{1}{2}$ lin.

Habitat in plantis diadelphicis.

D. Curtis.

Descr. Corpus totum griseum. Antennarum infimus articulus rufescens. Thorax lateribus et dorso niger, intra quam nigredinem color griseus striarum instar ducitur, unicâ lineâ in tergo, et dein unicâ in utroque latere, hinc thorax quasi fuscus, lineis tribus longitudinalibus pallidis sive cinereis exaratus. Oculi nigri. Elytra cinerea, singula striis quatuor exarata. Rostrum breve,' extra antennas brevissimum, et ferè nullum. Faun. Suec.

$$
\text { X } 3207 \text {. Cur. }
$$


cloropus. 207. Cur. niger, antennis tibiisque ferrugineis.

Linn. Syst. Nat.617.82. Faun. Suec.633. Vill, i. 209. I50. Gmel. I786. 82. Fab. Syst. Ent. 149. I16. Sp. Ins. i. I90. 163. Mant. i. I17.218. Ent. Syst. i. b. 471. 323. Panz. Ent. Germ. 328. 168. Faun. Fred. II. II3. Payk. Monog. I 10. Faun. Suec, iii. 3II. I34.

Panz. Faun. Germ. 19. t. I4. Herbst. Jablonsk. vi.. 56. 19. t. 62.f. 12. Bonsd. 18. f. 19.

Long. corp. 2 lin.

Habitat in plantis. Linn. In ligno quercino. Fab.

DESCR. Thorax oblongus, opacus, sub lente punctulis prominulis scabriusculus. Elytra striata, striæ punctis impressis.

bispiculus. 208. Cur. fuscus, thorace cinereo-lineato, elytris hispidis punctis obscurioribus striatis.

Fab. Gen. Ins. Mant. 226. Sp. Ins، i. 189. I58. Mant. i. II7. 211 . Ent. Syst. i. b. 468. 3II. Vill. i. 213. I67. Gme'. 1784. 368. Payk. Monog. 106. Panz. Ent. Germ. 327. 160. Faun. Etrusc. 333. Hellw. 333. Payk. Faun. Suec, iii. 305. 128.

Herbst. Jablonsk. vi. 354. 328. t. 87. f. I 4.

Long. corp. $2 \frac{r}{4}$ lin.

Habitat in plantis aquaticis. Fab.

Descr. Parvus, statura Cur. lineati. Antennæ clavatæ, articulo primo longiori. Thorax punctatus, fuscus, lineis tribus longitudinalibus, cinereis, mediâ tenuiori. Punctum utrinque laterale cinereum. Elytra fusca, pilis albis crectis hispida, punctisque obscurioribus striata, interjectis pilis albis, qui quasi lineas e maculis nigris albisque constituunt. Pedes nigricantes. Fab. Gen. Ins. Mant.

mufpies. 209. Cur. cinereus, pedibus rufis.

Linn. Syst. Nat. 617.83. Faun. Suec. 634. Vill. i. 209. I51. Gmel. I786. 83. Faun. Fred. I2. II4. Bonsd. Iо. $f$. 10.

Long. 
Long. corp. $\mathrm{I}_{4}^{\frac{3}{4}}$ lin.

\section{Habitat}

Ex mus. D. Hill.

Descr. Oblongus, pilis cinereis undique adspersus. Femora et tibiæ testaceo-rubra, nuda; ungulæ sive duæ squamæ, in omnibus pedibus ad exortum unguium, solæ nigræ sunt. Antennarum infimus articulus longissimus.

210. Cur. viridi-argenteus, antennis tibiis plan-uniformis. tisque rufescentibus.

Long. corp. $\mathrm{I} \frac{3}{4}$ lin.

Habitat

DESCR. Facies Cur.argentati; sed planè differt, femoribus muticis, nec dentatis. Totum corpus, præter antennas, tibias et plantas rufescentes, viridissimum, sericeum.

211. Cur. viridis nitidus, antennis pedibusque favipes. flavis.

De Geer, v. 245. 31. Vill. i. 215. I84. iv. 282. I84.

Curculio sericeus. Herbst. Jablonsk. vii. 37.595 .

Long. corp. 2 lin.

Habitat

DESCR. Corpus oblongum. Caput, thorax, elytra, abdomenque squamis aurato-viridibus obtectum, sub quibus insectum nigrum est. Antennæ pedesque nudi, dilutè lutei. Vill.

2 I2. Cur. flavescens, oculis nigris, thorace punctis favescens. albidis obsoletissimis.

Long. corp. $2 \frac{1}{2}$ lin.

Habitat

Descr. Magnitudo, statura, habitus Cur. lineati, at totum corpus flavescens. Thorax punctis quatuor, sæpè sex, albidis, valdè obsoletis. Elytra flavescentia, atomis nigris rarioribus conspersa. Pedes corpore concolores.

$$
\mathrm{x}_{4} 2 \mathrm{~s} 3 \text {. Cur. }
$$


nigriclavis. 2 I 3 . Cur. oblongo-ovatus niger obscurus, antennis tibiis plantisque rufis, antennarum clavâ nigrâ. Long. corp. 2 lin.

\section{Habitat}

Descr. Thorax ovatus, coleoptris ferè duplo angustior. Elytra striata. Tibiæ plantæque rufæ. Antennæ rufæ, sed quod in hoc singulare, clava nigra est.

ruficlavis. 2I4. Cur. niger nitidiusculus, antennis tibiis plantisque rufis.

Long. corp. $2 \frac{1}{4}$ lin.

\section{Habitat}

DEscr. Corpus oblongum, nitidiusculum. Thorax ovatus, coleoptris, sed non duplo, angustior. Elytra striata, strïs punctatis. Antennæ omninò ut et tibiæ plantæque rufæ. Satis distinctus a præcedenti, præcipuè clavâ antennarum rufâ, nec nigrâ.

macularius. 215 . Cur. rufo-griseus: maculis minutis nigris, thorace striis tribus pallidis, tibiis rufis.

Long. corp. 2 lin.

Habitat

DEsCR. Similis Cur. atomario, at satis differt, thorace lineis tribus longitudinalibus (unâ mediâ et duabus lateralibus) pallidis: tum tibiis solummodò, nec pedibus omninò rufis.

atomarius. 216. Cur. griseus: atomis maculisque minutis fuscis, pedibus rufis.

Long. corp. $\mathbf{I} \frac{3}{4}$ lin.

\section{Habitat}

Descr. Totum corpus suprà rufo-griseum, maculis minutis nigris conspersum; hoc in thorace notabilius. Elytra tenuiter striata. Pedes rufi. 
217 . Cur. suprà griseo-fuscus subtùs cincreus, grisetus. rostro canaliculato.

Fab. Syst. Ent. I48. 108. Sp. Ins. i, 188. 152. Mant. i. I16. 221. Ent. Syst. i. b. 464. 292. Vill. i. 212. 162.

Long. corp. $2 \frac{x}{2}$ lin.

Habitat

DESCr. Statura Cur. lineati, at paulò longior. Rostrum cylindricum, sulco longitudinali profundiore exaratum. Suprà totus obscurè griseus, subtùs cinereus, immaculatus. Femora simplicia. Fab. Syst. Ent.

218. Cur. sordidè fuscus, rostro longitudinaliter fuscus. sulcato, elytris obsoletè striatis.

Long. corp. 4 lin.

Habitat

DESCR. Corpus totum fuscum, præter oculos qui nigri sunt. Rostrum sulco tenui longitudinali exaratum. Coleoptra obsoletiùs striata, dorso longitudinaliter pallidiuscula. Corpus subtùs colore parùm dilutiori. Femora antica cæteris crassiora.

$$
\begin{gathered}
\text { c. Antennis fractis, femoribus dentatis. } \\
\text { * Corpore ovato. }
\end{gathered}
$$

219. Cur. cinereo-fuscus tomentosus, thoracis la- subglobosus. teribus pallidis, abdomine subgloboso.

Long. corp. 5 lin.

Habitat

DrsCR, Totum corpus unicolor fuscum, præter caput et thoracis latera quæ pallidiora sunt. Caput et thorax subsericea. Elytra tomentosa, striis obsoletis punctatis. Thorax globosus. Abdomen ex oblongo-ovato subglobosum.

220. Cur. fuscus elevato punctatus: punctis tho- Ligustici. racis globosi majoribus elytrorumque minimis. 
Linn. Syst. Nat.615.68. Faun. Suec. 621. Vill. i. 202. 122. Gmel. I774. 68. Panz. Ent. Germ. 33 I. 184. Fab. Syst. Ent. I55. I45. Sp. Ins. i. I97. 209. Mant. i. 122. 273. Ent. Syst. i. b. 484.377. Payk. Monog.77. Faun. Suec. 1ii. 274. 97. De Geer, v. 218.10.

Herbst. Jablonsk. iii. 337.310. t. 86. f. 8. Bonsd. Cur. Suec. ii. $32 \cdot f \cdot 33$.

Long. corp. 6 lin.

Habitat

Ex mus. D. Jones.

Descr. Totum corpus fuscum. Animal hoc ab omnibus differt punctis thoracis majoribus, et elytrorum longè minoribus, omnibus numerosissimis prominulis. Elytra obsoletissimè striata. Rostrum longitudine thoracis, valdè crassum, lineâ mediâ elevatâ, apice bifidum.

subclava- $22 \mathrm{~J}$. Cur. nigro-cinerascens, rostro brevi crasso tus. subclavato, elytris obsoletè striatis. Long. corp. 5 lin.

\section{Habitat - Ex mus. D. Hill.}

DESCR. Totum corpus nigrum, vellere cinerascenti obtectum est. Ex tactu autem nimis aspero vellus facillimè detrahitur, præcipuè $a b$ elytris; unde nigra videntur. Rostrum breve, crassum, supernè subcarinatum, ad apicem majus, unde clavatum apparet. Abdomen oblongum. Elytra sub-obsoletè striata; striæ punctis majusculis impressis notantur. Femora dente minori armantur.

floccosus. 222. Cur. fuscus, thorace lineis duabus lateralibus pallidis, elytris punctis nigris maculisque albidis.

Long. corp. 5 lin.

Habitat

DESCR. Rostrum breve, crassum. Thorax ovatus, lineis duabus latiusculis, lateralibus, pallidis. Elytra fusca, punctis plurimis nigris conspersa ; inter puncta nigra 
nigra puncta etiam albida; at apicem elytrorum versus maculæ plurimæ confluentes, lanæ expansæ instar, totum ferè occupant. Pedes fusci concolores.

223. Cur. abdomine ovato nigro, pedibus anten-ovatus. nisque rufis.

Linn. Syst. Nat. 615.69. Faun. Suec. 626. Vill. i. 203.123: Gmel. 1775.59. Fab. Syst. Ent. I56. I51. Sp. Ins. i. I99. 221. Mant. i. 1 23. 287. Ent. Syst. i. b. 490. 402. Payk. Monog. 79. Faun. Suec. iii. 277. I00. Poda, 30. I0. Faun. Etrusc. 343. Hellw. 343. Faun. Fred. I I. rog.

Herbst. Jablonsk. vi. $357 \cdot 33$ I. $t .88 . f .2$.

Curculio Rosæ. De Geer, v. 219. II. Bonsd. 25.f. 26.

Long. corp. $2 \frac{1}{8}$ lin.

Habitat in Fragaria vesce fructibus.

DEscr. Antennæ, tibiæ et plantæ obscurè ferrugineæ. Cætera niger est. Thorax subglobosus, punctis excavatis striato-rugosus. Abdomen ovatum, convexum. Elytra striata; striæ ex punctis majusculis excavatis. Corpus nitidiusculum.

224. Cur. niger, elytris excavato-striatis punctis sulcatus. 1 cstaceis conspersis, thorace scabro.

Fab. Syst. Ent. 155. I46. Sp. Ins. i. 197.212. Mant. i. 122. 276. Fab. Ent. Syst. i. b. 485.282. Payk. Monog.78. Faun. Suec. iii. 275:98.

Bonsd. 34.f. 35. Herbst. Jablonsk. vi. 347. 3 9. t. 87 . $f \cdot 5$.

Long. corp. 5 lin.

Habitat sub plantis maritimis, Betâ, Atriplice, prope Hastingas.

Descr. Totum corpus nigrum. Thorax punctis prominulis scaber. Elytra punctis profundè excavatis striata, punctisque aliquot testaceis conspersa; hæc puncta ex villis testaceis constant. Femora omnia dentata. Plantæ subtùs fulvæ. 
maurus. 225. Cur. niger, elytris punctato-striatis. Long. corp. 5 lin.

Habitat

Descr. Totum corpus unicolor, nigrum. Antennæ clavatæ, clavâ ovatâ acutâ; articulus etiam infimus clavatus. Thorax scabriusculus. Abdomen ovatum, gibbum. Elytra striata; striæ ex punctis impressis constant.

\section{* Corpore oblongo.}

oblongus. 226. Cur. niger, antennis elytris pedibusque ferrugineis.

Linn. Syst. Nat.615.71. Faun. Suec.625. Vill. i. 203. 125. Gmel. 1775.71. Fab. Syst. Ent. I56. I50. Sp. Ins. i. 199. 220. Mant. i. I23. 286. Ent. Syst. i. b. 489. 400. Payk. Monog. 87. Bonsd. 9. Harr. 282. Panz. Ent. Germ. 334. 204. Faun. Etrusc. 342. Hellw. 342. Faun.Ingr. 348. Payk. Faun. Suec. iii. 284. 107.

Mart. Eng. Ent. t. 20. f. 33. Scbaff. Icon.t. I63. f.6. Panz. Faun. Germ. I9. t. I5.

Le Charanson à étuis fauves. Geoff. i. 294. 39.

Long. corp. $2 \frac{3}{4}$ lin.

Habitat inter arbores. Linn.

DeSCr. Corpus nigrum. Antennæ et pedes testacei. Femora omnia dentata. Elytra livido-ferruginea, margine laterali inflexo nigra. Faun. Suec.

Variat corpore toto testaceo, præter marginem lateralem inflexum nigrum, et corpore toto nigro, præter antennas pedesque testaceos.

rufescens. 22\%. Cur. rufo-ferrugineus totus.

Long. corp. $2 \frac{x}{2}$ lin.

Habitat

DESCR. Totum corpus brunneum, sive rufo-ferrugineum. Elytra striata; striæ ex punctis impressis. In altero sexû pedes pallidiores.

228. Cur. 
228. Cur. cinereo-fuscus, antennis basi rufescen-cervinus. tibus, pedibus fuscis.

Linn. Syst. Nat. 61 5. 70. Faun. Suec. 627.

Lung. corp. $2 \frac{1}{2}$ lin.

Habitat

DESCr. Sordidè cinereus, sive cineren-fuscus. Antennæ ferrugineæ, capitulo nigro. Elytra adparent quasi adspersa punctis nigris obsoletis. Pedes fusci. Corpus subtùs squamulis aureis obsitum.

229. Cur. æneo-fuscus, pedibus rufescentibus. Pyri. Linn. Syst. Nat.615.72. Faun. Succ.623. Vill. i. 204.126. Gmel.1775.72. Fab. Syst. Ent.155. I47. Sp. Ins. i. I98. 21 7. Mant. i. 122.28r. Ent. Syst. i. b. 487.390. Payk. Monog. 82. Bonsd. 8. Poda, 3o. 8. Panz. Ent. Germ. 333. 197. Faun. Fred. II. 107. Faun. Etrusc. 341. Hellw. 34I. Faun. Ingr. 346. De Geer, v. 246. 34. Payk. Faun. Suec. iii. 280. 103. Hoppe, Ins. Erl. 66.

Donov. Brit. Ins. t. 12. I. f. 3. 4. Herlst. Jablonsk. vi. 259. 226. t. 79. f. 2. a. b. Scbaff. Icon. t. 2. f. II.

Le Charanson à écailles vertes et pattes fauves. Geoff. i. 282. I2.

Long. corp. $3-5$ lin.

Habitat in Pyri foliis larva, in Pruni corollis declaratus. Limn.

DesCr. Rostrum depressum, capite ipso ferè brevius. Caput et thorax punctis minutissimis inæqualia. Elytra oblonga, striis septem profundè excavata, interjectis striis (ferè elevatis) crenatis. Capiti, thoraci et elytris (quæ omnia nigra) insidet pilus vix conspicuus aureo-igneus. Pedes et antennæ rufescentes, infimo articulo longissimo. Foemina marito duplo major, minùs fusca, magis nitens. Faun. Suec.

230. Cur. cupreo-auratus, scutello niveo, pedibus Mali. flavis.

$\mathrm{Fab}$. 
Fab. Ent.Syst.i. b.487.393. Payk. Monog. 83. Faun. Suec. iii. 281. 104.

Herbst. Jablonsk. vi. 26I. 230. t. 79.f. 5 .

Long. corp. 3 lin.

\section{Habitat}

DESCr. Suprà vestitus pilis aureo-igneis. Antennæ testaceæ, capitulo nigro. Scutellum niveum. Subtùs albido-villosus, minus aureus. Pedes flavi.

Cnides.

231. Cur. viridis, pedibus nigrescentibus.

Curculio Urticæ. De Geer, v. 219. I2.

Curculio Pyri var. Linn. Syst. Nat. 615. 72. Payk. Faun. Suec, iii. 280. 103. var. $\beta$.

An Curculio Alneti ? Fab. Ent. Syst. i. b. 487 . 391.

Herbst. Jablonsk. vi. 260.227.t. 79.f. 3 ?

Long. corp. 4 lin.

Habitat in Urticá.

DESCR.

cresius. 232. Cur, viridis, pedibus nudis rufis.

Curculio argentatus var. a. Faun. Etrusc. 344? Hellw. 344 ?

Long. corp. 4 lin.

Habitat

DESCR.

argentatus. 233. Cur. viridis, pedibus tomentosis rufescentibus.

Linn. Syst. Nat. 6r5.73. Faun. Suec.624. Vill. i. 204. 127: Gmel. 1776. 73. Fab. Sy'st. Ent. 155. 148. Sp.Ins. i. 198. 218. Mant. i. 123. 284. Ent. Syst. i. b. 489.398. Scop.91. Payk. Monog. 86. Poda, 30. 9. Harr. 280. Bonsd. I2. Panz. Ent. Germ. 334. 203. Faun. Fred. 1I. I08. Faun. Ingr. 347. Faun. Etrusc. 344. Hellw. 344. Payk. Faun. Suec. iii, 283. 106. Laich. i. 209. 6.

Donov. 



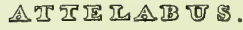

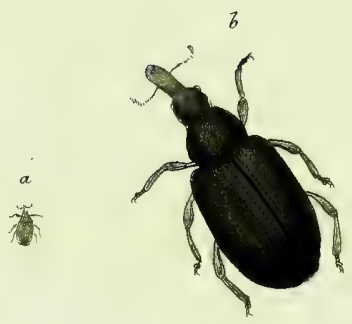

A. Betuta 
Donov. Brit. Ins. t. 97. Mart. Eng. Ent. t. 19. f. 21. 22. Scbaff: Icon. t. I70. f. I. Herbst. Jablonsk. vi. 260. 228. t. 79. $f \cdot 4$.

Le Charanson à écailles vertes. Genff. i. 293. 38 .

Long. corp. $2 \frac{1}{2} \operatorname{lin}$.

Habitat in Quercit.

DESCr. Hæ tres species, Cur. Cnides, casius et argentatus, ab III. Linnæo pro unâ eâdemque specie habitæ sunt. At ritè distinguas quòd $\mathrm{Cur}$. Cnides viridis est, et pedes, si tactu vel levissimo depilentur, semper nigri sunt. Cur. argentatus viridis est, at longè minor Curculione Cnides, tum pedes, si depilentur, semper rufi sunt. Cur. casius viridis est, at pedes semper nudos rufos exhibet: magnitudine Curculionem Cnides æquat.

234. Cur. niger canescens, antennis tibiis plan-amaurus. tisque obscurè rufis.

Long. corp. $2 \frac{\pi}{2}$ lin.

Habitat

DESCR. Caput et thorax sub lente punctulis prominulis scabriuscula, opaca. Elytra pilis incanis obsita, striata sunt; striæ punctis impressis. Abdomen subtùs nigrum, at etiam incanum. Femora nigra, basi rufa. Tibiæ et plantæ obscurè rufæ.

\section{ATTELABUS.}

Antenne subclavatæ, rostro insidentes.

Caput rostratum, posticè attenuatum, inclinatum.

Thorax anticè angustatus.

Corpus ovatum, obtusum.

I. Att. niger, thorace elytris femoribus tibiisque Avellanc. rubris. 
Linn: Syst. Nat. 619. 2. Gmel. 1809. 2.

Attelabus Coryli, var. $\beta$. Fizb. Syst. Ent. I56. 1. Sp. Ins. i. 199. I. Mant. i. 124. I. Ent. Syst. i. b. 384. I. Panz. Ent. Germ. 294. r. Payk. Faun. Suec. iii. I68. I. Faun. Etrusc. 348 . Hellw. 348. Ent. Helv. 118. 1. t. 15. $f$. 1. 2. Herbst. Jablonsk. vii. 243. I. t. I05. $f \cdot 5 \cdot$

Curculio collaris. Scop. 7I.

Curculio excoriato-ruber. De Geer, v. 257. 45. t. 8. f.3. Rhinomacer. La tête écorchée? Geoff. i. 273. II. Harr. 307. Laich. i. 241. 3.

Scboeff. Icon. t. 56. $f \cdot 5 \cdot 6$.

Long. corp. $3 \frac{1}{2}$ lin.

Habitat in foliis Coryli Avellana.

DESCR. Antennæ nigræ. Caput nigrum, collo instructum. Thorax ruber, lævis, lineâ dorsali impressâ, posticè circulatus, quasi filo constrictus. Scutellum nigrum, posticè rotundatum. Elytra rubra, punctis excavatis rugoso-striata. Corpus subtùs atrum. Pedes rubri, genubus tarsisque nigris.

Variat thorace anticè lineolâ dorsali nigrâ.

An distinctus ab Att. Coryli Linnæi?

curculionoi-2. Att. niger, thorace elytrisque rubris nitidis. des.

Linn. Syst. Nat. 619. 3. Vill. i. 218. 3. Gmel. 1809.3. Scop. 72. Fab. Syst. Ent. 157.2. Sp. Ins. 1. 200.3. Mant. i. 124. 6. Ent. Syst. i. b. 386. 12. Faun. Etrusc.349. Hellw. 349. Panz. Ent. Germ. 295. 3. Payk. Faun. Suec. iii. 169. 2.

Scbaff. Icon.t. 56. f. 7. Sulz. Ins. t. 4. $f$. 12. Donov. Brit. Ins. t. I49. Herbst.Jablonsk. vii. I45. 2.t. 105. f. 6. Mart. Eng. Ent. t. 23.f. 6 .

Curculio nitens. Payk. Monog. I22.

Rhinomacer curculionoides. Harr. 305. Laich. i. 242. 4 .

Le Becmare laque. Geoff. i. 273. I0.

I.ong. corp. $2 \frac{1}{2} \operatorname{lin}$.

Habitat

Descr. 
Descr. Similis Att. Avellance, sed minor. Elytra leviter punctato-striata. Pedes nigri.

3. Att. pedibus saltatoriis, corpore toto atro.

Betule.

Linn. Syst. Nat. 620.7. Faun. Suec.640. Vill. i. 219. 5. Gmel. 1810. 7. Fab. Syst. Ent. 157.3. Sp. Ins. i. 201. 6. Mant. i. I24. 10. Ent. Syst. i. b. 392. 37. Faun. Fred. 12. 120. Faun. Ingr. 321. Panz. Ent. Germ.298. 26. Payk. Faun. Suec. iii. 17.4 .7 .

Panz. Faun. Germ. 20. t. I5.

Curculio Betulæ. Pontop. i. 672. I5. Payk. Monog. 120. Curculio excoriato-niger.- De Geer, v. 259.47.

Rynchites Betulæ. Herbst. Jablonsk. vii. I33. 9. t. 104. $f \cdot 9 \cdot \mathrm{c}$.

Long. corp. 2 lin.

Habitat in Betule foliis, qux rodit ut crispa evadunt, eaque primo vere destruit.

Descr. Corpus oblongum, atrum. Elytra oblonga, punctis excavatis striata. Caput ante oculos magis angustatum. Femora crassa. Simillimus Curculioni. Faun. Suec.

\section{CLERUS.}

Antenne moniliformes, articulis tribus ultimis majoribus.

Caput declinatum.

Thorax convexus, posticè attenuatus.

Elytra flexilia.

Corpus objongo-elongatum.

I. Cl. niger, thorace piloso rufo, elytris fasciâ formicarius. duplici albâ basique rubris.

VOL. I.

$\mathrm{Y}$

Fab. 


\section{CLERUS.}

Fab. Syst. Ent. 157.2. Sp. Ins. i. 201. 4. Mant. i. 125.5. Ent. Syst. i. a. 207.5. Payk. Faun. Suec. i. 247. 1. Faun. Etrusc. 351. Hellw. 351. Panz. Ent. Germ. 85. 2.

Panz. Faun. Germ. 4.t. 8. Herbst. Jablonsk. vii. 208. 2. t. $109 . f .2$.

Attelabus formicarius. Linn. Syst. Nat. 620. 8. Faun. Suec.641. Vill.i. 219.6. Gmel. 18II.8. Scop. II1. Rai. 103. 29. Faun. Fred. 12. I21. Poda, 3 I. I. Harr. 392. Laicb. i. 245. 2.

Don. Brit. Ins. t. 231. f. 2. Mart. Eng. Ent. t. 23.f.8. De Geer, v. 160. 3.t. 5.f. 8. Scbaf: Icon.t. 186.f.4. Dermestes formicarius. Scbrank, 35 .

Cleroides. Scbaff: Elem. t. $\mathbf{3} 37$.

Long. corp. 4 lin.

Habitat

Descr. Caput nigrum est, thoraci immersum, depressum. Antennæ clavatæ, ori ferè insidentes, nigræ. Thorax rufus est et scaber, margine caput spectante nigro. Elytra oblonga, obtusa, planiuscula, punctis elevatis scabra, nigra, basi rubra, fasciis duabus transversalibus, linearibus, albis; quarum una thoraci propior supra mediam longitudinem antrorsùm flexa; altera vero fascia paulo supra apices elytrorum sita, etian alba, scd latior, ad suturam longitudinalem antrorsùm flexa. Faun. Suec.

mollis.

2. Cl. griseus pubescens, elytris fasciis tribus pallidis.

De Geer, v. 159.2.t.5.f.6.

Le Clairon porte-croix. Geoff.i. $305 \cdot 3$.

Attelabus mollis. Linn. Syst. Nat. 621. 11. Faun. Suec. 642. Vill. i. 220.8. Poda, 31. 3. Harr. 395. Laich. i. 246.3 .

Mart. Eng. Ent. t. 23. f. 7. Herbst. Jablonsk. vii. $210: 4 \cdot$. $109 \cdot f_{.}$. Scboef. Icon. 60. f. 2.

Notoxus mollis. Fab. Syst. Ent. 158. 1. Sp. Ins. i. 203. 1. Mant.i.127.3. Ent. Syst.i.a.211.5. Gmel. 1813.3. Payk. Faun. Suec. 1, 248. I. Panz. Ent. Germ. $87 \cdot 3$. 
Panz. Faun. Germ. 5.t. 5 .

Curculio. Udd. Diss. $28 . t$. r. $f .9$.

Dermestes mollis. Scbrank, 37 .

Long. corp. 5 lin.

Habitat in syliis.

Descr. Caput ferrugineum. Thorax niger, villosus. Elytra nigra, flexilia, fasciis tribus pallidis ; quarum prima ad basin, tertia in apice. Abdomen rubrum. Pedes pallidi, geniculis nigris. Totus subpilosus est. Faun. Suec.

3. Cl. cæruleus nitidus, thorace villoso.

Clerus cæruleus. De Geer, v. I63. 4. t. 5.f.13.

Le Clairon bleu. Geoff. i. 304. 2.

Dermestes violaceus. Linn. Syst. Nat. 563. 13. Faun. Suec. 422. Vill. i. 48. 12. Gmel. 1594. 13. Scop. 5 I. Scbrank, 45. Panz. Ent. Germ. 98. I8. Fab. Syst. Ent. 57. 10. Sp. Ins. i. 65. I3. Mant. i. 35. I5. Ent. Syst. i. a. 230. 16. Poda, 22. 2. Faun. Etrusc. 78. Hellw. 78 .

Panz. Fuun. Germ. 5. t. 6. Mart. Eng. Ent.t. 6. f. 7 . Attelabus Geoffroyanus. Laich. i. 247. 4 .

Corynetes violaceus. Payk. Faun. Suec. 1. 275. 1. Herbst. Jablonsk. iv. I50. I. t. 4 I, f. 8.

Long. corp. $2 \frac{1}{3}$ lin.

Habitat

DESCR. Villosus suprà nitens, præsertim elytra; antennæ stipite fusco, nitente, clavâ nigrâ, obscurâ, articulis tribus ferè æqualibus, ultimo obliquè truncato, ferè in formam literæ $S$ incurvæ. Thorax rariùs punctulatus. Elytra amœenè cærulea, punctata, sed vix striata. Subtùs atro-cærulescens.

4. Cl. atro-cærulescens, elytris cæruleis striatis, Quadru. antennarum articulo ultimo maximo quadrato.

Long. corp. 2 lin.

Habitat 
DESCR. Totus villosus. Antennæ incurvæ, stipite nitido, e nigro fuscescente, clavâ nigrâ, obscurâ, e tribus constante articulis, quorum inferior minor, extimus maximus, truncatus, ferè quadratus. Thorax punctulatissimus. Elytra striata, striis punctatis, atra, cum tincturâ æneâ, cæruleo maculata, sive nebulosa: oculo non armato cærulea tota apparent. Subtùs atro-cærulescens, sed valde obscurus.

$V$ ariat thorace virescenti cæruleo.

ruficollis. 5. Cl. cyaneus villosus, thorace elytrorum basi pedibusque rufo ferrugineis.

Dermestes ruficollis. Fab. Syst. Ent.57. I1. Sp. Ins. i. 65. I5. Mant. i. 35.17. Ent. Syst. i. a.230. 18. Anobium ruficolle. Tbunb. Now. Ins. Spec. 8. $f \cdot 7$.

Corynetes ruficollis. Herbst. Jablonsk. iv. 152.3.t.41.f.9. Long. corp. $2 \frac{3}{4}$ lin.

Habitat-In capite equino nuper interfecto cepi.

Descr. Faciem omninò Carabi cyanocepbali refert. Antennæ nigræ, clavâ compressâ. Caput et thorax punctatissima. Oculi atri, cancellati. Elytra striata, punctis impressis.

\section{CERAMBYX.}

Antenne setacex.

Oculi lunati, basin antennarum amplectentes. Thorax caput recipiens.

Elytra sublinearia.

Corpus oblongum.

* Thorace marginato, dentibus lateralibus.

* Tboracerotundato, spinis fixis lateralibus mucronato.

* * Tborace inermi, subcylindrico.

*** Tborace inermi, subrotundo, sive ex globosc depresso.

***** Thorace inermi, subgloboso, nec depresso. 


$$
\text { Pl.16. }
$$

CEIBAMETS.

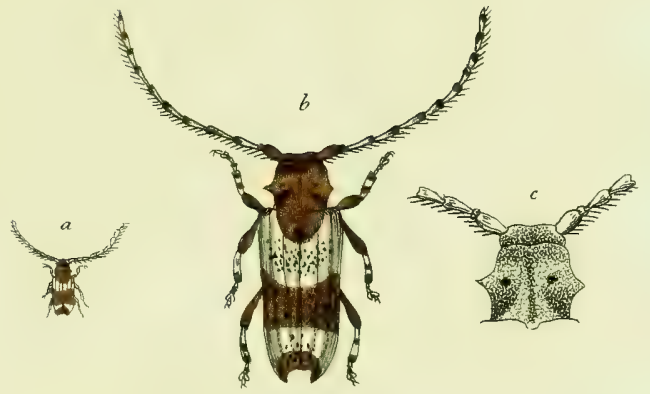

C. Bispidus. 

* Tborace marginato, dentibus lateralibus.

I. Cer. thorace tridentato, corpore piceo, elytriscoriarius. mucronatis, antennis brevioribus.

Linn. Syst. Nai.622. 7. Faun. Suec.647. Gmel.1815.7. Scop. 161. Vill. i. 224. 2. Rai. Ins. 95. Poda, Mus. Greec. 3 I. I. Harr. 190.

Mart. Eng. Ent. t. 24. f. 4. Roes, ii. 2. t. I. f. 1. 2. Scbaeff. Icon. t. 9. $f$. I. mas. t. 67. f. 3 . fem. Schaff: Elem.t. 103. Friscb. 13. t.9. Bergstraes. Nom. i. I3. 79.5.6.t. $13 \cdot f \cdot 5 \cdot 6$.

Prionus coriarius. Fab. Syst. Ent. 161.7. Sp. Ins. i. 206. 9. Mant. i. I29. 13. Ent. Syst. i. b. 246. I5. Hoppe, Ins. Erl. 58. Panz. Ent. Germ. 246. 5. Payk. Faun. Suec. iii. 51.2. Laicb. ii. 3. 2.

Oliv. iv. 66. 29. 37. t. I. f. 1. b-d. Panz. Faun. Germ. 9. t. 8.

Le Prione. Geoff. 198. 1. t. 3. f. 5 .

Cerambyx Prionus. De Geer, v. $59 \cdot$ 1. t. 3. $f \cdot 5$.

Scarabæus tridentatus? Linn. Faun. Suec. 406.

Lucanus tridentatus? Linn. Syst. Nat.560.3. Gmel. I589. 3 .

Long. corp. maris I unc. I lin.

fœem. I unc. 7 lin.

Habitat in truncis arborum.

Descr. Antennæ crassæ, serratæ, piceæ. Corpus subdepressum, totum suprà nigro-piceum. Thorax subrugosus, utrinque tridentatus, dente intermedio majore, acutiore, anticè et posticè flavo-ciliatus. Elytra subrugosa, lineis tribus obsoletis, elevatis, apice mucronata. Corpus subtùs rufo-piceum, pectore piloso, pilis flavescentibus. Pedes picei.

** Thorace rotundato, spinis fixis lateralibus mucranato.

2. Cer. elytris fastigiatis: punctis fasciisque nigris, nebuloszes. antennis longioribus.

Linn. Syst. Nat.627. 29. Fann. Suec.650. Vill. i. 225. 5. Scbrank, 246. Scop. I73. Fab. Syst. Ent. 168. 20. Sp. Ins. i. 215. 26. Mant. i. 134. 36. Y 3 Ent. 
Ent. Syst. i. b. 26r. 35. Gmel. 182r.29. Dc Geer, v. 71. 8. Foun Fred. 13. 124. Harr.321. Panz. Ent. Germ. 248. 7. Faun. Ingr. 265. Payk. Faun. Suec. iii. 56. 4 .

Mart. Eng. Ent. t. 24.f. 6. Scbeff: Icon. t. I92. f. 6. Voet. ii. 12. 4. t. iv. f. 4. Panz. Faun. Germ. 14. t. I3. Oliv. iv. $67 \cdot 54 \cdot 72 \cdot t \cdot 7 \cdot f \cdot 47 \cdot a-c$.

Le Capricorne noir marbré de gris. Geoff. i. 204. 7.

Long. corp. $3-4$ lin.

\section{Habitat}

Descr. Caput nigricans. Antennæ corpore sesquilongiores, apice tenuissimæ, articulis singulis supernè nigris, inferne pallidis. Thorax utrinque denticulo notatus, supernè cinceus, punctis nigris maculatus. Elytra cinerea, plinctis minimis excavata, non striata, præterea punctis inæqualibus nigris irrorata, densiùs versus basin; fascia dein nigra transversalis latiuscula in medio elytrorum. Faun. Suec.

bispidus.

3. Cer. elytris subpræmorsis: punctis tribus hispidis, antennis hirtis longioribus.

Linn. Syst. Nat. 627. 30. Faun. Suec.651. Vill. i. 225. 6. Scbrank, 248. Faun. Ingr. 267. Fab. Syst. Ent. 169.21. Sp. Ins. i. 215.27. Mant. i. 134. 38. Ent. Syst. i. b. 262. 40. Gmel. I821.30. Rai. 97. 4. Panz. Ent. Germ. 249. I1. Harr.322. Payk. Faun. Suec. iii. 59.8.

Scbaff. Icon. t. 14.f. 9. t. I76. f. 5.6. Panz. Faun. Germ. 14. t. 16. Friscb. 13.22. t. 16. Donov. Brit. Ins. t. 64. f. 2. 3. Mart. Eng. Ent. t. 24. f. 10. Oliv. iv. 66. 53. 7 1. t. i i. $f \cdot 77$. a. b.

Cerambyx fasciculatus. De Geer, v. $7 \mathrm{I}: 9 \cdot t \cdot 3 \cdot f \cdot \mathrm{r} 7$.

Le Capricorne à étuis dentelés. Geoff. i. 206. 9.

Long. corp. $2-3$ lin.

Habitat

DESCR. Totus cinereus est, punctisque nigris irroratus; striæ aliquot elevatæ in elytris, et fascia alba transver. salis latiuscula in medio elytrorum, basi tamen paulo propior. Thorax aculeis prominulis, præsertim lateralibus. 
tcralibus. Antennarum articuli supernè nigri, infernè cinerei.

Varictas in aliis fascia albida cordata in parte anteriore coleoptrorum: postica pars elytrorum retusa, acutè præmorsa, sive dentata. Faun. Suec.

4. Cer. elytris griseis apice unidentatis, antennis pilosus. mediocribus hirtis.

Fub. Mant.i. 134.39. Ent. Syst. i. b. 262.4I. Gmel. I822. 107. Panz. Ent. Germ. 249. 12.

Cerambyx hispidus var. ß. Payk. Faun. Suec. iii. 59. 8.

Long. corp. $2 \frac{1}{2}-3$ lin.

Habitat

Descr. Statura omninò Cer. bispidi at distinctus. Minor. Antennæ longitudine corporis, hirtæ. Thorax utrinyue bispinosus, griseus. Elytra punctis tribus elevatis, hispidis, grisea, basi parùm pallidiora, apice unidentata. Fab. Mant.

5. Cer. viridis nitens, elytris obtusís, antennis me- moscbatus. diocribus cyaneis.

Linn. Syst. Nat. 62\%. 34. Faun. Suec. 652. Vill. i. 226. 7. Gmel. 1824. 34. Scbrank, 249. Fab. Syst. Ent. 165.7. Sp.Ins. i. 210. 9. Mant. i. I3I. I1. Ent. Syst, i. b, 251. 1. Faun. Ingr. 264. Scop. 165. Rai.81.17. Poda, 32.2. Harr. 317. Pontop. i. 673.5. Panz. Ent. Germ. 247. I, Laich. ii. 10. 3. Payk. Faun. Suec, iii. 53. 1.

Don. Brit. Ins. t. 94. f. 2. Mart. Eng. Ent. t. 24. f. ?. Schaef: Icon. t. I1. f. 7. Frisch. I3.t. I1, Voet. ii. I4. t. 6. f. I4. Oliv, iv. 67. 23. 25. t. 2. $f, 7$. Bergstraes. Nom. ii. 1. 2. $t$. 2. $f .2$.

Cerambyx odoratus. De Geer, v. 63.2.

Le Capricorne vert à odeur de rose. Geoff. i. 203.5.

Long. corp. I unc. 3 lin.

Habitat in Salice, odorem spargens gratum et fragrantissimum.

Descr. Totus cæruleo-viridis, aureo-nitens. Abdomen suprà cæruleum. Alæ nigræ. Pedes colore cum Y 4 reliquo 
reliquo corpore conveniunt; pedum tarsi subtùs villosi, glauci; tibia terminatur spinâ. Thorax utrinque mucrone gaudet; intra hos mucrones tria tubercula paulo minora, elytris propiora, et nonnulla alia tubercula adhuc minora anteriùs. Elytra minutissimis rugis, fibrisque tribus longitudinalibus parùm elevatis notata, oblongo-lanceolata, flexilia. Antennæ vix longitudinem corporis adtingunt; harum articuli per gradus versus extremitalem breviores sunt, contrario ac in reliquis modo. Faun. Suec.

edilis.

6. Cer. thorace cinereo: punctis quatuor luteis, elytris obtusis nebulosis, antennis longissimis.

Linn. Syst. Nat.628.37. Faun. Suec.653. Vill. i. 228.9. Scbrank, 254. Gmel. 1825.37. Fab. Syst. Ent. I64. т. Sp. Ins. i. 209. I. Mant. i. I30. т. Faun. Fred. 13.125. Poda, 32. 4. Pontop. i.673.6. Harr. 316.

Don. Brit. Ins, t. 72. Mart. Eng. Ent. t. 26. f. 4. Oliv. iv. 67. 81. 106. t. 9. f. 59. a-d. De Geer, v. 66. 5.t. 4. f. 1. 2. Scbieff: Icon. $t$. 14. $f \cdot 7$. fem. Voet. ii. t. 4. f. 1. 2.3. Act. Nidros. iv. 323. 16. t. 16. f. 8. Friscb. '3.t. 12. Bergstraes. Nom. i. 3. 5. t. I. f. 5. 6.t.2. f. I.

Lamia ædilis. Payk. Faun. Suec, iii. 62.3. Laich. ii. 23. 5. Fab. Ent. Syst. i. b. 270.16. Faun. Ingr. 269. Panz. Ent. Germ. 250.2.

Long. corp. 8-io lin.

Habitat in truncis arborum. Captus D. Latbbury.

Descr. Corpus totum cinereum. Elytra obtusa, pilis minutissimis adspersa; inter quos pilos tubercula seu puncta minutissima prominent confertissima; umbra nigricans coleoptra transversim ambit versus posteriora, in medio curvata. Thorax etiam cinereus, mucrone utrinque prominulo, et punctis quatuor luteis transversalibus a tergo: Oculi nigri. Antennæ ipso corpore quintuplo longiores, ex 10 articulis cinereis, versus apicen nigris, quo capite propiores, eo breviores. Alæ nigricantes, venis fuscis. Fœmina ano prominet; huic antennæ ipso corpore triplo longiores: maris 
autem cornua quintuplo vel sextuplo corpore longiora. Faun. Suec.

7. Cer. elytris obtusis atris ferrugineo-subnebu-Sutor. losis, scutello luteo, antennis longissimis. Linn. Syst. Nat. 628. 38 . Faun. Suec. 655. Vill. i. 229. 10. Gmel. 1830.38. Scop. 162. Poda, 33. 6. Harr. 326.

Oliv. iv. 67. III. I49.t. $3 \cdot f \cdot 20$ a-c.

Lamia Sutor. Fab. Syst. Ent. 172. 10. Sp. Ins. i. 218. 15. Mant. i. 137. I7. Ent. Syst. i. b. 277.4I. Panz. Ent. Germ. 251, 6. Payk. Faun. Suec. iii. 62. 2. Laicb. ii. 17.2. Faun. Ingr. 270.

Panz. Faun. Germ. 19.t.2. Scbeff: Icon. t. 65. f. r. Voet. $t .5 \cdot f \cdot 7 \cdot$.

Cerambyx atomarius. De Geer, v. 65.4 .

Long. corp. 9 lin.

Habitat in sylvis.

Descr. Magnus et ater est. Oculi nigri. Thorax utrinque angulo majori armatur; maculâ ferrugineâ ad basin elytrorum introrsum. Thorax et elytra atra, punctis sparsis, ferè contiguis, excavatis, nudo oculo manifestis. Puncta flava, sparsa super thoracem et elytra. Mas antennis nigris, triplo aut quadruplo corpore longioribus: Fomina antennis corpore sesquilongioribus, nigris, articulis singulis versus basin cinereis. Faun. Suec.

** Tborace inermi, subcylindrico.

S. Cer. niger, coleoptris lineâ suturali dentatâscalaris. punctisque flavis, antennis mediocribus.

Linn. Syst. Nat.632. 55. Scop. 175. Vill. i. 240. 43. Scbrank, 258. Gmel. I837.55. De Geer, v. 77. I4. Hoeff. Ins. t. 7. Friscb. 12. t. 3. f. 3. Bergstraes. Nom. ii. 14. 4. t. 2. f. 4. Voet. Col. t. r7.f. 78 . Leptura scalaris. Linn. Faun. Suec. 697. Poda, 34. 10. Harr. 342.

Saperda scalaris. Fab. Syst. Ent. 184. 2. Sp. Ins. i. 
231. 2. Mant. i. 147.2. Ent. Syst. i. b. 307.2. Panz. Ent. Germ. 256. 2. Laich. ii. 35. 4. Payk. Faun. Suec. iii. 75. 6. Faun. Ingr. 278.

Long. corp. 7 lin.

Habitat

In mus. D. Swainson:

Descr. Totus niger est, oblongus, lævis. Thorax vellere flavo inclutus, maculâ nigrâ, quadratâ in dorso; utrinque ad latcra gibbus. Elytra nigra, glabra, punctis minutissimis excavatis, suturầ longitudinali flavâ, dentibus variis oppositis, quorum par primum incurvum, secundum trausversum, tertium adscendens, quartum deorsùm gibbum, quintum minimum, sextum ultimum adscendens per marginem exteriorem; puncta aliquot difformia, flava, in medin elytrorum. Antennæ corpore paulo longiores. Flavedo omnis e villis minutissimis constat. Faun. Suec.

populneus.

9. Cer. villosus viridescens, thorace flavo-lineato, elytris punctis quatuor flavis, antennis mediocribus.

Linn. Syst. Nat.632.57. Faun. Suec. 66r. Vill, i. 241.45. Scbrank, 266. Gmel. 1838.57.

Mart. Eng. Ent. t. 24. f. 8. 9 .

Cerambyx 10-punctatus. De Geer, v. 78. I5.

Leptura populnea. Harr. 347. Scbaff. Icon. 48. $f .5$.

La Lepture à corcelet cylindrique et à taches jaunes. Geoff. i. 208. 3.

Saperda populnea. Fab. Syst. Ent. 186. I2. Sp. Ins. i. 234. 18. Mant. i. 149. 27. Ent. Syst. i. b. 315.37. Panz. Ent. Germ. 258. II. Payk. Faun. Suec. iii. 77.9. Laicb. ii. 38. 6. Faun. Ingr.281.

Oliv. iv. 68. i6. í . t. 1. f. 1. b. c.

Long. corp. 6 lin.

Habitat in Populo tremula. Linn.

DESCR. Antennæ setaceæ, articulis supernè nigris, infernè albis. Thorax viridescens, lineis tribus flavis, longitudinalibus, pubescentibus. Elytra fusco-viridescentia, rugoso-punctata, punctis quatuor flavis.

I0. Cer. 
10. Cer. viridescens, thorace flavo trilineato, lineatoelytris nigris: atomis villosis flavescentibus, an- collis. tennis longioribus.

Don. Brit. Ins. t. 209.

An Cerambyx villoso-viridescens? De Geer, v. 76. I3.

Long. corp. 7 lin.

Habitat in Heracleo.

DESCr. Valdè affinis $C e r$. populneo, sed maculis flavis omninò caret. Elytra enim nigro-viridia, villis flavescentibus, variè constipatis ornantur, et exinde videntur atomis flavescentibus conspergi. Antennæ ut in Cer.populneo, at crassiores, et corpore dimidio longiores. Thoracis lineæ latiores, saturatiores, rectæ, distinctæ, neque ut in Cer. populneo, intra antennas incurvatæ, ad caput coeunt. Scutellum didymum flavum ut in Cer. populneo.

I I. Cer. niger, thorace albido-lineato, elytris fa-cylindricus. stigiatis, pedibus anticis pallidis, antennis brevioribus.

Linn. Syst. Nat.633.59. Faun. Suec.662. Vill. i. 242. 47. Gmel. 1839.59.

Roes. ii. 2.t. 3 .

Cerambyx cinereuis, De Geer, v. 75. I2.

Leptura cylindrica. Scop. ${ }^{5} 57$. Harr. 346.

La Lepture ardoisée. Geoff. i. 208. 2.

Saperda cylindrica. Fab. Syst. Ent. 185. 6. Sp. Ins. i. 232. 7. Mant. i. I48. 10. Ent. Syst. i. b. 3 Io. 14. Payk. Faun. Suec. iii. 74. 5. Laich. ii. 49. I2. Faun. Ingr. 280.

Oliv. iv. 68.23.26. t. ii. $f$. II.

Long. corp. 4 lin.

Habitat intra Coryli lignum. Limn. Ex mus. D. Hill.

Descr. Corpus minus, atrum, opacum, punctis minimis sparsis, cavis. Thorax cylindricus, lineâ longitudinali albidâ. Antennæ longitudine corporis. Pedum tibiæ et dimidia pars femorum anterioris paris ferruginea. Faun. Suec.

Antennæ vix corpore longiores. Syst. Nat.

12. Cer. 
oculatus. 12. Cer. thorace luteo: punctis duobus nigris, elytris fastigiatis linearibus nigris, antennis mediocribus.

Linn. Syst. Nat. 633.60. Faun. Suec.664. Vill. i. 242. 48. Sckrank, 269." Gmel. 1841.60.

Mart. Eng. Ent. t, 26. f. 26 . De Geer, v. 74. I I. t. 3. f. 20. Hofn. Ins. t. 13. Voet. ii. t. 18. f. 81, Scbaff: Icon.t. I28. f. 4 .

Leptura oculata. Scop. ${ }^{52 .}$ Harr. 344.

Saperda oculata. Fab. Syst. Ent. 184.3. Sp. Ins. i. 23I. 4. Mant. i. 147.6. Ent. Syst. i. b. 308.8. Panz. Ent. Germ. 257.3. Payk. Faun. Suec. iii. 72. 2. Laich. ii. 42. 8. Faun. Ingr. 279.

Oliv. iv. 68. 19. 20.t. I. f. 4. Panz. Faun. Germ. x. t. 18.

Long. corp. 8 lin.

Habitat in sylvis. Linn. Captus in Insulâ Eliensi, mense Augusto. D. Curtis.

DeSCr. Corpus testaceumuti abdomen et pedes. Thorax cylindricus, a dorso punctis duobus nigris. Antennæ longitudine corporis. Faun. Suec.

mubilus. I3. Cer. nigro-ferrugineoque varius, elytris punctatis: maculâ marginali cinercâ, antennis mediocribus.

Gmel. 1832.72.

Oliv. iv. 67. I09. I46. t. 3. f. I5. Scb̧aff. Icon. t. 55 . $f \cdot 4$.

Lamia nebulosa. Fab. Sp. Ins. i. 218.13. Mant. i. 137. 15. Ent. Syst. i. b. 277.38 . Faun. Etrusc. 367. Hellw. 367. Panz. Ent. Germ. 250.5.

Long. corp. 6 lin.

Habitat

DESCR. Totum corpus nigro ferrugineoque lineato varium. Antennæ longitudine corporis, nigræ, articulis basi cinereis. Thorax rotundatus, inermis, ferrugineus, nigro-lineatus. Elytra punctata, ferrugineo fuscoque 
fuscoque varia, maculâ magnâ cinereâ in medio marginis exterioris.

14. Cer. thorace fusco, elytris flavis apice nigris, praustus. antennis mediocribus.

Scbrank, 275. Gmel. I 842.223.

Leptura præusta. Linn. Syst. Nat.641.24. Faun. Suec. 698. Vill. i. 271.27. Harr. 350.

Mart. Eng. Ent. t. 28. f. 12. Schaff. Icon. t. 52.f. 8. La Lepture noire à étuis jaunes. Geoff. i. 209. 4.

Saperda præusta. Fab. Syst. Ent. 187. I6. Sp. Ins. i. 235.25. Mant. i. 150.37. Ent. Syst. i. b.317. 48. Panz. Ent. Germ. 259. I9. Payk. Faun. Suec. iii. 79. 12. Laich. ii. 54. I4. Oliv. iv. 68.33. 43.

Long. corp. 2 lin.

\section{Habitat}

Descr. Totum corpus pubescens. Antennæ ferè corporis longitudine, nigræ. Caput et thorax atra, nitida. Elytra obtusa, et ferè truncata, punctulatissima, flava, apicibus nigris. Pedes duo antici flavescentes; quatuor postici femoribus nigris, tibiis tarsisque flavescentibus.

**** Thorace inermi, subrotundo, sive exgloboso depresso.

I5. Cer. thorace pubescente, corpore violaceo, violaceus. antennis mediocribus.

Linn. Syst. Nat. 635. 70. Faun. Suec. 667. Vill. i. 247.71. Scbrank, 277. De Geer, v. 88. 24. - Poda, 36. I8. Faun. Fred.13. 130. Gmel. 1848. 70.

Donov. Brit. Ins. t. 64. f. I. Mart. Eng. Ent. t. 25. f. 15. Friscb. 12.t.3. Trans. Linn. Soc. v. 257. t. 12. Roem. Gen. Ins. tab. front. $f .2$.

Leptura violacea. Harr. 382 .

Leptura. Scbcef: Icon.t.4.f. I3.

Callidium violaceum. Fab. Syst. Ent. I 88. 4. Sp. Ins. i. $237.5 \%$ Mant. i. 152. 8. Ent. Syst. i. b. 320.9 . Panz. Ent. Germ, 261.5. Lich, ii. 72. 7. Payk.

Faun. Suec. iii. go. II.

$$
\text { Olie. }
$$


Oliv. iv. 70. 16. 18. t. 1. f. 2. Panz. Faun. Germ. 70. t. 4. Faun. Ingr. 285.

Long. corp. 6-8 lin.

Habitat in lignis exsiccatis.

DEscr. Totum corpus suprà subpilosum, e violaceo nitens, colore aureo et sericeo superbit. Antennæ corpore fermè breviores, atro-violaceæ, apice nigræ, subtomentosæ. Thorax elytris obscurior, planiusculus, punctis contiguis excavatus. Scutellum medio depressum. Elytra planiuscula, vix marginata, excavato-punctata, apice rotundata, humeris gibbis. Sternum violaceum. Abdomen nigrum. Pedes atri, interdum atro-violacei, femoribus clavatis.

Variat totus suprà virescens.

testaceus. 16. Cer. thorace glabro, corpore testacco, antennis mediocribus.

Linn. Syst. Nat.635.75. Faun. Suec, 670. Vill. i. 249. 74. Gmeel. 1850.75. De Geer, v. 93. 30.

Mart, Eng. Ent. t. 26 . f. 23 .

La Lepture livide à corcelet lisse. Geoff. i. 218. I8. Scbaff. Icon. t. 64. $f \cdot 6$.

Callidium testaceum. Fab. Syst. Ent. Igo. 13. Sp. Ins. i. 239.17. Mant. i. 153.26. Ent. Syst.i.b.326.36. Panz. Ent. Germ. 262. I2.

Oliv. iv. 70. I5. 17.t. I. $f$. I I.

Long. corp. $5 \frac{2}{3}$ lin.

Trabitat in sylvis.

Descr. Antennæ breviores, rufæ. Thorax testaceus, glaber, punctis quatuor elevatis, quadratìm positis. Elytra testacea, punctulata, lineâ elevatâ unicâ. Pedes rufi, femorum clavâ fuscâ.

bajulus. I7. Cer. niger, thorace villoso: tuberculis duobus, antennis brevibus.

Linn. Syst. Nat.635. 76. Faun. Suec.672. Vill. i. 249.75. Scbrank, 281. Gmel.1851.76. Faun. Fred. 13. 131. Poda, 36. 15. 
Mart. Eng. Ent. t. 24. $f . \mathrm{I}-5$.

Cerambyx caudatus. De Geer, v. 86. 22.

Leptura bajula. Scop. 156. Harr. 381 .

Scbreff. Icon. t. 64.f. 4. 5.t. 58.f. 1. Elem. t. 76. f. 4 . Callidium bajulum. Fab. Syst. Ent. 187. I. Sp. Ins. i. 236. I. Mani. i. 151.2. Ent. Syst. i. b. 318. 2. Punz. Ent. Germ. 260. I. Payk. Faun. Suec. iii. 85. 6. Laich. ii. 65.5. Faun. Ingr. 283.

Oliv. iv. 70. $7 \cdot 5 \cdot t \cdot 3 \cdot f \cdot 30$. a. b. Panz. Faun. Germ. 70. $t$. 1 .

Long. corp. $5-7$ lin.

Habitat in lignorum acervis.

Descr. Totus niger est, cum cineritiei mixturâ. Corpus totum scabrum, vel inæquale, punctis prominulis inordinatis, et pilis cinereis vagis. Thorax verò totus hirsutus, cinereus, sive niger, pilis albis, et duobus a tergo punctis prominulis glabris, quibus ab omnibus differt. Antennæ nigræ, parvæ, corpore dimidio breviores. Oculi in quibusdam deaurati. Pedes nigri : tibiæ duplici spinâ terminatæ. In dorso elytrorum fascia alba, undulata, sed obsoleta, ut vix visibilis sit. Elytra flexilia. Femora clavata. Faun. Suec.

18. Cer. thorace nigro villoso-cinereo: lineolis similis. duabus glabris, elytris testaceis, antennis brevibus.

Cerambyx bajulus var. $\beta$. Linn. Faun. Suec. 672. Scbeff.Icon.t. 64. f. 5. Voet. ii. t.22. f. 112.

La Lepture brune à corcelet rhomboidale. Geoff. i. 218.17.

Callidium Linnæanum. Laicb. ii. 69. 6.

Long. corp. 6- io lin.

\section{Habitat}

Descr. Facies antecedentis. Antennæ corpore breviores, testacex. Thorax villosus, cinereus, sive niger pilis albis, a tergo punctis duobus, oblongis, glabris. Elytra testacea, antennis pallidiora, punctis excavata, non tamen striata. Femora nigra. Oculi aurati. 
Antennæ pilis adspersæ, tertio articulo longissimo. Sæpè fasciâ albâ obsoletâ in dorso; hinc adfinitas cum præcedente summa. Faun. Suec.

sanguineus. 19. Cer. niger, thoracis dorso elytrisque sanguineis, antennis mediocribus.

Linn. Syst. Nat. 636.80. Faun. Suec. 673. Vill. i. 252.79. De Geer, v. 92.29. Scbrank, 284. Poda, 36. Gmel. 1855.80.

La Lepture veloutée couleur de feu. Geoff. i. 220. 21 .

Callidium sanguineum. Fab. Syst. Ent. Igo. 2. Sp. Ins. i. 238. I6. Mant. i. 153. 25. Ent. Syst. i. b. 326.35. Laich. ii. 59. 3. Panz. Ent. Germ. 262. 11. Payk. Faun. Suec. iii. 89. Io. Faun. Ingr. 288.

Oliv. iv. 70. 14. 15. t. r. f. 1. 6.

Long, corp. 5 lin.

\section{Habitat}

In mus. D. Donovan.

DESCr. Simillimus Cer. bajulo, sed thorax magìs depressus, ater, et thorax suprà, scutellum, elytra et anus sanguinea, holosericea, tomento vix conspicuo. Syst. Nat.

fennicus, 20. Cer. thorace subferrugineo: tuberculis obsoletis, elytris violaceis, antennis longiusculis. Linn. Syst. Nat.636.77. Faun. Suec. 674. Vill. i. 250.76. Scbrank, 282. Udd. Diss. 33. Gmel.1851. 77. Mart. Eng. Ent.t 25. $f .16$.

Leptura fennica. Harr. 383 .

Leptura. Scbaff. Icon. t. 4. f. 12. t. 69. f. I. mas. t. 64. f. 6. fem.

La Lepture noire à corcelet rougeâtre. Geoff. i. 219. I9. Callidium fennicum. Fab. Syst. Ent. 188. 2. Sp. Ins. i. 236. 2. Mant. i. 151.3. Ent. Syst. i. b. 319. 3 . Panz. Ent. Germ. 260. 2. Faun. Ingr. 284.

Tanz. Faun. Germ. 70. t. 12. Oliv. iv. 70. 20. 25. t. $1 . f \cdot 9$.

Long. corp. 6 lin.

Habitat

DESCR. 
DESCR. Antennæ rufæ, articulis primoribus apice fuscis. Caput violaceum. Palpi rufi Thorax rufus, vel ferrugineus, tuberculis duobus obsoletis. Elytra violacea. Pectus rufum. Abdomen nigrum, apice rufo. Pedes rufi, femoribus clavatis, clavis fuscis.

2r. Cer. rufo-fuscus, antennis longitudine cor-minutus. poris.

Gmel. 1842. 225 .

An Cerambyx pygmæus. De Geer, v. 80. 17. t. 4. $f \cdot 5$ ? Saperda minuta. Fab. Sp. Ins. i. 235. 27. Mant.i. I50: 39 .

Oliv. iv. 68. 4I. 53.t. 3. $f \cdot 3$ I. a. b.

Callidium pygmæum. Fab. Ent. Syst. i. b. 323. 24.

Long. corp. $2 \frac{x}{2}$ lin.

\section{Habitat}

DESCR. Media inter cylindricos et subrotundos. Totum corpus suprà unicolor, rufo-fuscum. Abdomen subtùs nigrum, nitidum. Elytra medio longitudinaliter angulatim elevata. Femoribus clavatis.

\section{**** Thorace inermi, subgloboso, nec depresso.}

22. Cer. thorace tomentoso, elytris fusco-cinereis mysticus. anticè rufis: fasciis linearibus arcuatis latèque canis.

Gmel. $1855 \cdot 290$.

Cerambyx albo-fasciatus. De Geer, v. 82. I9.

Cerambyx quadricolor. Scop. 177.

Leptura mystica. Linn. Syst. Nat. 639. 18. Faun. Suec. 693. Vill. i. 267. 21. Harr. 358.

Don. Brit. Ins. t. 84. f. 2. Scbaff. Icon. t. 2. f. 9.

La Lepture à raies blanche. Geoff: i. 215. I2.

Callidium mysticum. Fab. Syst. Ent. 194. 34. Sp. Ins. i. 244. 45. Mant i. 56.61. Ent. Syst. i. b. 337 . 81. Panz. Ent. Germ. 267.36. Payk. Faun. Suec. iii. 98.20.

Oliv. iv. 70. 50. 68. t. 1. f. 14.

Clytus mysticus, Laicb. ii, 107.7.

VOL. I. 
Long. corp. $7 \frac{1}{2}$ lin.

\section{Habitat}

DESCR. Corpus nigrum. Elytra basi ferè ad medium ferruginea; lineæ aliquot niveæ concurrunt in angulum acutum, ad suturam dorsalem; ante apicem fascia albida. Faun. Suec.

Alni.

23. Cer. niger, elytris fasciis duabus albis, elytrorum basi antennis tibiisque ferrugineis.

Gmel. $1855 \cdot 293$.

Leptura Alni. Linn. Syst. Nat. 639. 19. Vill. i. 268. 22. Mart. Eng. Ent. t. 28.f. 14 .

Callidium Alni. Fab. Syst. Ent. 195. 35. Sp. Ins. i. 245. 46. Mant.i. 157.64. Ent. Syst.i. b. 338.86. Panz. Ent. Germ. 267.33. Payk. Faun. Suec. iii. 100. 22. Oliv. iv. 70. 53. 72.t. 2. f. 16. b.

Long. corp. 3 lin.

Habitat

DESCR. Affinis Cer. mystico, sed octies minor. Elytra basi ferruginea, medio fasciâ lineari arcuatâ, albâ; posticè lineâ albâ obliquè transversâ. Syst. Nat.

arcuatus. 24. Cer. niger, elytris fasciis linearibus flavis; tribus retrorsùm arcuatis, antennis ferrugineis.

Gmel. 1853.279.

Leptura arcuata. Linn. Syst. Nat. 640. 21. Faun. Suec. 696. Vill. i. 269.24. Harr. 352. Schrank, 308.

Don. Brit. Ins. t. 84. f. I. Mart. Eng. Ent. t. 27. f. 2. 3. Scboeff. Icon. t. $3^{8} \cdot f \cdot 6 . t .107 \cdot f \cdot 3$. Voet. ii. $t$. I9. $f .89$ et 92 .

La Lepture à croissans dorés. Geoff. i. 212. IO.

Callidium arcuatum. Fab. Syst. Ent. 192. 25. Sp. Ins. i. 241.35. Mant. i. 155.50. Ent. Syst. i. b. 333.64. Panz. Ent. Germ. 265.25. Payk. Faun. Suec. iii. 95. I7. Faun. Ingr. 289.

Panz. Faun. Germ. 4. t. I4. Oliv. iv. 70. 35. 48. t. 3 . $f \cdot 37 \cdot$ a. b.

Clytus arcuatus. Laicb. ii. 95. 3 .

Long. 
Long. corp. $8-9$ lin.

Habitat in ligno quercino.

Descr. Antennæ et pedes postici ferruginei. Corpus atrum. Caput lineâ flavâ anticè, et inter antennas et ad basin. Thorax anticè lineâ flavâ, et duabus in medio ad latera. Puncta lutea ; unum elytris commune ad basin; dein unum utrinque; tum unum commune majus ; demum punctum cum lineolâ ; tandem arcus in singulo elytro et dein arcus communis; ultimo apices elytrorum lunulâ luteâ terminati. Faun. Suec. Fascia thoracis lutea interrupta. Femora anterıora fusca. Punctum scutellare flavum. Syst. Nat.

25. Cer. niger, elytris fasciis flavis ; secundâ an-Arietis. trorsùn arcuatâ, pedibus ferrugineis.

Gmel. $1853 \cdot 280$.

Cerambyx 4-fasciatus. De Geer, v. 81. 4 .

Leptura Arietis. Linn. Syst. Nat. 640. 23. Faun. Suec. 695. Vill. i. 270. 26. Harr. 353. Scbrank, 307. Poda, 39. II.

Schaff. Icon. t. 38.f. 7. 8. t. 107. f. 3. Don. Brit. Ins. t. 27. Mart. Eng. Ent. t. 27. f. 4 .

La Lepture à trois bandes dorées. Geoff. i. 2I4. II. Callidium Arietis. Fab. Syst. Ent. 193. 27. Sp. Ins. i. 242.36. Mant. i. I55.5 I. Ent. Syst. i. b. 333. 65. Panz. Ent. Germ. 265. 26. Payk. Faun. Suec, iii. 96. I8. Faun. Ingr. 290.

Panz. Faun. Germ. 4. t. I5. Oliv. iv. 70. 35. 49. t. 2. $f .20$.

Long. corp. 7 lin.

Habitat in pratis inter arbores, et in hortis.

DEscr. Totus fusco-niger, oblongus, angustus. Thorax margine superiore flavus est. Scutellum ubi elytra conjunguntur puncto flavo notatur. Ad angulos elytrorum macula oblonga, transversa, in utroque elytro, quæ ambæ non coëunt: in medio elytri utriusque est linea flava, arcuata, flexurâ deorsum spectante, pede interiore versus suturam cum oppositâ ferè coëunte, hinc figura arietis; intra hanc et apicem linea transversa flava cum oppositâ connexa ; apex elytrorum fla- 
vus, ut et anus, Caput, thorax et elytra villis tenuissimis tecta sunt. Elytra apice truncata, licet extùs præ pili-vix conspicuè. Pedes rufescentes; tibiæ spinâ terminatæ. Antennæ rufescentes, supernè fuscæ. Alæ, dum parùm dehiscunt elytra, aurato-purpurea lucent. Lineæ 4 flavæ sub abdomine. Faun. Suec.

Antenne setaceæ.

\section{LEPTURA.}

Caput exsertum.

Oculi rotundi, sive ovales, nec antennas amplectentes.

Thorax teretiusculus, anticè attenuatus.

Elytra apicem versus attenuata.

Corpus oblongum.

* Thorace spinoso, vel dentato. ** Tborace inermi.

* Tborace spinoso, vel dentato.

meridiana. $\dot{1}$. Lcp. nigra, elytris subfastigiatis abdomineque apice testaceis, pectore nitenti.

De Geer, v. I30. 5. Fab. Ent. Syst. i. b. 34I. II. Panz. Ent. Germ. 269. 7. Payk. Faun. Suec. iii. I04. 4 .

Panz. Faun. Germ. 45. t. 20.

Cerambyx meridianus. Linn. Syst. Nat. 630. 47. Faun. Suec. 648. Gmel. 186r. 47. Vill. i. 233. 17. Harr. 330. Scbrank, 257.

Mart. Eng. Ent. t. 25. f. II. I2. Scbaff. Icon. t. 3 . f. 13.t. 79. f. 7.t. 82. f. 4 ? t. 83.f. 2.t. 279.f. 3 , Stenocorus meridianus. Fab. Syst. Ent. I 78. I. Sp. Ins. i. 225. 1. Munt. i. I43. I. Laicb. ii. I33. 2. Oliv. iv. 6g. 18. I1. t. 1. f. 2. b. t. 3. f.2. c,

Long. 


\section{IFPTUESA.}
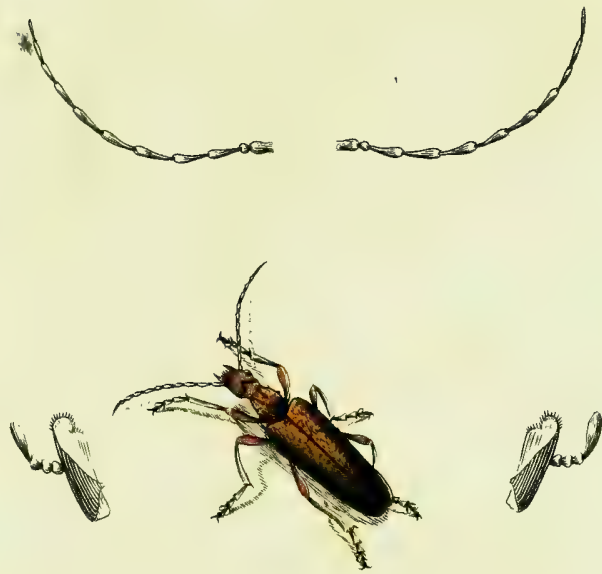

$I$ meriatiana. 

Long. corp. I unc.

\section{Habitat}

DEscr. Antennæ nigræ, basi rufæ. Frons apice palpique rufi. Thorax niger, fulvo-subvillosus, utrinque dente obtuso armatus, lineâ intermediâ longitudinali exaratus. Scutellum nigrum, fulvo-villosum. Elytra rufo-testacea, versus apicem attenuata, obliquè truncata, lineis tribus obsoletis elevatis. Corpus subtùs nigrum, aureo tomento villosum, abdominis tribus ultimis segmentis rufo-maculatis. Pedes rufo-testacei, geniculis nigris.

Fœmina tota nigra, tomento aureo suprà rariùs, subtùs præsertim pectore confertiùs conspersa.

An Cerambyx Chrysogaster. Scbrank, 252?

2. Lep. nigra, elytris pedibus abdomineque toto rufiventris. testaceis, pectore nitenti.

Long. corp. 8 lin.

Habitat

DESCr. Præcedenti simillima, sed longè minor. Antennæ testaceæ, articulis intermediis apice nigris. Caput et thorax obscurè nigra, aıreo-villosa, lineâ intermediâ longitudinali exarata; thorax tuberculo utrinque armatur. Elytra rufo-testace`, lineis elevatis tribus obsoletis. Pectus tomento aureo-virens. Pedes rufotestacei, geniculis nigris.

Sexus alter elytris fuscis, et omninò obscurior.

3. Lep. elytris nebulosis fusco subfasciatis, an-inquisitor. tennis brevioribus.

De Geer, v. I26. I. t. 4. f. 7 .

Cerambyx inquisitor. Linn. Syst. Nit, 630. 49. Faun. Suec.659. Gmel. 1845. 49. Poda, 33. 8. Harr. 331 . Act. Nidros, iii. 392. I1. Faun. Fred. 13. I28. Vill. i. 234. 19. Scbrank, $25^{8}$.

Scbaeff. Icon. t. 83. $f \cdot 3$.

Rhagium inquisitor. Fab. Syst. Ent. 182. I. Sp. Ins. i. 229. 1. Mant.i. 145. 2. Ent. Syst. i. b. 304. 2. Panz. Ent. Germ. 254. 2. Payk. Faun. Suec. iii. 66. I. Laicb. ii. 125. 5. Faun. Ingr. 274. 
Mart. Eng. Ent. t. 25. f. I9.

Stenocorus inquisitor. Oliv. iv. 69. 9. 2. t. 2.f. II.

Le Stencore noir velouté de jaune. Geoff. i. 223.2.

Long. corp. 9 lin.

Habitat passim in sylvis. Faun. Suer.

Descr. Caput vellere cinereo punctisque vix conspicuis nigris sub vellere; pone oculus versus pectus nigrum; punctum pone antennas nigrum. Antenn? cinereæ, undecim articulis corpore dimidio breviores, antrorsim protensæ: tibiæ ad apicem duabus spinis armantur. Thorax cinereus, margine laterali nigro, in cujus medio mucro niger. Linea nigricans longitudinalis thoracis in medio tergi. Elytra oblonga, arctá, striis tribus longitudinalibus, elevatis, nitidiusculis : cæteroquin nebulosa sunt elytra ob maculas nigricantes temerè sparsas; (et in quibusdam fascia duplex transversa nigra lateribus testacea.) Totum corpus alias cinereum, nigro nebulosum, qui cinereus color a pilis minutissimis, ad cervinum colorem accedentibus, oritur. Faun. Suec.

bifasciata. 4. Lep. elytris fuscis, fasciis duabus obliquis abbreviatis flavis.

Cerambyx inquisitor, var. $\beta$. Linn. Syst. Nat. 631. 49. Faun. Suec. 659. Harr. 332.

Scbaff: Icon. t. 2. f. 10. ? t.8.f. 3. Elem.t. II8.f. I. Cerambyx anglicus. Gmel. 1844. 237.

Rhagium bifasciatum. Fab. Syst. Ent. 183.3. Sp. Ins. i. 230. 4. Mant. i. 146. 7. Ent. Syst. i. b. 305. 7. Panz. Ent. Germ. 255. 7. Faun. Ingr. 276.

Donov. Brit. Ins. t. 94. f. I. Mart. Eng. Ent. t. 25. $f$. 18 .

Rhagium Linnei. Laicb. ii. 122. 4.

Stenocorus bifasciatus. Oliv. iv. 69. 1 1. 4. t. 1. f. 6. t. 2. $f .14$.

Long. corp. 8-rolin.

Habitat in sylvis.

DESCr: Statura Lep. inquisitoris. Antennæ ferrugineæ, primo articulo nigræ, corpore breviores. Caput atrum, canaliculatum, posticè gibbum. Thorax rotundatus niger, 
niger, subcanaliculatus, spinâ validâ utrinque armatus. Elytra fasciis duabus obliquis flavis, quæ tamen margines haud attingunt. Pedes nigri, femorum basi tibiisque rufis. Syst. Ent.

5. Lep. nigro-ænea, elytris flavis : basi lineisque nigrotribus longitudinalibus interruptis nigris.

lineata.

Don. Brit. Ins. t. 353. f. 1.

Long. corp. Io lin.

Habitat

In mus. D. Francis.

DesCr. Antennæ nigræ. Caput et thorax nigro-ænea. Scuellum griseum. Elytra flava, maculâ magnâ scutellari, suturâ et lineis elevatis tribus longitudinalibus interruptis nigris. Corpus subtùs nigrum, argenteovillosum. Pedes picei.

6. Lep. nigra, elytris flavis basi atro-cæruleis: bimaculata. maculâ lunatâ marginali ferrugineâ nigro-cinctâ.

J_ong. corp. 9 lin.

Habitat - In mus. D. Francis.

Descr. Antennæ ferrugineæ. Caput et thorax nigra. Scutellum flavum. Elytra flava, maculâ scutellari et suturân nigris ; in medio ad marginem macula lunaris ferrugine: cincta lineolâ undulatâ nigrâ, et macula altera oblonga prope suturam juxta apicem. Corpus subtùs nigro-ferrugineum. Pedes ferruginei, femoribus apice nigris.

7. Lep. nigra, elytris flavo-fasciatis: apice ma-dorsalis. culisque duabus marginalibus ferrugineis.

Long. corp. maris 8 lin.

Habitat

Capta prope Manchester.

\section{Pbillips.}

Descr. Antennæ breves, subferruginex. Caput nigro-æneum, oculis ferrugineis. Thorax rotundatus, nigro-æneus, utrinque spinâ acutâ recurvâ. Scutellum 
ferrugineum. Elytra punctato-rugosa, basi et apicem versus nigro-ænea; apex autem ipse ferrugineus. Margines etiam maculis duabus ferrngineis confluentibus inficiuntur, quarum altera humerorum locim occupat, altera vero media est: hæc posiscè punctum nigrum gerit. Pedes ferruginei, femoribus apice nigris.

* Tborace inermi.

micans.

8. Lep. elytris violaceo micantibus, femoribus posticis bidentatis, tibiis omnibns simplicibus.

Leptura aquatica, var. . Linn. Syst. Nat. 637. I. Faun. Suec. 677 .

Mart. Eng. Ent.t.28.f. 16. I7.

Leptura aquatica spinosa. De Geer, v. 340. 18. t. 4 . f. I4. I5:

Donacia micans. Hoppe Ins. Erlang 39. I. f. I.

Donacia crassipes. Fub Ent. Syst. i. b. I15. I. Payk. Faun. Suec. ii. 191. 4.

Le Stencore doré, var. ঠ. Geoff. i. 229. I2.

Long corp. 4 lin.

Habitat in plantis aquaticis æestate.

DEs CR. Antennæ nigrescentes; articulorum apices subtestacei. Caput læve, lineâ longitudinali in medio. Thorax viridis, impunctatus, canaliculatus, lateribus anticis prominulis. Elytra plana, punctato-striata, viridi-violacea, apice subtruncata. Corpus subtùs cinereovillosum. Pedes testacei : femora postica clavata, bidentata; dentes æquales recti: tibiæ posticæ simplices. Hoppe.

fasciata. 9. Lep. elytris viridibus; lineâ longitudinali mediâ coccineâ, abdomine pedibusque aureis.

Gmel. 1866. I8.

Leptura aquatica fasciata. De Geer, v. 142. 20.

Donacia fasciata. Hoppe Ins. Erl. 42.3.f.3.

Donacia dentipes. Fab. Ent. Syst. i. b. II6. 3. Panz. Ent. Germ. 214. 3. Payk. Faun. Suec. ii. 195. 8.

Panz. Faun. Germ. 29. $t$. 5 .

Long. 
Long. corp. 5 lin.

Habitat in plantis aquaticis, vere.

Descr. Antennæ nigrescentes. Caput subtilissimè punctatum; lineâ longitudinali in medio. Thorax cylindricus, canaliculatus, punctatus, lateribus anticis tuberculatus. Elytra lacunosa, viridia, fasciâ mediâ longitudinali coccineâ, cum maculâ impressâ aureâ juxta marginem interiorem versus basin, apice rotundata. Corpus subtùs cum pedibus aureo-villosum. Femora postica unidentata. Hoppe.

ro. Lep. elytris inauratis: margine laterali vit-vittala. tâque baseos abbreviatâ atro-violaceis.

Donacia vittata. Panz. Faun. Germ. 29. t. II.

Donacia marginata. Hoppe Ins. Erlang. $42 . f \cdot 4$.

Long. corp. $4 \frac{1}{2}$ lin.

Habitat in Nymphâ, Potamogetone.

Descr. Caput aureum, nitidulum, inter oculos lineâ impressâ. Antennæ fuscæ, articulo primo maximo. Thorax punctatus, subæqualis, medio lineâ impressâ. Elytra inaurata, opaca, punctato-striata, margine laterali vittaque baseos abbreviatâ atro-violaceis. Corpus subtùs argenteum. Pedes aurei, femoribus posticis clavatis. Panz.

I. Lep. elytris viridi-aureis lacunosis apice trun-Sagittaria. catis, abdomine pedibusque aureis.

Donacia Sagittariæ. Fab. Ent. Syst. i. b. I17. 5. Panz. Ent. Germ. 215. 6. Payk. Faun. Suec. ii. 192. 5.

Panz. Faun. Germ. 29. t. 7 .

Donacia aurea. Hoppe Ins. Erl. 43. $f \cdot 5$.

Long. corp. 5 lin.

Habitat in Sagittariâ.

DESCR. Antennæ nigricantes. Caput æneum, canaliculatum. Thorax rugosus, canaliculatus, lateribus anticis prominulis. Elytra lacunosa, punctato-striata, viridi-aurea, apice attenuata, truncata. Corpus subtùs pedesque 
pedesque aureo-villosa. Femora postica unidentata; tarsi nigri. Hoppe.

enea.

12. Lep. elytris aneis æqualibus apice rotundatis, abdomine pedibusque æneis.

Leptura aquatica ænea. De Geer, v. I43. 2 I.

Donacia ænea. Hoppe Ins. Erlang. $44 . f$. 6 .

Donacia impressa. Payk. Faun. Suec. ii. 193. 6.

Long. corp. 4 lin.

Habitat

Descr. Tota ænea. Caput lineatum, læve. Thorax cylindricus, canaliculatus, lævis, lateribus anticis tuberculatus. Elytra æqualia, argutè punctato-striata, apice rotundata. Femora postica unidentata; tarsi nigri. Hoppe.

Festuca. I3. Lep. elytris violaceis apice rotundatis, abdomine argenteo-villoso.

An Leptura sericea? Linn. Syst. Nat. 638. 8. Faun. Suec. 683 .

Donacia Festucæ. Fab. Ent. Syst. i. b. I16.2. Panz. Ent. Germ. 214. 2.

Panz. Faun. Germ. 29. $t .2$.

Donacia violacea. Hoppe Ins Erl. 44. f. 7 .

Donacia Nymphææ, var. B. Payk. Faun. Succ. ii. 195: 9.

Long. corp. $3 \frac{1}{2}-4$ lin.

Habitat in Festucâ aquaticá.

Descr. Antennæ nigræ. Caput et thorax violacea, canaliculata. Elytra violacea, æqualia, linearia, apice rotundata. Pedés nigri: femora postica unidentata. Hoppe.

discolor. I4. Lep. elytris æneis nigrisve apice rotundatis, abdomine cinereo-villoso, pedibus rufo-testaceis.

Donacia discolor. Panz. Ent. Germ.216. I2.

Hoppe Ins. Erl. 45. mas. f. 9. Panz. Faun. Germ. 29. t. $3 \cdot 4$. 
Long. corp. 4 lin.

Habitat in Calthe palustris floribus. Maio.

DESCR. Antennæ pedesque rubro-testacei. Thorax obsoletè punctatus, tuberculatus. Elytra obsoletè punctato-striata, apice rotundata. Femora incrassata: postica clavata unidentata. Hoppe.

15. Lep. elytris cupreis apice rotundatis, abdomine Nympbace. cinereo-villoso, pedibus argenteis.

Donacia Nymphææ. Fał. Ent. Syst. i. b. 116. 4. Panz. Ent. Germ. 215. 5. Payk. Faun. Suec. ii. 196. 9.

Long. corp. $4 \frac{x}{2}$ lin.

Habitat in Nymphae foliis frequens.

Descr. Reliquis paullo minor. Caput cupreum, antennis oreque nigris. Thorax cylindricus, canaliculatus, anticè utrinque puncto gibbo, prominulo, cupreus, immaculatus. Elytra crenato-striata, cuprea. Corpus totum subtùs cum pedibus villis argenteis nitidulum. Femora postica vix incrassata, at unidentata. Ent. Syst.

16. Lep. elytris linearibus apice truncatis æneo- linearis. nitidulis, pedibus subtestaceis.

Donacia linearis. Hoppe Ins. Erl. $46 . f$. Iо.

Long. corp. 5 lin.

Habitat ad piscinas in plantis aquaticis. Maio.

DESCR. Antennæ nigricantes. Caput punctatum, lineatum. Thorax rugosus, canaliculatus. Elytra argutè punctato-striata, linearia, apice truncata. Abdomen cinereo-nitidulum. Pedes subtestacei ; femora omnia simplicia.

I7. Lep. elytris cinereo-nitidulis apice rotundatis, Hydrocharis. corpore pedibusque cinereis.

Donacia Hydrocharis. Fab. Ent. Syst. i. b. 118. 10. Panz. Ent. Germ. 216. Io. Payk. Faun. Suec, ii. 189. I.

Panz. 
Panz. Faun. Germ. 29. t. I7.

Donacia cinerea. Hoppe Ins. Erl. 46.f. II.

Long. corp. $+\frac{i}{2}-5$ lin.

Habitat in plantis aquaticis, præsertim Typbis. Maio.

Descr. Antennæ cinereæ. Caput lineatum. Thorax rugosus, tuberculatus. Elytra cinereo-nitidula, obsoletè punctato-striata, apice rotundata. Corpus subtùs pedesque cinerei : femora omnia simplicia. Hoppe.

melanoceptrala.

I8. Lep. deaurata ænea, capite nigro, elytris liturâ dorsali obscurè cupreâ, femoribus rufo-piceis simplicibus.

Long. corp. 3 lin.

Habitat

Descr. Caput nigrum. Antennæ fuscæ. Thorax æneus, canaliculatus. Elytra aureo-nitentia, punctatostriata, liturâ dorsali versus apicem cupreâ, apice rotundata. Corpus subtùs nigro-æneum. Femora rufa, apice tibiisque nigro-piceis.

simplex.

I9. Lep. deaurata ænea, antennis pedibusque rufis, femoribus posticis longissimis muticis.

Gmel. 1866. I7.

Leptura aquatica mutica. De Geer, v. I42. I9.

Donacia simplex. Fab. Ent. Syst. i. b. 118. 9. Payk. Faun. Suec. ii. 189. 2. Panz. Ent. Germ. 216. 9. Mart. Eng. Ent. t.28. f. I5. Panz. Faun. Germ. 29. $t$. 15 .

Long. corp. 6 lin.

Habitat

DESCR. Totum corpus suprà æneum, concolor. Antennæ rufæ. Elytra punctato-striata, nec lacunosa. Corpus subtùs argenteo-villosum. Pedes rufi, femoribus posticis longioribus absque ullo dente. 
20. Lep. fusca, elytris punctato-striatis, ore an-fusca. tennis pedibusque rufis, femoribus posterioribus dente valido armatis.

Gmel. 1867.86.

Long. corp. 3 lin.

Habitat

DESCR. Corpus totum fuscum. Elytra punctatostriata. Antennæ rufæ. Pedes rufi, femoribus posticis dentatis.

21. Lep. abdomine pedibus antennisque rufis, palustris. clytris atro-æneis punctato-substriatis.

Gmel. 1866. 20.

Donacia palustris. Panz. Ent. Germ. 21\%. 13.

Panz. Faun. Germ. 29. $t$. I0.

Long. corp. 6 lin.

Habitat in plantis aquaticis.

DESCR. Caput atro-æneum, subviolaceum, medio fossulâ impressâ. Antennæ rufæ, articulo primo clavato, maximo. Thorax obscurè æneus, anticè margine laterali gibbo, medio lineâ exaratâ. Elytra obtusa, atroænea, punctato-substriata. Pedes rufi, femoribus posticis clavatis, in omni sexu dentatis. Corpus subtùs rufum. Panz. Faun. Germ.

22. Lep. thorace abdomineque rubris, elytris ni- collaris. gris.

Linn. Syst. Nat.639. I6. Faun. Suec.691. Vill. i. 267. I9. Scop. 159. Poda, 39. 10. Harr. 350. Fab. Syst. Ent. 198. 16. Sp.Ins.1. 249. 23. Mant. i. 160. 33. Ent. Syst. i. b. 349.5 I. Panz. Ent. Germ. 275. 42. Payk. Faun. Suec, iii. 126. 28. Gmel. I875. 16.

Mart. Eng. Ent. t. 27. f. 5. Scbaff. Icon. t. 58.f. $9 \cdot$ OTiv. iv. $73 \cdot 27 \cdot 3^{6} \cdot t \cdot 4 \cdot f \cdot 44$.

Leptura ruficollis. De Geer, v, 143. 22. 
Le Stencore noir à corcelet rouge. Geoff. i. 228. II. Long. corp. 4 lin.

\section{Habitat}

Descr. Corpus totum atrum, glaberrimum, sed thorax globosus ferrugineus, ut et abdomen post pedes, a tergo flavum. Faun. Suec.

melanura. 23. Lep. nigra, elytris rubescentibus lividisve, suturâ apiceque nigris.

Linn. Syst. Nat. 637.2. Faun. Suec. 678. Vill. i. 260. 5. Gmel. 1868. 2. Fab. Syst. Ent. 196. I. Sp. Ins. i. 245. 2. Mant. i. 158. 4. Ent. Syst. i, b. 340. 5. Payk. Faun. Suec. iii. I 10. I1. Faun. Fred. I4. I36. Poda, 37.2. Harr. 362. Rai. 499. Act. Nidros. iii. 394. 13. Faun. Etrusc. 398. Hellw. 398. Panz. Ent. Germ. 268. 3 .

Scheeff. 1con. t. 39. f. 8. 9. Frisch. 12. t. 3. ic. 6. f. 6. Panz. Faun. Germ. 69.t. 19. Oliv. iv. 73. 6.3.t.1. f. 6. Mart. Eng. Ent.t. 27.f. 7 .

Le Stencore noir à étuis rougeâtres. Geoff. i. 226. 7 . t. 4 . $f$. 1 .

Leptura suturâ nigrâ. De Geer, v. 138. 15 .

Long. corp. 4 lin.

Habitat in floribus frequens.

DESCR. Antennæ nigræ, maris corporis longitudine, foeminæ paulo breviores. Caput et thorax nigra, subtilissimè punctulata. Thorax posticè angulis prominulis acutis. Elytra punctulata, attenuato-præmorsa, maris testacea suturâ apiceque tenuissimè nigris, fœeminæ rubescentia apice suturâque post basin latè nigris. Corpus subtùs et pedes nigra, pube brevissimâ grisescenti, holosericeâ, vix nisi certo respectu ad lumen conspiciendâ. Pedes postici corpore longiores.

revestita. 24. Lep. testacea, elytris pectore antennisque atris.

Linn. Syst. Nat. 638, 6. Laich. ii. 153. Io. Vill. i. 262. 9. Gmel. 1870.6.

Leptura 
Leptura villica. Fab. Syst. Ent. 196.3. Sp. Ins. i. 246. 5. Mant. i. 158. 8. Ent. Syst. i. b. 341. 12. Payk. Faun. Suec. iii. 113. I4. Panz. Ent. Germ. 269. 8. Vill. i. 274. 48. Faun. Etrusc. 400. Hellw. 400. Gmel.1869.28.

Panz. Faun. Germ. 22.t. 13. Oliv. iv. 73. 13. 15. t.2. f. 25. t. I. f. 10. Mart. Eng. Ent. t. 27.f. I.

Long. corp. 5 lin.

Habilat

In mus. D. Beckwith.

DESCR. Caput, thorax, abdomen pedesque ferruginea. Elytra glabra, atra, apice bidentata. Pectus atrum. Antennæ atræ, sed primo articulo testaceo. Thorax ad latera utrinque mucrone planè obsoleto, et postico margine laterali acuto. Linn. Syst. Nat.

25. Lep. elytris fastigiatis, corpore nigro nitido, nigra. abdomine rufo.

Linn. Syst. Nat. 639. I4. Faun. Suec. 689. Vill. i. 266. 17. Fab. Syst. Ent. 197. 8. Sp. Ins. i. 247. 13. Mant. i. 159. 40. Ent. Syst. i. b. 344. 27. De Geer, v. I44. 24. Payk. Faun. Suec. iii. I 20. 22. Faun. Etrusc. 406. Hellw. 406. Panz. Ent. Germ. 27 I. I9.

Mart. Eng. Ent. t. 27. f. 8. Scbaff. Icon. t. 39. f. 7. Panz. Faun. Germ. 69. t. 18. Oliu. iv, 73. 21. 26. t. $3 \cdot f \cdot 3^{6}$. a. b.

Long. corp. $4 \frac{x}{2}$ lin.

Habitat

Descr. Tota nigra, abdomine excepto. Thorax nitidus, utrinque posticè mucronatus, ut in Lepturâ melanurâ. Elytra punctulata, fastigiata, apice obliquè truncata, præmorsa. Corpus subtùs pube brevissimâ grisescenti adspersum. Abdomen maris apice rufum, fœminæ totum rufum. Pedes postici corpore longiores.

26. Lep. nigra, elytris rufescentibus : suturâ apice-levis. que nigris, pedibus rufis.

Fab. 
Fab Ent. Syst. i. b. 340.6. Payk. Faun. Suec. iii. I28. 31. Panz. Ent. Germ. 269. 4 .

Panz. Faun. Germ. 34. t. 16. Schaff. Icon. t. 39. f. 5 . Oliv. iv. $73 \cdot 34 \cdot 5$ o. t. $4 \cdot f \cdot 5^{\text {I. }}$.

Leptura tabacicolor. De Geer, v. 139. 17. Vill. i. 274. 46.

An Leptura Chrysomeloides. Scbrank, 297?

Long. corp. 4 lin.

Habitat

DESCR. Maximè affinis $L$. melanurce quam profectò diceres, nisi pedes rufi aliter suaderent. Antennæ nigræ, articulo primo apice rufo. Caput et thorax nigra, pube grisescenti. Elytra fastigiata, rufescentia, sutura tenuiter summoque apice nigris. Corpus subtùs nigrum, pubescens, pube grisescenti.

Tivida.

27. Lep. nigra, elytris rufescentibus immaculatis. Fab. Gen. Ins. Mant. 233. Sp. Ins. i. 246. 3. Mant. i. 158. 5. Ent. Syst. i. b. 340. 7. Panz. Ent. Germ. 269. 5. Faun Etrusc. 399. Hellw. 399. Gmel. 1869. 26.

Oliv. iv. 73. 33. 49. t. 4. f. 50. Mart. Eng. Ent. t. 28. f. 13. Herbst. Arcb. t. 26. f. 23.

Leptura nigripes. De Geer, v. I36. I2. Payk. Faun. Suec. iii. х21. 23. Vill. i. 274. 45. Gmel. 1874. 60.

Long. corp. $3 \frac{1}{4}$ lin.

Habitat

Descr. Totum corpus villosum, nigrum. Antennæ filiformes, extrorsùm potiùs crassiores. Thorax ut in Lep. melanurâ punctis impressis numerosis. Elytra rubescentia, immaculata, obtusa, vix attenuata, apice rotundata. Pedes nigri.

femorata. 28. Lep. nigro-viridis tomentosa, antennis rubro nigroque variis.

Fab. Mant, i. I59. 17. Ent. Syst. i. b. 343. 24. Payk. F un. Suec. iii. 127.29. Panz. Ent. Germ. 271. 17. Gmel. 1870. 34 .

Oliv. 
Oliv. iv. $73 \cdot 3$ I. $44 \cdot t \cdot 2 \cdot f \cdot$ I $_{5}$ a. b. t. $4 \cdot f \cdot$ r $5 \cdot$ c. Le Stencore noir à cuisses rouges. Geof. i. 227. I0. Long. corp. $3 \frac{x}{4}$ lin.

Hiluilat

DESCR. Antennæ $\frac{2}{3}$ corporis æquant, rufæ, articulis nigris. Totum corpus atro-virens, sericeum, Elytra punctatissima. Pedes duo antici rufi, femoribus apicem versus extùs nigris; duo intermedii rufi, geniculis nigris; postici nigri, femoribus basi rufis; in omnibus tarsi nigri.

29. Le. atra, elytris luteis apice nigris.

Long. corp. 6 lin.

Hutitat -

Descr. Maximè affinis Lep. melanure, sed abundè differt, magnitudine triplo majori, tum suturâ elytrorum immaculatâ, nec ni râ. Præter elytra, quæ apice nigra sunt, totum corpus aterrimum. Animal hoc omninò pilis nigris, vel luteis, pro colore artuum obvestitur.

30. Lep. nigra, coleoptris testaceis: maculis octo 6-maculata. nigris.

Linn. Syst. Nat. 638. I1. Faun. Suec. 686. Vill. i. 264. 14. Gmel. 1871. I1. Fab. Syst. Ent. 197. I1. Sp. Ins. i. 248. 16. Mant. i. 160. 26. Ent. Syst. i. b. 346.37. Panz. Ent. Germ. 272.26. Payk. Faun. Suec. iii. I23. 25. De Geer, v. I33.9.

Panz. Fiun. Germ. 69.t. 2! Oliv. iv. 73. 26.35. t. 4.f. 43. Mart. Eng. Ent.t. 28.f. 22. Don. Brit. Ins. t. $353 \cdot f \cdot 2$.

Long. corp. 5 lin.

Habitat - Capta prope Barnstaple. Miss Hill.

DEscr. Nigra, thorax autem vellere subfulvo obtegitur. Coleoptra testacea maculis octo notantur. Utrumque scilicet lytrum quatuor exhibet; duas ad basin, quarum una ovata ad suturam minor, altera hinc paVOL. I.

$2 \mathrm{~A}$ rallela 
rallela ad marginem major sublunata; tertiam marginalem magnam ad medium elytri; quartam ad apicem. Macula apicis marginem ipsum inficit, cætera non item. In quibusdam maculæ ovatæ ad basin elytrorum suturæ adnexæ, simul coeunt in unam, hinc coleoptra clausa sex-maculata videntur. Abdomen subtùs vellere fulvo sive cinereo. Pedes nigri.

4-fasciata. 31 . Lep. nigra, elytris testaceis: fasciis quatuor dentatis'nigris, pedibus atris.

Linn. Syst. Nat.639.12. Faun. Suec.687. Vill. i. 265. 15. Gmel.1871. 12. Fab. Syst. Ent. 198. 13. Sp. Ins. i. 248. 19. Mant. i. I60. 29. Ent. Syst. i. b. 348. 44. Panz. Ent. Germ. 273. 31. Poda, 28. 4. Harr. 374. Payk. Fann. Suec. iii. 1I4. 15. Laicb. ii. 143. 6. Faun. Etrusc. 401. Hellw. 401. Schaff. Icon. t. 59. f. 6. Mart. Eng. Ent. t. 27. f. 9 . Leptura octo-maculata. De Geer, v. I32.8. t. 4. f. II.

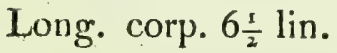

Habitat -

DESCR. Corpus totum nigrum, ut et elytra quæ maculis ferrugineis quatuor parium insigniuntur, quarum intermediæ undulatæ sunt. Thorax posticè complicatus quasi est : vel, si mavis, elytra testacea, fasciis quatuor nigris undulatis transversis, ultimâ terminatrice. Faun. Suec.

Foeminam sequentis esse monet. D. Scopoli.

attenuata. $3^{2}$. Lep, elytris fastigiatis attenuatis fulvis : fasciis quatuor nigris, pedibus testaceis.

Linn. Syst. Nat. 639. 13. Faun. Suec.688. Vill. i. 266. 16. Gmel. 1871. 13. Fab. Syst. Ent. 198. 12. Sp. Ins. i. 248. 18. Mant. i. 160.28. Ent. Syst. i. b. 346. 40. Panz. Ent. Germ. 273. 27. Poda, 28. 5. Harr. 373. Payk. Faun. Suec. iii. I 16. 18. Laich. ii. 150. 9. Faun. Etrusc. 407. Hellw. 407. Oliv. iv. 70. 17.20.t. 1. f. 8. Scbaef. Icon. t. 39. f.6. t. $65 . f .11$.

Long. 
Long. corp. lin.

\section{Habitat}

Descr. Corpus posticè valdè attenuatum. Caput, thorax, pectus nigra. Abdomen ferrugineum, apice nigro. Elytris fasciis quatuor flavis, totidemque nigris. Faun. Suec.

Femora postica apice nigra. Syst. Nat.

An præcedentis mas?

33. Lep. nigra, thorace subdentato, coleoptris elongata. flavis : fasciis quatuor nigris; anteriore punctatâ, secundâ interruptâ.

De Geer, v. 134. I0. Faun. Etrusc. Mant. 133. Hellw. Mant. 133. Linn. Faun. Suec, 2275.

Donov. Brit. Ins. t. 81. f. 4. Mart. Eng. Ent. t. 27. f. го. Scbaff: Icon. t. 58. f. 10.

Leptura armata. Gmel. 1872.44.

Fues. Arcb. 140. 5. t. 26. f. 24. mala.

Le Stencore noir à bandes noires. Geoff. i. 224. 5 .

Mas. Leptura calcarata. Fab. Ent. Syst. i. b. 347. 41. Payk. Faun. Suec. iii. I14. 16. Panz. Ent. Germ. 273. 28.

Oliv. iv. 73. 14. I7. t. I. $f$. 1. b.

Fœmina. Lept. subspinosa. Fa.. Ent. Syst. i. b. 347.42. Payk. Faun. Suec. iii. 115. 17. Panz. Ent. Germ. 273: 29.

Oliv. iv. $73 \cdot$ I5. $18 \cdot t \cdot 3 \cdot f \cdot 3^{\circ} \cdot$ a. b.

Long, corp. 7 lin.

Habitat in sylvis frequens.

DESCR. Corpus valdè attenuatum, præsertim in mare. Antennæ corpore sub. breviores, maris nigræ articulis basi parùm testaceis, fœeminæ flavæ articulis ad apicem dimidiato nigris. Caput nigrum, in quibusdam fascia frontali fulvâ. Thorax niger, in medio utrinque denticulo obsoleto, laterali, angulis posticis acutis. Coleoptra præmorsa, flava, fasciis quatuor nigris; primâ e punctis quinque quorum intermedium commune est, secundâ in medio interruptâ, tertiâ posticâ latá integrâ, et ultimâ integrâ in apice. Corpus subtùs 
nigrum, sub-pubescens, abdominis fœminæ segmentis tribus flavis. Pedes flavi, femoribus posticis apice nigris, tarsisque omnibus nigris fuscisve: tibiæ posticæ maris post medium internè erosæ; scilicet medio crassiores sunt, dente mutico, inde tenuiores evadunt, quasi interior pars recisa fuerit; ante apicem crassescunt dente interiore; apex ipse bispinosus ut in cæteris.

Variat fasciâ anteriore integrâ undatâ, et ultimis tribus per marginem exteriorem connexis.

An Leptura sinuata? Fab. Ent. Syst. i. b. $347 \cdot 43$. Panz. Ent. Germ. 273. 30.

aurulenta. 34. Lep. nigra, antennis pedibusque ferrugineis, elytris ferrugincis: fasciis quatuor nigris.

Fab. Ent. Syst.i.b. 348. 45. Panz. Ent. Germ. 274. 33 . Oliv. iv. $73 \cdot 18 \cdot 21 \cdot t \cdot 3 \cdot f \cdot 31$.

Long. corp. Io lin.

Habitat - Capta prope Barnstaple. D. Hill.

Descr. Antennæ ferrugineæ. Caput ex piceo nigrum. Os labio ferrugineo, maxillis nigris. Thorax villis aureis nitidis splendidus, villis autem detractis niger. Elytra apice erosa, punctulata, punctulis numerosissimis confertis, quadrifasciata; fascia ad basin minùs saturata; basis ipsa elytrorum suturam versus nigra; fasciæ omnes obliquæ; ultima apicem occupat. Pectus et sternum nigra. Abdomen nigrum, marginibus incisurarum villis aureis splendidis. Pedes ferruginei, villosi, femoribus basi sordidè nigris. Differt a $L e p$. 4-fasciatâ, antennis pedibusque ferrugineis, nec nigris; a Lep. elongatâ articulis antennarum unicoloribus, nec minimè quidem apice nigris.

exclamatio- 35. Lep. nigra, elytris puncto baseos lineâque nis. mediâ flavis.

Fab. Ent. Syst. i. b. 343. 20.

Oliv. iv. $73 \cdot 29 \cdot 39 \cdot t \cdot 2 \cdot f \cdot 19$.

Long. corp. 5 lin.

Habitat - Capta in sylvâ Clarendon dictâ, prope Salisburiam. D. Lambert.

DESCR。 

Pl.18,

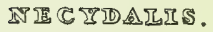

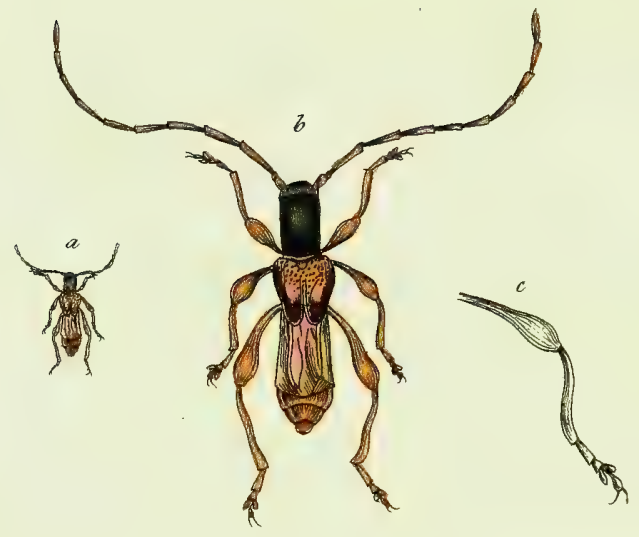

N. minor. 
Descr. Caput et thorax atra, nitida, immaculata. Elytra truncata, nigra, puncto baseos lineolâque mediâ lunatâ flavis. Abdomen argenteo-villosum. Pedes nigri. Ent. Syst.

36. Lep. ferruginea glabra, antennis extrorsùm fuscicornis. oculis sternoque nigris.

Long. corp. 6 lin.

Habitat

In mus. D. Lewin.

DESCr. Antennæ nigræ, basi ferrugineæ. Oculi atri. Sternum atrum. Plantæ quatuor anticæ nigricantes. Per cætera ferruginea est. Caput, thorax et pedes rubescunt.

37. Lep. nigra tomentosa, elytris puncto macu-punctolâque reniformi flavis. maculata. Long. corp. 5 lin.

Habitat In mus. $D$. Lewin.

Descr. Tota nigra, præter elytra, quæ basi punctum et medio maculam elongatam subreniformem exhibent.

\section{NECYDALIS.}

Antenna setaceæ, vix filiformes. Thorax angustus, rotundatus. Elytra alis minora (breviora sive angustiora). Cor/uus oblongum, immarginatum. Cauda simplex.

* Elytris alis abdomineque multo brevioribus. * Elytris subulatis longitudine abdominis. 
* Elytris alis abdomineque multo brevioribus.

minor. I. Nec. elytris testaceis apice lineolâ albâ, antennis longioribus.

Linn. Syst. Nat. 64r. 2. Faun. Suec. 837. Vill. i. 278. 2. Scop. 179. Faun. Fred.22.220. Gmel. 1878.2.

Oliv. iv. 74. 6. 2. t. I. f. 2. a. b. Mart. Eng. Ent. t. $23 . f . \mathrm{I}$.

Necydalis Ceramboides. De Geer, v. I51. 2.

Leptura dimidiata. Fab. Syst. Ent. 199.20. Sp. Ins. i. 250. 27. Mant. i. 160. 37.

Molorchus dimidiata. Fab. Ent. Syst. i. b. 357-3. Panz. Ent. Germ.281. 2. Payk. Faun. Suec. iii. 130. 2.

Panz. Faun. Germ. 4I. t. 2I.

Long. corp. 3 lin.

Habitat in sepibus. Linn.

Descr. Caput nigrum. Thorax oblongus, ater, punctis duobus nitidis, dorsalibus. Elytra grisea, basi angulata, abdomine dimidio breviora, apice dehiscentia inter se, et singula maculâ lineari albâ apice notata. Alæ seminudæ, ut in hemipteris, cruciatæ, nec intra elytra retractæ. Antennæ griseæ, corpore duplo longiores, setaceæ, articulo infimo crasso ; secundo minimo; tertio et reliquis oblongis. Pedes grisei. Femora versus apicem valdè crassa, clavata, et in eodem loco ferè globosa. Ex antennis esset Cerambyx! ex pedibus Leptura! ex elytris Forficula! cum Cerambyce tamen maximè adfinis, licet externa facie dissimilis. Faun. Suec.

Umbellata-2. Nec. elytris testaceis immaculatis, antennis rum. longis.

Linn. Syst. Nat.641.3. Vill. i. 279.3. Gmel. 1878.3. Necydalis minima. Scop. 180.

Oliv. iv. 74. 7.3.t. I. f. 3. a. b. Schaff. Icon. t. 95. f. 4. Mart. Eng. Ent. t. $23 \cdot f .2$.

Leptura Umbellatarum. Fab. Syst. Ent. 199. 21. Sp. Ins. i. 250. 28. Mant. i. 160. 38 .

Molorchus 
Molorchus Umbellatarum. Fab. Ent. Syst. i. b. 357 . 4 . Panz. Ent. Germ. 281. 3. Payk. Faun. Suec. iii. I3I. 3 .

Long. curp. 3 lin.

Habitat

Drscr. Simillima Nec. minori, sed dimidio minor, et absque lineolâ albâ ad apicem. Syst. Nat.

Obs. Specimen nostrum Nec. minorem magnitudine exæquat.

3. Nec. elytris subulatis nigris ba $\mathrm{i}$ flavis.

Tumeralis.

Fub. Syst. Ent. 209. 4. Sp. Ins. i. 263. 5. Mant. i. 170.7. Ent. Syst.i.b.352. 12. Panz. Ent. Germ. 277.11. Vill. i.283. I4. Gnel.1880. 18. Faun. Etrusc. 434. Hellw. 434. Mart. Eng. Ent. t. 23.f. 7. Don. Brit. Ins. t. $35^{8 .}$ f. $\mathrm{I}$.

Necydalis muralis. Forst. Cent. 48.

Cantharis humeralis. Oliv. iii. 46. 19.22. t. 2. f. 22.

La Cantharide à bande jaune. Geoff: i. 342. 2.

Long. corp. 6 lin.

Habitat

DEscr. Corpus nigrum. Elytra subulata, nigra, basi flavescentia, absque lineis aut margine elevatis. Pedes simplices nigri. Syst. Ent.

** Elytris subulatis longitudine abdominis.

4. Nec. cærulea, femoribus posticis clavatis ar-cerulea. cuatis.

Linn.Syst. Nat.642.4. Vill. i.279.4. Gmel.1879.4. Fab. Syst. Ent. 209. 6. Sp.Ins. i. 264. 7. Mant. i. 170. 2. Ent. Syst. i. b. 354. 19. Panz. Ent. Germ. 279. 21. Faun. Etrusc. 433. Hellw. 433.

Mart. Eng. Ent. t. 23.f.6. Scbeff. Icon. t. 94.f.7. Telephorus cæruleus. De Geer, iv. 76.8.

Cantharis nobilis. Scop. I 46 .

La Cantharide verte à grosses cuisses. Geoff. i. 342. 3 . 
Ædemera cærulea. Oliv. iii. 50. 13. 16.t. 2.f. x6. a.b. Long. corp. $5 \mathrm{lin}$.

\section{Habitat}

Descr. Tota cærulea, nitidissima. Femora tantùm postica incrassata, magna, curva. Tibiæ plantáque omnes nigræ. Syst. Nat

Obs. Color apud nos cæruleo-viridis, sive anreo-virid:s, potiùs quam cæruleus. Elytra lineis duabus elevalıs.

ceramboi- 5. Nec. cæruleo viridis, femoribus simplicibus. des.

Forst. Cent. 47.

Mart. Eng. Ent.t.23. f. 5 .

La Cantharide verte à grosses cuisses, var. N. B. Geoff: i. 342. 3.

Long. corp. $4 \frac{x}{2}$ lin.

Habitat in foribus umbellatis.

Descr. Præcedenti simillima, ut ovum ovo, sed femora postica non clavata, aut arcuata. An species distincta? An sexûs differentia?

lurida. 6. Nec. caruleo-lurida, femoribus posticis simplicibus.

Long. corp. $3 \frac{x}{2}$ lin.

Habitat - Capta prope Dubrem. D. Lvon.

Descr. Maximè affinis Nec. carulece et ceramboidi, sed differt a priori femoribus simplicibus, nec clavatis, et a posteriori magnitudine quæ minor est, et colore, qui obscurus, et cæruleo-luridus, nec nitens viridisque. Fatendum autem est, quod mas aurato-viridis, sed nitore quo Nec. ceramboides gaudet omninò caret.

Podagra- 7. Nec. flava, oculis thoracisque lateribus nirie. gris, elytris fusco-testaceis, femoribus posticis globosis.

Linn. Syst. Nat. 642. 9. Vill. i. 28r. 8. Gmel. उ880.9. Fab. Ent. Syst. i. b.354. 20. Panz. Ent. Germ.279.22. 

【A APIPIRIS.
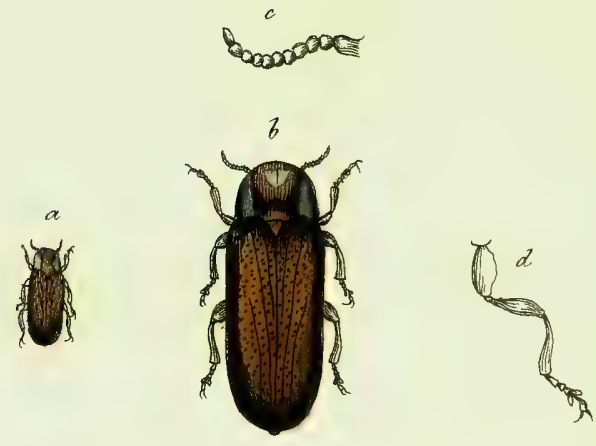

L. Noctitura. 
Payk. Fuun, Suec. iii. 134. 4. Faun. Etrusc. 432. Hellw. 432.

Lony. corp. 7 lin.

Habitat

Descr. Antennæ flavescentes. Caput flavum, maculá nigrâ inter nculos. Thorax flavus, marginibus nigris, lineisque tribus abbreviatis, elevatis; quarum media longior, a basi thoracis tendit, dure laterales breviores, ad apicem sitæ. Llytra fusca, lineis duabus elevatis ut in Nec. cceruled. Pedes flavi, apice tibiarum nigro, femoribus posticis globosis. Abdomen subtùs fuscum (exceptis tribus ultimis segmentis flavis) et elytris brevius.

8. Nec. Alava, oculis thoracisque lateribus nigris, simplex. e'y'ris fusco-testaceis, femoribus simplicibus.

Linn. Syst. Nat.643. 10. Vill.i.281.9. Gmel. 881. 10. Fab. Sp. Ins. i 264. 9. Mant. i. I7 I. I4. Ent. Syst. i. b. 355. 25. Panz. Ent. Germ. 280. 26.

Don. Brit. Ins. $t .358 . f .2$.

Necydalis flavescens? Payk. Faun. Suec. iii. 135. 5.

Long. corp.

Habitat

Descr. Staturâ, habitu et colore simillima Nec. Podagrarice, sed femoribus posticis simplicibus differt. An sexûs differentia? An species distincta?

\section{I. LAMPYRIS.}

Antenne filiformes.

Thorax planus, semiorbiculatus, caput subtùs occultans, cingensque.

Elytra flexilia.

Abdomen lateribus plicato-papillosis.

Famina aptera plerisque.

x. Lam. oblonga fusca, clypeo cinereo. Linn, noctiluca. 
Linn. Syst. Nat. 643. т. Vill. i. 284. 7. Gmel. 1882. 1. Fab. Syst. Ent. 200. I. Sp. Ins. i. 251. I. Mant.i. 161. 1. Ent. Syst. i. b. 98. 1. Ent. Germ. 209. I. Lecb. Nov. Spec. 23. 47. Payk. Faun. Suec. ii. I70. I. Rai. 78. 15. mas. 79. fem.

Oliv. ii. 28. 12. 2. t. I. f. 2. De Geer, i. 31. I. $t$. I. f. 19.20. Panz. Faun. Germ. 4I. t. 7 .

Cantharis noctiluca. Faun. Suec. 699. Poda, 39. I. Pontop. i. 674. I.

Long. corp. maris 6 lin. fœm. 8 lin.

Habitat in graminosis æstate.

DEscr. Fœmina elytris et alis caret; constat incisuris undecim; quarum prima est thoracis clypeus incumbens, planus, marginatus, semiovatus, ponè truncatus, sub quo caput minimum. Larva et pupa et insectum perfectum sinilia; sed larva puncto albo ad latus cujusvis segmenti, quibus caret perfecta. In omni statu puncta duo lucentia sub caudâ ; quamdiu vivit, nocte lucet; mortua lumen amittit. In cespite gramineo viridi et succulento diutiùs viva servari potest. Faun. Suec.

Antennæ fuscæ. Caput et thorax maris ut in fœminâ. Elytra depressa, abdomine longiora, fusca, oculo armato punctis confluentibus subrugosa, lineis tribus longitudinalibus, obsoletè elevatis, pube brevissima adspersa. Corpus subtùs dilutè fuscescens. Pedes breves lividi.

splendidula. 2. Lam. oblongiuscula fusca, clypeo supra oculos fenestrato.

Linn. Syst. Nat.644.3. Vill. i.285.3. Gmel.1882.3. Fab. Syst. Ent. 200. 2. Sp. Ins. i. 251.2. Mant. 1. 161. 2. Ent. Syst. i. b. 98. 2. Panz. Ent. Germ. 209. 2. Rai. 58. 15. Harr. I38. Payk. Faun. Suec. ii. I 7 I. 2.

De Geer, iv.31. I. t. I.f. 19-2I. Panz. Faun. Germ. 4I. t. 8. Scbaff: Elem. t. 74.f. I. 2. Oliv. ii. 28. I I. I. $t$. I. $f$. I. $\mathrm{a}-\mathrm{d}$.

Cantharis nnctiluca. Scop. I18. 
Le Ver luisant à femelle sans ailes. Gerff. i. 166. I. $t .2$. $f \cdot 7$.

Long. corp. 6 lin.

Habitat

Descr. Similis Lam. noctiluce, sed thoracis clypeus suprà utrunıque oculum hyalinus, et pellucidus, quo facilè distinguitur. Pedes lurido-ferruginei. Abdominis segmenta duo postrema lucentia. Syst. Nat.

3. Lam. atra, antennarum apicibus elytrisque san-pusilla. guineis.

Gmel. 1886. 32 .

Lampyris nigro-rubra. De Geer, iv. 46.3 .

Pyrochroa minuta. Fab. Mant.i. 163.6.

Lycus minutus. Fab. Ent. Syst. i.b. 108. 13. Panz. Ent. Germ. 2I I. 3 .

Oliv. ii. 29. 11. 13.t. 1. f. 13. Panz. Faun. Germ. 41. t. 11 .

Long. corp. $2 \frac{1}{2}$ lin.

Habitat -

DEscr. Antennæ nigræ, apicibus sanguineis, sive rufo-flavis. Totum corpus pedesque atra. Thorax valdè rugosus. Elytra sanguinea, striis longitudinalibus sex elevatis. Inter strias venæ reticulatæ, elegantissimæ.

\section{PYROCHROA.}

Antenne filiformes, dentato-pectinatæ.

Caput exsertum.

Thorax planus, orbiculatus, immarginatus. Elytra flexilia.

Corpus oblongum, posticè incrassatum.

7. Pyr. aterrima, capite thorace elytrisque san- rubens. guineis immaculatis. 
Fab. Ent. Syst. i. b. 105.2. Gmel. 1886. 35. Panz. Ent. Germ. 210. 2.

Pyrochroa satrapa. Scbrank, 324. Vill. i. 289.2.

Pyrochroa coccinea. Don. Brit. Ins. t. $56 . f$. 1 .

La Cardinale. Geoff. i. $33^{8}$. I. t. 6.f. 4 .

Long. corp. 6 lin.

Habitat

Descr. Antennæ dentato-pectinatæ, dentibus longis, crassis. Caput suprà infràque rubrum. Thorax, scutellum et elytra lævia, sanguinea. Corpus subtús aterrimum est.

coccinea. 2. Pyr. aterrima, thorace elytrisque sanguineis immaculatis.

Fab. Syst. Ent. 202. 1. Sp. Ins. i. 254. r. Mant. i. 163. I. Ent. Syst.i. b. Io4. I. Payk. Faun. Suec. ii. I72. I. Gmel. I886. 18. Panz. Ent. Germ. 210.1. Panz. Faun. Germ. $\mathbf{J}_{3 .}$. II.

Pyrochroa rubra. De Geer, v. 20. I. t. I. $f$. I4.

Long. corp. 7 lin.

Habitat

DEscr. Magnitudo, statura et habitus omninò præcedentis; at caput et scutellum aterrima alienum esse vehementiùs suadent.

\section{CANTHARIS.}

Antenne filiformes.

Thorax marginatus, capite brevior. Elytra flexilia.

Corpus oblongum.

Abdomen lateribus plicato-papillosis.

* Capite declinato, tborace depresso.

** Capite declinato, thorace teretiusculo.

** Capite prominente, posticè attenuato, tborace subrotundo. 


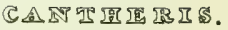
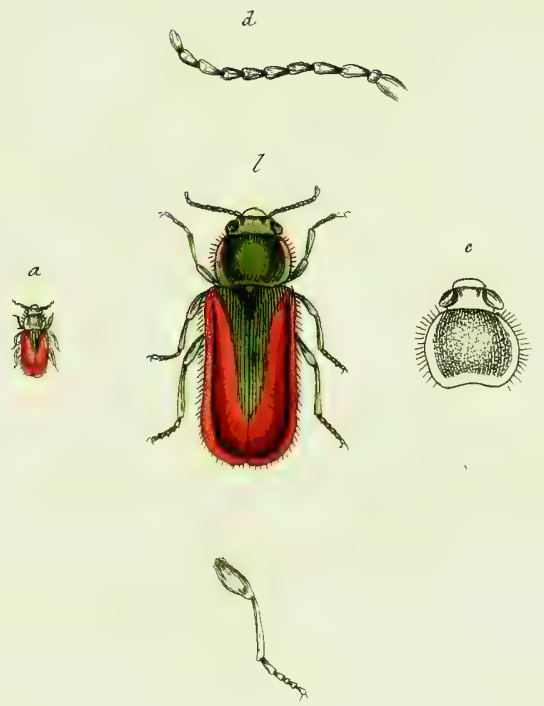

E. anea. 

* Capite declinato, tborace depresso.

I. Can. thorace rubro: maculâ nigrâ, elytris fusca. fuscis.

Linn. Syst. Nat. 647. 2. Faun. Suec. 700. Vill. i. 289. I. Gmel. 1890. 2. Fab. Syst. Ent. 205. I. Sp.Ins. i. 257. I. Mant. i. 167. 1. Ent. Syst, i.a. 213. I. Faun. Ingr. 109. Payk. Faun. Suec. i. 258. I. Panz. Ent. Germ. 88. I. Scbrank, 325. Scop. I20. Preys. Bob. Ins.59.61. Faun. Fred. 15. I44. Poda, 40. 2. Rai. 84. 29. et IOI. 2. Goez. i. 328. 2 . Faun. Eirusc. 414. Hellav. 4I4. Illiger. Kugel. Kaf. Preus. 295. 2.

Mart. Eng. Ent.t. 29. f. I3. 14 .

Telephorus fuscus. De Geer, iv. 6o. I. t. 2. f. I2. Oliv. ii. 26. 6. I. t. r. f. r. a. b. c. Scbeff. Elem. t. 123. f. I. Scbaff. Icon. t. I6. $f$. 10. II.

Donacia nigra. Panz. Voet. ii, th. I26.3.t. $46 . f \cdot 3$.

La Cicindele noire à corcelet maculé. Geoff: i. I yo. I.

Long. corp. 5-6 lin.

Habitat ubique frequens æstate. Sævit sæpè in propriam speciem.

Descr. Caput nigrum, planiusculum, infra oculos rufescens. Os minimum, forcipatum, maxillis arcuatis, simplicibus, quibus frusta mordet. Palpi ad maxillas minimi. Antennæ communes, corpore dimidio breviores, filiformes, articulis undecim, fuscæ, sed capiti propiùs rufescentes. Thorax a tergo planus, cordatus, marginibus eminentibus, rufescens, exceptâ maculâ magnầ nigrâ, capite contiguâ. Elytra plana, oblongo-linearia, mollissima, flexilia, sericea, fusconigra. Alæ diaphano-fuscæ. Abdomen fuscum, excepto ultimo seu septimo articulo rubicundo, ut et marginibus lateralibus rubris. Hi margines laterales compressi, singulâ incisurâ plicatìm incumbente, mollissimi, apicibus incisurarum lateralium mamillaribus. Faun. Suec.

2. Can. thorace nigro-piceo: marginibus rubris, obscura. elytris nigris. 
Linn. Syst. Nat.648.5. Faun. Suec. 706. Vill. i. 291.4. Gmel. 1892. 5. Fab. Syst. Ent. 205. 3. Sp. Ins. i. 258.3. Mant. i. 167.4. Ent. Syst. i. a. 214. 6. Faun. Ingr. II3. Scop.121. Schrank, 335. Faun. Fred. 15. 147. Payk. Faun. Suec. i. 262.7. Panz. Ent. Germ. 89. 4. Faun. Etrusc. 416. Hellw. 416. Illiger. Kugel. Kaf. Preus. 295. I.

Act. Nidros. iii. 396 . 1.5. t. 6.f.5.

Telephorus obscurus. Harr. 124.

Scbaff. Icon.t.16.f.8. Oliv. ii.26.8.3.t.2.f.10.a-d. l.ong. corp. 3 lin.

\section{Habitat}

Descr. Os incarnatum. Antennæ pallidæ. Thorax incarnatus, disco atro. Elytra obscurè nigricantia. Abdominis segmenta margine flavescentia. Pedes et femora suprà nigra, subtùs ferruginea. Faun. Suec.

Similis Can. fusce, sed duplo minor; abdominis ultima segmenta subtùs non rubra,sed nigra, quamvis latera segmentorum rufa. Thorax non rufus maculâ mediâ fuscâ, sed niger solis marginibus lateralibus rubris. Syst. Nat.

ruficollis. 3. Can. atra, thorace abdomineque rufis.

Fab. Syst. Ent. 206. 7. Sp. Ins. i. 259. I1. Mant. i. 168. 13. Ent. Syst. i. a. 217. 17. Panz. Ent. Germ. 90. 11. Vill. i. 297. 25. Faun. Etrusc. 419. Hellw. 419. Gmel. 1894. 30 .

De Geer, iv. 72. 5. t. 2.f. 1. ? Mart. Eng. Ent.t.29: $f .1 \mathrm{x}$.

La petite Cicindele noire. Geoff. i. 172.3.

Long. corp. 3 lin.

Habitat

DEscr. Summa affinitas Can. fusce, at duplo minor. Caput cum antennis serratis atrum. Thorax marginatus, rufus, immaculatus. Elytra, alæ et pectus atra. Abdomen rufum, pedes nigri. Syst. Ent.

liviale. 4. Can. livido-testacea, elytris obscurioribus. Linn. Syst. Nat. 647.3. Faun. Suec.70r. Vill. i. 
250. 2. Gnel. 1892. 3. Fab. Syst. Ent. 205. 2. Sp. Ins. i. 258. 2. Mant. i. 167. 2. Ent. Syst. i. a. 213. 2. Ent. Germ. 89. 2. Scop. 122. Scbrank, 326. Poda, 40. 2. Goeze, i. 529. 3. Faun. Fred. 15. 145. Faun. Etrusc. 415. Hellw. 414. var. ${ }^{2}$ 415. Illiger. Kugel. Kaf. Preus. 296.3. Faun. Ingr. I 10.

Mart. Eng. Ent. t. 29.f.7. Panz. Faun. Germ. 57.t.3. Telephorus flavus. De Geer, iv. 7o. 2. Harr. 127.

Oliv. ii. 26. 7.2. t. 2. f. 8. Scbaff. Icon. t. 16. f. ${ }_{5}$ ? Donacia lutea. Panz. Voet. ii. th. I25. I. t. $46 . f .1$. La Cicindele à corcelet rouge. Geoff.i. 171. 2. var. a.

Long. corp. 6 lin.

Habitat passim.

DESCR. Magnitudo, figura et omnia omninò ut in Can. fuscâ, excepto solo colore elytrorum luteo-pallido, et thorace immaculato. Oculi nigri sunt. Faun. Suec.

5. Can. thorace flavo: maculâ nigrâ, corpore ni- testacea. gro, elytris pedibusque testaceis.

Linn. Syst. Nat.649. 15. Faun. Suec. 714. Vill.i. 295. 14. Gmel. 1893.15. Fab. Syst. Ent. 207. I1. Sp. Ins. i. 26, 19. Mant. i. 168. 23. Ent. Syst. i. a. 220. 33. Scop. 123. Faun. Fred. 15. 149. Act. Nidros. iv. 325. 20. Payk. Faun. Suec. i. 265. II. Panz. Ent. Germ. 92. 20. Illiger. Kugel. Kaf. Preus. 300. 8. Faun. Ingr. 118.

Mart. Eng. Ent. t. 29.f. 6.

Telephorus testaceus. De Geer, iv. 7I. 4.

Oliv. ii. 26. 12. I1. t. 3. f. 19. a. b.

La Cicindele noire à étuis jaunes. Geoff. i. 173.6. var. b.

Long. corp. $2 \frac{3}{4}$ lin.

Habitat in plantis. Linn.

DESCR. Antennæ pallidæ. Similis Can. livide, sed quadruplo minor. Faun. Suec.

Femora nigra. Tibiæ flavæ, Linn. Mss.

6. Can. 
pallida. 6. Can. nigra, elytris pedibu£que pallido-testaceis. Fab. Mant. i. 167. 12. Ent. Syst. i. a. 217. 16. Panz. Ent. Germ. 90. 10. Gmel. 1893. 29. Payk. Faun. Suec. i. 264. 10. Illiger. Kugel. Kaf. Preus. 301. 9. Faun. Ingr. 114.

Telephorus pallidus. Oliv. ii. 26. I4. I4. t. 2. $f$. 9. a. b. La Cicindele noire à etuis jaunes. Geoff. i. 173. 6. var. a.

Long. corp. $3 \frac{\text { Tin. }}{2}$.

Habitat in floribus Crategi Oxyacanthe, Maio. et Junio.

Descr. Affinis Can. testacece, a quâ differt thorace toto nigro. Antennarum basis flavicans. Corpus atrum, elongatum, teretiusculum. Elytra pallidè testacea, immaculata. Pedes pallido-testacei.

melamara. 7. Can. rufo-ferruginea, elytris testaceis apice nigris.

Linn. Syst. Nat.65r. 27. Faun. Suec.719. Vill. i. 300. 35. Gmel. 1897.27. Fab. Syst. Ent. 206. 9. Sp.Ins. i. 260. 16. Mant. i. 168. 19. Ent. Syst. i.a. 219. 26. Panz. Ent. Germ. 9I. I4. Payk. Faun. Suec. i. 263. 8. Faun. Fred. I6. I53. Pontop. i. 675. I4. Faun. Etrusc. 420. Hellw. 420. Faun. Ingr. II5.

Scbaff. Icon. t. 16.. f. I4.

Telephorus bimaculatus. De Geer, iv. 7 7 . 3 .

Telephorus melanurus. Oliv. ii. 26. 8. 4. t. $3 \cdot f \cdot 2 \mathbf{1}$.

Donacia lutea ano nigro. Panz. Voet. ii. th. 126.2. t. $46 . f .2$.

La Cicindele à étuis tachés de noir. Geoff. i. 173. 5.

Long. corp. 4 lin.

Habitat

Descr. Simillima Can. lividee, a quâ differt præcipué apicibus elytrorum nigris. Antennæ nigræ. Pedes lutei.

8. Can. 
8. Can. viridi ænea, clytris extrorsùm undique anea. rubris.

Linn. Syst. Nat. 648.7. Faun. Suec. 708 . Scop. 126. Schrank, 329. Vill. i. 292. 6. Gmel. 1897.7. Poda, 40.

Don. Brit. Ins. t. 96. f. 2. Mart. Eng. Ent. t. 29. f. 4. Malachius æneus. Fab. Syst. Ent. 207. I. Sp. Ins. i. 261. I. Mant.i. I69. I. Ent. Syst.i. a. 22т. I. Payk. Faun. Suec. i. 269. 1. Faun. Fred. 16. 154. Panz. Ent. Germ. 92. I. Faun. Etrusc. 423. Hellw. 423. Illiger. Kugel. Kaf. Preus. 302. 36. Faun. Ingr. 120. Oliv. ii. 27. 4. 2. t. 2. f. 6. a-d. Panz. Faun. Germ. I0. $t .2$.

Telephorus æneus. De Geer, iv. 73. 6. Harr.129.

Scbaeff. Icon. $t .18, f .12,13$.

Donacia Ranunculorum. Panz. Voet. ii, th. 129, 7 . t. $46 . f .7$.

La Cicindele bedeau. Geoff. i. I74. 7 .

Long. corp. $4 \frac{\mathrm{t}}{2}$ lin.

Habitat

DESCR. Caput, thorax, antennæ, abdominis annuli suprà et infrà, elytra versus basin et marginem interiorem viridi-ænea, at elytrorum pars postica versus apicem et etiam versus marginem exteriorem sive lateralem rubra, ita ut elytra maxima ex parte rubra sint, et a basi versus suturam longitudinalem viridi-ænea. Ad latera thoracis, ut et abdominis, utrinque vesicula coccinea bicorniș. Alæ fuscæ. Faun. Suec.

9. Can. æneo-viridis, fronte flavicante, elytrisbipustulata. apice rubris.

Linn. Syst. Nat. 648. 8. Faun. Suec. 709. Faun. Fred. 15. 148. Poda, 40. 5. Scop. 127. Scbrank, 330. Vill. i. 292. 7. Gmel. 1898. 8.

Mart. Eng. Ent. t. 29. $f$. I.

Malachius bipustulatus. Fab. Syst. Ent. 208. 2. Sp. Ins. i. 262. 2. Mant. i. 169. 2. Ent. Syst. i. a. 222. 2. Payk. Faun. Suec. 1. 270. 2. Panz. Ent. yoL. I. 
Germ. 92. 2. Faun. Etrusc. 424. Hellw. 424. Illiger. Kugel. Kaf. Preus.303. 2. Faun. Ingr. 121. Panz. Faun. Germ. 10. t. 3. Oliv. ii. 27.5.3.t. I. f. r. a. b. c.

Telephorus bipustulatus. De Geer, iv. 75. 7. Harr. I30.

Scbaff. Icon. $t$. I8. $f$. Io.

Donacia Asparagorum. Panz. Voet. ii. th. I28. 6. $t .46$. f. 6 .

La Cicindele verte à points rouges. Geoff. i. I75. 8 .

Long. corp. 3 lin.

Habitat frequens in graminibus, præsertim in Caricibus. Larva rapax vorat minima insecta. Linn.

DEscr. Præcedenti, cui facie simillima est, omninò minor. Ad latera thoracis et abdominis etiam utrinque gerit vesiculam coccineam tricuspidatam. Alæ nigro-fuscæ. Antennæ nigræ. Caput, thorax et elytra æneo saturatè viridia, extimis apicibus elytrorum rubris, seu coccineis. Abdomen elytris longius, subtùs æneum, sub alis rubrum.

Variat elytrorum colore cæruleo, vel magìs viridi. Faun. Suec.

sanguino- ro. Can. nigro-ænea, thoracis margine elytrisque lenta. sanguineis, antennis serratis.

Malachius sanguinolentus. Fab. Mant. i. I69. 4. Ent. Syst. i. a. 223. 6. Panz. Ent. Germ. 93.3. Faun. Etrusc. 425. Hellw. 425. Illiger. Kugel. Kaf. Preus. 304. 3. Gmel. 1898.58.

Oliv. ii. $27 \cdot 7 \cdot 7 \cdot t \cdot 3 \cdot f \cdot \mathbf{I}_{3}$.

Long. corp. $2 \frac{\pi}{2}$ lin.

Habitat in spiculis Festuce fuitantis.

DEscr. Antennæ serratæ. Caput, thoracis discus, scutellum et pedes concolores, atro-virescentes. Elytra et margo thoracis amœnissimè sanguinea. Tibiæ postic arcuatæ. Pectus et abdomen subtù nitida. Abdomen subtùs atrum, marginibus segmentorum rubicundis. 
rubicundis. Elytra ne minimè quidem striata, ceram rubram sigillatoriam omninò referunt.

I I. Can. thorace virescente, elytris nigris : fasciis fasciata. duabus rubris.

Linn. Syst. Nat.648. 10. Faun. Suec.711. Vill.i. 292. 9. Gmel. I899. 10. Scop. 129.

Mart. Eng. Ent. t. 29. f. 8.

Malachius fasciatus. Fab. Syst. Ent. 208. 4. Sp. Ins. i. 262. 5. Mant. i. 169. 8. Ent. Syst. i. a. 224. I3. Panz. Ent. Germ. 93.9. Payk. Faun. Suec. i. 273. 6. Illiger. Kugel. Kaf. Preus. 304. 4. Faun. Ingr. I23. Panz. Faun. Germ. I0. t. 5. Oliv. ii. 27. 10. 12. t. I. $f$. 2. a. b.

Telephorus fasciatus. De Geer, iv. 76. 9. Harr. 131. Scbaff. Icon. t. I89. $f \cdot 3 \cdot$ a. b.

La Cicindele à bandes rouges. Geoff. i. 177. 12 .

Long. corp. $\mathrm{I} \frac{1}{2}$ lin.

\section{Habitat}

Descr. Antennæ et pedes nigri. Caput et thorax virescentia. Elytra atra, fasciâ duplici rubrâ transversâ, alterâ paulò supra basin, in medio ad suturam interruptâ; alterâ in ipsis apicibus elytrorum, vel paulò intra apices in quibusdam; hæc in medio contigua. Abdominis latera rubra. Faun. Suec.

I2. Can. nigra, thorace ely trorumque apicibus rubricollis. rufis.

Cantharis hæmorrhoidalis. Gmel. г898.86.

Malachius ruficollis. Fab. Ent. Syst. i. a. 223. 7.

Oliv. ii. 27.9. 10.t.2. $f \cdot 9 \cdot$

Long. corp. $1 \frac{7}{3}$ lin.

Habitat Capta in spicis Hordei murini prope Ealing. D. Hill.

Descr. Antennæ nigræ, basi subtùs rufæ. Caput nigrum. Thorax omuinò rufus. Elytra ex cæruleo nigra, apicibus rufis. Pectus et pedes nigra, Abdomen subtùs ferè omninò rufum. 
* Capite declinato, tborace teretiusculo.

viridissima. 1 3. Can. tota viridis.

Linn. Syst. Nat. 650. 23. Faun. Suec.717. Vill. i. 298. I. Faun. Fred. I5. I5I.

Cantharis viridis. De Geer, v. I5.3.t. I. f. I3.

Necydalis viridissima. Fab. Syst. Ent. 208. I.

Ins. i. 263. 1. Mant. i. 170. 1. Ent. Syst. i. b. 350. 2. Panz. Ent. Germ. 276. 2. Payk. Faun. Suec. iii. 133.3. Faun. Etrusc. 427. Hellw. 427. Gmel. 1879. I3.

Ædemera viridissima. Oliv. iii. 50. I3. I5. t. 2, $f$. I5. a-c.

La Cicindele verdâtre. Geoff. i. I77. I4.

Long. corp. 4 lin.

Habitat

DESCR. Antennæ filiformes, nigricantes, corpore paulò breviores. Thorax non marginatus, sed teres Lepturce. Corpus viridi-sericeum, nitens, solo capite viridi-aureo. Faun. Suec.

acuta. I4. Can. lutea, elytris acutis apice nigris.

Long. corp. 4 lin.

Habitat

DESCR. Maximè affinis Can. melanurce, sed abundè differt, antennis omninò luteis, nec nigris; femoribus nigris, nec luteis; thorace teretiusculo, nec depresso; elytris apice acutis, nec obtusissimis.

* Capite prominente, postice attenuato, thorace subrotundo.

biguttata. 15. Can. thorace marginato: medio atro, elytris abbreviatis nigris apice flavis.

Linn. Syst. Nat. 648. I1. Faun. Suec. 712. Vill. i. 294. Io. Gmel. 1892. II. Schrank, 332. Fab. Syst. Ent. 207. 12. Sp. Ins. i. 261. 20. Mant. i. 168. 24. Ent.Syst. i. 2.221.34. Panz. Ent. Germ. 
92.21. Faun. Etrusc. 421. Hellw. 421. Faun. Ingr. II 9 .

Mart. Eng. Ent.t.29.f.5. Panz. Faun. Germ. II. t. 15 :

Telephorus biguttatus. Oliv. ii. 26. 16. 18. t. 2. f. 12.

$\mathrm{La}$ Cicindele noire à points jaunes et corcelet noir. Geoff. i. I76. Ir.

Long. corp. 2 lin.

Habitat

DESCr. Caput et thorax omininò atra. Elytra apicibus summis flava, seu sulphurea. Abdominis latera flava. Faun. Suec.

Obs. Pedes fusci:

16. Can. thorace marginato rufo: maculâ nigrâ, minima. corpore fusco, elytris apice flavis.

Linn. Syst. Nat. 649. 12. Faun. Suec.713. Vill. i. 292. I1. Gmel. 1892. 12. Fab. Syst. Ent. 207. ro. Sp. Ins. i. 260. I8. Mant. i. I68. 22. Ent. Syst. i. a. 220. 32. Panz. Ent. Germ.91. 19. Payk. Faun. Suec. i. 268. 15 - B. Faun. Etrusc. 422. Hellw. 422.

Telephorus minimus, Oliv. ii. 26. I7. I9. t. I. f.6.a-d.

Long. corp. 2 lin.

\section{Habitat -}

DEscr. Caput nigrum, maxillis flavis. Thorax flavus, marginatus. Elytra nigricantia, in medio fusca, apice puncto flavo terminata. Alæ nigræ, elytris duplo longiores, cruciatim incumbentes. Antennæ corpore breviores, filiformes, nigricantes, versus basin tlavescentes. Femora nigra, tibiis flavis. Abdomen fuscum, lateribus flavis. Faun. Suec.

17. Can. nigro-ænea, fronte flavâ, pedibus an-frontalis. tennarumque basi sordidè testaceis.

Long. corp. I $\frac{x}{2}$ lin.

Habitat in sepibus, Aug.

Descr. Caput nigro-æneum, sive nigrum. Oculi 2 B 3 valdè 
valdè prominuli. Quasi media est, inter Can. biguttatam el minimam, alterutram diceres nisi elytra puncto essent immunia. Thorax vix ac ne vix quidem marginatus, unicolor.

melano- 18. Can. thorace flavo: puncto atro, elytris nicepbala. gris apice flavis.

Long. corp. $\mathbf{1} \frac{3}{4}$ lin.

\section{Habitat}

Descr. In omnibus simillima Can. minime præterquam capite, quod atrum et nitidum est, nec fronte flavâ.

bumeralis. 19. Can. thorace flavo medio atro, elytris fuscis : fasciâ apiceque flavis.

Long. corp. 2 lin.

Habitat

DESCR. Antennæ flavæ. Caput flavum, posticè nigrum. Thorax medio niger, lateribus flavis. Elytra fusca, fasciâ latâ ad basin apiceque flavis. Abdomen nigrum. Pedes flavi.

immunis. 20. Can. thorace flavo immaculato, elytris fuscis apice flavis, antennis longitudine corporis.

Long. corp. 2 lin.

Habitat

DEscr. Simillima præcedentibus, at differt thorace flavo, immaculato, et antennis extrorsùm nigricantibus, longitudine corporis. Occiput atrum, nitidum. Abdomen et pedes flavi.

serraticornis.

2r. Can. atra subvillosa, elytris testaceis, antennis pectinatis.

Drilus flavescens. Oliv. ii. 23. 4. 1. t. r. $f$. 1. a-e.

Ptilinus flavescens. Fab. Ent. Syst. i. a. 243.3.

Hispa? flavescens. Faun. Etrusc. 127. Hellw. I27. 



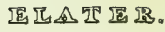

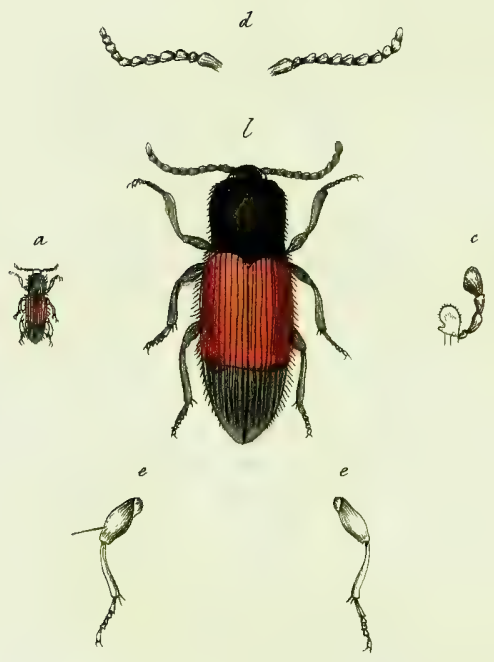

G. batteatrs. 
Long. corp. 3 lin.

Habitat in floribus. In mus. D. Lewin.

Descr. Antennæ nigræ, hinc serrato-pectinatæ. Caput et thorax atra, nitida, tomentosa. Elytra testacea, sive lutescentia. Abdomen nigrum. Pedes nigri, tibiis plantisque piceis.

22. Can. niger, thorace flavo, elytris fusco-testa-favicollis. ceis apice nigris.

Long. corp. 3 lin.

Habitat

In mus. D. Kirby.

DESCr. Antennæ fuscæ, basi rufæ. Caput nigrum. Thorax et sternum flava. Scutellum nigrum. Elytra fusco-testacea, margine exteriori ad basin apiceque nigris. Abdomen nigrum. Pedes testacei.

\section{ELATER.}

Antenne filiformes, plerisque serratæ.

Cahut parvum, insertum.

Thorax oblongus, convexiusculus, anticè attenuatus, posticè angulo utrinque prominulo.

Corpus elongatum, dorso impositum exsiliens, mucrone pectoris e foramine abdominis resiliente.

I. El. niger nitidus, clytris utrisque puncto baseos bipustularubro. tus.

Linn. Syst. Nat.652.9. Vill. i. 302. 1. Gmel. I904.9. Fab. Syst. Ent. 21 5. 36. Sp. Ins. i. 273 47. Mant. i. 175. 59. Ent. Syst. i. b. 235. 88. Panz. Ent. Germ. 243. 57. Harr. I 20. Payk. Faun. Suec. iii. 30. 34. Faun. Etrusc. 455. Hellw. 455 .

Oliv. 
Oliv. ii. 3 I. 49.69. t. 2. f. 13. a. b. Schaff. Icon. t. 104. f. 6. a. b. Fues. Arch. 147 . I r. t. 27. f. 8. Elater punctatus. Panz. Voet. ii. I1 8. 22.t. 44. $f .22$. Le Taupin noir à taches rouges. Geoff. i. 136. I5.

Long. corp. 4 lin.

\section{Habitat}

Descr. Caput, antennæ, thorax, elytra, abdomenque atra, nịtida. Thorax glaber. Elvtra striata, ad basin puncto sanguineo. Pedes picei. Linn. Syst. Nat.

raficollis.

2. El. thorace rubro vitido anticè nigro, elytris corporeque nigris.

Linn. Syst. Nat. 653. I4. Faun. Suec. 724. Scbrank, 351. Vill. i. 304. 5. Gmel 1905. 14. Fab. Syst. Ent. 214.27. Sp. Ins. i. 270.33. Mant. i. I73.37. Ent. Syst. i. b. 227.52. Panz. Ent Germ. 240.30. Payk. Faun. Suec, iii.38.43. Faun. Etrusc. 445. Hellw. 445. De Geer, iv. 153. 16.

Mart. Eng. Ent. t. 30. f.3. Uliv. ii. 31. 44. 60.t.6. f. 6r. a. b.

Long. corp. $3 \frac{1}{2}$ lin.

\section{Habitat}

Descr. Totus ater, sed elytra, quæ etiam striata, parùm ad cæruleum vergunt colorem. Thorax maximâ ex parte ruber, sed anticè niger, in medio tamen magis; posticè lævissimo margine elytra spectante etiam niger, hinc thorax quasi fasciâ transversali latâ, rubrâ, lunulatâ, cavitate lunulæ caput spectante. Antennæ nigræ, non pectinatæ, sed articulis parùm anticè gibbis. Faun. Suec.

thoracicus. 3. El. niger, thorace toto rufo.

Fab. Syst. Ent. 214. 76. Sp. Ins. i. 270. 32. Mant. i. 173. 36. Ent. Syst. i. b. 227. 51. Panz. Ent. Germ. 239. 28. Harr. 109. Gmel. 1905. 47.

Mart. Eng. Ent. t. 3r.f. 12. Oliv. ii. 3r. 44. 59.t. 3. f. 24. Panz. Faun. Germ. 6. t. 12. Schaff. Icon. t. $3 \mathrm{I} \cdot f \cdot 3$.

Le Taupin noir à corcelet rouge. Geoff. i. 132. 5 .

Erythrotus 
Erythrotus niger nitens. Panz. Voet. ii. Iog. 6. t. 42. $f .6$.

Long. corp. 5 lin.

Habitat

Descr. Nimis affinis videtur El. ruficolli, at paulo major. Caput atrum, antennis nigris, serratis. Thorax pubescens, totus rufus, nec uti in ruficolli posticè niger, solâ lineâ intermediâ pectoris nigrâ. Elytra subpubescentia, striata, atra. Pedes nigri, plantis piceis. An mera varietas El. ruficollis? Fab. Syst. Ent.

Nobis planè species distincta esse videtur.

4. El. thorace fusco obscuro, elytris æneo-testa-obscurus. ceis striatis.

Linn. Syst. Nat. 655.25. Faun. Suec. 735. Vill. i. 309. 16. Payk. Faun. Suec. iii. 2.2. Gmel. I908. 25. Faun. Fred.17. 165.

Mart. Eng. Ent. t. 30. f. I.

Long. corp. $4 \frac{1}{2}$ lin.

Habitat

Descr. Simillimus El.sputatori, sed latior, antennisque brevioribus. Syst. Nat.

Elytra striata sunt, et microscopii ope hirsutie cana. Pedes ferruginei magìs et minùs. Linn. Mss.

5. El. niger, elytris obscurè lividis fusco sub-li-lineatus. neatis.

Linn. Syst. Nat. 653. 15. Vill. i. 304. 6. Gmel. 1905 . 15.

Oliv. ii. 3 I. $46.63 \cdot t \cdot 3 \cdot f \cdot 3^{2}$.

Elater striatus. Fib. Syst. Ent. 215.32. Sp. Ins. i. 272.40. Mant. i. 174. 47. Ent. Syst. i. b. 23 1. 69. Payk. Faun. Suec. iii. 27. $3^{1}$.

Long. corp. $4 \frac{1}{2}$ lin.

Habitat Captus sub muscis latitans mense Januario.

DESCR. 
Descr. Corpus mediocre, fuscum. Antennæ subferrugineæ. Elytra obscurè livida, lineis duabus nigricantibus, versus suturam dorsalem positis. Syst. Nat.

An var. El. obscuri? similem vidi in copulâ cum fominâ El.obscuri. Linn. Mss.

mesomelus. 6. El. thorace margineque elytrorum ferrugineis, corpore elytrisque nigris.

Linn. Syst. Nat.653. I6. Faun. Suec. 725. Vill. i. 305.7. Gmel.1905. 16. Fab. Syst. Ent. 214.25.

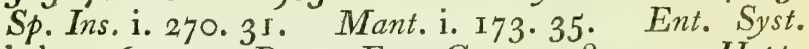
i. b. 226. 42. Panz. Ent. Germ. 238. I9. Hoppe Ins. Erl. 57. Faun. Ingr. 252 .

Oliv. ii. 3 I. 34. 44. t. 5. f. 54. Panz. Faun. Germ. 7. t. 6.

Elater dispar. Payk. Faun, Suec, iii. 37. 42.

Long. corp. 6 lin.

Habitat $\longrightarrow$ Captus in sylvâ Coombe-Wood dictâ, sub foliis virgultorum latitans.

DESCR. Corpus nigrum mediæ magnitudinis, angustius. Os ferrugineum. Thorax ferrugineus, lineâ longitudinali excavatâ. Elytra nigra, punctis excavatis striata, margine exteriore testacea, unde insolita facies. Scutellum nigrum, glaberrimum. Faun. Suec. Antecedenti paulo major. Pectus in medio nigrum. Anus flavus, Thorax rugis aliquot impressis. Syst. Nat.

bicolor. 7. El. niger, thorace rufo, elytris testaceis punctato-striatis.

Panz. Ent. Germ. 238. 21.

Panz. Faun. Germ. 8. t. II.

Long. corp. 6 lin.

Habitat - Captus in foliis virgultorum hornorum cum præcedenti.

Descr. Statura et magnitudo El. mesomeli, adeo ut forsan varietas ex sexu? Elytra parili more striatopunctata. Corpus subtùs nigrum, ano ferrugineo. 
Color pedum, thoracis et antennarum idem. Differt solummodò colore elytrorum testaceo, nec nigro, margine testaceo.

Variat thorace maculâ mediâ nigrâ.

8. El. totus rufo-testaceus, oculis nigris, thorace unicolor. elongato: lineâ intermediâ impressâ.

Long. corp. $4 \frac{1}{2}$ lin.

Habitat

Descr. Colore satis distinguitur. Oculi solùm nigri. Per cætera rufo-testaceus. Thorax paulò saturatior.

9. El. thorace sub-fusco, elytris testaceis margine marginatus. undique nigris.

Linn. Syst. Nat. 654.23. Faun. Suec. 733. Vill. i. 308. 14. Gmel. 1907.23. Scbrank, 352. Fab. Syst. Ent.213. 24. Sp. Ins. 1.270.30. Mant. i. 173.34. Ent. Syst. i. b. 227. 50. Panz. Ent. Germ.239.25. Harr. 108. Act. Nidros. iii. 397. 17. Payk. Faun. Suec. iii. 5. 6. Faun. Ingr. 255. Faun. Etrusc. 450. Hellw. $45^{\circ}$.

Scbaff. Icon. t. I94. f. I. Mart. Eng. Ent.t.31.f. 15. Oliv. ii. 3 I. 34. $43 \cdot t \cdot 3 \cdot f \cdot 29 \cdot t \cdot 8 \cdot f \cdot 29 \cdot \mathrm{b}$.

Long. corp. 5 lin.

\section{Habitat}

Descr. Corpus subtùs fuscum. Caput nigrum. Thorax fuscus, lateribus ferrugineis. Elytra pallidè testacea, margine omni nigro. Pedes pallidè testacei. Antennæ fusco-testaceæ. Faun. Suec.

I ○. El. totus ferrugineus, oculis nigris.

Long. corp. $3 \frac{1}{4}$ lin.

Habitat

DEscr. Totum corpus unicolor fulvum, sive ferrugineum. Oculi solummodó nigri. Elytra striata.

I I. El. niger, thorace nitidiusculo, elytris sordidè suturalis. testaceis : suturâ nigrâ. 
An Elater lineatus? $D e$ Geer, iv. 158.20.

Long. corp. 3 lin.

\section{Habitat}

Descr. Thorax niger; sed variat spinis posticis, et marginibus ferrugineis. Pedes et elytra ferruginea, sive sordidè testacea; sutura semper nigra.

naticlulus. I2. El. nitidus, thorace nigro, elytris testaceis striatis: margine apicem versus suturâque nigris.

Long. corp. 2 lin.

Habitat

Descr. Minutus, tomentosus, linearis. Abdomen nigrum. Antennæ et pedes testacei. Thorax valdè convexus.

lateratis. I3. El. thorace nigro-ferrugineo, elytris æneotestaceis: margine suturâque fuscescentibus.

Long. corp. 4 lin.

Habitat

DESCr. Sublinearis, affinis præcedenti, sed quadruplo major; minimè nitens, et thorax planiusculus, obscurus, nigro-ferrugineus, nec ater nitidus valdè convexus. Abdomen rufescens. Antennæ et pedes rufescentes, anteriores obscuriores.

Affinis maximè etiam El. lineato, sed differt, elytris punctato-striatis, nec striis impressis.

aterrimus. I4. El. ater, thorace opaco punctato, elytris striatis.

Linn. Syst. Nat.653. 17. Faun. Suec. 726. Vill. i. 305. 8. Scbrank, 344. Gmel.1905. 17. Fab. Syst. Ent.21 . 9. Sp. Ins. i. 267. 14. Mant. i. 172. 18. Ent. Syst. i. b. 221. 24. Panz. Ent. Germ. 235. 3. Payk. Faun. Suec. iii. 6.8. Faun. Ingr. 245. Faun. Etrusc. 435. Hellw. 435. Faun. Fred. I6. I60. Mart. Eng. Ent.t.3 I. f. I9. Oliv. ii. 31. 28. 33.t.5. $f \cdot 53$. 
Le Taupin en deuil. Geoff. i. 136. 13.

Long. corp. 6 lin.

Habitat

DESCR. Corpus totum carbonis instar aterrimum. Thorax scabriusculus. Elytra profundiùs striata, cavitatibus quasi crenulatis. Faun. Suec.

I5. El. ater, thorace punctato, elytris striatis, pe-castanipes. dibus castaneis.

Fab. Ent. Syst. i, b. 226. 46. Payk. Faun, Suec, iii. $23 \cdot 27$.

Elater fuscus major. De Geer, iv. 146.3.

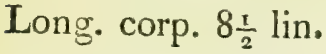

Habitat

Descr. Affinis El. aterrimo, sed pedes castanei, nec fusci. Porrò ferè dimidio major, et corpus undique cinereo-villosum.

16. El. ater obscurus, thorace rugoso, antennis rugosus. pedibusque rufis.

Long. corp. 8 lin.

Habitat

DESCR. Maximè affinis El. castanipedi, magnitudine et staturâ, sed differt thorace obscuro, ex punctis valdè confluentibus rugoso, nec nitidiusculo punctato. Pili thoracis si qui adsint adpressi. Elytra obsoletiùs striata.

I7. El. thorace nigro nitido, elytris nigris ob-minutus. scuris.

Linn. Syst. Nat.656.34. Faun. Suec. 744. Vill. i. 313.26. Gmel. 1907. 34. Fab. Syst. Ent. 215. 33 . Sp.Ins. i. 272. 4I. Mant. i. I74. 48. Ent. Syst. i. b. 231. 7 I. Panz. Ent. Germ. 242. 50. Payk. Faun. Suec, iii. 40. 46. Faun, Etrusc, 450. Faun. Ingr. 262. Hellw. 449.

Oliv. 
Oliv. ii. $3^{1 \cdot} 53 \cdot 76 . t \cdot 6 . f .62$, a-d.

Elater æneo-niger. De Geer, iv. I59.21.

Long. corp. 3 lin.

Habitat

Descr. Corpus totum nigrum. Thorax glaber. Elytra obscurè striata. Faun. Suec.

nigro-ceneus. I 8. El. linearis subtùs ater, suprà nigro-æneus, thorace nitido.

Long. corp. 3 lin.

Habitat

DESCR. Præcedentis staturâ et magnitudine, cui simillimus, sed paulò angustior, et suprà nigro-æneus. An satis distinctus?

fermaineus. I9. El. thorace elytrisque ferrugineis, corpore thoracisque margine postico nigris.

Linn. Syst. Nat. 654. 20. Faun. Suec. 729. Vill. i. 306. II. Gmel. I906. 20. Fab. Syst. Ent. 2II. 7. Sp. Ins. i. 266. I1. Mant. i. 172. 14. Ent. Syst. i.b. 220. 18. Panz. Ent. Germ. 235. 2. Harr. IOI. Payk. Faun. Suec. iii. 23. 26. Faun. Etrusc. 446. Hellw. 446.

Don. Brit. Ins.t.356.f. I. Panz. Faun. Germ. Io.t. 10. Mart. Eng. Ent. t. 31. f. 21. Oliv. ii. 31. 21. 22. t. 3. f. 35. Scbaff. Icon. t. 59. $f$. x.

Elater rufus. De Geer, iv. I 44. I. $t .5 \cdot f$. 18.

Le Taupin rouge. Geoff. i. 130. 1. $t .2 . f .4$.

Long. corp. ro lin.

\section{Habitat}

DEscr. Totus niger, exceptis thoraceetelytris ferrugineis. Thorax margine postico, vix manifesto, ater; dentesque thoracis postici obscuri sunt. Scutellum nigrum est. Antennæ serratæ, thorace paulò longiores. Faun. Suec.

sanguineus. 20. El. thorace atro, elytris striatis rubris, corpore nigro.

Linn. 
Linn. Syst. Nat.654.21. Faun. Succ.731. Vill. i. 307. I2. Gmel. 1906. 21. Scop. 287. Fab. Syst. Ent.214. 29. Sp.Ins. i. 271.36. Mant. i. 173.40. Ent. Syst. i. b. 228. 55. Panz. Ent. Germ. 240. 33. Harr. III. Faun. Fred. 16. 162. Poda, 4I. 2. De Geer, ivi I5I. I3. Payk. Faun. Suec. iii. 33. 37 . Faun. Ingr. 257. Faun. Etrusc. 443. Hellw. 443. Panæ. Faun. Germ. 5. t. I3. Scheeff. Elem. t.60. f. 2 . Icon. t. 31. f. 2. Oliv. ii. 31. 40. 53. t. 1. f. 7.t.5. f. 48. a. Mart. Eng. Ent. t. 40. f.6. Bergstraes. Nom. i. 10. 64. 10. t. 10. $f$. 10.

Elater melanocephalus ruber. Panz. Voet. ii. II7.2I. t. $44 \cdot f \cdot 2 \mathrm{I}$.

Le Taupin à étuis rouges. Geoff. i. ז3 2 . 2.

Long. corp. 6 lin.

Habitat

Drscr. Thorax glaber uti et caput nigra. Elytra rubra, striis tenuissimis, ex punctis per novem ordines in singulo elytro. Antennæ semipectinatæ. Os edentulum. Faun. Suec.

2I. El. ater, elytris striatis sanguineis: maculâ Epßippium. communi dorsali nigrâ.

Fab. Ent. Syst. i. b. 228.56. Panz. Ent. Germ.240.34. Panz. Faun. Germ. 5. t. I4. Oliv. ii. 31.4I. 54.t.5. $f \cdot 48$. b. Scbeeff. Icon. t. 3 I. $f \cdot 5$.

Elater sanguineus. Payk. Faun. Suec. iii. 33. 37. var. \% Fann. Etrusc. 443. Hellw. 443. var. $\beta$. 9 .

Elater sanguinolentus. Scbrank, 34I. Harr. II2. Gmel. I911.72.

Elater occidentalis parvus ruber, Panz. Voet. ii. III. II. t. 43 . $f$. II.

Long. corp. 5 lin.

Fabitat in Pinis putrescentibus. Fab.

DESCR. Statura et summa affnitas præcedentis. Differe tamen thorace pube nigrâ toto, coleoptrisque macula magnâ dorsali, communi, nigrâ; aliàs simillimus. 
balteatus. 22. El. thorace atro, elytris anticè dimidiato-rubris, corpore nigro.

Linn. Syst. Nat. 654. 22. Faun. Suec. 732. Vill. i. 307. 13. Gmel. 1906. 22. Fab. Syst. Ent. 215. 30. Sp. Ins. i. 271.37. Mant. i. 174.4I. Ent. Syst. i. b. 229. 59. Panz. Ent. Germ.24I. 38. De Geer, iv. I52. I4. Faun. Fred. 16.163. Harr. I13. Act. Nidros. iv. 326. 22. Payk. Faun. Suec. iii. 31. 5. Faun. Ingr. 259. Faun. Etrusc. 444. Hellw. 444. Oliv. ii. 31. 42. 56. t. 8. f. 77 . Scbceff. Icon. $t .77$. f. 2. Mart. Eng. Ent.t. 30. f. 5 .

Long. corp. 4 lin.

Habitat Captus prope Woodbridge. $D$. Latbbury.

DESCR. Corpus nigrum. Elytra punctato-striata, anticè dimidiato rubra, posticè nigra. Pedes picei.

supreus. 23. El. cupreus, elytris dimidiato-flavis, antennis maris pectinatis.

Fab. Syst. Ent. 212. I5. Sp. Ins. i. 268.20. Mant. i. I73. 24. Ent. Syst. i. b. 225. 37. Panz. Ent. Germ. 237. 15. Harr. 104. Vill. i.315.27. Gmel. I909. 59.

Oliv. ii. $3^{1} \cdot 3^{8 \cdot}$ 50.t.5.f. 50. Panz. Faun. Germ. 77.t.2. Mart. Eng. Ent. t. 31. f. 16. Schaff. Icon. $t \cdot 38 . f \cdot 2$. ?

Elater castaneus. Scop. 286. Scbrank, 337.

Long. corp. 7 lin.

Habitat

Descr. Statura omninò et magnitudo El.pectinicornis. Obscurè cupreus, seu rufo-æneus. Antennæ nigræ, pectinatæ. Elytra striata, basi testacea, apice cuprea. Syst. Ent.

sputator. 24. El. thorace fusco nitido, elytris testaceis, corpore nigro.

Linn. Syst. Nat.65t. 24. Faun, Suec, 734. Vill. i. 308. 
308. 15. Gmel. 1907.24. Scop. 285. Fab. Syst. Ent.215.31. Sp.Ins. i.272.39. Mant. i. 174.44. Ent. Syst. i. b. 230.62. Panz. Ent. Germ. 242. 43. Harr. II4. Poda, 41. 4. Faun. Fred. 17. 164. Payk. Faun. Suec. iii. 20. 23. Faun. Ingr. 260. Faun. Etrusc. 437. Hellw. 437.

Donov. Brit. Ins. t. 96. f. 4. Mart. Eng. Ent. t. $3 \mathbf{I}$. f. 20. Oliv. ii. 3 r. 30. $38 . t \cdot 3 \cdot f \cdot 3^{1}$.

Elater fuscus flavipes. De Geer, iv. I5I. II .

Long. corp. $6 \mathrm{lin}$.

Habitat

DESCR. Totus niger, sed elytra fusca, seu cinerascentia. Pedes rufi, adhuc antennæ magis rufæ. Faun. Suec.

25. El. totus castaneus, elytris striatis. elongatus. Long. corp. $5^{\frac{1}{2}}$ lin.

Habitat -

DEscr. Corpus elongatum, totum castaneum, sive fusco-ferrugineum. Thorax anticè latior, convexus, punctulatus, posticè excavatus, lineis tribus impressis. Elytra striata.

26. El. thorace obscurè cinereo, elytris cinereo-murinus. rebulosis, plantis rufis.

Linn. Syst. Nat. 655.28. Faun. Suec. 738. Vill. i. 310. I9. Gmel. 1908. 28. Fab. Syst. Ent. 211.10. Sp. Ins. i. 267. 15. Mant. i. 172. 19, Ent. Syst. i. b. 221.26. Panz. Ent.Germ.235.6. Harr. 102. Payk. Faun. Suec. iii. 34. 38. Scbrank, 346. Faun. Ingr. 247.

Mart. Eng. Ent. 31.t. 17. Scbaff. Icon. t. 4. f. 6. t. $45 \cdot f \cdot 5$. Oliv. ii. 31. 25.29. t. 2. f. 9 .

Elater rufipes. De Geer, iv. I50. IO.

Le Taupin gris de souris. Geoff. i. I34. 8.

Long. corp. 6-8 lin.

Habitat

VOL. $x$. 
Descr. Corpus medium, sive majusculum, nigrocinereum; solæ antennæ et pedum plantæ ferrugineæ. Faun. Suec.

- tessellatus. 27. El. thorace elytrisque cupreo-æneis, pedibus concoloribus.

Linn. Syst. Nat.655.29. Faun. Suec. 739. Vill. i. 310. 20. Gmel. 1908. 29. Fab. Syst. Ent. 211. II. Sp. Ins. i. 267. I6. Mant. i. I73.20. Ent. Syst. i. b. 222. 28. Panz. Ent. Germ. 236. 8. Faun. Fred. 17. 166. Harr. 103. Payk. Faun. Suec. iii. 7.9. Faun. Ingr. 248. Faun. Etrusc. 442. Hellw. 442 .

Oliv. ii. 31. 26. 30, t. 3. f. 22. Scbceff. Icon. t. 4 . $f .7$.

Elater rufo-unguiculatus, $D e$ Geer, iv. 148. 7 .

Elater variegatus major. Panz. Voet. t. $44 \cdot f \cdot 26$.

Le Taupin à plaques velues. Geof. i. I35. 9 .

Long. corp. 8 lin.

Habitat

Descr. Totum corpus unicolor, cupreo-æneum. Ungues pedum solummodò rufi. Totum corpus sed præcipuè elytra pilis brevissimis pallidis obvestiuntur, et nonnunquam obsoletiùs tessellata esse videntur.

Obs. Variat magnitudine 6-8 lineas, an ex sexu? an ex patriâ? Dom. Suederus scilicet ex Sueciâ 6-linearem misit, at noster 8 -linearis est.

bolosericens. 28. El. niger villosus, thorace elytrisque albido tessellatis.

Fab. Ent. Syst.i. b. 222. 27. Payk. Faun. Suec, iii.

oliv. ii. 3i. 27. 3 т. t. 3. f. 33. et t. 7. f. 69 .

Elater variegatus minor. Panz. Voet. I1. I I 9. t. 44. f.27.

Long. corp. 5 lin.

Habitat Captus in Spartio Scopario, CoombeWood.

DESCR. 
DESCR. Hoc animal tum apud nostrates, tum apud exteros, diu pro El. tessellato habitum est. Sed minus : tum differt colore nigro, obscuro, nec brunneo-æneo, nitidiusculo. Totum corpus suprà villis albidis obsitum: quin hic illic, sive naturæ arbitrio, feu cası quodam, pili deficiunt, unde tessellatus videtur. Elytra obsoletè striata. Tibiæ tarsique obscurè rufescentes. Affinis etiam El. murino, a quo differt thorace integro, nec tuberculis duobus muticis armato, tum elytris posticè subrufescentibus.

29. El. atro-cæruleus nitidus, thorace lineâ dorsali impressus. punctisque duobus impressis, pedibus piceis.

Fab. Ent. Syst. i. b. 223. 32. Payk. Faun. Succ. iii. I8. $2 \mathrm{I}$.

Long. corp. 9 lin.

Habitat

DESCR. Totum corpus, pedibus piceis exceptis, amœne nitet. Thorax lineâ dorsali posticè punctoque utrinque impressis, oculo armato punctulis numerosissimis sparsus. Elytra IQ-striata. In fundo striarum puncta impressa, et per totam superficiem punctula minima numerosissima sub lente conspicienda sunt.

Variat paulùm magnitudine pro sexu? Variat etiam colore sub-æneo, æneo-viridi, æneo-cæruleo, æneoviolaceo. Pedes semper picei ; nonnunquam etiam sternum piceum est, sed non semper.

30. El. nigro-æneus, elytris obsoletissimè striatis, obsoletus. antennis setaceis.

Long. corp. $5 \frac{1}{2} \mathrm{lin}$.

Habitat -

DEScr. Totum corpus unicolor, nigro-æneum, subtomentosum. Thorax posticè lineâ mediâ impressâ, obsoletiusculâ. Elytra sub lente vix striata.

31. El. thorace elytrisque æneis, antennis marispectinipectinatis.

cornis. 
Linn. Syst. Nat. 665. 32. Faun. Succ. 741. Vill. i. 31I. 23. Scop.278. Scbrank, 338. Gmel. 1909.32. Fab. Syst. Ent. 212. I4. Sp. Ins. i. 268. 19. Mant. i. I73. 23. Ent. Syst. i. b. 223. 33. Panz. Ent. Germ.237. 13. Harr. 105. Act. Nidros. iv. 326.23. Payk. Faun. Suec. iii. 9. II. Faun. Ingr. 250.

Don. Brit. Ins. t. $356 . f$. 2. Scbaff: Elcm. t. Ir. $f$. r. et $t$.60. $f$. r. Icon. $t$. 2. $f \cdot 5$. Poda, 4I. r. $t$. r. $f \cdot 4$. Panz. Faun. Germ.77. t. 1. Mart. Eng. Ent. t. 30. f. IO. II. Oliv. ii. 31. 23. 26.t. I.f.4.t. 6.f.4. b. Elater æneo-pectinicornis. De Geer, iv. 145. 2.t. 5.f.3. Elater flabellicornis. Panz. Voet. ii. I 20. 3I. t. 45.f. 3I. Le Taupin brun cuivreux. Geoff. i. 133. 7 .

Long. corp. 7-8 lin.

Habitat Captus prope montes Malvern dictos, in comitatu Glocestrienci. D. Dickson.

DESCR. Mas thorace et elytris magis saturatè viret, et angustior est ; antennis valdè pectinatis. Foemina magis ænea : thorace latiore, nitidiore, virescente; elytris magis nigricantibus; antennis filiformibus, minimè pectinatis. Faun. Suec.

cyaneus.

32. El. totus purpureo-cæruleus punctulatus, elytris striatis.

Long. corp. 6 lin.

Habitat -

DEscr. Totum corpus punctulis minutissimis conspersum. Elytra striata, striis satis profundis, punctis inpressis.

aneus.

33. El. thorace elytrisque cærulescenti-æneis, pedibus sanguineis.

Linn. Syst. Nat.665.31. Faun. Suec. 740. Vill. i. 311. 22. Scbrank, 339. Gmel. 1909. 31. Fab. Syst. Ent. 212. 13. Sp. Ins. i. 267.18. Mant. i. 173. 22. Ent. Syst. i. b. 223. 3I. Panz. Ent. Germ. 237.12. Faun.Fred.17.167. Poda, 41. 7. Payk. Faun. Suec, iii. I6. 19. Faun. Ingr. 249.

oliv. 



\section{PZ.22.}

CICIND呬A

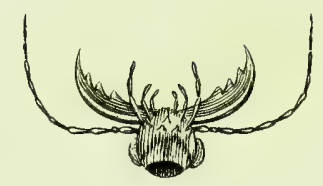

16

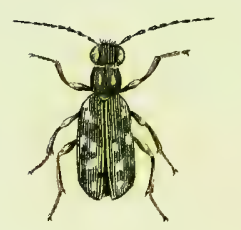

te

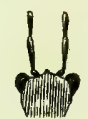

C.campostris. 
Oliv. ii. 3 1. 24. 28. $t .8, f .83$.

Elater æneus rufipes. De Geer, iv. I49. 8.

Long. corp. 3 lin.

Habitat

Descr. Elytra striata. Antennæ filiformes. Pedes rubri. Variat colore nigro-æneo, et viridi nitente.

34. El. ater, thorace nitido, elytris striatis, pe-rufipes. dibus rufis.

Fab. Ent. Syst. i. b. 23т. 70. Payk. Faun. Suec. iii. 39. 45. Faun. Etrusc. 448. Hellw. 448.

Oliv. ii. 3 I. $45 \cdot 62 \cdot t \cdot 7 \cdot f \cdot 72$. a. b.

Le Taupin noir à pattes fauves. Geoff. i. 136. I4.

Long. corp. 4 lin.

Habitat -

DEScr. Statura et summa affinitas El. minuti. Caput et thorax atra, nitida, immaculata. Elytra striata, nigra. Pedes omnes rufi, digitis nigris. Ent. Syst.

35. El. niger, thorace punctato, elytris striatis nigrinus. tomentosis.

Long. corp. 6 lin.

Habitat- In mus. D. Kirby.

DEscr. Totum corpus nigrum, vellere cinerascenti obtectum. Antennæ valdè serratæ.

\section{CICINDELA.}

Antenno setaceæ.

Maxille prominentes, denticulatx.

Oculi prominuli.

Thorax rotundato-marginatus.

I. Cic. viridis, elytris punctis quinque albis.

campestris.

2 c 3

Linn. 
Linn. Syst. Nat. 657. r. Faun. Suec. 746. Vill. i. 320. I. Gmel. 1920. I. Scop. 181. Fab. Syst. Ent. 124. I. Sp. Ins. i. 283.3. Mant. i. 185. 5. Ent. Syst. i. a. 170. 9. Panz. Ent. Germ. 67.2. Payk Faun. Suec. i. I70. I. Harr. 220. Poda, 42. 1. Pontop. i. 676. 14. Faun. Ingr. 80. Faun. Fred. 17. I73. Act. Nidros. iii. 398. 19. Faun. Etrusc. 475. Hellw. 475. Illiger. Kugel. Kaf. Preus. 220.3. Don. Brit. Ins. t. I2. De Geer, iv. II3. I. t. 4. f. I. Schceff: Icon. t. 24. f. 8. 9. et t.28.f.3. Bergstraes. Nom. ii. 15. 8. I1. t. 2. f. 8-II. Oliv. ii. 33. II. 8. t. x. f. 3. a. b. c.

Le Velours vert à I 2 points blancs. Geoff. i. I53. 27. Arenarius viridis. Panz. Voet. ii. 96. 4. t. 40. f. 4 .

Long. corp. 6 lin.

Habitat in campis arenosis.

DESCR. Inter Coleoptera certè hæc species unica ex præstantissimis dici debet, cum aureıs nitor ex toto corpore radiet, vel sericeo fulgeat. Elytra suprà viridia, planiuscula, lævia, punctis aliquot albis notata; quo. rum primum ad baseos angulum; secundum rotundum prope marginem ; tertium lunulatum prope marginem ; quartum oblongum ad marginem; quintum intra tertium, seu in medio elytri, reliquis interius; præter hæc et apex elytrorum albicat. Alæ fuscæ. Thorax angustus, rotundatus, viridi-nitens. Caput aureo-viride, depresso vertice. Oculi nigri, prominentes. Os prominens. Labium superius obtusum, album. Maxillæ superiores prominentes; dentibus plurimis validis ; inferiores maxillæ apice unico dente armatæ, sub his palporum duo paria, quorum superius constat articulis duobus, inferius quaternis. Labii inferioris loco palpi bini ex binis articulis pilosis. Abdomen viridi-aureum. Pedes longissimi, tenuissimi ; ad basin femorum corpus quoddam ovale, durum. Antennæ corpore breviores, Io articulis. Faun. Suec.

2. Cic. viridis, elytris puncto lunulâque ad apicem albis.

Linn. Syst. Nat.657.4. Vill.i.322.3. Gmel.1920.4. 
Scop. 182. Scbrank, 358. Fab. Syst. Ent. 225. 6. Sp.Ins. i.285. I1. Mant. i. 186. 15. Ent. Syst. i. a. I74.21. Panz. Ent. Germ. 68.7. Poda, 42.2. Harr. 222. Illiger. Kugel. Kaf. Preus. 220. 4.

Panz. Faun. Germ. 6. t. 5. Schaff. Icon. t. 4. f.8. Oliv. ii. 33. 2 I. 20. t. I. f. 9. a. b.

La Bupreste verte à six points blancs. Geoff. i. I5.5. 29. Arenarius carneolicus. Panz. Voet. ii. 97.6. t. 40. f. 6 . Long. corp. 4 lin.

\section{Habitat}

Descr. Simillima Cic. campestri, sed triplo minor. Tota æneo-viridis. Elytra viridia, apice lineolâ albicante, et punctis duobus albis ad marginem exteriorem. Syst. Nat.

3. Cic. purpurascenti-fusca;- elytris fasciâ undu-sylvatica. latâ punctisque tribus albidis.

Linn. Syst. Nat. 658.8. Faun. Suec. 748. Vill. i. 322. 4. Gmel. 1922. 8. Fab. Syst. Ent. 224. 3. Sp.Ins. i. 284. 5. Mant. i. 185. 7. Ent. Syst. i. a. I7I. II. Panz. Ent. Germ. 67. 4. Faun. Ingr. 82. Illiger. Kugel. Kaf. Preus. 2 I9. I.

De Geer, iv. I I 4. 2. t. 4. f. 7. Don. Brit. Ins. t. $35 \mathrm{I}$. $f$. I. Oliv. ii. 33. 15. I2. t. I. $f \cdot 5$.

Arenarius fuscus. Panz. Voet. ii. 95.2.t.40. f.2.

Long. corp. 7 lin.

Habitat

Capta in ericeto dicto Martlesham

Heath, juxta Woodbridge, in Suffolciâ, Septembre ineunti I797. D. Kirby.

Descr. Tota atra est. Coleoptra depressa, latiuscula; ad angulum exteriorem baseos elytrorum punctum album; paulo suprà, juxta exteriorem marginem aliud punctum, sed sublunulatum, apices elytrorum versus in singulo elytro punctum rotundum, album; fascia linearis, flexuosa sive undulata, arcuata, versus posteriora in medio deflexa, cingit in medio elytra: hæ maculæ omnes non constant ex pilis, cum elytra glabra infinitis 
punctis excavatis conspersa, sed translucent per ipsam crustam. Femora et pedes longi, tenues, atri, setis quibusdam adspersi. Tibiæ spinis duabus terminatæ. Thorax angustior, teretiusculus, cruce depressâ, uti caput niger. Oculi prominuli. Os prominens. Labium superius atrum, rotundato-acutum. Maxillæ superiores magnæ, prominentes, nigræ, versus basin extùs albæ, dentibus plurimis duris armatæ. Faun. Suec.

Obs. Mihi, color purpurascenti-fuscus est.

riparia. 4. Cic. viridi-ænea, elytris punctis latis excavatis. Linn. Syst. Nat.658. ro. Faun. Suec.749. Vill. i. 323.6. Faun. Fred. 18. I74. Poda, 42. 4. Harr. 223. Gmel. I925. 10.

Don. Brit. Ins. t. 301. De Geer, iv.117. 4. t. 4. f. 9 . Scbaff. Icon.t. 86. f. 4 .

Elaphrus riparius. Fab. Syst. Ent.227. I. Sp. Ins. i. 287. I. Mant. i. 187. I. Ent. Syst. i. a. I79.2. Panz. Ent. Germ. 68. 2. Faun. Ingr. 83. Payk. Faun. Suec. i. 174. 2. Faun. Etrusc. 477. Hellw. 477.: Illiger. Kügel. Kaf. Preus. 225. 2.

Oliv. ii. 34.4. I. t. I. f. 1. a. b. c. d. Panz. Faun. Germ.20. $t$. I.

Le Bupreste à mammelons. Geoff. i. I56. 30 .

Arenarius parvus. Panz. Voet. ii. 98. 7. t. 40. f. 7 .

Long. corp. 3 lin.

Habitat in locis bumidis.

Descr. Corpus sordidè æeneo-virens. Elytra admodùm singularia, quippe tres lineas elevatas interruptas gerunt. In omni autem interruptione, punctum latum excavatum mamillare, mamillâ purpurascenti. Quarta series punctorum excavatorum ad elytrorum marginem sita est. Pedes amœnissimè aureo-viricles.

uliginosa. 5. Cic. suprà violacea subtùs æneo-viridis, elytris punctis excavatis lineisque elevatis interruptis tuberculato-rugosis.

Elaphrus uliginosus. Fab. Ent. Syst. i. a. э78. 1. Panz. Ent. 
Ent. Germ. 68. 1. Payk. Faun. Suec. i. I73. I. Illiger. Kugel. Kaf. Preus. 225.3.

Long. corp. 4 lin.

Habitat

DEscr. Maximè affinis Cic. riparice, sed ferè duplo major: tum color suprà violaceus, nec virescens. Elytrorum superficies valdè inæqualis, quippe lineæ elevatæ manifestiores, et puncta excavata obsoletiora sunt; unde quasi tuberculato-rugosa; puncta excavata omninò ut in $C_{i c}$, ripariâ, sed obsoletiora, ac ejusdem cum elytris coloris. Pedes ut in Cic. ripariá.

6. Cic. ænea nitida, capite striato.

Linn. Syst. Nat.658. 14. Faun. Suec.752. Vill. i. aquatica. 325. 10. Scbrank, 361. Faun. Fred. 18. I77. Gmel. I 925.14 .

Don. Brit. Ins. t. $35^{1 . f .} .2$.

Elaphrus aquaticus. Fab. Syst. Ent. 227. 4. Sp. Ins. i. 288. 4. Mant. i. I88.4. Ent. Syst. i. a. I79.5. Panz. Ent. Germ. 69. 6. Faun. Ingr. 85. Payk. Faun. Suec. i. I77.5. Faun. Etrusc. 478. Hellw. 478. Illiger. Kugel. Kaf. Preus. 224. I.

Oliv. ii. $34 \cdot 6 \cdot 5 \cdot t$. I. f. 6. a. b.

Elaphrus germanicus. Panz. Faun. Germ. 20. t. 3 .

Lung. corp. 2 lin.

Habitat

Descr. Tota nitida. Thorax latiusculus, carinatus, marginatus. Elytra nitida, striis minutissimis e punctis minutissimis. Abdomen nigrum, nitidum. Pedes nigri. Rostrum prominulum. Faun. Suec.

7. Cic. ænea, elytris striatis, pedibus flavescen-striata. tibus.

Elaphrus striatus. Fab. Ent. Syst. i. a. I79.3. Payk. Faun. Suec. i. 175.3. Illiger. Kugel. Kaf. Preus. 227. 7. Panz. Fnt. Germ.69.3.

Long. corp. $2 \frac{x}{2} \operatorname{lin}$.

Habitat -

In mus. D. Donovan.

DESCR. 
Descr. Statura Cic. flavipedis at major. Antenna nigræ, primo articulo flavo. Thorax rotundatus, dorso canaliculato. Elytra striata, ænea, immaculata. Pedes flavescentes, femoribus obscurioribus. Puncta interdum duo impressa ad elytrorum suturam. Fab.

semipunc- 8. Cic. ænea nitida, elytris punctatis : dorso glatata. berrimo.

Vill. i. 326. 12. Gmel. 1925. 47 .

Cicindela striata. De Geer, iv. I 18. 5 .

Elaphrus semipunctatus. Fab. Syst. Ent. 227.5. Sp. Ins. i. 288. 5. Mant. i. 188. 5. Ent. Syst. i. a. 180.6. Panz. Ent. Germ. 69. 7. Faun. Etrusc. 479. Hella. 479.

Oliv. ii. 34 . 7.t. 1. f. 3. a. b.

Le Bupreste à tête cannelée. Geoff. i. I57.3 I.

Long. corp. $2 \frac{1}{2}$ lin.

\section{Habitat}

DESCr. Statura et summa affinitas Cic. aquatica. Antennæ nigræ, basi ferrugineæ. Corpus totum æneum, nitidum. Elytra striato-punctata, in medio ad suturam quasi polita, glaberrima. Pedes nigri, tibiis ferrugineis, sive piceis.

flavipes. 9. Cic. obscurè ænea, elytris subnebulosis, pedibus luteis.

Linn. Syst. Nat. 658. 11. Faun. Suec. 750. Vill. i. 324. 7. De Geer, iv. 119. 6. Faun. Fred. 18. 175. Gmel. I925. 1 I.

Elaphrus flavipes. Fab. Syst. Ent. 227.2. Sp. Ins. i. 287. 2. Mant. i. 187.2. Ent. Syst. i. a. 179. 4. Panz. Ent. Germ. 69. 4. Faun. Ingr. 84. Payk. i. I76. 4. Faun. Etrusc. 480. Hellw. 480. Illiger. Kugel. Kaf. Preus. 226. 4.

Panz. Faun. Germ. 20. t. 2. Oliv. ii. 34. 8. 7. t. I. f. 2. a. b.

Long. corp. 2 lin.

Habitat in sylvis. Linn.

Descr. 

IBUPIBISTYS.

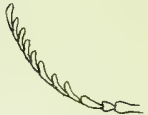

3

B. Saticis 
DEscr. Antennarum basis flavescens. Pedes lutei. Elytra sub-ænea, obscurè nebulosa. Faun. Suec.

Iо. Cic. ænea, elytris nitidis apice flavescentibus. biguttata. Vill. i. 325. 13. Gmel. 1925. 48.

Elaphrus biguttatus. Fab.Sp. Ins. i. 288. 6. Mant. i. 188. 6. Ent. Syst. i. a. 180. 7. Payk. Faun. Suec. i. $177 \cdot 5$. var. $\beta$.

Long. corp. 2 lin.

Habitat

DESCr. Caput et thorax rugosa, obscurè ænea. Elytra nitida, puncto medio impresso, et apice latè flavescentia. Ent. Syst.

\section{BUPRESTIS.}

Antenne filiformes, serratæ.

Caput rotundatum, dimidium intra thoracem retractum.

Thorax transversus, posticè latitudine elytrorum.

Elytra rigida.

Corpus oblongum, apicem versus conicum.

I. Bu. ænea, elytris striatis fastigiatis, thorace rustica. punctato.

Linn. Syst. Nat.660.8. Faun. Suec.756. Vill. i. 329. 4. Gmel. 1932. 8. Scbrank, 363. Fab. Syst. Ent.221. 28. Sp.Ins. i. 279. 40. Mant. i. 181.57. Ent. Syst. i. b. 205. 81. Panz. Ent. Germ. 229. I3. Payk. Faun. Suec. ii. 216. 3. Faun. Ingr. 24I. Faun. Etrusc. 458. Hellw. 458. Hoppe Ins. Erl. 56. Panz. Faun. Germ.68. t. 19. Oliv. ii. 32. 67. 90. t.3. f. 22. Herbst. Jablonsk. ix. 134. 76.t. 144. f. 8 .

Buprestis 
Buprestis violacea. De Geer, iv. 130.4.t. 4. f. IO-I 7 .

Le Richard doré à stries. Geof: i. 126. 3. t. 2. f. 2.

Mordella rustica. Scop. I 88 .

Long. corp. 6 lin.

Habitat in sylvis ad aquas. Linn.

DESCR. Thorax viridi-æneus, punctis excavatis, crassus, imo crassitie coleoptrorum, caput maximâ ex parte intra se recipiens. Elytra ænea, minùs virilia, immaculata, singula octo circiter striis exarata. Faun. Suec.

9-maculata.2. Bu. elytris integerrimis nigris: maculis tribus longitudinalibus fronte thoracisque lateribus luteis.

Linn. Syst. Nat.662. 17. Vill. i.332.9. Fab. Syst. Ent.223. 44. Sp. Ins. 1. 282.62. Mant. i. 179.36. Ent. Syst. i. b. 198. 54. Panz. Ent. Germ. 228.5. Faun. Etrusc. 463. Hellw. 463. Gmel. 1935. 17. Oliv. ii. 32. 49. 63. t. 4. f. 30. Herbst. Jablonsk. ix. $215.136 . t \cdot 156 . f \cdot 5$.

Long. corp. lin.

Habitat

DESCR. Corpus nigrum totum, oblongum, medincre. Maculæ luteæ: I in medio frontis, cum punctis; 2 ad thoracis latera; 3 in singulis elytris situ longitudinali, quarum anterior basi biloba. Abdominis segmenta punctis 4 luteis. Syst. Nat.

biguttata. 3. Bu. elytris integerrimis linearibus viridibus: puncto albo, abdomine cyaneo : punctis utrinque tribus albis.

Fab. Gen. Ins. Mant. 237. Sp. Ins. i. 281.55. Mant. i. 184. 82. Ent. Syst. i. b. 213.115. Panz. Ent. Germ. 232. 29. Harr. 97. Vill. i. 336. 24. Payk. Faun. Suec. ii. 224. I I. Faun. Etrusc. 473. Hellw. 473: Gmel. 1937.94.

oliv. ii. $32 \cdot 76.104 \cdot t \cdot 7 \cdot f \cdot 75$. Scbeff. Iion. $t .279$. 
f. 6. a. 6. b. Herbst. Jablonsk. ix. 2א6. 184. t. 155 . f. 2. Herbst. Arch. t. 28. f. 22.

Long, corp 7 lin.

\section{Habitat}

DESCR. Caput viride, frontc impressâ, antennis brevibus nigris. Thorax cylindricus, viridis, immaculatus. Elytra linearia, viridia, puncto parvo albo ad suturam. Abdomen suprà cyaneum, nitidum, utrinque punctis tribus albis, quorum anterius parùm remotum; subtùs itidem cæruleum, utrinque punctis tribus albis. $F_{a} b$. Gen. Ins, Mant.

4. Bu. elytris integerrimis sublinearibus punctatis, viridis. thorace deflexo, corpore viridi elongato.

Linn. Syst. Nat.663. 25. Fauñ. Suec. 762. Vill. i. 334. 16. Scbrank, 367. Gmel. 1937. 25. Fab. Syst. Ent. 223. 39. Sp. Ins. i. 28 r. 54. Mant. i. 184. 81. Ent. Syst. i. b. 2I3. II4. Panz. Ent. Germ. 232. 28. Harr. 95. Faun. Fred. 18. I8I. Payk. Faun. Suec. ii. 225. 12. Faun. Ingr. 243. Faun. Etrusc. 498 . Hellw. 498.

Don. Brit. Ins. t. I74. De Geer, iv. 133.6. t.5.f. r. 2. Herbst. Jablonsk. ix. 247. I64. t. 155. $f$. I. a. b. Oliv. ii. 32. 83. пा6. t. II. f. I27. Herbst. Arcb. t. 28. f. 2 I.

Le Richard vert allongé. Geoff. i. 127.5.

Long. corp. 3 lin.

Habitat in foliis Betule albee, quorum margines exedit. Linn.

DESCR. Corpus totum viridissimum, mediæ vel minoris longitudinis, reliquis angustius. Elytra non striata, nec nisi atomis confertissimè punctata. Faun. Suec.

5. Bu. elytris integris, viridis nitens, coleoptris Salicis. aureis basi viridibus.

Fab.Sp.Ins, i.282.60. Mant. i. I84.89. Ent. Syst.i. b. 215.125. Pans. Ent.Germ.233.35. Harr. Ioo. 
Vill. i. 337.26. Faun. Etrusc. 47 r. Hellw. 47 I. Gmel. $1935 \cdot 85$.

Don. Brit. Ins. t. 127. Panz. Faun. Germ. I. t. I2. Hert'st. Arcb. t. 46. f. 5. Scbeff: Icon. t. 3 I. f. I2. Oliv. ii. 32. 79. 108. t. 2. f. 13. a. b. Herbst. Jablonsk. ix. 240. 159.t. 147. f. 6. c.

Long. corp. 3 lin.

Habitat in Salice.

DEscr. Caput viride, antennis fuscis. Thorax depressus, marginatus, viridis, maculis duabus cyaneis impressis. Elytra rufa, a basi imprimis ad suturam viridia. Subtùs viridis, immaculata. Ent. Syst.

minuta. 6. Bu. ovata, elytris nigris integerrimis transversè rugosis, thorace subtrilobo lævi æneo.

Linn. Syst. Nat. 663. 23. Faun. Suec. 760. Vrill. i. 333. 14. Scbrank, 370. Gmel. 1937.24. Fab. Syst. Ent. 223. 38. Sp. Ins. i. 281.53. Mant. i. 183. 79. Ent. Syst. 1. b. 212. I11. Panz. Ent. Germ. 232. 27. Payk. Faun. Suec. ii. 232. 20. Faun. Etrusc. 472 . Hellw. 472.

Don. Brit. Ins. t. 256 . Oliv. ii. 32. 84, 118. t. 2. f. 14. a. b. Herbst. Jablonsk. ix. 272. I9o. t. i55. f. 3. a. b.

Le Richard triangulaire ondé. Geoff. i. I28. 6.

Long. corp. I $\frac{x}{2}$ lin.

Habitat

Capta in foliis arbustorum in Coombe-Wood.

Descr. Corplis ovatum. Thorax inæqualis, fuscocupreus, lævis, posticè subtrilobus. Elytra nigra, sive nigro-ænea, fasciis undulatis villoso-albidis.

pygmaa. 7. Bu. ovata, elytris integris cynaneis, capite thoraceque æneis nitidis.

Fab. Ent. Syst. i. b. 2 II. I10. Panz. Ent. Germ. 232. 26. Faun. Etrusc. Mant. 407. 152. Hellw. Mant. 407. 52. Gmel. 1936. 92.

Don. 
Don. Brit. Ins. t. 282. Oliv. ii. 32. 85. I Ig. t. 4. f. 34 . Herbst. Jablonsk. ix. 27 I. I89. t. 156. f. 2. a. b.

Long. corp. I $\frac{1}{2}$ lin.

Habitat - Capta in Coombe-Wood. D. MacLeay.

DESCR. Statura omninò præcedentis, at caput et thorax lævia, ænea, nitidissima. Elytra cyanea, nitida, immaculata. Corpus obscurum.

\section{PARNUS.}

Antennee perfoliatæ, capite breviores.

Cahut rotundatum, intra thoracem retractile. Thorax anticè attenuatus, posticè utrinque angulo acuminato.

Pectus mucronatum.

I. Par. niger vellere griseo obductus, antennis ap-proliferipendiculatis.

Fab. Ent. Syst. i. a. 245. I. Payk. Faun. Suec. i. 321. I. Illiger. Kugel. Kaf. Preus. 350 . I. Panz. Ent. Germ. I I6. I.

Panz. Faun. Germ. 13: t. 1.

Elater dermestoides. Linn. Syst. Nat. 656.38. Vill. i. 314. 29. Gmel. I910. $3^{8}$.

Elater prolifericornis. Faun. Etrusc. 447. Hellw. 447. Le Dermeste à oreilles. Geoff. i. 103. II. ? cornis.

Long. corp. 2 lin.

Habitat

DESCR. Antennæ brevissimæ, pallidæ, appendiculis trapeziformibus nigris latere superiori munitæ. Caput intra thoracem interdum penitus retrahit, adeo ut acephalus esse videtur. Pedes obscurè rubri, interdùm nigricantes. 


\section{[ 400$]$}

\section{HETEROCERUS.}

Antenne breves, recurvæ, articulis ultimis subserratis.

Caput porrectum, elongatum, maxillis exsertis apice denticulatis.

Thorax convexus, anticè attenuatus.

Corpus ovatum.

marginatus. I. Het. hirtus niger, elytris punctis septem ferrugineis.

Fab. Ent. Syst. i. a. 262. 1. Payk. Faun. Suec. i. 357. I. Panz. Ent. Germ. I30. 1. Scbneid. N. Magaz. v. 533 .

Panz. Faun. Germ. 23. t. II.

Apate marginatus. Fab. Mant. i. 33. 8.

Dermestes fenestratus. Thunb. Nov. Act. Ups. iv. 3. 2. Long. corp. $2 \frac{3}{4}$ lin.

Habitat in palustribus maritimis, in scrobibus cœnosis, ubi aqua per hyemem constiterit, prope Harvici oppidum, Maio. Prope Sheerness copiosè, Septembre.

DESCR. Totum corpus nigrum, vellere subferruginea obtectum. Elytra circiter puncta septem ferruginea, sæpiùs obsoleta gerunt. Hæc puncta ad hanc methudum disponuntur; antè medium elytrorum tria, transversim et quasi arcuatim sita; post hæc unum versus suturam, majus, lunare; apicem versus tria alia parva, triangulum æqualem efficientia. Tibiæ omnes spinosæ. 


\section{[ 401 ]}

\section{HYDR OPHILUS.}

Antenne clavâ perfoliatâ, trifidâ, palpis breviores.

Caput insertum.

Thorax transversus.

Corpus ovale, convexum.

Pedes postici in plerisque ciliati.

* Tborace lcevi.

* Tborace longitudinaliter rugoso.

* Tborace levi.

I. Hy. niger lævis, sterno carinato longissimo piceus. posticè spinoso.

Fab. Syst. Ent. 228. 1. Sp. Ins. i. 288. 1. Mant. i. 188. I. Ent. Syst. i. a. 182. I. Panz. Ent. Germ. 70. I. Payk. Faun. Suec. i. I78. I. Harr. 177. Faun. Ingr. 86. Faun. Etrusc. 481. Hellw. 481. Gmel. 1941. I.

Oliv. iii. 39. 9. x. t. I. f. 2. a-d. Herbst. Jablonsk vii. 294. 1. t. Ir 3. f.5. Scbaff. Elem. t. 7 I. Icon. t.33. f. 1. 2. Bergstraes. Nom. i. 9.46. 1. t.6. f. 3. t. 8 et $9 . f$. I.

Hydrophilus ruficornis. De Geer, iv. 371. 1. t. I4. f. I. 2. Le grand Hydrophile. Geoff. i. I82. t. 3. f. I.

Hydrous piceus. Linn. Mss. r.

Dytiscus piceus. Linn. Syst. Nat.664. I. Faun. Suec.764. Vill. i. 340. 1. Scop. 293. Faun. Fred. 19. 184. Pontop. i. 676. $\mathbf{x}$.

Mart. Eng. Ent.t.32. f. 3. 4. Sbaw Nat. Misc. t. 292. Iyon. Less. Theol. Ins. 158. t. I. $f$. I2-I5.

Long. corp. I unc. 5 lin.

Habitat in aquis.

DESCR. Corpus maximum, nigro-piceum, sive nigrum, læve, posticè acuminatum. Antennæ clavâ ovatâ, articulo ultimo atro, glabro, reliquis fuscis, non glabris. Caput nitidum, lunulâ utrinque anticâ e punctis impressis. vol. I. $2 \mathrm{D}$

Thorax 
Thorax convexus, nitidus, foveolâ utrinque e punctis confluentibus valde impressis, et punctis quibusdam minoribus marginalibus excavatis. Scutellum magnum, triangulare. Elytra nitida, valdè convexa, vix manifestè punctato-striata. Pectus subtomentosum. Sternum carinatum, compressum, valdè prominens, anticè obtusum, subtùs canaliculatum, posticè in spinam validam, longitudine ferè dimidii abdominis productum. Pedes nigri : tarsi compressi, ciliis flavescentibus, antici maris scuto subtriangulari.

caraboides. 2. Hy. niger nitidus, elytris substriatis, sterno brevi. Fab. Syst. Ent. 228. 4. Sp. Ins. i. 289.3. Mant. i. 188. 2. Ent. Syst. i. a. 183. 4. Panz. Ent. Germ. 71. 2. Harr. 178. Payk. Faun. Suec. i. 179. 2. Faun. Ingr. 87. Faun. Etrusc. 482. Hellw. 482. et Mant. 410. I58. Gmel. I941. 2.

Oliv. ïi. 39. II. 5. t. 2. f. 8. Herbst. Jablonsk. vii. 299. 5.t. II3.f.9. Scbceff. Icon. t. 33.f. 10. Panz. Faun. Germ. 67. t. Io.

Hydrophilus nigricornis. De Geer, iv. 376. 2 .

L'Hydrophile noir picoté. Geoff. i. 183.2.

Hydrocantharus aquaticus niger subrotundus. Rai. 95.7. Dytiscus caraboides. Linn. Syst. Nat. 664. 2. Faun. Suec. 765. Vill. i. 341. 2. Faun. Fred. 19. 185. Pontop. i. 6;6. 2.

Roes. Ins. ii. aquat. I. t. 4. f. I. 2. Mart. Eng. Ent. t. $34 \cdot f \cdot 28$.

Long. corp. 9 lin.

Habitat in aquis.

DESCr. Corpus nigrum, nitidum, posticè rotundatum. Antennæ nigræ. Caput lunulâ utrinque anticâ e punctis excavatis. Thorax convexus, foveolâ utrinque e punctis confluentibus valdè impressis, et punctis quibusdam marginalibus excavatis. Scutellum triangulare. Elytra convexa, lineis quinque, interioribus distinctioribus, e punctis minutis excavatis. Sternum posticè spinosum, ad femora postica sese extendens. Pedes nigri; tarsi ciliis flavescentibus.

Tarsi antici maris absque palmulis. Payk. 
3. Hy. nigcr, elytris punctato-striatis margine li-fuscipes. vidis, pedibus fuscis.

De Geer, iv. 377.3. Oliv. iii. 39. 12. 6. t. 2. f. 9. a. b. Hydrophilus scarabæoides. Fab. Syst. Ent. 228. 4. Sp. Ins. i. 289. 5. Mant. i. 188. 5. Ent. Syst. i. 184.8 . Payk. Faun. Suec. i. 180. 3. Panz. Ent. Germ.71. 4. Gmel. 1942. 4.

Panz. Faun. Germ. 67. t. I3.

L'Hydrophile noir strié. Geoff. i. 184. 4.

Dytiscus fuscipes. Linn. Syst. Nat.664. 4. Faun. Suec. 766. Vill. i. 342. 4 .

Mart. Eng. Ent. t. $33 \cdot f$. 15.

Dytiscus gyrinoides. Scbrank, 372.

Long. corp. $3 \frac{\mathrm{r}}{2}$ lin.

Habitat in aquis.

Descr. Niger, convexus, nitidus. Capul et thorax valdè punctata, punctis minutissimis conspersis. Elytra striato-punctata, et inter strias, oculo armato, punctis minutis confluentibus ornantur.

4. Hy. subrotundus, corpore glabro atro. orbicularis. Fab. Syst. Ent. 229.5. Sp. Ins. i. 290. 6. Mant. i. 188.7. Ent. Syst. i. 184. 10. Panz. Ent. Germ. 71. 5. Payk. Fizun. Suec. i. 181.4. Tbunb. Ins. Suec. vi. 73.6. Gmel. 1942. 9.

Oliv. iii. 39. 13. 8. t. 2. f. II. a. b. Panz. Faun. Germ. vii. 303. 9. $t$. II 4 . $f$. I.

L’Hydrophile lisse à points. Geoff. i. 184. 3.

Dytiscus orbicularis. Vill. i. $35^{\circ} .35$.

Long. corp. $2 \frac{1}{3}$ lin.

Habitat in aquis.

DESCR. Statura ferè præcedentis, at minor, et ferè orbiculatus. Totus lævissimus, nitens. Syst. Ent.

5. Hy. niger nitidiusculus, thoracis margine livido, sordidus. elytris lividis nigro-maculatis.

Long. corp. 3 lin. 
Habitat in aquis stagnantibus. In mus. D. Beckwith.

DESCr. Antennæ fuscæ, articulis quinque extremis crassioribus, quorum primus crassior rotundus, et remotiusculus. Caput anticè angulato-emarginatum. Thorax niger, lateribus pallidis. Elytra abdomine longiora, pallida, sive sordidè testacea, punctata, nigro sparsim maculata : ad apicem et marginem exteriorem striæ quædam obsoletiùs elevatæ. Pedes et abdomen nigra, obscura. Tarsi, articulo ultimo excepto, et ungues subferruginei.

verrucosus. 6. Hy. atro-ferrugineus obscurus, abdomine subtùs verrucoso.

Long. corp. 3 lin.

Habitat in aquis. In mus. D. Beckwith.

DEscr. Hæreo an hic sit diversus a Hy. sordido. Color sanè diversus, tum corpus obscurum: sutura et tarsi solummodò nitidiusculi. Pedes et abdomen nigra. Abdomen subtùs ad latera, et ad margines incisurarum, verrucis planis (tuberculorum Licbenis carpinei instar) ornatur. Elytra maculas quasdảm nigras, sed præ coloris obscuritate vix conspiciendas, gerunt.

huridus. $\quad$. Hy. luridus, elytris punctis tribus fuscescentibus, thorace lateribus flavicanti.

Fab. Syst. Ent. 229. 7. Sp. Ins, i. 290. 8. Mant. i. 188. 9. Ent. Syst. i. a. 186. 19. Panz. Ent. Germ. 72. 9. Payk. Faun. Suec. i. 18 . 5. Faun. Etrusc. 484. Hellw. 484. Gmel. 1943.5.

Panz. Faun. Germ. 7.t.3. Oliv. iii. 39. 13.9.t. I. f. 3.a.b. c. Herbst. Jablonsk. vii. 302.8. t. II3. f. 12. Hydrophilus fuscus. De Geer, iv. 378.4 .

Dytiscus luridus. Linn. Syst. Nat.665.5. Faun. Suec. 767. Vill. i. 342.5 .

Mart. Eng. Ent. t. 33. f. 10.

Long. corp. $2 \frac{1}{2}$ lin.

Habitat in aquis.

Descr. 
Descr. Totus luridus. Caput æneo-nigrum. Elytra striata, puncto nigro in medio ad marginem, duobus obsoletis vix manifestis ad suturam longitudinalem. Pedes ferruginei. Faun. Suec.

8. Hy. ovatus lividus lævissimus.

lividus.

Oiiv. iii. 39. r5. r. t. s. f. 4. a. b.

Dytiscus lividus. Forst. Cent. 52 .

Long. corp. $2 \frac{x}{2}$ lin.

Habitat in palustribus maritimis, in puteolis lutosis, in perforationibus luti præmollis ex quo aqua nondum discesserat.

Descr. Totus lividus, sive nigro-ferrugineus, nitidus, lævissimus. Ne punctulum quidem in toto corpore conspiciendum est. Antennæ basi testaceæ, perfoliatæ, tribus articulis. Pedes nigri, tibiis tarsisque testaceo-ferrugineis.

9. Hy. hemisphærico-ovatus luridus, capite nigro, dermestoithoracis lateribus obscurè ferrugineis. des.

Dytiscus dermestoides. Forst. Cent. 53 .

Long. corp. $2 \frac{1}{2}$ lin.

Habitat inter Lemnam in aquis stagnantibus.

Descr. Caput atrum, nitidum. Thorax ater, nitidus, margine pallido, Elytra undique lurida, nullis punctis vel lineis nigris. Pedes ferruginei. Forst. Cent.

I0. Hy. ovatus testaceus, capite posticè nigro. torquatus. Long. corp. 3 lin.

Habitat in aquis.

DESCr. Caput flavum, oculis et margine postico nigris. Variat lineâ nigrâ longitudinali frontali. Thorax et elytra testacea. Abdomen nigrum. Pedes nigro-picei. Corpus suprà nitescit, et omninò sub lente punctulis conspersum. 
bipunctatus. II. Hy. niger, thorace lateribus flavicanti, elytris pallido nigroque obscurè pulverulentis.

Fab. Syst. Ent. 229. 9. Sp. Ins. i. 290. 10. Mant. i. 189. 12. Ent. Syst. i. a. 186. 22. Payk. Faun. Suec. i. J88. I4. Panz. Ent. Germ. 73. I3.

Oliv. iii. 39. 16. 13. t.2. f. 14. a. b. Panz. Faun. Germ. 67.t. I5.

Hydrophilus coccinelloides. Faun. Etrusc. 486. Hellw. 486.

Dytiscus coccinelloides. Scbrank, 373. Vill. i. 351.40. Mart. Eng. Ent. t. 33. f. 9 .

Long. corp. $I \frac{1}{2}$ lin.

Habitat in aquis.

Descr. Habitus Coccinella et ita convexus. Subtùs niger, pedibus pallidè testaceis. Caput nigrum, anticè acutum, utrinque maculâ exiguâ flavescenti. Thorax niger, lateribus flavicantibus. Scutellum nigrum. Elytra flavicantia, sed singula striis I 8 punctorum minutissimorum nigrorum. Scbrank.

minutus.

12. Hy. ovatus piceus nitidus, elytrorum thoracisque lateribus pallidis.

Fab. Syst. Ent. 229. 8. Sp. Ins. i. 290. 9. Mant. i. 188. 10. Ent. Syst. i. a. 186. 20.

Oliv. iii. 39. 15. 12. t. 2. f. 13. a. b. Mart. Eng. Ent. $t .33 \cdot f .16$.

Long. corp. $\mathrm{I} \frac{1}{3}$ lin.

Habitat in aquis.

Descr. Corpus nitidum, nigro-piceum. Thorax lateribus pallidis. Elytra etiam quæ sub lente punctulata, marginibus pallidis. Abdomen subtùs et pedes nigropicei.

bipustula- I3. Hy. niger, capite anticè maculis duabus fultus. vis, elytris testaceis nigro-pulverulentis. Long. corp. $I \frac{x}{4}$ lin.

Habitat in aquis.

DESCR. 
Descr. Caput nigrum, maculis duabus fulvis ante oculos. Thorax testaceus, maculis tribus fuscis, in medio confluentibus. Elytra testacea, punctis nigris sparsis. Abdomen nigrum. Pedes rufi.

I4. Hy. fuscus, elytris striatis: striis ex punctis lutosus. impressis.

Long. corp. $\frac{3}{4}$ lin.

Habitat in aquis.

DeScr. Thorax rugosus, lineis transversis elevatis, flexuosis. Elytra punctato-striata. Totum animal obscurum et lutosum est.

I $5 . \mathrm{Hy}$. ater politus, margine thoracis pedibusque nitidus. rufis.

Long. corp. $\frac{3}{4}$ lin.

Habitat in aquis.

Descr. Primo intuitu non dissimilis Dytisco, sed satis distinctus. Antennæ clavâ perfoliatâ, nec setaceæ ut in Dytiscis.

I6. Hy. ater nitidus, thorace elytrisque fusco-mollis. testaceis.

Long. corp. $\frac{x}{2}$ lin.

Habitat in aquis.

DESCR. Totum animal molle. Caput et abdomen nigra. Per cætera fusco-testaceum est.

r 7. Hy. ovatus piceus nitidus, perlibus rufis. picinus. Long. corp. $\frac{x}{2}$ lin.

Habitat in aquis.

DESCR. Totum animal præter pedes piceum.

I 8. Hy. niger, palpis antenniformibus, antennis Longipalpis. pedibusque rubris. 
Long. corp. I $\frac{1}{8}$ lin.

Habitat in aquis.

In mus. D. Kirly.

Descr. Palpi porrecti, tribus articulis; articulus primus longus, simillimus antennis Curculionis. Caput nigrum. Thorax niger, posticè attenuatus, anticè lineâ transversâ, impressâ.. Elytra nigra, punctatostriata.

impressus. I9. Hy. niger, thoracis lateribus utrinque forcâ sive puncto magno impresso, pedibus testaceis.

Long. corp. I lin.

Habitat in aquis.

Descr. Totum corpus nigrum. Caput punctulatum, medio lineâ transversâ impressâ, posticè punctis duobus excavatis. Thorax punctulatus, lineâ longitudinali exaratâ in medio; ad marginem utrinque foveâ seu puncto magno excavato. Elytra striata : striæ punctis valdè impressis. Pedes picei.

fulvus. 20. Hy. fulvus, elytris lineis obscuris nigris, abdomine nigro.

L'Hydrophile fauve. Geof: i. 184.5.

Long. corp. $2 \frac{x}{2}$ lin.

Habitat in aquis.

Descr. Antennæ fuscæ. Palpi testacei, apice nigri. Caput fulvun, punctatum. Oculi nigri. Thorax fulvus, punctatus, anticè niger. Elytra fulva, lineis obsoletis longitudinalibus nigris. Abdomen subtùs nigrum, villis tectum. Pedes testacei, villosi.

margipal- 2I. Hy. piceus totus nitidus, thoracis marginibus lens. pallidioribus.

Long. corp. $\frac{3}{4}$ lin.

Habitat in aquis.

In mus, D. Kirby. DESCR. 
DESCR. Totum animal piceum, marginibus dilutioribus.

22. Hy, niger, elytrorum thoracisque lateribus lu- ocbropteridis, maculâ ante utrumque oculum luridâ. rus.

Long. corp. 2 lin.

Habitat in aquis. In mus. D. Kirby.

DEscr. Caput nigrum, maculis duabus luridis ante oculos. Thorax et elytra subtilissimè punctata, marginibus lateralibus pallidis. Tarsi ferruginei.

* Thorace longitudinaliter rugoso.

23. Hy. fuscus, elytris punctato-striatis, thorace stagnalis. emarginato virescente.

Hydrous stagnalis. Linn. Mss.

Hydrophilus ænens. De Geer, iv. 379. 5. t. I5. f. 5.6 .

Silpha aquatica. Linn. Syst. Nat. $573 \cdot 25$. Faun. Suec. 46r. Stroem. Act.Nidros. iii. 387.4. Vill. i. 82.22. Elophorus aquaticus. Fab. Syst. Ent.66. I. Sp. Ins. i. 77. I. Mant. i. 42. I. Ent. Syst. i. a. 204. I. Panz. Ent. Germ. 83. r. Payk. Faun. Suec. i. 240. I. Preys. Bob. Ins. 58. 60. Herbst. Arcb. 87.1.

Panz. Faun. Germ. 26. t. 6. Oliv. iii. 38. 5. r. t. . . f. I. a-d. Herbst. Jablonsk. v. 139. 2. t. 49. f. 6 .

Le Dermeste bronze. Geoff. i. 105. I5.

Long. corp. $2 \frac{1}{2} \operatorname{lin}$.

Habitat in aquis, frequenter inter Confervas stabulans.

Descr. Faune Suecice obscura. De Geer bene depinxit his verbis, "viridi-æneus, thorace virescente "sulcato, elytris punctato-striatis, antennis pedibusque "rufis." Scilicet corpus oblongum. Thorax rugosus, lineis longitudinalibus elevatis, flexuosis. Antennæ clavâ ovatầ, triarticulatâ.

24. Hy. cinereus, elytris punctato-striatis : punctis affinis. duobus nigris, thorace emarginato æneo-viridi.

Elophorus 
Elophorus minutus. Fab. Syst. Ent. 66.2. Sp. Ins. i. 77.3. Mant. i. 4.2.3:

Oliv. iii. $38 \cdot 7 \cdot 5 \cdot t .1 . f .6$. a. b.

An Hydrophilus griscus? Herbst. Jablonsk. v. I43. 7. t. $49 \cdot f .12$.

Long. corp. $\mathbf{I} \frac{\mathrm{I}}{4} \operatorname{lin}$.

Habitat in aquis stagnantibus.

Descr. Simillimus Hy. stagnali, at triplo minor. Elytra pallidiora: puncta duo nigra in singulo elytro.

dorsalis. 25. Hy. fuscus, thorace viridi, elytris striatis testaceis nigro nebulosis.

Long. corp. 2 lin.

Habitat in aquis.

Descr. Caput et thorax ut in Hy. stagnali. Elytra punctato-striata, testacea, liturâ magnâ communi nigrâ, in quâ maculæ duæ testaceæ apicem versus positæ sunt.

cinereus. 26. Hy. cinereus, elytris striis tribus elevatis nigro obsoletiusculè maculatis.

An Elophorus rugosus? Oliv. iii. $38.6 .2 . t .1 . f \cdot 5 \cdot$ a. b. Long. corp. $2 \frac{1}{2}$ lin.

Habitat in aquis.

Descr. Totum corpus unicolor, exceptò quod elytra hinc indè maculas quasdam nigras obsoletiusculas gerunt; et in medio dorsi puncta duo nigra. Elytra striis tribus elevatis, spatio inter strias punctato-rugoso. Thorax fermè ut in $H y$. stagnali.

mubilus. 27. Hy. fuscus, elytris striis tribus elevatis.

Elophorus nubilus. Fab. Gen. Ins. Mant.2r3. Sp. Ins. i.77.2. Mant.1.42.2. Ent.Syst.1.a. 204.2. Payk. Faun. Suec. i. 244. 5.

Oliv. iii. $3^{8}$. 6. 3. t. . . f. 2. a. b. Herbst. Jablonsk. v. I $40 \cdot 3 \cdot t \cdot 9 \cdot f \cdot 2 \cdot \mathrm{a}, \mathrm{b}$.

Long. corp. $\mathrm{I}_{4}^{3}$ lin.

Habitat in aquis.

DESCR. 

PZ.24.

DITISCே.
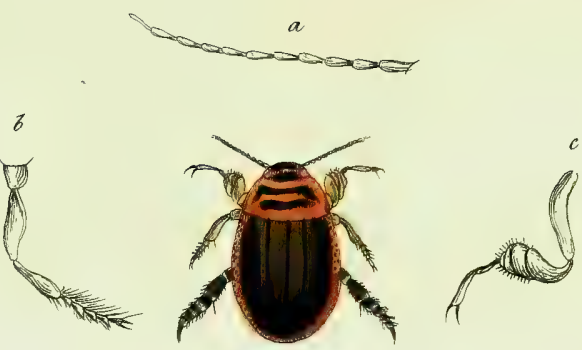

Of. cinereas. 
DEsCr. In omnibus præcedenti simillimus, sed colore fusco et magnitudine duplo minori differt.

28. Hy. nigro-æneus, oculis prominentibus, ely-cicindeloitris porcato-striatis.

Long. corp. 2 lin.

Habitat

Captus ad Barton. D. Sbeppard.

DEscr. Totum corpus nigro-æneum. Caput porrectum, oculis prominulis. Thorax posticè quadratus, foveolis tribus impressis. Elytra porcato-striata; inter strias lineæ duæ punctorum impressorum.

Obs. Cicindele simillimus est adeo ut tyronem facilius fallat.

\section{DYTISCUS.}

Antenna setacex.

Sternum bifidum.

Corpus ovatum, subtùs carinatum.

Pedes postici ciliati, natatorii.

* Elytris fomineis sulcatis. Majores.

** Utroque sexu lavi.

*** Capite exserto, femoribus posticis laminâ latâ tectis†.

* Elytris fomineis sulcatis. Majores.

I. Dyt. niger, thoracis marginibus coleoptrorum-marginalis. que limbo flavis, elytris masculis obsoletè bistriatis, fœmineis dimidiato-sulcatis.

Linn. Syst. Nat. 665. 7. Faun. Suec. 769. Vill.

$\uparrow$ Hanc laminam primus observavit et descripsit Dom. De Geer, iv. 104. 13.t. 16. f. 10.

i. $343 \cdot 7$. 
i. 343. 7. Scop. 294. Fab. Syst. Ent. 230. 3. Sp.Ins. i. 29r. 3. Mant. i. 189.3. Ent. Syst. i. a. 187.3. Panz. Ent. Germ. 73. 2. Harr. 181. Poda, 43. x. Faun. Fred. 19. 186. Preys. Bob. Ins. 19. I5. Faun. Ingr.90. Payk. Faun. Suec. i. 192. 2. Faun. Etrusc. 488. Hellw. 488. Gmel. 1944. 7.

Don. Brit. Ins.t. $161 . \quad$ Mart. Eng. Ent.t. $34 \cdot f \cdot 25 \cdot 26$.

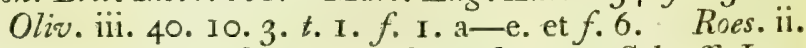
aquat. I. $t$. I. $f .9$. mas. $f$. Io. fom. Scbceff. Icon. t. 6. f. 42 .

Dytiscus toto-marginalis. De Geer, iv. 391. 2. t. I6. $f$. 2. mas. $f$. r. foem.

Le Ditique noir à bordure. Geoff. i. r86. 2 .

Fomina. Dytiscus semistriatus. Linn. Syst. Nat. 665.8. Faun. Suec. 772. Vill. i. 344. 8. Fab. Syst. Ent. 231. 5. Gmel. 1945. 8. Scbrank, 374.

Herbst. Jabionsk. vi. I66.2. t. 255. f.2. Scheef. Icon. t. $8 . f .7 .8$.

Dytiscus marginalis var. $\beta$. Fab. Sp. Ins. i. 29I. 3 .

Hydrocantharus nostras. Rai. 93. I.

Long. corp. maris I unc. 2 lin.

Habitat in aquis.

Descr. Niger. Os flavum. Vertex lineâ sublunulari et maculis duabus prope oculos rubentibus. Thorax cingitur undequaque margine luteo. Elytra margine cxteriori flava. Antenux, pedes et abdomen subtùs ferruginea. Apex sterni bifurcus.

Mas lavis. Elytra striis duabus vix manifestis longitudinalibus e punctis minutissimis notata: umbra flava vix manifesta apices visa est tingere. Pedes anteriores plantis hemisphæricis, patellitormibus, ad arctiorem copulam, nimirùm.

Femina punctata. Caput et thorax subtilissimè punctata. Elytra valdè sulcata, sulcis decem dimidiatis.

Obs. Color vivi olivaccus nec niger.

punctitatils.

2. Dyt. niger, thoracis elytrorumque margine flavo, elytris masculis obsolete bistriatis, foemineis dimidiato-sulcatis.

$F a b$. 
Fab. Ent. Syst. i. 2. 188. 4. Payk. Faun. Suec. i.193.3. Ent. Germ. 73. 3. Gmel. 1945. 2. Faun. Etrusc. 487. Hellw. 487. Harr. 182 .

Mart. Eng. Ent. t. 34. f. 24. Roes. ii, aquat. i. t. 2. $f: 3 \cdot 4 \cdot 5$. Scbaff. Elem. $t$. 7. $f$. I.

Dytiscus punctatus. Oliv. iii. 40.22. 4. $t$. I. $f$. 6. b. et f. 1. e.

Dytiscus laterali-marginalis. De Geer, iv. 396. 3 .

Le Ditique brun à bordure. Geoff: i. I85. I.

Long. corp. maris I unc. I lin. fœm. I unc.

Habitat in aquis.

Descr. Maximè affinis Dyt. marginali; sed abundè differt thorace lateribus solummodò nec omninò flavo; præterea abdomen subtùs atrum, nec ferrugineum. Pedes etiam picei, nec ferruginei. Fœminæ elytra multò minùs sulcata.

3. Dyt. cinereus, elytrorum margine thoracisque cinereus. medietate flavis, elytris masculis punctulatis, fomincis sulcatis.

Linn. Syst. Nut.666. I1. Faun. Suec.771. Vill. i. 345. I I. Fab.Syst.Ent.23 I.8. Sp.Ins. i. 293. I I. Mant. i. 190. I3. Ent. Syst.i. a. I90. 15. Pavk. Faun. Suec. i. 197.6. Harr. 183. Faun. Ingr. 94. Faun. Fred. 19. 187. Poda, 43. 2. Panz. Ent. Germ. 74. 8. Faun. Etrusc. 490. Hellw. 490.

Oliv. iii. 40. I7. I1.t. $4 \cdot f \cdot 32$. a. b. Roes. ii, aquat. i. t. 3. f. 6. Act. Nidros. 425. t. 16. f. II. Schaff: Icon. t.90. f. 7. Elem. t. 59. Mart. Eng. Ent. t. 32. f. 7. Panz. Faun. Germ. 3t. t. 9 .

Dytiscus fasciatus. De Geer, iv. 397. 4.

Le Ditique à corcelet à bandes. Geoff. i. I88. 4 .

Fœmina. Dytiscus sulcatus. Linn. Syst. Nat. 666. I3. Faun. Suec. 773. Vill. i. 345. I2. Fab. Syst. Ent. 231. 6. Sp. Ins. i. 292. 6. Mant. i. 190. 7. Ent. Syst.i.a.189.8. Payk.Faun.Suec. i. 195.4. Panz. Ent. Germ. 74. 5. Faun. Ingr. 91 . Faun. Fred. 19. 189. Faun. Etrusc.491. Hellw.49r. Rai.94.3. 


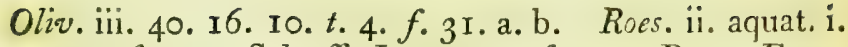
t. 3.f. 7. Scbaff. Icon. t. 3.f.3. Panz. Faun. Germ.31.t. Io. Don. Brit. Ins. t. 68. f.5. Mart. Eng. Ent.t. 32. f.8. Bradl. Nat.t. 27.f.2. A.

Long. corp. 9 lin.

Habitat in aquis frequens.

Descr. Os flavum. Caput nigrum, maculis quinque flavis, quarum duæ rotundæ prope oculos sunt: inter has altera cordata et in occipite duæ distinctæ lunulares transversè positæ sunt. Thorax niger, margine et lineâ transversâ flavâ. Apex sterni bifurcus est.

Mas. Elytra cinerea, striis tribus elevatis, vix manifestis, et punctis minimis confertis, lutescentibus : margo exterior elytrorum flavus, punctis nigris. Pedes anteriores ut in præcedentibus.

Fomina. Elytra cinerea, singula quatuor vel quinque sulcis latis longitudinaliter excavata, et pilis albidis in sulcis. Margo exterior elytrorum ut in mare.

\section{** Utroque sexu locvi.}

striatus. 4. Dyt. fuscus, elytris transverè̀ subtilissimè striatis. Linn. Syst. Nat.665.9. Faun. Suec.770. Vill. i. 344.9. Gmel. 1946. 9. Fab. Syst. Ent. 231. 7. Sp.Ins. i. 293.8. Mant. i. 190. 9. Ent. Syst. i. a. 189. то. Payk. Faun. Suec. i. 202. II. Panz. Ent. Germ. 74. 6. Faun. Ingr. 92. Faun. Etrusc. 494. Hellw. 494. Illiger. Kugel. Kaf. Preus. 257. 7.

Mart. Eng. Ent. t. 34. f. 27. Oliv. iii. 40. 18. I3. t. 2. $f .20$.

Dytiscus transversè striatus. De Geer, iv. 399.5.t. 15 . $f .16$.

Long. corp. 9 lin.

Habitat in aquis.

DESCR. Corpus mediæ magnitudinis. Elytra adeo tenuibus transversis confertissimis striis signata, ut vix armato oculo conspiciantur. Faun. Suec.

obscurus. 5. Dyt. niger, elytris maculis duabus fenestratis obsoletiusculis, antennis pedibusque piceis.

Dytiscus 
Dýtiscus ater? De Geer, iv. 40 r. 8.

Long. corp. 6 lin.

Habitat in aquis.

DESCR. Suprà niger, oculo benè armato punctis minimis adspersus. Elytra maculis duabus vix manifestis, alterâ in medio prope marginem, alterâ in apice. Corpus subtùs, antennæ et pedes picei.

6. Dyt. niger, fronte thoraccque flavis, elytriscollaris. flavis : punctulis numerosissimis nigris.

Payk. Faun. Suec. i. 200.9.

Long. corp. 5 lin.

Habitat in aquis.

Descr. Caput nigrum, maculâ triangulari flavâ in fronte, et lineâ transversâ interruptâ in occipite. Antennæ articulis supernè nigris, infernè flavis. Thorax flavus, lineâ posticè nigrâ. Elytra flava, punctulis per discum numerosissimis, nigris, confluentibus, sparsis. Pectus flavum, sterno canaliculato, posticè bifido, rotundato. Abdomen fusco-flavum. Pedes testacei, sive ferruginei.

Variat pectore nigro, et abdomine nigro marginibus segmentorum flavis.

7. Dyt. ater lævis, capite posticè punctis duobus bipustularubris.

Linn. Syst. Nat.667. 17. Vill.i. 347.16. Gmel.1948. I7. Fab. Syst. Ent. 232. 2. Sp. Ins. 1. 294. 15. Mant. i. 190.17. Ent. Syst. i. a. 191.20. Punz. Ent. Germ. 75. 10. Payk. Faun. Suec. i. 208. 17. Harr. 184. Faun. Etrusc. 492. Hellw. 492. Illiger. Kugel. Kaf. Preus. 260. I4.

Oliv. iii. 40.21. 18.t. 3. f. 26.

Long. corp. 5 lin.

Habitat in aquis.

Descr. Totus niger. Antennæe, palpi pedesque picea. 
Caput posticè juxta thoracem punctis duobus, sanguineis, paribus. Syst. Nat.

Obs. Puncta duo capitis rubra, vix nudo oculo conspicua. Ent. Syst.

acuductus. 8. Dyt. nigro-æneus lineolatus, elytris substriatis, antennis tibiis tarsisque anticis ferrugineis.

Long; corp. 5 lin.

Habitat in aquis.

Descr. Totus, etiam pectus et abdomen, lineolis quasi acu ductis variatus. Suprà obscurus, nigro-æneus, subtùs nigro-piceus; sed antennæ, palpi, os, tibiæ et tarsi primi paris ferruginei, seu rufo-picei. Interstitia striarum punctis aliquot sparsis.

uliginosus. 9. Dyt. ater nitidus, antennis pedibus clytrorumque latere exteriori ferrugineis.

Linn. Syst. Nat. 667.20. Faun. Suec.776. Vill. i. 348. 19. Gmel. 1950. 20. Fab. Syst. Ent. 232. I5. Sp. Ins. i. 295. 21. Mant. i. 191. 28. Ent. Syst. i.a. I94.3r. Panz. Ent. Germ. 77.21. Payk. Faun. Suec. i. 212. 22. Faun. Fred. 19. 191. Harr. 185 .

Mart. Eng. Ent. t: 32. f. 2. et 5 .

Long. corp. 5 lin.

Habitat in aquis.

Descr. Corpus ovatum, atrum, glaberrimum, adspersum punctis excavatis, obsoletis. Elytra margine laterali ferruginea. Pedes et antennæ rufæ. Faun. Suec.

fenestratus. 10. Dyt. suprà niger, subtùs ferrugineus, elytris punctis duobus fenestratis.

Fab. Sp. Ins. i. 294. 17. Mant. i. 190. 20. Ent. Syst. i. a. 192. 23. Vill. i. 349.23. Panz. Ent. Germ. 75. 12. Payk. Faun. Suec.1.207. 16. Gmel. 1949.37. Oliv. iii. 40.23.21.t. 3. f. 27. a. b.

Long. 
Long. corp. 5 lin.

Habitat in aquis.

Descr. Corpus subtùs ferrugineum, sive piceum. Caput nigrum, ore, antennis, punctisque duobus baseos ferrugineis. Thorax niger, margine ferrugineo. Elytra nigra, punctis duobus fenestratis, hyalinis, altero in medio, altero versus apicem. Sp. Ins.

I . Dyt. fuscus, ore thoracis medio elytrorum incequalis. marginibus maculisque ferrugineis.

Fab. Gen. Ins. Mant. 239. Sp. Ins. i. 297.35. Mant. i. 193. 50. Ent. Syst.i. a. 200. 62. Vill. i. 350. 32. Ent. Germ. 80.42. Gmel. 1951.55. Payk. Faun. Suec. i. 237. 52. var. $\beta$. ?

Panz. Faun. Germ. 14. t. 8.

Long. corp. $3 \frac{1}{2}$ lin.

Habitat in aquis.

D. Davie.

Descr. Antennæ et os ferruginea. Caput fuscum, maculis duabus triangularibus, ferrugineis. Thorax ferrugineus, basi apiceque fuscus. Elytra fusca, maculis octo irregularibus, marginibusque ferrugineis; macularum una posita est ad basin marginis exterioris lunulata, una in medio prope marginem irregularis, et una parva in apice obsoleta. Corpus totum subtùs pedes. que ferruginei.

I2. Dyt. lævis ater, ore thoracisque margine fer-Hybneri. rugineis, elytris lineâ marginali flavâ.

Fab. Mant. i. 190.21. Ent. Syst. i. a. 192.24. Panz. Ent. Germ. 75. 13. Gmel. 1949. 38. Payk. Faun. Suec. i. 205. I4. Illiger. Kugel. Kaf. Preus. 258. 9.

Oliv. iii. 40. 24. 22. t. 4. $f \cdot 33$.

Long. corp. 4 lin.

Habitat in aquis.

Descr. Caput nigrum, ore ferrugineo. Thorax niger, margine imprimis anticè ferrugineo. Elytra lævia, atra, lineâ marginali flavâ, quæ tamen apicem haud attingit. Corpus nigrum. Fab. Mant.

vol. I. $2 \mathrm{E}$ I3. Dyt. 
Hermanni. 13. Dyt. gibbus, capite thorace elytrorumque basi ferrugineis, elytris truncatis.

Fab. Syst. Ent. 232. 14. Sp. Ins. i. 295. 19. Mant. i. 191. 24. Ent. Syst. i. a. 193. 28. Vill. i. 349. 25. Panz. Ent. Germ. 76. 18. Gmel. 1949. 41.

Oliv. iii. 40. 25. 24. t. 2. f. 14. a. b. Mart. Eng. Ent.t. 33. $f$. 17 .

Dytiscus undulatus? Scbrank, 379.

Long. corp. $4 \frac{x}{2}$ lin.

Habitat in aquis.

Descr. Caput obscurè ferrugineum, oculorum orbitâ nigrâ. Thorax ferrugineus, margine antico et postico nigris. Elytra lævia, nigra, basi ferruginea, apice truncata. Abdomen ferrugineum, apice nigrum. $S p$. Ins.

maculatus. 14. Dyt. ovatus niger, thorace nigro: fasciâ pallidâ, elytris albo-maculatis.

Linn. Syst. Nat.666. 15. Faun. Suec. 777 . Vill. i. 346. I4. Gmel. I948. 15. Fab. Syst. Ent. 233. 17. Sp. Ins. i. 295. 23. Mant. i. 191. 30. Ent. Syst. i. a. 194. 34. Panz. Ent. Germ. 77. 23. Payk. Faun.wSuec. i. 218. 28. Faun. Fred. 19. I92. Poda, 44. 3. Udd. Diss. 22. 43. Illiger. Kugel. Kaf. Preus. 262.18.

Mart. Eng. Ent. t. 33. f. 18. Oliv. iii. 40. 27. 29. t. 2. f. 16. Bergstraes. Nom. i. 8. 45. 13. t. 8. f. 13. Dytiscus ornatus. Herbst. Arcb. t. 28. b. $f$. в.

Long. corp. $3 \frac{1}{2}$ lin.

Habitat in aquis.

DEsCr. Thorax pallidus, anticè et posticè nigricans. Elytra fusca, striis longitudinalibus pallidis, et nonnullis maculis pallidis versus latera. Faun. Suec.

bipunctatus. 15. Dyt. ater, thorace flavo: punctis duobus nigris, elytris flavo fuscoque variis.

Fab. Mant. i. 190. 19. Ent. Syst. i. a. 192.22. Vill. i. 350.36. Panz. Ent. Germ. 75. II. Payk. Faun. Suec. 
Suec.1.216.25. Faun. Fred.20.194. Gmel.1948.36. Faun. Etrusc. Mant. 167. Hellw. Mant. 167. Illiger. Kugel. Kaf. Preus. 262. 17.

Don. Brit. Ins. t. 3०3. Mart. Eng. Ent. t. 33. f. I9. Oliv. iii. 40. 22. 20. t. 2. f. I5.

Long. corp. $4 \frac{x}{2} \operatorname{lin}$.

Habitat in aquis.

DEsCr. Caput nigrum, ore subferrugineo. Thorax flavus, punctis duobus dorsalibus atris. Elytra lævia, glabra, fusca, flavo variegata. Corpus atrum. Pedes ferruginei. Fab. Mant.

16. Dyt. piceus nitidus, elytris dilutioribus. politus. Long. corp. 3 lin.

Habitat in aquis.

Descr. Antennæ rufo-ferrugineæ. Caput et thorax picea, thoracis lateribus dilutioribus. Elytra glaberrima, thorace paulò pallidiora, sordidè ferruginea. Pedes rufo-ferruginei. Abdomen nigro-piceum.

I7. Dyt. convexus ferrugineus totus. ovatus.

Linn. Syst. Nat.667.18. Vill.i.347.17. Scbrank, 380. Gmel. 1950. 18. Payk. Faun. Suec. 1. 234. 47. Fab. Ent. Syst. i. a. 196. 45. Illiger. Kugel. Kaf. Preus. 270.31. Faun. Etrusc. 496. Hellw. 466.

Mart. Eng. Ent. t. 33. f. I2. Oliv. iii. 40. 33. 39. t. 3. f. 28. Donov. Brit. Ins. t. 68. f. 3. 4 .

Dytiscus sphæricus. De Geer, iv, 402.9. t. I5.f. I7-19. Ditique sphérique. Geoff. i. 191. I0.

Long. corp. 2 lin.

Habitat in aquis.

Descr. Corpus valdè convexum, obscurum, totum rufum, sive ferrugineum.

Variat. Elytris rufo-fuscis, sive piceis nitidis.

18. Dyt. elytris fuscis basi lateribusque pallidis, minutus. thorace flavo immaculato, corpore ovato. 
Linn. Syst. Nat. 667.23. Faun. Suec. 778. Vill. i. 348.22. Gmel. 195I. 23. Fab. Syst. Ent. 234. 26. Sp.Ins. i. 297.36. Mant. i. 193.51. Ent. Syst. i. a. 200. 63. Panz. Ent. Germ.81.47. Payk. Faun. Suec. i. 229. 40. Scbrank, I50.

Mart. Eng. Ent. t. 13. f. 13 .

Dytiscus hyalinus. De Geer, iv. 406. I4. $t$. I5. f. $21-23$. Dytiscus amœenus. Oliv. iii. 40.32. 38.t. 5. f. 49. a. b. Dytiscus obscurus. Panz. Faun. Germ. 26. $t$. 3 .

Long. corp. 2 lin.

Habitat in aquis.

DEscr. Thorax pallidus. Elytra cinerea, lateribus striis pallidis aliquot et obliquis. Faun. Suec.

byalinus. I9. Dyt. ovatus fuscus, capite thoraceque flavis, elytris punctulatis pellucidis.

Long. corp. 2 lin.

Habitat in aquis.

Descr. Caput et thorax obscurè flava. Oculi nigri. Elytra sublente punctulata, punctulis numerosissimis, et quod in hoc singulare, pellucida, adeo ut alarum plicæ manifestè transluceant. Abdomen subtùs testaceum. Pedes ex piceo-ferruginei.

crassicor - 20. Dyt. ferrugineus, antennis medio crassioribus, nis. abdomine piceo.

Fab. Mant. i. 193.52. Ent. Syst. i. a. 201. 66. Payk. Faun. Suec. i. 227. 38. Panz. Ent. Germ. 81. 48. Illiger. Kugel. Kaf. Preus. 267. 25.

Oliv. iii. $40.37 \cdot 45 \cdot$ t. $4 \cdot f_{\text {. }}$ II. a. b.

Dytiscus clavicornis. De Geer, iv. 402. Io. Vill. i. 353.16.

Le Ditique à grosses antennes. Genff. i. 193. I5.

Dytiscus capricornis. Herbst. Arch. v. 128. 25. t. 28. b. $f$. C. b. c.

Long. corp. $2 \frac{r}{2}$ lin.

Habitat in aquis.

DËSCR. 
DESCR. Antennæ articulis quatuor mediis majoribus, ferrugineæ. Oculi nigri. Caput et thorax ferruginea, elytris paulò pallidiora. Abdomen subtùs piceum. Pedes ferruginei.

21. Dyt. niger pubescens, capite thoracis elytro-dorsalis. rumque marginibus pedibusque rufis.

Fab. Mant. i. 192.36. Ent. Syst. i. a. 196. 42. Panz. Ent. Germ. 78. 28. Gmel. 1948. 33.

Oliv. iii. 40.30.34.t. I. f.3. a.b. Panz. Faun. Germ. I4. $t .2$.

An Dytiscus rufifrons? Fab. Ent. Syst. i. a. 198. 53.

Long. corp. 2-2 $\frac{x}{2} \operatorname{lin}$.

Habitat in aquis.

DEscr. Antennæ filiformes, extrorsùm nigræ, basi rufæ. Oculi nigri. Caput rufum, foveolis duabus excavatum. Thorax niger, lineà mediâ transversâ elevatâ, lateribus præcipuè ad lineam elevatam rufis. Elytra nigra, lævia, marginibus punctoque medio obsoleto ad basin rufis. Pedes rufi. Abdomen subtùs piceum. Alter sexus absque puncto in medio elytrorum.

22. Dyt. testaceo-ferrugineus, elytrorum discoelegans. nigro lineato utrinque pinnato-sinuato.

Panz. Ent. Germ. 8r. 46. Illiger. Kugel. Kaf. Preus. 265. 22.

Panz. Faun. Germ. 24. $t .5$.

Dytiscus Neuhoffi. Faun. Ingr. Ior. t. 2.f.1.

Dytiscus 12-pustulatus var. Oliv. iii. $t \cdot 5 \cdot f \cdot 46$. c. d.

Long. corp. 2 lin.

Habitat in aquis stagnantibus.

DESCR. Antennæ, caput, thorax testaceo-ferruginea. Thorax posticè maculâ nigrâ, marginali, bilobâ. Elytra disco nigro-lineata. Nigredo autem utrinque pinnato-sinuata, haud marginem exteriorem aut apicem attingens; undè elytra visa sunt nigro ferrugineoque varia; sive maculis sex notata, quatuor lateralibus connexis. Corpus subtùs ferrugineum. Pedes ferruginei.

\section{E 3}

23. Dyt. 
I2-pustu- 23. Dyt. testaceus, elytris nigris: maculis sex latus.

\section{testaceis.}

Fab. Ent. Syst. i. a. 197. 50. Payk. Faun. Suec. i. 220. 29.

Oliv. iii. $40.31 \cdot 35 \cdot t \cdot 5 \cdot f \cdot 4^{6}$. a. b.

Long. corp. 3 lin.

Habitat in aquis.

Descr. Caput cum antennis testaceum. Thorax testaceus, margine antico laté posticèque maculâ bilobâ nigris. Elytra lævia, nigra, maculis sex 2.2.2. obliquè positis, apice ipso nigro. Corpus et pedes testacea. Obs. Duo quæ præcedunt insecta, Dytiscus elegans et 12-pustulatus, valdè affinia sunt, (forsitan ex sexu solummodò differre putes,) adeò ut perdifficile est rectè dijudicare. Auctores ad quos de Dyt. eleganti relatum est, icones hujusce speciei fidissimas sanè exhibuerunt, at I2-pustulatum neque descripserunt neque adumbraverunt. Contra autem Olivier utrumque depinxit, quasi alterutrum unum idemque animal, aut saltem quasi hæc duo meræ ejusdem species fuerint varietates. His autem omnibus ritè perpensis, visum est tutius fore, si species distinctas dicam, donec dies tandem dubitationem melior ademerit. Dyt. I2-pustulatus $\frac{1}{3}$ major Dyt. eleganti evadit, et apud nos rarus admodum; duo specimina tantùm hactenus mihi contigit videre; hæc duo autem eodem tempore et ab eâdem manu capta fuerunt. Dyt. elegans vulgaris est, capiendusque in ferè omni aquâ stagnali.

Bumeralis. 24. Dyt. capite thoraceque atris, elytris margine baseos obsoletè ferrugineo.

Long. corp. 2 lin.

Habitat in aquis stagnantibus.

Descr. Caput et thorax atra, opaca. Elytra picea, sub lente punctulata, tomentosa, ad angulum baseos exteriorem maculâ obsoletâ, ferrugineầ. Antennæ filiformes, nigræ, basi rufæ. Pedes picei. Macula basens elytrorum variat satìs magna et minuta; inde Dyt. 
Dyt. melanocepbalo simillimus, sed dignoscitur magnitudine; tum elytris sub lente tomentosis, nec glaberrimis.

25. 'Dyt. niger glaberrimus, antennis pedibusque melanopiceis. cepbahus.

Long. corp. $\mathrm{I} \frac{\mathrm{T}}{4}$ lin.

Habitat in aquis. Captus in horto D. Goodenough, Ealing.

Descr. Antennæ filiformes, ut in Stapbylinis quibusdam, nigræ, basi rufæ. Totum corpus unicolor, pi- ceo-nigrum. Pedes ex rufo-picei. Sub lente elytra minutissimè punctata videntur. Corpus haud nitet, neque tamen omninò obscura.

26. Dyt. obscurè ferrugineus, coleoptris maculâ lituratus. magnâ nigrâ utrinque repando-sinuosâ.

Fab.Sp.Ins, i. 296. 31. Mant. i. 192. 4I. Ent. Syst. i. a. 197.47. Vill.i. 350.30. Gmel. 1950.46. Panz. Ent. Germ. 78. 32.

Panz. Faun. Germ. I4. $t .4$.

Long. corp. $\mathrm{I} \frac{3}{4}$ lin.

Habitat in aquis.

Descr. Totum corpus obscurum. Antennæ et pedes rufo-ferruginei. Thorax niger, marginibus ferrugineis. Coleoptra medio maculam nigram gerunt; quæ macula a basi elytrorum conspecta, quodammodò pupam lusoriam expansam quâ gaudent puellæ, refert.

27. Dyt. ferrugineus, thoracis basi apiceque ni-trifidus. gro-marginato, coleoptris maculâ communi irregulari nigrâ.

Panz. Ent. Germ. 76. 16.

Panz. Faun. Germ. 25. t. 2.

An Dytiscus inæqualis? Oliv. iii. 40. 36. 44. t. 3. $f$. 29. a. b. 
Long. corp. $\mathrm{I} \frac{x}{4}$ lin.

Habitat in aquis.

Descr. Caput ferrugineum. Oculi nigri. Thorax ferrugincus, margine antico et postico nigro. Coleoptra punctulata, ferruginea, maculâ nigrâ, magnâ, valdè irregulari, aquilæ expansæ haud multùm absimili. Abdomen subtùs et pedes ferruginei. Macula coleoptrorum vix nisi eleventur conspicienda.

confluens. 28. Dyt. testaceus, elytris pallidis posticè atrolineatis.

Fab. Mant. i. 193.46. Ent. Syst. i. a. 198.55. Gmel. 1951.61. Panz. Ent. Germ. 79. 35. Payk. Faun. Suec. i. 230.42.

Panz. Faun. Germ. 14. t. 5 .

Long. corp. I $\frac{x}{2}$ lin.

Habitat in aquis stagnantibus.

Descr. Antennæ, caput, thorax et pedes testacei. Elytra pallida, posticè lineis quatuor atris depicta. Abdomen subtùs nigrum. Oculi et sinciput nigra.

recurvus. 29. Dyt. testaceus gibbus, thoracis margine postico nigro, elytris suturâ lineisque nigris.

Dytiscus collaris. Panz. Ent. Germ. 79.38.

Panz. Faun. Germ. 26. t. 4.

Long. corp. $1 \frac{\mathrm{x}}{4}$ lin.

Habitat in aquis.

Descr. Antennæ testaceæ. Caput testaceum, occipite nigro. Oculi nigri. Thorax testaceus, margine postico tenui nigro. Elytra testacea, basi suturẩ lineisque nigris; nigredo autem baseos non ad margines pertingit. Linearum, illa quæ ad marginem exteriorem sita est, a basi ortum ducit, et sub medio recurva est, unco extrorsùm verso: quæ autem ad suturam, intra apicem incipit, et ante basin desinit: cæteræ huic parallelæ sed multò breviores. Abdomen subtùs et pedes rufo-testacei. 
30. Dyt. oblongo ovatus planus niger, tibiis solis planus. rufis.

Fab. Sp. Ins. App. ii. 501.24: Mant. i. 192.32. Ent. Syst. i. a. 195. 36. Vill. i. 350.34. Panz. Ent. Germ. 77. 26. Payk. Faun. Suec. i. 223. 33.

Long. corp. $1 \frac{1}{4}$ lin.

Habitat in aquis. Ex mus. D. Kirby.

Descr. Corpus planum, læve, vix nitidum. Tibiæ ferrugineæ. Sp. Ins. App.

3r. Dyt. niger ovatus convexus, capite flavo, flexuosus. elctris lineâ flavâ literæ $\mathrm{G}$ instar flexuosâ.

An Dytiscus arcuatus? Panz. Ent. Germ. 75, 15.

Panz. Faun. Germ. 26. t. I.

Long. corp. I lin.

Habitat in aquis. Ex mus. D. Latbbury.

DEscr. Antennæ nigræ, basi flavâ. Caput flavum. Oculi nigri. Elytra punctulata, nigra, lineâ flavầ flexuosâ, literam $\mathrm{G}$ referenti; sinus literæ marginem exteriorem spectat. Abdomen subtùs nigrum. Pedes ferruginei. Corpus parùm nitescit.

32. Dyt. ferrugineus, elytris fuscis margine fer-ovalis. rugineis.

Long. corp. $1 \frac{1}{2}$ lin.

Habitat in aquis stagnantibus.

Descr. Antennæ, caput, thorax, corpus subtùs et pedes ferruginea. Elytra fusca, maculâ obsoletâ ad basin, margineque exteriori ferrugineis.

33. Dyt. fuscus, elytrorum marginibus flavican-frontalis. tibus, capite thoraceque flavis nigro maculatis.

Long. corp. 5 lin.

Habitat in aquis.

DESCR. 
Descr. Antennæ flavæ, articulis apice nigris. Caput flavum, posticè nigrum, punctis duobus flavis. Oculi nigri. Thorax flavus, maculis nigris : macula dorsalis longè major est. Elytra lævia, ne minimè quidem striata, fusca, marginibus flavicantibus. Pectus et sternum nigra. Abdomen flavum, punctis lateralibus, marginibus incisurarum nigris. Pedes flavi.

gramularis. 34. Dyt. niger, elytris lineis duabus flavescentibus, pedibus rufis.

Linn. Syst. Nat.667.22. Vill. i. 348.21. Fab. Syst. Ent. 234. 24. Sp. Ins, i. 296.33. Mant. i. 193.45. Ent.Syst. i. a. 198.54. Payk. Faun. Suec. i. 231.43 . Faun. Etrusc. 503. Hellw. $5 \circ 3$.

Long. corp. $\frac{3}{4}$ lin.

Habitat in aquis.

Descr. Elytra singula lineis duabus diaphanis, longitudinalibus, apice concurrentibus, quæ, dum animal adhuc in aquis versatur, aureæ apparent.

lineatus. 35. Dyt. testaceus, elytris pallidis atro-lineatis. Fab. Ent. Syst. i. a. 200. 6r. Payk. Faun. Suec, i. 227.37. Panz. Ent. Germ. 80. 4I.

Oliv. iii. 40. 35 . 43. t. v. $f$. 44. a. b.

Long. corp. $2 \frac{2}{3}$ lin.

Habitat in aquis. In mus. D. Kirby.

Descr. Antennæ, caput, thorax et pedes testacei.

Thorax maculâ rhomboideâ, mediâ, nigrâ. Elytra pallida, lineis octo longitudinalibus nigris, exterioribus interruptis. Sutura nigra. Abdomen atrum.

punctatus. 36. Dyt. ater, fronte thoraceque fulvis, elytris fulvis atro-nebulosis punctatis.

Long, corp. 2 lin.

Habitat in aquis.

In mus. D. Kirby.

Descr. Caput atrum, fronte fulvâ. Thorax fulvus, anticè et posticè fuscus. Elytra fulva, atro-nebulosa, punctata, 
punctata, striis duabus longitudinalibus in singulo elytro. Abdomen atrum, punctatum. Antennæ pedesque fulvi.

37. Dyt. griseus, capite nigro: posticè maculis conspersus. duabus rubris.

Long. corp. 4 lin.

Habitat in aquis.

DESCR. Antennæ ferrugineæ. Caput nigrum, ore ferrugineo, posticè punctis duobus rubris, sive obscurè ferrugineis. Thorax flavus, ad medium obscurior. Elytra grisea, obsoletè striata; striis ex punctulis impressis. Corpus subtùs atrum, nitidum. Pedes picei.

38. Dyt. nigro-æneus nitidus, abdomine pedibus-concinnus. que rufo-ferrugineis.

An Dytiscus æneus? Panz. Faun. Germ. 38. t. 16.

Long. corp. 4 lin.

Habitat in aquis.

Descr. Antennæe et os ferruginea. Caput, thorax, elytra et sternum nigro-ænea. Elytra obsoletè striata, striis ex punctulis impressis. Abdomen er pedes rufoferruginei.

39. Dyt. niger nitens, pilis brevissimis sparsis. bolosericeus. Lung. corp. 2 lin.

Habitat in aquis.

DESCR. Totum corpus suprà nigrum, pilis nitentibus flavis obtectum, quasi holosericeum. Corpus subtùs atrum. Pedes ferruginei.

40. Dyt. lævis niger, fronte thoracisque margine parapleurus. ferrugineis, elytrorum marginibus flavis nigro punctatis.

Long. corp. $6 \frac{2}{3}$ lin.

Habitat in aquis.

In mus. D. Kirby.

DEscR. 
Descr. Antennæ et frons ferruginea. Thorax niger, lineis tortuosis impressis, quasi vermiculatus, margine ferrugineo. Elytra nigra, obscurè striata, lineâ flavâ latâ ad marginem : in lineâ puncta nigra longitudinaliter posita.

nigroaneus.

4I. Dyt. lævis obscuro-æneus, ore thoracis elytrorumque marginibus brunneis.

Long. corp. 5 lin.

Habitat in aquis.

In mus. D. Kirly.

Descr. Antennæ et os brunnea. Thorax lævis, nigroæneus. Elytra nigro-ænea, punctis minutis impressis, striatim positis, marginibus brunneis. Corpus subtùs et pedes brunnei.

picinus. 42. Dyt. nigro-piceus nitidus, antennis pedibusque ferrugineis, elytris rarò punctulatis.

Long. corp. 4 lin.

Habitat in aquis. In mus. D. Kirby.

DESCR. Corpus totum politum, nigro-piceum. Elytra punctulis raris seriatim positis.

*** Capite exserto, femoribus posticis laminâ latâ tectis.

ruficollis. 43. Dyt. rufus, elytris striatis flavo-griseis : maculis quatuor nigris.

De Geer, iv. 404. 13. t. 16. f. . .

Dytiscus impressus. Oliv. iii. 40.34.42.t.4. f. 40. a. b. Panz. Faun. Germ 14, t. 7.?

Dytiscus minutus. Don. Brit. Ins. t. 68. f. I. 2.

Le Ditique strié à corcelet jaune. Geoff. i. I9I. I2.

Hydrophilus minutus. Fab. Syst. Ent. 229.8. Sp. Ins. i. $290.9 . M . n t$. i. 188. тo.

Chrysomela minuta. Linn. Syst. Not.593.50. Faun. Suec. 533. Vill. i. 133.36. Goeze, i. 271. 50.

Long. corp. 1 lin.

Habitat in locis subhumidis, et in aquosis.

DESCR. 
Descr. Corpus ovatum, gibbum. Caput, thorax et abdomen subtùs ferruginea. Oculi nigri. Elytra pallida, flavescentia, maculis nigris et striis fuscis ; striæ ex punctis nigricantibus, oculo armato conspicuis. Antennæ et pedes ferruginei.

Obs. Hunc cum Ill. De Geer Dytiscis adscripsimus; quippe characteres Dytiscorum omnes sibi vindicat; at pedes postici unguiculati, nec ut in congeneribus acuti, inermes.

44. Dyt. rufus, elytris striatis flavo-griseis: ma-assimilis. culis sex nigris.

Long. corp. 2 lin.

Habitat -

Descr. Statura omninò Dyt. ruficollis, sed duplo major; differt etiam in macularum numero, et in longitudine pedum, qui in hâc specie breviores sunt.

45. Dyt, rufus, thorace depresso utrinque foveato : lineatolineâ intermediâ nigricanti, elytris testaceis ni- collis. gro-maculatis.

Long, corp. $1 \frac{1}{2}$ lin.

\section{Habitat}

Descr. Caput saturatè rufum. Oculi nigri. Antennæ ferrugineæ. Thorax posticè trilobus, lobo intermedio subacuminato, per totam latitudinem depressus. Elytra striata, punctis nigris, maculis aliquot nigris oblongis notata. Subtùs rufo-ferrugineus.

46. Dyt. rufo-ferrugineus, elytris maculis pluri-interpuncbus nigris obliquè positis.

tatus.

Long. corp. $2 \frac{1}{4}$ lin.

Habitat in aquis.

Descr. Capitis colores intensiores. Thorax subtrilobus, posticè excavato-punctatus. Elytra punctatostriata, punctis nigris, interstitiis nigro-maculatis. 
Aavicollis. 47. Dyt. rufus, elytris flavo-testaceis nigro-nebulosis, pedibus posticis longissimis.

Long. corp. $I \frac{x}{2}$ lin.

Habitat in aquis.

Descr. Caput rufum. Oculi prominuli, nigri. Antennæ testaceæ. Thorax flavicans, posticè obsoletè trilobus, punctatus. Elytra striata, striis e punctis nigris constantibus, maculis aliquot obsoletis nigris confluentibus nebulosa. Pedes postici longissimi.

elevatus. 48. Dyt. testaceus, elytris striatis nigris: lineâ elevatâ abbreviatâ.

Panz. Ent. Germ. 81. 44.

Panæ. Faun. Germ. I4. . 9 .

Long. corp. 2 lin.

Habitat in aquis.

Descr. Caput testacenm. Oculi nigri. Thorax latus, truncato-cordatus, testaceus. Elytra testacea, striata, striis nigris ex punctis nigricantibus oculo armato conspicuis. Quod notabile est in hoc animali, linea longitudinalis elevata abbreviata in singulo elytro videtur. Abdomen subtùs nigrum. Pedes laminæque testaceæ.

sparsus. 49. Dyt. oblongo-convexus ferrugineus nitidus, thoracis dorso coleoptrorumque disco obscurioribus, elytris punctis sparsis impressis.

Long. corp. 5 lin.

Habitat in aquis.

DESCR. Antennæ, caput et pedes rufo-ferruginei. Thorax rufo-ferrugineus, maculâ dorsali obscuriori, sive fuscâ. Elytra fusca, sive fusco-ferruginea, margine dilutiora, punctis impressis ad basin in tribus lineis dispositis, ad apicem sparsis inordinatis. Corpus subtùs ferrugineum. 



\section{CABBABGOS.}
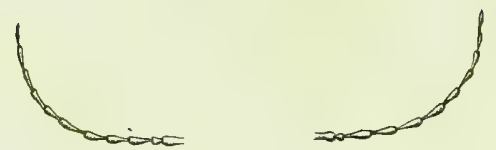

8

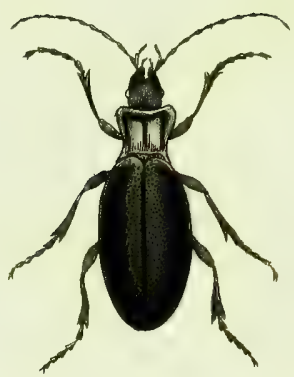

is

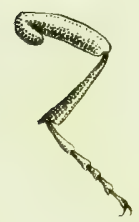

C. viotaceus. 


\section{[ 43 r ]}

\section{CARABUS.}

\section{Antennce filiformes.}

Thorax obcordarus, posticè truncatus, marginatus.

Elytra inarginata. Abdomen ovatum.

Femora postica basi appendiculata.

* Tborace posticè angulato.

* Tborace posticè truncato integro, elytris cequali.

*** Thorace postice truncato integro, elytris angustiori. *** Tbor ce posticè truncato integro, elytris angustiori, sub-elongato, attenuato.

***** Thorace posticè rotundato.

****** Tborace remoto.

\section{* Tborace posticè angulato.}

I. Car. alatus niger, elytris lævibus: striis obso-leucopbletis octo, apice thoracis elytris sub-duplo an- thalmus. gustiori.

Linn. Syst. Nat. 668. 4. Faun. Suec. 784. Faun. Fred. 20. 199.

Carabus spiniger. Payk. Monog. 25. Faun. Suec. i. I 14.23 .

Oliv. iii. $35 \cdot 44 \cdot 45 \cdot t \cdot 5 \cdot f \cdot 5^{8}$. et $t .12 \cdot f \cdot 58 . \mathrm{b}$.

Carabus planus. Fab. Ent. Syst. i. a. 133.37.

Panz. Faun. Germ. II. t. 4 .

Carabus obsoletus. Faun. Etrusc. 514. Hellw. 514.

Long. corp. I unc.

Habitat

DESCR. Diu apud entomólogos contentio fuit, quisnam sit Linnæi Car. leucopbtbalmus. Apud plerosque noster 
Car. angustior leucopbtbalmus audivit. At ille Linnæana descriptione minimè convenit, quippe elytra manifestissimè striata, tum thorax posticè non angustior quam in cæeteris. Quem nos leucopbtḅalmum diximus, in omnibus descriptioni Faun. Suec. consentaneus, præterquam quod alatus est. Hoc autem signum, ut mox ostendemus, fallax est. Striæ elytrorum obsoletæ, punctatæ, quasi acu tenuissimâ elaboratæ. Thorax posticè elytris simul sumptis ferè duplo angustior est, et lineâ mediâ foveâque utrinque excavatur. Antennarum articulus tertius (ratione a basi habitâ, basi autem ipsâ in numerum receptâ) longissimus.

Sexus alter appendiculo ad basin femorum-posticorum spinaso, longitudine ferè dimidii femoris.

eus. 2. Car. apterus, elytris læviusculis nigris: margine aureo, thorace subviolaceo.

Linn. Syst. Nat. 669. 8. Faun. Suec. 787. Vill. i. 360. 8. Scbrank, 392. Gmel. 1963.8. Fab. Syst. Ent.236. 2. Sp. Ins. i. 299. 3. Mant. i. I95. 5. Ent. Syst. i. a. 225.5. De Geer, iv. 89.3. Payk. Monog. 3. Faun. Suec. i. Ioo. 3. Panz. Ent. Germ. 44. 3. Illiger. Kugel. Kaf. Preus. 148. 9. Act. Nidros. iv. 330. 29. Harr. 193.

Don. Brit. Ins. t. 222. f. I. Mart. Eng. Ent. t. 36. f. 16. Oliv. iii. 35. 19. 10. t. 4. f. 39. Panz. Voet. ii. 80. 30.t.37.f.30. Bergstraes. Nom. ii. 16. I4. t. 2.f. 14. Panz. Faun. Germ. 4. t. 4 .

Le Bupreste azuré. Geoff. i. 144. 4.

Long. corp. I 3 lin.

Habitat

DESCR. Corpus nigrum, thoracis elytrorumque marginibus violaceis. Elytra lævia, subtilissimè rugosa, minimè striata. Antennæ nigræ, apice fuscæ. Oliथ.

intricatus. 3. Car. aptcrus violaceo-niger, elytris intricatis elevato-striatis punctulatisque.

Linn. Faun. Suec. 780. Vill. i. 363. 12.

Oliv. iii. 35 . 20. 11.t. 1. f. 11.t. 4. f. 44 .

Carabe 
Carabe azure. De Geer, iv. 89. 3 .

Long. corp. I unc.

Habitat

DEscr. Statura et magnitudo omninò Car. violacei, al differt thorace magìs violaceo, elytris magis rugosis, substriatis, triplicique serie punctorum impressorum. Oliv.

4. Car. apterus viridi-æneus, clytris obsoletè ru-bortensis. gosis: punctis excavatis triplici serie.

Linn. Syst. Nat. 668. 3. Faun. Suec.783. Vill. i. 358. 3. Gmel. 196r.3. Sibrank, 389. Fab. Syst. Ent. 237. 7. Sp. Ins. 1. 300. 10. Mant. i. 196. 16. Ent. Syst. i. a. 127. 13. Payk. Monog. 7. Payk. Faun. Suec. i. 102. 7. Panz. Ent. Germ. 46. 9. Faun. Fred. 198. Illiger. Kugel. Kaf. Preus. I50. 13. Faun. Etrusc. 506. Hellw. 506.

Oliv. iii. 35.27.22.t. 4. f. 33. a. Scbaff. Icon.t. II. f. 2. Panz. Voet. ii.83. 33. t. 37.f. 33. Panz. Faun. Germ. 5. t. 2.

Long. corp. I I lin.

Habitat

Descr. Affinis maximè Car. violaceo, sed differt colore viridi-æneo, nec violaceo; margines autem thoracis elytrorumque sæpiùs subviolacei; elytra striis tribus punctorum excavatorum, quibus Car, violace is caret.

5. Car. apterus, elytris striis tribus punctorum ele-gramilatus. vatorum : lineâ unicâ elevatâ interpositâ.

Linn. Syst. Nat. 668. 2. Faun. Suev.781. Vill. i. 355. 2. Gmel. 1960.2. Scop. 263. Fab. Syst. Ent.238. 14. Sp.Ins. i, 301. I7. Mant. i. 197.25. Ent. Syst. i. a. 130. 28. Scbrank, 393. Payk. Monog. 9. Faun. Suec. i. IO4. 9. Faun. Fred. 20. 197. Pontop. 1. 577.2. De Geer, iv. 88. 2. Panz. Ent. Germ.47. 18. Illiger. Kugel, Kef. Prens. 154. 17. Faun. Etrusc. 508. Hellw. 508.

Don. Brit. Ins. t.221.f.3. Mart. Eng. Ent. t. 37.f.30. VOL. I. 
Scbaff. Icon. t. 18. f. 6. Oliv. iii. $35 \cdot 34 \cdot 32 . t .2$. f. 13. et $f .20$. a. b. Panz. Voet. ii. 81. 3 I. t. 37 . f. 3i. Bergstraes. Nom. i. 12.73. 4. 5.t. I2. $f .4 \cdot 5$. Le Bupreste gallonné. Geoff. i. 143. 3 .

Long. corp. Io lin.

Hebitat

DEscr. Color variat modò æneus, modò violaceus. In singulo elytro, lineæ tres elevatæ, singula inter singulam punctorum elevatorum seriem. Puncta elevata variant ovata, oblonga, aut linearia. Lineæ elevatæ utrinque propter sua latera lineolam obsoletam habent. Geoffroyus primus characterem notavit.

catenula- 6. Car. apterus, elytris striis tribus punctorum tus. elevatorum lineis ternis elevatis interpositis.

Scop. 264. Scbrank, 39o. Vill. i. 363. 14. Panz. Ent. Germ.45.5. Gmel. I968. 89.

Oliv. iii. $35 \cdot 3^{6 \cdot 34 \cdot t \cdot 3 \cdot f \cdot 29 .}$ Panz. Faun. Germ. 4. t. 6. Scbaff. Icon. $t$. I I. $f$. 2.?

An Carabus arvensis? Payk. i. 105. I0.

Long. corp. I I lin.

\section{Habitat}

Descr. Simillimus Car. granulato, at tres lineæ omnes æquali magnitudine, singulo punctorum elevatorum ordine interpositæ, abundè indicant. Variat colore æneo, viridi-æneo aut violaceo.

Variat $\beta$ lineis ternis elevatis, mediâ majori, lateralibus obsoletiusculis; distinctus tamen a Car. granulato, thorace utrinque ad apicem producto, tum magnitudine ferè duplo majori.

rugulosus. 7. Car. apterus, thorace æneo, elytris viridibus anticè striatis: apicibus marginibusque rugosis. Long. corp. I $₫$ lin.

Habitat

In mus. D. Kirby.

DESCR. Aspectu primo simillimus Car. catenulato, at lineæ duæ punctorum elevatorum solùm distinctæ videntur; 
dentur; tum in hoc puncta elongatiora sunt. Lineæ tertia, quarta et quinta dimidiatæ concurrunt.

8. Car. apterus, elytris porcatis : striis passim in-nitens. terruptis sulcisque scabriusculis inauratis.

Linn. Syst. Nat. 669. 6. Faun. Suec. 785. Vill. i. 359.6. Gmel. 1963.6. Fal. Syst. Ent. 239. I7. Sp. Ins. i. 302. 22. Mant. i. 197.30. Ent. Syst. i. a. I3I. 30. Payk. Monog. I2. Faun. Suec. i. 106. 12. Harr. 197. Panz. Ent. Germ. 48. 20. De Geer, iv. 91. 6. Illiger. Kugel. Kaf. Preus. 158.22. Don. Brit. Ins. $t .3 \mathrm{I} 3 . \quad$ Mart. Eng. Ent. $t .3^{6 . f .} .20$. Oliv. iii. 35. 38. 38. t. 2. f. I8. Scbaff. Ícon. t. $5^{\text {I. }}$ f. $\mathrm{x}$.

Buprestis marginatus. Panz. Voet. ii. 87. 41. t. $3^{8 .}$ f. $4 \mathrm{I}$.

Long. corp. $7-9$ lin.

Habitat

DEscr. Antennæ nigræ. Thorax scabriusculus, aureus, anticè posticèque emarginatus. Elytra viridiaurea, sulcis quatuor rugosis, lineisque tribus elevatis, lævibus, nigris. Margo aureo-nitens. Corpuss subtùs pedesque nigra. Oliv.

* Thorace posticè truncato integro, elytris cequali.

9. Car. ater, elytris striatis: posticè utrinque li-depressus. neolis duabus abbreviatis excavatis.

Oliv. iii $35 \cdot 54 \cdot 63 \cdot t \cdot 4 \cdot f \cdot 46$.

Carabus striola. Fab. Ent. Syst. i. a. 146. 95. Panz.

Ent. Germ. 53. 45 .

Panz. Faun. Germ. 1 I. $t .6$.

Long. corp. 9 lin.

\section{Habitat -}

DESCR. In omnibus Car. angustiori simillimus, præterquam theracis latitudine. In hoc apex thoracis basin elytrom exactè rquat. Thorax etiam rugis sive lineis transversis undulatis insignis.

$$
2 F_{2}
$$

'10. Car. 
gibbosus. 10. Car. ovatus convexus gibbus, elytris crenatostriatis, pedibus antennisque piceis.

Long. corp. 7 lin.

Habitat Captus in Rubo frulicoso, prope Colchester. D. Curtis. Propter sepes in agro Dorsetsiensi.

DESCr. Habitus Tenebrionis; antennæ autem et femorum appendiculæ verum genus produnt. Corpus obesum, crassum, valdè convexum, adeò ut gibbum videtur. Thorax lævis, rugis hinc inde obsoletis, posticè autem omninò manifestissimis. Elytra striata ; striæ punctis impressis, undè crenato-striatæ apparent. Corpus subtùs piceum. Antennæ piceæ.

muficornis. II. Car. ater, elytris sulcatis lævibus, antennis pedibusque rufis.

Fab. Syst. Ent.24I. 27. Sp. Ins. i. 305.35. Mant. i. 199. 48. Ent. Syst, i. a. I34. 42. De Geer, iv. 95. 10. Harr. 202. Payk. Faun. Suec. i. 158, 78. Payk. Monog. 74. Panz. Ent. Germ. 50. 28. Illiger. Kugel. Kaf. Preus. 170. $3^{8 .}$

Mart.Eng. Ent.t.36. f. I3. Oliv. iii. 35. 56.67.t.8. f. 91. Panz. Faun. Germ. 30. t. 2.

Le Bupreste noir velouté. Geoff. i. 160. 38.

Long. corp. 7 lin.

Habitat in sylvis, in viis.

DEscr. Similis Car. leucopbtbalmo (qui, noster, scilicet, DEPRESSUS et ANGUSTIOR) at paulò minor. Elytra interdum colore fugaci-aureo nitent. Syst. Ent.

bicolor. I2. Car. suprà niger, subtùs ferrugineus.

Fab. Syst. Ent. 241. 28. Sp. Ins. i. 306. 36. Mant. i. 199. 49. Ent. Syst. i. a. I5I. II7. Payk. Faun. Suec.i. 159. 79. Monog. 75 .

Oliv. iii. $35 \cdot 57 \cdot 67 \cdot t$. II. $f \cdot 92.6$.

- Long. corp. 7 lin.

Habitat

DESCR. 
DESCR. Statura et summa affinitas Car. ruficornis, at corpus totum subtùs, cum pedibus et antennis, ferrugineum. Elytra striata. Syst. Ent.

I3. Car. ater, capite thoraceque coleoptra sub-obscurus. æquanti glaberrimis nitidis, elytris. obscuris striatis.

An Carabus ambiguus? Payk. Monog. 80.

Oliv. iii, 35. 77. 101. t. I2. $f$. I47.

Long. corp. 6 lin.

\section{Habitat}

Descr. Antennæ subferrugineæ, basi rufæ. Oculi nigri. Caput et thorax glaberrima, nitida. Thorax lineâ mediâ foveisque ad apicem prope latera impressis; porrò elytrá simul sumpta subæquat. Elytra obscura striata ; in striis 2. 3. 4. et suturâ, puncta aliquot impressa, remota, quasi acu tenuissimâ effecta, irregularitèr posita, sub lente conspicienda sunt. Pedes nigri, nitidi, sed femorum basis, et præcipuè appendix, picea sunt. Totum corpus subtùs nitidum.

I4. Car. niger, antennis pedibusque rufis, tho-flaripes. race quadrato, elytris adnato.

Payk. Faun. Suec. i. I12.20. Monog. 21 .

Oliv. iii. $35 \cdot 76$. 100. t. 8. $f .86$.

Carabus Cisteloides. Panz. Ent. Germ. 57. 64.

Panz. Fuun. Germ. II. t. I2.

Le Bupreste noir à pattes brunes. Geoff. i. I6I. 39.

Long. corp. 6 lin.

Habitat

Descr. Similis Car.melanocepbalo, at duplò aut triplò major. Corpus nigrum, nitidum. Antennæ fuscorufescentes. Thorax planus, quadratus, canaliculatus, posticè impressus, elytris adnatus. Elytra striis novem lævibus, striâ laterali punctatâ. Pedes rufi.

Variat pedibus nigris, antennis fuscis, basi rufis. Oliv.

Obs. Simillimus Car. obscuro, at elytra nitida, nec ob- * . scura; pedes sæpiùs rufi quam flavi.

$$
2 \text { F } 3
$$$$
\text { I5. Car. }
$$ 
melanocepbalus.

15. Car. thorace pedibusque ferrugineis, capite elytrisque atris.

Linn. Syst. Nat. 671. 22. Faun. Suec. 795. Vill.i. 367.26. Fab. Sy'st. Ent.245.52. Sp. Ins. i. 310.64 . Mant. i. 202. I9. Ent. Syst. i. a. 159. 153. Panz. Ent. Germ. 6r. 86. De Geer, iv. 93.8. Payk. Faun. Suec. III. I9. Monog. 20. Act. Nidros, iii. 401.22. Harr. 21 5. Faun. Eirusc.541. Hellw.541. Illiger. Kugel. Kaf. Preus. 161.25.

Mart. Eng. Ent. t. 37.f.26. Oliv. iii. 35. 9I. I24. t. 2.f. I4. a. b. Scbaff. Icon.t.237.f.5. Panz. Faun. Germ. 30. t. I9.

Buprestis dorso rubro. Panz. Voet. ii. 73. I 5. t. 35.f. 15. Le Bupreste noir à corcelet rouge. Geoffi, i, 162. 42 .

Long. corp. $3 \frac{x}{2}$ lin.

Habitat in sylvis. Linn.

Descr. Caput nigrum. Elytra atra, striata. Thorax ruber. Pedes et antennæ omninò unicolores ferrugineæ. Faun. Suiec.

vulgaris. I6. Car. nigro-æneus, pedibus antennisque nigris. Linn. Syst. Nat. 672. 27. Faun. Suec. 799. Vill. i. 369.31. Gmel. 1974. 27. Fab. Syst. Ent. 244. 42. Sp.Ins. i. 308. 52. Mant. i. 201.70. Ent. Syst.i.a. I54. I28. Faun. Fred. 21. 206. Poda, 46. 8. Act. Nidrós, iv. 402. 24. Harr. 210. Panz. Ent. Germ. 56. 61. De Geer, iv. 97. 14. Faun. Etrusc. 515. Hellw. 515. Illiger. Kugel. Kaf. Preus. 167.33.

Mart. Eng. Ent. t. 37. f. 28 . Oliv. iii. 35. 75. 98. t. $4 \cdot f \cdot 36$.

Carabus ovatus. Faun. Etrusc. Mant. 200. Hellw. Mant. 200.

Carabus affinis. Schrank, 399.

Le Bupreste rosette. Geoff. i. 160. $3^{6 .}$

Long. corp. $3 \frac{x}{4}-4$ lin.

Habitat paffim.

Descr. Nigro-æneus. Thorax atrior, nitidior, punctis duobus concavis, obsoletis. Elytra striata, sed ex- 
tima stria elytrorum serrata. Thorax posticè latitudinem elytrorum attinonit. Variat punctis impressis in elytris, et non impressis. Antennæ ad basii sæpè griseæ; sublùs niger est hic Carabus. Faun. Suec.

I7. Car. alatus æneus, antennis basi tibiisque communis. rufis.

Panz. Faun. Germ. 40. t, 2.

Long. corp. 3 lin.

\section{Habitat}

DESCR. Habitat vulgaris cum antecedenti, cui similis ideoque sæpiùs cum illo confusus, at differt, staturâ minori, antennis basi tibïsque rufis. Variat et pedibus totis rufis. Panz. Faun. Germ.

I 8. Car. æneus, antennis basi rubris.

Linn. Syst. Nat. 672. 29. Faun. Suec. 801. Vill, i. 370.33. Gmel. 1975.29. Fab. Syst. Ent. 243. 40. Sp.Ins. i. 308. 50. Mant. i. 201.58. Ent. Syst. i. a. I53. I26. Payk. Monog. 71. Faun. Suec. i. 155. 7.5. Harr. 208. Faun. Fred. 21. 206. Panz. Ent. Germ. 56. 60. Illiger. Kugel. Kaf. Preus. I66. $3 \mathrm{I}$.

Mart. Eng. Ent. t. 35. f. 2. 3. Oliv. iii. 35.73.95. t.3.f. 25. Panz. Faun. Germ. 75. t. 2. De Geer, iv. $97 \cdot 13 \cdot t \cdot 3 \cdot f \cdot 1_{5}$.

Le Bupreste perroquet. Geoff. i, 161. 40.

Long. corp. 6 lin.

Habitat ubique in viis publicis.

Descr. Corpus nigrum, capice, thorace, et elytris ænei coloris. Aniennarum primus articulus sæpiùs ruber est. Faun. Suec.

Obs. Cave ne Car. cupreum cum vulgari confundas. Hic dignoscitur striâ ad basin suturæ abbreviatâ obsoletâ; nec manifestâ punctatâ.

I 9. Car. alatus suprà æncus, antennis pedibusque erieus. ferrugineis. 
Fab. Ent. Syst. i. a. I56. 142.

Long. corp. 5 lin.

\section{Habitat}

Descr. Vix Car. cupreo minor. Caput, thorax, elytraque ænea, nitida. Pedes et antenna ferruginei. Corpus mox nigrum, mox ferrugineum. Fab. Ent. Syst.

latus. 20. Car. niger, pedibus antennisque rufis.

Linn. Syst. Nat. 672.24. Vill. i. 368.28. Scbrank, 397. Fab. Syst. Ent. 244. 44. Sp. Ins. i. 308. 54. Mant. i, 201.73. Ent. Syst.i. a. I54.129. De Geer, iv. 100. 18. Faun. Fred. 20. 196. Act. Nidros. iii. 402. 23. Harr. 212.

Scbeff. Icon. $t \cdot 194 \cdot f \cdot 7$.

Carabus Proteus var. e. Payk. Monog. 72. Faun. Suec. var. $\delta$. i. $163 \cdot 73$.

Le Bupreste en deuil. Geoff. i. 160.37. ?

Long. corp. 3 lin.

Habitat

DESCR. Corpus nigrum, nitidum. Elytra striata. Linn. Mss.

ferrugineus. 2I. Car. ferrugineus totus convcxus.

Fab. Syst. Ent. 244. 46. Sp. Ins. i. 309.56. Mant, i. 201.76. Ent. Syst. i. a. 155. 137. Gmel. 1974. 25. Payk. Monog.76. Faun. Suec. i. 161.81. Panz. Ent. Germ. 57. 70 .

Scbeff: Icon.t. I37.f.3. Oliv. iii. 35.80. 107. t.9. f. 105. a. b. Panz. Faun. Germ. 39.t. 9.

Buprestis luteus. Panz. Voet. ii. 74. 16. t. 35. f: 16.

Long. corp. 4 lin.

\section{Habitat}

Descr. Totum corpus ferrugineum. Thorsx brevis, anticè excavatus, posticè truncatus, coleoptra magnitudine adæquat. Animal crassum sanè, et quasi obesum,

22. Car. 
22. Car. niger convexus, antennis plantisque fer-rufimanus. rugincis.

Long. corp. 4 lin.

\section{Habitat}

DESCr. Corpus et præcipuè anticè convexum, gibbum. Caput et thorax atra, glabra. Thorax lineầ mediầ longitudinali impressâ, valdè obsoletâ, foveolâ posticè utrinque obsoletiusculâ. Elytra striata; striæ punctis carent, attamen unica ad basin suturæ abbreviata subpunctata est, et obsoletiuscula. Pedes nigri; tarsis plantisque ferrugineis. Antennæ etiam ferrugineæ.

23. Car. niger, clytris obscuris, antennis pedi-rufangulus. busque ferrugineis, thoracis marginibus rufis.

Long. corp. $5 \frac{1}{2}$ lin.

Habitat

Descr. Antennæ, palpi et pedes ferruginei. Caput et thorax nigra, glaberrima, nitida. Elytra obscura, obsoletè striata : striæ punctis carent; oculo bene armato, quodammodì crenatæ sunt. Thoracis margines, præcipuè posticè, rufi.

24. Car. viridis tomentosus punctulatissimus, tho-nigricornis. race aureo-nitente, elytris obsoletè striatis obscuris, pedibus piceis.

Fab. Ent. Syst. i. a. 157. 143. Payk. Monog. 70. ?

Long. corp. 5 lin.

Habitat

Descr. Totum corpus suprà viride tomentosum. Caput et thorax metalli instar nitentia. Thorax punctulatissimus, punctulis confertissimis, et quasi confuentibus. Elytra obscura, punctulatissima, punctulis confertissimis distinctis, striata, striis obsoletiusculis. Pedes picei. Thorax elytris paulò angustior. 
** Tborace posticè truncato integro, elytris angustiori.

subcqualis. 25. Car. nigcr, elytis obsoletè striatis, apice thoracis cljtra sub-aquanti.

Long. coip. 11 lin.

Hibirat

Descr. Fuere qui hunc Car. leucopbibalmum Linnæi esse voluerunt, sed perneràm. Llytra sanè obsoletè striata, at thorax postice non angustior quam in cæteris. Elytra enim simul sumpta ferè æequat. Elytra striata, at puncia nulla in striis conspicienda sunt; exinde a Car. leucopbibalmo satis distinctus.

angustior. 26. Car. ater, elytris siriatis, thorace posticè utrinque lineolis duabus abbreviat is excavatis.

Carabus leucophihalmus. Fab. Syst. Ent. 240. 23. Sp. Ins. i. 304.29. Mant. i. 198.41. Ent. Syst. i. a. 132.36. Act. Nidros. iv. 329.28. Panz. Ent. Germ. 49.23. Payk. Monog. I6. Faun. Suec. i, 108. 15. Scop.265. Scbrank, 396. Faun. Etrusc.511. Hellw. 511. Gmel. 1962. 4 .

Oliv. iii. 35. 48.5 I. t. I. f. 4. Scbaff. Icon. t. I8.f. I. Panz. Faun. Germ. 30. t. I. Bergstrues. Nom. i. 9. I3. t. I. f. 4. Scriba, i. 7.4. t. I. f. 4 :

Carabus nigro-striatus. De Geer, iv. 96. I2.

Buprestis niger major. Panz. Voet. ii. 68, I. t. 33, f. I. Le Bupreste tout noir. Geoff. i. 146. I7.

Long. corp. $9 \frac{1}{2}$ lin.

Habitat -

Descr. Ferè omnes uno ore hunc itidem Car. leucopbtbalmum Linnæi esse conclamaverunt; sed malè, elytra enim profundiùs nec obsuletè siriata. Sed quod in hoc singulare, thorax, præter lineam mediam excavatam, duas alias abbreviat's uirinque, sive foveæ duplicis excavationem, exhibet. Thorax etiam ejusdem, ac in cæeteris observandum est, latiudinis. Hæc 111. Linnæi oculos nunquam fefellissent. Pedes atri.

Obs. 
Obs. Thorax transversc̀ rugosus, rugis obsoletis undulatis; apex thoracis elytrorum basi angustior.

27. Car. niger, thorace posticè ulrinque impresso, madidus. femoribus rufis.

Fab. Syst. Ent. 241. 31. Sp. Ins. i. 306. 39. Mant. i. I99.54. Ent. Sysi. i. a. I35. 48 . Vill. i. 379. 83. Payk. Monog. 15. Faun. Suec. i. 107. 14. Panz. Ent.Germ.50.33. Faun. Eirusc.527. Hellw. 527. Gmel. 1975. 123.

Oliv. iii. $35 \cdot 60.73 \cdot t \cdot 5 \cdot f \cdot 6$ I.

Le Bupreste paresseux. Geoff. i. 159. 34.

Long. corp. 7 lin.

Habitat

Descr. Corpus atrum, quasi humore inunctum. Antennæ apice fuscescentes. Thorax basi puncto majori ntrinque excavatus. Abdomen obtusum. Syst. Ent. Variat long. corp. 5 lin. et femoribus nigris.

28. Car. ater, thorace gliherrimo coleoptris multò Terricola. angustiori, elytris obsoletè striatis.

Payk. Monog. 17. Faun. Suec. i. I09. 16. Fab. Ent. Sysí. i. a. 135. 49. Gmel. I982. 164 .

Oliv. iii. 35.57.68.t. I1. f. 124. Herbst. Arch. 140. 5x. t. 29. $f$. 14 .

Long. corp. 7 lin.

Habitat — Captus in cellis vinariis, Ealing, per totam restatem.

Descr. Antenna et pedes picei. Caput et thorax glaberrima, nitida. Thorax coleoptris $\frac{\frac{1}{3}}{3}$ angustion. Elytra obsoletiusculè striata, basi mediâ leviter excavata, sive depressa.

29. Car. totus nigro-piceus, thorace glaberrimo collaris. coleoptris multò angustiori, elytris profundiusculè striatis.

Long. corp. 5 lin.

Habitat

Descr. 


\section{4}

DEScr. Staturâ et habitu affinis admodum Car. Terricolec.

Vix ovum ovo similius, at duplò minor. Color omninò nigro-piceus. Thorax sub lente transversè rugosus, anticè lineâ impressâ, abbreviatâ, transversâ; porrò aljam lineam mediam longitudinalem, et tertiam ad basin integram transversam exhibet. Thoracis apex elytrorum basi $\frac{1}{3}$ angustior, marginibus elevatis. Elytra profundè striata, interstitiis convexis, nec, ut in Carabo Terricolit, planis.

aterrimus. 30. Car. ater, thorace marginato, elytris striatis: punctis tribus impressis.

Fab. Ent. Syst. i. a. I56. I4I. Payk. Monog. 78. Faun. Suec. i. I56. 76.

Oliv. iii. $35 \cdot 5^{8} \cdot 69 \cdot t$. 12. $f$. т41.

Long. corp. 5 lin.

Habitat

Descr. Corpus aterrimum, nitidum. Thorax rotundatus, marginatus, margine parùm reflexo, in medio canaliculatus. Elytra striata, punctis duobus in striâ secundâ a suturâ, tertioque anteriori in tertiâ impressis.

rugimargi-3 I. Car. nigro-ferrugineus depressiusculus, elynatus. $\quad$ tris striis profundis punctatis, thoracis margine punctato-rugoso.

Long. corp. 5 lin.

Habitat

Descr. Antennæ et pedes ferruginei. Caput et thorax nigra, sive nigro-ferruginea. Thorax sub-obcordatus, marginatus, et intra marginem punctato-rugosus. Elytra fusco-ferruginea, profundè striata, striâ primâ a suturâ brevissimâ; in omnibus striis puncta impressa. Corpus suprà planiusculum. Abdomen subı̀̀ nigro-ferrugineum. Thorax ferè coleoptra æquat.

Variat niger et nigro-ferrugineus.

piceus. $\quad 3^{2}$ Car. niger planiusculus, thoracis disco tumescenti, antemnis pedibusque piceis. 
Linn. Syst. Nat.672.30. Faun. Suec. 802. Vill. i. 370. 34. Gmel. 1975. 30. Fab. Syst. Ent. 241. 29. Sp.Ins. i. 306.37. Mant. i. 199.5I. Ent. Syst.i.a. 135. 46. Harr. 205. Panz. Ent. Germ. 50. 32. oliv. iii. $35 \cdot 58 \cdot 70$. t. I I. f. 123 .

Long. corp. 3 lin.

Habitat

Ex mus. D. Hill.

Descr, Corpus nigrum, minimè nitidum. Pedes et antennæ ferè piceæ. Elytra fusco-nigra. Faun. Suec.

33. Car. ater nitidus, tibiis plantisque piceo-fer-tibialis. rugineis.

Long. corp. 3 lin.

Habitat

DESCR. Antennæ piceo-ferrugineæ, sive piceæ. Caput et thorax atra, lævissima. Thorax convexiusculus, lineâ medià longitudinali impressâ, obsoletiusculâ, ad apicem foveolâ utrinque simplici. Elytra striata, striis omnibus integris, nec quod in plerisque accidit, unicâ ad basin suturæ abbreviatâ; striæ punctulis minimis impressis. Pedes nigri, tibiis plantisque piceoferrugineis, sive piceis.

34. Car. niger, elytris striatis: striis punctatis, convexus. antennis ferrugineis, pedibus piceis.

Long. corp. 6-7 lin.

\section{Habitat}

DESCR. Antennæ ferrugineæ. Caput et thorax nigra, glabra. Thorax convexus, posticè depressus, et punctulis scaber; ad utrumque angulum lineolæ duæ breves, sive foveolæ. Elytra nigra, vel, si paulùm eleventur, picea, profundè striata, striis punctis impressis. Pedes picei.

35. Car. æneo-virens, clytris striatis: interstitiis dimidiatus. convexiusculis, pedibus nigris.

Oliv. 
Oliv. iii. $35 \cdot 72 \cdot 94 \cdot t .11 . f .121$.

Carabus Kugelannii. Punz. Faun. Germ.39. t. 8.

Carabus Kugelannii. Illiger. Kugel. Kaf. Preus. I66.30. Long. corp. 6 lin.

Mabitat

DESCR. Affinis admodùm Car. vulgari, at satis differt thorace coleoptris angustiori, nec æquali. Antennæ nigræ, basi rufâ. Elytra profundiusculè striata; in striis punctula impressa. Hæc autem punctula præ nimiâ interstitiorum (quæ convexiuscula sunt) intumescentiâ, sæpè latent; in striis autem duabus ad basin suturæ abbreviatis, semper conspicienda. Pedes nigri. Variat æneo-virens, et thorace cupreo elytris viridibus.

pilicornis. 36. Car. thorace rotundato, elytris striatis punctisque impressis, antennis pilosis.

Fab. Syst. Ent. 243. 33. Sp. Ins. i. 307.48. Mant. i. 200.65. Ent. Syst. i. a. I52. I22. Payk. Monog. 47. Faun. Suec. 1. 134. 47. Vill. i. 330.85 .1 Panz. Ent. Germ.55.57. Ginel. I971. 104. Illiger. Kugel. Kaf. Preis. 199.71 .

Panz. Faun. Germ. II. t. Io. Oliv. iii. 35. 67. 85. t. I. f. I I9. Mart. Eng. Ent. t. $3^{6 . f .}$. 8.

Long. $\operatorname{corp} \cdot 3 \frac{\mathrm{x}}{2} \operatorname{lin}$.

Habitat

Descr. Antennæ pilis lonmioribus hirtæ, ferrugineæ, primo articulo æneo. Thorax rotundatus, æneus, posticè uirinaue impressus. Llytra ænea, striata, punctisque trious impressis. Pedes rufi, femoribus nigris.

Variat colore nigro et æneo.

carulescens. 37. Car. nigro-cæruleus, antennis basi rubris.

Linn. Syst. Nat. 672. 28. Faun. Suec. 800. Vill. i. 370.32. Gmel. 1974. 28. Fab. Syst. Ent.243.39. Sp.Ins. i.308.49. Mant. i. 200.66. Ent. Sy'st.i.a. 152.123. Faun. Fred.21. 207. Hurr. 207. Panz. Ent. Gtrm.55.58. Funn. Etrusc.516. Hellw. 516. Mart. 
Mart. Eng. Ent. t. 35.f. т. Oliv. iii. 35. 68. 86. t. I2. $f$. I32. a. b.

Carabus cupreus, var. ₹.Payk. Monog.7I. Faun. Suec.i. I55. 75 .

An Carabus elegans? Scop. 269.

Long. corp. 4 lin.

Habitat - Ex mus. D. Lyon.

DESCr. Color totius animalculi a teroo viridi rubroque fusco-æneıs. Elvira striata, singulis tribus punctis longiiudinalibus impressis. Femord nigra: tibie rufæ. Antennæe a! articulos inferiores tribus setis armatæ. Faun. Suec.

Vuriat colore nigro-æneo.

38. Car. subæheus, elytris punctis longitudinalibus sexpunctasex imp:essis.

tus.

Linn. Sy'st, Nut.672.35. Faun. Suec. 807. Vill. i. 372.39. Scbrank, 402. Gmel. 1977.35. Fab. Syst. Ent.24.5.50. Sp. Ins. i. 309. 60. Mant. i. 202.83. Ent. Sy, i. a. 57. I45. Harr. 214. De Geer, iv. 99. I6. Pe'n. Misnog. 42. Faun. Suec. i. 130. 43. Faun. Fied. 2I. 210. Pen. Ent. Germ. 59. 76. Illiger. Kugel. Kaf. Prous. 195. 76.

Oliv. iii. 35. 8.. I14. $1.5 \cdot f_{0} 50$. Panz. Foun. Germ. 30. t. I3. Scboif. Ic.n. t. 66. f. 7 .

Le Bupres'e à six poinis enfoncés. Geoif. i. I47. Io.

Buprestis nitens minor. Punz. Voet. ii. 69. 4.t.33.f. 4 . Long. corp. lin.

Hobitat

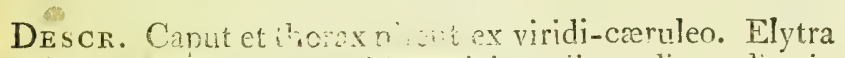
ignei coloss, vel cupi jar, striis nudis oculis vix manifent flurimis, mang laierali extimo cyaneo; puncta is ser longitudinaliter, inter secundam et tertia suam a sutura, impressa. Abdomen e fusco nitet. Thorax posícè angustior. Faun. Suec.

39. Car. virifi-aneis, el, ris punctis quatuor im-8-punctatus. pressis.

Fab. 
Fab. Supp. 55. 70 .

Long. corp. 5 lin.

Habitat

DESCR. Corpus parvum, viridi-æneum, antennis nigris. Elytra punctis quatuor secundum suturam impressa. Pedes obscurè rufescentes, femoribus nigris. Fab. Supp.

inquisitor. 40. Car. elytris striatis viridi-æneis: punctis triplici ordinc.

Linn. Syst. Nat.669.11. Faun. Suec.789. Vill. i. 361. 10. Gmel. 1965. I1. Fab. Syst. Ent. 239. I8. Sp.Ins. i. 303. 23. Mant. i. 197.31. Ent. Syst.i.a. 149. Io9. De Geer, iv. 94. 9. Payk. Monog. 39. Faun. Suec. i. 127.40. Panz. Ent. Germ. 54. 50. Illiger. Kugel. Kaf. Preus. 142. 2.

Oliv. iii. 35. 40. 40. t. I. f. 3. Mart. Eng. Ent. t. $3^{8 .}$ f.42. Panz. Voet.t.38. f.39. Panz. Faun. Germ. 8 I. t. 8.

Le Bupreste quarré couleur de bronze antique. Geoff. i. I 45. 6 .

Buprestis Sycophanta minor. Panz. Voet. ii. 86. 39. t. $3^{8} \cdot f \cdot 39$.

Long. corp. io lin.

Habitat in sylvis, cursitans per plantas nocta, insecta legens.

DESCr. Corpus suprà viridi-aureum, subtùs fuscovirescens. Elytra subtilissimè striata, et triplici ordine punctorum obscurissimorum notata. Faun. Suec.

vestitus. 4 4 . Car. subtùs niger suprà viridis, elytris striatis sericeis : margine apiceque flavis.

Fab. Ent. Syst. i. a. 158. 148. Payk. Monog.44. Faun. Suec. i. 132. 45. Illiger. Kugel. Kaf. Preus. I78. 50. Oliv. iii. 35. 86. I 16.t. 5. f. 49. Panz. Faun. Germ. 3 I. $t \cdot 5$.

Carabus marginatus. Linn. Syst. Nat. 670. I6.

Le Bupreste vert à bordure. Geoff. i. 162.4I. 
Long. corp. 5 lin.

Habitat

DESCR. Caput viridi-æneum, nitidum, ore antennisque pallidis. Thorax æeneus, nitidus, lineâ dorsali impressâ, margineque pallido. Elytra striata, viridia, rufo pubescentia, margine pallido. Corpus fuscum. Pedes pallidi. Ent. Syst.

42. Car. fuscus, capite thoraceque viridi-æneis, cinctus. elytrorum margine pedibusque pallidis.

Fab.Sp. Ins. i. 310.62. Mant. i. 202. 85. Ent. Syst. i. a. 138.6r. Gmel. 1970. 100.

Oliv. iii. 35. 87. II 8. t. 3. f. 28. Panz. Funn. Germ. 30. t. 7. Herbst. Arcb. t. 29. f. 7. Mart. Eng. Ent. t. $3^{8 .} f \cdot 39$.

Long. corp. 7 lin.

\section{Habitat}

DESCr. Caput et thorax viridi-ænea, glabra, nitida. Antennæ palpique pallidæ. Elytra striata, fusca, margine pallido. Corpus fuscum, abdominis margine pallido. Pedes pallidi. Sp. Ins.

43. Car. viridis nitens, elytris striatis: punctis tri-marginatus. bus impressis, margine tibiisque testaceis.

Linn. Faun. Suec. 804. Vill. i.363.21. Fab. Syst. Ent. 245.51. Sp. Ins. i. 3 10.61. Mant. i. 202.84. Ent. Syst. i. a. 158. 147. Payk. Monog. 43. Faun. Suec. i. 131. 44. Panz. Ent. Germe. 59. 78. Gmel. 1970. I6. Illiger. Kugel. Kaf. Preus. 196. 78.

Mart. Eng. Ent. t. 36. f. I9. Oliv. iii. 35. 85. II5. t. 9. f. 98. Panz. Faun. Germ. 30. t. I4.

Long. corp. 4 lin.

Habitat

DESCR. Magnitudo et statura omninò Car. sexpunctati. Antennæ nigræ, articulo primo rufescente. Caput viride. Thorax rotundatus, canaliculatus, viridis. Elytra striata, viridia, margine tenuissimè testaceo, puncvol, I.

$2 \mathrm{G}$ tulato, 
tulato, punctis tribus discoidalibus, impressis. Corpus subtùs nigro-æneum. Tibiæ femorumque basis testacea. Oliv.

circulatus. 44. Car. niger, antennis pedibus elytrorumque margine testaceis.

Long. corp. $3^{\frac{1}{2}}$ lin.

Habitat - Captus propter fluvium Usk prope

Crickhowell sub lapidibus, et prope Ealing.

DESCR. Corpus parùm nitescit. Elytra striata, striæ verùm punctis omninò immunes. Pedes et elytrorum margo pallidè testacea. Antennæ forsan paulùm saturatiores, sive subferrugineæ; basis autem testacea.

purpuro- 45. Car. nigro-cæruleus, elytris striatis abdomine caruleus. subbrevioribus, antennis palpis pedibusque rufis. An Carabus sabulicola? Panz. Faun. Germ. 30. t. 4 . Long. corp. 6 lin. sed variat magnitudine.

Habitat in agris et ad sepes. Inter umbellulas seminales Dauci Carote latitabat, prope Maldon com. Essex.

DESCR. Thorax punctatus. Elytra violacea, striata, et inter strias punctulis numerosissimis conspersa.

azureus. 46. Car. cyaneus, antennis pedibusque rubris. Fab. Syst. Ent. 244. 43. Sp. Ins. i. 308.53. Mant. i. 201. 7I. Ent. Syst. i. a. I55. I33. Vill. i. 380.86. Panz. Ent. Germ. 57. 67. Faun. Etrusc. 550. Hellw. 550. Gmel. 1974. 117.

Mart. Eng. Ent. t. 36. f. I5. Oliv. iii. 35. 76. 99. t. $\mathrm{I} 2 . f . \mathrm{I} 35$.

Long. corp. 5 lin.

Habitat

DESCR. Elytra striata, margine ante apicem dentato, dente unico; hinc elytra apice erosa esse videntur. Variat pedibus piceis et nigro-piceis.

47. Car. 
47. Car. suprà cyaneus nitidus, subtùs ferrugi-discolor. neus.

Long. corp. 4 lin.

Habitat

Descr. Antennæ ferruginex, thoracis apicem vix attingunt. Caput et thorax cyanea, glaberrima, nitida. Elytra cyanea, margine tenuiter ferrugineo, striata. Totum corpus subtùs ferrugineum.

48. Car. cyaneus, ore antennis pedibusque rufo-spinibarbis. testaceis, capite lateribus subtùs ciliato.

Fab. Syst. Ent. 243. 37. Sp. Ins. i. 307.47. Mant. i. 200.64. Ent. Syst. i. a. 137.55. Vill. i. 380.84. Panz. Ent. Germ. 51. 36. Faun. Etrusc. 539. Hellw. 539. Gmel. I971. 105.

Oliv. iii. 35.67.84.t. 3. f. 22. a. b. c. Panz. Faun. Germ. 30. $t .6$.

Long. corp. 4 lin.

Habitat

Descr. Antennæ, palpi, os et caput subtùs rufa. Oculi prominentes. Palpi capite longiores; et quod singulare est, os subtùs undique pilis cinctum est; quippe genæ tum pectus anticè ciliata. Cilia genarum fortia spinarum instar, pectoris verò setacea omnia, undique ad os convergentia. Caput, thorax et elytra cyanea, sive cæruleo-viridia. Thorax subcordatus. Elytra striata, punctis impressis. Abdomen nigrum. Pedes omnes rufo-testacei.

49. Car. thorace pedibusque ferrugineis, capite cyanoelytrisque cyaneis.

Linn. Syst. Nat. 671. 21. Faun. Suec.794. Vill. i. 366. 25. Gmel. 1972. 21. Fab. Syst. Ent. 245. 53. Sp.Ins. i. 3 I0. 65. Mant. i. 203.90. Ent. Syst.i. a. 159. 154. Panz. Ent. Germ. 61. 87. Payk. Monog. 63. Faun. Suec. i. 125. 37. Faun. Fred.21. 204. Harr. 216. Faun. Etrusc.540. Hellw. 540. Illiger. Kugel. Kaf. Preus. 206. 92. 
Donov. Brit. Ins. t. 86. f. 1. 2.3. De Geer, iv. I00. I 7.t.3.f. I7. Oliv. iii.35.92. 125.t. 3.f.24. a. b.c. Mart. Eng. Ent. t. 36. f. 14.

Le Bupreste bleu à corcelet rouge. Geoff. i. I49. I6.

Long. corp. $3 \frac{x}{4}$ lin.

Habitat

DEscr. Antennæ nigræ, basi ferrugineæ. Caput et elytra viridissima, subtruncata, lata. Thorax, sternum et basis abdominis subtùs rubro-ferruginea. Pedes thorace concolores, geniculis tarsisque nigris. Elytra thoracem latitudine longè superant.

bumeralis. 50. Car. ater, thorace ferrugineo, coleoptris striatis planiusculis obtusissimis margine ferrugineis.

Payk. Monog. 23. var. $\beta$. Faun. Suec. i. I22. 33. var. $\beta$. Long. corp. 5 lin.

Habitat

Descr. Antennæ et pedes ferruginei. Caput niger. Thorax fusco-ferrugineus, ab abdomine remotiusculus. Elytra atra, sive atro-cærulescentia, depresso-planiuscula, profundè striata, apice obtusissima, sive obliquè truncata. Margo exterior ferrugineus. Linea scilicet ferruginea marginem ambit, et ad basin in unci morem interiùs ducta reflectitur.

littoralis. $5 \mathbf{1}$. Car. thorace nigricanti, elytris obscuris ferrugineis bifasciatis.

Oliv. iii. 35. IIO. I53. t. 9. f. IO3. a. b. et t. I4. f. I63. c. d. Panz. Faun. Germ. $3^{8 . t}$. 9 .

Carabus ustulatus var. B. Payk. Monog. 53 .

Long. corp. $2 \frac{1}{2} \operatorname{lin}$.

Habitat -

DEsCr. Corpus nigrum. Pedes ferruginei. Elytra nigra, posticè unâ alterâve obscurâ fasciâ: non rarò etiam maculâ pallidâ versus basin in exteriore parte elytri. Faun. Suec. 
52. Car. atro-cæruleus, elytris punctato-striatis Doris. apice obsoletè ferrugineis.

Pañ. Faun. Germ. 38. t. 9 .

Long. corp. 2 lin.

Habitat

DESCR. Corpus nitidum. Elytra striata, punctis excavatis, apice maculâ lunari obsoletè ferrugineâ, vix nisi elevatis elytris conspiciendâ. Antennæ nigræ. Pedes rufescentes. Thorax politus, punctis omninò aspersus.

53. Car. atro-cæruleus, pedibus testaceis.

immunis.

Long. corp. $2 \frac{1}{8}$ lin.

Habitat

DESCR. Antennæ nigræ, basi testaceæ. Totum corpus atro-cærulescens, nitidiusculum. Elytra striata, striæ ex punctis concinnè impressis. Pedes omninò testacei.

54. Car. subæneus, pedibus rufis, thorace gla-rufipes. bcrrimo, elytris integris subtilissimè punctatostriatis.

Payk. Monog. 63.

Oliv. iii. 35 . I12. 158, t. I4, f. I64. a. b.

Long. corp. $\mathbf{I} \frac{x}{2}$ lin.

\section{Habitat}

DESCR. Similis Car. bipunctato, at paulò minor, et elytra absque punctis impressis. Antennæ nigræ. Corpus suprà æneum, subtùs nigrum. Thorax vix capite latior. Elytra striato-punctata. Pedes fuscoferruginei, tibiis pallidioribus. Oliv.

55. Car. sub-æeneus, elytris punctis duobus im-bipunctatus. pressis.

Linn. Syst. Nat. 672. 33. Faun. Suec. 806. Vill. i. 371. 37. Gmel.1977.33. Fab. Syst. Ent. 249.69. Sp.Ins. i. 313.86. Mant. i. 205. J21. Ent. Syst. i. a. 167. 189. Payk. Monog. 62. Faun. Suec. i. $2 \mathrm{G} 3$ 
148. 66. Panz. Ent. Germ. 65. II5. Faun. Etrusc. 561.. Hellw. 561.

Oliv. iii. 35. II2. I57.t. I4. f. I63. a. b.

Long. corp. I lin.

Habitat

Descr. Corpus nigrum, at suprà sunt caput, thorax et elytra ænea. Elytra notantur punctis duobus impressis : altero anteriùs, altero posteriùs. Faun. Suec.

nitidulus. 56. Car. nigro-carulescens nitidus, antennarum basi tibiis tarsisque rufescentibus, elytris punctato-striatis.

- Long. corp. 2 lin.

Habitat

DESCr. Antennæ nigra, basi rufescenti. Caput et thorax nigra. Elytra nigro-cærulescentia, punctatostriata. Pedes nigri, femorum apicibus, tibiis, tarsisque rufescentibus. Nimis affinis Car. Doris, at thorax posticè sub-attenuatus, angulis aliquantulùm extantibus.

pulcbellus. 57. Car. nigro-cærulescens nitidus, pedibus rufescentibus, elytris punctato-striatis.

Long. corp. I $\frac{1}{2}$ lin.

\section{Habitat}

DESCR. Antennæ omninò nigræ. Thorax ater, glaberrimus, nitidus. Elytra nigro-cærulescentia, striata, striis punctulis impressis. Pedes rufescentes.

Maximè affinis Car. nitidulo; sed differt basi antennarum nigrâ, nec rufâ; pedibus omninò rufescentibus, nec femoribus nigris, tibiis plantisque rufescentibus; tum ferè duplo minor est.

meridianus. 58. Car. niger, elytris anticè pedibusque testaceis. Linn. Syst. Nat. 673.36. Faun. Suec. 797. Vill. i. 373. 40. Gmel. 1978. 36. Fab. Syst. Ent. 247. 62. Sp. Ins. i. 312.77. Mant. i. 205. III. Ent. Syst. 
i. a. 164. 177. Payk. Monog. 59. Faun. Suec. i. 147. 65. Panz. Ent. Germ. 63.101. Faun. Etrusc. 554. Hellw. 554. Illiger. Kugel. Kaf. Preus. 198.82. Oliv. iii. 35. 106. 148.t. 13. $f$. 153. a. b.

Long. corp. $\mathbf{I} \frac{1}{2}$ lin.

\section{Habitat}

DEScr. Corpus nigrum. Antennæ et pedes fusco-ferruginea. Elytra basi albida; sutura longitudinalis testacea. Faun. Suec.

59. Car. ferrugineus hispidus, capite thoraceque echinatus. obscuris punctatis, elytris striatis : maculâ magnâ nigrâ.

Long. corp. 3 lin.

\section{Habitat}

DESCR. Antennæ ferrugineæ. Caput ferrugineum, punctatum, pilosum, lineâ mediâ longitudinali nigrâ. Oculi prominuli. Thorax ferrugineus, punctatus, pilosus, disco obscuro lineâ longitudinali impressâ. Elytra punctato-striata, ferruginea, maculâ magnâ nigrâ, pilis densis erectis adspersa. Pectus et pedes ferruginei. Abdomen nigrum.

6o. Car. ferrugineus, thorace glaberrimo obcor-brunneus. dato.

Le Bupreste fauve. Geoff. i. 162. 43.

Long. corp. $2 \frac{x}{2}$ lin.

Habitat

DESCR. Corpus totum ferrugineum. Thorax glaberrimus, politus. Elytra striata. Pedes et antennæ pallidiores. Observandum est quod elytrorum striæ pulcherrimè punctatæ, et thorax egregiè obcordatus.

6I. Car. fusco-ferrugineus punctulatus, thorace punctulatus. obscuro sub-cordato. 
Long. corp. $3 \frac{1}{2}$ lin.

\section{Habitat}

DEscr. Totum corpus suprà fusco-ferrugineum, et punctulis conspersum. Elytra striata; inter strias etiam punctula exhibent. Thorax obscuriusculus, subobcordatus. Abdomen subtùs et pedes concolores.

ruficollis. 62. Car. niger, capite atro nitido, antennis thorace pedibusque rufo-ferrugineị.

Long. corp. 3 lin.

Habitat

DESCr. Antennæ ferrugineæ. Caput atrum, nitens. Thorax ferrugineus. Elytra nigro-striata. Pedes ferruginei. Abdomen subtùs nigro-rufescens.

An Car. melanocepbalus var.?

mollis.

63. Car. piceo-ferrugineus, pedibus pallidis, thorace sub-æquali.

Long. corp. $3-4$ lin.

Habitat in hortis, Ealing.

DESCR. Totum corpus nigro-ferrugineum, nitidum. Antennæ ferrugineæ. Pedes pallidè testacei. Elytra tenuiter striata, molliuscula.

fulvus. $\quad 64$. Car. ferrugineus, pedibus pallidioribus, oculis nigris.

Long. corp. 2 lin.

Habitat

Descr. Simillimus Car. nigricipeti, at duplò major. Caput etiam ferrugineum, nec nigrum. Pedes variant unicolores et pallidiores.

inaqualis. 65. Car. ater, antennis pedibusque rufis.

Long. corp. $2 \frac{x}{2}$ lin.

Habitat

DESCR. 
DEscr. Antennæ et pedes rufi. Caput et thorax atra, glaberrima, nitida. Elytra striata, striis ex punctis impressis, nitidiuscula, nec nitida. Coleoptra latitudine thoracem paulò superant.

66. Car. niger, thoracis lateribus posticè ferrugi-lateralis. neis, pedibus pallidis.

Long. corp. $2 \frac{1}{2}$ lin.

Habitat

DESCR. Antennæ nigræ, basi ferrugineâ. Caput et thorax atra, nitida. Thorax posticè lateribus ferrugineis. Elytra striata, nigro-picea, marginibus dilutioribus. Pedes testacei, sive pallidi, geniculis nigris.

67. Car. pallidè-ferrugineus, thorace glaberrimo rotundatus. posticè rotundato.

Long. corp. $2 \frac{x}{2}$ lin.

\section{Habitat}

DESCR. Affinis Car. brunneo, sed facilè dignoscitur, thorace subrotundato, neque exactè obcordato. Tum color pallidior. Pedes subtestacei,

68. Car. niger, elytris obscurè piceis striatis : sordidus. striis immunibus, elytrorum marginibus pedibusque testaceis.

Long. corp. $3 \frac{1}{2}$ lin.

Habitat

Ex mus. D. Hill.

DESCR. Palpi, antennæ, pedes et margines elytrorum testacei. Caput piceum. Thorax niger, glaber, lineâ mediâ longitudinali impressâ, abbreviatâ, obsoletiusculâ, ad apicem rugoso-punctulatus. Elytra obscuriusculè picea, striata; striæ ne minimè quidem punctis impressis ornantur. Abdomen subtùs nigrum.

69. Car. piceus, thorace punctato, elytris striatis, foraminupedibus ferrugineis.

losus.

\section{Long.}


Long. corp. 4 lin.

\section{Habitat}

Descr. Thorax punctatus, punctis plurimis sub-distantibus, et pedibus pallidioribus, ferè testaceis. Elytra punctulata, punctulis numerosissimis, et obsoletiusculè striata; striæ punctis impressis omninò carent. Antennæ et pedes ferruginei.

picicolor. 7o. Car. piceus, elytrorum striis punctatis, antennis pedibusque paulò dilutioribus.

Long. corp. $2 \frac{x}{2}-3 \frac{x}{2}$ lin.

Habitat

DESCR. In Carabis ritè distinguendis, notæ omnes studiosissimè observandæ sunt; quippe cum numerosi adeo sint Carabi, et cum in colorum tenui variatione usque adeo quod tangit idem est, haud mirum est si gradus differentiæ levissimo sæpiùs charactere signatur. In hoc Carabo describendo cura summa adhibenda est. Masimè enim affinis Car. sordido, magnitudine, colore, staturâ, habitu. Duobus tamen signis facilè dignoscitur. Striæ elytrorum in hoc punctatæ, in Car. sordido punctis carent. In hoc thorax lineâ perpetuâ mediâ impressâ, nec abbreviatâ, et posticè lævis, nec punctato-rugulosus, foveolâ utrinque tenuiusculâ. In hoc etiam pedes picei, nec pallidè-testacei.

nufescens. 71. Car. thorace rotundato, ferrugineus, vertice anoque nigris.

Fab. Syst. Ent. 247.58. Sp.Ins. i. 3T2.73. Mant. i. 204. 104. Ent. Syst. i. a.162. 169. Vill. i. 38r.91. Payk. Monog. 35. Faun. Suec. i. 123. 35. var. $\beta$. Gmel. 1976.126. Illiger. Kugel. Kaf. Preus. 190.70. Oliv. iii. 35 . 10I. I41. t. I2. $f$. 146 .

Long. corp. 3 lin.

Habitat

Descr. Totus ferrugineus, solo vertice capitis anoque nigris. Syst. Ent.

72. Car. 
72. Car. thorace flavo, elytris obtusissimis fuscis: 4-maculamaculis duabus albis. tus.

Linn. Syst. Nat.673.4 I. Faun. Suec.813. Vill. i. 374.45. Gmel. 1979. 41. Fab. Syst. Ent.248. 64. Sp.Ins. i. 313. 79. Mant. i. 205. II3. Ent. Syst. i. a. I65. I80. Payk. Monog. 5I. Faun. Suec. i. 140. 56. Faun. Etrusc. 560. Hellw. 560. Panz. Ent. Germ. 64. 108. Illiger. Kugel. Kaf. Preus. 202. 88.

Pontop. i. 678. 24. t.29. Mart. Eng. Ent. t. 38. f. 47. Oliv. iii. 35. I07. I50.t. 8. f. 89. a. b. c. d.

Le Bupreste quadrille à corcelet plat, brun, et étuis striés. Geuff. i. 152. 22.

Long. corp. $2 \frac{1}{2}$ lin.

Habitat

Descr. Caput nigrum. Thorax ferrugineus. Elytra obtusissima, et quasi truncata, abdomine breviora; singula basi maculâ lividâ ovatâ, quæ maculæ ex utrisque interdum coeunt; aliâ maculâ in singulo elytro juxta apicem lividâ, ovatâ, interdum undique distinctâ nigredine ipsius coleoptri. Pedes ferruginei, seu pallidi, maculâ fuscâ ad flexuram alæ. Antennæ ferrugineæ. Faun. Suec.

73. Car. thorace rotundato posticè attenuato atro, 4-guttatus. elytris nigris : punctis quatuor albis.

Fab. Syst. Ent. 248. 65. Sp. Ins. i. 313. 80. Mant. i. 205. I14. Ent. Syst.i. a. 165. I81. Payk. Monog. 55. Faun. Suec. i. 142. 59. Vill. i. 38I. 93. Panz. Ent. Germ. 64. Io9. Faun. Etrusc. 558. Hellw. $55^{8}$. Gmel. 1979. I45.

Pontop. i. 678.26.t. 29. Mart. Eng. Ent. t. 38. f. 37 . Oliv. iii. 35. 108. 151. t. 13. f. 160. a. b. Panz. Faun. Germ. 40. t. 5 .

Chlorocephalotes mas. Panz. Voet. ii. 76, 20, t. 35. f. 20. fœm. $t .35 \cdot f \cdot 2 \mathrm{I}$.

Long. corp. 2 lin.

Habitat

DESCR. 
Descr. Differt manifestè a Car. quadrimaculato. Elytra haud obtusa. Thorax valdè rotundatus, ater. Tibiæ pallidæ.

puncto- 74. Car. niger lævis nitidus, elytris truncatis: maculatus. maculis duabus albis.

Long. corp. I $\frac{x}{2}$ lin.

Habitat

Descr. Antennæ et pedes fusco-ferrugineæ. Caput et thorax nigra, glabra, nitida. Elytra sub lente obsoletissimè striata. Ad basin elytrorum macula satis magna ovata, alba. Ad apicem suturæ macula minor, sive punctum majusculum; hæc macula intra apicem est, et vix in medium disci procurrit. Differt a Car. 4-maculato triplò minor, thorace nigro, nec flavo, maculâ exteriori intra apicem suturæ, nec totum apicem occupanti.

chalceus. 75. Car. æneus, elytris punctato-striatis: interstitiis planis, pedibus rufescentibus.

Long. corp. 3 lin.

Habitat

Descr. Affinis admodùm Car. cupreo, at satis differt, thoracis apice coleoptris angustiori. Color omninò æneus, pedes solummodo ex nigro rufi. Elytra striata, striis punctatis; pars inter strias plana, nec convexiuseula. Antennæ nigræ.

par. 76. Car. niger, antennis pedibusque rufis, thorace brevi coleoptra sub-æquanti.

Long. corp. 3 lin.

Habitat

Descr. Animal crassum et obesum. Corpus nigrum. Thorax coleoptra modo non æquat. Pedes rufi. Antennæ rufæ, breves, corpore plusquam dimidio breviores.

77. Car. 
77. Car. nigro-piceus nitidus, antennis pedibus-aquaticus. que rufescentibus.

Panz. Faun. Germ. 38, t. Io.

Long. corp. $1 \frac{1}{2}$ lin.

Habitat

DESCR. Antennæ et pedes rufescentes, sive rufo-ferruginei. Caput, thorax et elytra obsoletè striata, præcipuè ad margines exteriores: striæ punctis carent. Animalculum pulchellum.

78. Car. nigro-piceus nitidus, pedibus rufis, ely-erytbropus. tris striatis : striis punctulatis.

Long. corp. 3 lin.

\section{Habitat}

DESCR. Antennæ piceæ. Caput et thorax nigro-picea, glaberrima, nitida. Elytra profundiuscule striata, in striis punctula plurima conspicienda. Pedes ex piceo rufi. Ne confundas cum Car. aquatico, duplò enim major est; tum elytra manifestè nec obsoletè striata.

79. Car. ferrugineus, capite nigro, thorace gla-nigriceps. berrimo sub-obcordato.

Long. corp. 2 lin.

\section{Habitat}

DeSCR. Antennæ, thorax, elytra et pedes ferruginea.

Caput nigrum. Abdomen subtùs nigro-rufescens. Thorax sub-obcordatus, glaberrimus, nitidus.

Variat thorace ferrugineo, piceo, et nigro.

80. Car. nigro-æneus nitidissimus, elytris sub-acutus. attenuatis acutis, tibiis pallidis.

Long. corp. 2 lin.

Habitat

DESCR. Præ cæteris ferè omnibus nitidissimus, quasi vernice 
vernice obductus. Animal nigro-æneum, tibiæ solǔn testaceæ.

Ephip- 3r. Car. ater nitidus, coleoptris testaceis : maculá pium. communi nigrâ, abdomine subtùs nitido.

Long. corp. $\mathrm{I} \frac{\mathrm{r}}{2} \mathrm{lin}$.

Habitat

Descr. Antennæ et pedes testacei. Caput et thorax aterrima, nitida. Elytra pallidè testacea, nebulâ sive maculâ communi nigrâ. Abdomen atrum, nitidum.

convexius- 82. Car. niger convexiusculus, thoracis disco culus. æquali, antennis pedibusque piceis.

Long. corp. 6 lin.

Habitat -

Descr. Ne Car. convexiusculum et piceum confundas, hæc ritè animadvertas. In Car. convexiusculo corpus totum convexiusculum; in piceo elytra planiuscula. In Car. convexiusculo thorax convexiusculus, et ab omni parte æqualis, lineâ mediâ longitudinali impressâ, obsoletiusculâ, posticè foveolâ utrinque didymâ ; porrò sub lente transversè striato-rugosus est, et posticè punctulato-rugosus. In Car. piceo thorax disco tumefacto, lineâ mediâ longitudinali impressâ, marginatus est, et intra marginem punctulato-rugosus, posticè foveolâ utrinque simplici. In utroque elytra striata, striis punctatis; at in Car. convexiusculo interstitia planiuscula, in piceo convexa. In utroque antennæ et pedes ferruginei, at in piceo femora nigro-picea. In Car. convexiusculo tibiæ anticæ ad apicem extrorsum setaceo-spinosæ, setis approximatis, serie simplici. In Car. piceo non item.

An Car. spinipes Linnæi et auctorum?

atricapillus. 83. Car. flavus, capite nigro, elytris obtusissimis. Linn. Sy'st. Nat. 673.42. Vill. i.375.46. Fab. Syst. Ent.248.67. Sp. Ins. i. 3 [3. 82. Mant. i. 205. II\%. Ent. Syst. 1. a. 140.69. Panz. Ent. Germ. 52.41. 
Faun. Etrusc. 556. Hellw. 556. Illiger. Kugel. Kaf. Preus. 204. 89. Gmel. 1980.42.

Mart. Eng. Ent. t. 38, f. $3^{6}$. Oliv. iii. $35 \cdot$ III. I55. t. 9. f. Іо6. a. b. Panz. Faun. Germ. 30.t. 9.

Carabus agilis var. d. Payk. Monog. 64. Fann. Suec. i. 150.69 .

Le Bupreste fauve à tête noire. Geoff. i. 153. 25 .

Long. corp. 2 lin.

Habitat

DESCr. Antennæ os et thorax ferruginea, sive rufoferruginea. Caput atrum. Elytra et pedes testacea. Abdomen basi nigrum. Elytra obliquè sub-truncata, obsoletiùs striata; striæ octo punctis minutissimis impressis. Thorax non marginatus, lineolâ mediâ. Quare thoracem rotundatum dicit Fabricius? Totum corpus nitidum. Tibiæ anticæ sub medio apiceque spinosæ.

84. Car. fusco-ferrugineus, elytris pedibusque pal- linearis. lidioribus, elytris abbreviatis apice truncatis.

Oliv. iii. 35. I1 . I56. t. 14. f. 167. a. b.

Long. corp. $2 \frac{1}{3}$ lin.

Habitat in sepibus prope Hastingas.

DESCR. Corpus angustum, sublineare. Oculi nigri. Caput, thorax et apex abdominis saturatiùs sive nigroferruginea sunt. Antennæ, pedes et elytra pallidiora, subtestacea. Elytra striata, punctis impressis, apice truncata, abbreviata, ad abdominis segmentum penultimum desinunt.

85. Car. niger obscurus, elytris apice subtruncatis, femoralis. femoribus basi pallidis.

Long. corp. $I \frac{T}{2}$ lin.

Habitat

DESCR. Satis dignoscitur appendicibus femoralibus, et femorum ipsorum basi pallidis.

86. Car. 
truncatellus. 86. Car. niger suprà æneus, elytris apice subtruncatis.

Linn. Syst. Nat.673. 43. Faun. Suec. 814. Vill. i. 375. 47. Panz. Ent. Germ. 66. ז20. Fab. Mant. i. 206. 123. Ent. Syst. i. a. 168. 194. Faun. Etrusc. 555. Hellw. 555. Gmel. I980. 43. Payk. Monog. 61. Faun. Suec, i. II4. 22.

Oliv. iii. $35 \cdot 113 \cdot 160 \cdot t \cdot 13 \cdot f$. I59. a. b.

Long. corp. $\mathrm{I} \frac{\mathrm{x}}{4} \mathrm{lin}$.

Habitat

DESCR. Elytra substriata, apice obliquè truncata. Faun. Suec.

stapbylinoi- 87. Car. niger, elytris nigro-rufescentibus abbreviatis.

Carabus dimidiatus. Panz. Ent. Germ. Add. 367.

Panz. Faun. Germ. 36.t. 3 .

Long. corp. $I \frac{1}{2}$ lin.

Habitat

Descr. Antennæ, pedes et elytra ex nigro-rufescunt. Elytra $\frac{1}{3}$ abdomine breviora. Caput, thorax et abdomen nigra. Elytra sub lente punctulatissima, ex punctulis autem pili brevissimi prodeunt.

bipustula - 88. Car. nigger, thorace coleoptris anticè margitus. nibus suturâ maculâque comınuni posticè flavis. Fab. Ent. Syst. i. a. 16I. 164. Payk. Faun. Suec. i. 138. 54. Illiger. Kugel. Kaf. Preus. 200. 86.

Panz. Faun. Germ. 16. t.3.

Carabus Crux minor. Fab. Syst. Ent. 246. 56. Sp. Ins. i. 311. 69. Mant. i. 204. 100. Payk. Monog. 52. Faun. Etrusc. 547. Hellw. 547.

Oliv. iii. $35 \cdot 99 \cdot$. $137 \cdot t \cdot 8 \cdot f \cdot 96$. a. b.

Long. corp. 3 lin.

\section{Habitat}

DESCR. Antennæ fuscæ, basi et apice rufescentes. Caput autem 
autem glaberrimum, nitidum. Thorax flavus, lineâ mediâ longitudinali impressâ, obsoletiusculâ, et posticè foveolâ utrinque satis magnâ. Elytra striata, striæ punctis carent; ad basin flava sunt, postice nigra; in medio ad suturam macula rotunda flava; margines exteriores et sutura omninò flava sunt. Pedes et thorax subtùs flavi. In plurimis elytra videntur testacea esse, liturầ posticè magnâ, nigrâ, reniformi, sive auriformi.

89. Car. thorace luteo glabro, elytris posticè ni- Crux minor. gris: maculis duabus flavis.

Linn. Syst. Nat.673.40. Faun. Suec. 809. Vill. i. 374. 44. Fab. Ent. Syst. i. a. 160. 159. Panz. Ent. Germ.61.90. Payk. Faun. Suec. i. 137.53. Illiger. Kugel. Kaf. Preus. 201. 87. Gmel. 1979.40.

Panz. Faun. Germ. 16. t. 2.

Carabus Crux major. Fab. Syst. Ent. 246. 55. Sp. Ins. i. 311. 67. Mant. i. 203. 94. Payk. Monog. 50. Faun. Etrusc. 536 . Hellw. 536, Oliv, iii. $35 \cdot 96$. I32. t. $4 \cdot f \cdot 4 \mathrm{I}$. a. b.

Long. corp. 3 lin.

\section{Habitat}

DESCR. Corpus nigrum. Caput nigrum. Thorax et pectus ferrugineo lutea. Elytra anticè lutea, posticè atra, cum maculâ rotundâ luteâ ad apicem. Pedes lutei. Thorax etiam huic ferè orbiculatus. Faun. Suec.

90. Car. ferrugineus obscuriusculus, capite pal-pallidior. lidiore.

Long. corp. $4 \frac{x}{8}$ lin.

Habitat

Descr. Affinis Car. brunneo, sed quadruplò major. Tum corpus obscuriusculum, nec ut in Car. brunneo nitidum. Porrò vertex pallidior, subtestaceus, nec ut in Car. brunneo thoraci concolor; at elytra striata, punctis impressis, et pedes paulò pallidiores ut in Car. brunneo.

VOL. I.

$2 \mathrm{H}$

91. Car. 
lunatus. 91. Car. thorace orbiculato rufo, elytris flavis: maculis tribus nigris.

Fab. Syst. Ent. 247.60. Mant. i. 204. 108. Ent. Syst. i. a. 163. I72. Panz. Ent. Germ. 63. 98. Faun. Etrusc. 538. Hellw. 538. Harr. 219. Gmel. 1976. 130 .

Oliv. iii. 35. I04. I45.t. 3. f. 27. Scbaff. Icon. t. I4. $f \cdot 4 \mathrm{I}$.

Long. corp. 3 lin.

Habitat

DESCR. Antennæ nigræ, basi ferrugineæ. Caput cyaneo-nigrum, nitens. Thorax orbiculatus, subcanaliculatus, lævis, glaber, rufus. Elytra glabra, substriata, flava, puncto minori orbiculato ad basin, et duobus majoribus margine exteriori connatis ad apicem. Abdomen atrum. Pedes rufi, femoribus apice nigris. Syst. Ent.

macer. 92. Car. nigro-ferrugineus depressiusculus, elytris striis integris, thoracis margine integro, pedibus rufis.

Long. corp. 5 lin.

Habitat

Descr. Maximè affinis Car. depresso, sed satìs distinctus, thorace glaberrimo, margine integro, nec punctato-rugoso ; tum elytra striis ex lineâ exaratâ integrâ, nec punctis impressis ornata. Pedes rufi.

unifasciatus.93. Car. rufo-ferrugineus, coleoptris maculâ dorsali piceâ, pedibus ochraceis.

Panz. Faun. Germ.38.t. 7 .

Lung.corp. 2 lin.

Habitat Captus volando tempore vespertino Julio medio 1797 .

Descr. Oculi nigri, prominuli. Thorax verè obcordatus. Coleoptra pilosula, substriata, ferruginea, ma- 
culis duabus conniventibus, fuscis. Pedes ochracei, sive pallidè-testacei. Cætera rubello-ferrugineus est.

94. Car. sub-æneus, elytris punctis vagis plurimis multi-puncimpressis.

tatics.

Linn. Syst. Nat. 672.32. Faun. Suec. 805. Vill. i. 37I.37: Fab. Syst. Ent.245.48. Sp.Ins. i. 309.58. Mant. i. 201. 79. Ent. Syst. i. a. 138. 59.' Payk. Monog. 49. 29. Faun. Suec. i. II7.27. Panz. Ent. Germ.51.37. Illiger. Kugel. Kaf. Preus, 189. 67: Gmel. I977. 32 .

Oliv. iii. 35.81 . Iog. t. I2.f. I38. Panz. Faun. Germ. II. $t \cdot 5$.

Long. corp. 6 lin.

Habitat in sylvis. Linn.

DEscr. Corpus nigrum, glabrum, subtùs sub-æneum. Thorax lineâ longitudinali excavatâ. Elytra margine laterali sub ænea, disco striata, et adspersa punctis ma. joribus obtusis impressis. Faun. Suec.

*** Thorice posticè truncato integro, elytris angustiori, sub-elongato, attenuato.

95. Car. cyaneus, thorace obcordato, pedibus viridanus. elytrisque rulescentibus, elytris posticè maculâ communi cyaneâ.

Fab. Mant. i. 204. 105. Payk. Monog. 34. Faun. Etrusc. 543. Hellw. 543 .

Mart. Eng. Ent.t. 37.f.25. Oliv. iii. 35. 102. 142. t. $5 \cdot f \cdot 55$.

Long. corp. 3 lin.

Habitat

Descr. Caput et thorax cyanea. Antennæ, palpi et elytra rufa. Posticè ad suturam, macula dorsalis utrique elytro communis, cyanea. Hæc autem macula non omninò ad apicem pervenit. Elytra striata. Corpus subtùs atrum, nitidum. 
crepitans. 96. Car. capite thorace pedibusque ferrugineis, elytris nigris.

Linn. Syst. Nat. 671. 18. Faun. Suec. 792. Vill. i. 365. 23. Fab. Syst. Ent. 242. 35. Sp. Ins. i. 307. 44. Mant. i. 200. 61. Ent. Syst. i. a. 136.53. Payk. Monog. 66. Faun. Suec. i. I52. 71. Preys. Bob. Ins. 44. 44. Harr. 206. Panz. Ent. Germ. 51. 35. Faun. Etrusc. 535. Hellw. 535. Illiger. Kugel. Kaf. Preus. 209. 94.

Oliv. iii. 35. 64. 80. t. 4. f. 35. Panz. Faun. Germ. 3 o. t. 5. Mart. Eng. Ent. t. 36. f. I7. De Geer, iv. 103. 22. t. 3. $f_{\text {. }} 18$. Bergstraes. Nom. i. 13. 84. 9. t. 13. f. 9. Scbaff. Icon. t. I1. f. I3. Act. Acad. Suec. I750. 292. t. 7.f. 2.

Le Bupreste à tête, corcelet et pattes rouges et étuis bleus. Geoff. i. I5I. I9.

Buprestis erythrocephalus anglus. Panz. Voet. ii. 78.26. t. $36 . f .26$.

Long. corp. 4 lin.

Habitat -

DESCR. Corpus ferrugineum. Elytra nigro-cærulescentia, vix manifestè e cæruleo nitentia. Thorax congeneribus angustior. Abdomen fuscum. Tibiæ posticæ latere postico atro-cærulescentes. Faun. Suec.

tenuis. 97. Car. piceo-niger, antennis palpis pedibusque rufis, elytris striatis : striis punctatis.

An Carabus rufipes? De Geer, iv. 96. II.

Long. corp. $3 \frac{x}{4}$ lin.

Habitat

DESCR. Color hujusce animalculi ex nigro-piceus. At palpi, antennæ et pedes rufi. Thorax obovatus, posticè tenuior et aliquantulùm productus, glaber est, lineâ mediâ longitudinali, impressâ, et posticè utrinque foveolâ oblongâ, impressâ. Elytra striata, striis punc. tatis. Superficies nitidiuscula.

nigro- 98. Car. nigro-ferrugineus, antennis pedibusque piceus. paulò-dilutioribus, elytris profundiusculè striatis. Long. 
Long. corp. 2 lin.

Habitat

DESCR. Statura, habitus et magnitudo Car. nigricipitis. Differt colore multo nigriori, et elytris profundiusculè striatis, interstitiis convexis. Pedes ferruginei.

99. Car. pallidè ferrugineus, oculis nigris, pedibus dilutus. testaceo-pallidis.

Long. corp. $3 \frac{1}{2}$ lin.

Habitat

Descr. Totum corpus pallidè ferrugineum. Pedes pallidiores. Oculi solùm nigri. Minimè confundendus cum Car.brunneo. Thorax enim non egregiè obcordatus, nec elytrorum striæ punctatæ. Thorax posticè sub-attenuatus.

ıоo. Car. oblongus cupreo-niger obscurus, an-parallelitennis pedibusque rufescentibus.

Long. corp. $2 \frac{3}{4}$ lin.

pipedus.

Habitat

DESCR. Corpus suprà obscurum, subtùs nitidum. Hoc animalculum præ cæteris sui generis oblongum et compactum. Antennæ et pedes rufescentes. Caput nigrum, attamen certâ lucis incidentiâ,, cærulescentis quoddam præ se ferre visum est. Thorax ex cupreo niger, lineâ mediâ longitudinali, foveolâque ad apicem utrinque impressâ. Elytra ex cupreo nigra, striata ; striæ punctulis minimis impressis. Oculo benè armato, tota superficies punctulata.

Ió. Car. cyaneus nitidus, capite thoraceque pro- cbrysostofundè punctatis, antennarum articulo primo mos. longissimo.

Long. corp. $3 \frac{1}{2}$ lin.

Habitat - In mus. D. Beckwith.

DESCR. Antennæ ferrugineæ, articulo primò longis2. 3 simo, 
simo, apice nigro. Os, maxillæ et palpi ferruginea. Oculi nigri, prominuli. Caput et thorax cyanea, profundè punctata. Thorax posticè angustatus. Elytra villosa, cyanea, striata, striis punctis impressis. Abdomen cyaneum. Pedes ferruginei.

elegantulus. I02. Car ater, antennis ferrugineis, elytris pedibusque testaceis.

Long. corp. $2 \frac{1}{4}$ lin.

Habitat

Descr. Antennx ferruginex, ferè piceæ. Caput et thorax atra, glaberrima, nitida. Elytra testacea, medio ad suturam obsoletè fuscescenti; striata sunt, striis punctulatis. Pedes omninò testacei.

***** Thorace postizè rotundato.

rostratus. 103. Car. apterus, elytris læeviusculis nigris, thorace augustiori, capite angustissimo.

Fab. Syst. Ent. 240. 21. Sp. Ins. i. 304.26. Mant. i. 198. 36. Ent. Syst. i. a. 131. 31. Payk. Monog. 26. I4. Panz. Ent. Germ. 48. 21. Gmel. I966.72. Mart. Eng. Ent. t. 37.f. 27. Oliv. iii. 35. 44. 46. t. 4. f. 37 .

Tenebrio rostratus. Linn. Syst. Nat.677.20. Faun. Suec. 823. Vill. i. 39 I. 16.

Cychrys rostratus. Payk. Faun. Suec. i. 97. I. Faun. Ingr. 79. Illiger. Kugel. Kaf. Preus, 2 16. I.

Carabus coadunatus. De Geer, iv. $92 \cdot 7 \cdot t \cdot 3 \cdot f$. I3.

Long. corp. 8 lin.

Habitat in sylvis et sepibus, Ealing.

DEscr. Totus niger. Caput elongatum, angustissimum. Thorax convexus, subtilissimè punctatus, elytrorum vix dimidia latitudine. Elytra connata, valdè convexa, abdomen amplectentia, undique punctis minutissimis confertissimis elevatis.

Crux major. 104. Car. thorace capiteque nigro-villosa, coleoptris ferrugineis: cruce nigrâ. 
Linn. Syst. Nat. 673. 39. Faun. Suec. 808. Vill. i. 373.43. Fab.Ent. Syst.i. a. 160.158. Payk. Faun. Suec, i. 137.52. Panz. Ent. Germ.61. 89. Gmel. 1978. 39. Illiger. Kugel. Kaf. Preus. 193. 72.

Mart. Eng. Ent. t. 38. f. 49. Panz. Faun. Germ. I6. t. I. Scbceff. Icon. t. I. f. I3.

Carabus bipustulatus. Fab. Syst. Ent. 207. 59. Sp. Ins. i. 312. 74. Mant. i. 204. 106. Payk. Monog. 49.

Oliv. iii. 35. 103. 143.t. 8. f. 95 .

Le Chevalier noir. Geoff. i. 150. I7.

Buprestis cruciata. Panz. Voet. ii. 70, 7. t. 34. f. 7 .

Long. corp. 4 lin.

\section{Habitat}

Descr. Niger. Thorax orbiculatus, convexus, villosus, punctatus. Coleoptra ferruginea, basi, apice et suturấ nigra; fascia dein in medio lata nigra. Alienus est ab hoc genere ob pubescentiam, et thoracem orbiculatum, nec succurrit aliud, cui aptiùs inseratur. Faun. Suec.

105. Car. piceo-ferrugineus, elytris dilutioribus, rotundiantennis pedibusque testaceo-pallidis. .

collis.

Long. corp. $2 \frac{x}{2}$ lin.

Habitat

DESCr. Habitus omninò Car. nigricipitis cui simillimus, at major ; tum thorax posticè rotundatus. Elytra, capite et thorace aliquantulùm pallidiora, et ad margines exteriores striam manifestè punctatam gerunt. Pedes pallidè testacei.

I06. Car. nigro-piceus, antennis pedibusque tes-ocbropus. taceo-pallidis.

Long. corp. $3 \frac{x}{2}$ lin.

Habitat

Descr. Antennæ sub-ferrugineæ. Caput ex nigropiceum, glabrum. Thorax piceus, glaber, sub lente obsoletè transversè rugosus; anticè lunato-excavatus, 
posticè rotundatus. Elytra nigro-picea, striata; strixe punctis immunes, interstitiis planis. Pedes pallidotestacei.

\section{****** Tborace remoto.}

cepbalotes. 107. Car. ater, thorace posticè attenuato, margine postico punctato-rugoso, elytris lævibus obsoletissimè striatis.

Linn. Syst. Nat. 669. 9. Faun. Suec. 788. Vill. i. 361. 9. Gmel. 1964. 9. Fab. Syst. Ent. 240. 22. Sp. Ins. i. 304.27. Mant. i. 198.39. Ent. Syst. i.a. I43. 85. Faun. Fred. 20. 201. Payk. Monog. 65. Faun. Suec. i. 5 I. 70.

Mart. Eng. Ent.t. $3^{8}$. f. $4 \mathrm{I}$. Scheff. Icon. t. II. f. . . Scarites cephalotes. Panz. Ent. Germ. 37. 5. Illiger. Kugel. Kaf. Preus. п1о. I.

Oliv. iii. 36. 8. 6. t. I. f. 9 .

Pseudocupis major. Panz. Voet. ii. 64. 2. t. 33. $f .2$.

Long. corp. $10 \frac{1}{2}$ lin.

Habitat Captus in littore Harvicensi et Sussexiensi.

Descr. Ex omni parte ater, nitidus. Antennæ, palpi, maxillæ, oculi, caput et thorax valdè nitida. Thorax obcordatus, posticè attenuatus, lineâ mediâ impressâ ; ad marginem posticum punctato-rugosus, marginibus antico et postico ciliatis, ciliis brevissimis, ferrugineis. Desunt foveæ quæ cæteros notant. Elytra minùs quam thorax nitida; lævia, striis octo obsoletissimis, non nisi sub lente conspiciendis ; striæ ex punctis minutissimis constant. Ad margines elytrorum, series punctorum remotorum. Totum corpus subtùs nitidissimum. Tibiæ anticæ apice et sub medio spinosæ, alæ ex carne albidæ. Apex thoracis $\frac{\mathrm{r}}{3}$ angustior basi elytrorum.

distans. 108. Car. nitidus, elytris striatis, thorace exserto oblongo, tibiis anticis palmato-spinosis.

Tenebrio fossor. Linn. Syst. Nat.675. 7. Faun. Suec. 817. 
817.Vill. i. 386. 4. Herbst.Jablonsk. vii. 255. 20. Gmel. 1994: 7.

Scarites arenarius. Fab. Syst. Ent. 249. 3, Sp. Ins. i. 314. 4. Mant. i. 206. 6. Ent. Syst. i. a. 96.9. Payk. Faun. Suec. i. 84. I. Faun. Etrusc. 569. Hellw. 569. Illiger. Kugel. Kaf. Preus. IIr. 2.

Oliv. iii. 36. 13. 16. t. 1. f. 6. a. b. Panz. Faun. Germ. 43. t. II.

Attelabus fossor. De Geer, iv. 350 . 1. t. 30. f. 12.

Pseudocupis minor. Panz. Voet. ii. 65.3.t. $33 \cdot f \cdot 3$.

Long. corp. 3 lin.

Habitat

DEscr. Thorax nitidus, lineâ longitudinali, foveolisque duabus lateribus excavatis; porrò distat paululùm $\mathrm{ab}$ abłomine isthmo quodam interceptus, adeò ut petiolatus esse videtur. Elytra striata. Tibiæ anticæ apicem versus crassiores, palmato spinosæ. Nec $T_{e}$ nebrio ut Linnæus, neve Attelabus ut De Geer monuit, dicendus est. Quod si thorax non omninò obcordatus sit, at linea media foveolæque laterales, tum præcipuè femora postica appendiculata, Carabis conscribi vehementiùs suadent.

Variat colore ferrugineo, nigro, piceo.

109. Car. ater nitidus, thorace exserto remotoremotus. subgloboso, elytris striatis.

Scarites gibbus. Fab. Ent. Syst. i. a. 96. 10. Pañ. Ent. Germ. 37. 2.

Oliv. iii. 36. 15. 19. t.2.f. 16. a. b. Panz. Faun. Germ. 5.t. I.

Scarites globosus. Herbst. Arch. t. 29. f. 17 .

Long. corp. $1 \frac{1}{4} \operatorname{lin}$.

Habitat

Descr. Minutum hoc animalculum satis distinguitur, thorace $a b$ abdomine paulùm distanti, globoso, glaberrimo, nitido. 


\section{TENEBRIO.}

Antenne moniliformes, extrorsùm sensìm crassiores.

Capht exseftum.

Thorax plano-convexus, marginatus."

Elytra rigida, longitudine corporis.

Corlıus oblongum, planiusculum.

molitor.

I. Ten. niger totus, femoribus anticis crassioribus.

Linn. Syst. Nat. 674. 2. Faun. Suec. 815. Vill. i. 385. I. Gmel. 1995. 2. Fab. Syst. Ent. 255. 2. Sp. Ins. i. 322. 2. Mant.i. 21 1. 4. Ent. Syst. i. a. I11. 6. Payk. Faun. Suec, i. 89.3. Pontop. i. 678. I. Faun. Fred. 21. 213. Panz. Ent. Germ. 40. 3. Faun. Etrusc. 577. Hellw. 577. Illiger. Kugel. Kaf. Preus. II3. I.

Mart. Eng. Ent. t. 39. f. 2. Herbst. Jablonsk. vii. 240. I. $t$. III. f. I. De Geer, v. 34. 3. t. 2. f. 4 . Le Ténébrion à neuf stries lisses. Geoff. i. 349. 6 .

Long. corp. 8 lin.

Habitat larva pallida, glabra, in farina pistorum, inque pane martio et militari, in quo sæpè hæret per duos annos antequàm mutetur, ipsa Lusciniis gratissimus cibus. Linn.

DEsCr. Totus niger est, colore omninò picis. Elytra parùm striata. Thorax margine prominulo. Antennæ breves, obtusæ et quasi moniliformes, undecim articulis (exceptis tribus primis longiusculis) lentiformibus, nigris, ultimo globoso, pallidiore. Os, antennæ, margo thoracis, pedes e ferrugineo atra sunt. Faun. Suec.

2. Ten. 
IETIERIBUTO
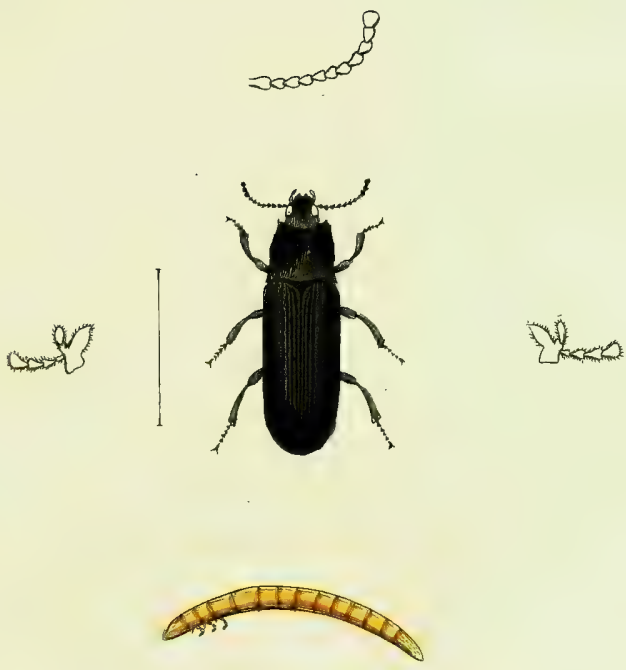

I.molitor. 

2. Ten. ater, thorace anticè excavato posticè obsoletus. truncato, elytris striatis obsoletiùs rugosis.

Long. corp. 5 lin.

Habitat

DESCR. Antennæ filiformes, II-articulatæ. Thorax convexiusculus, scabro-punctulatus, anticè excavatus lunulæ instar, posticè truncatus. Elytra obsoletè striata, et obsoletè rugosa. Corpus subtùs aterrimum, nitidiusculum.

3. T en. niger, elytris striis octo punctatis per pa-gemellatus. ria dispositis.

Vill. i. $395 \cdot 32$.

Le Ténébrion à stries jumelles. Geoff. i. 348. 3 .

An Blaps gemellata? Oliv. iii. 60.9.8. t. 1. f. 8 .

Long. corp. 4 lin.

Habitat C Captus in littore juxta LandguardFort.

Descr. Oblongus nigro-piceus, nitidus, punctatissimus. Antennæ moniliformes. Thorax ponè angustatus, marginatus, margine utrinque curvo. Elytra subacuta, quatuor paribus striarum excavato-punctatarum striata. Tibiæ intermediæ et posticæ, et femora postica basi intús fulvo-ciliata.

4. Ten. ater, thorace anticè sub-cxcavato, elytris arenosus. punctato-striatis obscuris.

Long. corp. 4 lin.

Habitat in arenosis.

DESCr. Totum corpus atrum. Capitis clypeus antice emarginatus. Thorax anticè sub-excavatus, margine ipso sub-denticulato, posticè truncatus, lateribus angulatus. Elytra obsoletissima, rugosa, striis obsoletis punctatis. Tibiæ anticæ spathulæformes.

5. Ten. niger, ore pedibusque ferrugineis.

quisquilius. Linn. 
Linn. Syst. Nat. 676.13. Faun. Suec. 821. Vill. i. 388. 10.

Helops quisquilius. Fab. Syst. Ent. 258. 8. Sp. Ins. i. 326. 13. Mant. i.214. I8. Ent. Syst. i. a. 122. 26. Panz. Ent. Germ. 43. 7. Faun. Etrusc. 588. Hellw. $5^{88 .}$

Long. corp. 3 lin.

Habitat

DEscr. Corpus nigrum, opacum. Pedes piceo-ferruginei. Faun. Suec.

bumeralis. 6. Ten. fuscus, thorace elytrisque lævibus obsoletissimè punctulatis.

Long. corp. 3 lin.

Habitat

DESCR. Antennæ et corpus suprà fusca. Corpus subtùs pedesque brunnei. Thorax et elytra lævia, punctulis obsoletissimis conspersa. Thorax elytris latior.

nigrimus. 7. Ten. ater, elytris obsoletissimè striatis punctulatisque, plantis piceis.

An Helops piceus? Oliv. iii. 58. 17. 22. t. 2. f. 13.

Long. corp. $2 \frac{x}{4}$ lin.

Habitat

DESCR.

stygius. 8. Ten. ater, elytris lævibus obsoletissimè punctulatis, plantis piceis.

Long. corp. 2 lin.

Habitat

Descr. Hic præcedenti simillimus; differt solummodó elytris non striatis præterquam striâ unicâ abbreviatâ apicem suturæ versus; tum antennis æqualibus, nec basi tenuioribus. Utrique thorax elytris paulò latior, anticè et posticè truncatus. Elytra sub lente obsoletissime 
tissimè punctulata. Pedes nigri, tarsis plantisque subferrugineis.

9. Ten. pallidè testaceus, oculis nigris. pallens.

Linn. Syst. Nat. 675. 10. Faun. Suec. 820. Vilh i. 387.7. Gmel. 1997. Io. Fab. Sp. Ins. i. 324. II. Mant. i. 212. 16. Ent. Syst. i. a. ז13. 17. Payk. Faun, Suec. i. 90. 5.?

Oliv. iii. 57.19.26.t.2.f. 25. Herbst. Jablonsk. vii. 257.24. viii. 9.t. I17.f. 10. Mart. Eng. Ent.t.39. $f \cdot 3$.

An Hypophlæus fraxini? Payk. Faun. Suec. iii. 322.2. Long. corp. $2 \frac{\pi}{4} \operatorname{lin}$.

Habitat

DESCR. Totus teretiusculus, opacus, unicolor, pallidus, ad testaceum vergens colorem, exceptis oculis nigris, minimè striatus. Faun. Suec.

ro. Ten. ovatus, thorace emarginato sanguineo: coccineus. maculâ nigrâ, elytris sanguineis: maculis duabus nigris.

Chrysomela coccinea. Linn. Syst. Nat.592. 43. Faun. Suec.532. Vill. i. 132. 35. Gmel. 1682. 43. Faun. Etrusc. 202. Hellw. 202. Goeze, i. 269. 43. Fab. Syst. Ent. 105. 59. Sp. Ins. i. 131.83. Mant. i. 75. 109.

Mart. Eng. Ent. t. 16. f. $3^{8}$.

Chrysomela 4-maculata. De Geer, v. 301. Io. t. 9. f. I.

Coccinella coccinea. Udd. Diss. I3.

Galleruca coccinea. Fab. Ent. Syst. i. b. 20.31.

Endomychus coccineus. Panz. Ent. Germ. I75. I. Payk. Faun. Suec. ii. I12. I. Fab. Supp. 100.2.

Panz. Faun. Germ. 44. t. I7.

Long. corp. 3 lin.

Habitat

Descr. Caput parvum, nigrum. Thorax quadrangularis, coccineus, medio niger. Elytra coccinea, in singulis 
singulis maculæ rotundæ duæ. Abdomen sanguineum. Pedes et antennæ nigræ. Faun. Suec.

Boviste. II. Ten. ater nitidus, antennis pedibusque ferrugineis, elytris apice piceis.

Galleruca Bovistæ. Fab. Ent. Syst. i. b. 20. 34 . Endomychus Bovistæ. Panz. Ent. Germ. 75. 4. Fab. Supp. ror. 5. Payk. Faun. Suec. ii. I15. 4 .

Faun. Germ. 8. t. 4 .

Long. corp. 2 lin.

Habitat in Lycoperdo bovistâ. D. Kirby.

Descr. Antennæ rufæ. Caput atrum, nitidum. Thorax ater, nitidus, margine sub-reflexo. Elytra atra, lævia, nitida, apice picea. Pedes ferruginei.

mauritani- I 2. Ten. niger, subtùs piceus, thoracis marginicus. bus anticè posticèque dente angulatis.

Linn. Syst. Nat. 674. 4. Gmel. 1995. 4. Faun. Etrusc. 579. Hellw. 579. Mant. 93. 208. Fab. Ent. Syst. i. a. I I3. 15. ?

Trogosita mauritanica. Oliv. ii. 19.6.2. t. I. f. 2. a. b. Trogosita caraboides. Fal. Ent. Syst. i. a. II5.2. Panz. Ent. Germ. 41. I. Illiger. Kugel. Kaf. Preus. II7.2. Panz. Faun. Germ. 3. t. 4 .

La Chevrette brune. Geoff. i. 64.5.

Long. corp. 3--4 lin.

Habitat in granis hordeis; in mercatorum tabernis frequens. D. Donoran.

DEscr. Corpus depressum. Antennæ piceæ, capite paulò longiores. Thorax punctatus, anticè utrinque dente prominulo, et posticè obsoleto. Elytra striata, punctata. Corpus suprà nigricans, subtùs pedesque picea. Oliv. 


\section{[ 479$]$}

\section{BLAPS.}

\section{Antenne filiformes.}

\section{Caput exsertum.}

Thorax plùs minùs marginatus.

Elytra rigida, abdomen arctè amplectentia.

Corpus oblongum, gibbum.

I. Bl. atra, thorace elytris angustiori, coleoptris mortisaga. lævibus mucronatis.

Fab. Syst. Ent.254. 3. Sp.Ins. i. 321.3. Mant. i. 210.3. Ent. Syst. i. 107.3. Payk. Faun. Suec. i. 89. I. Panz. Ent. Germ.39. I. Gmel. 200r. 3. Faun. Etrusc. 576. Hellw. 575. Illiger. Kugel. Kaf. Preus. II 2. I.

Panz. Faun. Germ.3.t.3.

Tenebrio mortisagus. Linn. Syst. Nat. 676. 15. Faun. Suec. 822. Faun. Fred.21. 214, Harr. 189.

Tenebrio acuminatus. De Geer, v. 3 I. I.

Long, corp. io lin.

Habitat in suffocatis.

Descr. Oblonga, tota atra obscura. Antennæ longiusculæ, articulis duobus primis brevissimis, tertio longissimo, proximis quatuor oblongis nigris, tribus sequentibus lentiformibus, et ultimo ovato acuminato ferrugineo. Palpi clavati. Oculi reniformes. Thorax quadratıs, marginatus, süb-æqualis, punctulatus. Coleoptra obovata, acuminata, obsoletè elevato-striata, et punctulata, connata, abdominis latera obvolventia. Sæpè terminantur elytra apice in dorso rimulâ. Pedes postici prælongi, præsertim femora.

2. Bl. atra, thorace æquali valdè marginato, co-letbifera. leoptris lævibus mucronatis. 
Tenebrio lethifer. Schaff. Icon. $t .37 \cdot f \cdot 6$.

Long. corp. I I lin.

Habitat $\longrightarrow$

DESCr. Præcedenti simillima, sed latior, magis ovata. Antennæ thorace breviores, articulis intermediis ovatis. Thorax latus, punctatus, lineâ intermediâ longitudinali obsoletè exaratus. Elytra connata, punctulatissima, obtusa. Pedes respectu magnitudinis breviores, crassiores quam præcedenti. Cætera simillima.

violacea.

3. Bl. violacea, thorace obcordato posticè trunçato, antennis pedibusque piceis.

Long. corp. 10 lin.

Habitat sub cortice Quercuum veternarum.

DESCR. Antennæ 8-articulatæ, moniliformes, crassæ, articulo ultimo paululùm crassiori, apice sub-truncato. Thorax ut in Carabis obcordatus, violaceus, scabropunctatus. Caput nigrum, scabro-punctatum, ore pilis brevibus ferrugineis obsito. Elytra violacea, striata, striis octo impressis, omnibus æqualibus. Abdomen nigrum. Pedes picei; plantæa introrsùm pilis ferrugineis splendentibus ornatæ. Carabus apprimè dicendus foret nisi quod appendix femorum defuerit.

alrata. 4. Bl. atra pilosa, thorace anticè angustiori, elytris obsoletè striatis.

Long. corp. 8 lin.

Habitat

DESCR. Totum corpus atrum, pilis brevissimis obsitum. Sub lente, quisque pilus ex punctulo minutissimo impresso prodire videtur. Thorax anticè angustus, postice dilatatus, ut in Silpbis quibusdam, præcipue Sil. lavigata. Elytra obsoletè striata; in fundo striarum puncta obsoleta impressa. Corpus subtùs aterrimum, nitidum. Antennæ filiformes, moniliformes, II-articulatæ, articulis obovatis, apice truncatis. 

XIEIOE。
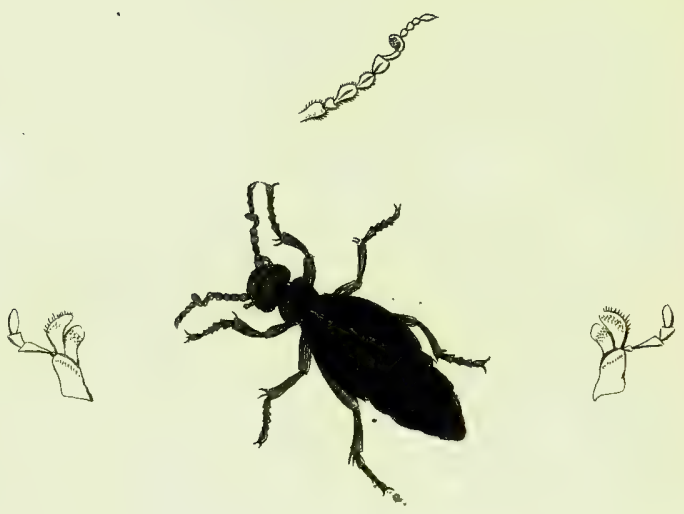

है

Mproscarabous. 
5. Bl. picea nitescens, elytris striatis.

Spartii.

Long. corp, maris $3 \frac{3}{4}$ lin.

fœm. $4 \frac{x}{2}$ lin.

Habitat in Spartio scopario.

DESCR. Totum corpus piceum, sive castaneum, nitescens, punctulatissimum. In elytris punctula subconfluentia, per cæetera membra distinctissima, Elytra striis octo punctatis mediocriter exarata.

\section{MELOE.}

Antenna moniliformes, articulo ultimo ovato, maris irregulares.

Cafut gibbum, inflexum.

Thorax sub-quadratus.

Elytra mollia, flexilia, abbreviata, apice rotundata.

Abdomen valdè gibbum, ovatum.

I. Mel. corpore suprà atro, subtùs violaceo. Linn. Syst. Nat.679. I. Faun. Suec. 826. Vill. i. beus. 397. I. Scop. 184. Gmel. 2017. 1. Fab. Syst. Ent. 259. I. Sp. Ins. i. 327. I. Mant. i. 215. I. Ent. Syst. i. b. 517. I. Panz. Ent. Germ.350. 1. Faun. Fred. 22.215. Faun. Ingr. 353. Harr. 400. Poda, 47. I. List. Goed. 292. 120. a. Hoppe, Ins. Erl.67. Payk. Faun. Suev, iii. 361. 1. Faun. Etrusc. 590. Hellw. 590.

Don. Brit. Ins. t. 43. Sulz. t. 7. f. 10. Panz. Faun. Germ. I0. t. I2. Scbeff. Icon. t. $3 \cdot f_{\cdot} 5$. Oliv. iii. 45. 5. I. t. I. f. I. a-d. Mart. Eng. Ent. t. 39. f. 6 . voL. I.

2 I

Cantharis

proscara- 
Cantharis proscarabæus. $D_{\epsilon}$ Geer, v. 3. 1.t. 1. f. 1. Le Proscarabé. Geoff. i. $377 \cdot 1 . t .7 \cdot f \cdot 4$.

An Meloe tecta? Panz. Faun. Germ. 10.t. 14. Don. Brit. Ins. t. 240.

Long. corp. maris 10 lin. fœem. 18 lin.

Habitat in campis apticis.

DESCr. Antennæ maris singulares sủnt. Hæ violaceæ, pilosæ, undecim articulationum, quarum sex prima sensim crassiores sunt; sexta compressa; : septima etiam compressa, paulò minor, ubtuser-cordata, inrmans angulum cum sextâ; cættræ quatuor articulatinres multò minores et sensim tenuiores, ultimâ longâ conicâ. Antennæ foeminæ moniliformes sunt. Totum animal molle est. Elytra coriacea, mollia, rugosa, minimè nitida. In foeminâ abdomen longius elytris. Caput, thorax, elytra et abdomen suprà (ultmo segmento abdominis excepto) nigra sunt. Totum corpus subtùs, anus et pedes violacea sunt.

violaceus. 2. Mel. corpore toto violaceo, thorace posticè emarginato.

Long. corp. maris ro lin. fœem. 13 lin.

Habitat

DESCR. Antennæ ut in Mel. proscarabero cui maxime affinis est, sed totus violaceus, nec niger suprà.

similits. 3. Mel. corpore suprà viulaceo, subtùs atro. Long. corp. 10 lin.

Habitat

Descr. Antennæ ut in duobus præcedentibus quibus maximè affinis est. Differt a Mel. violacuo thorace latiore, elytris longioribus, et corpore subrùs atro.

An tres præcedentes meræ varietates? An species distinctie?

4. Mel. 
4. Mel. corpore atro, elytris rugosis.

Long. corp. 5 lin.

Habitat

In mus. D. Latbam.

Descr. Duplò minor Mel. proscarabceo, sed color omninò ater, nec violaceus, et elytra magìs rugosa. Thorax subtuberculatus, medio longitudinaliter sulcatus.

5. Mel. sub-auratus, capite thorace elytrisque ru-scabrosus. gosis scabris.

Meloe maialis. Panz. Ent. Germ. 350. 2.

Panz. Faun. Germ. 10. t. I3. Oliv. iii. 45.6.2. t. I. $f .4$. a. b. d. t. 2. $f$. 4. c. Schaeff. Icon. $t .3 \cdot f \cdot 6$.

Meloe varieg ttus. Don. Brit. Ins, t. 67. Mart. Eng. Ent. $t .39 \cdot f . \mathbf{I}$.

Long. corp. I unc.

\section{Habitat}

DESCR. Totum córpus nigro-viride, colore aureo fugaci spondet. Caput et thorax scabra, punctis prominulis quæe et rugas efficiunt. Elytra valdè rugosa, sublacunosa. Abdomen glabrum, marginibus incisurarum latè aureis.

6. Mel. violaceus, thorace posticè emarginato, punctatus. elytris punctatis corporis ferè longitudine.

Long. corp. 5 lin.

Habitat Captus apud Ringstead, Norfolciæ, Septembre ineunte. D. Kirby.

DESCR. Totus ater-cærulescens. Thorax posticè depressus, emarginatus. Elytra corporis ferè longitudine, vix rugulosa, sed punctis impressis, haud confertis irrorata. 


\section{[ 484 ]}

\section{LYTTA.}

Antenne filiformes.

Caput gibbum, inflexum, thorace latior.

Thorax plerisque cylindricus.

Elytra mollia, flexilia, linearia.

Corpus elongatum.

vesicatoria. 1. Lyt. viridissima nitens, antennis nigris.

Fab. Syst. Ent. 260. I. Sp. Ins. i. 328. т. Mant. i. 215. 1. Ent. Syst. i. b. 83. 1. Panz. Ent. Germ. 203. I. Hoppe, Ins. Erl. 36. Payk. Faun. Suec. ii. I59. 1. Gmel. 2013. I. Faun." Etrusc? 592. Hellw. 592.

Panz. Faun. Germ. 4I. t. 4.

La Cantharide des boutiques. Geoff. i. 341. 1. t. 6. f. 5 . Meloe vesicatorius. Linn. Syst. Nat. 679. 3. Fuun. Suec. 827. Vill. i. 398. 3. Scop. 185 . Scbrank, 418. Faun. Fred. 22. 217. Poda, 47. 2. Pontop. i.678.3. Amoen. Acad. 135. T.

Mart. Eng. Ent. t. 39. f. 2.

Cantharis vesicatoria. De Geer, v. 12. 2. $t$. 1. $f$. 9 . Oliv. iii. 46. 6. I.t. I. f. I. a-c. Schaff. Elem. t. 33 .

Cantharis officinarum. Linn. It. Scan. 186.

Cantharis vulgaris officinarum. Rai. I0I.

Long. corp. 1o lin.

Habitat in Ligustro, Fraxino, Sambuco.

Vesicatoria celeberrima in omnibus officinis Europæis nomine Cantharidis. Veterum verò Cantbaris est Meloe cichorii. Faun. Suec.

DESCR. Tota viridi-aurea, nitidissima, suprà glabra, subtùs pilis cinerascentibus parciùs adspersa. Antennix 
tennæ nigfæ, basi virides. Thorax sub lente subtilissimè punctulatus. Elytra convexa, thorace paulò latiora, oculo armato subtilissimè rugosa. Tarsi cærulescentes.

2. Lyt. nigra, elytris maculis duabus pallidis ob-floralis. soletis.

Meloe floralis. Linn. Syst. Nat. 681. 15. Faun. Suec. 83o. Vill. i. $402: 10$.

Mart. Eng. Ent. t. 39. f. 4.

Lagria floralis. Fab. Syst. Ent. I26. 12. Sp. Ins. i. 161. 15. Mant. i. 94. 25. Faun. Etrusc. 279. Hellw. 279.

Notoxus floralis. Fab. Ent. Syst. i. a. 212. ro.

Cryptocephalus floralis. Gmel. 1731. 235.

Anthicus floralis. Payk. Faun. Suec. i. 356. 3 .

Long. corp. $x \frac{x}{4}$ lin.

Habitat in Cardui floribus frequens. Linn.

DEscr. Thorax glaberrimus, et elytra fusca, maculis duabus, ovatis, transversis, pallidis; alterâ priore, alterâ posteriore; neutrâ marginem elytri tangente. Faun. Suec.

3. Lyt. nigra, elytris fasciis duabus ferrugineis:antberina. primâ interruptâ.

Meloe antherinus. Linn. Syst. Nat. 681. 16. Faun. Suec. 829. Vill. i. 402. I1.

Mart. Eng. Ent. t. $39 \cdot f \cdot 3$.

Lagria antherina. Fab. Syst. Ent. 126. 12. Sp. Ins. i. I60. 14. Mant. i. 94. 26. Faun. Etrusc. 278. Hellw. 278.

Notoxus antherinus. Fab. Ent. Syst.i. a.212. 9. Panz.

Ent. Germ. 87. 6.

Panz. Faun. Germ. II. $t$. I4.

Cryptocephalus antherinus. Gmel. I73 1. 234 .

Anthicus antherinus. Payk. Faun. Suec. i. 255.2.

Long. corp. I $\frac{3}{4}$ lin.

Habitat 
Descr. Corpus nigrum. Coleoptra fascîâ unâ ferrugineâ interruptâ ad basin, alterâ pone medium. Thorax subglobosus, niger.

fusca.

4. Lyt. ferruginea, elytris fuscis basi obsoletè ferrugineis.

Notoxus floralis. Panz. Ent. Germ. 87. 7 .

Panz. Faun. Germ. 23. $t$. 4 .

Long. corp. $1 \frac{1}{4}$ lin.

Habitat in floribus syngenesiis in pratis, in hortis totâ æstate.

Descr. Antennæ, thorax, pedes fusco-ferruginei. Caput nigro-ferrugineum. Elytra glabra, nitidiuscula, nigro-fusca, basi pallida, at obsoletè ferruginea. Abdomen nigro-fuscum.

picea.

5. Lyt: picea nitida, antennis pedibusque ferrugineis.

An Notoxus minutus. Fab. Ent. Syst. i. a. 212. 11. Panz: Ent. Germ. 88. II.

Panz. Faun. Germ. 23. $t .5$.

Long. corp. $\frac{3}{4}$ lin.

Habitat in hortis, Ealing.

DEsCr. Antennæ ferrugineæ, extrorsùm crassiores, subclavatæ. Thorax gibbosus. Caput, thorax et elytra polita, picea, nitida. Pedes ferruginei.

Boleti. 6. Lyt. testaceo-ferruginea glabra, capite nigro. Notoxus calycinus. Panz. Ent. Germ. 87.8.

Panz. Faun. Germ. 8. t. 3 .

Long. corp. I lin.

Habitat in Boleto velutino. Larva et imago simul semper adsunt.

DEscr.. Affinis admodùm Lyt. fusce, at elytra non basi dilutiora. Caput et abdomen nigra. Thorax et elytra 
elytra testaceo-ferruginea. Sub lente elytra ut in $L y t$. fusce, punctulatissima.

7. Lyt. nigra, anfennis elytris pedibusque ferru-nigricollis. gineis.

Long. corp. $\mathbf{x}$ lin.

\section{Habitat}

DESCr. Antennæ ferrugineæ. Caput et thorax nigra. Elytra ferruginea, apicibus nigris. Corpus subtùs nigrum. Pedes ferruginei. Sub lente elytra punctulatissima, villis obtecta videntur.

8. Lyt. thorace in cornu suprà caput protenso.

monoceros.

Meloe monoceros. Linn. Syst. Nat.651, 14. Vill. i.

401.10.

Don. Brit. Ins. t. 182.

Attelabus monoceros. Faun. Suec. 639. Harr. 397.

Scbaff. Icon. t. 188. f.3.

Notoxus monoceros. Fa. Syst. Ent. 158. 2. Sp. Ins. i. 203. 2. Mant. i. 127. 4. Ent. Syst. i. a. 210.6. Faun. Etrusc. 354. Hellw. 354. Gmel. 1813. 4. Panz. Ent. Germ. 87.4.

Oliv. iii. 5 I. 4. I. t. 1. f. 2. a-c.

Anthicus monoceros. Payk. Faun. Suec. i. 254. I.

La Cuculle. Geoff: i. $35^{6}$. t. 6. $f .8$.

Long. corp. 2 lin.

Habitat in floribus syngenesiis, imprimis Senecion tenuifolio et Jacobeâ.

Descr. Caput nigricans. Antennæe et pedes testacei. Thorax posticè ferrugineus, anticè niger, recta antrorsùm exiens in cornu nigricans ultra caput extensum, unde verè monstrosa et insectis insolita facies. Elytra testacea : suturâ longitudinali nigrâ, et fasciâ posticâ nigrà, punctoque anticè nigro. Corpus suprà pilis brevibus adspersum. 


\section{[ 488$]$}

\section{MORDELLA.}

Antenna filiformes, plerumquè serratx. Caput deflexum sub collo. Elytra deorsùm curva apicem,versus. Corpus oblongum, posticè attenuatum. Ante femora lamina lata ad basin abdominis.

$$
\frac{\text { * Aculeatce. }}{\text { * Inermes. }}
$$

aculeata. I. Mor. oblonga tota atra.

Linn. Syst. Nat. 682. 2. Faun. Suec. 832. Vill. i. 406. 2. Scop. 192. Scbrank, 427. Gmel. 2023.2. Fab. Syst. Ent. 263. 5. Sp. Ins. i. 333. 7. Mant. i. 218. II. Ent. Syst, i. b. 113. I. Payk. Faun. Suec. ii. 185. 3. Faun. Fred. 22. 218. Poda, 47. I. Harr. 259. Faun. Etrusc. 598. Hellww. 598. Panz. Ent. Germ. 212. I. De Geer, v. 28. I.

Oliv. iii. 64. 4. I. t. I. $f$. I. a-c.

La Mordelle noire à pointe. Geoff. i. 353. 1. t. 6. f. \%.

Long. corp. 2 lin.

Habitat in floribus.

Descr. Tota atra, glabra, oblonga. Caput parvum, inflexum. Elytra oblonga, atra, non striata. Thorax glaber, convexus. Corpus versus caudam sensim angustius. Abdomen compressum, desinens in aculeum, sive spinam subulatam, acutam, nigram, elytris longiorem, minimè pungentem. Pedes longiusculi, quibus saltat. Faun. Suec.

fasciata. 2. Mor. nigra, elytris fasciis duabus cinereis. Fab. Syst. Ent. 263.6. Sp. Ins. i. 333. 8. Mant. i. 218. 
PZ.28.

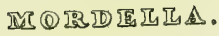

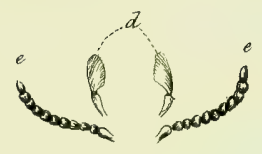

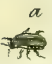
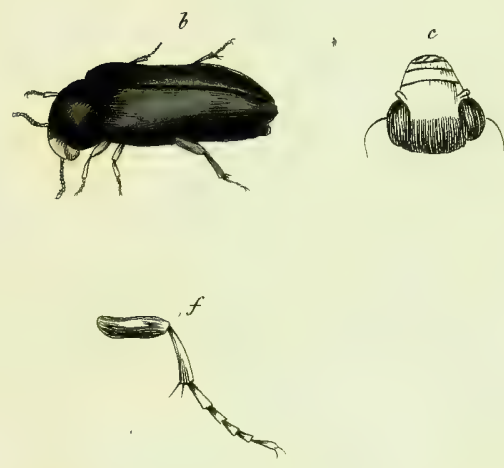

M. frontatis. 

218. 12. Ent. Syst. i. b. 1:3.2. Payk. Faun. Suec. Add. iii. 455. I-2. Gmel. 2023. x6. Faun. Etrusc. 599. Fiellw. 599. Panz. Ent. Germ. 212.2.

Oliv. iii. 64. 4.2.t. I. f.2. a. b. Scbaff: Icon.t. 127.f. 7 .

La Mordelle veloutée à pointe. Geoff. i. 354. 2 .

Long. corp. 3 lin.

Habitat in floribus.

Descr. Simillima præcedenti, cum quâ etiam conjunxit celeb. Linné. Differt tamen elytris basi fasciâque mediâ villoso-cinereis, nitentibus. Syst. Ent.

3. Mor. atra, lateribus thoracis baseosque elytro-bumeralis. rum flavescentibus.

Linn. Syst. Nat. 682. 3. Faun. Suec, 833. Vill. i. 406. 3. Gmel. 2024 3. Fab. Syst. Ent. 264.9. Sp.Ins.i. 333.1 Mant. i. 219.16. Ent. Syst.i.b. I14. 7. Payk. Faun. Suec, ii. 187.6. Panz. Ent. Germ. 2 13. 5 .

Oliv. iii. 64. 8. 7.t. I. f. 7. a. b. Panz. Faun. Germ. 62. $t .3$.

L'Anaspe à taches jaunes. Geoff: i. 3 16. 2.

Long. corp. $2 \frac{x}{2}$ lin.

\section{Habitat - In mus. D. Beckwith.}

DESCR. Statura el magnitudo præcedentium. Caput flą vum. Thorax flavescens, medio nigricans. Elytra basi ferruginea. Faun. Suec.

4. Mor. atra, thorace abdomineque rufis.

abdomina-

Fab. Ent. Syst. i. b. I14.6. Vill. i. 408.7. Payk. lis.

Foun. Suec. ii. 186.5. Gmel. 2024. I9.

Oliv. iii. 64.7.5.t.x. $f \cdot 5 \cdot$ a. b.

Long. corp. 3 lin.

Habitat

DESCr. Antennæ nigræ, basi rufâ. Caput nigrum, ore rufo. Thorax, pectus et abdomen rufa. Aculeus exsertus ater. Elytra et lamina ad basin abdominis nigra. Pedes duo antici rufi, postici quatuor nigri.

5. Mor. 
nigra. 5. Mor. atra, abdomine rufo.

Long. corp. $2 \frac{1}{2}$ lin.

Habitat

Descr. Antennæ nigræ, basi rufâ. Caput nigrum, ore flavo. Thorax, pectus, elvtra, pedes et lamine ad basin abdominis nigra. Abdomen rufum. Aculeus exsertus ater ut in Mor.abdominali, cui maximè affinis, sed thorax et pectus nigra, nec rufa.

ferruginea. 6. Mor. ferruginea, oculis nigris.

Long. corp. $2 \frac{1}{2}$ lin.

\section{Habitat}

Descr. Tota ferruginea, præter oculos, qui omnind nigri sunt. Corpus subtùs pallidius. Abdomen compressum, desinens in aculeum, sive spinam subulatam, acuram, castaneam, longam. Pedes concolores, femoribus posticis saltatoriis.

Aavescens. 7. Mor. testacea, elytris saturatioribus.

Long. corp. $2 \frac{1}{2}$ lin.

Habitat -

DESCr. Antennæe, caput et thorax testacea, oculis niwris. Elstra obscure sive fusco-testacea. Aculeus fuscus. Corpus subtùs et pedes pallidiora.

bicolor. 8. Mor. nigra, ore thoracis angulis anterioribus el! trorumque basi testaceis.

Long. corp. $2 \frac{1}{2}$ lin.

\section{Habitat}

DesCr. Antennæ fuscæ. Caput nigrum, ore flavo. Thorax niger, deflexus, marginibus et angulis anterioribus testaceis, sive flavis. Elytra fueca, basi testacea. Corpus subtus ut et aculeus sigrum. Pedes flavi. 
* Inermes.

9. Mor. antennis pectinatis, thoracis lateribus paradoxa. elytrisque testaceis.

Linn. Syst. Nat. 682. 1. Faun. Suec. 831. Vill. i. 405. I. Gmel. 2022. I. Fab. Syst. Ent. 262. 2. Sp. Ins. i. 332. 2." Mant. i. 219. 4. Faun. Etrusc. 603 . Hellw. 603 .

Ripiphorus paradoxus. Fab. Ent. Syst. i. b. III. 5. Payk. Faun. Suec. ii. 177. I.

oliv. iii. $65 \cdot 7 \cdot 7 \cdot t$. $1 . f \cdot 7$.

Long. corp. lin.

Habitat

Descr. Caput nigrum. Antennæ longitudine thoracis, simplici serie pectinatæ, atræ. Thorax gibbus : posticè trilobus, lobis lateralibus testaceis; dorso lacunâ profundà latâ extavatus. Scutellum nullum. Elytra Lepturce, testacea, posticè attenuata, apice nigra, thoracis laminæ affixæ nigræ. Alæ fuscæ. Ábdomen testaceum ; primo segmento margine nigro et ano nigro. Pedes nigri. Magnitudine nostrates reliquas superat. Faun. Suec.

10. Mor. atra, fronte pedibusque flavescentibus. frontalis. Linn. Syst. Nat.682. 4. Faun. Suec. 834. Vill. i. 407.4. Gmel. 2024. 4. Fab. Syst. Ent. 264. Io. Sp.Ins. i. 333. I3 Mant. i. 219.17. Ent. Syst, i. b. I14. 9. Panz. Ent. Germ. 213. 7. Payk. Faun. Suec. 183.1 .

Oliv. iii. 64.7. 6. t. r. f. 6. a-c.

Long. corp. 2 lin.

Habitat

DEscr. Nigra. Frons flava, et pedes, præsertim anteriores.

II. Mor. atra, thorace pedibusque fiavescentibus ruficollis.

Fab. Ent. Syst. i. b. II5. 12

Oliv. iii. $64 \cdot 9 \cdot 9 \cdot t .1 . f \cdot 9 \cdot$ a. b. 
L'Anaspe à corcelet jaune. Geoff. i. 3I 3 - 3 .

Long. corp. I lin.

Habitat

Descr. Affinis Mor. abdominali; sed dimidio minor. Thorax flavus, nec rufus. Pedes omnes testacei. Abdomen totum nigrum.

biguttata. I2. Mor. atra, elytris maculâ baseos flavescenti.

Long. corp. I $\frac{x}{4}$ lin.

Habitat

DESCR. Corpus totum atrum, basi elytrorum exceptâ, quæ maculam sordidè flavescentem gerit.

nigricollis. 13. Mor. nigra, elytris testaceis : maculâ mediâ marginibusque nigris.

Long. corp. $\mathbf{I} \frac{1}{2}$ lin.

Habitat -

Descr. Os et basis antennarum ferruginea. Affinis Mor. obscurce at thorax niger, nec testaceus; tum macula elytrorum saturatior, nec obsoletiuscula; porrò margines et sutura elytrorum saturatè nigra. Pedes nigri.

obscura. 14. Mor. testacea, elytris basi maculâque mediâ fuscis obsoletiusculis.

Long. corp. $\mathbf{I} \frac{k}{2}$ lin.

Habitat

DeSCR. Antennæ, oculi, pectus et abdomen nigra. Caput rufescens. Thorax, pedes et elytra testacea. Thorax tamen punctum medium fuscum gerit. Elytra basi præcipuè ad suturam, maculâque mediâ fasciæformi obsoletè fuscis; sutura apicem versus fuscescens, et quasi maculâ communi notata.

pallida. 15. Mor. pallido-testacea, oculis abdomine antennarumque apice nigris.

Long. 
Long. corp. I $\frac{1}{4}$ lin.

Habitat

DESCr. Magnitudo Mor. flava, et testacere, quibus maximè affinis, sed abdomen nigrum nec testaceum ut in Mor. testaceâ, nec elytra apicibus nigris ut in Mor. flavâ.

16. Mor. sub-testacea, oculis antennarumque apice testacea. nigris.

Long. corp. I $\frac{1}{2}$ lin.

Habitat -

DESCr. Magnitudo Mor. flava, cui maximè affinis, sed tota sub-testacea, nec apicibus elytrorum aut abdomine nigris, ut in Mor. flavâ.

17. Mor. flava, elytris obscurioribus fuscescenti-fusca. bus.

Scbrank, 431 .

Long. corp. I $\frac{\pi}{2}$ lin.

Habitat in floribus.

DESCR. Caput, thorax, elytra flavicant. Elytra tamen multò obscuriora, et ferè fusca. Pedes et antennarum bases flavi coloris. Oculi nigri. Scbrank.

18. Mor. nigra, elytris fasciis duabus flavis undu-bifasciate. latis.

Long: corp. $1 \frac{1}{2}$ lin.

Habitat

Descr. Caput nigrum. Thorax niger, margine omni pallescente. Elytra glabra, nigra, fasciis duabus flavis undulatis, sive angulatis. Subtùs omninò nigra est hæc Mordella.

r. Mor. nigra, antennis subclavatis acutis, ely-silpboides. tris ferrugineis.

Long. 
Long. corp. $\frac{\pi}{2}-1 \frac{1}{2}$ lin.

Habitat

DESCR. Antennæe acutæ, ante apicem crassiores, nigræ, basi ferrugineæ. Caput et thorax nigra. Elytra ferruginea, sericeo-tomentosa. Abdomen nigrum. Pedes ferruginei.

Boleti. . 20. Mor. oblonga ferruginea, capite nigro, ely* tris liturâ longitudinali ad apicem nigrâ obsoletâ. Long. corp. 2 lin.

Habitat in Roleto putrido. In mus. D. Kirby.

DESCr.॰ Antennæe extrorsùm crassiores, ferrugineæ. Caput nigrum. Thorax ferrugineus. Elytra ferruginea, ad apicem disco liturâ longitudinali nigrâ obsoletấ inquinato. Pedes et corpus subtùs omninò ferruginea. Corpus oblongum, sub elongatum, nec ut in Mor. piceâ ovato-oblongum, crassum. Salit agillimè.

picea.

2I. Mor. ovato-oblonga picea, thorace saturatiori, pedibus dilutioribus, elytris striatis.

Long. corp. $2 \frac{2}{4}$ lin.

\section{Habitat}

DESCR. In hoc animalculo caput semper nigrum. Cæteroquin piceum est. Thorax plerumquè saturatior, et pubescit. Pedes cæteris membris dilutiores. Elytra obsoletè striata, et oculo bene armato, per totam superficiem punctulata. Antennæ piceæ. Color etiam thoracis variat, nigro-piceus, piceus et ferrugineus. At in omnibus caput nigrum.

clavicornis. 22. Mor. picea tota, antennis clavatis.

Forst. Cent. 66.

Dermestes fornicatus. De Geer, iv. 216. 9.

Long. corp. 2 lin.

Hahitat -

Descr. Corpus ovato-oblongum. Antennæ fuscæ, hasi ferrugineæ, 
ferrugineæ, clavatæ. Os ferrugineum. Thorax hemisphæricu", major quàm in congeneribus, pilis minutissimis pallentibus consitus Elvtra picea atque pilosa; lineá obscurâ longitudinali ad suturam. Pedes concolores.

23. Mor. oblongn-ovata nigro-fusca, thorace ci-cicatricata. catricato, ely tris punctulatis obsoletissimè striatis.

Long. corp. $2 \frac{r}{4}$ lin.

Habitat

DESCR. Totum corpus ferè unicolor, at pedes paulò dilutiores. Thurax convexus, cicatricatissimus, cicatricibus tenussimis longitudinalibus exaratus. Elytra per totam payinam p!nctulis conspersa, porrò valdè obsoletè striata; striæ punctulis impressis. Habitus Tenebrionis.

24. Mor. flava, elitrorum apicibus nigris.

Linn. Syst. Nat. 692.6. Faun. Suec. 836. Vill. i. 407.6. Gme!. 2024. 6. Fab. Syst. Ent. 264. I2. Sp. Ins. i. 334. 14. Mant. i. 219. I9. Ent. Syst. i. b. 115. 13. Fuun. Fred. 22. 219 . Panz. Ent. Germ. 2i3. II. Faun. Eitrusc. 604. Hellw.604.

Panz. Fuun. Germ. 13. t. 14 .

Long. cor\%. I lin.

Habit t-

Drscr. Caput, thorax, antennæe et elytra flava, solis elorerum apicibus nigris. Abdomen totum atrum. Faun. Suec. 


\section{[ 496 ]}

\section{STAPHYLINUS.}

Antenna moniliformes.

Elytra dimidiata, alas tegentia.

Corkus elongatum.

Cauda simplex, exserens vesiculas duas oblongas.

* Tborace ovato, posticè rotundato, capite paulò angustiori sive subequali.

* Tborace oblongo-elongato, capite petiolato angustiori. ** Tborace posticè dilatato, capite sessili latiore, abdomine conico.

*** Cicindeloidei. Scabri, thorace teretiusculo, capite angustiori, oculis distantibus prominulis.

* Tborace ovato, posticè rotundato, capite paulò angustior: sive subcquali.

birtus.

I. St. hirsutus niger, thorace abdomineque posticè flavis.

Linn. Syst. Nat. 683. I. Faun. Suec. 839. Vill. i. 409. I. Gmel. 2025. I. Fab. Syst. Ent. 264. I. Sp.Ins. i. 334. I. Mant. i. 219. 2. Ent. Syst. i. b. 519. 2. Panz. Ent. Germ. 35I. I. Harr.410. Payk. Faun. Suec. iii. 368. I.

Panz. Faun. Germ. 4. t. 19. Oliv. iii. 42. 7. 2. t. I. f. 6. Mart. Eng. Ent. t. $42 . f$. 40.

Staphylinus Bombylius. De Geer, iv. 20. 5 .

Le Staphylin bourdon. Geoff. i. 363.7.

Long. corp. Io lin.

Habitat

DESCR. 
SIAREIRINUS.
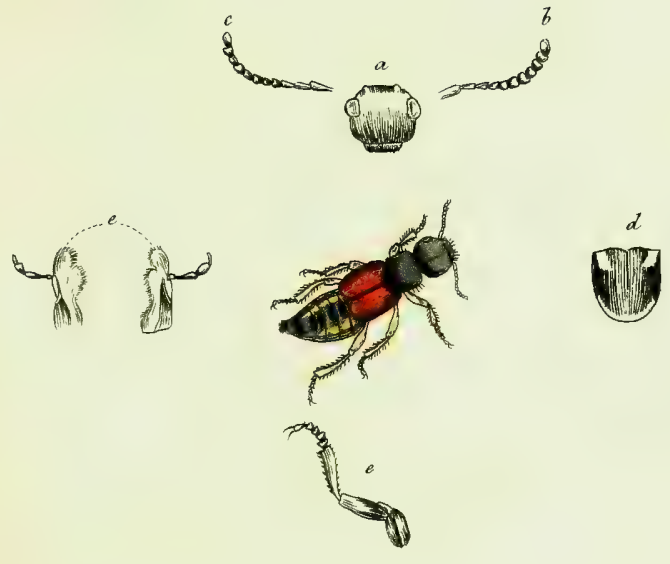

S.ervtropterus. 

Descr. Magnitudo Bombylii; totus valdè hirsutus. Caput nigrum. Thorax flavus. Elytra cinerea. Abdomen anticè nigrum, posticè luteum. Pedes nigri etiam hirsuti. Faun. Suec.

2. St. tomentosus niger unicolor.

Fab. Mant. i. 219. 4. Ent. Syst. i. b. 520. 6. Vill. i. 424. 66. Payk. Faun. Suec. iii. 371. 5. Monog. 4. Gmel. 2026. 28. Faun. Fred.23. 228. Faun. Ingr. 356. Ent. Germ. 352. 5 .

Oliv. iii. 42.9.4.t. I. f. I. a-c. Mart. Eng. Ent. t. $4 \mathrm{I} \cdot f \cdot 2 \mathrm{I}$.

Staphylinus major. De Geer, iv. I8. 3.

Le Staphylin noir lisse. Geoff. i. 360. I. t. 7. $f$. r.

Long. corp. I unc. I lin.

\section{Habitat}

DESCR. Linnæus hunc Stapbylinum maxillosum provectiori ætate esse censuit; hoc De Geer perstrenuè negat, et speciem esse distinctam affirmat : huic lubenter manus dare volumus; nam St. olens apud nos frequens, maxillosus autem rarior; e contra De Geer maxillosum vulgarem in Sueciâ esse, olentem autem rarissimum prædicat, adeo ut ne unum quidem cepisse dolet.

3. St. niger immaculatus, capite thoraceque po-similis. litis.

Payk. Monog. 5. Faun. Suec. iii. 37r. 6.

Long. corp. 6 lin.

\section{Habitat}

DESCR. Caput thorace latius, nigrum, nitidum. Antennæ filiformes, capite duplò longiores. Thorax niger, nitidus, longitudine ferè capitis. Elytra depressa, nigra, opaca, thorace longiora. Sternum nigrum. Abdomen depressum, nigrum, opacum, elytris triplò longius.

voL. I.

$2 \mathrm{~K}$

Obs. 
Obs. Magnitudo dimidia præcedentis, a quo etiam differt capite thoraceque politis, abdomineque, respectu elytrorum, breviore. Payk. Monog.

concolor. 4. St. ater, thorace glabro marginato, elytris tomentosis.

Long. corp. 9 lin.

Habitat

Descr. Antennæ crassiusculæ, articulato-per foliaæ, serratæ. Caput et thorax glabra, nitida. Thorax punctulis rarioribus impressis. Elytra tomentosa, minimè nitentia. Abdomen pilosum. Totum corpus atrum, unicolor, exceptis tarsis anticis intùs fulvis.

maxillosus. 5. St. pubescens niger: fasciis cinereis, maxillis longitudine capitis.

Linn. Syst. Nat.603.3. Faun. Suec. 841. Vill. i. 410.3. Scbrank, 434. Gmel. 2026.3. Fab. Syst. Ent. 265.3. Sp.Ins. i. 334.3. Mant. i. 220. 5. Ent. Syst. i. b. 521. 9. Faun. Fred. 23. 222. Faun. Ingr. 357. Poda, 48. I. Panz. Ent. Germ. 353. 8. Act. Nidros. iii. 403. 25. Payk. Monog. 2. Faun. Suec. iii. 369.2. Scbeff. Icon. t. 20. f. I. Faun. Etrusc. 607. Hellw. 607.

Don. Brit. Ins. t. 96. f. 3. Oliv. iii. 42. 9. 5. t. I. f. 5 . a. b. Mart. Eng. Ent. t. 29. f. 4. 5. Panz. Faun. Germ. 27. t. 2.

Staphylinus balteatus. De Geer, iv. I 8. 4. t. 1. f. 7. 8 . Staphylin nebuleux. Geoff.i. 362.5.

Long. corp. Io lin.

Habitat

Descr. Caput et thorax atra, glabra. Elytra atra (in quibusdam cineritie lævi nebulosa) obtusa. Dorsum abdominis caudæ concolor. Pedes nigri. Os duabus maxillis arcuatis duris, acuminatissimis, simplicibus, capite longioribus. Faun. Suec.

6. St. 
6. St. ater, antennarum basi elytris pedibusque rufis. erytbroLinn. Syst. Nat.683.4. Faun. Suec. 842. Vill. i. 4ri. 4. pterus. Scbrank, 435. Gmel.2027. 4. Fab. Syst. Ent. 265.5. Sp. Ins. i. 335.5. Mant. i. 220. 8. Ent. Syst. i. b. 522. 14. De Geer, iv. 21. 6. Faun. Fred. 23. 223. Faun Ingr.358. Panz. Ent. Germ.353. 10. Harr. 41 I. Poda, 48. I. Act. Nidros. iii. 404. 26. Payk. Monog.3. Faun. Suec. iii.369.3. Fun. Etrusc.609. Hellw.609. Panz. Fann. Germ. 27. t. 4. Don. Brit. Ins. t. 308. Mart. Eng. Ent. t. 40. f. 8. Oliv. iii. 42. I2 10. t. 2. f. 14. Frisch. v. t. 25. Scbaff. Icon. t. 2. f. 2. Le Staphylin à étuis couleur de rouille. Geoff. i. $3^{6+} \cdot 9$. Long. corp. 9 lin.

Habitat

Descr. Caput et thorax nigra. Abdomen nigrum, micante puncto deaurato in singulo segmento utrinque. Elytra et pedes rufa. Antennæ nigræ, basi et apice rufescentes. Faun. Suec.

7. St. ater, antennis nigris, elytris pedibusque stercorarius. rafis, femoribus anticis basi nigris.

Oliv. iii. 42. 18. 18. t. 3. f. 23 .

Long. corp. 5 lin.

Habitat

DESCR. In omnibus simillimus St. erytbroptero, sed differt plusquam duplò minor; tum antennis totis nigris, femoribusque anticis basi nigris.

Variat antennis ferrugineis.

8. St. pubescens cinereus nigro-nebulosus.

Linn. Syst. Nat. 683. 3. Faun. Suec. 840. Vill. i. 409.2. Scbrank, 433. Gmel.2026.2. Fab. Syst. Ent. 265.2. Sp.Ins. i. 334. 2. Mant. i. 219.3. Ent. Syst. i. b. 520. 4. Faun. Fred. 23. 221. Faun. Ingr. 354. Pinz. Ent. Germ. 352. 3. Harr. 415. Preys. Bob. Ins. I8. I2. Payk. Monog. 8. Faun. Suec. iii. 376. I2. Faun. Etrusc. 608. Hellw. 608. 
De Geer, iv. 12. 1. t. I. f. I. Scbeff. Icon. t. 4. f. I r. Panz. Faun. Germ. 66. $t$. I6. Oliv. iii. 42. I5. I4. t. 6. f. 51. a. b. Mart. Eng. Ent. t. 41. f. 22 .

Long. corp. 7 lin.

Habitat

DESCR. Insectum inter majores non maximos, numerandum est, oblongum, pubescens, cinereo-æneum, maculis nigris, perlucentibus. Antennæ articulis 9. Caput depressum. Os forcipatum. Thorax angustus. Elytra brevia, capiti et thoraci concolora. Abdomen fuscum, maculis nigris. Cauda duabus setis villosis; abdomine presso, exeunt ad caudam duo cornicula mollia, recurva, alba, pellucida. Faun. Suec.

bybridus. 9. St. fulvo-aureo-pubescens nigro-nebulosus, abdomine apice nigro, femoribus annulo flavo.

Long. corp. $6 \frac{x}{2}$ lin.

Habitat $\longrightarrow$ Captus Octobre medio 1799. D. Kirby.

DESCR. Intermedius inter St. murinum et St.pubescentem, sed utroque major. Caput thorace majus, pilis fulvo-aureis pubescens, punctis quatuor nigricantibus notatum; ore palpisque rufescentibus. Antenniæ capite longiores, nigræ, basi rufæ. Nucha fulvo-aurea, puncto nigro utrinque. Thorax pilis fulvo-aureis pubescens, nigro-tessellatus. Scutellum maculâ cordatâ velutino-atrâ. Elytra certo situ aureo-pubescentia, nigro-nebulosa. Abdomen basi aureo-pubescens, nigrotessellatum, ano atro. Venter fasciis quatuor sericeopallidis. Femora omnia tibiæque anticæ annulo flavo apud apicem.

pubescens. Io. St. niger nebulosus, capite femoribusque annulo flavo-ferrugineo, abdomine obtuso.

Fab. Ent. Syst. i. b. 520. 5. Gmel. 2034. 79. De Geer, iv. I7. 2. Payk. Monog. 9. Faun. Suec. iii. 376. 13. Faun. Ingr. 355. Panz. Ent. Germ. 352. 4. Oliv. iii. 42. 16. 15. t. 2. $f$. 15 .

Le Staphylin à tête jaune. Geoff. i. 363. 8. 
Long. corp. 6 lin.

Habitat -

DESCR. Caput flavo-lanuginosum, latitudine thoracis. Palpi maxillæque nigræ. Antennæ capite duplò longiores, extrorsùm crassiores, basi flavæ, apice nigricantes. Thorax capite longior, anticè truncatus, posticè rotundatus, niger, lanugine brevissimâ ferrugineâ, parciùs tessellatus. Elytra thorace longiora, nigra, maculis paucioribus, lanuginosis, ferrugineis. Abdomen obtusum, elytris vix duplò longius, dorso nigro, ferrugineo, parùm lanuginoso, subtùs nigrum, lanugine densâ, cinereâ, certo sitı micante, tectum. Pedes fusci, annulo femorali ferrugineo. Payk. Monog.

II. St. ater opacus, thorace elytrisque cærules-cyaneus. centibus.

Fab. Ent. Syst. i. b. 521. I1. Payk. Monog. 7. Faun.

Suec. iii. 370.4 .

Oliv. iii. 42.14. 13.t. 1.f.4. Panz.Faun. Germ. 27.t.3.

Le Staphylin bleu. Geoff. i. 361. 2.

Long. corp. Io lin.

Habitat

DESCR. Caput thorace latius et thorax lævia, cærulescentia. Corpus atrum. Ent. Syst.

I2. St. niger nitidus, capite thoraceque punctu-punctulatus. latissimis, antennis apice ferrugineis.

Payk. Monog. 22. Faun. Suec. iii. 380, 17.

Mart. Eng. Ent.t. 42. f. 27.

Long. corp. $6 \frac{3}{4}$ lin.

Habitat $\longrightarrow$ Captus prope Harwich.

DESCr. Hic etiam oculo nudo St. politum refert. Sed caput et thorax, punctulis numerosissimis ornata, errorem vel a tyronibus arceant. Plantæ sub-ferruginez.

$$
2 \times 3 \text { s. St. }
$$


brunnipes. I3. St. niger, pedibus antennarum basi apiccque ferrugineis.

Fab. Sp. Ins. i. 336. 8. Mant, i. 220. 12. Ent. Syst. i. b. 524. 23. Vill. i. 419. 27. Gmel. 2028. 33. Oliv. iii. 42. 13. II. t. I. f. 7. Mart. Eng. Ent. t. 41. $f . \pm 5$.

Long. corp. $6 \frac{1}{2}$ lin.

Habitat

Descr. Antennæ nigræ, articulo primo et ultimis duobus ferrugineis. Caput et thorax atra, nitida, oculis albis. Elytra et abdomen atra, at obscuriora. Pedes rufi. Sp. Ins.

rufus.

14. St. rufus, capite elytrorum abdominisque posticis nigris, femoribus basi nigris.

Linn. Syst. Nat. 684.6. Faun. Suec. 844. Vill. i. 4I2. 6. Scbrank, 438. Scop. 307. Faun. Ingr. 367. Harr. 4r6. Poda, 49. 4. Gmel. 2037. 6. Payk. Monog. 10.

De Geer, iv. 24. 10. t. I. f. II. I2. Scbaff. Icon. t. 85. f. 3. Mart. Eng. Ent. t. 4I. $f .25$.

Le Staphylin jaune à tête, étuis et anus noir. Geoff. i. 370.22 .

Oxyporus rufus. Fab. Syst. Ent. 267. I. Sp. Ins. i. 338. I. Mant. i. 222. i. Ent. Syst. i. b. 53 I. I. Panz. Ent. Germ. 359. I. Payk. Faun. Suec, iii. 425. I. Faun. Etrusc. 624. Hellw. 624.

Panz. Faun. Germ. I6.t. I9. Oliv. iii. 43. 4. I.'t. I. f. 1. a-d.

Long. corp. 4 lin.

Habitat in Agaricis. D. Latbbury.

DESCR. Rufa sunt thorax, pedes, abdomen maximâ ex parte, et elytra anticè ; nigra vero os, caput, elytra pone et in medio ad suturam, nee non abdominis tria ultima segmenta. Antennæ ferè clavatæ. Faun. Suec. 
15. St. niger obscuruc, antennarum basi apiceque compressus. pedibusque compressis rufescentibus.

I ong. corp. 7 lin.

Habitat — Captus prope Hastingas.

DESCR. Affinis St. obscuro, sed articuli duo baseos antennarum, duoque apicis ferruginei, sive rufescentes; intermedii nigri. Pedes rufescentes, femoribus compressis dilatatis. Punctula capitis thoracisque multò minora confertioraque quàm in St. obscuro.

16. St. ater, thorace nitido punctato, elytris anoque fulgicius. rufescentibus.

Payk. Monog. I4. Faun. Suec, iii. 377. 14. Panz. Ent. Germ. 354. I7.

Oliv. iii. 42. 18. 19. t. 4. $f \cdot 34$ a-d.

Long. corp. $3 \frac{\mathrm{T}}{4}$ lin.

Habitat

DESCR. Antennæ extrorsùm crassiores, piceæ, sive obscuriùs rufescentes. Caput et thorax nigra. Thorax nitens, punctis aliquot impressis. Elytra rufo-ferruginea. Abdomen atrum, ano elytris concolori. Pedes obscurè rufescentes, femora autem paulùm dilutiora. Totum corpus pilis aliquot longiusculis conspersum.

I7. St. rufus, elytris cæruleis, capite abdominis-riparius. que apice nigris.

Linn. Syst. Nat. 684. 8. Faun. Suec. 846. Vill. i.413.8. Scbrank, 44I. Payk. Monog. 19. Harr. 417. Gmel. 2038.9 .

Donov. Brit. Ins. t. 167. Mart. Eng. Ent. t. 4I. f. 23. Scbaff: Icon. t. $71 \cdot f \cdot 3$.

De Geer, iv. 28. 14. t. r. $f$. 18.

Staphylinus gregarius. Scop. 308 .

Le Staphylin rouge à tête noir et étuis bleus. Geoff. i. $369.2 \mathrm{r}$ :

Pæderus riparius. Fab. Syst. Ent. 268. I. Sp. Ins. i. 339. I. Mant. i. 223. 1. Ent. Syst. i. b. 536. I. Panz. Ent. Germ. 362. I. Faun. Ingr. 373. Payk. 2 K 4

Faun. 
Faun. Suec, iii. 427. 2. Faun. Etrusc, 626. Hellw. 626.

Panz.Faun.Germ.9.t.I I. Oliv. iii.44.4.2.t. I.f.2.a-d. Long. corp. 4 lin.

\section{Habitat}

DESCR. Totus incarnatus, sed caput et abdominis tria quatuorve ultima segmenta atra. Elytra tota cærulea. Femora incarnata, geniculis nigris. Antennæ articulis undecim ovalibus, caput versus angustis, excepto ultimo extrorsùm angustato; sunt etiam antennæ pallidæ, apice nigræ. Maxillæ acutæ, denticulo laterali interno. Faun. Suec.

politus.

r. St. niger, thorace elytrisque nigricantibus nitidis.

Linn. Syst. Nat. 683.5. Faun. Suec. 843. Scop. 304. Vill. i. 412.5. Scbrank, 437. Fab. Syst. Ent.266.7. Sp.Ins. i. 335.7. Mant. i. 220. II. Ent. Syst. i. b. 524. 20. Gmel. 2028. 5. De Geer, iv. 22. 7. Faun. Fred. 23.224. Faun. Ingr. 360. Poda, 49.3. Act. Nidros. iii. 404. 27. Panz. Ent. Germ. 354. I4. Payk. Monog. 3I. Faun. Suec. iii. 39I. 3I. Faun. Etrusc. 606. Hellw. 606.

Panz. Faun. Germ. 27. t. 7. Oliv. iii. 42. 25. 3 I. t. 2. $f .10$.

Le petit Staphylin noir. Geoff. i. 36r. 3 .

Long. corp. 4 lin.

Habitat

Descr. Caput et thorax polita. Elytra punctis minutissimis adspersa. Antennæ undecim articulis.

Variat colore thoracis et elytrorum : in aliis thorax æneus, et elytra atro-cærulea : in aliis thorax ater, nitidus, et elytra atra.

Differentia specifica essentialis consistit in thorace decem punctis excavatis, sed vix absque lente conspiciendis. Faun. Suec.

dilatatus. 19. St. niger nitidus, antennis tibiis plantisque ferrugineis, tarsis anticis dilatatis.

Fab. 
Fab. Ent. Syst. i. b. 522. 22 ? Panz. Ent. Germ. 353. 9?

Long. corp. 4-6 $\frac{1}{2}$ lin.

\section{Habitat}

DESCr. Plerique auctores de varietatibus St. politi, verba fecerunt, re verâ, duas species confundentis. St. politus scilicet antennis nigrrs, tarsis anticis sub-simplicibus. At St. dilatatus antennis, tibiis plantisque ferrugineis. Ex his, tum præcipuè ex anticis tarsis dilatatis, species facillimè eruatur. Fatendum sanè quod habet omnia ferè ut in St.polito, et quod adeo similis ut vix nisi oculo aut armato aut per se acutissimo dijudicandus. Thorax punctulis impressis pluribus quam decem nec viginti. Antennæ laxiores, tenuiores, quam in S. polito; nec articulis adeo arctè connexis aut truncatis.

20. St. ater pilosus, elytris punctulatissimis to- simplex. mentosis, capite thoraceque glaberrimis, pedibus piceis.

Long. corp. $2 \frac{\pi}{2}$ lin.

\section{Habitat}

DESCR. Antennæ nigræ. Caput et thorax atra, glaberrima, nitida. Thorax punctis circiter 16 impressis. Elytra nitidiuscula, punctulatissima; ex omni punctulo pilus brevissimus enascitur, unde elytra tomentosa, ut in plurimis accidit. Abdomen nigrum, pilosum. Pedes picei. Ne cum St. dilatato confundas, in hoc tarsi antici non dilatati; tum antennæ nigræ, nec ferrugineæ.

2r. St. niger nitidus, elytris suturâ margineque marginelpostico ferrugineis: striis tribus punctorum im- lus. pressorum.

Fab. Sp. Ins. i. 337.20. Mant. i. 221.27. Vill. i. 420. 34. Gmel. 2030. 43 .

Staphylinus cinctus. Payk. Monog. Carabi. App. 35 . Fuun. Suec. iii. 395. 36:

Long. corp. 4 lin.

\section{Habitat}

DESCR. 
DEscr. Antennæ filiformes. Totum corpus, præter suturam (t marginem posticum elytrorum quã furruginea, nigrum est. Caput et thorax niticla, punctulis aliquint impressis. Elytra tres punctulorum impressorum serics gerunt; quarum una ad sutram, duæ aliæ in nudio sitæ sunt. Pedes nigri.

leucopus. 22. St. niger lævis, plantis pallidis. Long. corp. I $\frac{T}{3}$ lin.

Habitat - Captus propter furium Usk prope Llangallock.

DESCr. Nec thorax nec elytra punctata. Corpus præcipuè opacum admodùm. Plantæ solummodò pallidæ.

piceus. 23. St. niger, elytris piccis, thorace depresso: striis tribus longitudinalibus.

Linn. Syst. Nat. 686. 25. Vill. i. 418. 25. Gmel. 203 1. 25. Fab. Syst. Ent. 267. 20. Sp. Ins. i. 338. 25. Mnt. i. 220.35. Ent. Syst. i. b. 530. 55 . Panz. Ent. Germ.358.44. Payk. Monog. I2. Faun. Suec. iii. 384.22.

Panz. Faun. Germ. 27. t. 14. Oliv. iii, 42, 20, 23,t. 3. $f \cdot 3$. a. b.

Long. corp. 2 lin.

Habitat in stercore bovino.

Descr. Corpus nigrum. Thorax subrotundus, planus, depressus, in medio striis tribus. Elytra brevissima, truncata, picea. Antennæ longitudine thoracis, obtusæ. Pedes pallidi. Syst. Nat.

rugosus. 24. St. niger, thorace elytrisque rugosis.

Fab. Syst. Ent. 267. 19. Sp. Ins. i.338. 24. Mant. i. 220.34. Ent. Syst. i. b. 530. 54. Panz. Ent. Germ. 358. 43. Vill. i. 420. 35. Payk. Monog. I2. var. B. Faun. Suec, iii. 384. 22. var. ß. Gmel. 203 I. 47.

Long. corp. $2 \frac{1}{2}$ lin.

Habitat

DESCR. 
Descr. Valdè affinis St. piceo, at paulò major. Totus niger. Caput planum. Thorax depressus, longitudinalitur rugosus. Elytra rugosa, nigra. Pedes nigri.

Variat elytris testaceis. Syst. Ent.

25. St. rufo-flavus, capite abdominisque cingulo canaliculaante apicein nigris, thorace posticè canaliculato. tus.

Fab. Mant. i. 221. 29. Ent. Syst.i.b.528.42. Gmel. 2030. 44. Payk. Monog. 23. Faun. Suec. 1ii. $385 \cdot 23$. Panz. Ent. Germ. 35 6. 32 .

Panz. Faun. Germ.27.t.13. Oliv. iii.42. 21.25.t.3. f. 3 I. a. b.

Long. corp. 2 lin.

Habitat

DESCR. Caput atrum, antennis basi flavis. Thorax gibbus, canaliculatus, immaculatus. Abdomen planum, flavum, ante apicem cingulo atro. Pedes flavi. Fab. Mant.

26. St. niger glaber, thorace lon gitudinaliter uni-trilobus. sulcato.

Oliv. iii. 42. 20.22.t.5.f.48. a. b.

Long. corp. $1 \frac{x}{2}$ lin.

\section{Habitat}

DESCR. Caput vix thorace latius, nigrum. Antennce fuscescentes, extrorsum crassiores, capite thoraceque longiores. Thorax niger, cordatus, per totam longitudinem profundè sulcatus. Elytra thoracis longitudine, sed latiora, nigra, convexa. Sternum nigrum. Abdomen nigrum, longitudine dimidii corporis. Pedes fusci, interdum minus, interdum magis flavescentes. Payk. Monog.

27. St. niger, thorace cordato profunde sulcato, sulcatus. pedibus flavescentibus.

Payk. Monog. 24. Faun. Suec. iii. 385.24.

Oliv. iii. $42 \cdot 23 \cdot 27 \cdot t \cdot 6 \cdot f \cdot 52 \cdot$ a. b. 
Long. corp. I lin.

\section{Habitat}

Descr. Antennæ fuscæ. Thorax cordatus, in medio profundè sulcatus. Corpus elongatum. Pedes fla. vescentes.

morsitans. 28. St. niger lævis, thorace longitudinaliter unisulcato elytrorum latitudine.

Payk. Monog. Cur. App. 145. 23-24. Faun. Suec. iii. 383. 21.

Long. corp. 2 lin.

Habitat

DESCR. Caput magnum, nigrum, thorace paulò latius. Maxillæ validæ, exsertæ. Antennæ capite thoraceque breviores. Oculi magni, prominuli. Frons rugosa. Thorax niger, longitudine latior, anticè transversus, posticè paulò rotundatus, minimè vero subcordatus, convexus, glaber, sulculo unico longitudinali, impresso. Elytra nigro-fusca, thoracis latitudine sed paulò breviora, posticè rotundata, dehiscentia, parùm convexa; oculo acutè armato subtilissimè punctata apparent. Sternum nigrum. Abdomen nigrum, vix dimidii corporis longitudine. Pedes nigri, rariùs rufi, vel flavescentes.

Obs. Differt a St. sulcato magnitudine triplò majore, antennis brevioribus, et thorace, ratione magnitudinis, latiore. Payk. Monog. Cur. App.

sericeus. 29. St. fusco-æneus tomentosus nitidus, antennis tibiis plantisque rufescentibus.

Long. corp. 7 lin.

Habitat Captus cum jam percurrebat murum antiquum, Ealing.

DESCr. Antennæ et palpi ferruginei. Totum corpus suprà fusco-æneum, nitidum et tomentosum, quin etiam caput, præcipuè ad os, et thorax pilis longioribus rarioribus ad latera obsitus. Thorax punctulorum impres- 
impressorum serie duplici in medio, aliisque præsertim marginalibus, ornatur. Elytra punctulis quinque impressis gaudent; tribus marginalibus, unico medio ad basin, altero medio apicem versus. Tibiæ, plantæ, elytrorum sutura marginesque rufescentes. Corpus subtùs et femora nigra.

30. St. niger, elytris brevissimis, margine pedi-limbatus. busque rufescentibus.

Payk. Monog. Stapb. 39. Faun. Suec. iii. 399.4I.

Long. corp. $2 \frac{x}{2}$ lin.

Habitat

Descr. Caput thorace angustius, nigrum. Antennæ capite thoraceque paulò longiores, basi apiceque rufescentes, extrorsùm crassiores, primo ultimoque articulo reliquis longioribus. Thorax fusco-nigrescens, nitidus, convexus, longitudine latior; anticè angulatus, posticè rotundatus. Sternum rufescens. Elytra nigra, margine, præsertìm anteriore, rufo-fuscescente; seu rufo-fuscescentia, maculầ magnâ subquadratâ nigrâ. Abdomen reliquo corpore longius, dorso nigro, plano, marginato; subtùs convexum, rufescens. Pedes rufi. Payk. Monog.

Variat abdomine subtùs nigro-fusco.

3I. St. niger, antennis pedibus elytrorum margi-suturalis. nibus suturầque ferrugineis.

Long. corp. $2 \frac{\pi}{2}$ lin.

Habitat -

Descr. Antennæ filiformes, ferrugineæ. Caput et thorax nigra, nitida. Thorax punctulis aliquot impressis. Elytra sub lente punctulatissima, nigra, sive nigro-picea, margine exteriori et suturâ ferrugineis. Abdomen nigrum, sive nigro-piceum. Pedes ferruginei.

Obs. Caput et thorax nitida. Elytra et abdomen suprà nitidiuscula. 
mesomeli. 32. St. oblongus ater nitidus, elytris piceis.

nus.

\section{Long. corp. 3 lin.}

Habitat

Descr. Antennæ nigræ, filiformes. Caput et thorax nitida. Thorax punctis aliquot impressis. Elytra punctulatissima, picea, sive obscurè ferruginea. Abdomen et pedes atra.

divisus. 33. St. niger obscurus, thorace lineâ mediâ impressâ, elytris pedibusque testaceis.

Long. corp. 2 lin.

Habitat

DESCR. Antennæ subfiliformes, nigræ, basi testaceæ. Caput et thorax nigra, obscura. Thorax lineolâ mediâ longitudinali impressâ. Elytra, pedes, palpi testacea. Elytra obscura. Abdomen suprà et totum corpus infrà nigrum, nitidum.

concinnus. 34. St. niger nitidliusculus, antennis ore elytris pedibusque ferrugineis.

Long. corp. 2 lin.

Habitat _-

DESCR. Antennæ filiformes, ferrugineæ, breves. Caput et thorax nigra, nitidiuscula. Os, elytra et pedes ferruginei. Ahdomen nigrum, nitidiusculum.

Variat elytris basi et apice fuscescentibus.

bracby- 35. St. niger, thorace depresso antice truncato pterus. posticè rotundato rugoso, elytris brevioribus pedibusque ferrugineis.

Long. corp. 2 lin.

Habitat

DesCr. Antennæ subfiliformes, nigræ. Caput nigrum, depressum, subquadratum. Thorax depressus, sulcis longitudinalibus obsoletiusculis rugosus. Palpi, elytra 
et pedes rufo-ferruginea. Elytra valdè brevia, et sub lente punctulatissima. Abdomen nigrum.

36. St. totus ferrugincus nitidus, oculis solùm ni-minulus. gris.

Long. corp. vix I lin, aequat.

Habitat

DESCR. Hoc animalculum omninò ferrugineum est, præterquam oculi qui nigri sunt. Antennæ sub-clavatæ.

37. St. glaber aneo-viridis nitidus, abdomine pe-aneus. dibusque nigris.

Gmel.2034. 81. De Geer, iv. 23.9. Vill. i. 423. 59.

Le Staphylin à étuis bronzés. Geoff. i. 367 . 17.

Long. corp. 4 lin.

\section{Habitat}

Descr. Caput, thorax et elytra ænea, nitida: Antennæ, pedes et abdomen nigra.

38. St. ater nitidus, elytris testaceis.

niticlus.

Fab. Mant. i. 220. 13. Ent. Syst.i.b.524. 24. Payk. Monog. 30. Faun. Suec. iii. 390.30. Faun. Ingr. 36r. Panz. Ent. Germ. 354. 16.

Long. corp. 3 lin.

Habitat

DEscr. Corpus totum atrum, nitidum, solis elytris testaceis. Fab. Mant.

39. St. pubescens nigro-piceus, oculis albis. Long. corp. 7 lin.

Habitat

In mus. $D$. Kirby.

Drscr. Antennæ rufo-fuscæ. Caput nigro-piceum, punctulatissinum. Oculi albi. Thorax, elytra et ab-

leucopb-

thalmus. puretulatisoinume domen 
domen nigro-picea, punctata, pilis cinereis obtecta. Abdomen segmentis singulis utrinque punctis duobus impressis.

margina- 40. St. ater, thoracis lateribus pedibusque rufis.

tus.

Fab. Syst. Ent. 266. 8. Sp. Ins. i. 336. 9. Mant. i. 221. 15. Ent. Svst.i. b. 526.30. Payk. Monog. 32. Faun. Suec. iii. 392. 32. Panz. Ent. Germ. 355. 2 r. Faun. Fred.23.230. Vill. i.419.28. Gmel.2028.36. Oliv. iii. 42. 26. $33 \cdot t \cdot 3 \cdot f \cdot 29 \cdot$ a. b.

Long. corp. $3^{\frac{1}{2}}$ lin.

Habitat

Descr. Totus ater, glaber, nitens, at thoracis latera et pedes omnes flavescunt. Fab. Syst. Ent.

semiobscu- 4I. St. ater, capite thoraceque nitidis, elytris obrus. scuris piceis, antennis pedibusque rufo-ferrugineis.

Long. corp. $3 \frac{1}{4}$ lin.

\section{Habitat}

DEscr. Caput et thorax atra, nitida. Thorax posticè rotundatus, punctis aliquot impressis, ut in St. polito. Elytra picea, obscura. Abdomen nigrum, obscuriusculum. Antennæ subfiliformes, tenues, ferrugineæ. Pedes una cum patellis, quæ admodum magnæ sunt, ex rufo-ferruginei. Abdomen subtùs nigro-piceum.

rufitarsis. 42. St. ater, capite thoraceque nitidis, abdomine obscuriusculo, elytris plantisque ferrugineis.

Long. corp. 3 lin.

Habitat

DesCr. Antennæ nigræ. Caput et thorax atra, nitida. Thorax punctis aliquot impressis, ut in St. polito. Elytra ferruginea, sub lente punctulatissima apparent. Pedes nigri, plantis ferrugineis. 
43. St. niger, thorace depresso sulcato-rugoso rizularis. posticè truncato, elytris longioribus, pedibus rufo-brunneis.

Payk. Monog. Stapb. 45. Faun. Suec. iii. 407. 50. Panz. Ent. Germ. 356. 37.

Panz. Faun. Germ. 27.t. I5. Oliv. iii. $42 \cdot 35 \cdot 49 \cdot t \cdot 3$. $f \cdot 27$. a. b.

Long. corp. 2 lin.

Habitat

DESCR. Caput nigrum, thorace angustius, depressum. Oculi prominuli. Antennæ extrorsùm crassiores, vix capitis thoracisque lnngitudine, basi rufæ, apice nigræ. Thorax niger, longitudine latior, quadrisulcatus : sulcis exterioribus marginalibus; anticè rotundatus; posticè truncatus; intra sulcos medios interdum anticè sulculi minores. Sternum nigrum. Elytra depressa, obscure picea, subtilissimè punctata, capite thoraceque ferè longiora. Abdomen obtusum, depressum, nigrum, vix capitis thoracisque longitudine. Pedes rufo-brunnei. Payk. Monog.

44. St. ater nitidus, femoribus anticis testaceis. aterrimus. Long. corp. $3 \frac{3}{4}$ lin.

\section{Habitat}

DESCR. Thorax politus, punctulorum impressorum serie duplici in medio aliisque marginalibus ornatur. Totum corpus pilosum, et sub lente villosum. Totum animal atrum, præter femora anteriora quæ testacea sunt.

45. St. niger, elytris rufis, thorace depresso: striis laqueatusi tribus longitudinalibus, pedibus rufis.

Long. corp. 3 lin.

Habitat - In mus. D. Kirby.

DesCr. Simillimus St. piceo sed angustior. Elytra, antennæ et pedes rufa. Corpus nigrum.
VOL. I.
$2 L$
46. St. 
diapbanus. 46. St. ater nitidus elongatus, elytris testaceis, antennis pedibusque rufis.

Long. corp. $2 \frac{1}{2}$ lin.

Habitat

Descr. Antennæ rufæ. Corpus totum atrum, nitidum. Caput et thorax punctulata. Elytra diaphana, testacea. Pedes rufi.

fasciatus. 47. St. rufus, capite thorace abdominisque fasciâ nigris.

Long. corp. $\mathrm{I} \frac{\mathrm{x}}{4}$ lin.

Habitat in Boleto.

DESCr. Antennæ rufo-fuscæ, basi rufæ. Caput et thorax nigra, nitida. Elytra rufa, nitida. Abdomen rufum, fasciâ nigrâ prope anum. Pedes rufi.

sordidus. 48. St. niger nitidus, elytris pedibusque testaceis. Long. corp. 2 lin.

Habitat in Boleto.

Descr. Antennæ fuscæ. Caput et thorax nigro-fusca. Elytra sordidè testacea. Abdomen nigrum. Pedes testacei.

fuscus. 49. St. fuscus opacus, pedibus piceis.

Long. corp. $1 \frac{1}{4}$ lin.

Habitat in Boleto.

Descr. Corpus totum antennæ etiam fuscæ. Caput, thorax et elytra pilis brevissimis obtecta. Pedes picei.

obscurus. 50. St. ater, elytris obscuris, capite thoraceque punctulatissimis, plantis antennarumque apice ferrugineis.

Long. corp. 7 lin.

Habitat Captus sub lapidibus prope $\mathrm{Ha}$ stingas.

DESCR. 
DESCR. Antennarum articuli duo postremi ferruginei. Plantæ rufescentes, sive ferrugineæ. Cætera ater. Elytra obscura. Caput et thorax nitidiuscula, non nitida.

5 I. St. testaceus, capite nigro.

Long. corp. 2 lin.

Habitat

Descr. Caput nigrum. Antennæ, thorax, elytra pedesque testacea. Abdomen testaceum, at non omninò, quippe segmentum penultimum, et antepenultimum sæpe, nigrescunt. Corpus obscurum, nec nitidım.

* Thorace oblongo-elongato, capite petiolato angustiori.

52. St. niger, elytris posticè pedibus antennisque elongatus. ferrugineis.

Linn. Syst. Nat.685. 14. Payk. Monog. 17. Vill. i. 415. I4. Scbrank, 439 .

Mart. Eng. Ent. t. $40 . f$. I.

Pæderus elongatus. Fab. Syst. Ent. 268. 2. Sp. Ins. i. 339. 3. Mant. i. 223.3. Ent. Syst. i. b. 537.3.

Faun. Ingr. 374. Panz. Ent. Germ. 362. 4.

Panz. Faun. Germ. 9. t. 12.

Long. corp. 4 lin.

Habitat in stercore.

DEscr. Oblongus, glaber. Elytra testacea, anticè tantùm nigra. Syst. Nat.

Obs. Elytra posticè obscurè rufa, nec testacea. Thorax et elytra sub lente punctulis numerosissimis confertis. Tum femora antica valido nec tenui dente unico, nec inermia.

53. St ater glaber, pedibus rufis, femoribus an-dentatus. ticis dentatis.

L ong. corp. 4 lin.

Habitat Captus sub lapidibus, in ascensu montis prope Crickhowell.
$2 \mathrm{~L}_{2}$
DESCR. 
Descr. Affinis maximè St. elongato, a quo differt elytris nigris, nec posticè rufis.

An sexûs differentia? An species distincta?

linearis. 54. St. ater elongatus nitidus, capite thoraceque punctulatis clongatis, antennis pedibusque piceis.

Oliv. iii. 42. 19. 21. t. 4. $f \cdot 3^{8}$. a. b.

Long. corp. 3 lin.

Habitat -

Descr. Corpus elongatum, lineare. Antennæ piceæ, sive nigro-ferrugineæ. Caput oblongum, punctulis aliquot impressis. Thorax quoque parùm elongatus, punctulis plurimis impressis. Pedes picei, sive nigroferruginei. Totum corpus suprà nitidum. Caput et: thorax pilis aliquot longis sed rarioribus obsita.

tricolor. 55. St. elongatus niger, elytris pedibusque rufis, thorace anticè rubro.

Fab. Mant. i. 221. 30. Payk. Monog. 15. Faun. Suec. iii. 378. I5. Gmel. 2030. 45 .

Pæderus tricolor. Fab. Ent. Syst. i. b. 537. 7 .

Long. corp. 2 lin.

Habitat in fimetis. Payk.

Descr. Caput oblongum, nigrum, nitidum, punctu* latum, thoracis latitudine. Antennæ vix extrorsùm crassiores, capite longiores. Thorax capite paulò brevior, nitidus, anticè truncatus, ruber; posticè subattenuatus, rotundatus, niger. Elytra rufa, longitudine thoracis. Sternum rufescens. Alæ rufescentes. Abdomen dorso nigrum, summo apice subtùsque rufescens, elytris triplò longius. Pedes rufi. Payk. Monog.

cruentatus. 56. St. elongatus ater, elytris sanguineis, thorace punctulato.

Long. corp. $4 \frac{1}{2}$ lin.

Habitat Captus prope Harwich.

DEsCr. 
Descr. Totum corpus nitidum, et, præter elytra sanguinea, atrum. Elytra punctulis impressis, præcipue ad latera, sparsis. Thorax quatuor seriebus punctulorum impressorum; duæ exteriores propter latera ducuntur, et ad basin deflectuntur. Abdomen pilosum, pilis tenuibus divergentibus.

57. St. elongatus rufo-fuccus nitidus, subtùs di-affinis. lutior, palpis filiformibus.

Payk. Monog. 16.

An Staphylinus elegans? Oliv. iii. 42. 19. 20, t. 5 . f. 5 o. a. b.

Long. corp. 4 lin.

\section{Habitat}

DEscr. Caput latitudine thoracis, elongatum, declive subpilosum. Oculi nigri, minuti. Nucha magis nigricans, subtùs magìs rufescens. Antennze capite longiores, extrorsùm paulò crassiores, rufescentes. Palpi filiformes. Thorax rufo-fuscus, nitidus, subtùs dilutior, convexus, immarginatus, posticè rotundatus, vix capite longior. Elytra rufo-fuscescentia, inangulata, longitudine et latitudine thoracis. Sternum rufum. Abdomen cylindricum, dorso rufo fuscum; subtùs dilutius, longitudine ferè dimidii corporis, latitudine thoracis. Pedes breves, rufi. Payk. Monog.

58. St. totus niger lævis, nuchâ longâ, pedibus quadratus. sordidè piceis.

Payk. Monog. $2 \mathrm{I}$.

Pæderus filiformis, Payk. Faun. Suec. iii. 429.4. Fab. Ent. Syst. i. b. 538.8 .

Long. corp. 3 lin.

Habitat in fimetis.

DEsCr. Caput latitudine thoracis, nigrum, pilis rarioribus. Antennæ filiformes, articulis subæqualibus, longitudine dimidii corporis. Palpi anteriores clavati; posteriores filiformes. Thorax quadratus, angulis obtusis, niger, nitidus, elytrorum fere magnitudine.

$$
2 \mathrm{~L}_{3} \text { Elytra }
$$


Elytra nigra, subquadrata. Sternum nigrum. Abdomen nigrum, longitudine thoracis elytrorumque setis longioribus. Femora et tibiæ nigra; tarsi fuscescentes. Payk. Monog.

** Tborace posticè dilatato, capite sessili latiore, abdomine conico.

subterra- 59. St. niger, elytris anticè extrorsùm flavis, peneus. dibus nigris.

Linn. Syst. Nat. 684. 12. Faun. Suec. 849. Vill. i. 4I4. 12. Gmel. 2028. 12. Payk. Monog. 52. Faun. Suec. iii. 420. 66. Faun. Etrusc. 6I7. Hellw. 6I7. Oxyporus subterraneus. Fab. Ent. Syst. i. b. 532 . 4 . Long. corp. $2 \frac{1}{2}$ lin.

Habitat sæpiùs in cellis subterraneis. Linn.

DEsCr. Corpus atrum, nitidum. Antennæ filiformes, corpore dimidio breviores. Elytra nigra, truncata, a medietate anteriore, sed latere exteriore, maculâ magnâ flavescente. Thorax lævis, convexus. Abdomen glabrum, elytris duplò longius, apice setis duabus parvis subulatis. Faun. Suec.

rufipes. 6o. St. ater glaber, pedibus rufis.

Linn. Syst. Nat. 685.24. Faun. Suec. 858. Vill. i. 418.24. Gmel. 2030. 24. Fab. Syst. Ent. 267. 17. Sp.Ins. i. 337. 22. Mant. 1. 222 3I. Faun. Fred. 23. 227. Faun. Ingr. 372. Payk. Monog. 53. Faun. Suec. iii. 418. 65. Act. Nidros. iii. 405. 29. Faun. Etrusc. 618. Hellw.618.

De Geer, iv. 24. II. t. i. f. I4. Oliv. iii. 42.32 .46$. t. $4 \cdot f \cdot 35 \cdot \mathrm{a}-\mathrm{d}$.

Le Staphylin noir à corcelet lisse et bordé. Geoff. i. 367 . I5.

Oxyporus rufipes. Fab. Ent. Syst. i. b. 535. 21. Panz. Ent. Germ. 361. 16.

Panz. Faun. Germ. 27. t. 20.

Long. corp. $2 \frac{1}{2}$ lin.

Habitat

DEscr. 
Descr. Totus ater, glaber, exceptis pedibus rufis. Nec thorax, nec elytra punctata. Os flavescens. Caput et antennæ nigræ. Abdomen glabrum a tergo.

6I. St. niger glaberrimus, thoracis marginibuscinctus. omnibus elytris pedibusque fusco-castaneis.

Long. corp. 3 lin.

Habitat in Boletis.

Descr. Corpus subovatum. Antennæ nigræ, basi castaneæ. Thorax niger, nitidus, ab omni latere ferrugineo, sive castaneo cinctus. Caput nigrum, nitidum. Caput et thorax oculo benè armato punctulatissima. Elytra fusco-castanea, nitidiuscula, sub lente punctulatissima, et plusquam dimidium abdominis tegunt. Abdomen nigrum, ad margines et præcipue posticè pilis rarioribus obsitum. Pedes ferruginei, sive castanei.

62. St. niger glaberrimus nitidus, thoracis elytro-levigatus. rumque marginibus pedibusque ferrugineis.

Long. corp. 2 lin.

Habitat

In mus. D. Latbbury.

DESCr. Antennæ nigræ, basi ferrugineæ. Caput nigrum, nitidum. Thorax niger, nitidus, lateribus ferrugineis. Elytra nigra, nitida, marginibus exterioribus et posticis ferrugineís. Abdomen nigrum, nitidum. Pedes ex piceo ferruginei.

63. St. niger, thorace elytris pedibusque subtestaceis. chrysomeLinn. Syst. Nat. 685. 21. Faun. Suec. 855. Vill. i. limus. 417.21. Scbrank, 448. Fab. Syst. Ent. 267. 16. Sp. Ins. i. 337.21. Mant.i.221.28. Faun. Etrusc. 6ı6. Hellw.616. Faun. Ingr.37 I. Act. Nidros.iii. 405.28. Gmel. 2030.21.

Oliv. iii. 42. 33. 47. t. 3. f. 22. a. b. Mart. Eng. Ent. $t .42 . f .37$.

Staphylinus dispar. Payk. Monog. 54. Faun. Suec. iii. 423.69 . 
Le Staphylin couleur de paille. Geoff. i. 368 . 18.

Oxyporus chrysomelinus. Fab. Ent. Syst. i. b. 534. I5. Panz. Ent. Germ. 360. 12.

Panz. Faun. Germ. 9. $t .14$.

Long. corp. $1 \frac{1}{2}$ lin.

Habitat -

Descr. Caput nigrum. Thorax glaber, convexus, suprà et subtùs cereus, sive pallidè testaceus. Elytra thorace concolora, sed anticè et ad marginem exteriorem nigricantia, posticè omninò, eodem quo thorax colore et glabritie. P(des magis saturatè ferruginei. Abdomen nigrum, pone elytra pilis hispidum. Facies Cbrysomela, sed elytra brevia et abdomen pilosum. Faun. Suec.

nitidulus. 64. St. niger, thoracis lateribus pedibus elytrisque ferrugineis; elytris nigro marginatis.

Fab. Sp. Ins. i. 337. 27. Mant. i. 221. 24. Vill.i. 420.31. Gmel. 2030. 41 .

Oliv. iii. $42 \cdot 34 \cdot 48 \cdot t \cdot 3 \cdot f \cdot 28$. a. b.

Staphylinus dispar var. $\beta$. Payk. Monog. Stapb.54. Faun. Suec, iii. 423.69.

Le Staphylin noir à taches jaunes. Geoff. i. 369. 20.

Long. corp. $1 \frac{2}{3} \operatorname{lin}$.

Habitat - Captus in arvis prope Harwich.

DEscr. Totum corpus nitidum. Figura St. melanuri, obovata. Abdomen pilosum, ut in St. silpboide, nigrum. Pedes ferruginei. Thoracis latera posticè ferruginea. Margo exterior elytrorum niger. Antennæ basi ferrugineæ, apicem versus crassiores, nigricantes.

obiusus. $\quad 65$. St. testaceus, elytris anticè anoque nigris.

Linn. Syst. Nat.684. 9. Scbrank, 45I. Vill. i. 414. I9. Gmel.2028.9. Fab. Syst. Ent. 266. 10. Sp. Ins. i. 336. II. Mant. i. 221. 17. Faun. Etrusc. 621. Helliw. 621.

Staphylinus dispar. var. $\gamma$. Payk. Monog. 54. Faun. Suec. iii. 423. 69.

Oxyporus 
Oxyporus analis. Fab. Ent. Syst. i. b. 553. 10.

Long. corp. $1 \frac{1}{2}$ lin.

Habitat

DEsCr. Pectus inter femora posteriora fuscum. Syst. Nat.

66. St. niger, thoracis lateribus pedibusque lividis, silpboides. elytris lividis: margine maculâque longitudinali nigris.

Linn. Syst.Nat.684. I I. Vill.i.4I4. II. Gmel.2028. II. Staphylinus dispar var. Һ. Payk. Monog. Staph. 54. var. E. Fuun. Suec. iii. 423.69.

Long. corp. 1 lin.

\section{Habitat}

DESCr. Similis St. obtuso, etiam abdomine piloso. Syst. Nat.

67. St. flavus totus.

caraboides.

Linn. Syst. Nat. 685. 20. Faun. Suec. 854. Vill. i. 417. 20. Sebrank, 443. Fab. Syst. Ent. 267. I8. Sp.Ins. i. 337. 23. Mant. i. 222.33. Ent. Syst. i. b. 530. 53. Faun. Ingr. 366. Payk. Monog. I1. Faun. Suec. 1il. 386.25 . Gmel. 2029. 20. Panz. Ent.Germ. $35^{8} . .42$.

Oliv. iii. 42. 22. 26.t.2. f. 17. a. b.

Staphylinus fulvus. De Geer, iv. 25. 12.

Long. corp. 1 lin.

Habitat in plantis et stercore.

DESCR. Totus ejusdem coloris, seu dilute testaceus, aut flavescens excepto abdomine, a tergo pone elytra, paulò magis fusco, seu obscuro Antennæ longiusculæ sunt, et facies ferè Carabi. Duas setas in caudâ nondùm vidá. Faun. Suec.

68. St. ater, thorace elytris pedibusque rufis. Fab. Syst. Ent. 266. 14. Sp. Ins. i.337. 18. Mant。i. 221.25 . Vill. i. $420.3^{2 .}$. Oliv. iii. $42 \cdot 29 \cdot 39 \cdot t \cdot 5 \cdot f \cdot 45$.

Long。 
Long. corp. I lin.

\section{Habitat}

Descr. Antennæ ferrugineæ, apice fuscæ. Caput atrum. Thorax rufus. Scutellum nigrum. Elytra rufa. Abdomen nigrum. Syst. Ent.

conicus. 69. St. niger, elytris piceo-ferrugineis, abdomine conico acuto.

Vill. i. $425 \cdot 72$.

Long. corp. $2 \frac{x}{2}$ lin.

Habitat

DESCr. Antennæ, elytra et pedes piceo-ferruginei, sive ferruginei. Caput et thorax nigra, glabra, nitida. Abdomen nigrum, posticè attenualum, acutum. Certâ lucis incidentiâ, caput, thorax et elytra tomentosa apparent.

analis. 70. St. ater nitidus, elytris ano pedibusque rufoflavescentibus.

Fab. Mant. i. 221. 19. Ent. Syst. i. b. 526.35. Gmel. 2029.38. Payk. Monog. 34. Faun. Suec, iil. 394. 34. Panz. Ent. Germ. 355.25.

Oliv. iii. 42.28. $38 . t \cdot 3 \cdot f \cdot 24$. a. b.

Long. corp. $2 \frac{x}{2}$ lin.

Habitat

Descr. Caput et thorax atra, nitida, immaculata. Elytra lævia, nitida, testacea, immaculata. Abdomen atrum, ano testaceo. Antennæ et pedes testacei. Fab. Mant.

atricapillus. $7 \mathrm{I}$. St. rufus, capite ano sterno elytrisque medio nigris.

Fab. Syst. Ent. 267. 15: Sp. Ins, i. 337. 20. Mant. i. 221. 25. Ent. Syst. i. b. 527. 40. Payk. Monog. 35. Faun. Suec. iii. 4I4. 60. Vill. i. 420.33. Gmel. 2030. 42 .

Oliv. 
Oliv. iii. 42. 29. 40. t. 4.f.39. a. b.

Long. corp. $2 \frac{\mathrm{I}}{2}$ lin.

Habitat

DESCR. Antennæ extrorsùm crassiores, apice fuscæ, ultimo articulo ferrugineo. Caput atrum, nitidum. Thorax rufus, glaber, immaculatus. Elytra fusca, puncto baseos margineque postico albis. Abdomen ferrugineum, apice fuscum. Syst. Ent.

72. St. rufus, capite abdominis elytrorumque pos- lunulatus. ticis nigris, femoribus totis rufis.

Linn. Syst. Nat. 684. 7. Faun. Suec. 845. Vill. i. 413. 7. Gmel. 2037. 7. Faun. Fred. 23. 225. Faun. Ingr.369. Payk. Monog. 41. Faun. Suec. iii. 4I5. 61 .

Oxyporus lunulatus. Fab. Syst. Ent. 268. 2. Sp. Ins. i. 338. 2. Mant. i. 219.2. Ent. Syst. i. b. $532.3 \cdot$ Panz. Ent. Germ. 359.3.

Panz. Faun. Germ. 22. t. I5. $_{5}$

Long. corp. 3 lin.

Habitat

DEscr. Similis St.rufo, sed dimidio minor, nec femora basi nigra. Faun. Suec.

73. St. testaceus capite atro, thorace rotundato. melanoPayk. Monog.42. Faun. Suec.iii. 4 6.63. Gmel. 203 г. cepbalus. 46. Fab. Ent. Syst. i. b. 529. 49 .

Long. corp. 3 lin.

Habitat in Boletis.

Descr. Caput nigrum, nitidum, thorace paulò angustius. Antennæ testaceæ, extrorsùm crassiores, capite thoraceque longiores. Thorax testaceus, rotundatus, parùm convexus. Elytra testacea, thorace paulò longiora, et latiora. Sternum rufo-testaceum. Abdomen testaceum, longitudine vix dimidii corporis, versus apicem, non tamen in ipso apice fuscescens, dorso depresso, marginato. Pedes testacei. Puyk. 
hrzmneus. 74. St. rufo-brunneus, capite elytris posticè abdomineque apice nigris.

Payk. Monog. 45. Fuun. Suec, iii. 404. 47. Fab. Supp. Ent. 180. 44 .

Long. corp. $I \frac{1}{2}$ lin.

Habitat -

Descr. Caput nigrum, thorace angustius. Oculi prominuli. Antennæ rufo-brunneæ, extrorsùm crassiores, capitis thoracisque longitudine. Thorax rufo-brunneus, longitudine latior, subtilissimè punctatus, submarginatus, anticè rotundatus, posticè ferè truncatus. Elytra longitudine ferè capitis thoracisque, subtilissimè striatopunctata ; apice rotundata, anticè ultra dimidiam partem rufo-brunnea, posticè nigra. Scutellum nullum. Sternum brunneum. Abdomen longitudine capitis thoracisque, basi rufo-brunneum, apice nigrum. Pedes rufi. Payk. Monog.

splendens. 75. St. ater nitidus, elytris ano pedibusque rufis, thorace posticè latiori truncato.

Long corp. $2 \frac{1}{2}$ lin.

Habitat

DESCR. Antennæ clavatæ, nigræ, basi tenues, testaceæ.

Caput thorace duplò angustius, nitidum. Thorax antice angustus, posticè dilatatus, truncatus, nitidus. Elytra nitida, rufa. Abdomen nigrum, nitidum, ano ferrugineo. Pedes ex ferrugineo testacei.

2atus. $\quad 76$. St. ater nitidus, thoracis lateribus posticè rufis, elytris rufis : marginibus latis nigris.

Long. corp. 3 lin.

Habitat

Ex mus. D. Kirby.

Descr. Antennæ fuscæe, basi rufâ. Caput atrum. Thorax ater, lateribus postice rufis. Elytrá rufa, marginibus apicibus suturâque nigris. Abdomen atrum, ano piceo. Pedes rufi. 
77. St. niger, elytris tibiisque rufo-fuscis. Linn. Syst. Nat. 685. 23. Faun. Suec. 857. Vill. i. 418. 23. Gmel. 2030. 22. Fab. Syst. Ent. 266. 12. Sp. Ins. i. 336. 15. Mant. i. 221.22. Ent. Syst. i. b. 527. 38. Faun. Ingr. 364. Poda, 49.5. Panz. Ent. Germ. 356. 28. Faun. Etrusc. 619. Hellw. 619.

Panz. Faun. Germ. 27. t. 12.

Long. corp. $3 \frac{1}{2}$ lin.

Habitat

Descr. Totus ater, glaber. Elytra fusca. Tibiæ flavescentes, non verò femora. Thorax, caput et maxillæ ratione magnitudinis insignes. Faun. Suec.

73. St. niger pilosus, elytris maculâ rufâ. Long. corp. 3 lin.

Captus prope Harwich.

DESCR. Thorax politus, striis circiter quatuor punctulorum impressorum. Maculæ elytrorum satis magnæ, in medio ad apicem sitæ sunt, imò apicem inficiunt, haud verò suturam cui propinquant, nec margines a quibus longiùs distant. Totum corpus pilosum, et sub lente villosum.

79. St. ater lavis, thoracis lateribus elytris pedi-Hyprorum. busque testaceis.

Fab. Syst. Ent. 266. 13. Sp. Ins. i. 336. 16. Mant. i. 221.23. Vill i. $420.30 . \quad$ Gmel. 2030.40.

Oxyporus Hypnorum. Fab. Ent. Syst. i. b. 53.5. 22.

Long. corp. 2 lin.

Habitat

Descr. Ater, glaber, lævis, nitens. Thoracis latera iuprinis basi testacea. Elytra testacea, immaculata, scutello tamen nigro. Syst. Eut.

80. St rufo-flverens nitijus, elytrorum basimelamurus. abdominisque apice myris.

Long. 
Long. corp. $\mathrm{I} \frac{3}{4}$ lin.

Habitat - Captus in arvis prope Harwich.

Descr. Oculi, elytrorum basis, tria ultima abdominis segmenta, et sterni medium, omnia nigra. Cætera rufoflavescens est. Corpus totum nitens, obconicum, sive obovatum; capite enim obtuso, et abdomine acutiusculo gaudet. Abdomen pilosum, ut in St. silpboide. Antennæ flavicantes, extrorsùm crassiores et fuscæ. An var. St. obtusi? sed color non testaceus, nec elytra anticè fusca.

**** Cicindeloidei. Scabri, tborace teretiusculo, capite angustiori, oculis distantibus prominulis.

biguttatus. $8 \mathrm{I}$. St. niger, elytris puncto flavo.

Linn. Syst. Nat.685. 15. Faun. Suec. 85 J. Vill. i. 415. 15. Scbrank, 426. Gmel. 2029. 15. Fab. Gen. Ins. Mant. 24I. Sp. Ins. i. 336. I3. Mant. i. 221. 20. Ent. Syst. i. b. 527. 36. Panz. Ent. Germ. $355 . .26$.

Oliv. iii. 44. 5. 4. t. I. f. 3. a. b. Panz. Faun. Germ. II. $t$. 17 .

Staphylinus Juno var. B. Payk. Monog. 25 .

Le Staphylin Junon. Geoff. i. 37I. 24.

Stenus Juno var. B. Payk. Faun. Suec. iii. 343. I:

Long. corp. 3 lin.

Habitat

Descr. Statura Cicindelee, thorace cylindrico. Oculi magni, prominuli. Antennæ nigræ, tenues, articulis tribus ultimis majoribus. Caput, thorax et elytra nigra, obscura, punctis prominulis scabra. In medio elytrorum punctum magnum fulvum sive flavum. Abdomen suprà punctis prominulis scabrum. Pedes lutei, geniculis plantisque nigris.

Maximè affinis St. bipustulato at duplò latior, tum punctum elytrorum magnum est guttulæ instar. Pedes lutei sive ferruginci, geniculis nigris, nec, ut in St.bipustulato, omninọ nigri. 
82. St. niger, elytris puncto ferrugineo.

Linn. Syst. Nat. 685. 16. Faun. Succ. 847. Vill. i. tus.

bipustula416. 16. Gmel. 2029. 16. Fab. Syst. Ent. 266. I1. Sp. Ins. i. 336. 12. Mant. i. 221. I8. Ent. Syst. i. b. 526. 34. Faun. Ingr. 365. Panz. Ent. Germ. 355. 24. Faun. Etrusc. 620. Hellw. 620.

Panz. Faun. Germ. 27. t. 10.

Long. corp. 3 lin.

Habitat

DESCR. Corpus valdè oblongum, omnibus partibus nigrum. Antenne clavatæ. Elytra brevia, in singuli medio punctum ferrugineum. Faun. Suec.

83. St. niger obscurus scabriusculus, antennis angustatus. pedibusque testaceis, elytris posticè testaceis.

Fab. Ent. Syst. i. b. 528.4I. Panz. Ent. Germ. 356.3 I. Oliv. iii. 42. 21. 24. t. 2. f. 18. a. b. Panz. Faun. Germ. I . $t$. I8.

Long. corp. $I \frac{x}{2}$ lin.

Habitat

Descr. Corpus tenue admodum. Antennæ testaceæ. Caput nigrum, rolundatum, depressum. Thorax niger, orbiculatus, capite filo tenui adhærenti, ut in St. orbiculato. Cap!nt thorax et elytra punctulis prominulis, ef præcinuè clytra, scabra. Elytra posticè testaceo inquinata idque quidem irregulariter, haud aliter ac si gutta ad suturam demissa secus marginem ducta decurreret. Pedes omninò testacei.

84. St. niger obscurus scaber, antennis pedibusque clavicomis. tentaceis, genubus nigris.

Fub. Gen. Ins. Mant. 242. Sp. Ins.336. 14. Mant. i. 221.2 - Ent. Syst. i. b. 527.37. Panz. Ent. Germ. 356.27 .

Panz. Fuun. Germ. 27. t. r 1 .

Staphylinus Juno. Pa,k Monog. 25 .

Stenus Juno, Puyk. Funn. Suec, iii. 433. I. 
Long. corp. $2 \frac{1}{2}$ lin.

\section{Habitat}

DEscr. Totus niger, præter antennas et pedes, qui testacei sunt; apex autem femorum et basis tibiarum nigra. Caput, thorax et elytra obscura, et punctis prominulis scabra.

orbiculatus. 85 . St. niger, thorace convexo orbiculato, antennis palpis pedibusque fusco-rufescentibus.

Payk. Monog. 26.

Pæderus orbiculatus. Fab. Ent. Syst. i. b. 538. 9. Panz. Ent.Germ.363. Io. Payk. Faun. Suec. iii. 431. 6.

Oliv. iii. 44. 7.6. t. 1. f. 7. a. b. Panz. Faun. Germ. 43. $t .2 \mathrm{I}$.

Long. corp. $2 \frac{\mathrm{T}}{2}$ lin.

Habitat

DEscr. Caput nigrum, suprà infràque convexum, orbiculatum, thorace latius. Antennæ filiformes, vix capitis thoracisque longitudine. Palpi fusco-rufescentes. Thorax niger, orbiculatus, convexus, capite elytrisque angustior, profundâ incisurâ ab illis disjunctus, adeo ut tenuissimo filo illis adhæreat. Elytra nigra, quadrata, thorace longiora et latiora. Sternum nigrum. Abdomen nigrum, vix thorace elytrisque longius. Pedes fusco-rufescentes.

melanopus. 86. St. niger obscurus scaber, pedibus concoloribus. Long. corp. $I \frac{x}{2}$ lin.

\section{Habitat}

Descr. Simillimus St. immuni, at pedes omninò nigri.

immunis. 87. St. niger obscurus scaber, pedibus testaceoferrugineis.

Long. corp. I lin.

Habitat

Descr. 



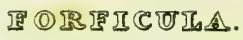
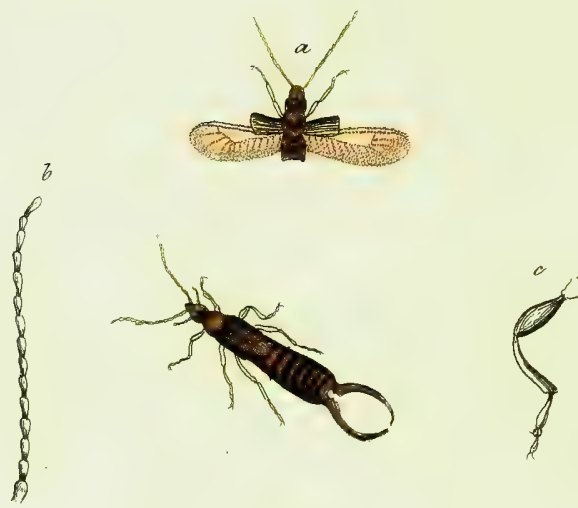

F. auricularia. 
DESCR. Proximè cum St. clavicorni convenit, at quadruplò minor: tum pedes omninò testacei, nec geniculis nigris.

\section{FORFICULA.}

Antenne setacex.

Elytra dimidiata, alas tegentia.

Corpus elongatum.

Cauda forcipata.

I. For. elytris rufis, forcipe arcuatâ basi dentatâ, auricularià. antennis I 4 articulatis.

Linn. Syst. Nat.686. т. Faun. Suec. 860. Vill. i.425. x. Gmel. 2038 . 1. Fab. Syst. Ent. 269. J. Sp. Ins. i. 340. I. Mant. i. 224. I. Ent. Syst. ii. I. I. Faun. Fred. 24. 231. Faun. Ingr. 375. Poda, 49. I. Pontop. i. 679. I. Act. Nidros. 3. 405. 30.

Scbeeff. Elem. t.63. Icon. t. I44. f. 3. 4. Sulz. Hist. Ins. t. $7 \cdot f \cdot 17$.

Forficula major. Harr. 408.

Long. corp. 8 lin.

Habitat passim. Plantas et fructus maturos sæpius rodit.

DESCR. Clypeus thoracis planus; anticè truncatus, ponè rotundatis, pallidus, in medio niger. Elytra pallidè rufa, A'se extra elytra prominulæ, apice extrorsùm albæ; maculâ ovatâ. Abdomen rufescens, nucum. Cauda duobus unguibus arcuatis, apice conniventibus, corneis, forcipata. Faun. Suec.

2. For. elytris pallidis, forcipe rectâa subcrenatâneglecta. apice aduncâ, antennis $\mathbf{I} 4$ articulatis. VOL. I.

Long. 
Long. corp. 6 lin.

Habitat

D. Lebmann.

Descr. Forficula auricularice simillima; fusca, elytris, thoracis marginibus, pedibus, antennisque pallidis; processibus in ultimo abdominis segmento obsoletis.

media.

3. For. elytris testaceis, antennis decem articulatis, forcipe longiusculâ incurvatâ.

Long. corp. 4 lin.

Habitat — Capta prope Dartford. D. Latham.

DESCR. In hac specie forceps multò longior quàm in For. minore, et intùs incurvata.

minor.

4. For. elytris testaceis immaculatis, antennis Io articulatis, forcipe erectiori.

Linn. Syst. Nat.686.2. Faun. Suec. 86r. Gmel. 2039.2. Fab. Syst. Ent. 269. 2. Sp. Ins. i. 340. 3. Mant. i. 224. 5. Ent. Syst. ii. 3. 7. Faun. Fred. 24. 232. Faun. Ingr. 376. Harr. 409.

Schaff. Icon. $t$. 4 I. $f$. I2. I3.

Long. corp. $2 \frac{i}{2}$ lin.

Habitat in sterquiliniis.

Descr. Color castaneus. Caput et thorax nigricantia. Elytra et alæ (quæ complicatæ apice prominent) castanea. Abdomen castaneum. Forceps caudæ erectior. Pedes et abdomen subtùs pallidiora. Faun. Suec. 


\section{$\left[\begin{array}{ll}531 & ]\end{array}\right.$ \\ INDEX}

GENERUM ET SPECIERUM.

ATTELABUS. p. 319-321. BOLETARIA. p. 138-141.

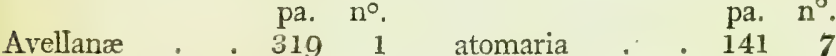

Betulæ . 3213 bicolor . . $141 \quad 8$

curculionoides . $320 \quad 2$ multipunctata * $139 \quad 3$

4-pustulata . . $138 \quad 1$

AUCHENIA. p. 213-219, rufa : : $\quad \begin{array}{lll}139 & 2\end{array}$

Asparagi . 2143 undulata ? 1406

cyanella : 2154 varia $4.140 \quad 5$

12-punctata $\quad 214 \quad 2$

flavicollis . . $217 \quad 8$

flavipes . $216 \quad 6$ BRUCHUS. p. 235. 236.

hirta . . 218 10 ater . . $236 \quad 4$

melanopa : 2155 granarius : . $235 \quad 2$

merdigera - . 2131 scabrosus @. 2351

4-maculata . . 21811 seminarius . . 2363

rufipes $\quad .2179$

subspinosa : . 2167

tenella $\quad 21912$ BUPRESTIS. p. 395-398.

BLAPS. p. $479-481$.

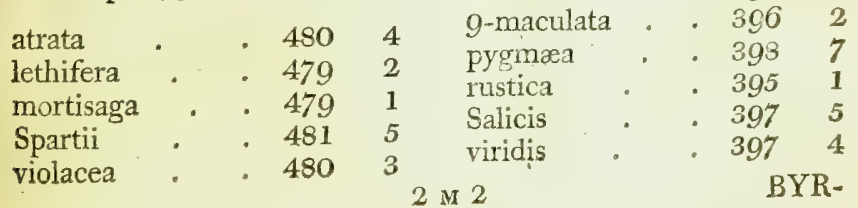


BYRRHUS. p. 101. 102.

pa. $n^{\circ}$.

Pimpinellæ pa. $\mathrm{n}^{\circ}$.

Pini . . 1023

Verbasci . . $101 \quad 1$

CANTHARIS. p. $364-375$.

$\begin{array}{llll}\text { acuta } & 372 & 14\end{array}$

ænea . 3698

biguttata * . $372 \quad 15$

bipustulata - $369 \quad 9$

fasciata . . $371 \quad 11$

flavicollis . . $375 \quad 22$

frontalis - . $373 \quad 17$

fusca . . $365 \quad 1$

humeralis $\quad \begin{array}{lll}374 & 19\end{array}$

immunis . 37420

livida . 3664

melanocephala . $374 \quad 18$

melanura . 368

minima - . 373

obscura . . 365

pallida . . 368

rubricollis . . $371 \quad 12$

ruficollis . . 3663

sanguinolenta $\quad .370 \quad 10$

serraticornis - 37421

testacea . . $367 \quad 5$

$\begin{array}{llll}\text { viridissima } & \quad 372 \quad 13\end{array}$

C $\triangle R \triangle B U S$. p. $431-473$.

\begin{tabular}{|c|c|c|}
\hline acutus & & - 461 \\
\hline neus & & 439 \\
\hline angustior & . & 442 \\
\hline quaticus & . & . 461 \\
\hline terrimus & & - 444 \\
\hline atricapillus & & 462 \\
\hline azureus. & & 450 \\
\hline icolor & & 436 \\
\hline bipunctatus & & . 453 \\
\hline bipustulatus & & 464 \\
\hline unneus & & - 455 \\
\hline culescens & & 446 \\
\hline enulatus & & 434 \\
\hline
\end{tabular}

cephalotes . . 472107

chalceus . . 46075

chrysostomos $\quad 469101$

cinctus . * 44942

circulatus . . 45044

collaris • . $443 \quad 29$

communis . . $439 \quad 17$

convexiusculus . $462 \quad 82$

convexus . . $445 \quad 34$

crepitans • . 46896

Crux major $\quad 4 \quad 470 \quad 104$

Crux minor $465 \quad 89$

cupreus . . $439 \quad 18$

cyanocephalus . $451 \quad 49$

depressus . . 4359

dilutus . . $469 \quad 99$

dimidiatus . . 445 35

discolor . . 45147

distans . . $472 \quad 108$

Doris . . $453 \quad 52$

echinatus . . $455 \quad 59$

elegantulus $\quad 4 \quad 470 \quad 102$

Ephippium . $462 \quad 81$

erythropus . . 46178

femoralis $\quad 463 \quad 85$

ferrugineus $\quad 440 \quad 21$

flavipes . . $437 \quad 14$

foraminulosus $\quad 457 \quad 69$

fulvus . . $456 \quad 64$

gibbosus . 43610

granulatus . . $433 \quad 5$

hortensis : $433 \cdots 4$

humeralis * . $452 \quad 50$

immunis : . $452 \quad 53$

inæqualis . $456 \quad 65$

inquisitor . . 44840

intricatus . . $432 \quad 3$

lateralis . $457 \quad 66$

latus ... 440 20

leucophthalmus $431 \quad 1$

linearis $\quad 463 \quad 84$

littoralis : $452 \quad 51$

lunatus : : 46691

macer . . $466 \quad 92$

madidus 


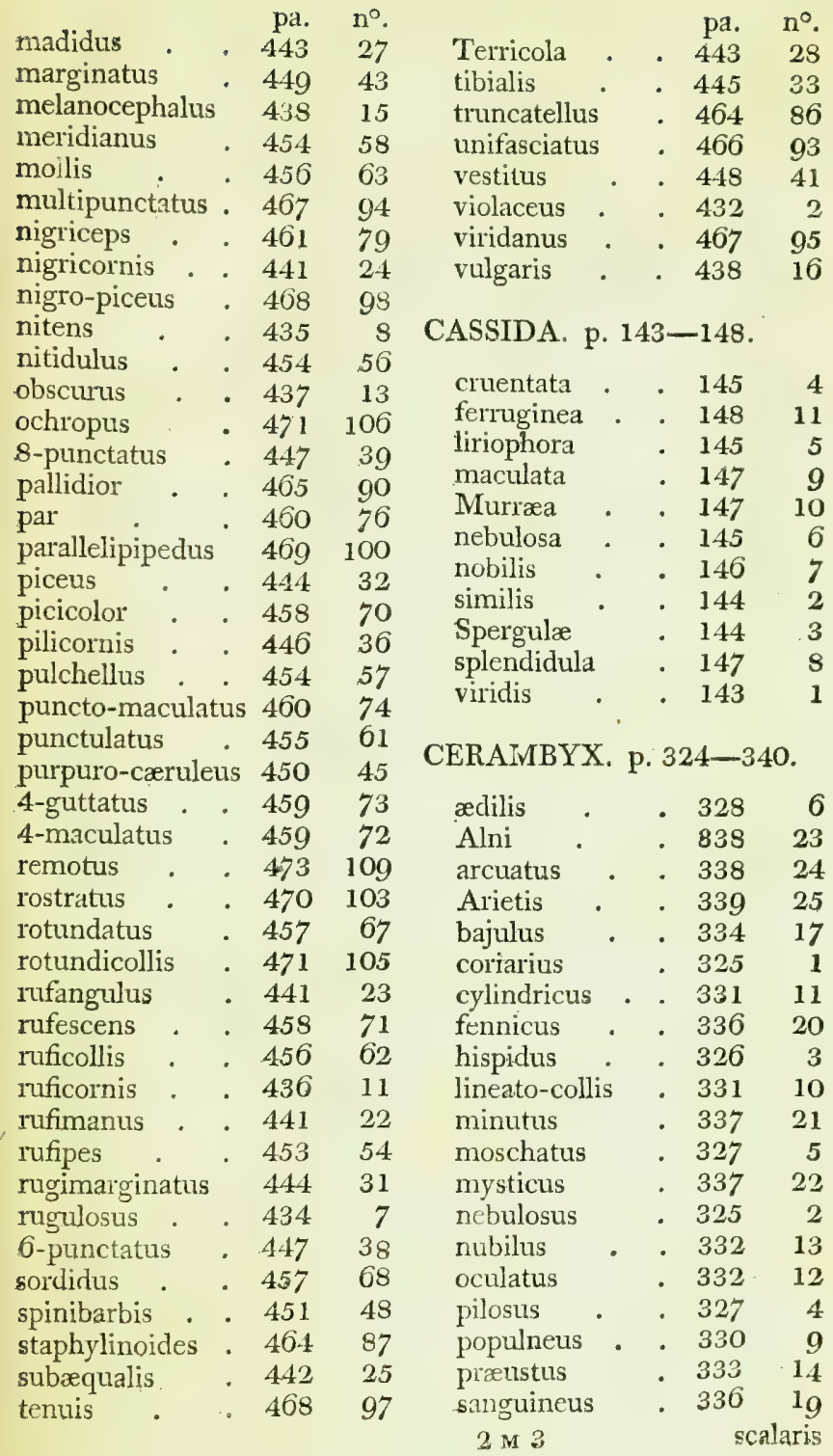




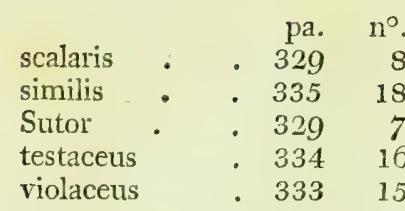

CHRYSOMELA. p. 169-206.

\begin{tabular}{|c|c|c|c|}
\hline nea & & . 189 & 46 \\
\hline rata & & 204 & 87 \\
\hline ahenea & & $\cdot 176$ & 162 \\
\hline Alni . & & . 172 & \\
\hline Armoraciæ & & . 179 & \\
\hline errima & & 183 & \\
\hline ricilla & & 200 & \\
\hline ro-violasc & & 184 & \\
\hline cta & & 181 & \\
\hline rata & & 195 & \\
\hline allotæ & & 205 & \\
\hline Banksii & & 187 & \\
\hline Beccabungx & & 186 & \\
\hline Betulæ & & 178 & \\
\hline Boleti . & & . 176 & \\
\hline buprestoide & & . 192 & \\
\hline realis & & 185 & \\
\hline alcea & & 183 & \\
\hline irysocepha & & 193 & \\
\hline oncinna & . & 196 & \\
\hline riaria & . & 170 & \\
\hline ranea . & & 196 & \\
\hline Cynoglossi & & 205 & \\
\hline 10-notata & & 175 & \\
\hline 10-punctata & & 175 & \\
\hline Erucæ . & & . 193 & \\
\hline Euphorbio & & . 204 & \\
\hline oleta & & . 201 & \\
\hline stuosa & . & 174 & \\
\hline moralis & . & . 201 & \\
\hline xuosa & . & . 198 & \\
\hline cipes . & & 199 & \\
\hline xttingensi & & 171 & \\
\hline raminis & . & - 172 & \\
\hline moptera & . & . 171 & \\
\hline ensis & & 177 & \\
\hline & & 194 & \\
\hline
\end{tabular}

\begin{tabular}{|c|c|c|}
\hline hemisphœrica & . 199 & \\
\hline Hyoscyami & . 193 & \\
\hline Hyperici & . 173 & \\
\hline Hypochæridis & . 184 & \\
\hline incrassata & : 186 & \\
\hline iopa . & . 170 & \\
\hline Litura & . 182 & \\
\hline limbata & . 191 & \\
\hline marginata & . 190 & \\
\hline arginella. & . 181 & \\
\hline Marshami & . 173 & \\
\hline Modeeri . & . 194 & \\
\hline Nemorum & . 197 & \\
\hline nigricollis . & . 205 & \\
\hline gro-ænea & . 197 & \\
\hline itidula & 195 & \\
\hline odicornis & . 204 & \\
\hline hroleuca & . 202 & \\
\hline oleracea . & . 192 & \\
\hline olivacea & . 181 & \\
\hline orbiculata & . 200 & \\
\hline pallida ... & 174 & \\
\hline Phellandrii & 185 & \\
\hline picina . & 206 & \\
\hline polita & 188 & \\
\hline Polygoni . & 178 & \\
\hline Populi . & 188 & \\
\hline Pseudacori & 196 & \\
\hline pubescens & 183 & \\
\hline Pulex & 204 & \\
\hline punctulata & 200 & \\
\hline 4-pustulata & 198 & \\
\hline Quinquejugis & 173 & \\
\hline ruficornis & 199 & \\
\hline rufipes . & 198 & \\
\hline rufitarsis & 182 & \\
\hline sanguinolenta & 190 & \\
\hline semiænea . & 194 & 57 \\
\hline staphylea & 186 & \\
\hline striatula . & 205 & \\
\hline suturalis . & . 201 & \\
\hline stygia & . 183 & \\
\hline tabida & 203 & \\
\hline Tanaceti & 177 & 17 \\
\hline tenebricosa & . 169 & \\
\hline
\end{tabular}




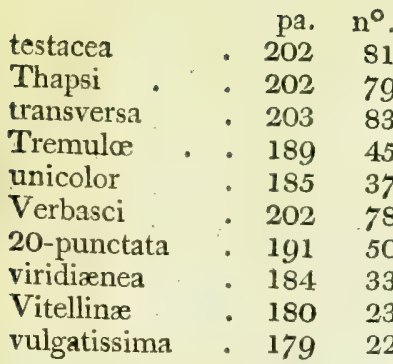

CICINDELA. p. 389-395.

\begin{tabular}{|c|c|c|}
\hline aquatica & & - 393 \\
\hline bigut tata & & - 395 \\
\hline campestris & & . $\quad 389$ \\
\hline flavipes & & 394 \\
\hline germanica & & - 390 \\
\hline iparia . & & - $\quad 392$ \\
\hline emipunctata & & - 394 \\
\hline riata & & - 393 \\
\hline tica & & . 391 \\
\hline osa & & 392 \\
\hline
\end{tabular}

CISTELA. p. 102-106.

\begin{tabular}{|c|c|c|}
\hline bicol & & \\
\hline dorsalis & & \\
\hline ferruginea & & - 104 \\
\hline & & 105 \\
\hline laritıma & - & 105 \\
\hline lartıma & & 105 \\
\hline picea & - & 106 \\
\hline picipes & - & 105 \\
\hline Pilula & - & - 102 \\
\hline ericea & & - 104 \\
\hline striata & - & 103 \\
\hline lata & & - 103 \\
\hline
\end{tabular}

CLERUS. p. 321-324.

formicarius . 321 mollis . . 322 Quadra . . 323 ruficollis . 324 violaceus 81

78
COCCINELLA. p. 148-169.

79

83

45

50

33

23

22

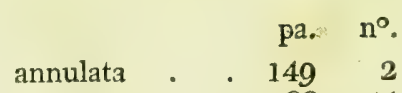

biliturata . $166 \quad 44$

bimaculata . $166 \quad 42$

bipunctata . $150 \quad 5$

bipustulata $\quad 164 \quad 37$

bisbipustulata * $167 \quad 46$

Cacti . . $163 \quad 36$

10-guttata $\quad 16130$

10-punctata . $154 \quad 15$

10 pustulata $\quad 165 \quad 41$

12-punctata * $155 \quad 18$

12-pustulata $\quad 168 \quad 51$

flava . . $160 \quad 27$

fulvifrons $\quad \cdot 168 \quad 48$

hæmorrhoidalis $\quad 168 \quad 49$

humeralis o $166 \quad 43$

impunctata . $148 \quad 1$

lineolata $\quad \begin{array}{ll}153 & 12\end{array}$

lunularis $\quad 168 \quad 50$

margine- $\} \quad 1504$

19-punctata $\quad 158 \quad 23$

9-punctata $\quad .154 \quad 14$

$\left.\begin{array}{c}\text { oblongo- } \\ \text { guttata }\end{array}\right\} \quad 162 \quad 34$

$6 \quad 18$-guttata $\quad 162 \quad 33$

4 8-punctata $\quad 153 \quad 13$

7 parvula . . $167 \quad 47$

o perforata $.151 \quad 6$

11 4-maculata $\cdot 167 \quad 45$

9 4-punctata $151 \quad 7$

1 4-pustulata $\quad 164 \quad 38$

5 4-verrucata . $163 \quad 35$

3 5-punctata . . 1518

214 -guttata $\quad 16131$

14-maculata $\quad 157 \quad 22$

14-punctata $\quad 157 \cdot 21$

7 -notata $\quad \cdot \begin{array}{ll}153 & 11\end{array}$

7 -punctata $\quad 152 \quad 10$

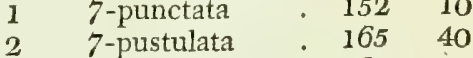

4 16-guttata $\quad 161 \quad 32$

56 -punctata $\quad 152 \quad 9$

3 6-pustulata $\quad 165 \quad 39$ $2 \times 4$

sinuata 
I N D E X.

\begin{tabular}{|c|c|}
\hline sinwata & 160 \\
\hline sintrosa & 160 \\
\hline 13-maculata & 157 \\
\hline 13-punctata & 156 \\
\hline 11-notata & 155 \\
\hline 11-punctata & 155 \\
\hline unifasciatá & 149 \\
\hline 22-punctata & 158 \\
\hline 20-punctata & 158 \\
\hline 24-punetata & 159 \\
\hline
\end{tabular}

CORTIGARIA. p. $106-113$.

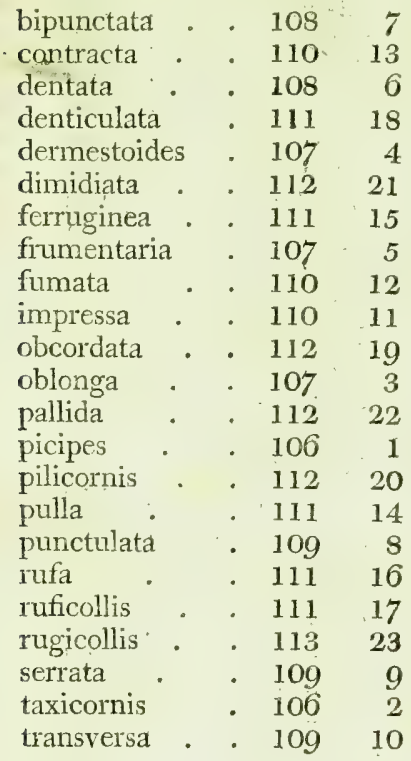

CRIOCERIS. p. 219-229.

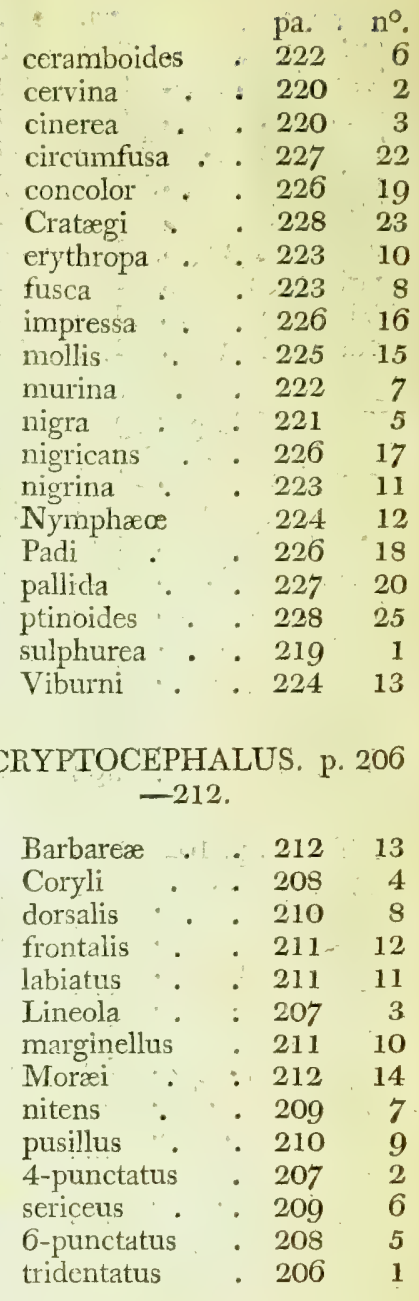

CURCULIO. p. 236-319.

$$
\begin{aligned}
& \text { acephalus . . } 271 \quad 102 \\
& \text { Eccidii . . } 307201 \\
& \text { æneo-virens . } 239 \quad 5 \\
& \text { æneus . } 24313 \\
& \text { æquatus }
\end{aligned}
$$




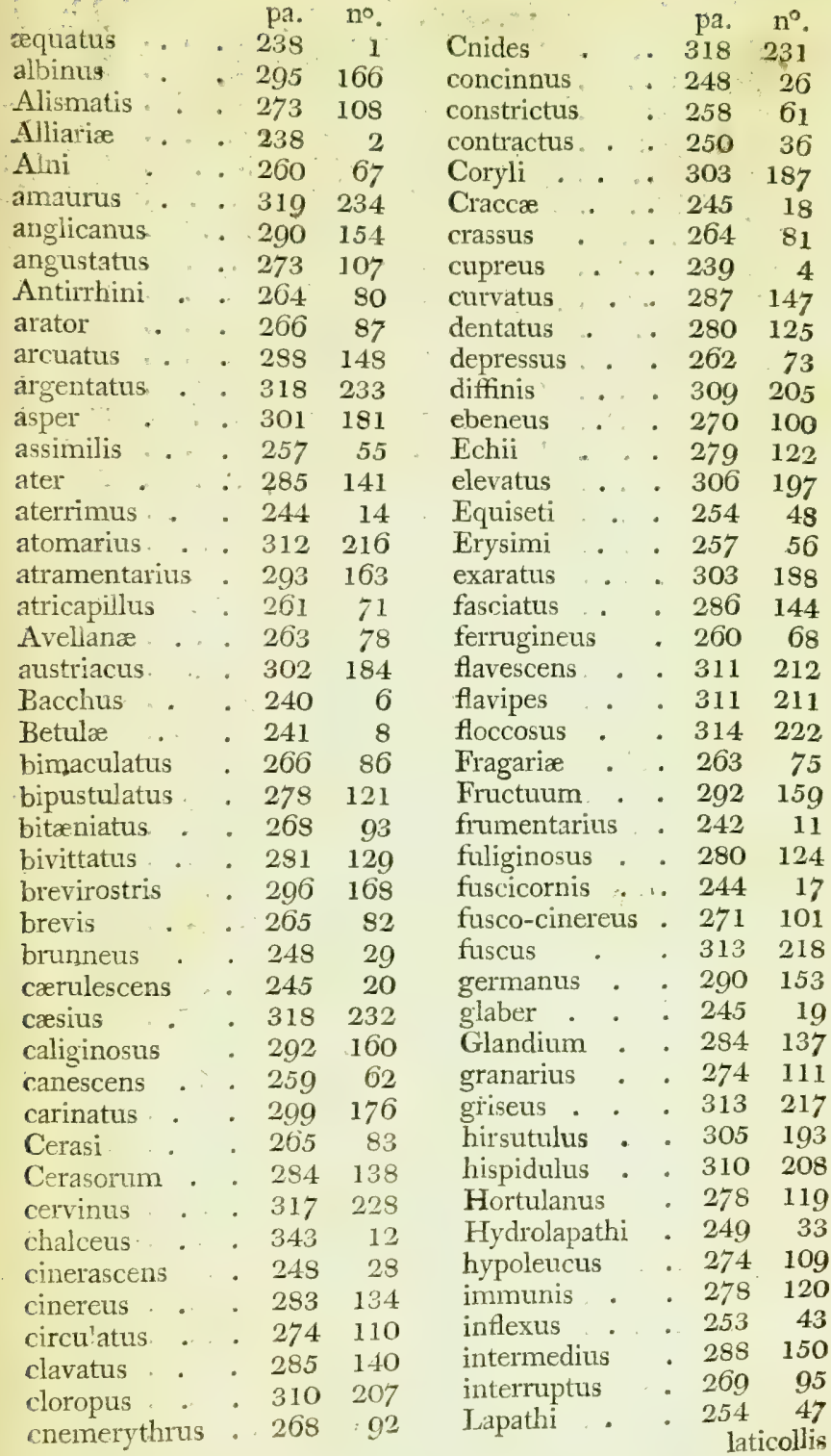




\begin{tabular}{|c|c|c|c|c|c|c|c|}
\hline laticollis & 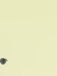 & $\begin{array}{c}\text { pa. } \\
276\end{array}$ & $\begin{array}{l}n^{\circ} \\
116\end{array}$ & parapleurus . & - & $\begin{array}{c}\text { pa. } \\
306\end{array}$ & $\begin{array}{l}n^{\ominus} \\
198\end{array}$ \\
\hline latirostris & - & . 295 & 167 & pedicularius & . & 286 & 143 \\
\hline leucugaster & & . 253 & 45 & phæorhynchus & . & 258 & 58 \\
\hline leucostigma & & 255 & 51 & piceus . . & - & 305 & 194 \\
\hline lignarius . & - & 275 & 113 & picicornis & . & 276 & 115 \\
\hline Ligustici & - & 313 & 220 & picipes . & - & 272 & 104 \\
\hline Lima & . & 298 & 173 & pilosulus . & - & 299 & 175 \\
\hline limbatus & . & 301 & 183 & pilosus . . & . & 262 & 72 \\
\hline linearis & & 271 & 103 & Pini . & - & 289 & 152 \\
\hline lineatus . & - & 309 & 206 & planirostris . & . & 297 & 170 \\
\hline longimanus & & 293 & 161 & Plantaginis . & . & 265 & 84 \\
\hline Lythri . & - & 252 & 41 & pleurostigma & & 282 & 131 \\
\hline macularius & . & 312 & 215 & plumbeus . & . & 302 & 186 \\
\hline maculatus & . & 292 & 158 & Pomorum & & 285 & 142 \\
\hline Mali . . & - & 317 & 230 & Populi . & & 241 & 9 \\
\hline Malvæ . & . & 246 & 23 & porcatus . & ( & 255 & 49 \\
\hline maritimus & - & - 307 & 202 & Pruni . . & - & 247 & 24 \\
\hline maurus . & . & . 316 & 225 & ptinoides & . & 258 & 59 \\
\hline medius : & · & - 302 & 185 & pubescens & - & 240 & 7 \\
\hline melanocepha & ralus & 253 & 44 & punctatus & . & 291 & 155 \\
\hline ielanopteru & & 289 & 151 & Pyri . . . & 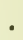 & 317 & 229 \\
\hline relanopus & & 248 & 27 & pyrrhoceras & . & 288 & 149 \\
\hline telanothyno & chus & 250 & 37 & pyrrhodactylus & $\because$ & 259 & 63 \\
\hline relanostictu & & 282 & 132 & pyrthorhynchus & & 257 & 57 \\
\hline melanostigm & & . 256 & 53 & 4-maculatus & . & 252 & 42 \\
\hline nanus ... & . & . 238 & 3 & 4-pustulatus . & . & 297 & 171 \\
\hline nebulosus & . & 308 & 203 & Quercicola . & . & 280 & 126 \\
\hline nervosus & - & 282 & 130 & radiolus . & . & 247 & 25 \\
\hline niger . & . & 297 & 172 & raucus . & - & 300 & 179 \\
\hline nigriclavis & . & 312 & 213 & Resedæ . . & • & 256 & 52 \\
\hline nigticollis & . & 261 & 70 & resinosus . & & 268 & 91 \\
\hline nigrinas . & - & 250 & 35 & retusus . & & 306 & 196 \\
\hline nigrirostris & . & 267 & 89 & rhododactylus & & 262 & 74 \\
\hline nitens . & . & 242 & 10 & rhodopus . & & 263 & 76 \\
\hline Nucum & & 283 & 136 & rigidus . & - & 270 & 97 \\
\hline obesus . & . & 304 & 191 & rubellus & • & 293 & 162 \\
\hline oblongus & . & 316 & 226 & ruber . & & 251 & 39 \\
\hline obscurus & $\cdot$ & 244 & 16 & rufescens & & 316 & 227 \\
\hline obstrictus & . & 255 & 50 & ruficlavis & & 312 & 214 \\
\hline Oryzæ . & & 275 & 114 & ruficollis & & 296 & 169 \\
\hline ovalis . & & 279 & 123 & ruficrus . & & 258 & 60 \\
\hline ovatus . & & 315 & 223 & rufimanus & & 270 & 99 \\
\hline Oxyacanthæ & & 263 & 77 & rufipes . & & 310 & 209 \\
\hline pallens . & . & 251 & 38 & rufirostris & & 246 & 21 \\
\hline pallidactylus & & 259 & 64 & 1utus & & 261 & 69 \\
\hline Daraplecticus & & 272 & 106 & Rumicis & & $\begin{array}{r}266 \\
\text { Sal }\end{array}$ & 85 \\
\hline
\end{tabular}




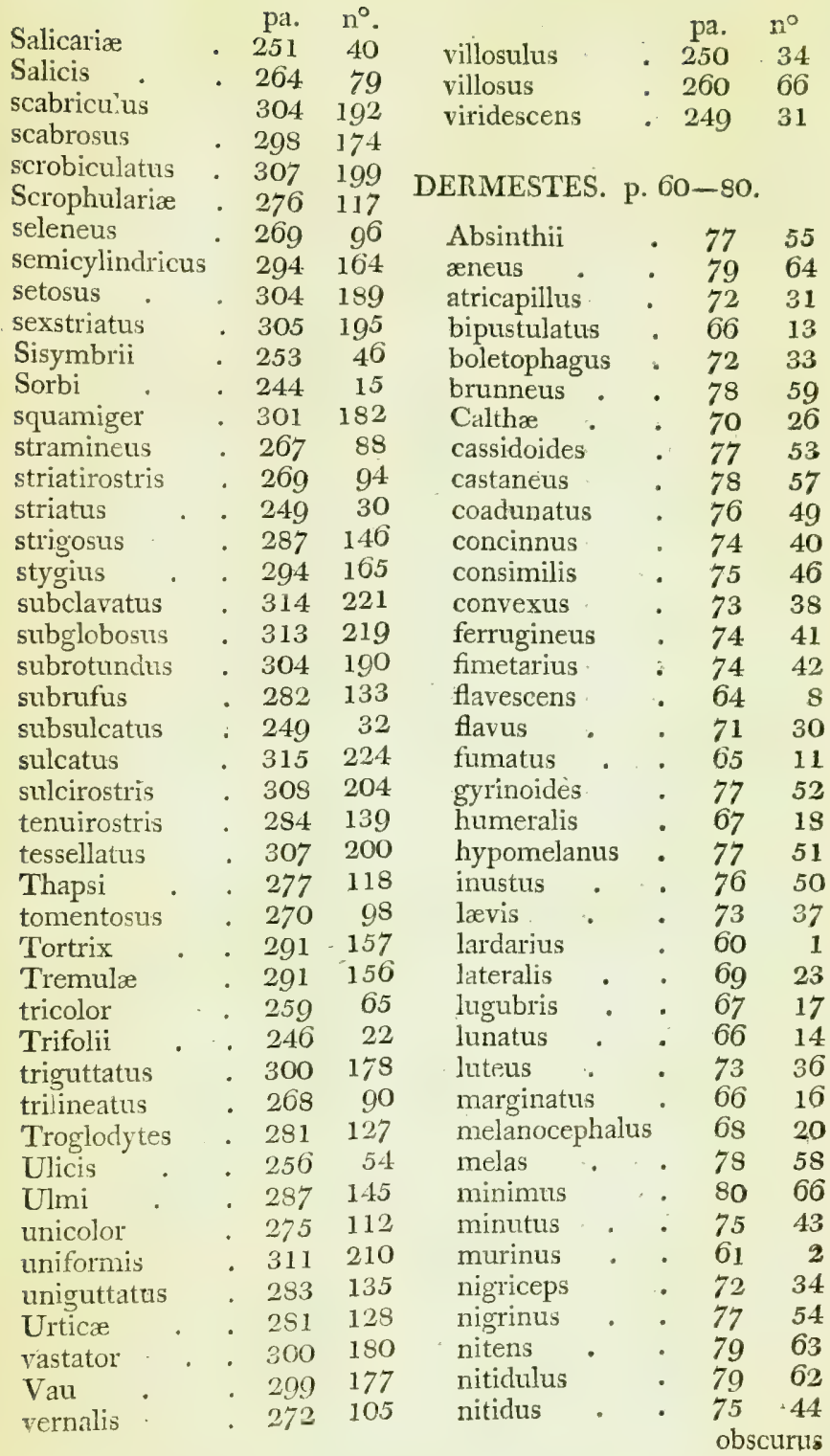




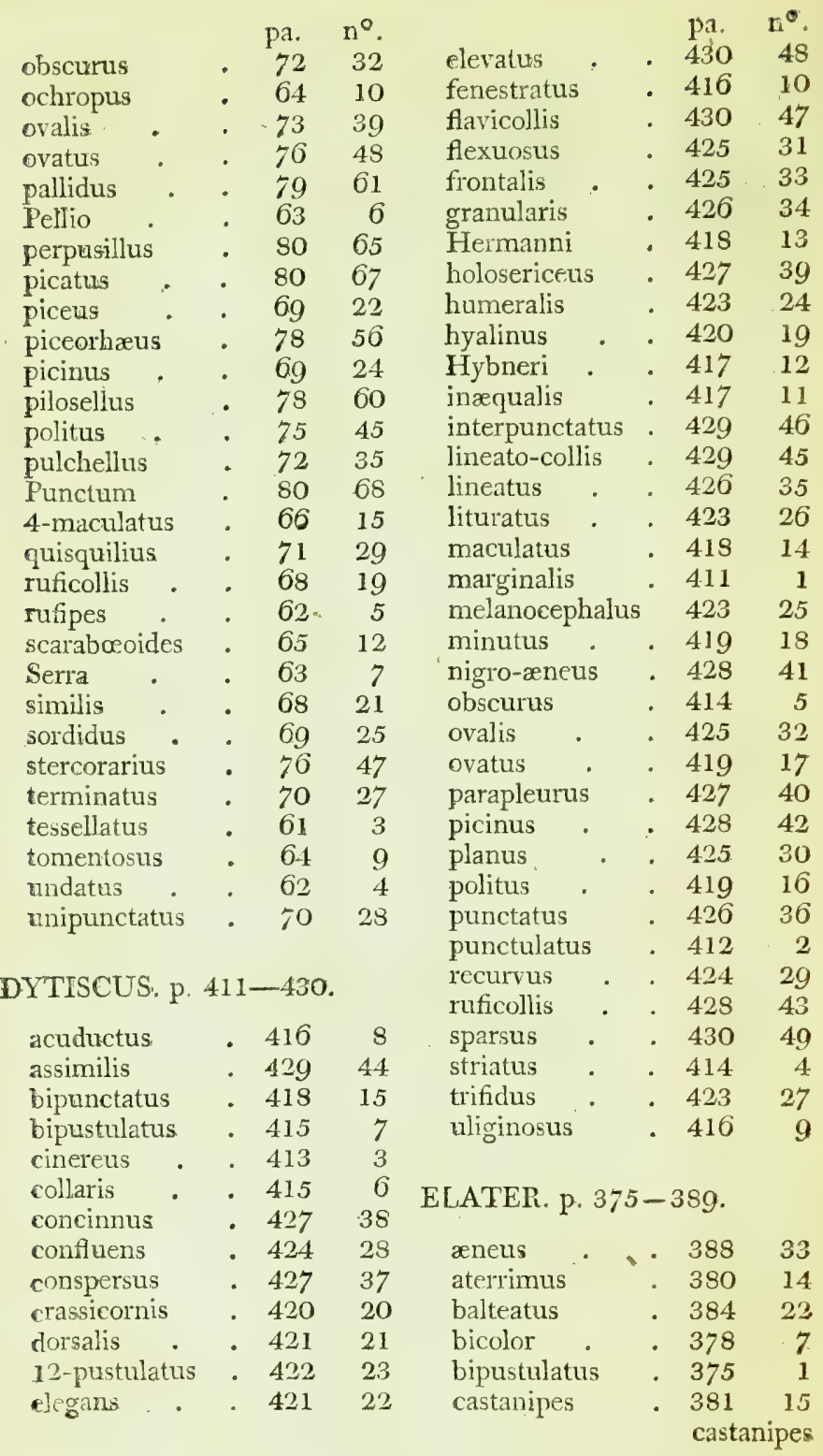




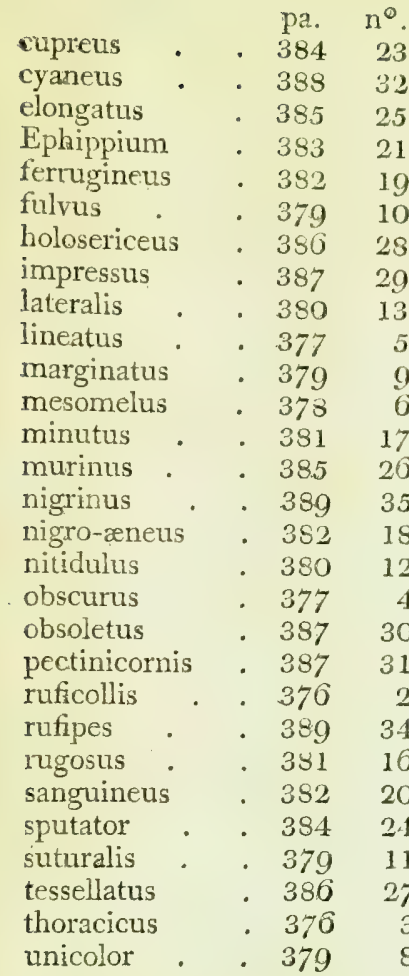

FORFICULA. p. 529. 530.

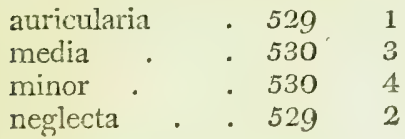

GYRINUS. p. 99. 100.

elongatus $\quad 100$

Kirbii . . 100

Modeeri . 100

Natator . 99

HFTEROCERUS,

marginatus

$400 \quad 1$

HISPA. p. 231. 232.

$\begin{array}{llll}\text { atra } & 231 & 1 \\ \text { mutica } & \cdot & 232 & 2\end{array}$

HISTER. p. 92-99.

\begin{tabular}{|c|c|}
\hline & \\
\hline bimaculatus & 93 \\
\hline bipustulatus & 94 \\
\hline unneus & 97 \\
\hline depressus & 98 \\
\hline 2 -striatus & 90 \\
\hline ææqualis & 93 \\
\hline minimus & 99 \\
\hline arvus . & 93 \\
\hline perpusillus & 99 \\
\hline piceus . & 97 \\
\hline pygmæus & 98 \\
\hline 4-guttatus & 95 \\
\hline 4-maculatus & 94 \\
\hline semipunctatus & 95 \\
\hline striatus . & 97 \\
\hline nicolor & 92 \\
\hline iolaceus & 96 \\
\hline irescens & . $\quad 96$ \\
\hline
\end{tabular}

HYDROPHILUS. p. 401411.

\begin{tabular}{|c|c|}
\hline affinis . & . 409 \\
\hline bipunctatus & . 406 \\
\hline bipustulatus & . 406 \\
\hline caraboides & . 402 \\
\hline cicindeloides & . 411 \\
\hline cinereus . & . 410 \\
\hline lermestoides & . 405 \\
\hline dorsalis . & . 410 \\
\hline fulvus & . 408 \\
\hline fuscipes & . 403 \\
\hline impressus & . 408 \\
\hline lividus . & 405 \\
\hline Longipalpis & 407 \\
\hline luridus . & 404 \\
\hline lutosus . & 407 \\
\hline argipallens & 408 \\
\hline nutus . & 406 \\
\hline ollis & 407 \\
\hline
\end{tabular}




$\begin{array}{lrrr} & & \text { pa. } & \mathrm{n}^{\circ} . \\ \text { nitidus } & . & 407 & 15 \\ \text { nubilus } & . & 410 & 27 \\ \text { ochropterus } & . & 409 & 22 \\ \text { orbicularis } & . & 403 & 4 \\ \text { piceus } & . & 401 & 1 \\ \text { picinus } & . & 407 & 17 \\ \text { sordidus } & . & 403 & 5 \\ \text { stagnalis } & . & 409 & 23 \\ \text { torquatus } & . & 405 & 10 \\ \text { verrucosus } & . & 404 & 6\end{array}$

IPS. p. 51-59.

\begin{tabular}{|c|c|c|}
\hline ater & & . $\quad 59$ \\
\hline Boleti & - & . 59 \\
\hline coadunatus & & . 58 \\
\hline furcatus & - & . 55 \\
\hline fuscus & - & . 53 \\
\hline griseus & & . 55 \\
\hline hæmorrhoi & idalis & . 56 \\
\hline inermis & . & . 54 \\
\hline micrograph & hus & . 52 \\
\hline multistriat & tus & . 54 \\
\hline niger & - & . 59 \\
\hline obscurus & & - 57 \\
\hline piceus & - & . 58 \\
\hline piniperda & . & . 57 \\
\hline platycephal & alus & . 56 \\
\hline polygraphu & & . 52 \\
\hline pubescens & . & . 58 \\
\hline rhododacty & ylus & . 58 \\
\hline rufescens & & $\therefore \quad 55$ \\
\hline rufus & . & . 57 \\
\hline scaber & . & . 56 \\
\hline Scolytus & . & . 53 \\
\hline riceus & . & . 55 \\
\hline lcatus & • & . 59 \\
\hline ographu & & . 51 \\
\hline & . & · $\quad 54$ \\
\hline & & . 53 \\
\hline
\end{tabular}

LAMPYRIS. p. $361-363$. noctiluca : . $361 \quad 1$ pusilla . . $363 \quad 3$ splendidula $\quad 362 \quad 2$
LEPTURA. p. $340-357$.

pa. $n^{\circ}$.

ænea - . $346 \quad 12$

affinis $\quad 353 \quad 29$

attenuata $\quad 354 \quad 32$

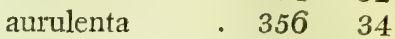

bifasciata . . $342=4$

bimaculata . 3436

collaris . . $349 \quad 22$

$\begin{array}{llll}\text { discolor } & 346 \quad 14\end{array}$

dorsalis . 3437

elongata $\quad$. 355.33

exclamationis - $356 \quad 35$

fasciata $\quad 344 \quad 9$

femorata $\quad 352 \quad 28$

Festucæ $\quad 346 \quad 13$

fusca . . $349 \quad 20$

fuscicornis $\quad 357 \quad 36$

Hydrocharis . $347 \quad 17$

inquisitor $\quad 3413$

$\begin{array}{lllll}7 & \text { lævis } & \text { l } & 351 & 26 \\ 2 & \text { linearis } & \text {. } & 347 & 16\end{array}$

8 livida . . $352 \quad 27$

24 melanocephala . $348 \quad 18$

17 melanura . $350 \quad 23$

21 meridiana . $340 \quad 1$

18 micans . . 3448

16 nigra . . $351 \quad 25$

3 nigro-lineata . $343 \quad 5$

23 Nymphææ $\quad 347 \quad 15$

22 palustris 34921

11 puncto-maculata $357 \quad 37$

19 4-fasciata $\quad .35431$

14. revestita . . 35024

6 rufiventris . $341 \quad 2$

2 Sagittariæ $\quad 345 \quad 11$

26 6-maculata - $353 \quad 30$

1 simplex . $348 \quad 19$

9 vittata . . $345 \quad 10$

4 LUCANUS. p. 46-51.

$\begin{array}{lllr}\text { caraboides } & & 50 & 5 \\ \text { Cervus } & \text {. } & 46 & 1 \\ \text { cylindricus } & \cdot & 50 & 4 \\ \text { inermis } & \text {. } & 48 & 2 \\ \text { parallelipipedus } & 48 & 3 \\ & & 4 Y T T A\end{array}$


LYTTA. p. 484-487.

$\begin{array}{lrrr}\text { antherina } & & \text { pa. } & \mathrm{n}^{\circ} \text {. } \\ \text { Boleti } & \text {. } & 486 & 3 \\ \text { floralis } & \text {. } & 485 & 6 \\ \text { fusca } & \text {. } & 486 & 4 \\ \text { monoceros } & \text {. } 487 & 8 \\ \text { nigricollis } & \text {. } 487 & 7 \\ \text { picea } & \text {. } 486 & 5 \\ \text { vesicatoria } & \text {. } 484 & 1\end{array}$

MELOE. p. $481-483$.

$\begin{array}{llll}\text { proscarabæus } & \text {. } & 481 & 1 \\ \text { punctatus } & \text {. } 483 & 6 \\ \text { rugosus } & \text {. } 483 & 4 \\ \text { scabrosus } & \text {. } 483 & 5 \\ \text { similis } & \text {. } 482 & 3 \\ \text { violaceus } & \text {. } & \text {. } 482 & 2\end{array}$

MORDELLA. p. 48s-495.

\begin{tabular}{|c|c|}
\hline d & 489 \\
\hline culeata & 488 \\
\hline jicolor & 490 \\
\hline ifasciata & 493 \\
\hline jiguttata & 492 \\
\hline Boleti & 494 \\
\hline cicatricata & 495 \\
\hline vicornis & 494 \\
\hline fasciata & 488 \\
\hline ferruginea & 490 \\
\hline ava . & 495 \\
\hline avescens & 490 \\
\hline frontalis & 491 \\
\hline fusca . & 493 \\
\hline ameralis & 489 \\
\hline gra . & 490 \\
\hline gricollis & 492 \\
\hline scura & 492 \\
\hline llida & 492 \\
\hline radoxa & 491 \\
\hline ea & $49-1$ \\
\hline collis & 491 \\
\hline hoides & 403 \\
\hline tacea & 493 \\
\hline
\end{tabular}

NECYDALIS. p. 357-.361:

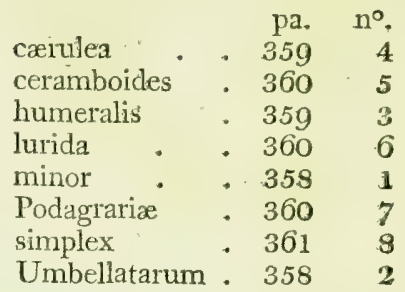

NITIDULA. p. 129-138.

$\begin{array}{lrrr}\text { ænea } & \text { : } & 131 & 8 \\ \text { zstiva } & : & 135 & 18 \\ \text { bipustulata } & : & 129 & 1 \\ \text { crerulea } & : & 132 & 9 \\ \text { Colon } & : & 132 & 11 \\ \text { decemguttata } & : & 135 & 20 \\ \text { depressa } & : & 133 & 14 \\ \text { discoidea } & : & 133 & 12 \\ \text { erythropa } & : & 132 & 10 \\ \text { flexuosa } & : & 133 & 13 \\ \text { fulva } & : & 136 & 21 \\ \text { grisea } & : & 134 & 15 \\ \text { latipes } & : & 131 & 6 \\ \text { melanocephala } & : & 136 & 22 \\ \text { nebulosa } & : & 134 & 17 \\ \text { nigrina } & : & 138 & 27 \\ \text { obscura } & : & 130 & 3 \\ \text { obsoleta } & : & 135 & 19 \\ \text { porcata } & : & 137 & 26 \\ \text { psyllia } & : & 138 & 28 \\ \text { pyrrhopa } & : & 135 & 29 \\ \text { 4-pustulata } & : & 130 & 2 \\ \text { rufa } & : & 136 & 23 \\ \text { ruficornis } & : & 131 & 7 \\ \text { rufifrons } & : & 136 & 24 \\ \text { rufipes } & : & 130 & 4 \\ \text { staphylinoides } & : & 137 & 25 \\ \text { undata } & : & 134 & 16 \\ \text { viridescens } & : & 131 & 5 \\ & & & \\ & & & \end{array}$


OPATRUM. p. 142. 143.

$\begin{array}{lrrr} & & \text { pa. } & \mathrm{n}^{\circ} \\ \text { Agricola } & \text {. } & 143 & 3 \\ \text { sabulosum } & \text {. } & 142 & 1 \\ \text { tibiale } & \text {. } & 142 & 2\end{array}$

PARNUS.

$$
\text { prolifericornis . } 399
$$

PTINUS. p. 81-91.

$\begin{array}{lrrr}\text { bidentatus } & \text { : } & 86 & 17 \\ \text { Boletorum } & : & 85 & 13 \\ \text { castaneus } & : & 83 & 7 \\ \text { Cerevisiæ } & : & 90 & 29 \\ \text { concinnus } & : & 87 & 19 \\ \text { cylindricus } & \text { : } & 83 & 6 \\ \text { fissicornis } & : & 82 & 3 \\ \text { Fur } & : & 89 & 27 \\ \text { germanus } & : & 89 & 25 \\ \text { imperialis } & : & 88 & 24 \\ \text { inermis } & : & 87 & 18 \\ \text { lævis } & : & 84 & 9 \\ \text { Lichenum } & : & 89 & 26 \\ \text { mollis } & : & 84 & 8 \\ \text { nigricornis } & : & 87 & 21 \\ \text { ovatus : } & : & 90 & 28 \\ \text { pectinicornis } & : & 81 & 1 \\ \text { pertinax } & : & 82 & 4 \\ \text { piceus } & : & 88 & 23 \\ \text { pygmæus } & : & 86 & 16 \\ \text { pyrrhocephalus } & 86 & 15 \\ \text { rhododactylus } & : & 87 & 22 \\ \text { rubellus } & : & 85 & 12 \\ \text { ruficornis } & : & 87 & 20 \\ \text { rufipes } & : & 83 & 5 \\ \text { serraticornis } & : & 82 & 2 \\ \text { similis } & : & 90 & 30 \\ \text { sulcatus } & : & 91 & 32 \\ \text { tenuicornis } & : & 84 & 10 \\ \text { tessellatus } & : & 85 & 11 \\ \text { testaceus } & : & 91 & 31 \\ \text { villosulus } & : & 86 & 14 \\ & & \end{array}$

PYROCHROA. p. 363. 364.

$$
\begin{aligned}
& \text { pa. } n^{\circ} \\
& \text { coccinea } \quad 364 \quad 2 \\
& \text { rubens . . . } 363 \quad 1
\end{aligned}
$$

\begin{tabular}{|c|c|}
\hline Agricola & 43 \\
\hline arenarius & 25 \\
\hline argentens & 45 \\
\hline Arvicola & 40 \\
\hline auratus . & 41 \\
\hline attaminatus & 13 \\
\hline bilituratus & 15 \\
\hline brunneus & 38 \\
\hline castaneus & 12 \\
\hline centrolineatus & 14 \\
\hline ciliaris : . & 14 \\
\hline Cœnobita & 33 \\
\hline conflagratus & . $\quad 11$ \\
\hline conspurcatus & 12 \\
\hline coprinus . & 12 \\
\hline Donovani & 44 \\
\hline emarginatus & 32 \\
\hline erraticus & 9 \\
\hline fasciatus & 43 \\
\hline fimetarius & 10 \\
\hline fœdatus. & 14 \\
\hline fœetens & 17 \\
\hline Fossor & 16 \\
\hline foveatus & 21 \\
\hline Frischii & 40 \\
\hline Fullo & 36 \\
\hline Gagates & 26 \\
\hline granarius & 19 \\
\hline hæmorrhoidalis & 19 \\
\hline Herticola & 44 \\
\hline
\end{tabular}

SCAPHIDIUM. p. 233. 234.

$\begin{array}{llll}\text { acuminatum } & \cdot & 234 & 3 \\ \text { Boleti } & \cdot & 234 & 5 \\ \text { dubium } & \cdot & 234 & 4 \\ \text { griseum } & . & 233 & 1 \\ \text { 4-maculatum } & \cdot & 233 & 2\end{array}$

SCARABÆUS. p. 7-46. 


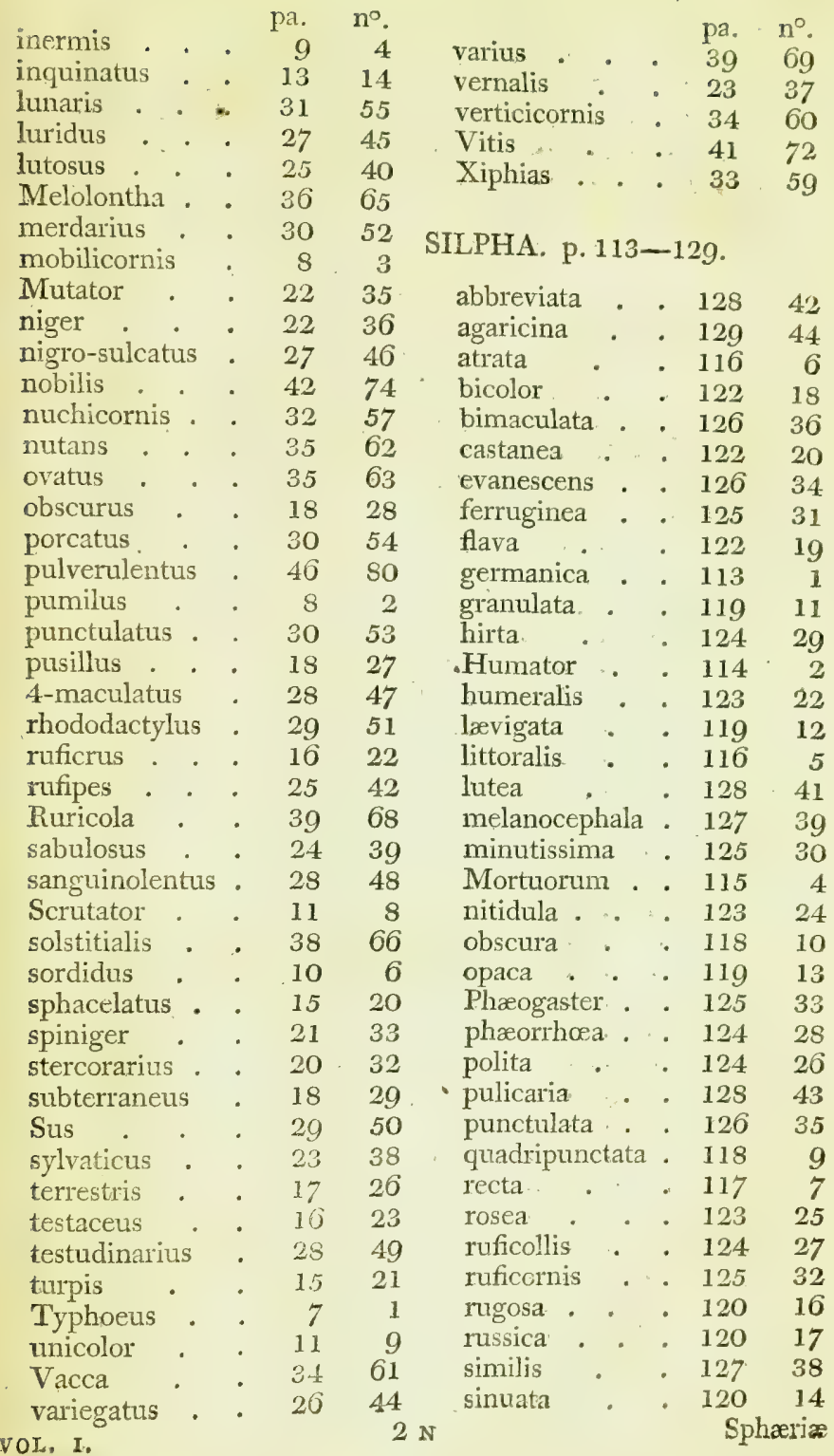




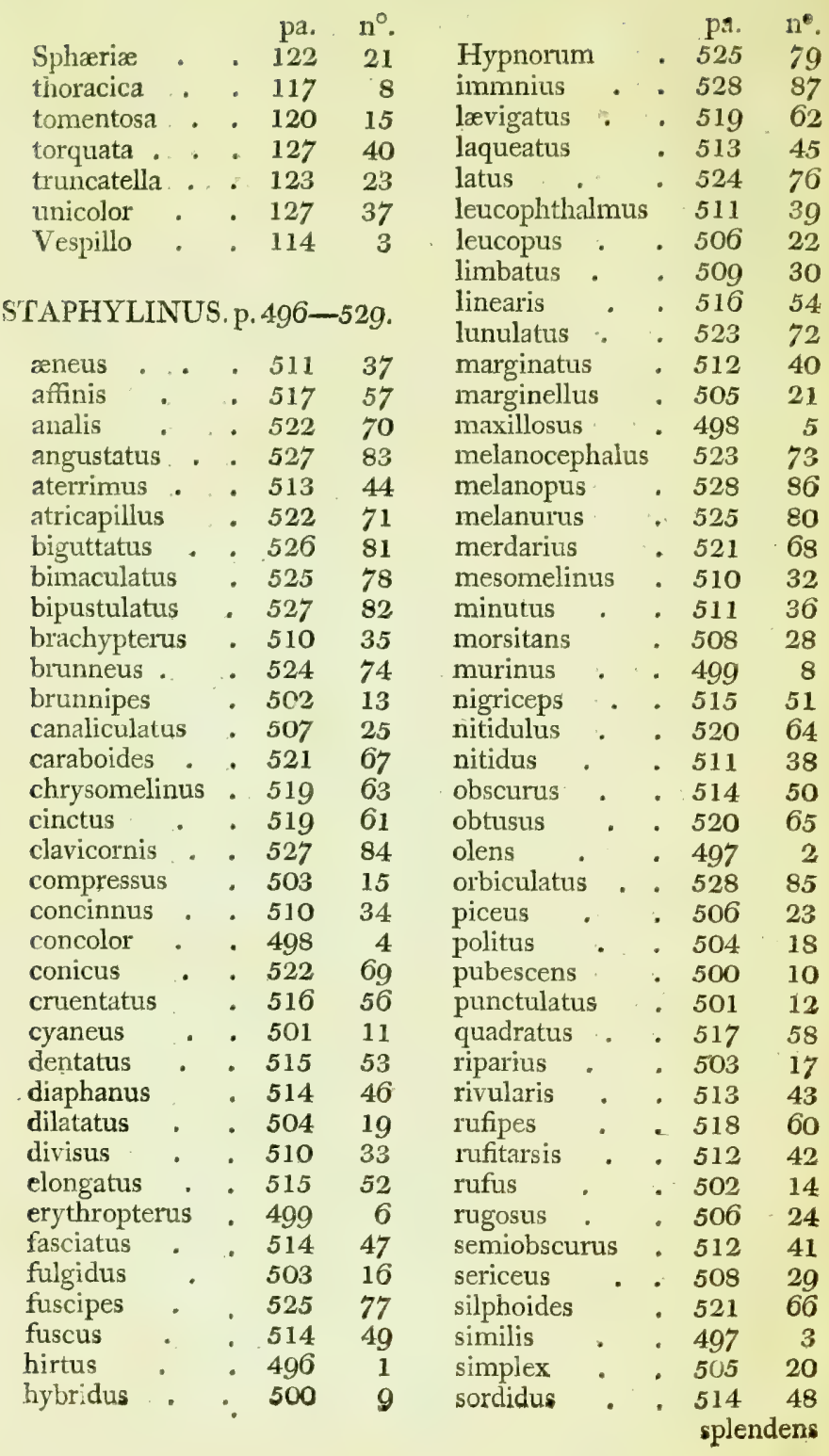




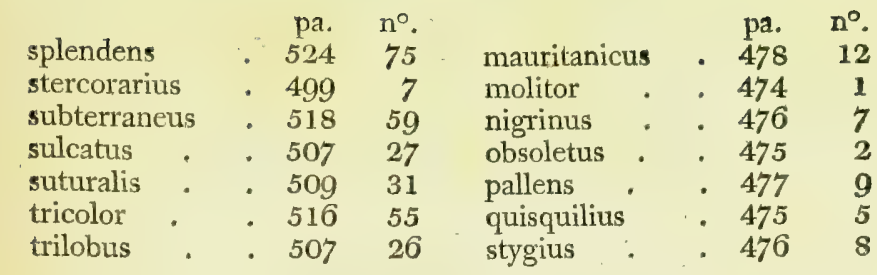

TENEBRIO. p. $474-478$. TILLUS. p. 229-231.

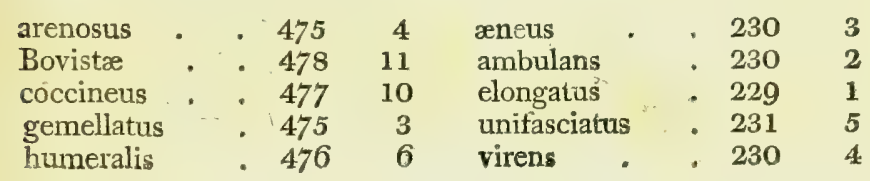




\section{ERRATA ET CORRIGENDA.}

pag. lin.

II 14 pro ' rabidus' lege ' rubidus.'

179 pro " concolorata' le'ge ' concolora"

I8 5 et rz pro ' lavissimè' lege ' levissimè"

$23-4$ a calce, pro 'punctulatis' lege 'punctulatus'

$243^{y}$ pro 'Silpbse sabulose' lege ' Opatro sabuloso'

27 antepenult. dele comma post ' exaratum'

30 " 4 a calce, pro ' animaculi' lege ' animalculi'

346 pro 'nigro' lege 'nigro-viridi'

46 'Ig pro 'ciliatis' lege ' ciliatus'

5313 pro 'stria' lege 'strias'

$5^{6} 6$ pro ' denuo' lege ' demum'

852 I pro 'roseat' lege ' roserat'

9 [ 3 pro 'Licbeni' lege 'Licbenun'

IOO 8 pro 'æream' lege ' aeream'

I I 20 post ' corp.' supple ' 1."

I 47 a calce, pro ' simillimus' lege ' simillima"

I2 8 antepenult. pro 'Subvillosus obsurè niger,' lege

'Subvillosa obscurè nigra'

136 I2 pro 'Bovistec' lege 'Bovistâ"

I39 4 pro ' 4-pustulata' lege ' 4-pustulatus"

160 penult. pro 'lineolâquæ' lege 'lineolaque'

184 I5 pro 'atro-violescens' lege 'atro-violascens'

$2 I_{2}$ I post ' nitidissimus' adde 'lævis, margine angulisque anticis flavis. Elytra nitida, striata,'

21723 pro' 39.10 ' lege ' 10.39.'

222 penult. pro 'tsstacea' lege ' testacea'

223 penult pro 'articuli' lege ' articulus'

223 ult. pro 'ferruginei' lege ferrugineus'

2257 a calce, pro ' artctè lege ' arctè'

2967 pro 'entomorrbiza' lege 'fraxinea'

342 penult. pro ' nigræ' lege ' nigro'

393 I4 a calce, pro 'germanicus' lege ' aquaticus'

4097 pro 'maculis duabus luridis'lege ' macula lurida'

$45^{8} 4$ dele 'et pedibus pallidioribus, fere testaceis'

$4^{8} 3$ I7 pro 'spondet' lege 'splendet' 




(纟) (V) (

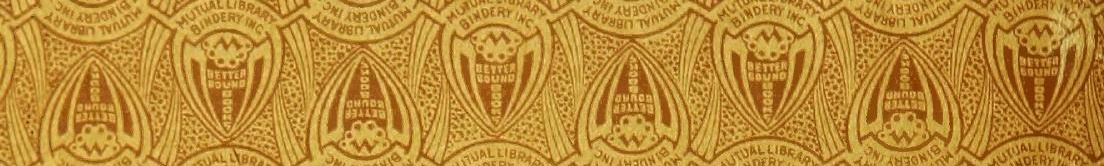

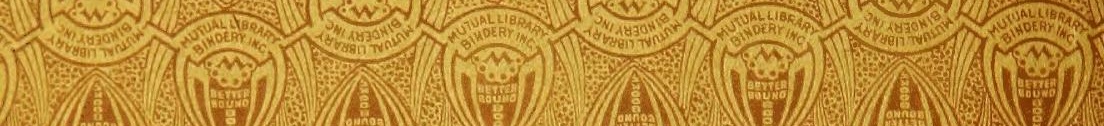

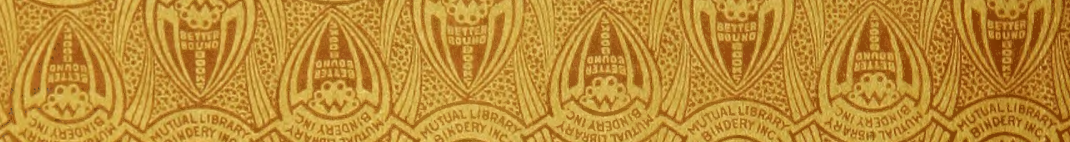

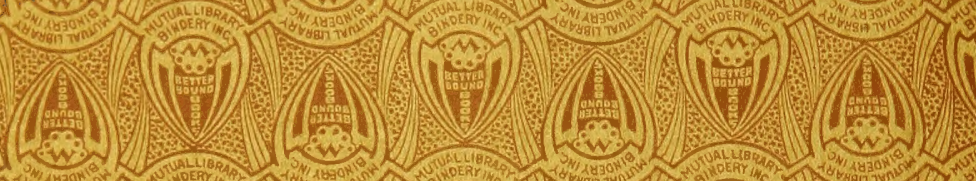
(

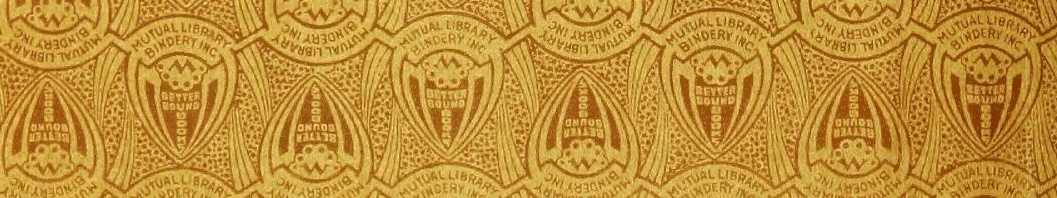

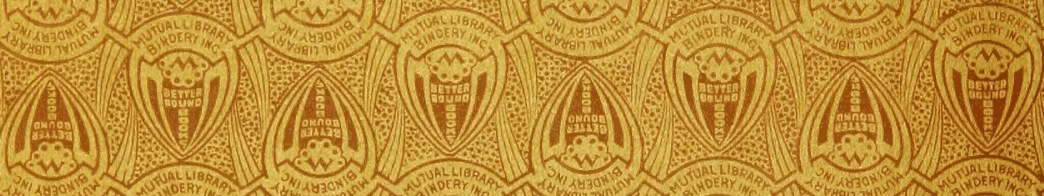

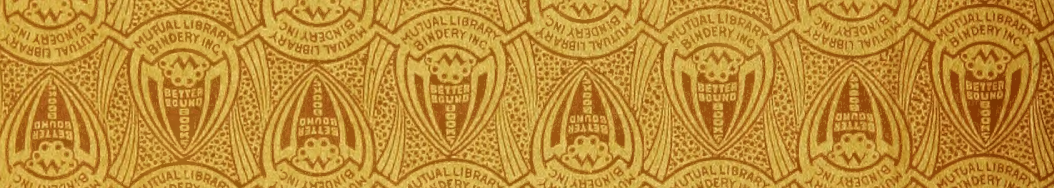

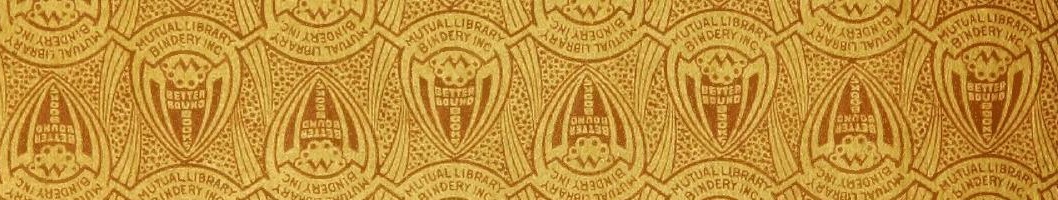

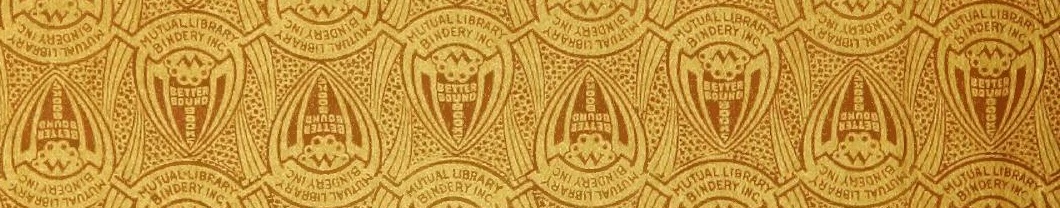

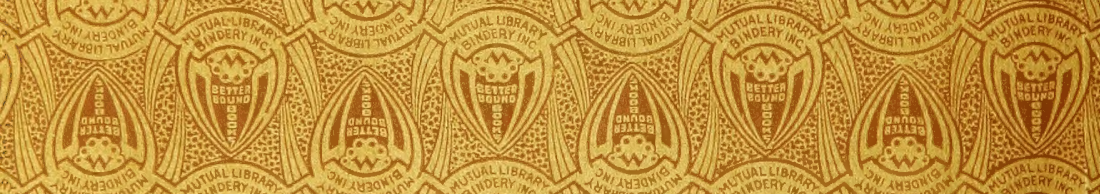

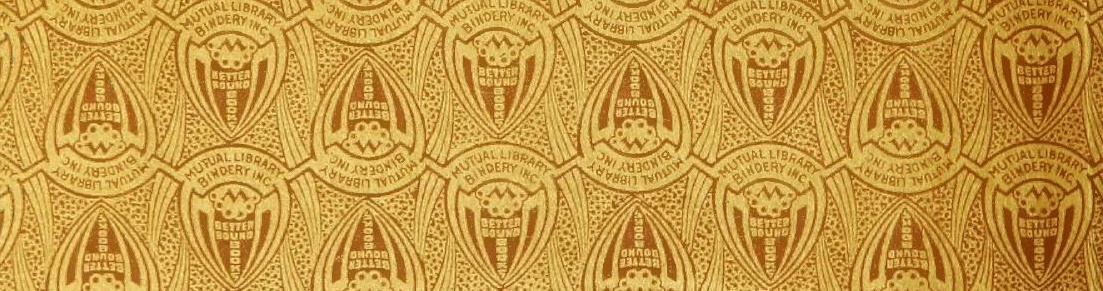


$($ (2)) V (

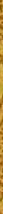

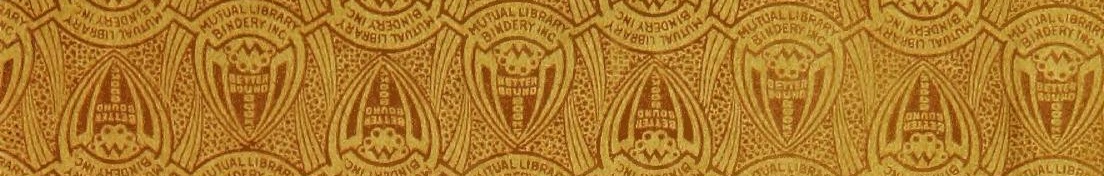

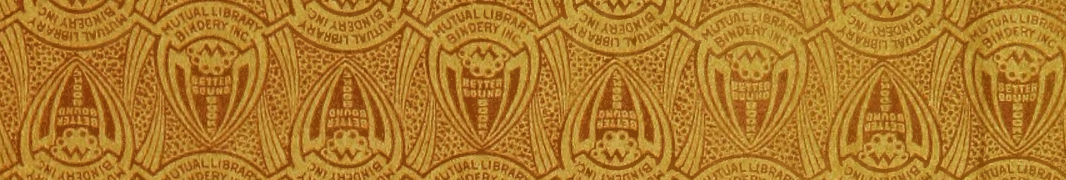

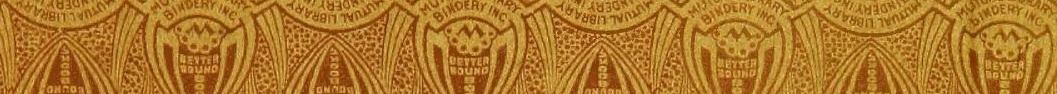
(M) (v) ( $)$ ( ind 1.1.

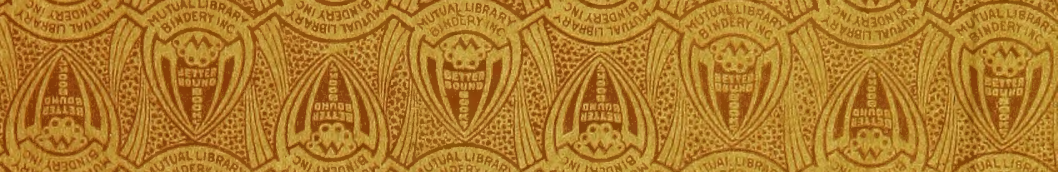
(a) (v) (v) ( (v) ( iv)

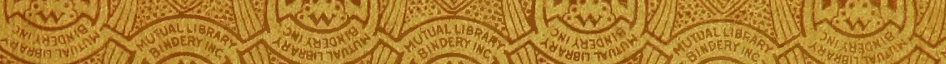

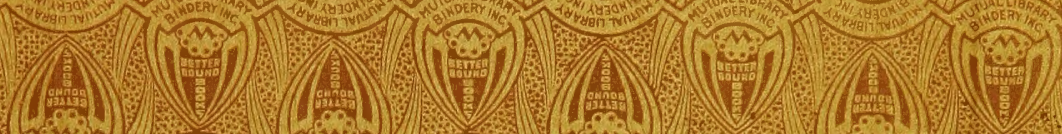

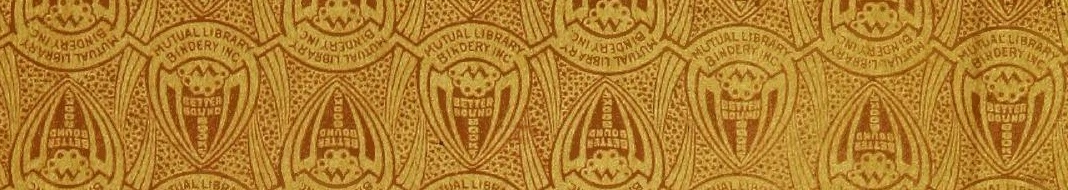

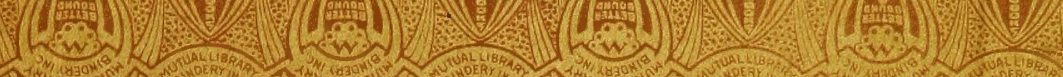

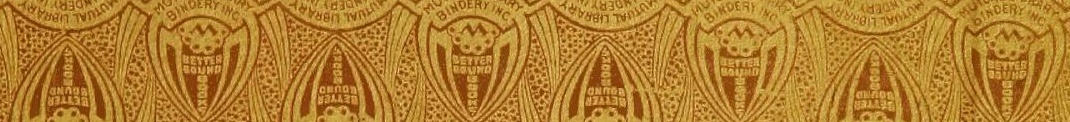

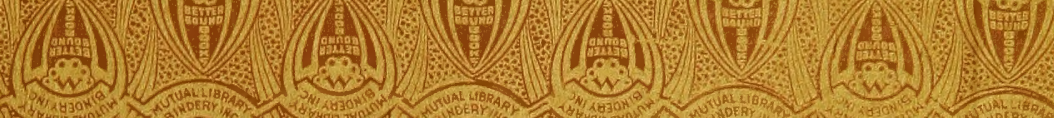

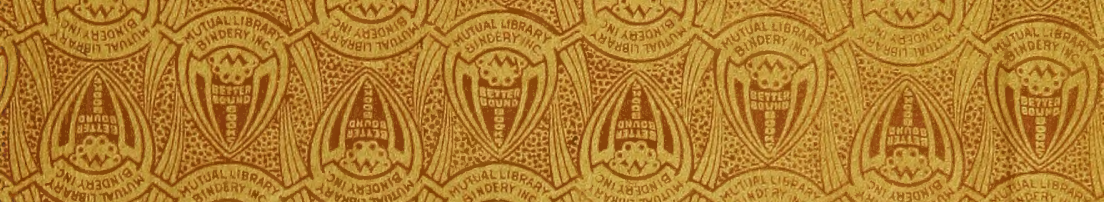

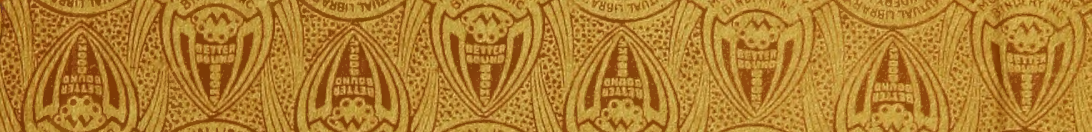

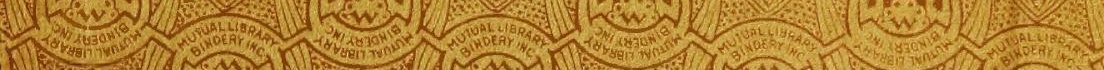
$\Re(v) \wedge(v) \&(v)$ 
